\title{
OECD $\$$
}

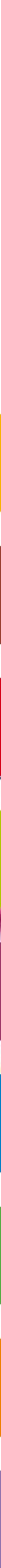





\section{OECD Science, Technology and Industry Scoreboard 2011}

INNOVATION AND GROWTH

IN KNOWLEDGE ECONOMIES 
This work is published on the responsibility of the Secretary-General of the OECD. The opinions expressed and arguments employed herein do not necessarily reflect the official views of the Organisation or of the governments of its member countries.

Please cite this publication as:

OECD (2011), OECD Science, Technology and Industry Scoreboard 2011, OECD Publishing.

http://dx.doi.org/10.1787/sti_scoreboard-2011-en

ISBN 978-92-64-11165-3 (print)

ISBN 978-92-64-12326-7 (PDF)

ISBN 978-92-64-10525-6 (HTML)

The statistical data for Israel are supplied by and under the responsibility of the relevant Israeli authorities. The use of such data by the OECD is without prejudice to the status of the Golan Heights, East Jerusalem and Israeli settlements in the West Bank under the terms of international law.

Photo credits: Cover: @ DouDou - Fotolia.com

Chapter 1: ๑ ag visuell - Fotolia.com

Chapter 2: @ SVLuma - Fotolia.com

Chapter 3: ๑ Dmitry Sunagatov - Fotolia.com

Chapter 4: @ Uladzimir Bakunovich - Fotolia.com

Chapter 5: ๑ XtravaganT - Fotolia.com

Chapter 6: ๑ Engine Images - Fotolia.com

Corrigenda to OECD publications may be found on line at: www.oecd.org/publishing/corrigenda.

(c) OECD 2011

You can copy, download or print OECD content for your own use, and you can include excerpts from OECD publications, databases and multimedia products in your own documents, presentations, blogs, websites and teaching materials, provided that suitable acknowledgment of OECD as source and copyright owner is given. All requests for public or commercial use and translation rights should be submitted to rights@oecd.org. Requests for permission to photocopy portions of this material for public or commercial use shall be addressed directly to the Copyright Clearance Center (CCC) at info@copyright.com or the Centre français d'exploitation du droit de copie (CFC) at contact@cfcopies.com. 


\section{Foreword}

$T_{\text {he }}$ he OECD Science, Technology and Industry Scoreboard 2011 draws on the latest internationally comparable data to explore the challenges faced by OECD and other leading economies as repercussions from the recent financial and economic crises continue to be felt. It presents indicators traditionally used to monitor developments in science, technology, innovation and industry, and complements them with experimental indicators that provide new insights into areas of policy interest.

The STI Scoreboard is not about "ranking" countries or developing composite indicators. It is about allowing policy makers and analysts to compare their economies with others of a similar size or with similar structure and monitor their progress towards desired national or supranational policy goals. It draws on the OECD's longer-term efforts to build the data infrastructure needed to link actors, outcomes and impacts; it highlights the potential and the limits of certain metrics and points to directions for further work.

The selected indicators have been developed with the following criteria in mind:

- The validity of a set of indicators depends on its use.

- Indicators do not necessarily reveal causal relations.

- Indicators should be based on high quality statistics and analytically robust principles and be measurable - internationally, over time and with prospects of improvement.

- Indicators should be relevant - particularly for policy decision making.

The first chapter, Knowledge economies: trends and features, provides a broad "narrative". It looks at long-term sources of growth; the new geography of growth and emerging players; the changing landscape of innovation against the backdrop of the economic crisis; the characteristics of innovation beyond formal research and development; and the challenges ahead and the need for knowledge and innovation.

The five thematic chapters focus on five key areas of policy interest:

- Building knowledge looks at the knowledge assets that many firms and governments view as their current and future strengths for long-term sustainable growth. It focuses on indicators of human resources in science and technology and investment in research. It also introduces experimental indicators of public funding "modes" (institutional versus project funding).

- Connecting to knowledge considers the extent to which countries' science-innovation systems are connected, open and tap into international "brain circulation". Novel indicators are presented such as the impact of scientific collaboration (based on normalised patent citations) and indicators of science-industry linkages (based on citations of non-patent literature in patent documents). Also included are indicators of researcher mobility and of the extent of firms' collaboration in innovation processes. 
- Targeting new growth areas examines the direction of countries' scientific efforts and the technologies on which they build their comparative advantage. It presents $R \& D$ and innovation indicators in health and environmental technologies and looks at developments in smart ICT infrastructure.

- Unleashing innovation in firms is concerned with the dynamism of the business sector, the main types of innovation in firms, and the extent to which governments create the conditions for innovation to flourish. It uses firm-level surveys to analyse broader, non-technological innovation. It presents indicators on the policy environment for innovation, including estimates of government support via R\&D tax incentives and indicators of entrepreneurial culture.

- Competing in the global economy examines how countries seek to build their competitive strengths. An eclectic range of indicators examines the import content of exports, the characteristics of innovative firms, industrial specialisation and diversification, technology specialisation, innovation intensity in different sectors and indexes of patent quality and impact.

The main audience of the STI Scoreboard is the policy analyst with a good level of understanding of the use of indicators and all those engaged in producing indicators for policy making. A few paragraphs introducing an indicator, and offering interpretations, are accompanied by a "Definitions" box for those less familiar with the methods used. A "Measurability" box summarises measurement challenges, gaps and recent initiatives. All charts and underlying data can be downloaded via the Statlinks (hyperlink to a webpage). 


\section{Acknowledgments}

$\mathrm{T}$ his volume is the result of a collective effort by the Economic Analysis and Statistics Division (EAS) of the OECD Directorate for Science, Technology and Industry (DSTI), under the guidance of Alessandra Colecchia, with contributions from Laudeline Auriol, Brigitte van Beuzekom, Catherine Bignon, Agnès Cimper, Hélène Dernis, Rebecca Freeman, Fernando Galindo-Rueda, Chrystyna Harpluk, Pedro Herrera-Gimenez, Sandrine Kergroach, Elif Köksal-Oudot, Guillaume Kpodar, Vladimir Lopez-Bassols, Valentine Millot, Toshiyuki Misu, Pierre Montagnier, Vincenzo Spiezia, Mariagrazia Squicciarini, Julien Vavasseur, Fabien Verger, Colin Webb, Bo Werth, Norihiko Yamano and Shiguang Zhu. The contributions of Marcos de la Torre (EPO) and Carmen López-Illescas (CSIC), while on secondment to EAS, were greatly appreciated. Brigitte van Beuzekom supervised the preparation of statistics and figures. Andrew Wyckoff provided overall guidance and comments.

Others in DSTI and elsewhere in OECD made available their respective areas of expertise: Ester Basri, Frédéric Bourassa, Sarah Box, Mario Cervantes, Chiara Criscuolo, Koen de Backer, Isabelle Desnoyers-James, Julien Dupont, Dominique Guellec, Ivan Haščič, Corinne Heckmann, Nick Johnstone, Seung-Hee Koh, Joseph Loux, Mariarosa Lunati, Laurent Moussiegt, Alistair Nolan, Dirk Pilat, Cristina Serra-Vallejo and Karen Wilson.

The contribution of the SCImago Research Group (CSIC), www.scimago.es, which provided normalised data and research expertise for bibliometric indicators, is gratefully acknowledged. EAS matched 68 million patents in EPO's Worldwide Patent Statistical Database (PATSTAT) and 80 million companies in Bureau van Dijk's ORBIS@ database thanks to the efficient matching software developed for the OECD by IDENER, Seville, www.idener.es/nosotros_en.html. Thanks also go to Stéphane Maraut for matching scientific publications data from Scopus Custom Data, Elsevier, with non-patent literature citations in patents. Several indicators are based on special data requests to national statistical offices or ministries. The time and help granted by national experts have been instrumental to this project. 



\section{Table of Contents}

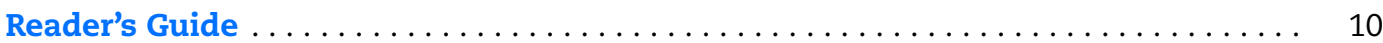

Acronyms........................................ 10

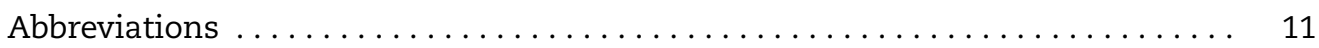

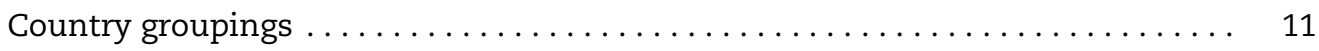

Executive Summary.................................... 13

1. Knowledge Economies: Trends and Features.................... 19

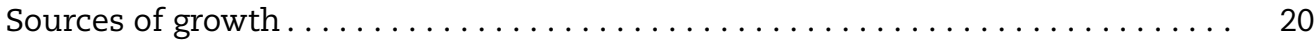

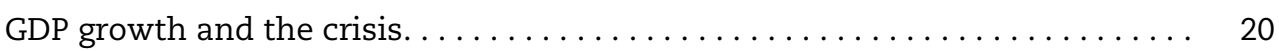

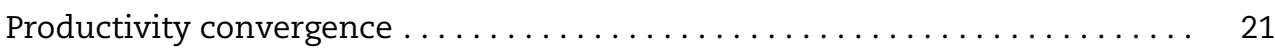

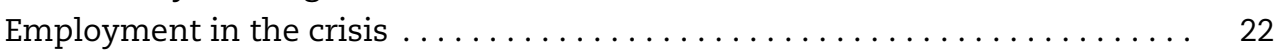

New sources of growth: intangible assets $\ldots \ldots \ldots \ldots \ldots \ldots \ldots \ldots \ldots . \ldots \ldots 24$

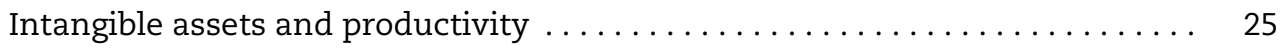

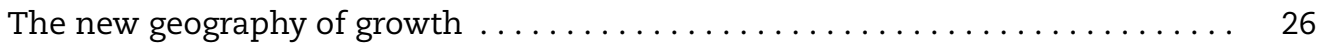

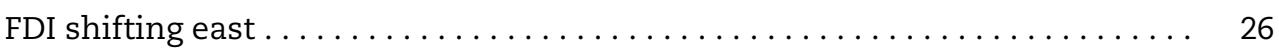

Emerging players in high-technology trade $\ldots \ldots \ldots \ldots \ldots \ldots \ldots \ldots \ldots . \ldots \ldots$

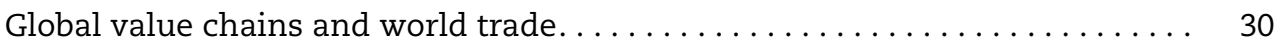

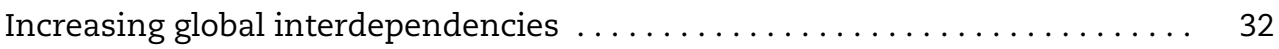

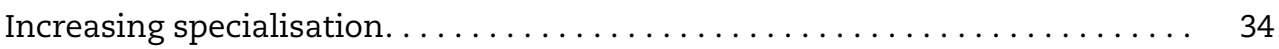

Global manufacturers ................................... 35

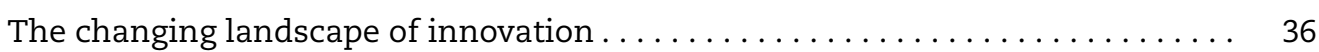

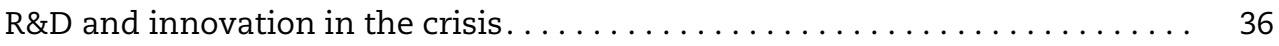

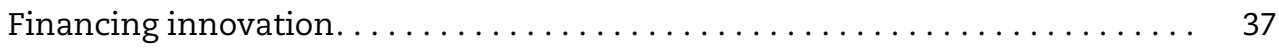

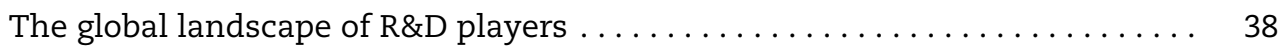

A shift in the policy mix for R\&D . . . . . . . . . . . . . . . . . . 39

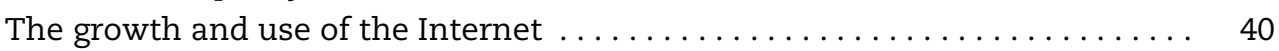

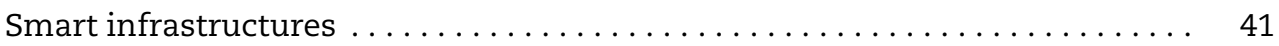

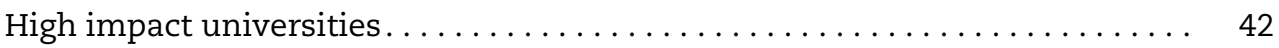

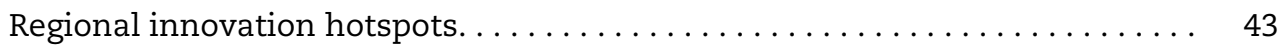

Rising innovation in services . . . . . . . . . . . . . . . . . . 44

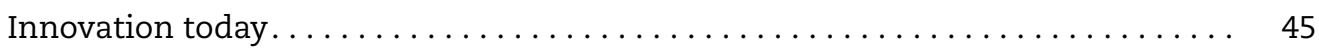

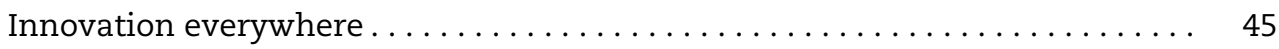

Intensifying collaboration in research $\ldots \ldots \ldots \ldots \ldots \ldots \ldots \ldots \ldots \ldots \ldots$

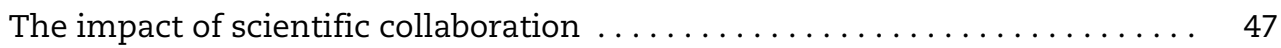

International collaboration in science and innovation $\ldots \ldots \ldots \ldots \ldots \ldots$

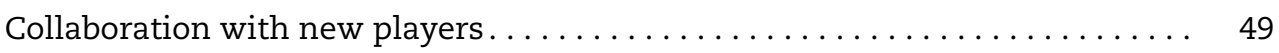

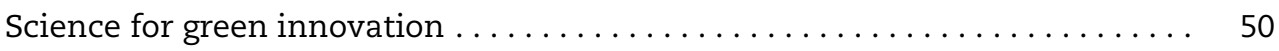

Technology transfers ................................ 51 


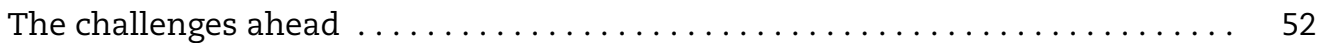

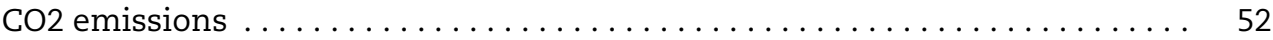

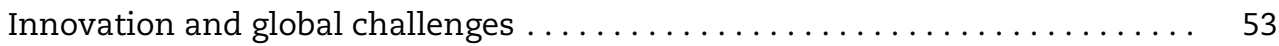

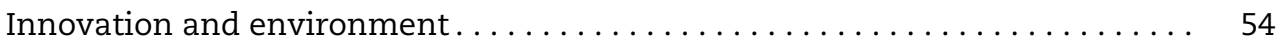

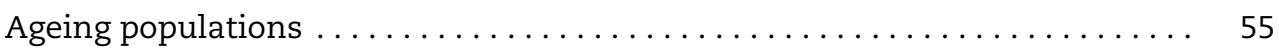

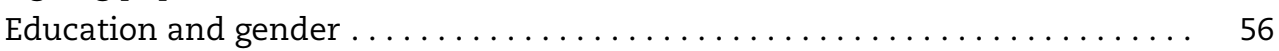

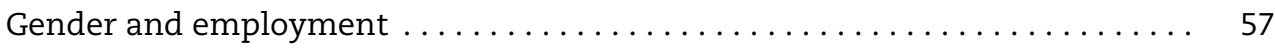

Notes........................................... 58

References ........................................... 64

2. Building Knowledge . . . . . . . . . . . . . . . . . . . . . . . . . . . . . . 67

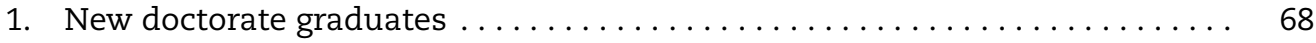

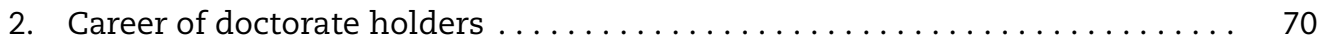

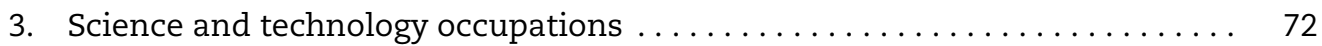

4. Researchers........................................... 74

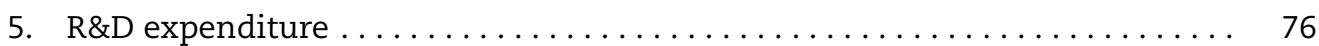

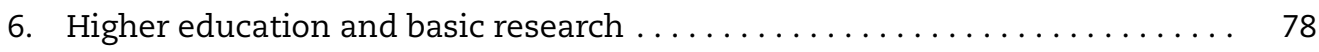

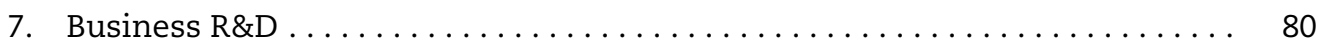

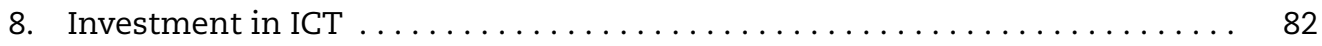

Notes............................................ 84

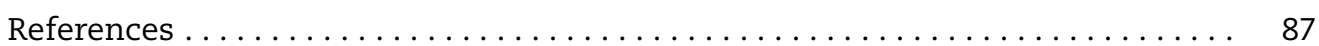

3. Connecting to Knowledge . . . . . . . . . . . . . . . . . . . . . . . . . . . 89

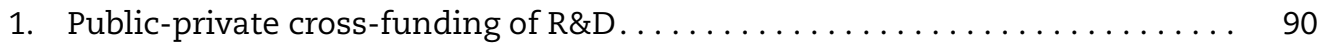

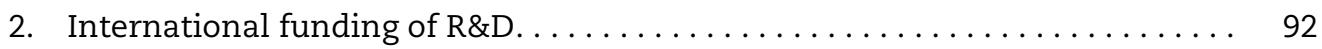

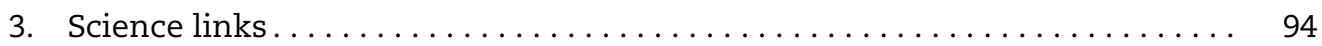

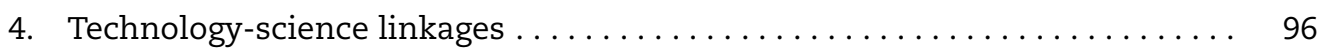

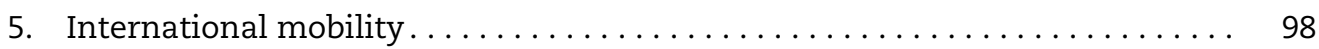

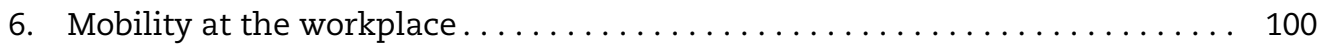

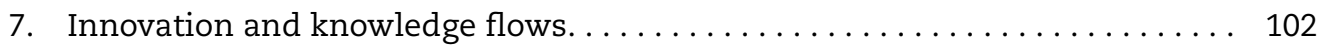

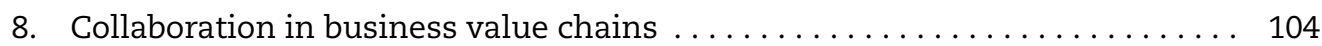

9. International collaboration on innovation . . . . . . . . . . . . . . . 106

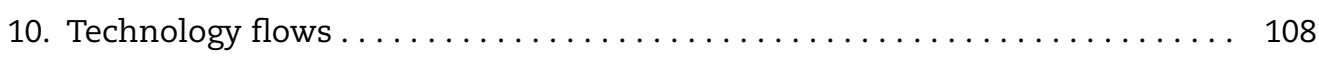

Notes........................................ 110

References ....................................... 115

4. Targeting New Growth Areas ............................. 117

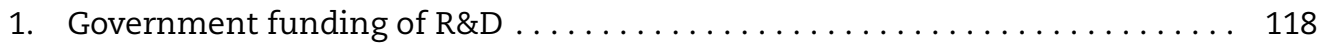

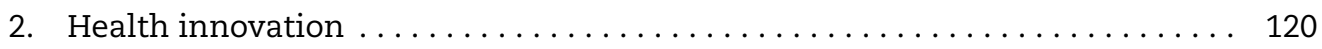

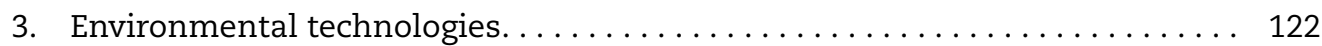

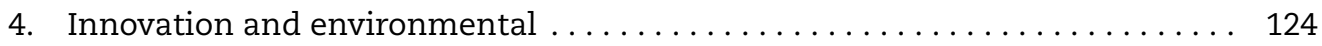

5. Broadband speed and prices ........................... 126

6. Fixed and wireless broadband ........................... 128

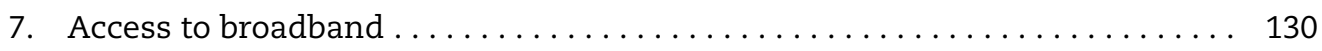

8. Biotechnology R\&D . . . . . . . . . . . . . . . . . . . . 132

Notes. . . . . . . . . . . . . . . . . . . . . . . . . . . . . . . . . . . . . . . . 134

References ......................................... 137 
5. Unleashing Innovation in Firms. . . . . . . . . . . . . . . . . . 139

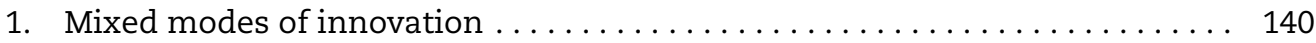

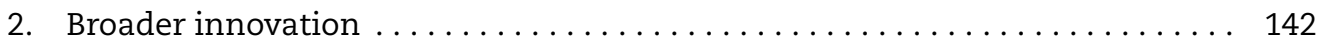

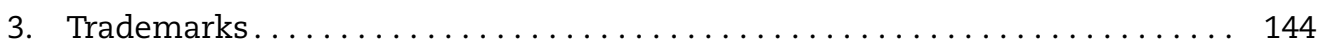

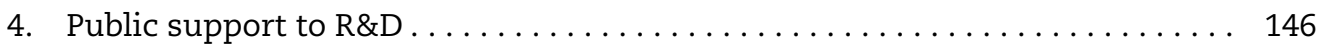

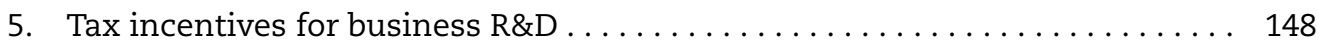

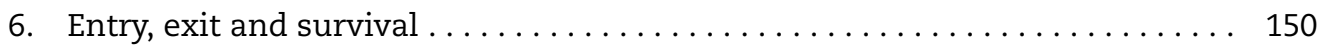

7. Access to capital. ...................................... 152

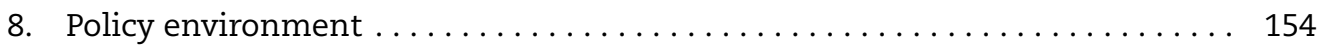

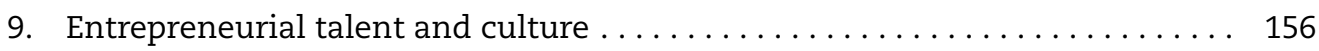

Notes. . . . . . . . . . . . . . . . . . . . . . . . . . . . . . . . . . . 158

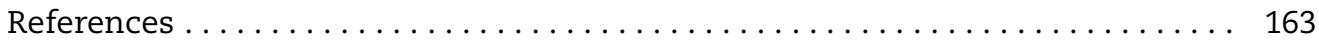

6. Competing in the Global Economy......................... 165

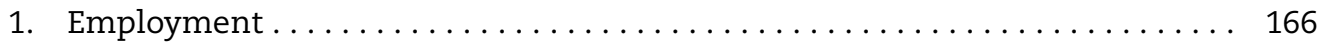

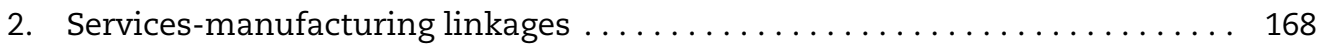

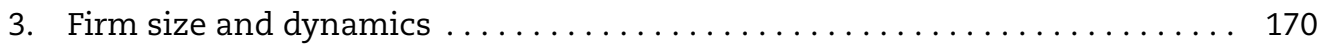

4. Sectoral specialisation. ............................. 172

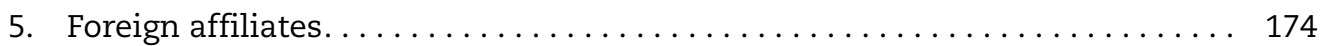

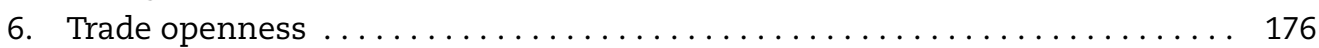

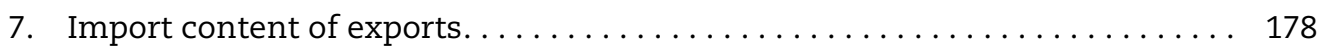

8. R\&D specialisation. . . . . . . . . . . . . . . . . . . . . . 180

9. Technology specialisation. . . . . . . . . . . 182

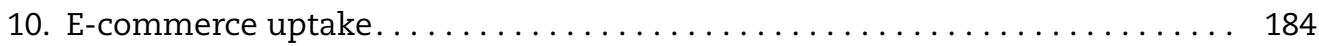

11. Patenting firms . . . . . . . . . . . . . . . . . . . . . . . . . 186

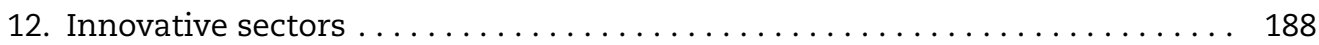

13. Technology performance: quality $\ldots \ldots \ldots \ldots \ldots \ldots \ldots \ldots \ldots \ldots \ldots \ldots$

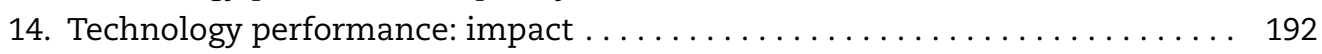

Notes. . . . . . . . . . . . . . . . . . . . . . . . . . . . . . . . . . . . . . . . . . 194

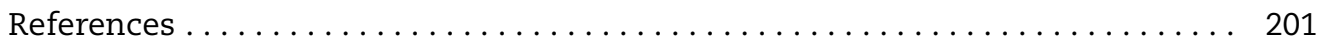

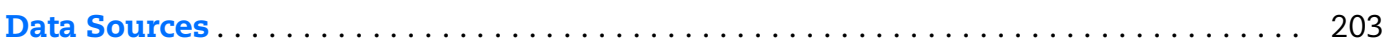

\section{This book has...}

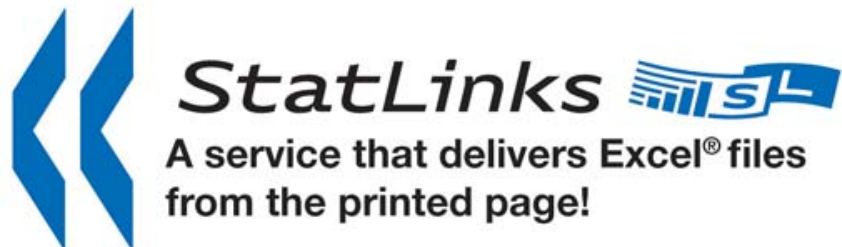

Look for the StatLinks at the bottom right-hand corner of the tables or graphs in this book. To download the matching Excel ${ }^{\otimes}$ spreadsheet, just type the link into your Internet browser, starting with the $h t t p: / / d x$.doi.org prefix.

If you're reading the PDF e-book edition, and your PC is connected to the Internet, simply click on the link. You'll find StatLinks appearing in more OECD books. 


\section{Reader's Guide}

\section{Acronyms}

BERD Business enterprise expenditure on research and development

CIS Community Innovation Survey

CTM Community trademark

DSL Digital subscriber line

EPO European Patent Office

EU European Union

FDI Foreign direct investment

FTE Full-time equivalent

GBAORD Government budget appropriations or outlays for R\&D

GDP Gross domestic product

GERD Gross domestic expenditure on R\&D

HERD Higher education expenditure on R\&D

HRST Human resources in science and technology

ICT Information and communication technology

IMF International Monetary Fund

I-O Input-output

IP Intellectual property

IPC International Patent Classification

IPv4 Internet Protocol version 4

IPv6 Internet Protocol version 6

ISCED International Standard Classification of Education

ISCO International Standard Classification of Occupations

ISIC International Standard Industrial Classification

JPO Japan Patent Office

KLEMS Capital, labour, energy, material and service inputs

LFS Labour Force Survey

MFP Multi-factor productivity

NACE Statistical classification of economic activities in the European Community (Nomenclature statistique des activités économiques dans la Communauté européenne)

NPL Non-patent literature

OHIM Office for Harmonization in the Internal Market

PCT Patent Cooperation Treaty

PPP Purchasing power parity

PRO Public research organisation

R\&D Research and development

RD\&D Research, development and demonstration

S\&E Science and engineering

S\&T Science and technology 
SME Small and medium-sized enterprise

SNA System of National Accounts

TM Trademark

USD United States dollar

USPTO United States Patent and Trademark Office

Wi-Fi Wireless fidelity

WIPO World Intellectual Property Organization

\section{Abbreviations}

For most of the charts, this publication uses ISO codes for countries and economies.

\begin{tabular}{llllll}
\hline ARG & Argentina & GBR & United Kingdom & NLD & Netherlands \\
AUS & Australia & GRC & Greece & NOR & Norway \\
AUT & Austria & HKG & Hong Kong, China & NZL New Zealand \\
BEL & Belgium & HRV & Croatia & POL & Poland \\
BGR & Bulgaria & HUN & Hungary & PRT & Portugal \\
BMU & Bermuda & IDN & Indonesia & ROU & Romania \\
BRA & Brazil & IND & India & RUS & Russian Federation \\
BRB & Barbados & IRL & Ireland & SAU SUdi Arabia \\
CAN & Canada & ISL & Iceland & SGP & Singapore \\
CHE & Switzerland & ISR & Israel & SVK & Slovak Republic \\
CHL & Chile & ITA & Italy & SVN & Slovenia \\
CHN & People's Republic of China & JPN & Japan & SWE & Sweden \\
CYM & Cayman Islands & KOR & Korea & THA & Thailand \\
CZE & Czech Republic & LIE & Liechtenstein & TUR & Turkey \\
DEU & Germany & LTU & Lithuania & TWN & Chinese Taipei \\
DNK & Denmark & LUX & Luxembourg & UKR & Ukraine \\
ESP & Spain & LVA & Latvia & USA & United States \\
EST & Estonia & MEX & Mexico & VGB & Virgin Islands (British) \\
FIN & Finland & MLT & Malta & ZAF & South Africa \\
FRA & France & MYS & Malaysia & & \\
\hline
\end{tabular}

\section{Country groupings}

\begin{tabular}{ll}
\hline BRIICS & Brazil, the Russian Federation, India, Indonesia, People's Republic of China and South Africa \\
EA15 & Euro area \\
EU27 & European Union \\
G7 & Canada, France, Germany, Italy, Japan, the United Kingdom and the United States \\
OECD & Total OECD \\
ROW & Rest of the world \\
WLD & World
\end{tabular}





\section{Executive Summary}

To oday, the world's economies are facing some extraordinary challenges. While the effects of the recent economic downturn are still being felt, new pressures are stretching many governments' ability to instigate a recovery and national debt levels and unemployment remain high. The pace and scale of globalisation is unprecedented. Its distinctive features are increasing international trade, deepening economic integration, especially in emerging economies, and greater geographic fragmentation of production processes generating ever more complex global value chains. In this new geography of growth, international competition from new players is eroding the lead of more established economies. Environmental pressures challenge the sustainability of development models. Longer life expectancy is putting a greater strain on the capability of health systems to meet the needs of an ageing population.

Innovation is increasingly seen as being critical for effectively meeting these challenges. It will play a major role in lifting economies out of the downturn and finding new and sustainable sources of growth and competitiveness.

The OECD Science, Technology and Industry Scoreboard 2011 builds on 50 years of indicator development at OECD to look at major trends in knowledge and innovation in the global economy. Over 180 indicators illustrate and analyse trends in science, technology, innovation and industrial performance in OECD and major non-OECD countries (notably Brazil, the Russian Federation, India, Indonesia, the People's Republic of China and South Africa).

Chapter 1 uses traditional, new and experimental indicators to build a narrative around the features of today's landscape of knowledge and innovation. The five thematic chapters focus on five key areas of policy interest:

- Building Knowledge looks at the knowledge assets which many firms and governments view as their current and future strengths for long-term sustainable growth.

- Connecting to Knowledge considers the extent to which countries' science-innovation systems are connected, open and tap into international "brain circulation" - the mobility and interconnectedness of highly skilled labour across nations.

- Targeting New Growth Areas examines the direction of countries' scientific efforts and the technologies on which they build their comparative advantage.

- Unleashing Innovation in Firms is concerned with the dynamism of the business sector, the main types of innovation in firms and the extent to which governments create the conditions for innovation to flourish.

- Competing in the Global Economy examines how economies seek to build their competitive strengths. 
The economic landscape and emerging players

Between 2008 and 2009, in the immediate aftermath of the crisis, the OECD as a whole suffered a net loss in employed persons of about 11 million, a $2 \%$ drop. Half of these losses occurred in the United States. For many OECD countries, significant losses in employment continued well into 2010. This occurred against the backdrop of longer-term trends characterised by greater international competition from new players. In 1990 the G7 countries accounted for two-thirds of world manufacturing value added but they now account for less than half. By 2009 China had almost caught up with the United States in manufacturing production, and the share of Brazil and India among world manufacturers is now similar to that of Korea.

The decline of manufacturing production in many OECD countries means that, on average, services now account for about 70\% of OECD gross domestic product (GDP). Moreover, in many countries, the share of service activities necessary for manufacturing production has increased in recent years. In 2008, services-related employees accounted for about $35 \%$ of employees in manufacturing in the OECD area, although it varied between $17 \%$ and $52 \%$ across countries.

Increasing global interdependencies

and knowledge flows...

BRIICS economies have become more integrated in the global economy. China is set to become the second largest recipient of foreign direct investment. Average outward investment flows from China increased ninefold between the early and late 2000s; those of India increased more than sevenfold. The last 15 years have seen increased trade in primary resources such as energy inputs, a more than ten-fold increase in the value of exports from China, and China's growing role as an exporter of high-end intermediates and consumer goods. Meanwhile, OECD countries' share of world exports has declined from $75 \%$ to $60 \%$. In the BRIICS, high-technology manufacturing trade now represents about $30 \%$ of their total manufacturing trade, compared to $25 \%$ for the OECD area.

Knowledge increasingly flows across borders. The rate of patenting activities is rapidly increasing in non-OECD economies. On average, over $40 \%$ of OECD inventions are also protected in China. These technology flows mirror the strategic behaviour of firms, the location of both subsidiaries and competitors, and the attractiveness of emerging markets.

... in a world of rising specialisation

As economic activities become more global, economies increasingly rely on fewer sectors. Novel indicators show rising economic specialisation since the 1970s, with Canada the only G7 country to experience periodic bursts of diversification. In contrast, Korea reflects the development path previously travelled by G7 countries - early increasing diversification (into industry and services), peaking in the late 1980s, followed by gradual specialisation as its new comparative advantages became evident. In the G7 countries, the concentration ratio has grown over the last 30 years; the top four sectors represent on average $55 \%$ of total value added with a few broad sectors, typically "Wholesale and retail" and "Business activities", consistently among the top four. 
Countries' sectoral specialisations can be taken into account when comparing widely used indicators such as R\&D intensity (business R\&D expenditure as a percentage of GDP). Estimating a country's total R\&D intensity as if it had the same industrial structure as the OECD average provides an interesting picture. In Finland, Germany and Korea (countries with high R\&D intensities), the "adjusted R\&D intensity" is below the OECD average of $2.5 \%$. Conversely, if France, Iceland and the Netherlands had an average OECD industry structure, their business R\&D intensity would be higher than currently observed. For countries in southern and eastern Europe and for Mexico, an industry structure closer to the OECD average would not raise their overall R\&D intensity - indicating that their business R\&D is lower than average regardless of industrial specialisation.

While countries "specialise", newly matched enterprise and patent data reveal the benefits of a broad industrial base for the development of key enabling technologies. Chemical firms, for example, contribute to the advancement of pharmaceuticals and biotechnologies, and to a lesser extent also to nanotechnologies. Research and development service providers are also essential to these fields, as are institutions such as universities. New information and communication technologies are concentrated in a set of computer and communications industries, while environmental technologies are shaped by the patenting activity of specialised machinery manufacturers and certain technical and engineering service activities.

Science and innovation build on local strengths...

Many countries are building centres of excellence to create the optimum conditions for raising research quality and impact. Non-OECD economies account for a growing share of the world's R\&D, measured in terms of both number of researchers and R\&D expenditures. Worldwide, the 50 universities with the highest impact - measured by normalised citations to academic publications across all disciplines - are concentrated in a handful of countries. Overall, 40 of the top 50 are located in the United States, and the rest in Europe. A more diverse picture emerges on a subject-by-subject basis. There is evidence that some universities in Asia are emerging as leading research institutions. Many of the leading firms in knowledge-intensive industries - such as ICT and the life sciences - have emerged in a limited number of regions in the world.

... but collaboration and a multidisciplinary

approach are key

The production of scientific knowledge is shifting from individuals to groups, from single to multiple institutions, and from a national to an international scope. Comparisons of certain indicators across countries suggest a positive relationship between measures of research collaboration and scientific impact.

New technologies often draw on a broad base of scientific knowledge. Focussing on "clean" energy technologies, a new indicator based on citations to scientific publications reveals that material science makes the single largest contribution to clean energy, followed by chemistry and physics; energy and environmental science only account for $10 \%$ and $1.7 \%$ respectively. The diversity of scientific sources highlights the difficulty of identifying a single major scientific contributor to innovation in this area. 
Collaboration is part of innovation processes whether firms perform R\&D or not. In all countries $R \& D$-active firms tend to collaborate more frequently on innovation (usually twice as much) than non-R\&D-active firms. In the United Kingdom, collaboration is embedded in the innovation processes of over $50 \%$ of non-R\&D-active firms.

Innovation is broader than R\&D and a key source

of growth...

New indicators based on trademarks point to large numbers of incremental and marketing innovations and confirm that firms perform both technological and non-R\&D-based innovation. Analysis of firm-level data on innovation shows that firms follow various innovation strategies and that these are not always based on formal R\&D. However, product innovation is often associated with $R \& D$. Indeed, in most countries, more than half of all product-innovating firms also engage in R\&D. Remarkably, more than two-thirds of product innovators are not engaged in R\&D in New Zealand and the United States and more than $90 \%$ in Chile and Brazil.

Broader innovation is essential for economic growth and social advancement. Innovation entails investment in a range of complementary assets beyond $R \& D$ such as software, human capital and new organisational structures. Investment in these intangible assets is rising and even exceeds investment in physical capital (machinery and transport equipment) in Finland, Sweden, the United Kingdom and the United States. Encouragingly, in some countries, recent estimates of intangible assets explain a significant portion of multi-factor productivity growth.

... as is a dynamic and innovative business sector

The presence of young firms among patent applicants underlines the inventive dynamics of firms early in their development and their desire to develop new activities and products - crucial to their survival and relative growth. During 2007-09 firms less than five years old filing at least one patent application represented on average $25 \%$ of all patenting firms, and generated $10 \%$ of patent applications. The share of young patenting firms varies considerably across countries, led by Ireland (42\%) and followed by the Nordic economies.

Mapping knowledge and innovation flows is a complex endeavour; it requires a data infrastructure that allows linkages between actors, outputs and outcomes. Large datasets have been linked together to develop new indicators for the 2011 edition of the STI Scoreboard, such as those that look at the fields of science that new technologies draw upon or the demographic characteristics of innovative firms. By exploiting OECD's "harmonised" Input-Output tables and bilateral trade data, world production value chains have been investigated and international transfers of "embodied" $\mathrm{CO}_{2}$ emissions revealed. 
Several "traditional" indicators have been re-engineered to change the perspective of international comparisons, e.g. business R\&D intensities adjusted by industry structure or new indicators of the impact of scientific output based on counts of citations received. Finally, some experimental indicators are proposed such as quantitative estimates of R\&D tax incentives and indicators of public funding "modes" (institutional versus project funding). While international comparisons based on these indicators need to be interpreted with caution, they are a step towards new insights into areas of policy interest. 


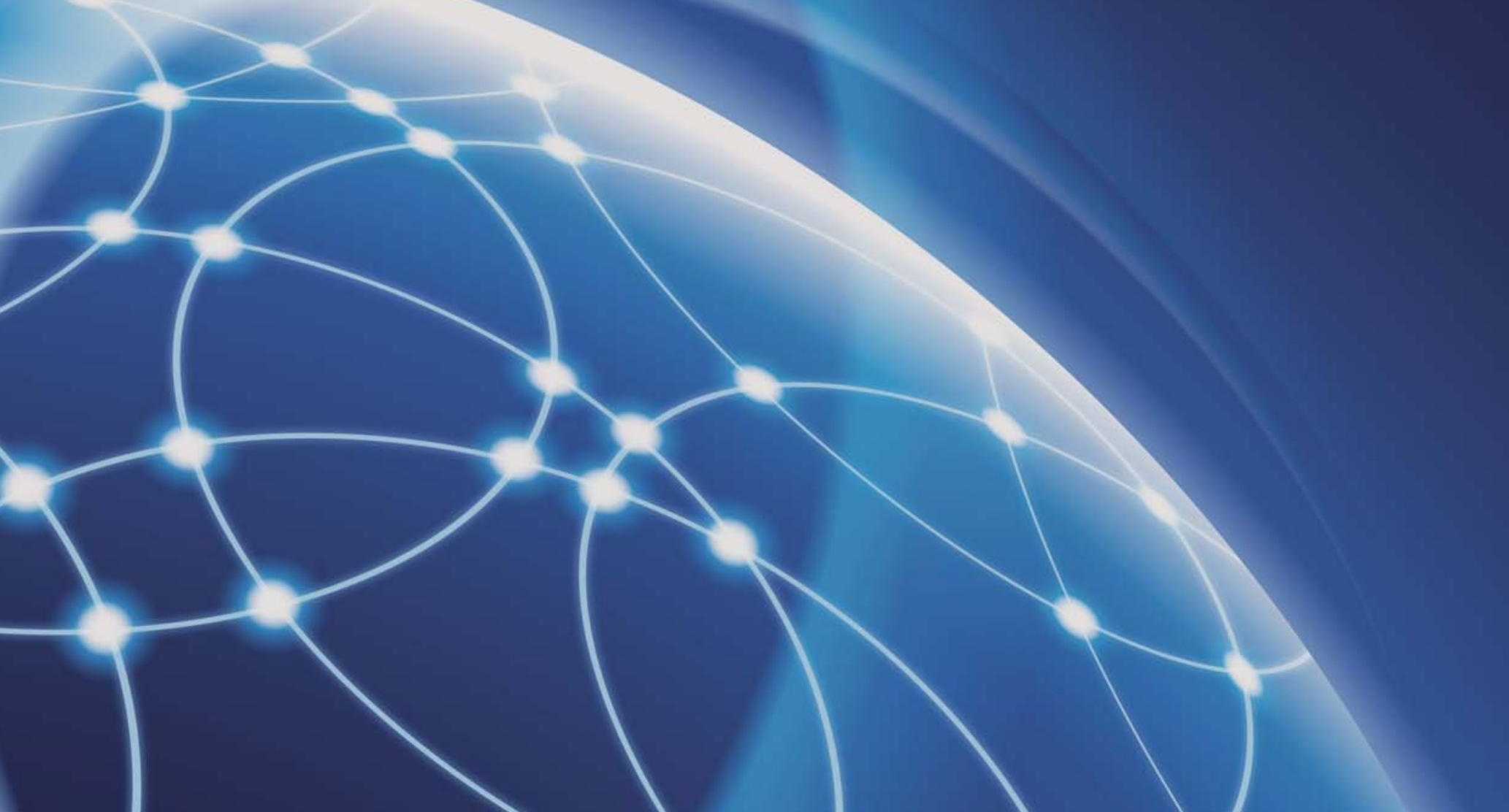




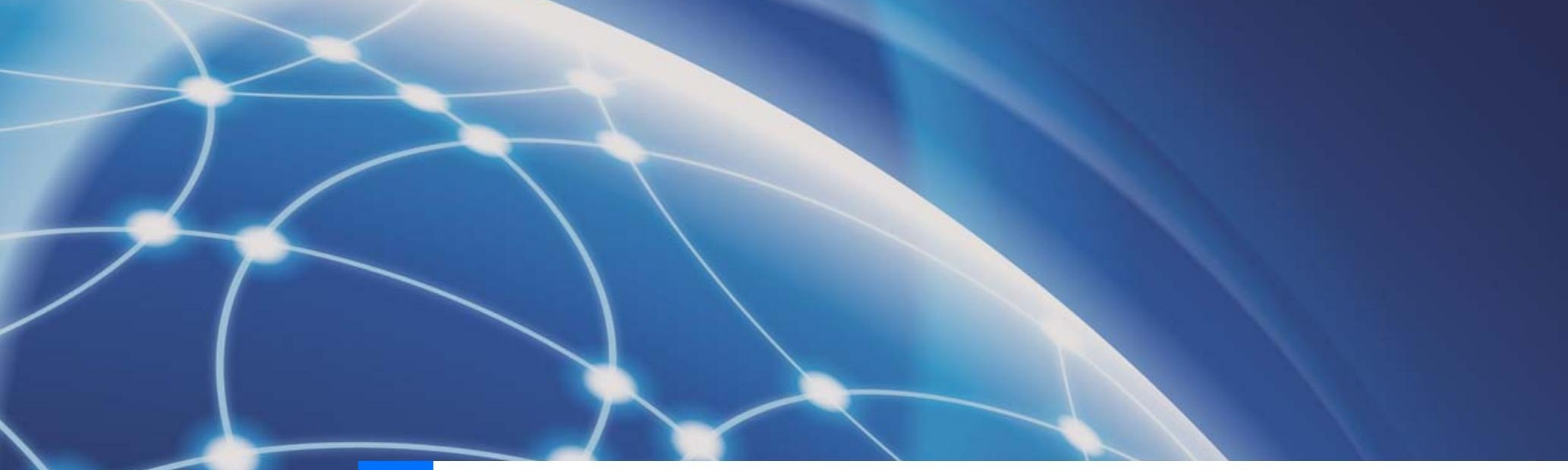

\title{
1. KNOWLEDGE ECONOMIES: TRENDS AND FEATURES
}

\author{
Sources of growth \\ The new geography of growth \\ The changing landscape of innovation \\ Innovation today \\ The challenges ahead
}

Notes

References

This chapter presents a range of indicators that highlight the long-term trends and characteristics of global knowledge economies. It addresses the following questions: What are the features of today's economic landscape? What have been the sources of growth and productivity in the last two decades and what is the role of knowledge in our economies? Who are the emerging players? How dispersed or how concentrated are economic and innovation activities? How intertwined are the actors in the innovation system and how "collaborative" is the innovation process? What are the main challenges for knowledge economies in the coming years? How fast are the accumulation and spread of technology and innovation today? Indicators accompanied by short texts develop a narrative to help policy makers understand knowledge and innovation today. 


\section{KNOWLEDGE ECONOMIES: TRENDS AND FEATURES}

\section{Sources of growth}

\section{GDP growth and the crisis}

Today's world faces some extraordinary challenges and the effects of the economic downturn will be felt by our societies for years to come. A traditional measure used to gauge nations' welfare is gross domestic product (GDP) per capita. Changes in this measure can result from changes in labour productivity (GDP per hours worked) and labour utilisation (hours worked per person employed and employment per capita). Slowing labour productivity was already eroding growth performance prior to the crisis, and data for 2007-09 show the effect of the downturn on labour and capital. In 2010 widespread growth signalled the start of a global recovery. However, the pace of recovery varies among OECD countries and unemployment remains high in most. This condition creates an imperative for countries to find new and sustainable sources of growth.

Decomposition of growth in GDP per capita, 2001-07, 2007-09 and 2009-10

Total economy, percentage change at annual rate

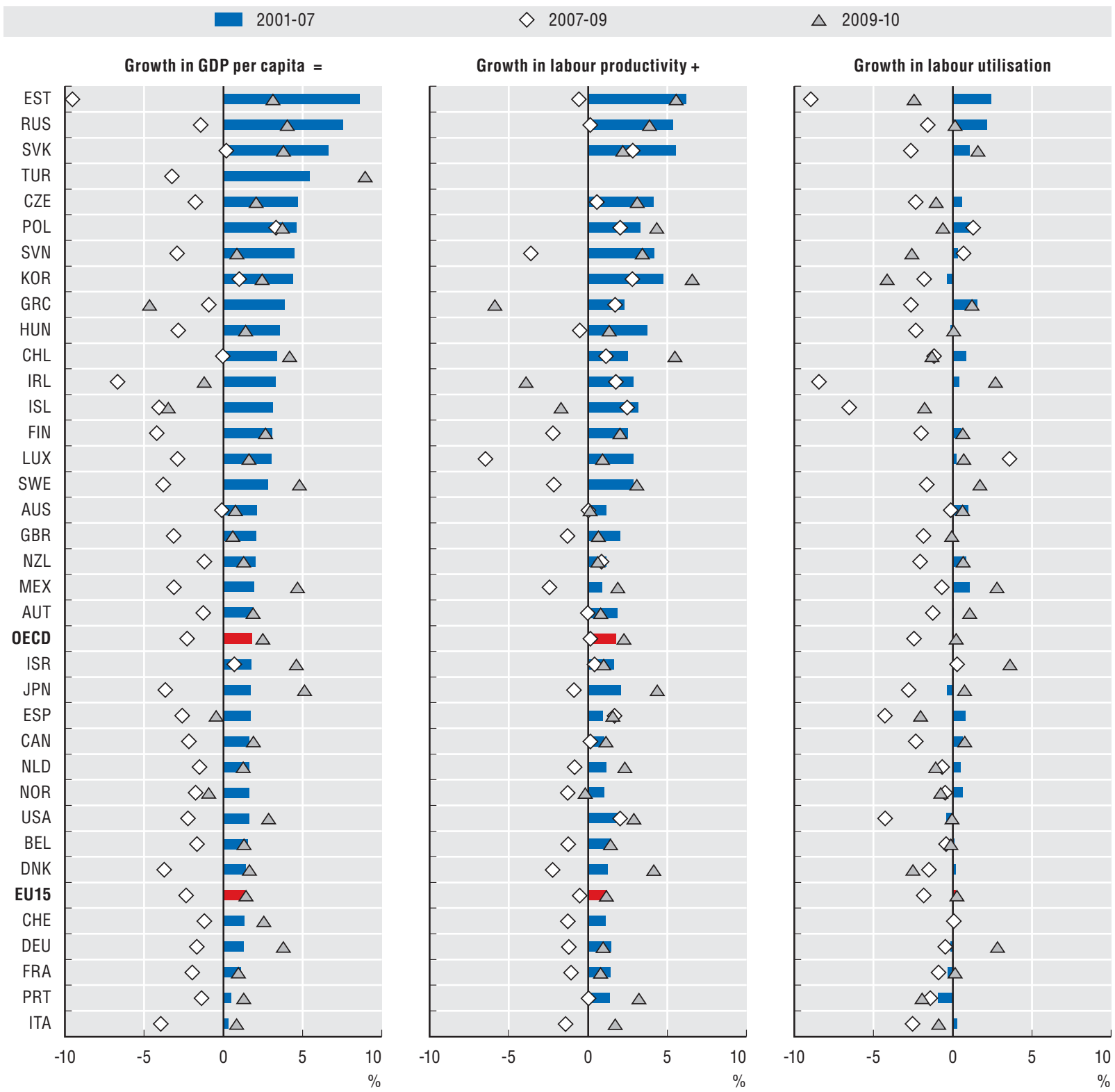

Source: OECD, Productivity Database, June 2011. See chapter notes. 
Sources of growth

\section{Productivity convergence}

Over the 1980s and into the early 1990s, labour productivity grew faster in Japan than in the United States, owing in part to longer working hours per employee. It accelerated in the United States in the second half of the 1990s to $2.5 \%$, and a new gap emerged, notably with the euro area. After 2003 the salient feature was downwards convergence so that, by 2007 , all major OECD areas had a similar productivity growth rate of around $1 \%$ to $2 \%$. In 2008 a new gap appeared, with productivity growth in the United States of about 1.1\%, while productivity slowed significantly in the aftermath of the crisis in Japan and the euro area, to then bounce back in 2010 to $2.9 \%$ and $1.1 \%$, respectively. In 2009, after 20 years of a persistent gap in both GDP and labour productivity compared with the upper half of OECD countries, the BRIICS (Brazil, the Russian Federation, India, Indonesia, the People's Republic of China and South Africa), particularly China, were showing a positive trend, albeit with a significant gap remaining.

Labour productivity growth, total economy level, 1985-2010

Annual growth rates

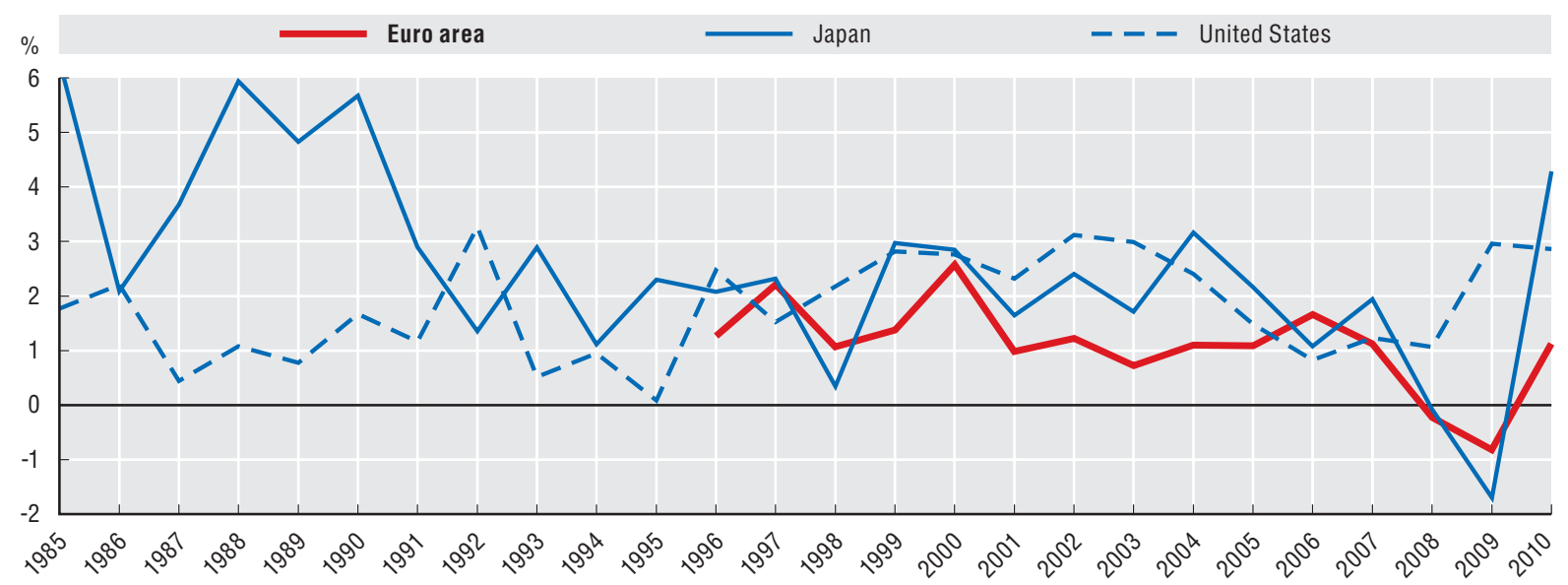

Source: OECD, Productivity Database, June 2011. See chapter notes.

GDP per capita and labour productivity in the BIICS, 1991-2009

Gap with respect to the average of the upper half of OECD countries, percentage points

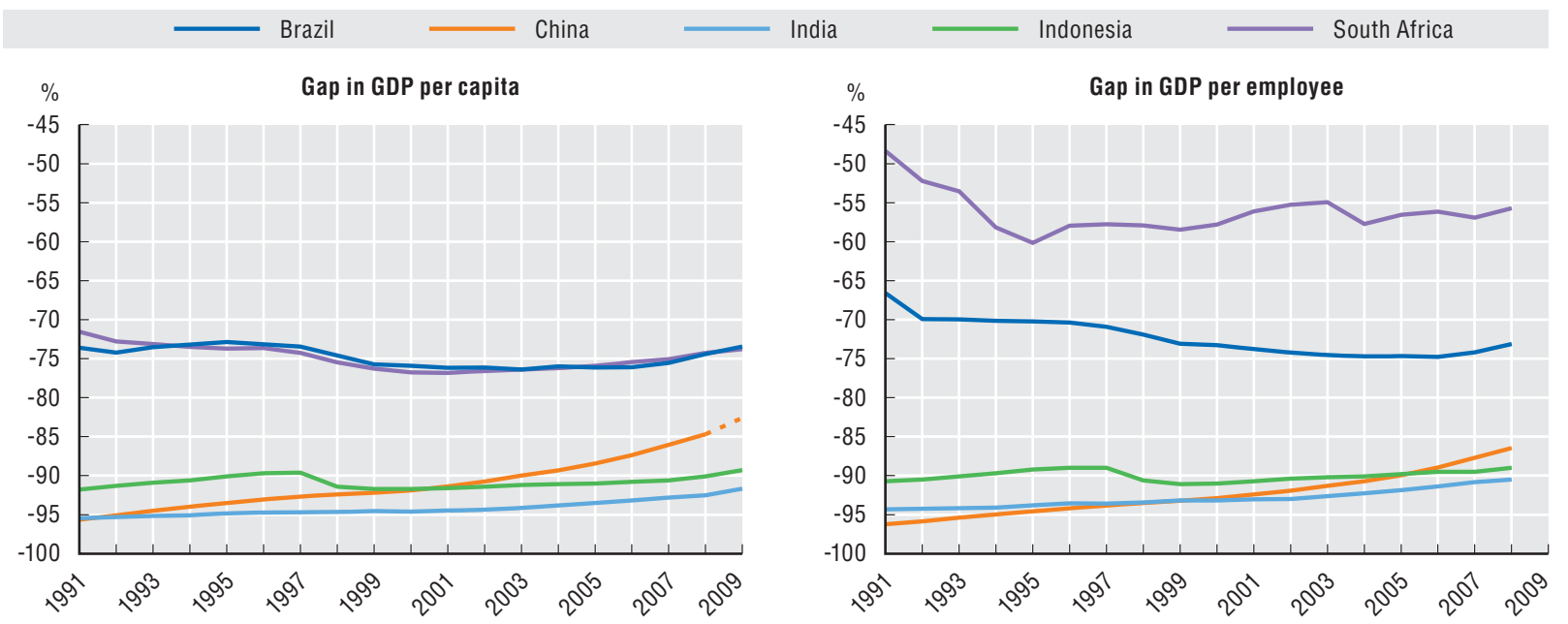

Source: OECD (2011), Economic Policy Reforms 2011: Going for Growth, OECD Publishing, Paris; based on World Bank, World Development Indicators (WDI) and ILO, Key Indicators of the Labour Market (KILM) Databases, 2010. 


\section{KNOWLEDGE ECONOMIES: TRENDS AND FEATURES}

\section{Sources of growth}

\section{Employment in the crisis}

Between 2008 and 2009, in the immediate aftermath of the crisis, the OECD as a whole suffered a net loss in employed persons of about 11 million, a 2\% drop. Half of these losses occurred in the United States. An increase in employment of 3.2 million in OECD "Community, social and personal services" only partly offset a fall of 14.2 million in other sectors. Manufacturing was the hardest hit, with significant declines in all OECD countries. The construction sector was most affected in Chile, Estonia, Iceland, Ireland, Greece and Spain. For finance and business services, losses were particularly significant in France, Japan, the Netherlands, the United Kingdom and the United States. The wholesale, retail, hotel and transport sectors remained unscathed in very few OECD countries.

Where people lost their jobs, 2008-09

Relative contribution to change in total employment by major sectors of economic activity
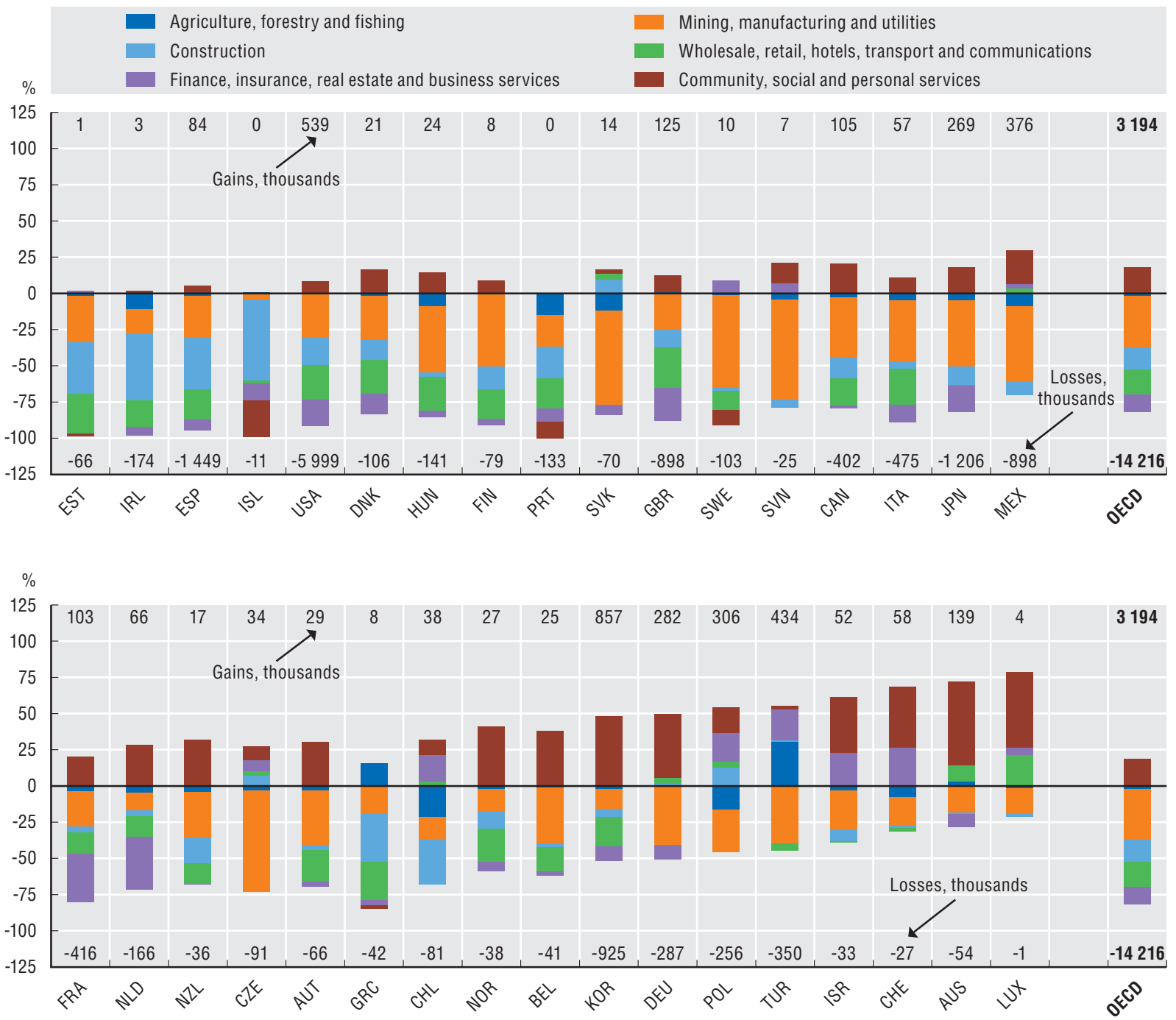

Source: OECD, Structural Analysis (STAN) Database, OECD National Accounts (SNA) Database and national statistical institutes, June 2011. See chapter notes. 
A corrigendum has been issued for this page. See: http://www.oecd.org/dataoecd/26/8/48742541.pdf For many OECD countries, significant losses in employment continued well into 2010. Available data for Europe show that countries such as Denmark, Estonia, Greece, Ireland and Spain endured further falls of more than $2 \%$ compared to 2009.

\section{Where people lost their jobs in Europe, 2009-10}

Relative contribution to change in total employment by major sectors of economic activity

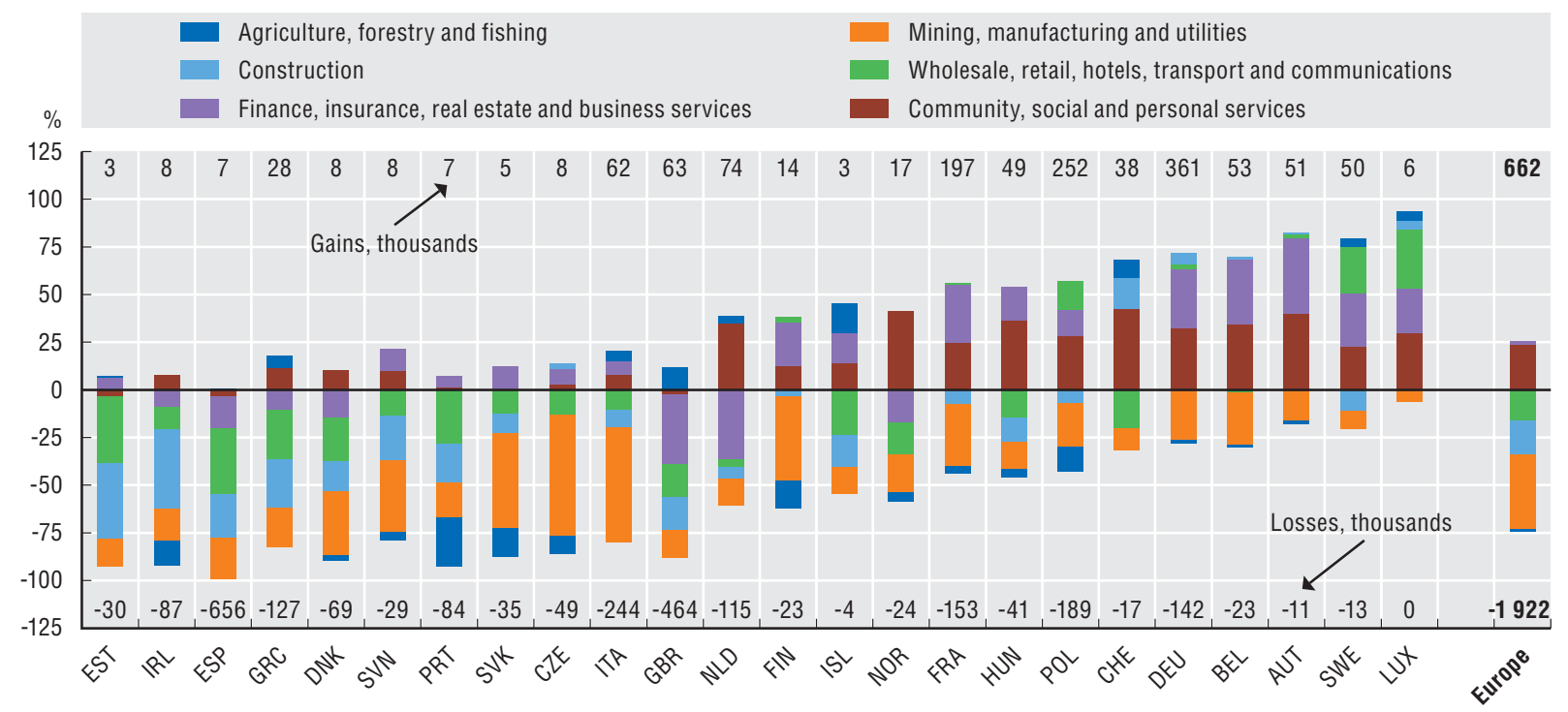

Source: OECD, National Accounts (SNA) Database and national statistical institutes, June 2011. See chapter notes.

\section{How to read these figures}

To assess the impact of the recent economic crisis on employment in different sectors of activity, sectoral changes in levels of employment can be "normalised" in order to highlight their relative contributions, within each country, to the total change in employment between 2008 and 2009. This is achieved, for each country, by expressing the sectoral changes as a percentage of the sum of the absolute changes. The aggregate activity groups are defined according to ISIC Rev. 3 Classes 01-05, 10-41, 45, 50-64, 65-74 and 75-95 respectively. The source data provided to the OECD are defined according to ISIC Rev. 3. However, for France, Iceland and Switzerland the recent national data published with NACE Rev. 2 (ISIC Rev. 4) breakdowns have been used.

The gains and losses, in thousands, represent respectively the sum of the aggregate sectors with positive changes and the sum of the aggregate sectors with negative changes. With a finer activity breakdown (for example, 2-digit ISIC Rev. 3) the estimates for total gains and losses would be different. For example, within the losses noted for Finance, insurance, real estate and business services (65-74), certain (2-digit) business services may have experienced modest gains in employment. However, given the widespread falls across activities between 2008 and 2009, using 2-digit data (if available) would not make a notable difference to the analysis.

The employment data are mostly drawn from National Accounts (SNA) sources and are measured in terms of persons except for Canada, Japan and New Zealand where figures for jobs are provided. Care should be taken when comparing the changes in structural employment in these three countries with the others. In general, for countries that provide employment measured in both persons and jobs, loss of jobs outnumbered loss of employed persons, as people switched to part-time work, job sharing, etc. For example, while the United States lost about 6.5 million jobs between 2008 and 2009, in terms of persons the drop is closer to 5.5 million. 


\section{KNOWLEDGE ECONOMIES: TRENDS AND FEATURES}

\section{Sources of growth}

\section{New sources of growth: intangible assets}

Innovation results from more than investment in research and development (R\&D). It requires complementary assets such as software, human capital and appropriate organisational structures. Investment in such intangible assets is rising and even exceeds investment in physical capital (machinery and equipment) in Finland, the Netherlands, Sweden, the United Kingdom and the United States.

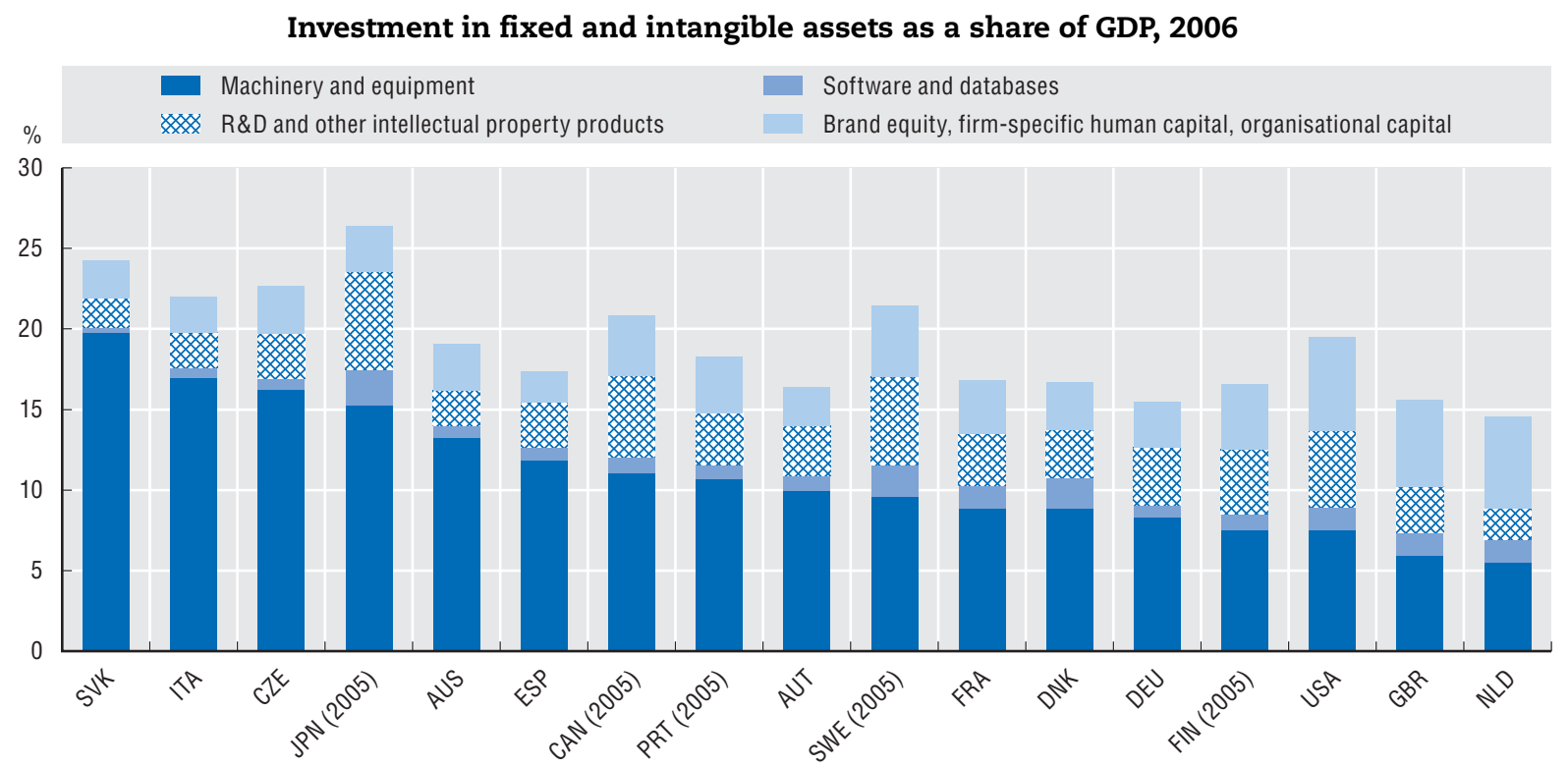

Note: Estimates are based on national studies. They do not reflect standardised methods and definitions.

Source: OECD, data on intangible investment are based on COINVEST, www.coinvest.org.uk and national estimates by researchers. Data for fixed investment are OECD calculations based on OECD, Annual National Accounts and EU KLEMS Databases, March 2010. See chapter notes.

StatLink काISL http://dx.doi.org/10.1787/888932484854

\section{What do we mean by "intangible assets"?}

Sometimes referred to as "knowledge assets" or "intellectual capital", intangible assets have been defined as "claims on future benefits that do not have a physical or financial embodiment" (Lev, 2001). Much of the focus has been on R\&D, key personnel and software, but the range of intangible assets is considerably broader. One classification, offered by Corrado, Hulten and Sichel (2006), groups intangible investments into three main types: computerised information (such as software and databases); innovative property (such as scientific and non-scientific R\&D, copyrights, designs, trademarks); and economic competencies (including brand equity, firm-specific human capital, networks of people and institutions, the organisational know-how that increases enterprise efficiency, and aspects of advertising and marketing). Using this paper as their basis, researchers in several countries have computed aggregates for intangible investment. Some intangibles - software and, more recently, R\&D - are now recognised by the international statistical community as capital assets and will be accounted for in the System of National Accounts (see the OECD Handbook on Deriving Capital Measures of Intellectual Property Products, 2010). More work is needed to harmonise the definition of intangible assets and collect data on an internationally comparable basis so as to better identify and measure new sources of growth. 


\section{Intangible assets and productivity}

A new stream of research argues that firms' investment in intangible assets contributes to their output growth not only in the present but also in future years. Estimates of the contribution of intangible assets to growth of labour productivity show that, in some countries, these explain a significant portion of multi-factor productivity growth (a measure of technological change and of our inability to properly measure economic performance).

\section{Labour productivity growth: adding the contribution of intangible assets, 1995-2006}

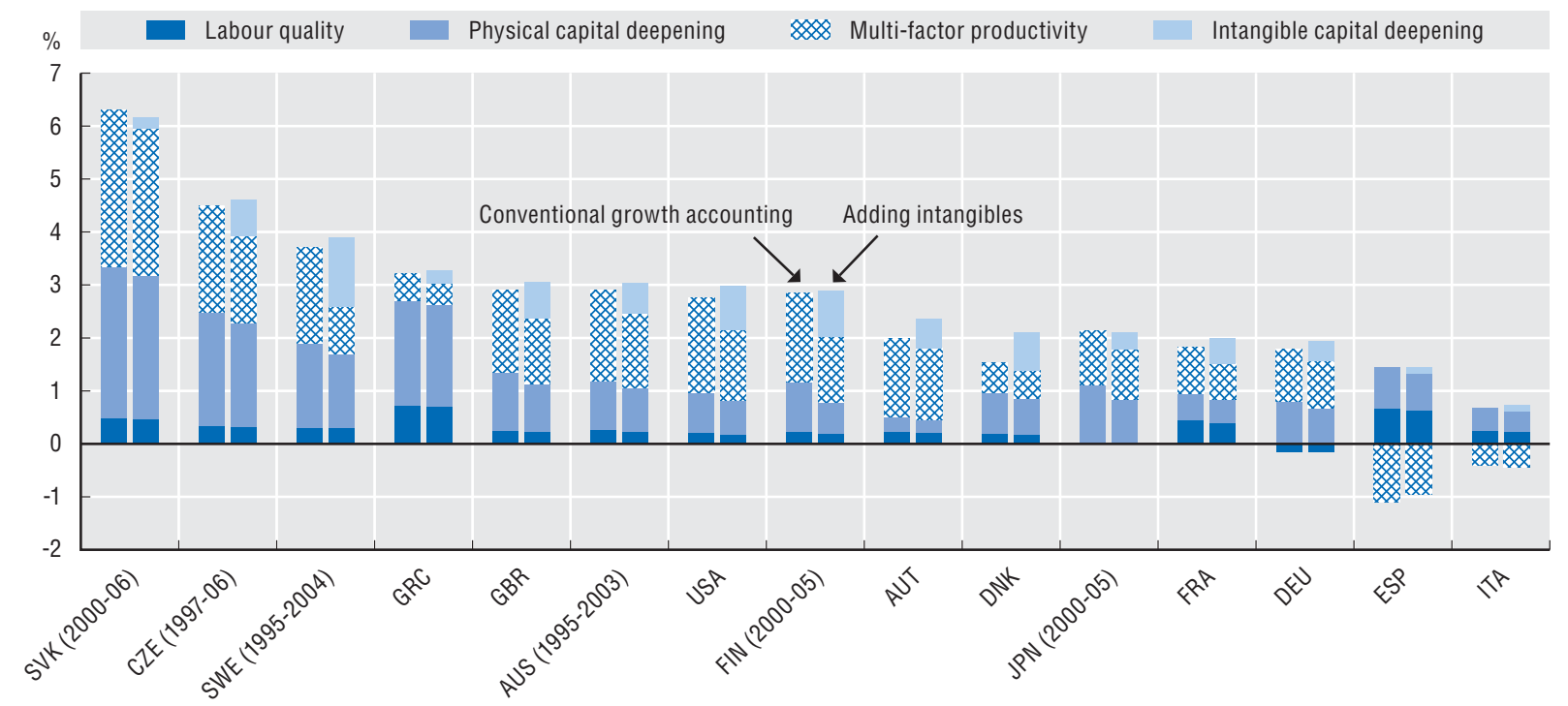

Note: Estimates based on national studies. They do not reflect standardised methods and definitions.

Source: OECD, based on research papers, 2009. See chapter notes.

StatLink ला1sस http://dx.doi.org/10.1787/888932484873

\section{How to read this figure}

What happens when investment in intangible assets other than software is included in estimates of GDP and added to the breakdown of labour productivity growth? In this case GDP is roughly expected to increase by the equivalent of investment in those intangibles, adjusted for trade in intangibles. The contribution of physical capital (machines and information and communication technologies, ICT) to labour productivity growth declines because investment in software becomes part of the investment in intangible assets. Multi-factor productivity (MFP) reflects efficiency in the use of labour and capital inputs, for example through improvements in the management of production processes, organisational change or more generally, R\&D and innovation. MFP declines as investment in R\&D and in other intangible assets related to innovation is accounted for as a distinct source of growth: "intangible capital deepening". Although the comparability of these estimates is still poor, owing to differences in data sources, methodologies and assumptions for deflators and depreciation rates, they are a first step in recognising the importance for growth of investment in intangible assets. 


\section{KNOWLEDGE ECONOMIES: TRENDS AND FEATURES}

\section{The new geography of growth}

\section{FDI shifting east}

Foreign direct investment (FDI) provides recipient countries with access to new technologies and generates knowledge spillovers for domestic firms and additional investment in research and development (R\&D). In the last 15 years FDI flows have tripled. FDI inflows to Europe still exceed those to the rest of the world, but FDI flows to China and the rest of South-East Asia have leapt from an average of about USD 50 billion a year in 1995-99 to about USD 150 billion a year in the latest period. The United States remains the biggest recipient and investor, with China set to become the second largest FDI recipient.

\section{Foreign direct investment inflows, 1995-99, 2000-04 and 2005-09}

Yearly averages

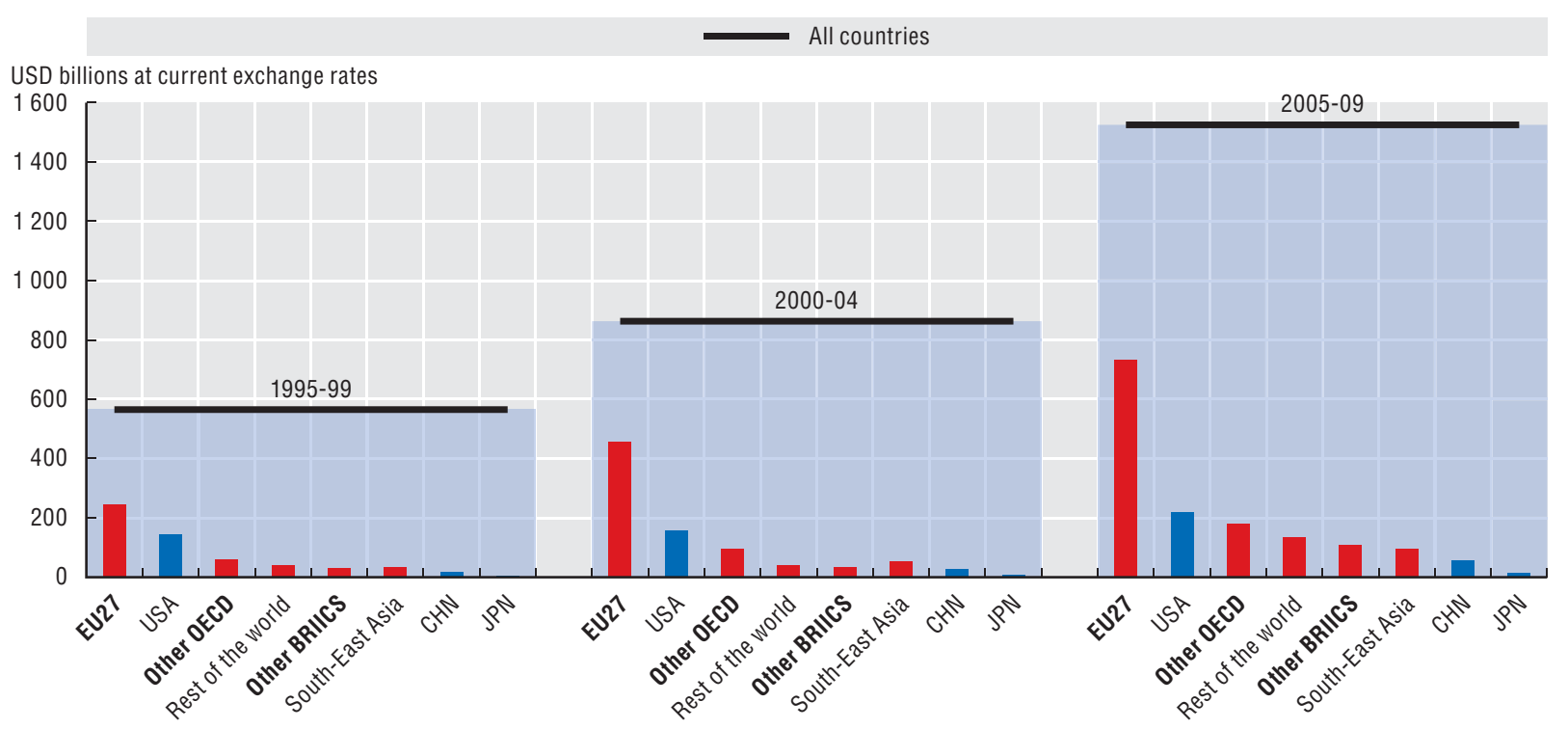

Source: IMF, Balance of Payments Database, May 2011. See chapter notes. 
During the period 2003-09, EU countries invested four times as much in the BRIICS economies as the United States or Japan. European direct investment in China averaged USD 6.5 billion a year, 75\% more than that from the United States, and over USD 9 billion a year in Brazil, four times that from the United States. In the meantime, international direct investment by the BRIICS themselves increased substantially as these economies became more integrated in the global economy. Average outward flows from China increased nine-fold between the early and late 2000s while those of India increased more than seven-fold.

Outward foreign direct investment flows from EU, Japan and the United States to BRI*CS ("India), yearly average 2003-09

USD billions at current exchange rates

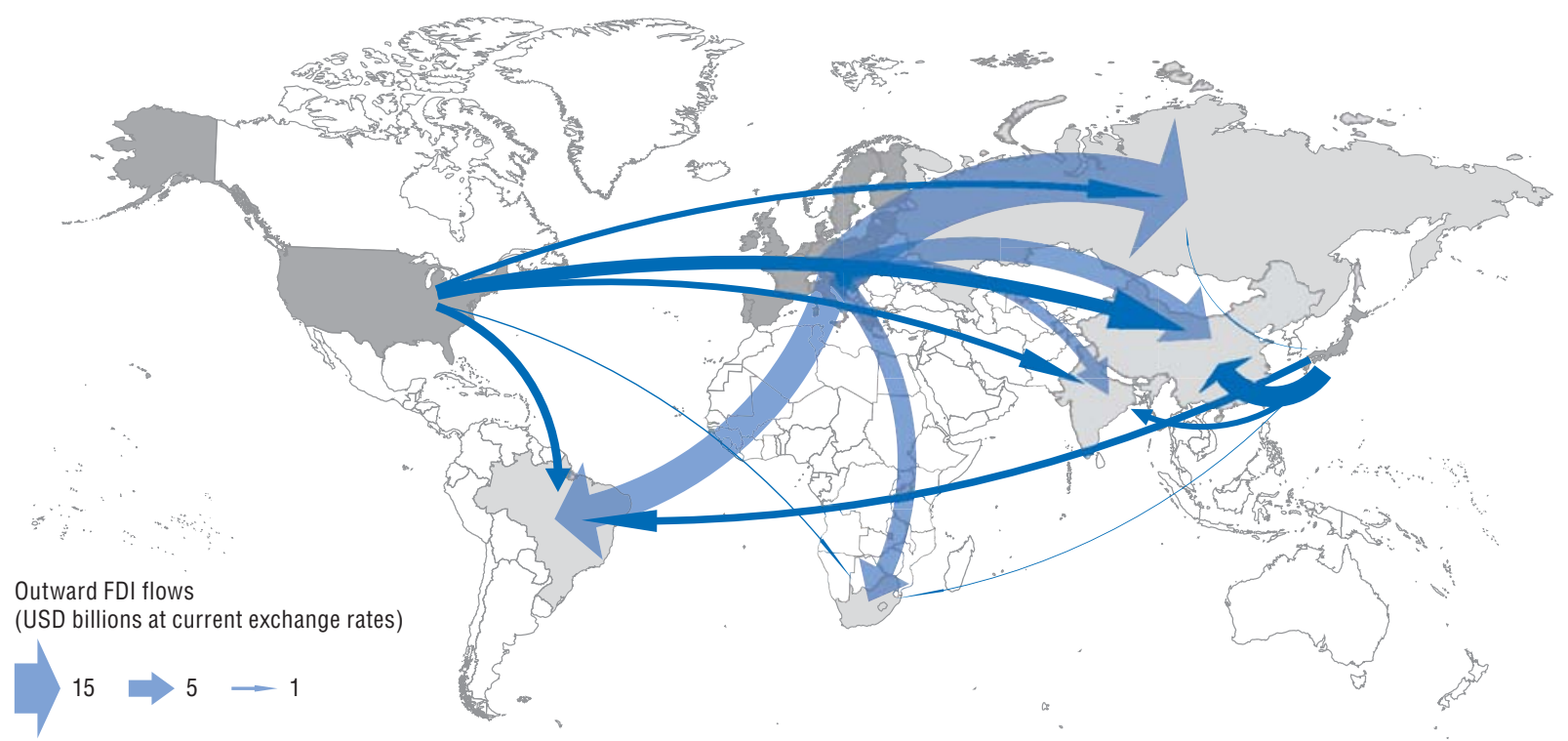

Source: OECD calculations based on OECD, International Direct Investment Database, May 2011. Map source: ARTICQUE® - all rights reserved. See chapter notes.

Foreign direct investment outward flows from BRIICS, 1994-97, 2002-05 and 2006-09 Yearly averages

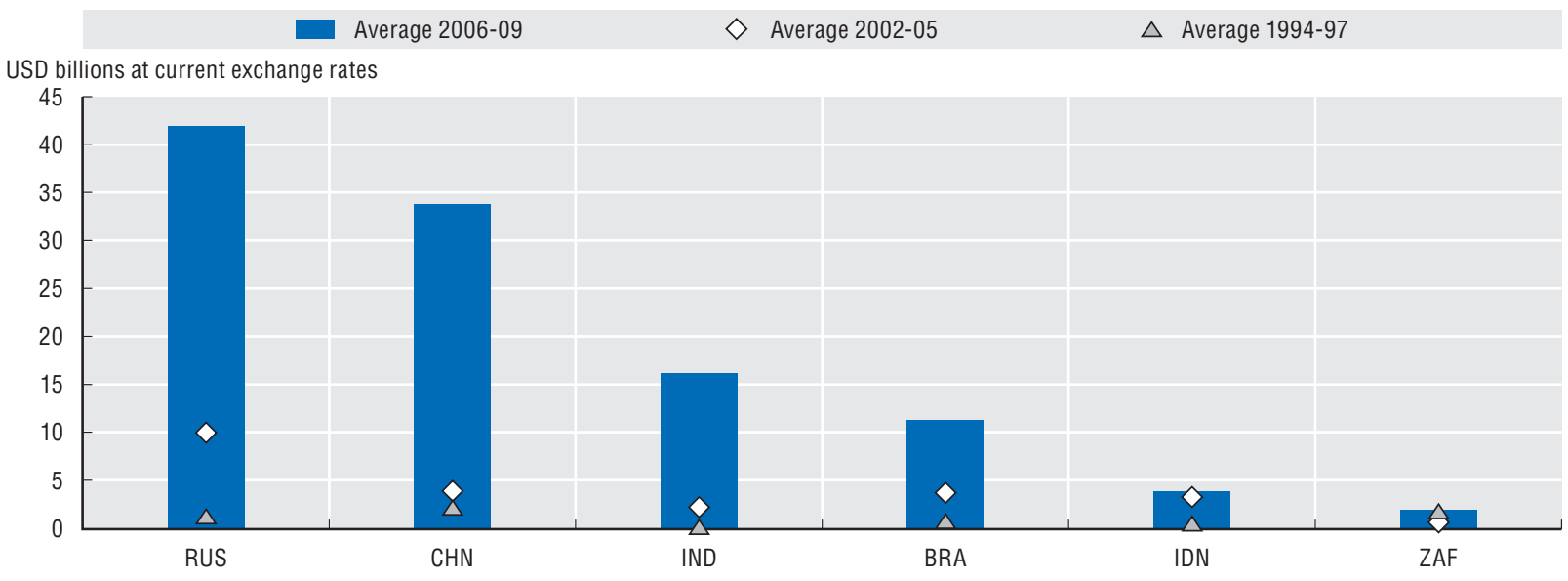

Source: IMF, Balance of Payments Statistics, June 2011. See chapter notes. 


\section{KNOWLEDGE ECONOMIES: TRENDS AND FEATURES}

The new geography of growth

\section{Emerging players in high-technology trade}

Unsurprisingly, the crisis negatively affected the value (and volume) of manufacturing trade in the OECD area. A look at broad trends by technology intensity indicates that the value of OECD manufacturing trade was essentially driven by high-technology manufactures from the second half of the 1990s to the mid-2000s. Early in 2005, OECD trade in high-technology manufactures started to drop to around the same level as trade in medium-high-technology manufactures; at the same time, trade in medium-low-technology industries rose sharply. The peak in the value of trade in medium-low-technology manufactures was partly due to the increase in prices for oil, petroleum products and basic metals, notably those required for the manufacture of ICT goods.

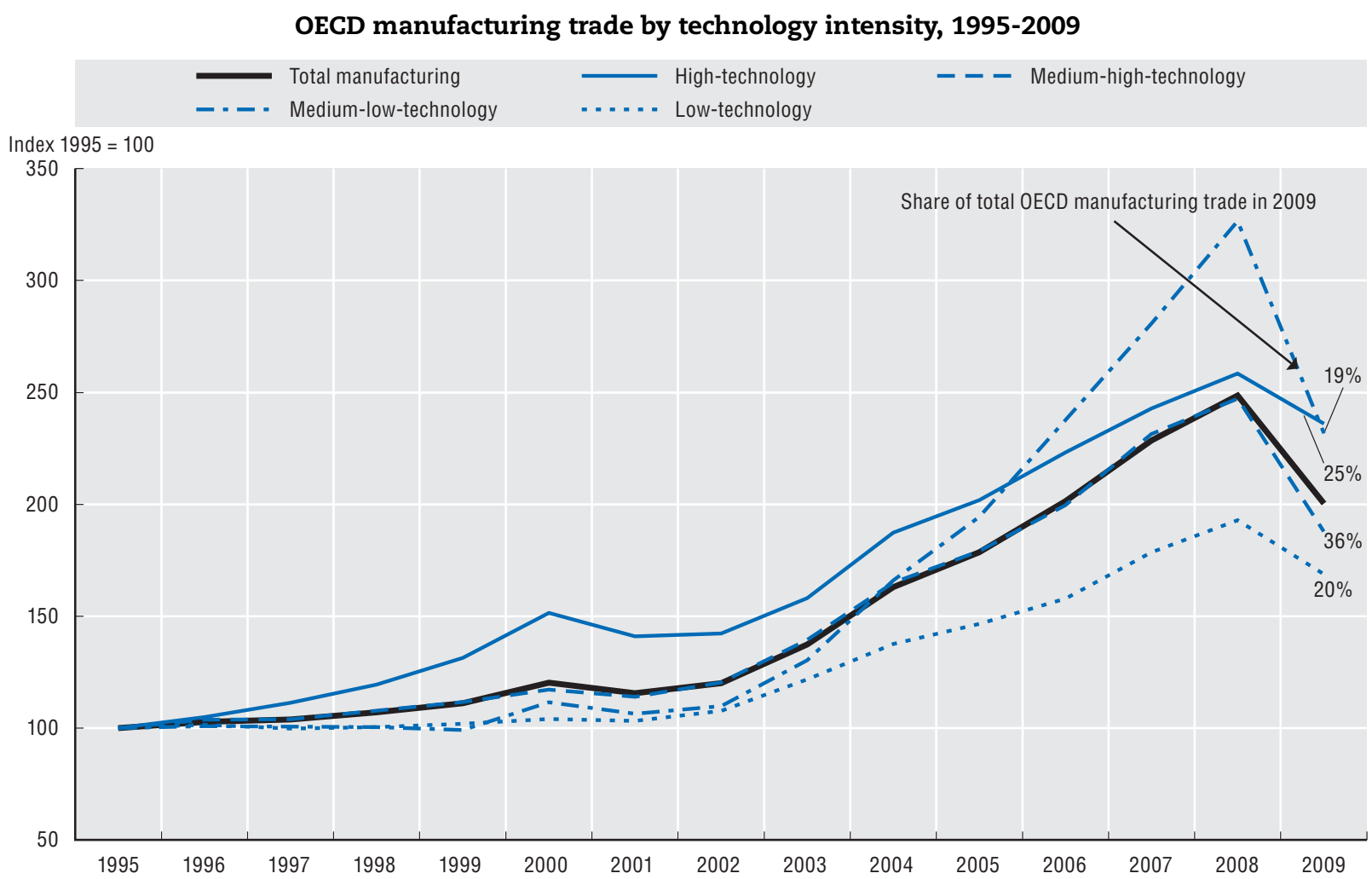

Source: OECD, STAN Bilateral Trade Database, May 2011. See chapter notes. 
In the BRIICS, high-technology manufacturing trade has increased continuously in the last 20 years and now represents about $30 \%$ of their total manufacturing trade, compared to $25 \%$ for the OECD area.

BRIICS manufacturing trade by technology intensity, 1995-2009

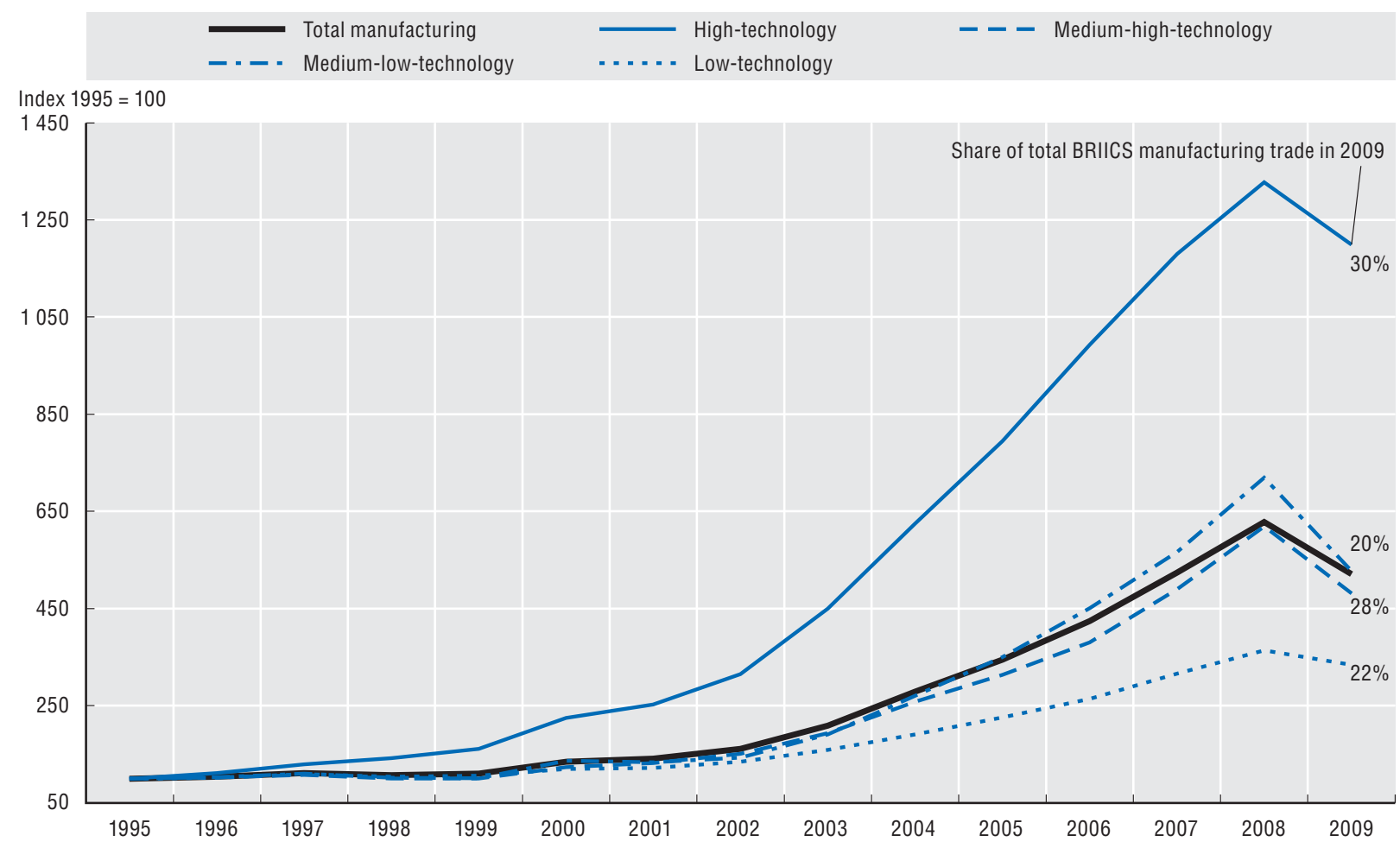

Source: OECD, STAN Bilateral Trade Database, May 2011. See chapter notes.

\section{What is technology intensity?}

The OECD classification for manufacturing industries (high, medium-high, medium-low and low technology) is based on indicators of direct and indirect R\&D intensity and reflects to some degree technology-producer aspects. The analysis of trade flows by technology intensity requires allocating each product to an industry. This classification has some limitations since some products from a high-technology industry do not necessarily have only high-technology content. 


\section{KNOWLEDGE ECONOMIES: TRENDS AND FEATURES}

\section{The new geography of growth}

\section{Global value chains and world trade}

The pace and scale of today's globalisation process is unprecedented. Its distinctive features are increasing international trade, deepening economic integration, especially in emerging economies, and greater geographic fragmentation of production processes and more complex global value chains. A new OECD database provides estimates of bilateral trade broken down by industry and end-use categories. It reveals how much a country's exports satisfy foreign household consumption or how much they are used in production processes in foreign countries, either as intermediates or as capital goods (machinery and equipment).

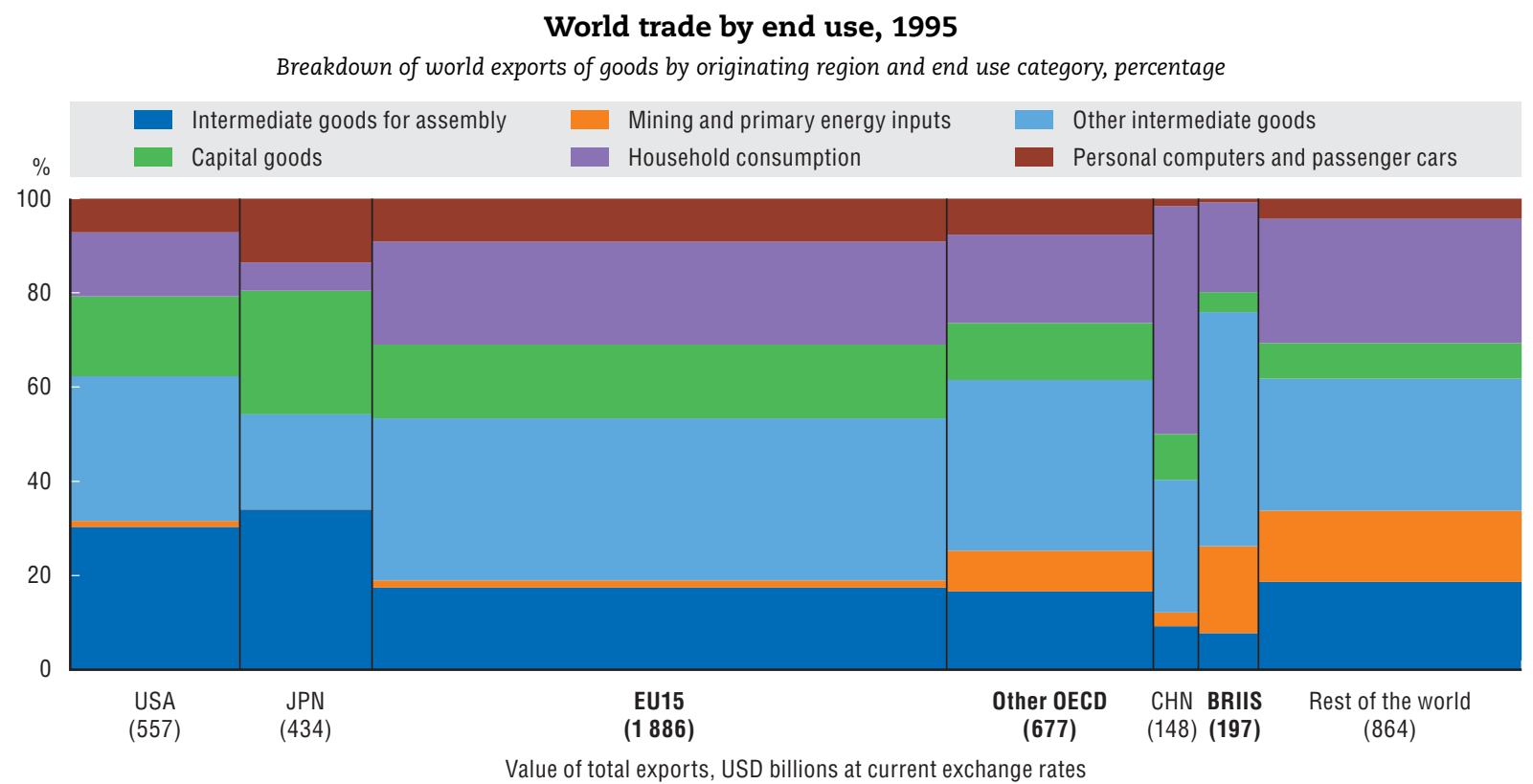

Source: OECD, Bilateral Trade Database by Industry and End-Use Category (forthcoming). See chapter notes.

StatLink काजि http://dx.doi.org/10.1787/888932484987

\section{How to read this figure}

The width of each bar is proportional to the value of each region's total manufacturing exports. The height of each category, e.g. household consumption, is proportional to the share of that end-use category in each region's exports. Converting commodity-based statistics into industry and end-use based figures presents certain challenges. For example, personal computers and passenger cars can be both consumer and investment goods: 6-digit HS codes do not give information on the final purchaser. As a result, it is hard to tell whether a computer exported from country A to country B is eventually purchased by a household for final consumption or by an enterprise as investment. For this reason, personal computers and passenger cars are shown separately. 
In 1995 the value of China's exports was USD 148 billion, of which 60\% was destined for final consumption. By 2009, the value of China's exports had increased more than tenfold from USD 148 billion to USD 1529 billion and the structure of its exports had changed substantially. The last 15 years have seen increased trade in primary resources such as energy inputs, a more than tenfold increase in the value of exports from China, and China's increased role as an exporter of high-end intermediates and capital goods. OECD countries' share of world exports declined from $75 \%$ to $60 \%$.

World trade by end use, 2009

Breakdown of world exports of goods by originating region and end use, percentage

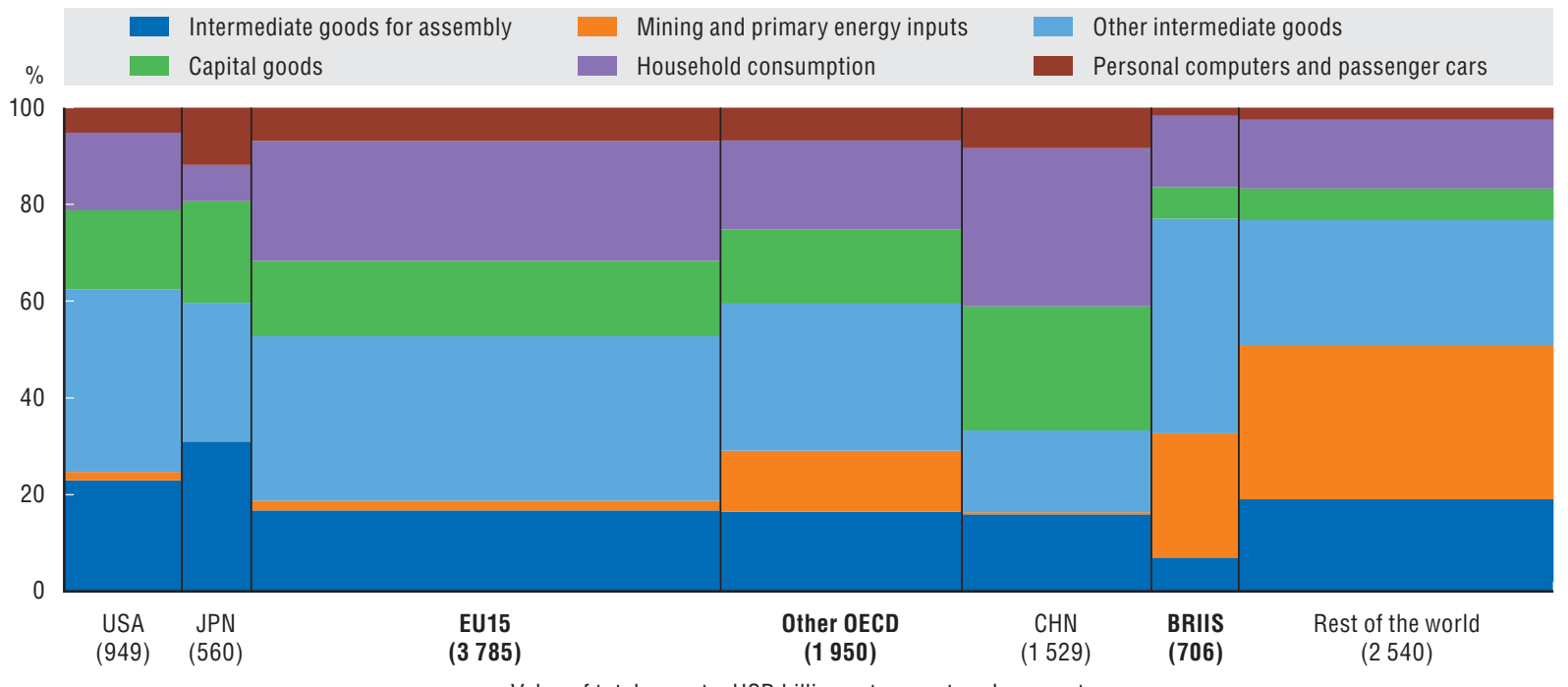

Value of total exports, USD billions at current exchange rates

Source: OECD, Bilateral Trade Database by Industry and End-Use Category (forthcoming). See chapter notes.

StatLink क्ञाइस http://dx.doi.org/10.1787/888932485006

\section{The new BTDIXE}

World production value chains can be mapped by combining world trade data and multi-country input-output (I-O) tables. The OECD STAN Bilateral Trade Database by Industry and End-Use Category (BTDIxE) is a step in that direction. It provides estimates (1990-2009) of the values of imports and exports of goods by industrial sectors and by end-use categories (e.g. use for final consumption or as intermediate inputs into production). BTDIxE is built by applying standard conversion keys to map products (according to HS classifications) to ISIC Rev. 3 industries and to the Broad Economic Categories (BEC) classification. It provides a first glimpse as to where countries are on industry value chains by identifying which categories of goods are imported and from whom and where the final products for household consumption and investment go. Linking with OECD's industry by industry "harmonised" I-O databases could provide more insight into end use and eventually highlight the origins of value added in internationally traded goods. 


\section{KNOWLEDGE ECONOMIES: TRENDS AND FEATURES}

The new geography of growth

\section{Increasing global interdependencies}

The time when all stages of production of final goods took place within an economy, and only raw materials were imported as intermediate inputs, is long gone. Today, companies exports various stages of production of many final goods, and now services, across many economies. This international fragmentation of production has ballooned in the last two decades to become truly global, and many economies' production processes have become vertically specialised for a range of goods and services. To begin to understand this development it is not enough to compare direct imports to measures of domestic production. For example, a computer manufacturer who imports components may also purchase components from domestic manufacturers who have used imports in their production processes. In that case, the computer manufacturer's imports may contain elements produced in its economy.

Import content of exports for selected economies and regions, 1995

By economy/region of origin of imports, USD millions, at current prices
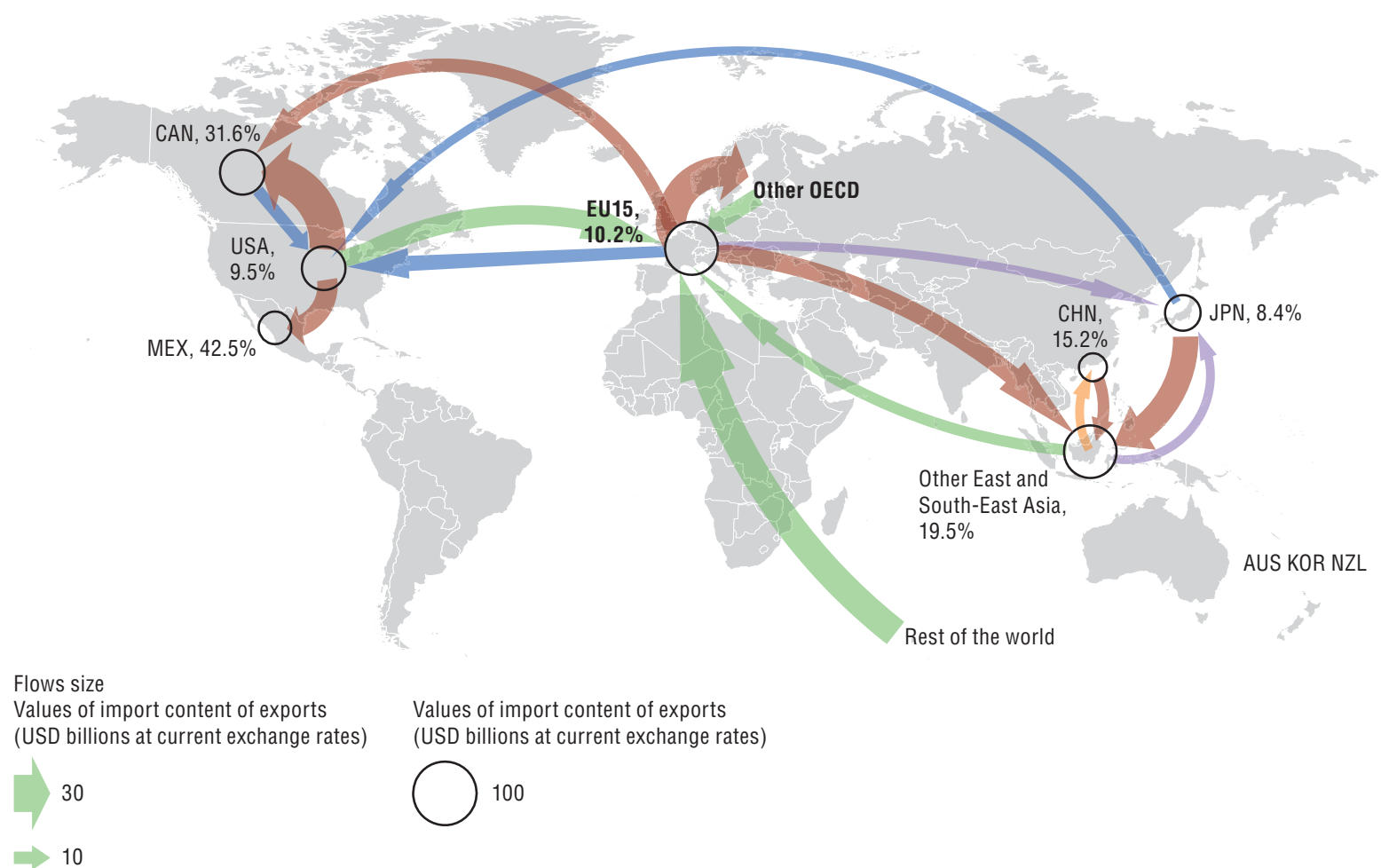

Source: OECD, STAN Input-Output Database, May 2011; STAN Bilateral Trade by Industry and End-Use Category (forthcoming); map source: ARTICQUE@ - all rights reserved. See chapter notes.

StatLink काIs http://dx.doi.org/10.1787/888932485025

\section{How to read this figure}

The size of the bubble represents the total amount of imports, direct and indirect, embodied in an economy's, or a region's, total exports of goods and services for final demand (e.g. household and capital consumption). Percentages indicate the share of that "import content of exports" in total exports. This is broken down to reveal the origin of the imported (intermediate) content (arrows). For example, the import content of Chinese exports for final demand is estimated to have increased from $15.2 \%$ to $27.4 \%$ between 1995 and 2005. 
The vertical specialisation measure, import content of exports, tries to reflect the resulting interdependencies by determining, via input-output tables linked to bilateral trade statistics, the extent to which imported inputs, both direct and indirect, contribute to an economy's exports. For most economies, the presence of embodied imports in exports has increased in the last decade (size of the bubbles). Their origins have changed, a clear sign of growing and evolving interdependencies. For example, while in recent years China has increasingly relied on imports (notably from Europe, Japan and other OECD economies) to produce final goods for export, other economies (such as Japan) have seen significantly more content of Chinese origin embodied in their exports of final goods.

Import content of exports for selected economies and regions, 2005

By economy/region of origin of imports, USD millions, at current prices

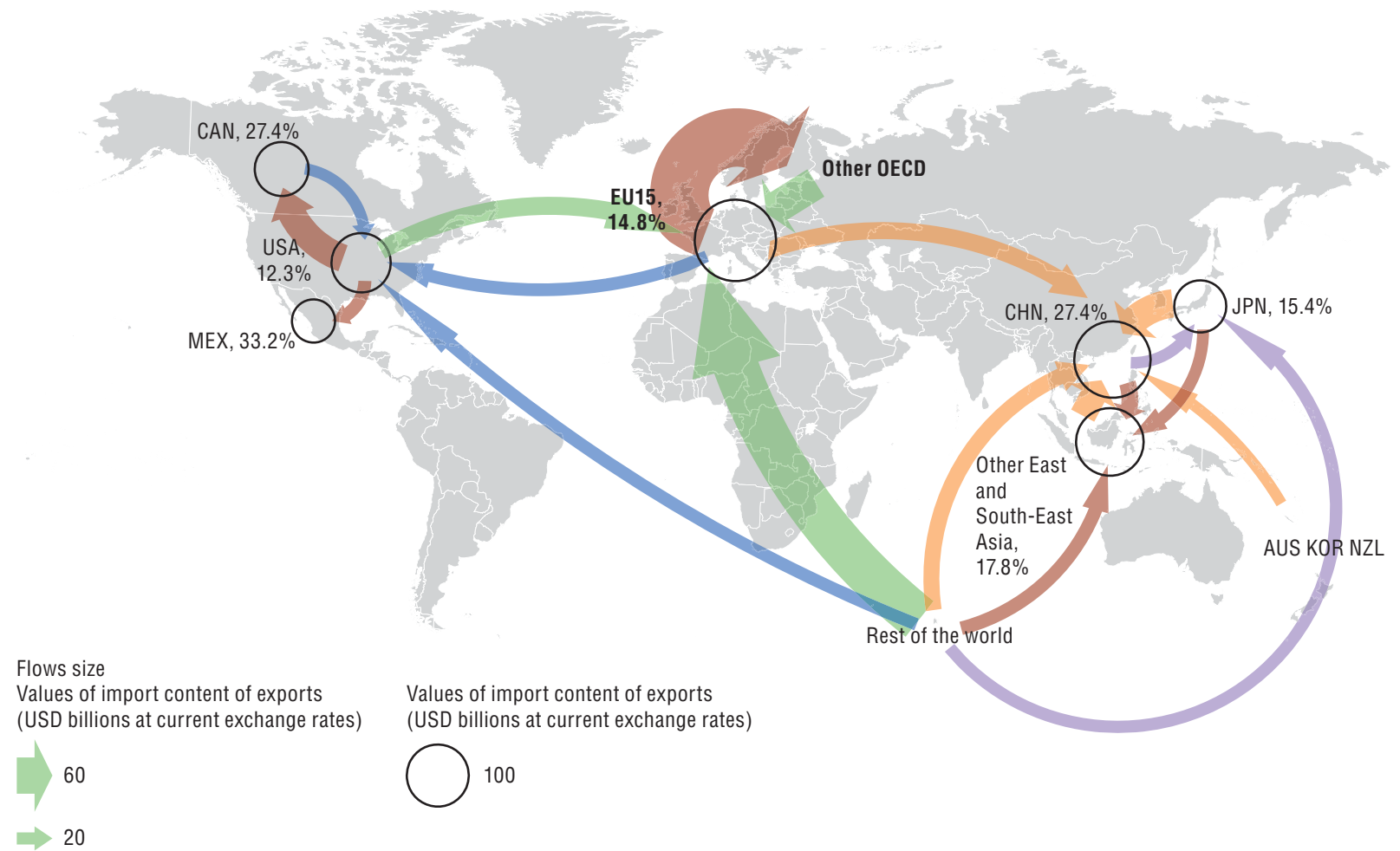

Source: OECD, STAN Input-Output Database, May 2011; STAN Bilateral Trade by Industry and End-Use Category (forthcoming); map source: ARTICQUE@ - all rights reserved. See chapter notes. 


\section{KNOWLEDGE ECONOMIES: TRENDS AND FEATURES}

The new geography of growth

\section{Increasing specialisation}

Over the last three decades countries' economies have increasingly relied on fewer sectors. The Hannah-Kay (HK) index reflects sectors' contributions to a country's GDP and accounts for the extent to which economies are influenced by larger sectors. A falling HK correspond to rising economic specialisation. G7 countries appear to have become increasingly specialised since the 1970s, with Canada the only G7 country to experience periodic bursts of diversification. In contrast, Korea's HK index partially reflects the development path previously travelled by G7 countries - early increasing diversification (into industry and services), peaking in the late 1980s, before embarking on gradual specialisation as its new comparative advantages became evident.

Diversification index (Hannah-Kay) for selected countries, 1978-2009

Sectoral concentration measured by shares of sectors in total value-added, current prices
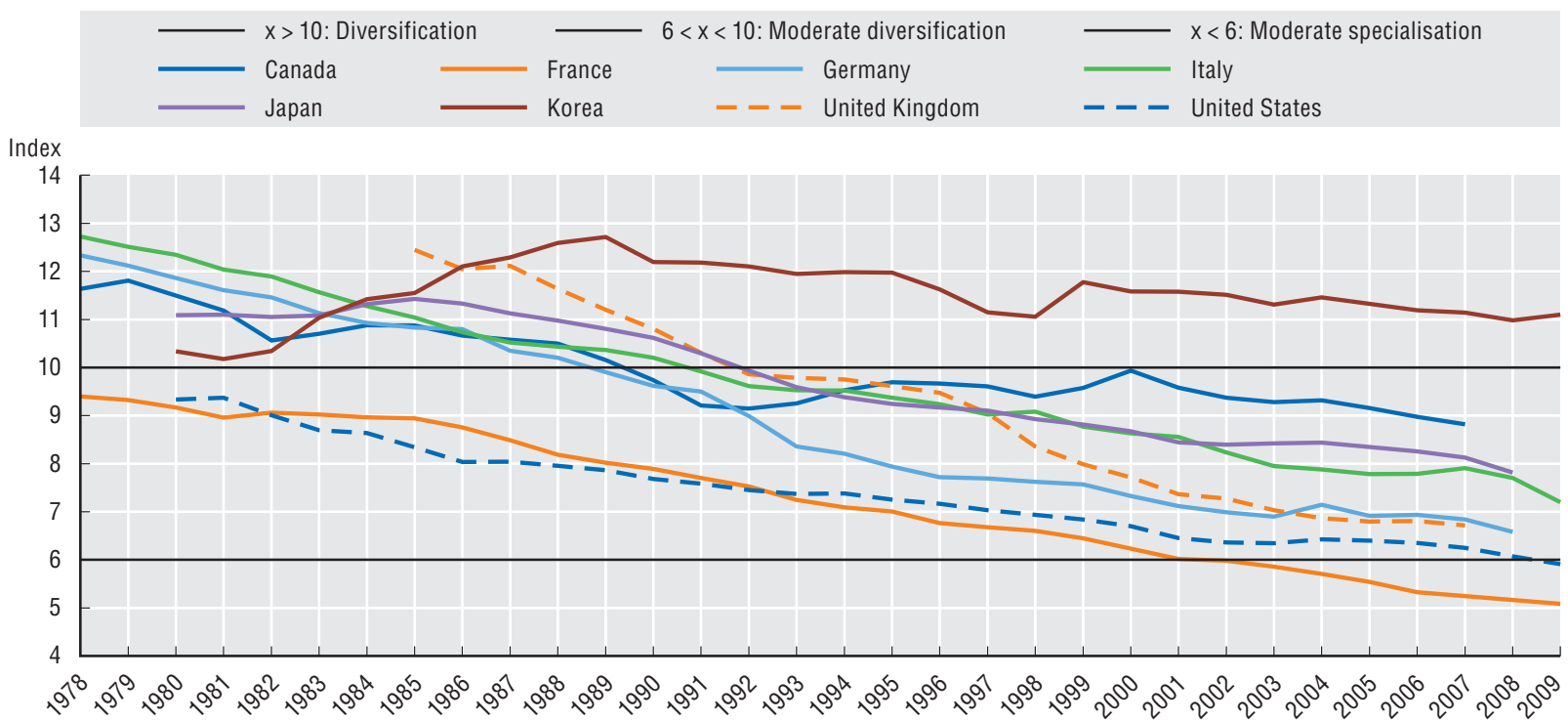

Source: OECD, Structural Analysis (STAN) Database, May 2011. See chapter notes.

StatLink का1sL http://dx.doi.org/10.1787/888932485063

\section{How to read this figure}

The figure uses the HK(2) index, which corresponds to the inverse of the Herfindahl Index. It relies on 20 sectors and takes values ranging from 1 to 20. According to the measure used, countries can be considered diversified for values of $H K(2)$ greater than 10, moderately diversified for $\mathrm{HK}(2)$ values between 10 and 6, moderately specialised for $\mathrm{HK}(2)$ values between 6 and 4, and specialised for values smaller than 4.

\section{What happens to major sectors in the economy?}

Between 1978 and 2009 business activities and the real estate sector grow - in Korea up to 2.6 times its initial value. The importance of agricultural activities generally decreases, as does the manufacturing of textile and leather products. At the beginning of the period the top sectors' shares of GDP range between $15 \%$ and $22 \%$; by the time countries specialise the top sectors' share account for $22 \%$ to $34 \%$ of total value added. Countries' top-scoring sectors seldom remain the same over time, even if there is a general tendency for manufacturing activities to lose importance progressively as compared to services. Korea is an exception, as the importance of the transport equipment industry was multiplied by 4.2. The patterns observed for Canada and Korea mirror changes over time in the relative importance of sectors. For instance, in Canada the share generated by mining and quarrying halved during 1978-98 (from almost $8 \%$ to $4 \%$ of GDP), and increased constantly from 1999 onwards (to almost 11\% in the 2007). In Korea, experimentation in the form of alternate phases of rise and fall characterise many sectors, including electricity, gas and water supply; construction; and financial intermediation. 


\section{Global manufacturers}

Manufacturing activities have globalised over the last 20 years. In 1990 the G7 accounted for two-thirds of world manufacturing value added but now accounts for less than half. By 2009 China had almost caught up with the United States in manufacturing production, and the role of Brazil and India among world manufacturers is now the same as Korea's. As manufacturing production declines in OECD economies, the contribution of services to GDP rises: it now represents $70 \%$ of OECD value added. In contrast to OECD economies, the industrial sector in the BRIICS has expanded by more than $4 \%$ largely in the last 20 years, owing to a shrinking agriculture sector $(-7 \%)$. This trend is accompanied by the rising importance of the services sector in the Russian Federation, China and India, following income growth and increased participation in global trade.

Top manufacturers in the last 20 years, 1990, 2000 and 2009

Percentage share of total world manufacturing value added

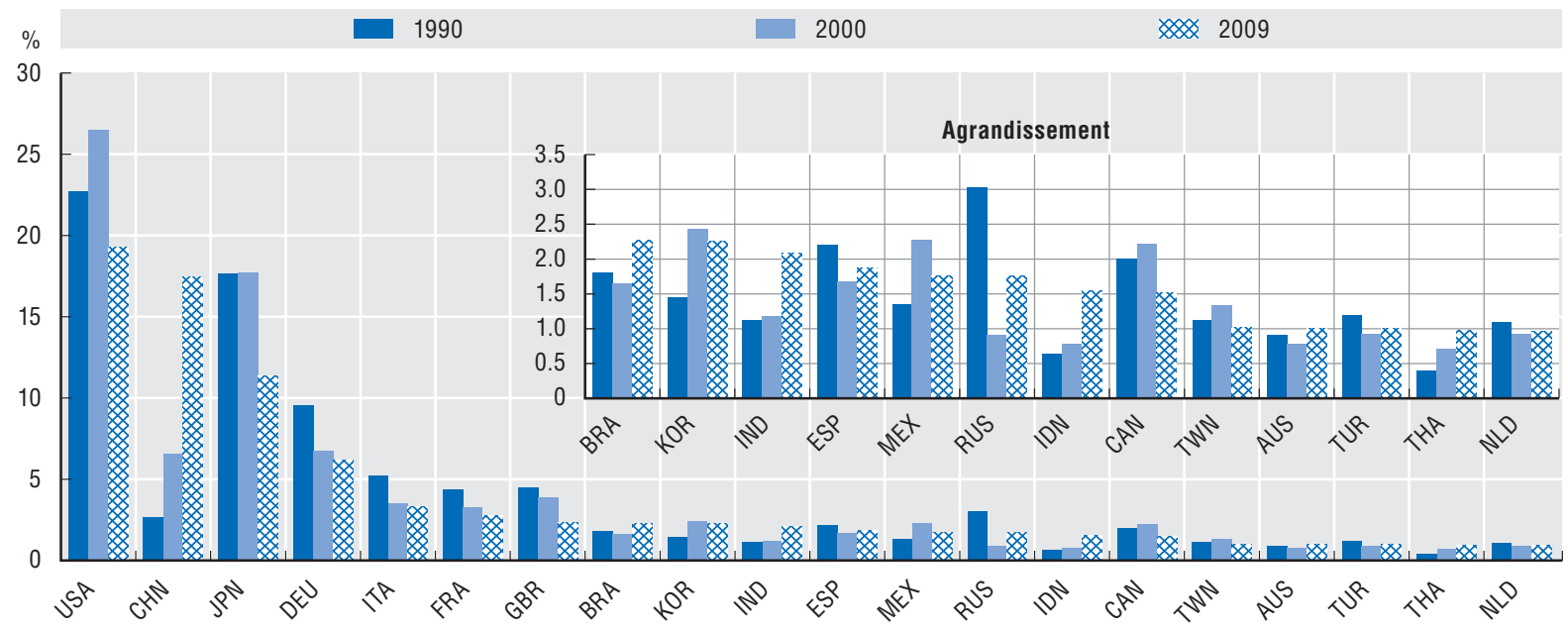

Source: United Nations Statistical Division, National Accounts Main Aggregates Database, May 2011.

StatLink क्तारम http://dx.doi.org/10.1787/888932485082

Composition of GDP in OECD and BRIICS countries, 2008

Value added of major activity groups as a percentage of total industry value added

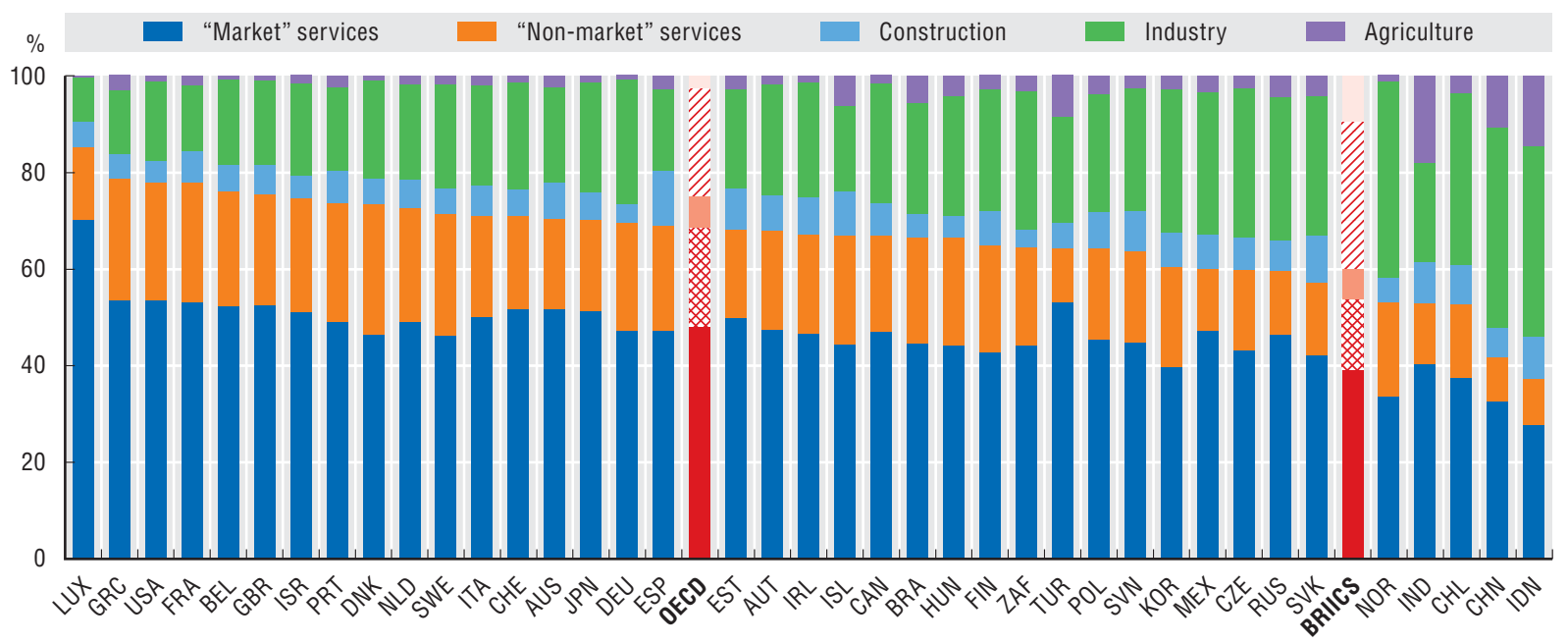

Source: OECD, Structural Analysis (STAN) Database, May 2011; OECD, National Accounts Database and national statistical institutes, May 2011. See chapter notes. 


\section{KNOWLEDGE ECONOMIES: TRENDS AND FEATURES}

\section{The changing landscape of innovation}

\section{R\&D and innovation in the crisis}

R\&D (research and development) expenditure is an investment aimed at new knowledge, products or processes. Funding may come from government or business. Government-funded R\&D aims mainly at producing new fundamental knowledge or satisfying social needs such as health or defence and is not expected to affect productivity as currently measured. Business-funded R\&D is typically oriented towards new processes and new products and is expected to increase productivity when successful. It is normally mildly pro-cyclical, i.e. it is affected by the business cycle, as it is subject to financing constraints (the availability of cash limits R\&D expenditures, as high risk and little collateral make financial markets reluctant to fund R\&D). The most recent data show that trademark activity has been strongly affected by the economic crisis, with a marked drop in finance- and insurance-related trademarks at the US Patent and Trademark Office (USPTO) from mid-2007. Goods and other services trademark activity turned down with the cycle and then up with the cycle at the beginning of 2009.

R\&D growth over the business cycle by source of financing, OECD area, 1982-2008 Average annual real growth rate, percentage

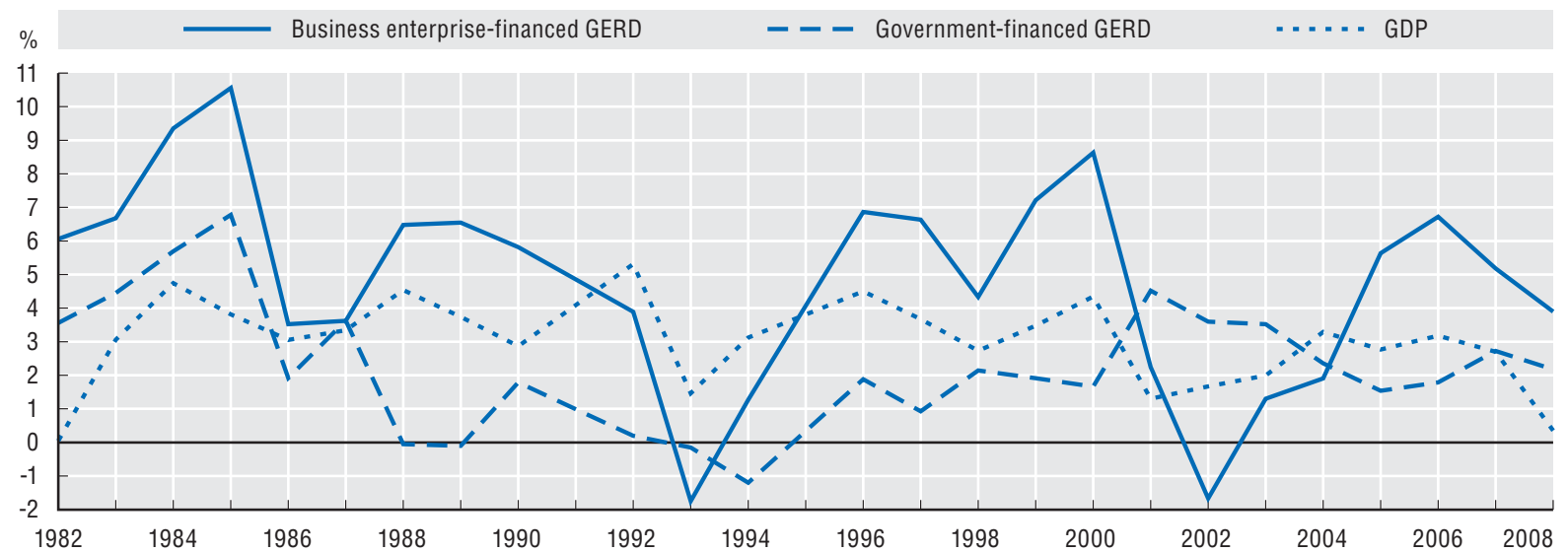

Source: OECD, Main Science and Technology Indicators Database, June 2011.

US gross domestic product and trademark applications at the USPTO, 1999-2011

Comparing cycles, by type of trademarks, percentage deviation from the long-term trend

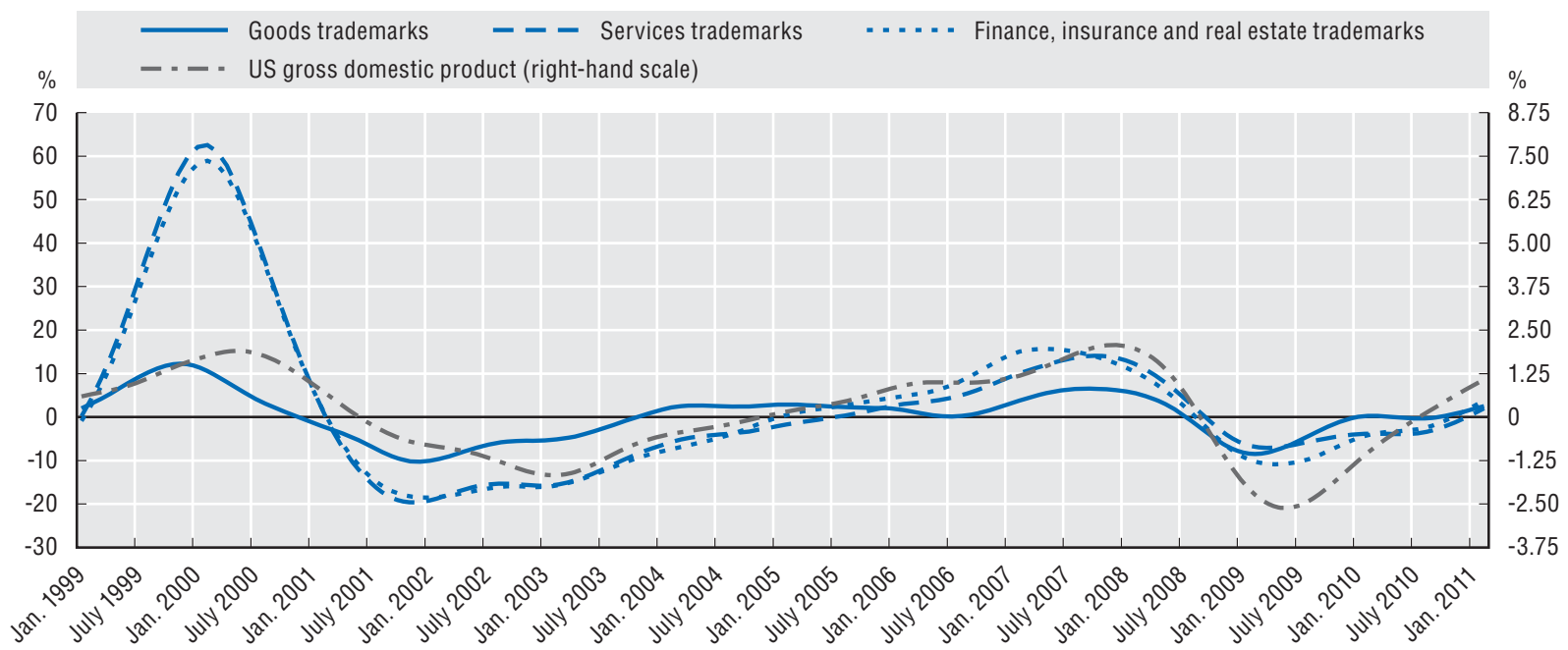

Source: OECD, based on USPTO, Trademark Electronic Search System (TESS), May 2011; and OECD, Quarterly National Accounts Database, May 2011. See chapter notes. 


\section{Financing innovation}

Access to finance for new and innovative small firms involves both debt and equity finance. Even before the recent financial crisis, banks were reluctant to lend to small, young firms. The financial crisis widened the existing gap for seed funding and early-stage financing, as venture capital firms moved to later-stage investments where risks are lower. Angel investors are often experienced and successful entrepreneurs or business people. As more and more venture capitalists have moved to later-stage financing to reduce risk, the role of angel financing has grown.

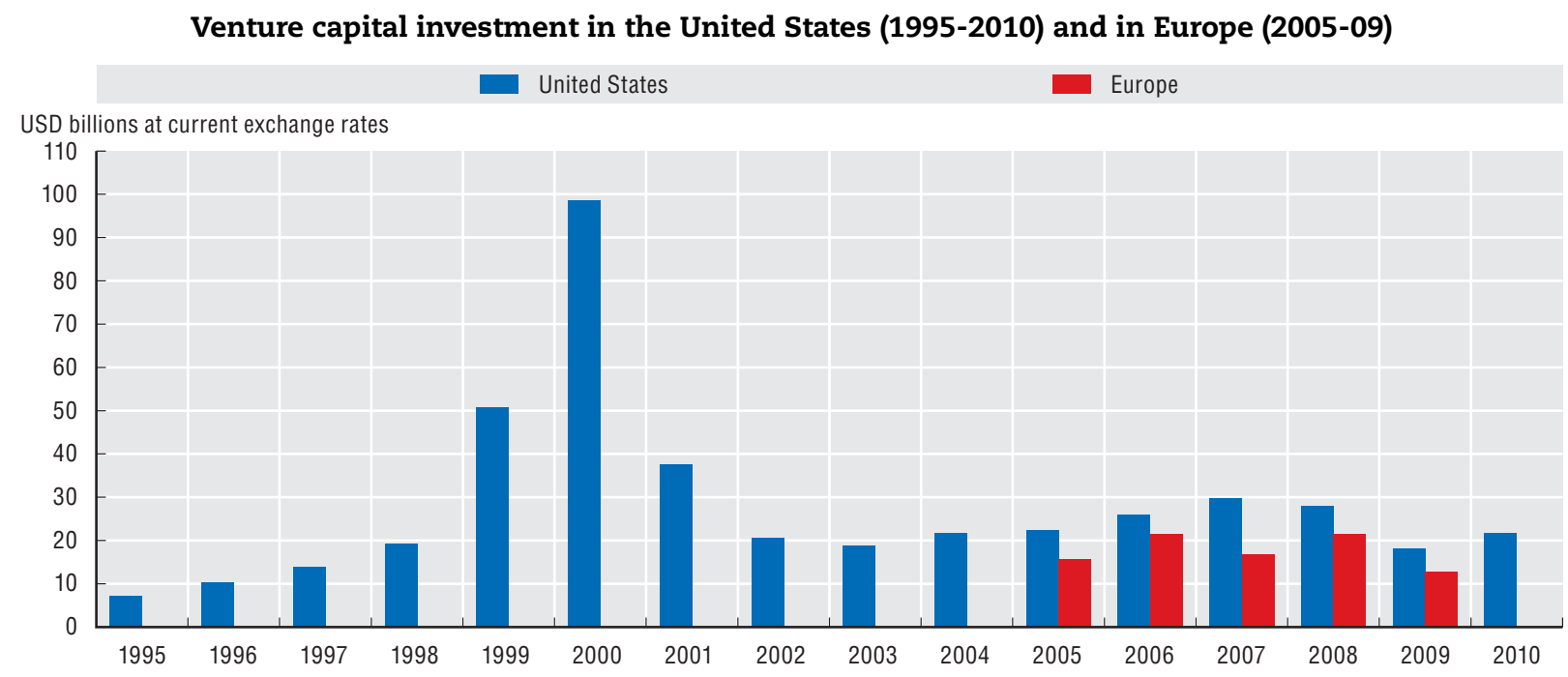

Source: OECD, calculations based on PwC/National Venture Capital Association MoneyTree, EVCA/PEREP_Analytics and EVCA/Thomson Reuters/PwC, March 2011. See chapter notes.

StatLink क्तारा http://dx.doi.org/10.1787/888932485158

\section{Investment by business angel groups/networks in the United States and Europe, 2006-09}

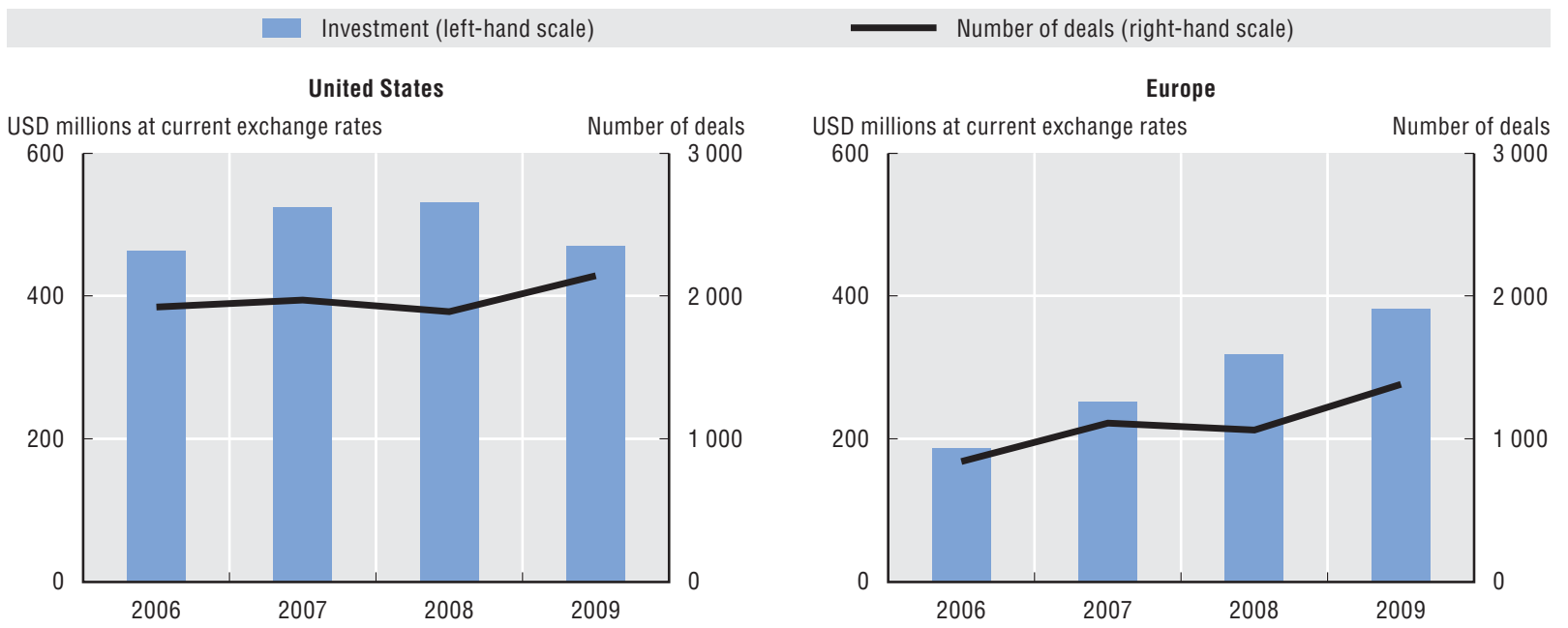

Source: OECD, calculations based on ACA (Angel Capital Association) and networks surveyed by EBAN (The European Trade Association for Business Angels, Seed Funds, and other Early Stage Market Players), March 2011. See chapter notes. 


\section{KNOWLEDGE ECONOMIES: TRENDS AND FEATURES}

The changing landscape of innovation

\section{The global landscape of R\&D players}

The United States, with nearly USD 400 billion of intramural R\&D expenditures in 2008, performs the most research and development (R\&D). It is followed by China with nearly one third of that value (in current purchasing power parity terms), just ahead of Japan. The combined European Union accounts for nearly three quarters of the US R\&D total. Non-OECD economies account for a growing share of the world's R\&D, measured in terms both of total researchers and R\&D expenditures. Personnel costs, which include researcher costs, account in most economies for the largest share of R\&D expenditures. This explains the close relationship between R\&D as a percentage of GDP and number of researchers as a percentage of total employment. Finland exhibits the highest research intensity on both measures. Variations can be related to differences in the price of R\&D inputs, such as researcher costs, the pattern of R\&D specialisation and the requirements in terms of capital expenditure, and the possibility that some countries may be developing their research infrastructure for future use.

R\&D in OECD and non-OECD economies, 2009 or latest available year

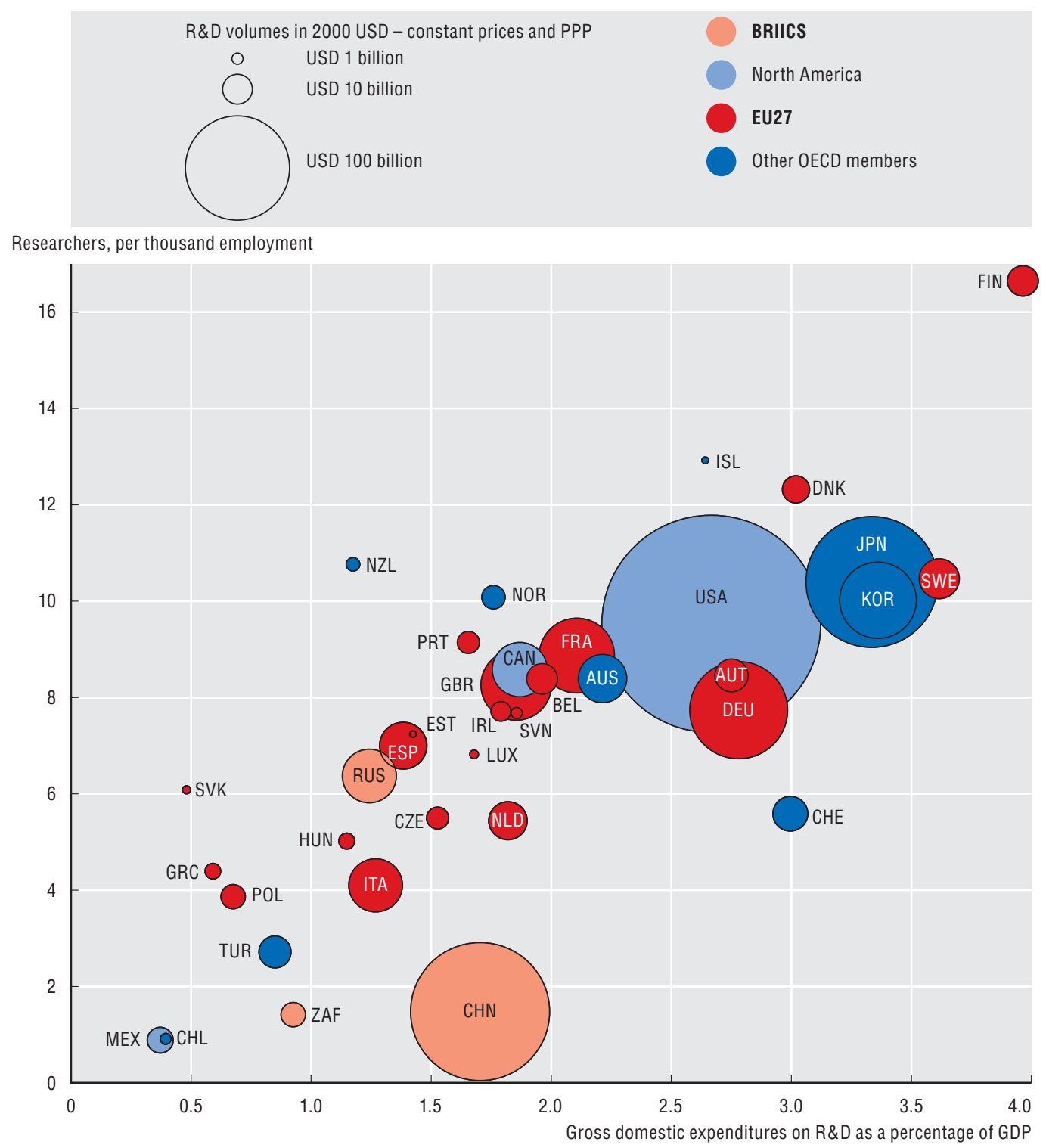

Source: OECD, Main Science and Technology Indicators Database, June 2011. See chapter notes.

StatLink sils http://dx.doi.org/10.1787/888932485196 


\section{A shift in the policy mix for R\&D}

Governments can choose among various tools to leverage private-sector R\&D. They can procure R\&D from companies, provide direct support via grants or loans, or use fiscal incentives, such as R\&D tax credits or allowances. Direct R\&D grants/subsidies target specific projects with potentially high social returns: tax credits reduce the marginal cost of R\&D activities and allow private firms to choose which projects to fund. Today, 26 out of 34 OECD countries and a number of non-OECD economies have R\&D tax incentives in place. New estimates of the cost of R\&D tax incentives and data on the value of direct public funding to support business R\&D show that some countries provide more indirect than direct support (e.g. Denmark and Portugal) while others provide relatively greater direct support (e.g. the United States and the United Kingdom). In recent years there appears to have been a general shift towards greater reliance on $R \& D$ tax incentives, as revealed by the number of countries located above the 45-degree line. This shift has been particularly marked for Canada, Portugal and Belgium. Several countries are considering introducing new tax incentives or increasing the generosity of their schemes.

R\&D tax incentives versus direct support to business R\&D, 2004 and 2009

Cost of foregone tax revenues on R\&D for USD 1 of direct support

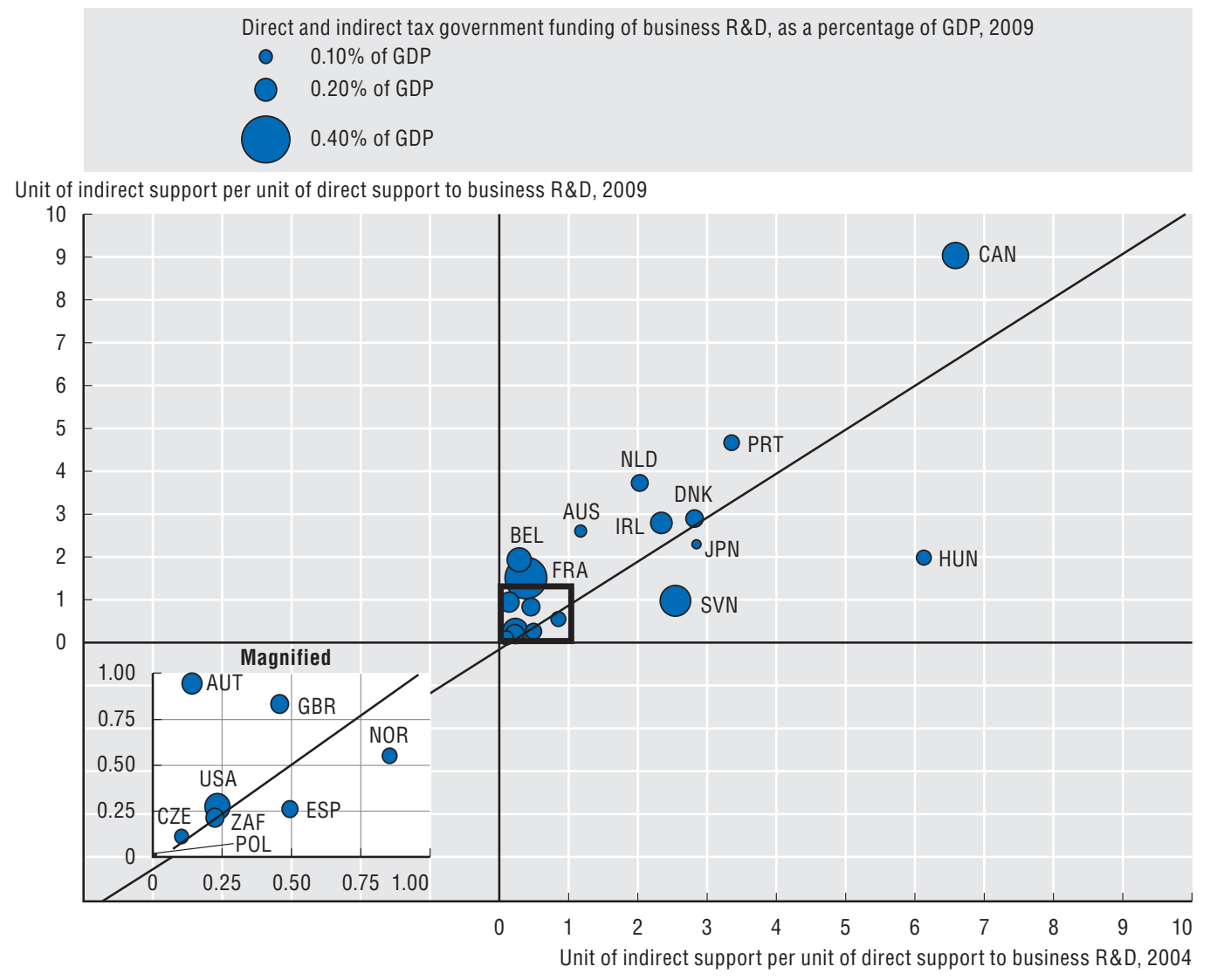

Source: OECD, based on OECD R\&D tax incentives questionnaires, January 2010 and June 2011; and OECD, Main Science and Technology Indicators Database, June 2011. See chapter notes.

StatLink Aाs http://dx.doi.org/10.1787/888932485215

\section{How to read this figure}

The figure charts a country's balance of support in 2004 (X axis) and 2009 (Y axis). Countries with a value higher than one place relatively more emphasis in their support mix on R\&D tax incentives. A country located above the 45 degree line should be interpreted as having increased its ratio of tax to direct support funding over the period. The size of the bubbles represent the combined volume of support for business R\&D (the sum of the figures for government-funded business R\&D and the reported cost of R\&D tax incentives) relative to GDP. For example, having further increased its relative preference for tax incentives over direct support for business R\&D, Canada has a high value of total support relative to GDP. 


\section{KNOWLEDGE ECONOMIES: TRENDS AND FEATURES}

The changing landscape of innovation

\section{The growth and use of the Internet}

The Internet has become a critical infrastructure that supports businesses, consumers/users and the public sector. It continues to experience remarkable growth, from 72 million hosts in 2000 to over 730 million in 2010. According to CISCO traffic over the Internet has grown exponentially since 1984 to reach just over 20000 Petabytes (PB) a month in 2010. It has increased eightfold since 2005. Greater online interactivity and the willingness to share, contribute and create online communities are changing media consumption habits of Internet users, in particular among younger age groups. Various social networking sites have emerged in recent years. Among the most popular are Facebook, MySpace and Twitter, while Orkut is one of the most visited websites in India and Brazil. On average, 50\% of Internet users in OECD countries declared having a social networking activity in 2010. Blogs, wikis, podcasting, tagging technologies and techniques from community and social networking sites can help to advance product development and raise the quality of interactions with users and consumers. They also lead to the creation of virtual goods and services. It is not always clear how consumer protection laws apply in these new environments. New uses of the Internet have raised privacy concerns among consumer groups and privacy advocates, particularly with respect to the collection and use of consumers' and children's personal information.

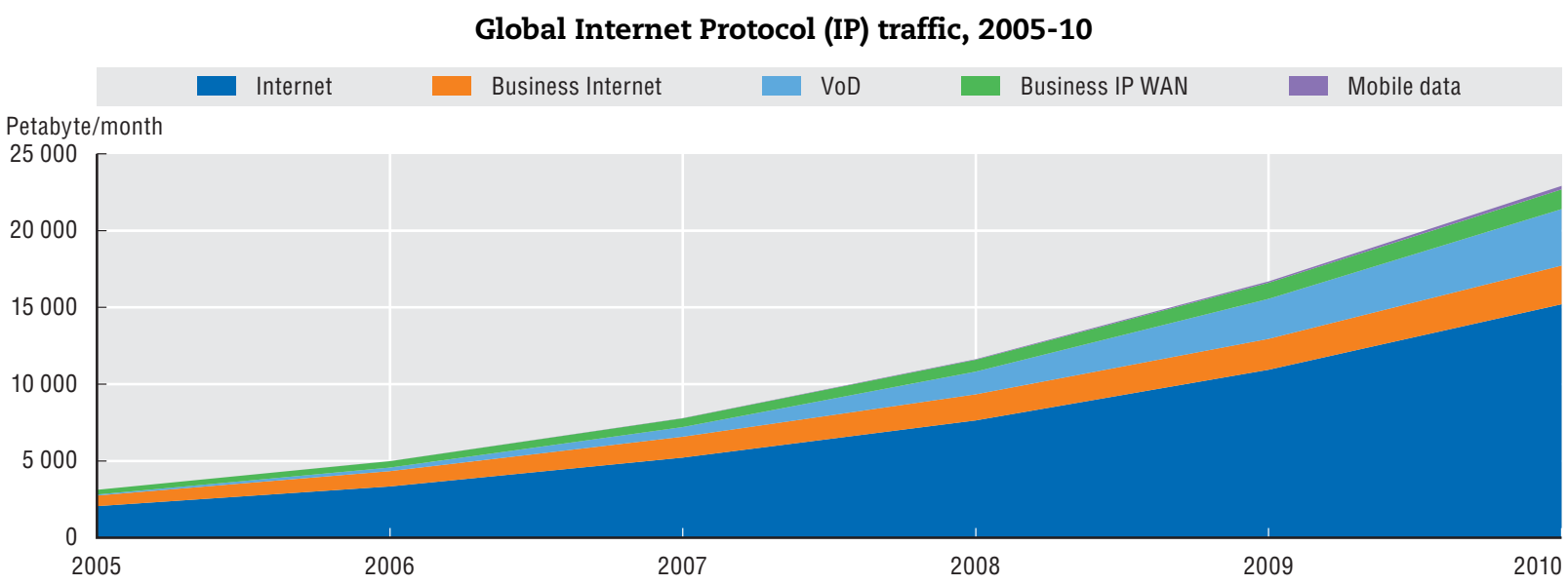

Source: Cisco Visual Networking Index (VNI). See chapter notes.

StatLink AाISL http://dx.doi.org/10.1787/888932485234

New uses of the Internet: social networking and health information, 2010

Individuals having used Internet for social networking and seeking health information as a percentage of Internet users

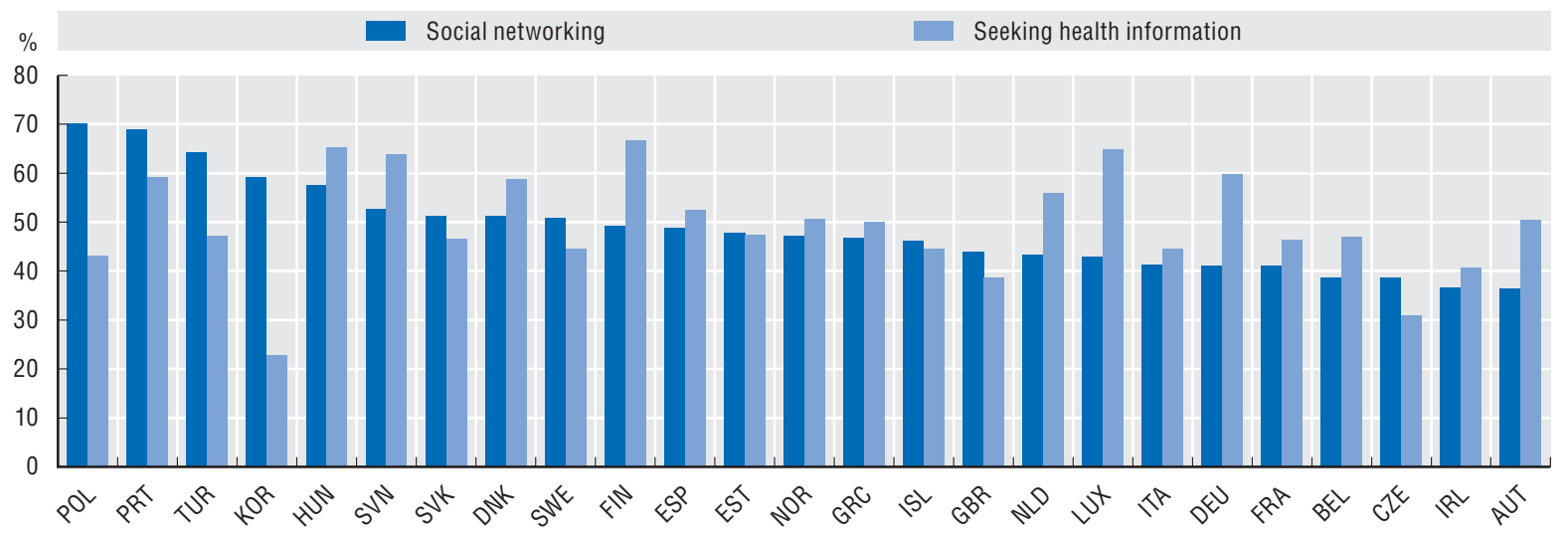

Source: OECD, ICT Database, May 2011; and Eurostat, Community Survey on ICT usage in Households and by Individuals, April 2011. See chapter notes. 


\section{Smart infrastructures}

Mobile devices, always-on broadband connections and virtualised hosts on a single computer have greatly increased the demand for IP addresses. However, the Internet was originally designed as a research network, and its subsequent widespread commercialisation and expansion has meant that the Internet Protocol, IPv4, is now insufficient to meet today's needs. In fact the central pool of unused IPv4 addresses ran out in February 2011 and the Regional Internet Registries (RIRs) are expected to assign the remaining IPv4 addresses relatively soon. IPv6, which was designed to succeed IPv4 and whose deployment began in 1999, provides significantly greater address space. However, its implementation remains slow, and considerable challenges must be met to achieve a complete and successful transition. The costs of deployment of IPv6 and the need for a critical mass of actors to adopt the new protocol are the main hurdles. Experience to date indicates the need for increased awareness and the commitment of the necessary resources.

\section{Routed IPv4 addresses per country, year end 2010}

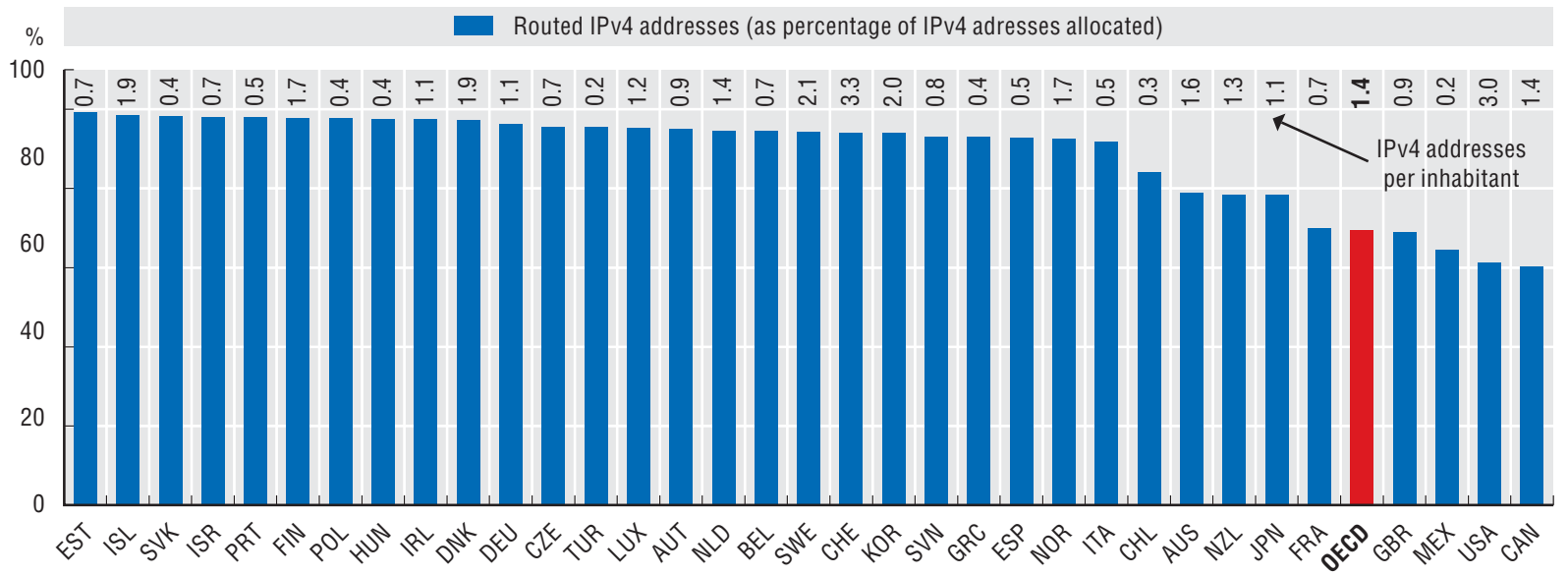

Source: OECD (2011), OECD Communications Outlook 2011, OECD Publishing, Paris. Based on data from the RIRs and Potaroo (www.potaroo.net). See chapter notes.

StatLink AाIs http://dx.doi.org/10.1787/888932485272

\section{OECD countries with IPv6-enabled networks, 2010}

Percentage of autonomous systems supporting IPv6

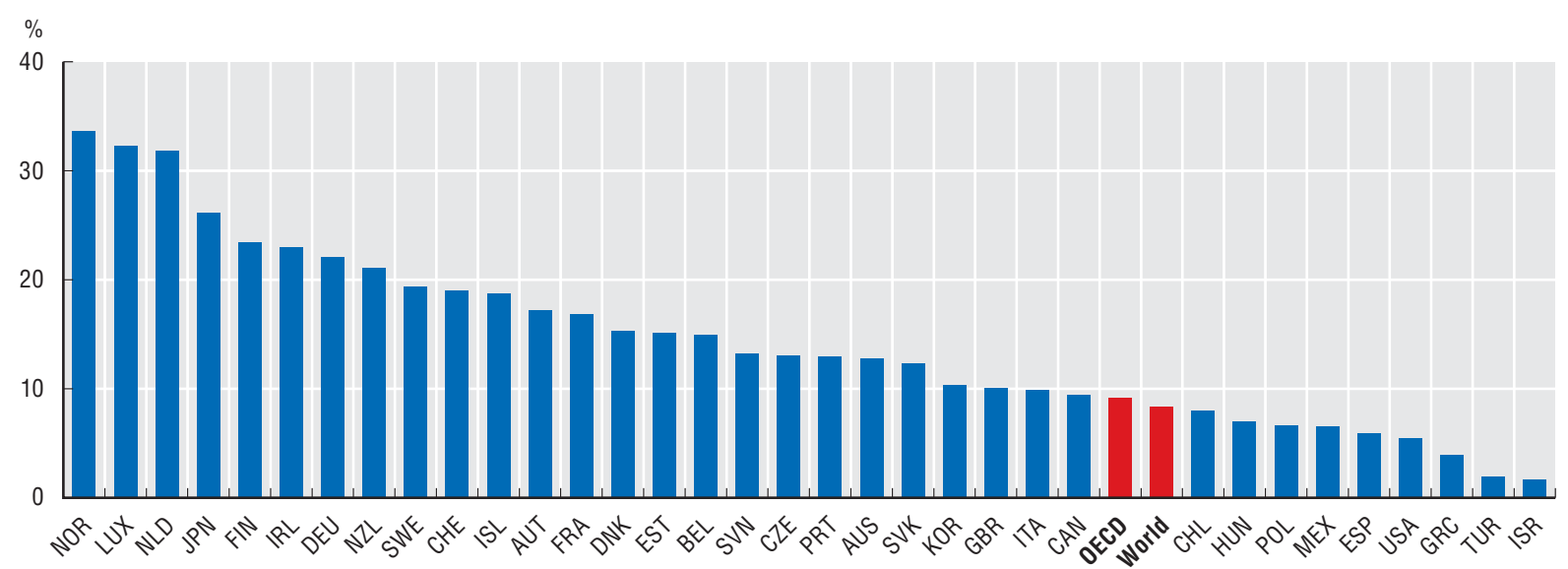

Source: OECD (2011), OECD Communications Outlook 2011, OECD Publishing, Paris. Based on Potaroo (www.potaroo.net). See chapter notes. statLink ताs http://dx.doi.org/10.1787/888932485291 


\section{KNOWLEDGE ECONOMIES: TRENDS AND FEATURES}

\section{The changing landscape of innovation}

\section{High impact universities}

World-wide, the 50 universities with the highest impact - in terms of normalised citations to academic publications across all disciplines - are concentrated in a handful of economies. Overall, 40 of the top 50 are located in the United States, with the rest in Europe. A more diverse picture emerges on a subject-by-subject basis. The United States accounts for less than 25 of the top 50 universities in social sciences, a field in which the United Kingdom plays a key role. The universities producing the top-rated publications in the areas of Earth sciences, environmental science and pharmaceutics are spread across economies. There is evidence that universities in Asia are emerging as leading research institutions: China has six in the top 50 in Pharmacology, Toxicology and Pharmaceutics. The Hong Kong University of Science and Technology is among the top universities in computer science, engineering and chemistry. In the United States, some universities excel in a wide range of disciplines. Stanford University features among the top 50 for all 16 subject areas, and 17 other US universities feature in the top 50 in at least 10 scientific fields.

\section{University hotspots - geographical distribution of highest impact institutions, 2009}

Location of top-50 universities by main subject areas

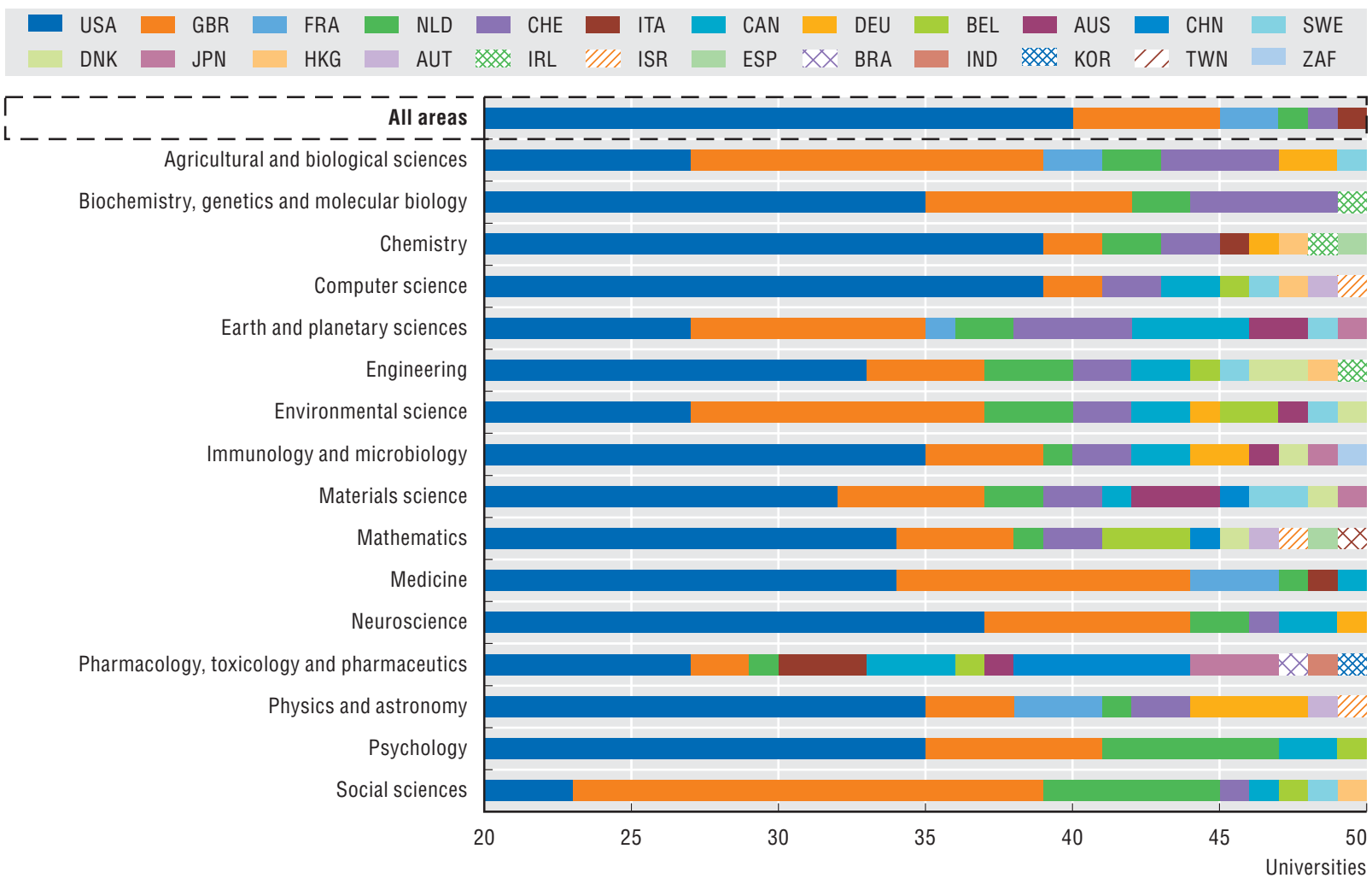

Source: OECD and SCImago Research Group (CSIC) (forthcoming), Report on Scientific Production, based on Scopus Custom Data, Elsevier, June 2011. See chapter notes.

StatLink क्ञाs http://dx.doi.org/10.1787/888932485310

\section{How to read this figure}

The $\mathrm{X}$ axis (note that the value starts at 20) shows the geographic distribution of the top 50 universities in the main subject areas (Y axis) according to their normalised impact. The publication threshold set for the institutions is at least 100 documents in 2009. The normalised impact is the ratio between the average number of citations received by a specific unit and the world average of citations in the same time period, document type and subject area, i.e. the normalisation is done at the level of the individual article. If an article belongs to several subject areas a mean value of the areas is calculated. The normalised impact of these institutions is calculated for 2003-09. 


\section{Regional innovation hotspots}

Many of the leading firms in knowledge-intensive industries - such as information and communication technologies (ICT) and the life sciences - have emerged in a limited number of regions. Such regions appear to provide particularly conducive environments for business innovation. Much of the effort of policy makers in other regions aims to replicate or nurture the positive environmental conditions that the best-performing regions offer.

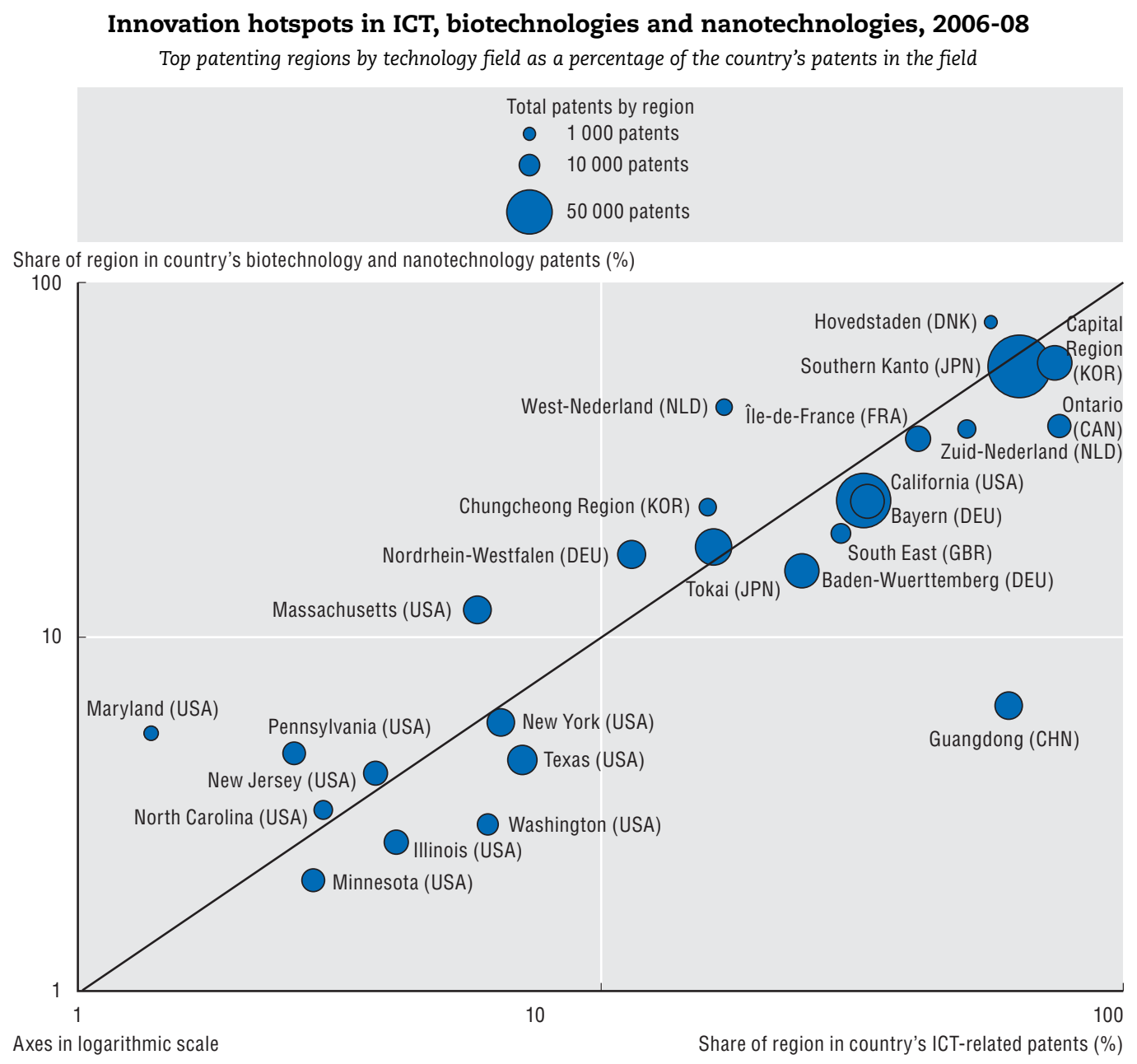

Source: OECD, REGPAT Database, June 2011. See chapter notes.

StatLink inlsL http://dx.doi.org/10.1787/888932485329 


\section{KNOWLEDGE ECONOMIES: TRENDS AND FEATURES}

The changing landscape of innovation

\section{Rising innovation in services}

The average share of trademark applications relating to service classes has increased over the last decade from $32 \%$ to $39 \%$ in all economies except South Africa and Iceland. Most service trademarks are related to knowledge-intensive activities, particularly in emerging countries such as Indonesia and Brazil. Trademarks can be R\&D-related. For example "Siemens climate solution" covers research and development consultancy services in the fields of electrical engineering, electronics, information technology, medical engineering, physics, chemistry and mechanical engineering.

\section{Service-related trademarks applications at USPTO and OHIM, OECD and BRIICS, 1997-99 and 2007-09} As a percentage of total trademark applications at OHIM and USPTO

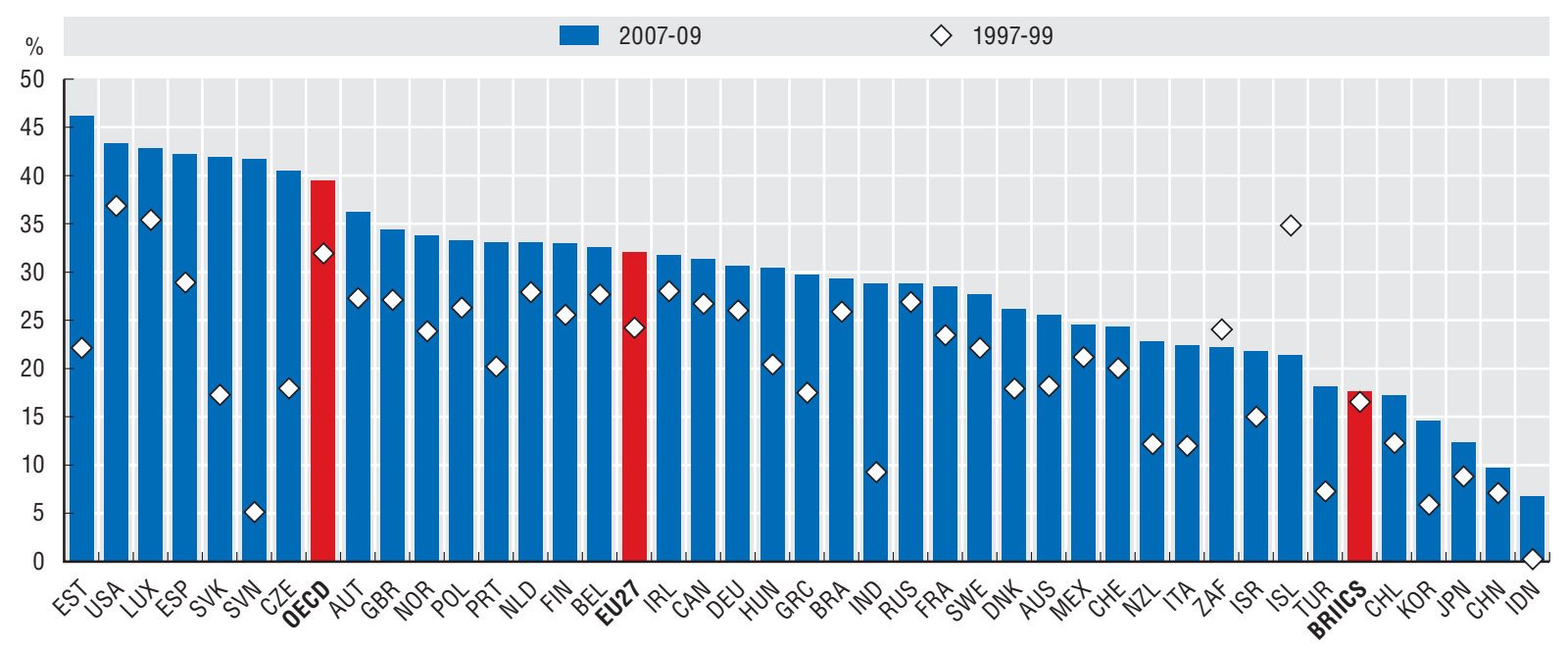

Source: US Patent and Trademark Office (2011), "The USPTO Trademark Casefile Dataset (1884-2010)"; OHIM Community Trademark Database; CTM Download, April 2011. See chapter notes.

Trademarks in knowledge-intensive services, OECD and BRIICS, 2007-09 As a percentage of total service-related trademarks

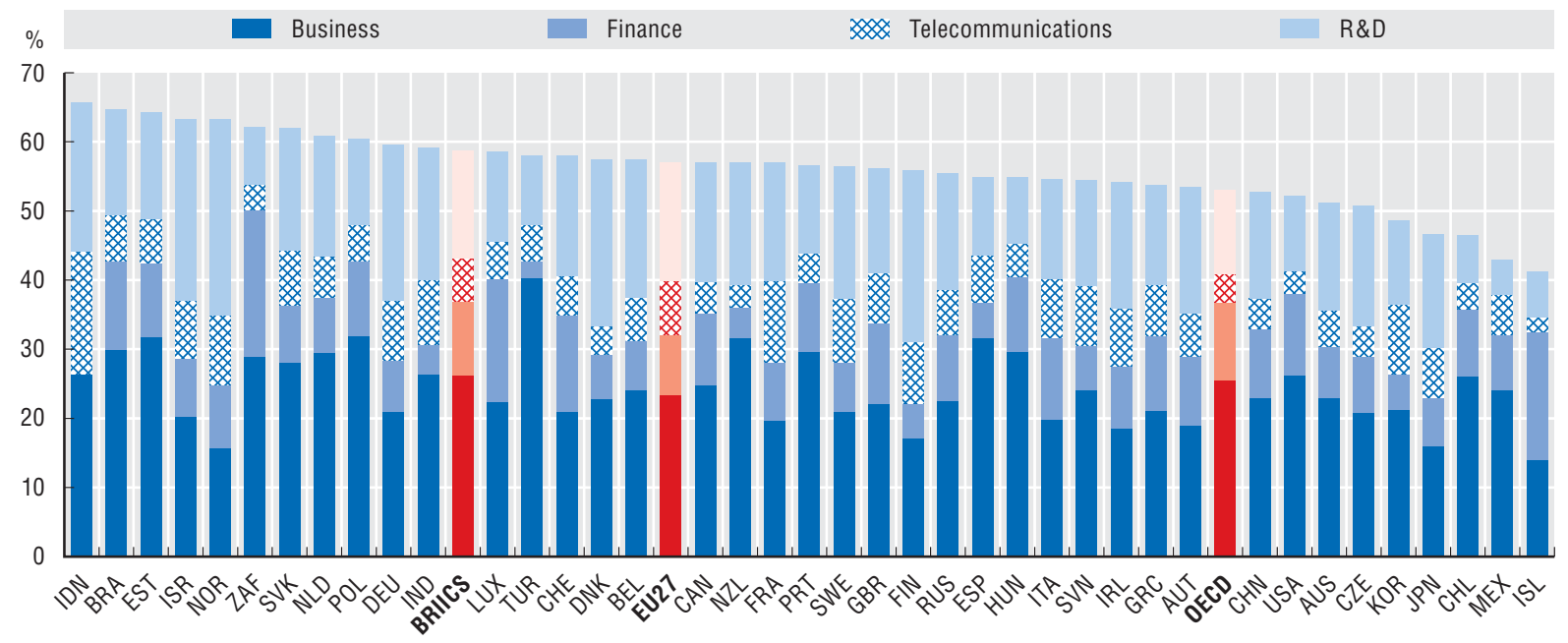

Source: US Patent and Trademark Office (2011), “The USPTO Trademark Casefile Dataset (1884-2010)"; OHIM Community Trademark Database; CTM Download, April 2011. See chapter notes. 


\section{Innovation everywhere}

New indicators on trademarks point to large numbers of incremental and marketing innovations and suggest that countries perform both technological and non-R\&D-based innovation. Countries with a large manufacturing sector or an ICT specialisation have a greater propensity to patent than to "trademark". Countries with a large services sector tend to engage more in trademark protection. Countries in the process of catching-up have a lower propensity to innovate or to seek protection for their innovations (via patents or trademarks) than OECD countries.

\section{Patents and trademarks per capita, 2007-09}

Average number per million population, OECD and G20 countries

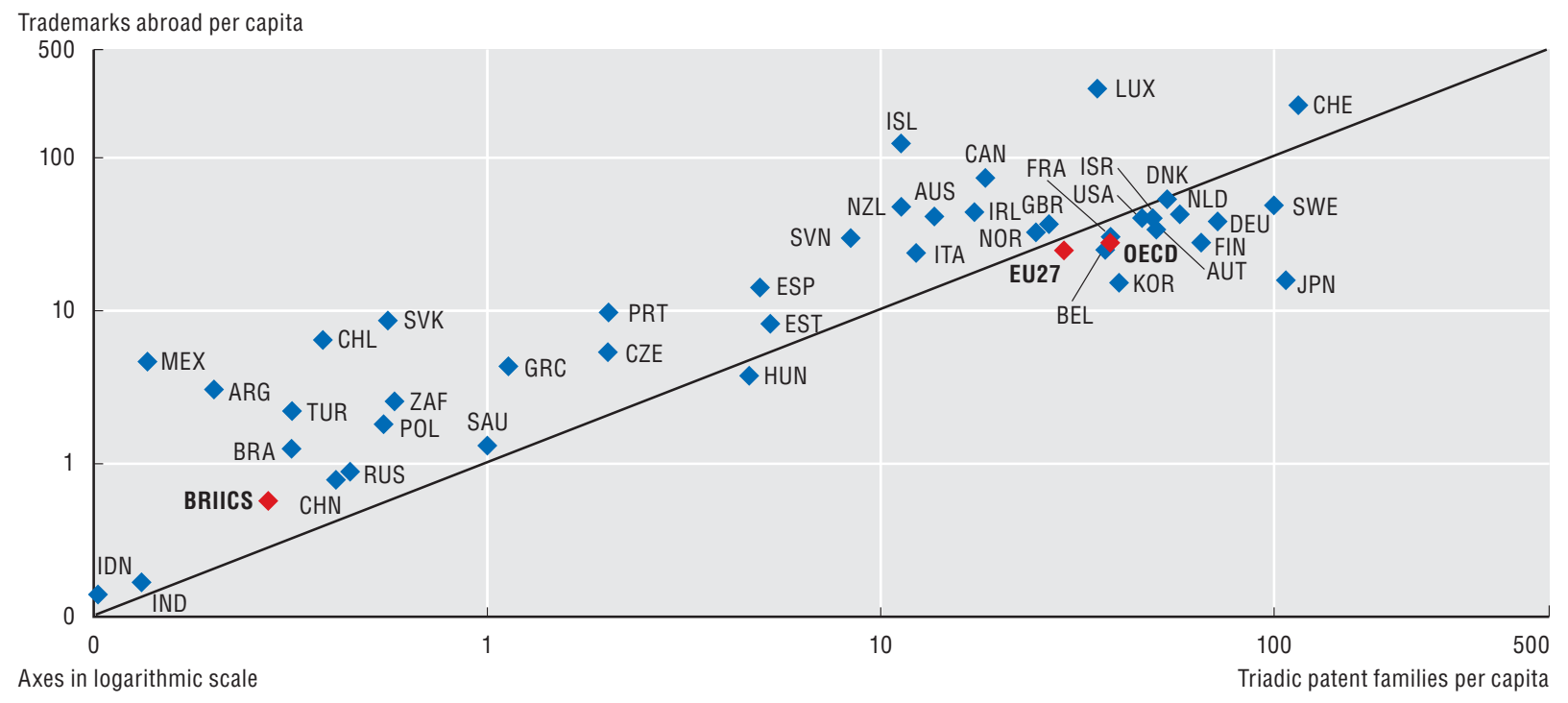

Source: OECD, Patent Database, May 2011; US Patent and Trademark Office (2011), “The USPTO Trademark Casefile Dataset (1884-2010)"; OHIM Community Trademark Database; CTM Download, April 2011; JPO Annual Reports 2008-2010. See chapter notes.

\section{What is a triadic patent?}

Triadic patent families are defined as patents applied for at the European Patent Office (EPO), the Japan Patent Office (JPO) and the US Patent and Trademark Office (USPTO) to protect a same invention. Triadic patents are typically of higher value and eliminate biases from home advantage and the influence of geographical location.

\section{What is a trademark "abroad"?}

Trademark counts are subject to home bias, as firms tend to file trademarks in their home country first. Trademarks abroad correspond to the number of applications filed at the USPTO, the Office for Harmonisation in the Internal Market (OHIM) and the JPO, by application date and country of residence of the applicant. For the United States, EU members and Japan, counts exclude applications in their domestic market (USPTO, OHIM and JPO respectively). Counts are rescaled taking into account the relative average propensity of other countries to file in those three offices.

\section{Why use trademarks as indicators of innovation?}

A trademark is a sign used to distinguish the goods and services of one undertaking from those of other undertakings. Firms use trademarks to signal novelty and to appropriate the benefits of their innovations when they launch new products on the market. The number of trademark applications is highly correlated with other innovation indicators. With their very broad perimeter of applications, they convey information on product innovations but also on marketing and services innovations. Because the data relating to trademark applications are publicly available immediately after the filing, trademark-based indicators can provide very timely information on the level of innovative activity. 


\section{KNOWLEDGE ECONOMIES: TRENDS AND FEATURES}

\section{Innovation today}

\section{Intensifying collaboration in research}

New players are emerging in the research landscape (the size of the bubble reflects the number of scientific publications) and collaboration is intensifying (the thickness of the link reflects the intensity of collaboration, i.e. co-authorships).

\section{Scientific articles and co-authorship, 1998 and 2009}

Numbers based on whole counts

1998

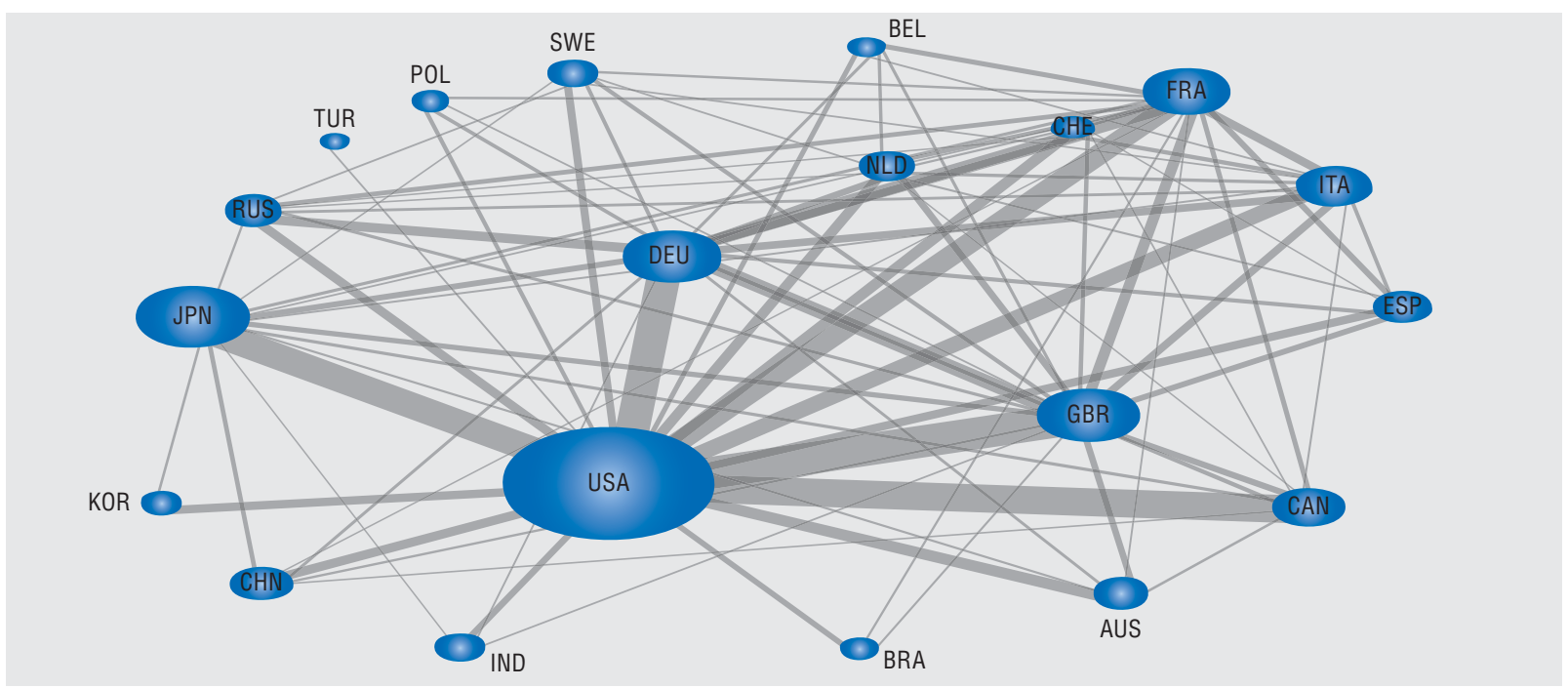

2009

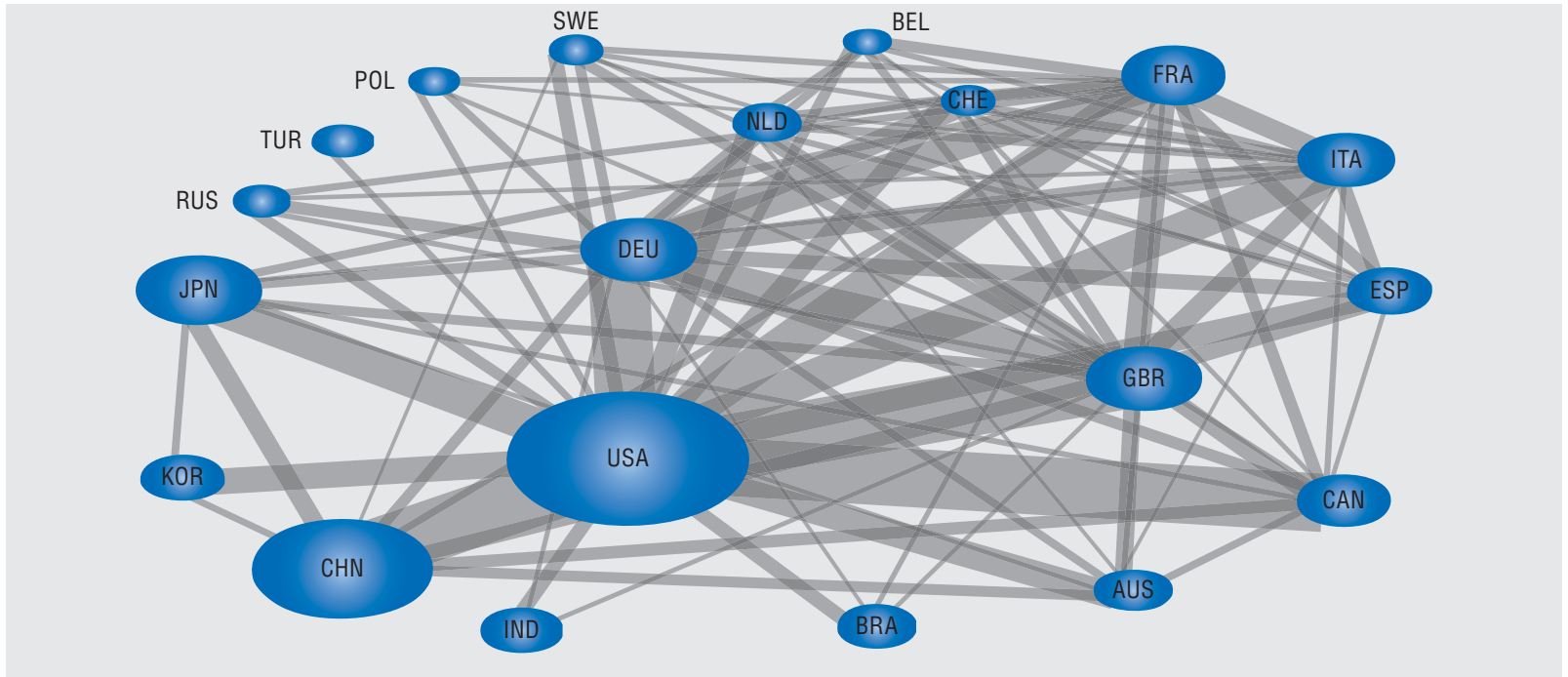

Source: OECD, calculations based on Scopus Custom Data, Elsevier, December 2010. 


\section{The impact of scientific collaboration}

The production of scientific knowledge is shifting from individuals to groups, from single to multiple institutions, and from a national to an international scope. Researchers are increasingly networked across national and organisational borders. Greater scientific specialisation and cross-border collaboration can result in increased innovation. Because they draw on a larger pool of expertise, international research collaborations can be expected to have a bigger impact in terms of citations of scientific publications. Differences across countries suggest a positive relationship between measures of research openness and scientific impact, the latter proxied by the average normalised citation index.

\section{The impact of scientific production and the extent of international scientific collaboration, 2003-09}
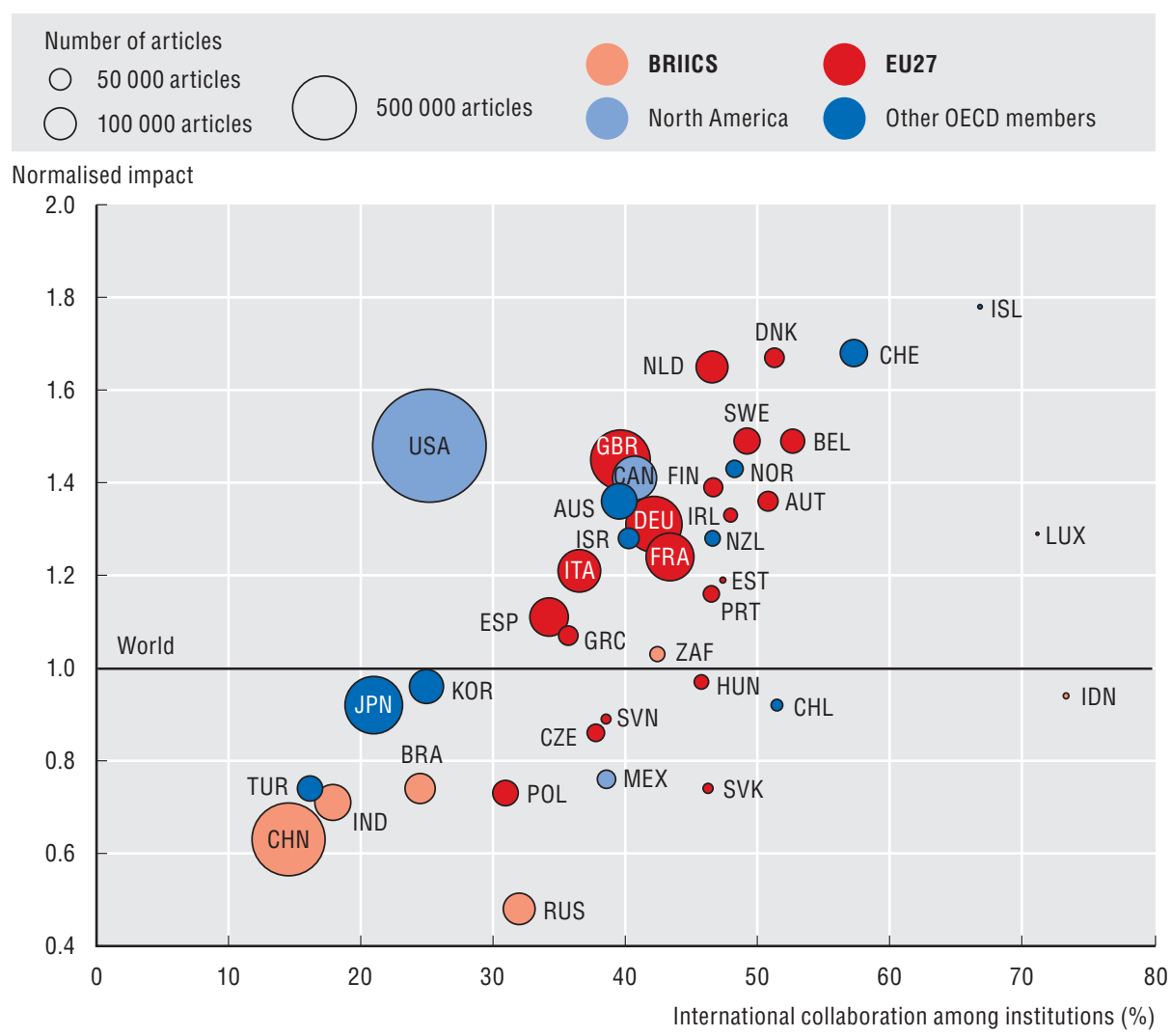

Source: OECD and SCImago Research Group (CSIC) (forthcoming), Report on Scientific Production, based on Scopus Custom Data, Elsevier, June 2011. See chapter notes.

StatLink काIsL http://dx.doi.org/10.1787/888932485424

\section{How to measure the impact of scientific collaboration}

To measure the impact of scientific publications it is possible either to use the citations received by an article or to assess its quality on the basis of the level of citations relative to the record of the journal in which the article is published. Here, the focus is on publications and citations received in 2003-09. The normalised impact is the ratio between the average number of citations received by the documents published by a specific unit (country, institution and author) and the world average of citations of the same time period, document type and subject area. The normalisation of citation values is item-oriented, i.e. carried out at the level of the individual article. If an article belongs to several subject areas, a mean value of the areas is calculated. The values show the relationship of the unit's average impact to the world average, which is 1, i.e. a score of 0.8 means the unit is cited $20 \%$ below average and 1.3 means the unit is cited $30 \%$ above average. Although article citation has the advantage of focusing directly on the impact of the articles examined, citation takes time, particularly in some disciplines. The more time allowed to measure the impact, the less timely the indicator becomes.

\section{How to read this figure}

Bubbles plot a country's share of articles resulting from international collaboration - as implied by the share of domestic articles co-authored with individuals affiliated with foreign institutions - against the normalised impact of its publications. The size of the bubbles represents the volume of scientific production, with the United States and China the largest producers of scientific output. Switzerland has both a high share of international scientific collaboration and average impact, although its total output volume is smaller than that of countries such as France or the United Kingdom. 


\section{KNOWLEDGE ECONOMIES: TRENDS AND FEATURES}

\section{Innovation today}

\section{International collaboration in science and innovation}

Collaboration across institutions has become a more pervasive feature of research activities in most countries. This is apparent in the affiliations and geographic locations of co-authors and co-inventors in scientific publications and patent documents. International co-authorship is more widespread for scientific publications than for patented inventions, except in Poland and India. There is a positive correlation between the indicators for international scientific collaboration and patent applications across countries, an indication of common underlying factors. Smaller countries tend to have higher rates of international collaboration, which may be partly driven by the need to overcome limited opportunities to collaborate domestically and, in some cases, by proximity to external centres of knowledge.

\section{International collaboration in science and innovation, 2007-09}

Co-authorship and co-invention as a percentage of scientific publications and PCT patent applications

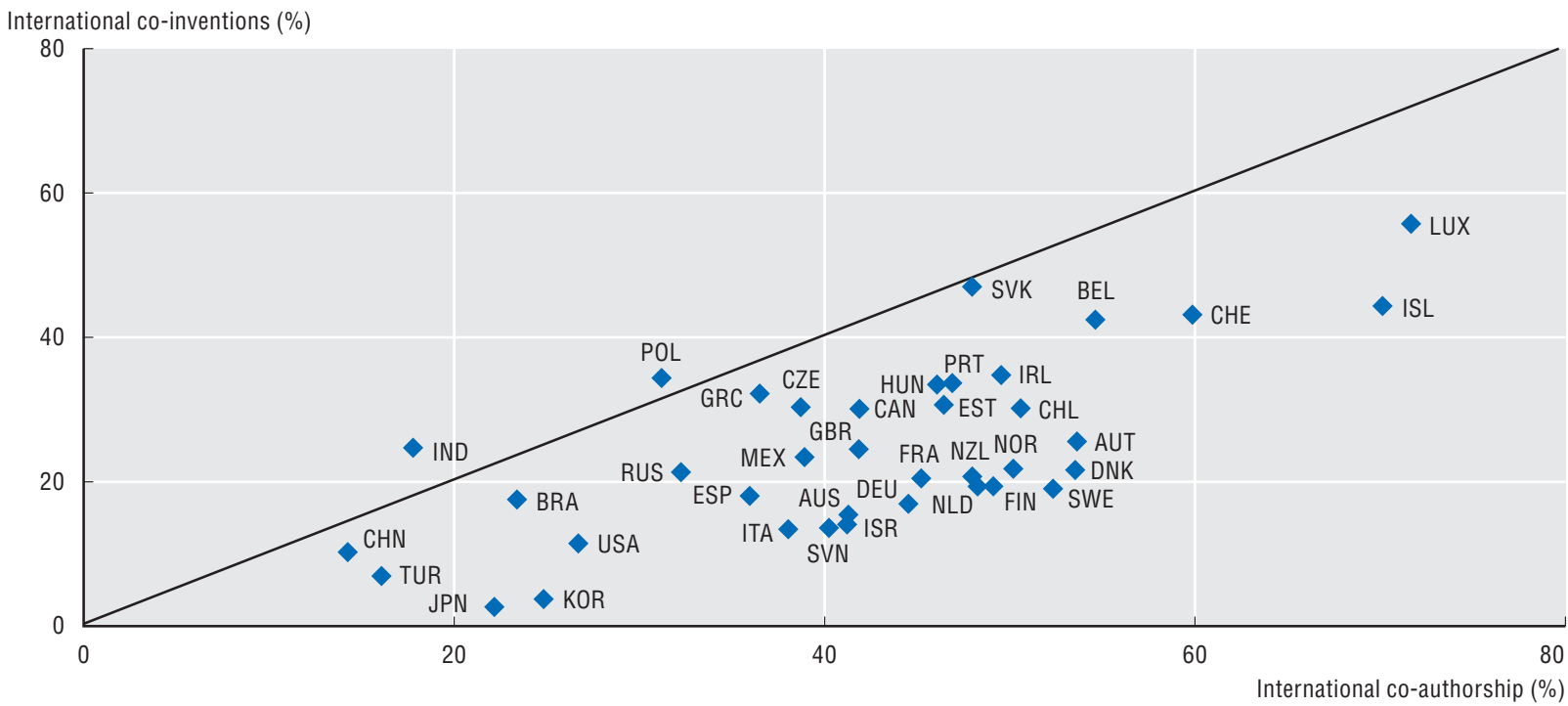

Source: OECD, Patent Database, May 2011; OECD and SCImago Research Group (CSIC) (forthcoming), Report on Scientific Production, based on Scopus Custom Data, Elsevier, June 2011. See chapter notes.

\section{What are international co-authorship and international co-invention?}

International co-authorship of scientific publications is based on the share of articles with authors affiliated with foreign institutions in total articles produced by domestic institutions. Co-inventions are measured as the share of patent applications with at least one co-inventor located abroad in total patents invented domestically.

\section{How to read this figure}

For Switzerland, $60 \%$ of publications featuring Swiss institutions involve co-authorship with institutions based abroad. For Japan, scientific co-authorship is at just above $20 \%$ but this is still higher than its international patent co-invention, at less than $5 \%$. Most countries lie below the 45 degree line; this indicates that international scientific co-authorship is more prevalent than patent co-invention. Judging by the upward sloping cloud of data points, there appears to be a positive correlation between international scientific co-authorship and patent collaboration. This needs not imply a causal effect from science to patents, but the possible presence of common factors driving research openness. 


\section{Collaboration with new players}

Geographical and cultural proximity, among other factors, is known to influence international scientific collaboration. The widespread use of English, as well as information and communication technologies, have helped to extend the scope of international research collaboration. Co-inventions are an indication of formal $R \& D$ co-operation and knowledge exchange among inventors located in different countries. International co-inventorship is affected by countries' skills endowment and by appropriability conditions, especially intellectual property rights regimes. International co-invention typically takes place in multinational corporations with units in several countries and through joint research ventures between firms and institutions of various types (e.g. universities, public research organisations). Europe increases scientific collaboration in the European research area and the rest of the world reaches out to emerging economies.

\section{Scientific collaboration with BRIC countries, 1998 and 2008}

As a percentage of total international co-authored articles

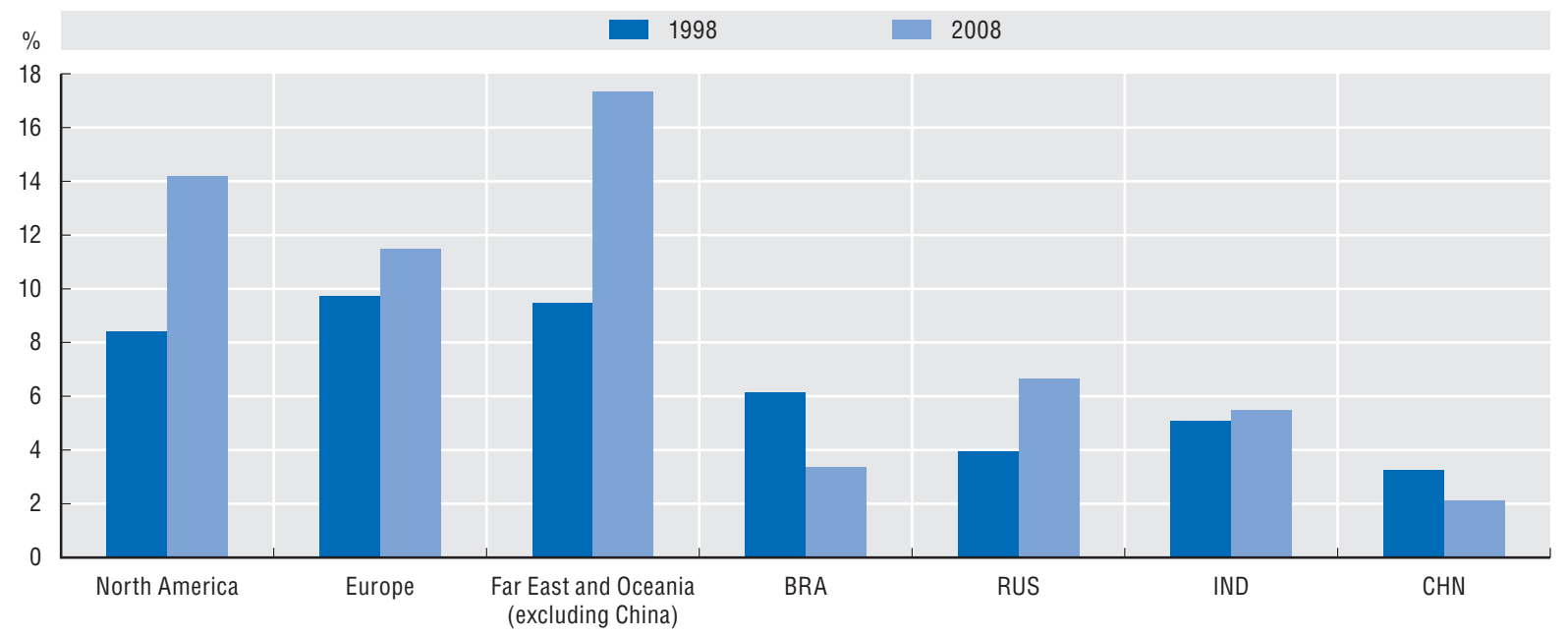

Source: OECD, calculations based on Scopus Custom Data, Elsevier, July 2009.

Co-inventions with BRIICS countries, 1991-2009

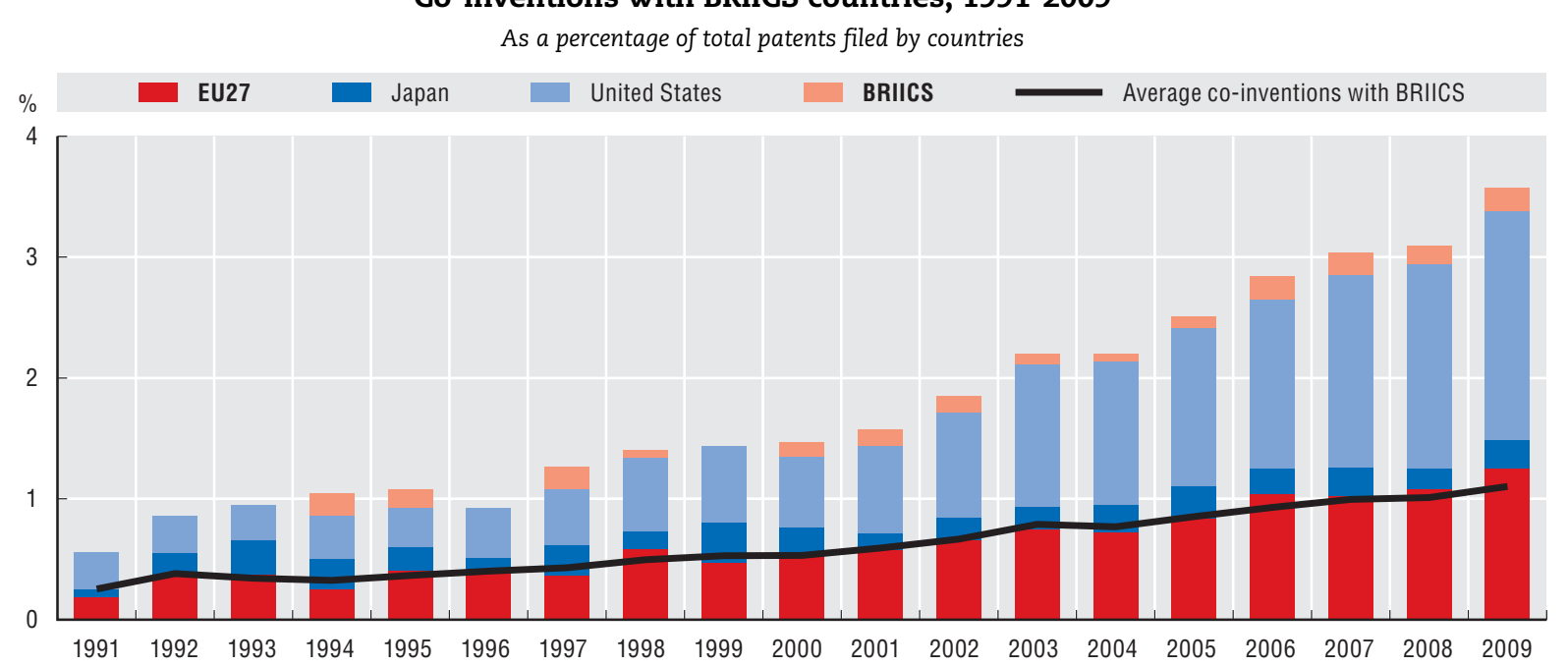

Source: OECD, Patent Database, May 2011. See chapter notes. 


\title{
1. KNOWLEDGE ECONOMIES: TRENDS AND FEATURES
}

\section{Innovation today}

\section{Science for green innovation}

Much can be learned from citations to scientific articles by patents in specific technology areas. This new indicator shows how innovations in "clean" energy technologies draw on a broad base of scientific knowledge. The single largest field is materials science, with nearly a quarter of all scientific publications cited. This confirms the importance of new materials research for areas such as solar energy (e.g. photovoltaic cells) and energy storage (e.g. better-performing batteries). Chemistry and physics follow with a combined 33\%, while energy and environmental science only account for $10 \%$ and $1.7 \%$ respectively. The diversity of scientific sources highlights the impossibility of identifying a single major scientific contributor to innovation in this area. It also underlines the dependence of "clean" energy innovation on fields of science that lack well-defined technological applications.

The innovation-science link in "clean" energy technologies, 2000-09

Share of scientific fields cited in total non-patent literature cited in patents for "clean" energy technologies

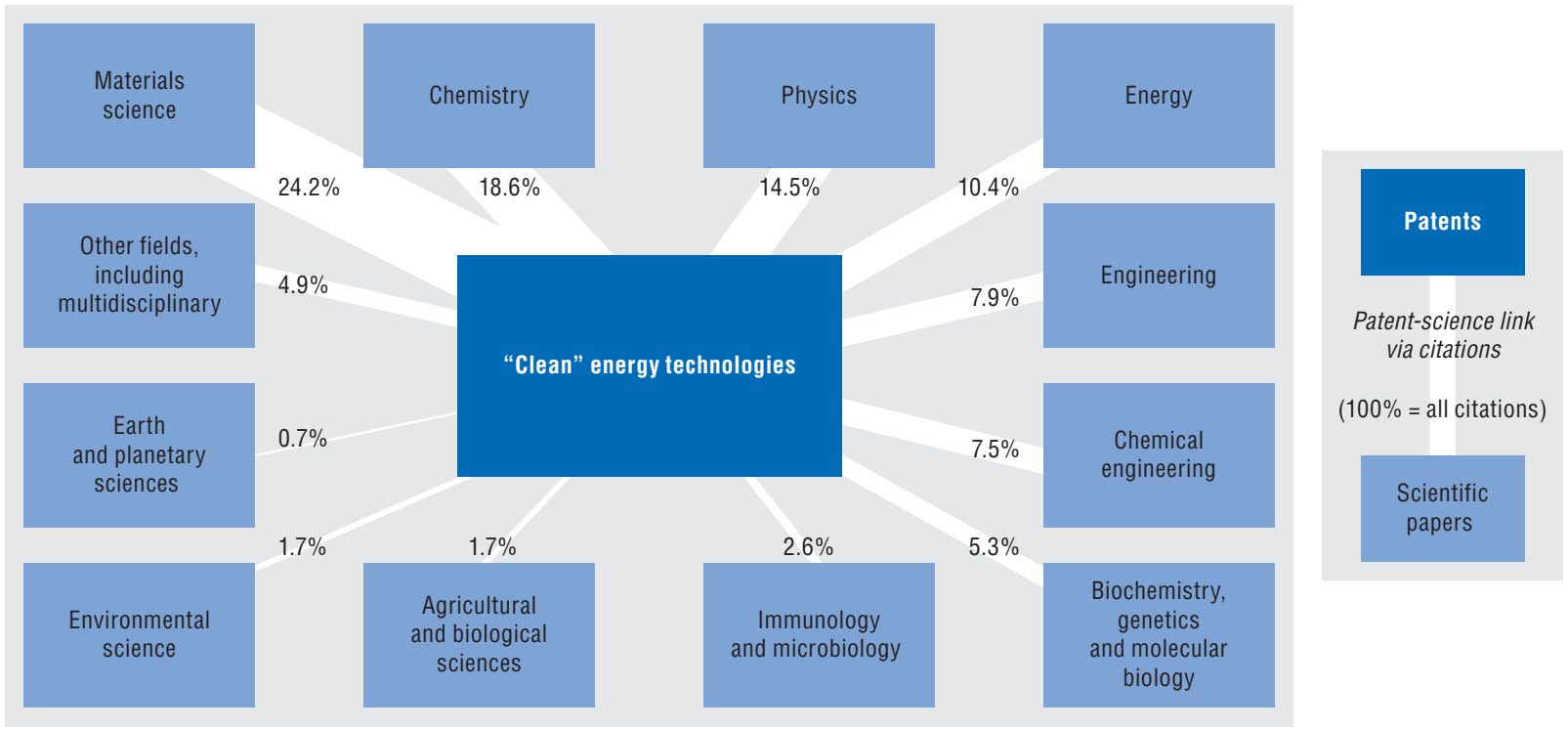

Source: OECD, calculations based on Scopus Custom Data, Elsevier, December 2010; and EPO, Worldwide Patent Statistical Database, April 2011. See chapter notes.

StatLink क्ञाजा http://dx.doi.org/10.1787/888932485500

\begin{abstract}
What is a "clean energy" technology?
The European Patent Office (EPO) has established a new classification for technical attributes of technologies that can be loosely referred to as "clean" energy technologies, a subsector of climate change mitigation technologies. The new categories were defined with the help of experts from both the EPO and the Intergovernmental Panel on Climate Change (IPCC). The Y02 subclasses already available relate to clean energy technologies, namely Y02C (greenhouse gases: capture and storage/sequestration or disposal) and Y02E (greenhouse gases: emissions reduction technologies related to energy generation, transmission or distribution).
\end{abstract}

\section{What is a patent-science link?}

Analysis of the link between patents and scientific literature is based on the "non-patent literature" (NPL) listed as relevant references in patent documents published by the EPO, the US Patent and Trademark Office (USPTO) or through the Patent Cooperation Treaty (PCT) that meet the "clean energy" definition. The NPL was matched with the scientific literature database (Scopus), to determine whether the cited NPL article corresponds to an article published in a scientific journal. For linked articles it is possible to extract bibliographical information, including field of science, not otherwise available in the patent's NPL source.

\section{How to read this figure}

"Clean" energy technologies draw on scientific knowledge that comes from materials science (24.2\%), chemistry (18.6\%), physics (14.5\%) and energy $(10.4 \%)$. 


\section{Technology transfers}

The rate of "higher quality" patenting (triadic patent families) is rapidly increasing in non-OECD economies. On average over $40 \%$ of OECD inventions are also protected in China. These technology flows mirror the strategic behaviour of firms, the location of both subsidiaries and competitors, and the attractiveness of emerging markets.

\section{Triadic patent families by blocs, 1999 and 2009}

Share in total triadic patent families

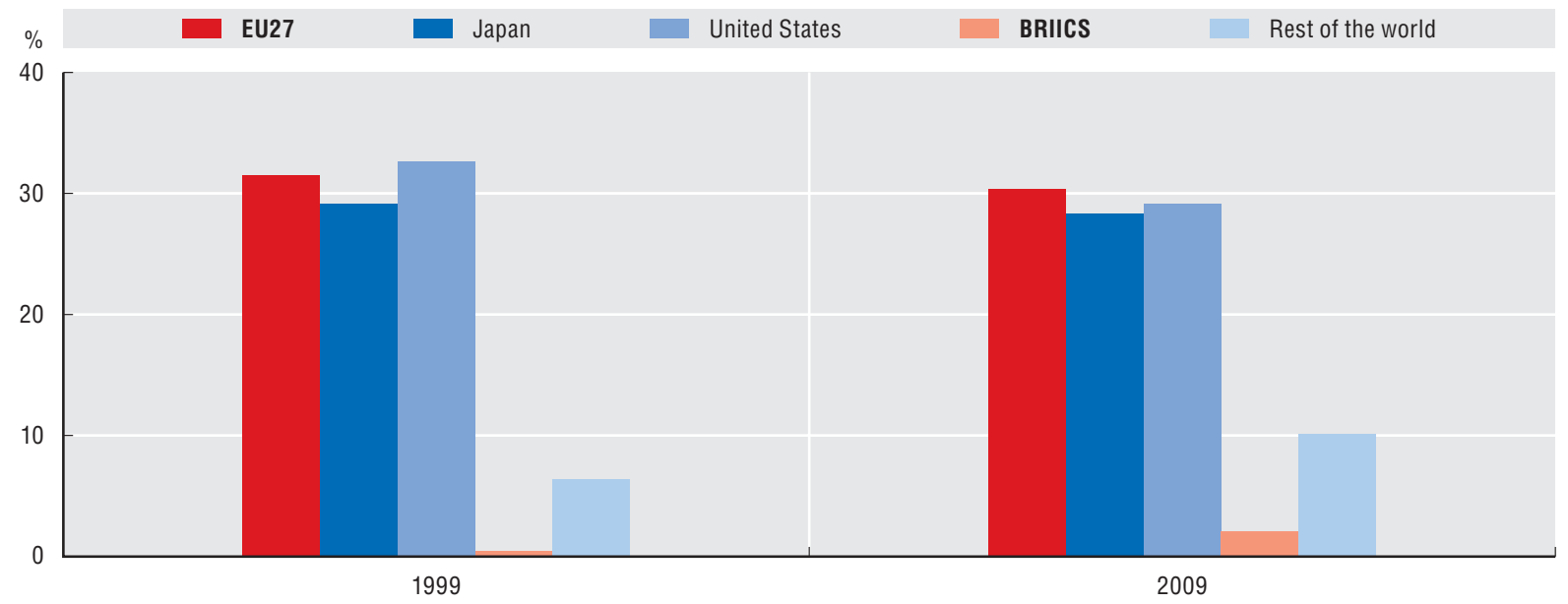

Source: OECD, Patent Database, May 2011. See chapter notes.

StatLink : जाञास http://dx.doi.org/10.1787/888932485519

Technology transfers to selected BRIICS, 2005-07

Share of patents by origin of inventor and patent office of destination

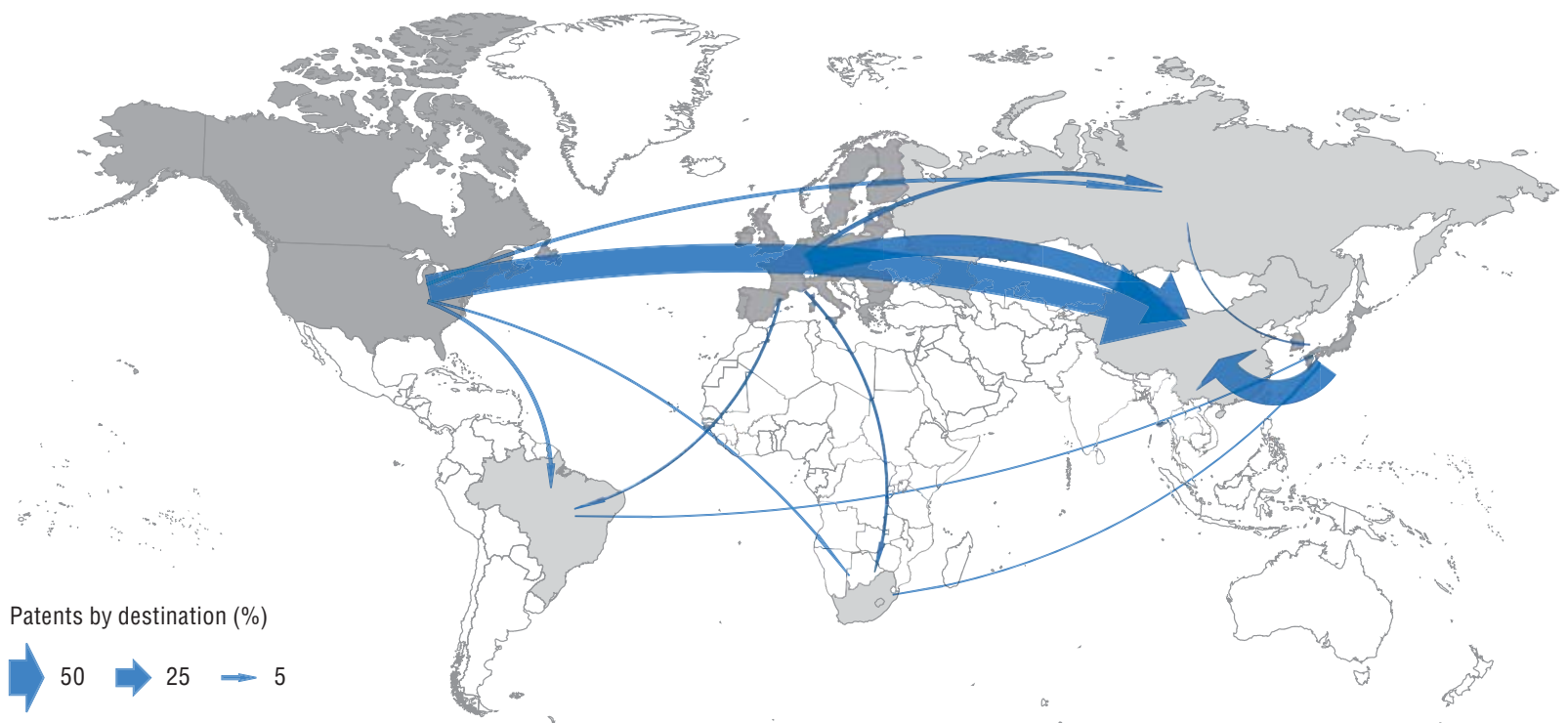

Note: Figures for the Russian Federation, Brazil and South Africa may be underestimated.

Source: OECD, calculations based on the Worldwide Patent Statistical Database, EPO, April 2011; map source: ARTICQUE@ - all rights reserved. See chapter notes. 


\section{KNOWLEDGE ECONOMIES: TRENDS AND FEATURES}

\section{The challenges ahead}

A corrigendum has been issued for this page. See: http://www.oecd.org/dataoecd/26/8/48742541.pdf $\mathrm{CO}_{2}$ emissions

The gains from growth, while distributed unevenly around the world, have been dramatic. Over the past 150 years life expectancy increased by around 30 years in most regions, including some of the world's least developed. The growth dynamic that has yielded these improvements in living standards has imposed substantial costs on the physical environment on which human well-being ultimately depends. It is increasingly apparent that the current use of natural resources could put higher living standards and even conventionally measured growth at risk. Without decisive action, energy-related emissions of $\mathrm{CO}_{2}$ will double by 2050. Efforts to mitigate greenhouse gas (GHG) emissions, such as the Kyoto Protocol, will be less effective in reducing global emissions of GHG if countries with emission commitments source their carbon-intensive production activities from economies without such commitments, particularly if production in the latter countries is GHG-intensive.

Biggest net $\mathrm{CO}_{2}$ importers and exporters, 2005

Estimates of consumption-based emissions and production-based $\mathrm{CO}_{2}$ emissions, selected countries

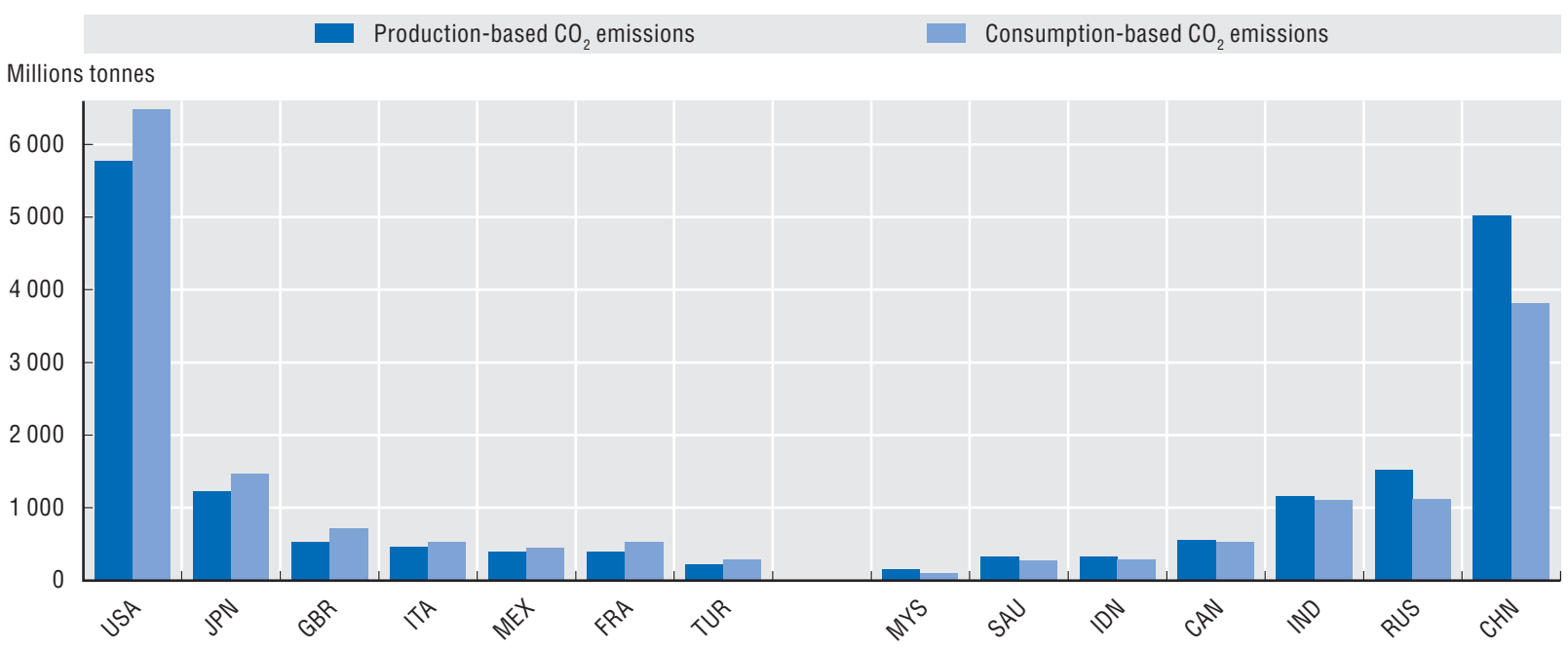

Source: OECD, Input-Output Database, May 2011; International Energy Agency (2010), CO 2 Emissions from Fuel Combustion 2010, OECD, Paris. See chapter notes.

\section{How to estimate imports and exports of $\mathrm{CO}_{2}$ ?}

The OECD's input-output tables, bilateral trade in goods and services statistics and the IEA's energy statistics (e.g. fuel-combustion-based $\mathrm{CO}_{2}$ and international electricity transfer), together with other industry statistics, can be used to estimate the effects of international transfers of $\mathrm{CO}_{2}$ emissions. The results highlight differences among countries in production-based and consumption-based emissions. Consumption-based $\mathrm{CO}_{2}$ emissions of OECD countries were, on average, about 16\% higher in 2005 than conventional measures of production-based emissions suggest. The divergence exceeds 30\% in seven OECD countries (Austria, France, Luxembourg, Portugal, Sweden, Switzerland and the United Kingdom). The magnitude of the differences increased in the late 1990s as trade in goods and services increased. The emissions structure of countries varies owing to differences in consumption activities, sources of electricity generation and the carbon intensity of imported goods. Electricity-sourced emissions are relatively high in emerging economies (e.g. China and India), whereas emissions due to transport activity and consumption of imported goods are relatively high in developed OECD economies (e.g. Japan and Germany). 
The challenges ahead

A corrigendum has been issued for this page. See: http://www.oecd.org/dataoecd/26/8/48742541.pdf Innovation and global challenges

Wherever they originate, the effects of greenhouse gas emissions are universal, and any solution that reduces these emissions will benefit all countries. Similarly, many infectious diseases have no regard for national borders, and new medicines can benefit all. High food prices and water scarcity are another important issue for both developed and developing countries. Innovation is increasingly perceived as essential for tackling such challenges. Meeting these challenges depends crucially on the pace of innovation in new technologies, for example in the areas of renewable energy, carbon capture and storage, lower emissions, bioremediation, smart grids, synthetic biology, bio-informatics and personalised medicine.

R\&D spending for energy and the environment, OECD countries, 1990-2009

Percentage of GDP

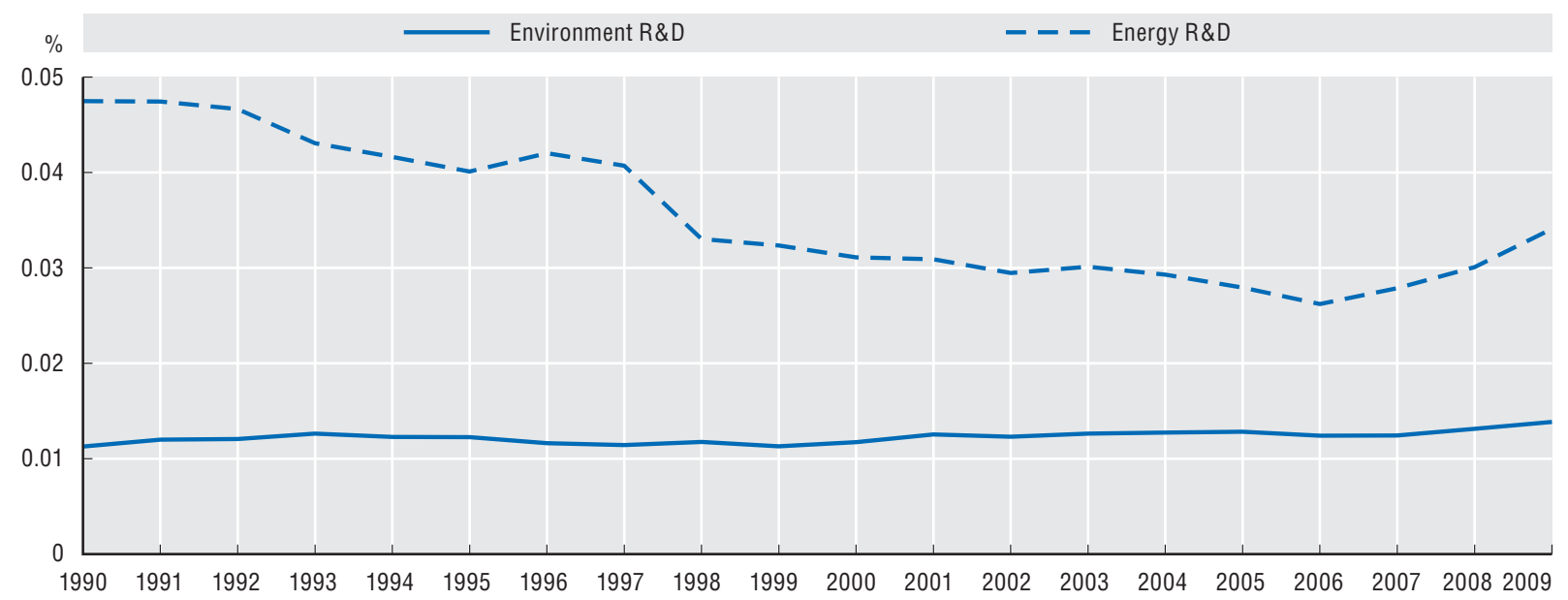

Source: OECD, Research and Development Statistics Database, May 2011. See chapter notes.

StatLink ला1sL http://dx.doi.org/10.1787/888932485576

Trends in patents by technology fields, 1995-2008

"Claimed priorities" (patent counts) in selected technology fields (index $1995=1$ )

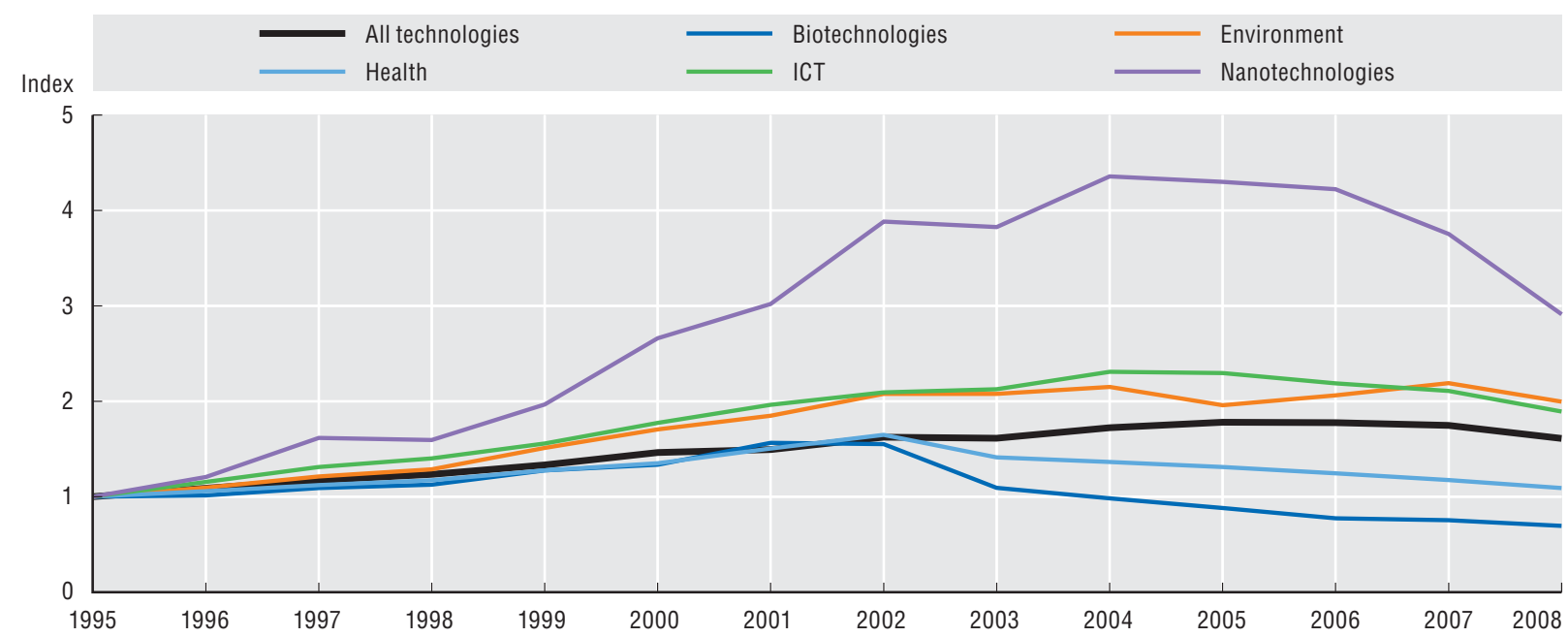

Source: OECD, calculations based on the Worldwide Patent Statistical Database, EPO, April 2011. See chapter notes.

StatLink काISL http://dx.doi.org/10.1787/888932485595 


\section{KNOWLEDGE ECONOMIES: TRENDS AND FEATURES}

\section{The challenges ahead}

\section{Innovation and environment}

Encouraging innovation that reduces environmental impacts requires appropriate sequencing of policy measures. It is necessary to "price" the negative environmental effects of the production and use of goods and services in order to develop and adopt new, less environmentally damaging technologies, although changes in relative prices may not suffice to encourage breakthrough technologies. Alternative-fuel vehicles (AFV) have seen the introduction of a combination of policy instruments, sometimes with different but related environmental objectives. The mix of policies that, directly or indirectly, provide incentives for development of AFV technologies includes fleet-level fuel-efficiency standards (e.g. US ZEV mandates), after-tax fuel prices, targeted public support for $R \& D$, as well as measures such as public procurement programmes or differentiated vehicle taxes. As a result of such measures, innovation in AFV technologies has accelerated and is now the fastest-growing type of technology in the motor vehicles sector. However, the rate of innovation in AFV remains low in absolute terms, although there are important differences among countries.

\section{Transition to alternative-fuel vehicle (AFV) technologies, 1990-99 and 2000-07} Share of AFV patent applications (claimed priorities) in motor vehicles patents

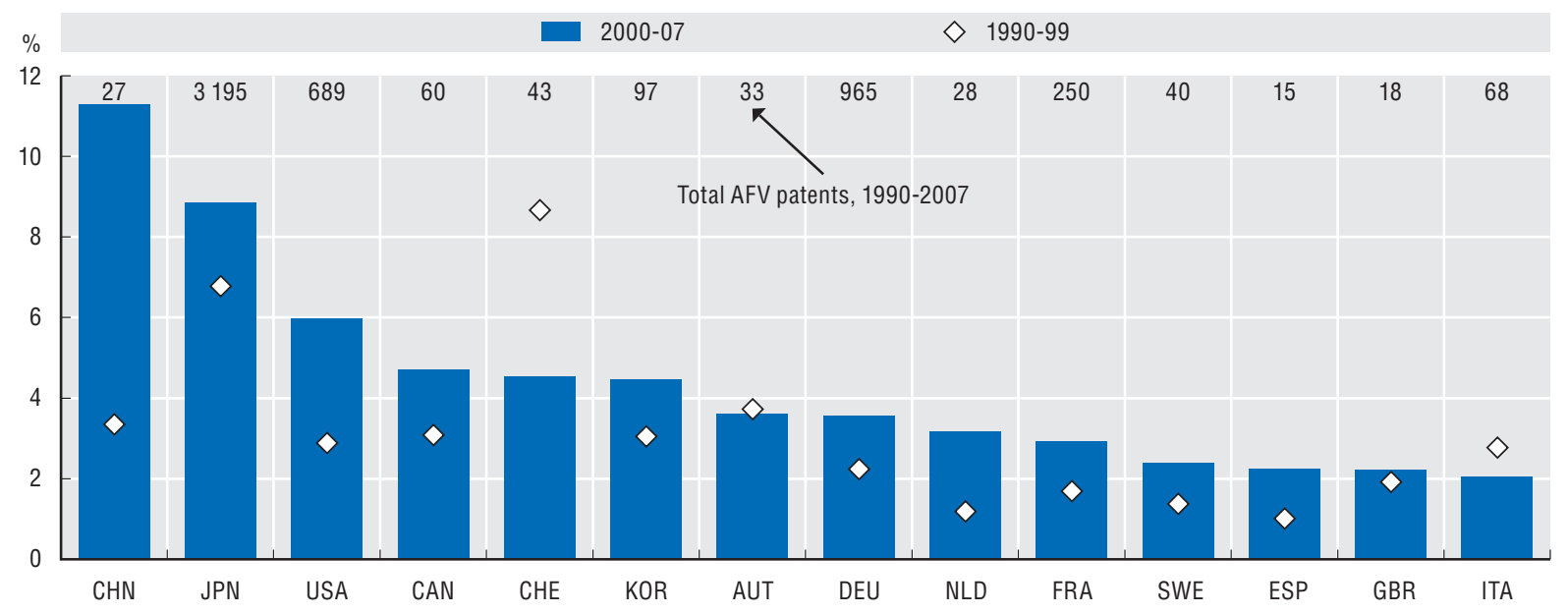

Note: Only countries with a minimum of ten patents (claimed priorities) deposited during the two decades are included.

Source: OECD, calculations based on the Worldwide Patent Statistical Database, EPO, April 2011. See chapter notes.

StatLink काजि http://dx.doi.org/10.1787/888932485614

\section{The impact of policy drivers}

An econometric model based on the characteristics of the policy instruments implemented in different countries, combined with measures of inventive activity based on patent data, and controlling for other important factors, has been used to examine empirically the importance of various policy drivers. It has found significant differences between electric and hybrid propulsion, the types of technologies studied. For example, the role of after-tax fuel prices is insignificant for electric cars, but standards play an important role. The reverse applies for hybrid cars. R\&D plays a much more important role for electric than for hybrid cars. Simulations conducted using these results indicate that relatively minor changes in a performance standard or automotive fuel prices would yield effects that are equivalent to a much greater proportional increase in public R\&D budgets. 
The challenges ahead

\section{Ageing populations}

In 2008 there were on average about four persons of working age for every older person in the OECD area. In 2050 there will be on average two workers per retired person. Countries with the highest current old-age support ratios are expected to experience the biggest drop, with support rates converging over the next 40 years. There are many promising but few proven models for anticipating and responding to the emerging societal needs of ageing societies through innovation. Yet this is a critical challenge for all OECD countries in the years ahead. Stimulating innovation to deal with the needs of the elderly has benefits not just for their quality of life but potentially for the economy as well. There is the potential for the "silver economy" to create jobs and economic activities, especially in sectors such as public services, health and well-being, leisure, sports, culture, tourism, new media, telecommunications and financial services.
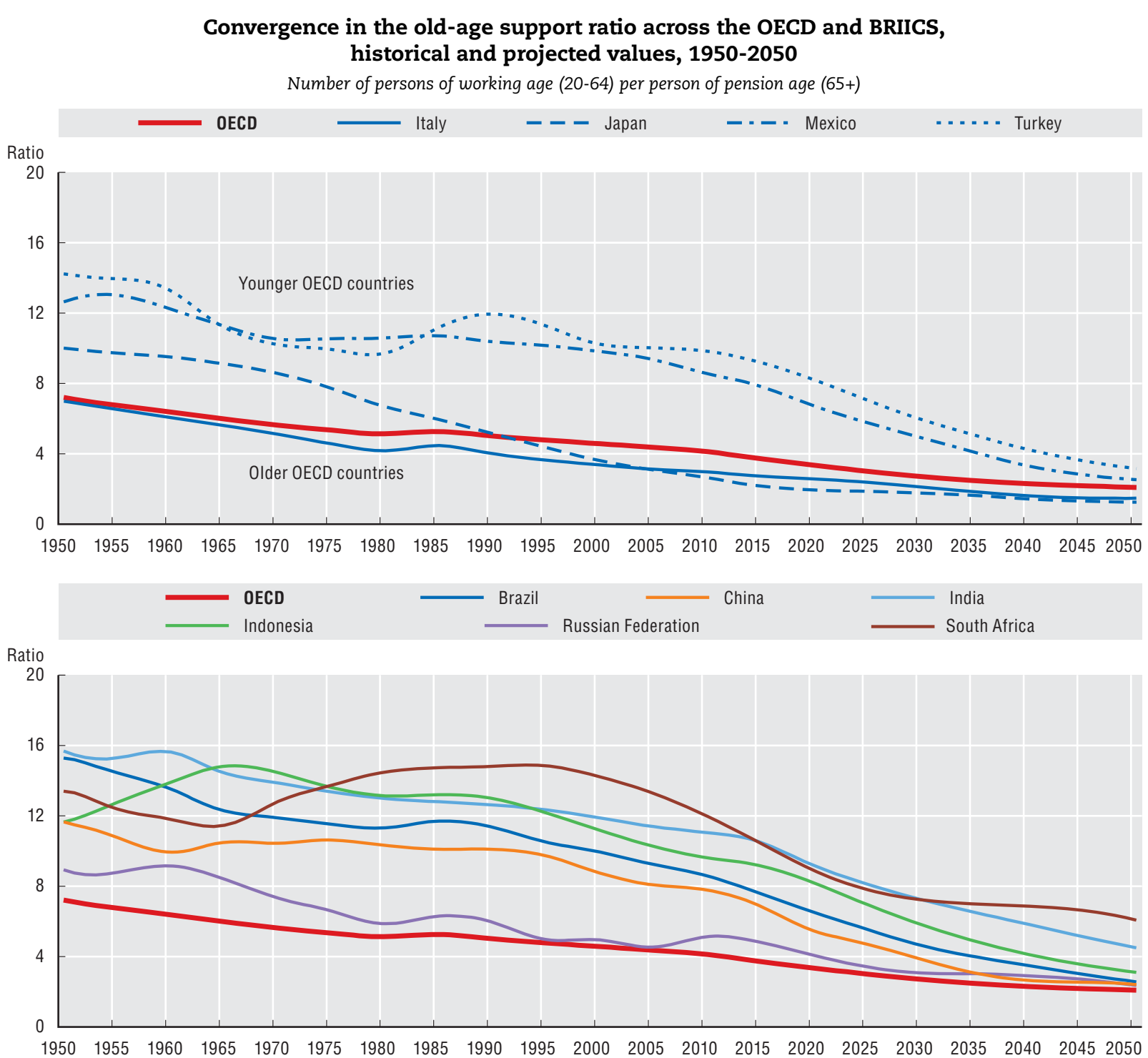

Source: OECD (2011), Pensions at a Glance 2011: Retirement-Income Systems in OECD and G20 Countries, OECD Publishing, Paris. See chapter notes. StatLink Ails http://dx.doi.org/10.1787/888932485633 


\section{KNOWLEDGE ECONOMIES: TRENDS AND FEATURES}

\section{The challenges ahead}

\section{Education and gender}

People are at the heart of the innovation process and education systems play a key role in the development of a highly qualified and flexible labour force. Relatively high levels of education are often related to higher earnings and productivity, better career progression, health and overall outcomes. Increased labour participation has helped to propel economic growth, often owing to the entry of women into the labour market in many OECD economies. As shortages of skills begin to emerge and as demographic pressures grow, tapping into this source of human capital becomes imperative.

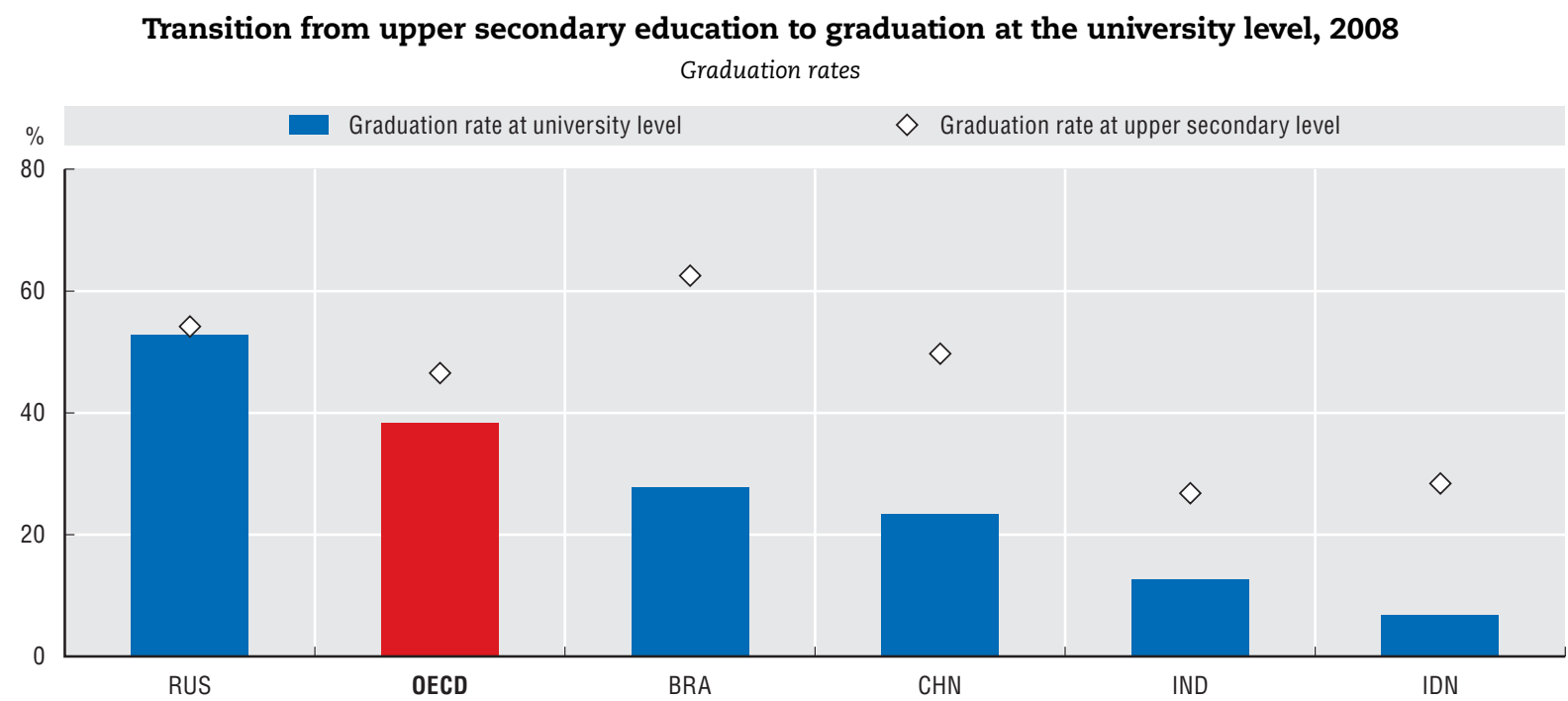

Source: OECD (2010), Education at a Glance 2010: OECD Indicators, OECD Publishing, Paris; and OECD (2011), Economic Policy Reforms 2011: Going for Growth, OECD Publishing, Paris. See chapter notes.

Women graduates in the OECD area, 2000 and 2009

As a percentage of all graduates at the corresponding level

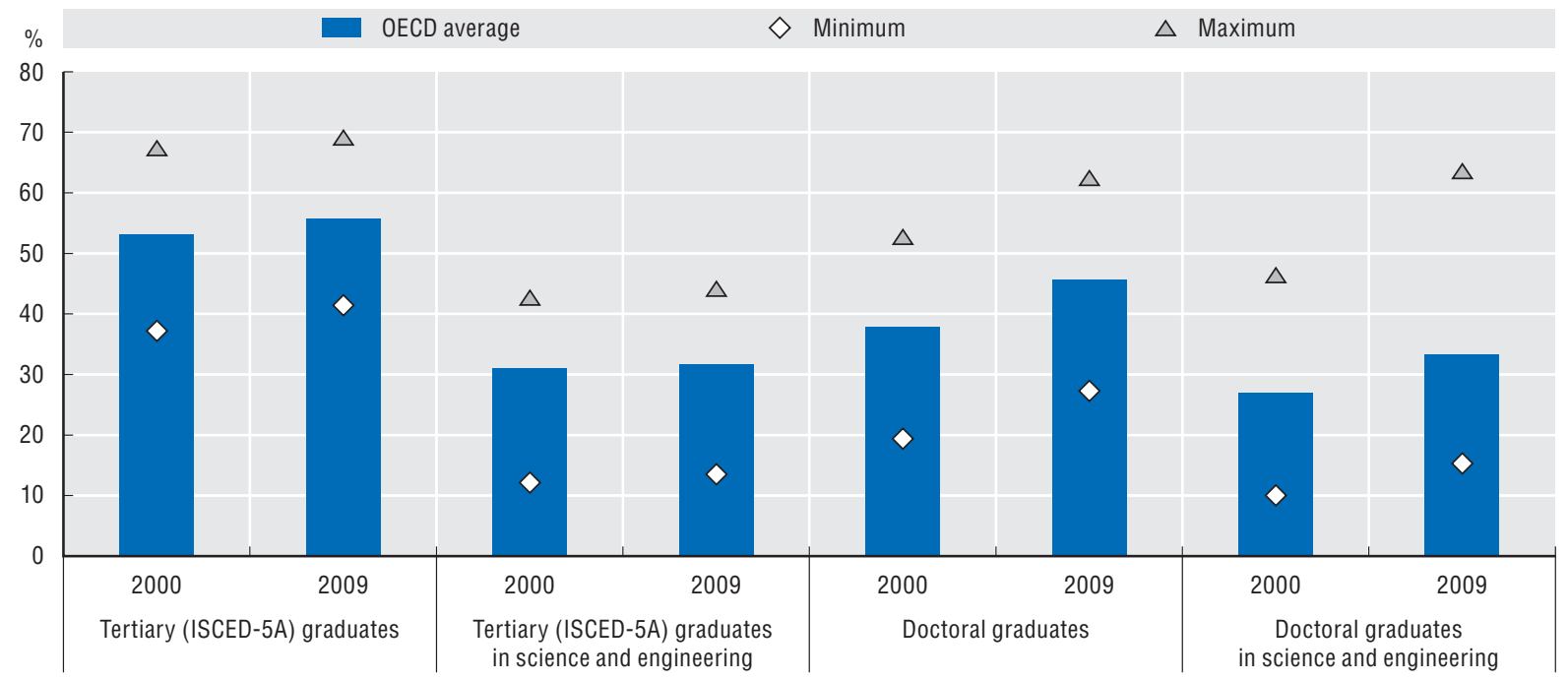

Source: OECD, Education Database, September 2011. 
The challenges ahead

\section{Gender and employment}

In the OECD area more than half of university graduates are women and they play an increasing role as consumers. Yet, despite recent progress, gender differences still persist in labour force participation, hours spent in paid and unpaid work, employment conditions and earnings. China and the Russian Federation display a smaller employment gender gap than OECD economies, while in India, where many women are employed in the informal sector, the gap has not narrowed in the last 30 years. In developing countries policies are needed to support the design, development and diffusion of technologies in sectors in which women work, including environment, health, energy, agriculture, education and information. Earnings differentials between males and females with the same educational attainment remain substantial. On average, a woman with tertiary education in the OECD area can expect to earn $70 \%$ of male earnings. The gap in earnings between males and females is due in part to differences in occupations and in the amount of time spent in the labour force. However, low earnings, particularly for females who have completed tertiary education, will in many instances be detrimental to the supply of labour and thus to the utilisation of the skills produced by the educational system.

\section{Gender gap in employment, 1980, 1990, 2000 and 2009}

Difference in male-female labour force participation rates as a share of male labour participation rate

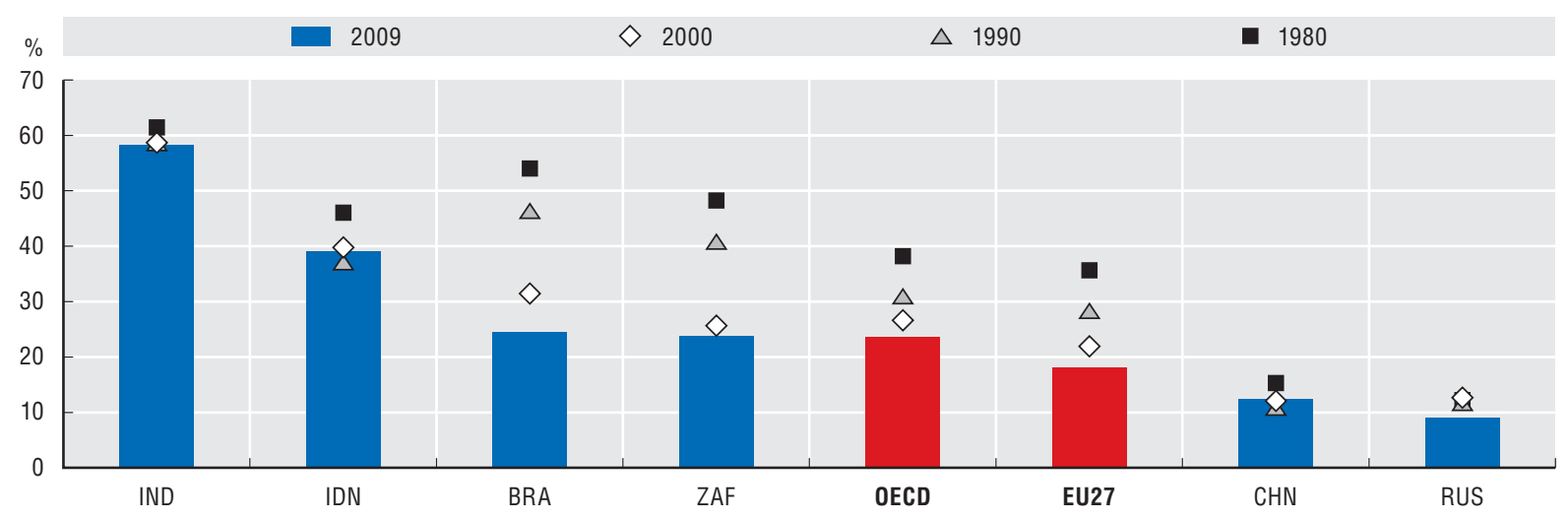

Source: OECD, calculations based on International Labour Organization, Key Indicators of the Labour Market Database, June 2011. See chapter notes.

\section{Earning differentials at the tertiary level educational attainment, 1999 and 2009}

Average annual earnings of women as a percentage of men's earnings
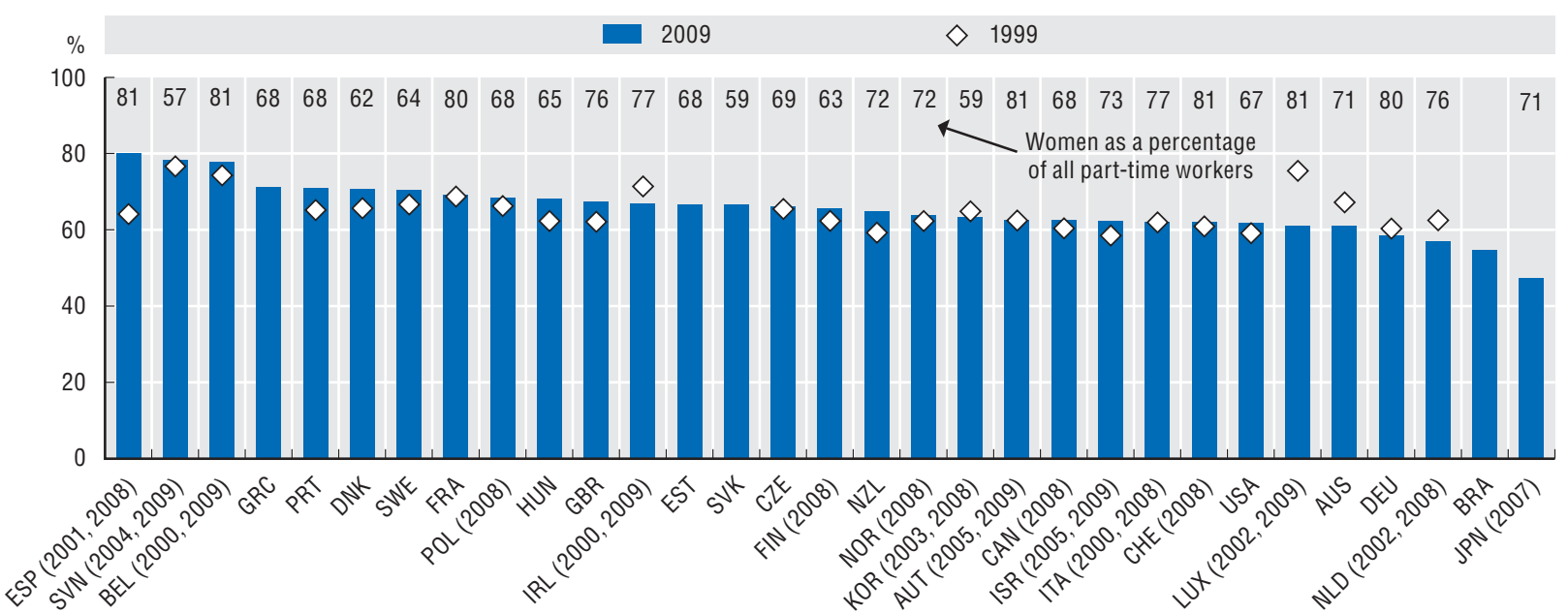

Source: OECD (2011), Education at a Glance 2011: OECD Indicators, OECD Publishing, Paris; and OECD, Employment Database, June 2011. See chapter notes. 


\section{KNOWLEDGE ECONOMIES: TRENDS AND FEATURES}

\section{Notes}

\section{Cyprus}

The following note is included at the request of Turkey:

"The information in this document with reference to 'Cyprus' relates to the southern part of the Island. There is no single authority representing both Turkish and Greek Cypriot people on the Island. Turkey recognises the Turkish Republic of Northern Cyprus (TRNC). Until a lasting and equitable solution is found within the context of the United Nations, Turkey shall preserve its position concerning the 'Cyprus issue'."

The following note is included at the request of all the European Union member states of the OECD and the European Commission:

"The Republic of Cyprus is recognised by all members of the United Nations with the exception of Turkey. The information in this document relates to the area under the effective control of the Government of the Republic of Cyprus."

\section{Israel}

"The statistical data for Israel are supplied by and under the responsibility of the relevant Israeli authorities. The use of such data by the OECD is without prejudice to the status of the Golan Heights, East Jerusalem and Israeli settlements in the West Bank under the terms of international law."

"It should be noted that statistical data on Israeli patents and trademarks are supplied by the patent and trademark offices of the relevant countries."

\section{Decomposition of growth in GDP per capita, 2001-07, 2007-09 and 2009-10}

\section{OECD excludes Turkey.}

Euro area includes the 15 countries which are also OECD members.

OECD estimates for 2007-09 and 2009-10 exclude Switzerland for which hours worked for 2009 and 2010 are missing.

\section{Labour productivity growth, total economy level, 1985-2010}

Euro area excludes Estonia and Slovenia for which productivity estimates are only available from 2000.

GDP per capita and labour productivity in Brazil, India, Indonesia, China and South Africa (BIICS), 1991-2009 Calculations are based on GDP in constant 2005 purchasing power parities.

Percentage gap with respect to the simple average of the 17 highest OECD countries in terms of GDP per capita and GDP per employee.

\section{Where people lost their jobs, 2008-09}

Iceland and Turkey: Labour Force Survey (LFS) data by industry are used in the absence of employment by activity statistics published in an SNA context.

New Zealand: based on employment estimates for fiscal years 2008/09 and 2009/10.

\section{Where people lost their jobs in Europe, 2009-10}

Europe includes the 24 countries shown in the figure.

Iceland: Labour Force Survey (LFS) data by industry are used in the absence of employment by activity statistics published in an SNA context.

\section{Investment in fixed and intangible assets as a share of GDP, 2006}

Estimates refer to the total economy for Canada, Japan and Sweden; the market sector for Australia, France, Germany, Italy, Spain and the United Kingdom; the non-financial business sector for Finland; the commercial sector for the Netherlands and the non-farm business sector for the United States.

Data on intangible assets for the United States provided by C. Corrado; data for Japan provided by T. Miyagawa; data for Sweden provided by H. Edquist; data for the Netherlands provided by M. Tanriseven; data for Germany, Italy, Spain and the United Kingdom provided by J. Haskel, A. Pesole and members of the COINVEST project; data for Austria, Denmark and the Czech Republic provided by J. X. Hao and B. van Ark; data on intangible and tangible 
investment for Australia provided by P. Barnes; for Canada by N. Belhocine. Data on tangible investment for France is based on INSEE. For other countries figures for tangible investment are OECD calculations based on the OECD, Annual National Accounts and the EU KLEMS Databases.

Labour productivity growth: adding the contribution of intangible assets, 1995-2006

Japanese estimates do not account for the contribution of labour quality.

Data for the United States is from C. Corrado, D. Sichel and C. Hulten (2009), data for Sweden is from H. Edquist (2009); data for Japan is from K. Fukao, T. Miyagawa, K. Mukai, Y. Shinoda and K. Tonogi (2009); data for Australia is from P. Barnes and A. McClure (2009); data for the United Kingdom is from G.M. Marrano, J.E. Haskel and G. Wallis (2009); data for Austria, the Czech Republic, Denmark, France, Germany, Greece, Italy, Spain and the Slovak Republic is from B. van Ark, J.X. Hao, C. Corrado and C. Hulten (2009).

\section{Foreign direct investment inflows, 1995-99, 2000-04 and 2005-09}

Other OECD includes: Australia, Canada, Chile, Iceland, Israel, Korea, Mexico, New Zealand, Norway, Switzerland and Turkey.

Other BRIICS includes: Brazil, India, Indonesia, the Russian Federation and South Africa.

Outward foreign direct investment flows from EU, Japan and the United States to BRI*CS ("India), yearly average 2003-09

EU includes OECD EU countries except Slovenia.

Foreign direct investment outward flows from BRIICS, 1994-97, 2002-05 and 2006-09

For Indonesia, the 2002-05 average corresponds to 2004-05.

OECD manufacturing trade by technology intensity, 1995-2009

OECD manufacturing trade is calculated as the average value of total OECD exports and imports of goods. Calculations exclude Luxembourg for which data are only available from 1999.

BRIICS manufacturing trade by technology intensity, 1995-2009

BRIICS manufacturing trade is calculated as the average value of total BRIICS exports and imports of goods. Data for South Africa are available from 2000; data from the South African Customs Union (SACU) were used as a proxy for 1995-99.

\section{World trade by end use, 1995 and 2009}

EU15 includes EU members as of 1 January 1995: Austria, Belgium, Denmark, France, Finland, Germany, Greece, Ireland, Italy, Luxembourg, the Netherlands, Portugal, Spain, Sweden and the United Kingdom.

Other OECD includes: Australia, Canada, Chile, the Czech Republic, Estonia, Hungary, Iceland, Israel, Korea, Mexico, New Zealand, Norway, Poland, the Slovak Republic, Slovenia, Switzerland and Turkey.

BRIIS consists of Brazil, India, Indonesia, South Africa and the Russian Federation (i.e. BRIICS without China).

\section{Import content of exports for selected economies and regions, 1995 and 2005}

EU15 includes Austria, Belgium, Denmark, Finland, France, Germany, Greece, Ireland, Italy, Luxembourg, the Netherlands, Portugal, Spain, Sweden, the United Kingdom.

Other OECD includes: Chile, the Czech Republic, Estonia, Hungary, Iceland, Israel, Norway, Poland, the Slovak Republic, Slovenia, Switzerland and Turkey.

Other East and South-East Asia includes: Chinese Taipei, Indonesia, Singapore, Hong Kong SAR of China, Malaysia, Philippines, Thailand, Viet Nam, Brunei Darussalam and Cambodia.

Rest of the world estimated using input-output tables and bilateral trade data for Argentina, Brazil, India, South Africa, Saudi Arabia, the Russian Federation, selected non-OECD European countries and a residual aggregate covering all other countries.

The percentage under the country names shows the import content share of a country's or region's total exports. Country/region bubble size is proportional to the total value of the import content of exports in USD.

Bilateral trade flows are highlighted by arrows if they represent more than $1.5 \%$ of the world total import content of exports. 


\section{KNOWLEDGE ECONOMIES: TRENDS AND FEATURES}

Diversification index (Hannah-Kay) for selected countries, 1978-2009

Data for Germany prior to 1991 are for western Germany only.

\section{Composition of GDP in OECD and BRIICS countries, 2008}

The major activity groups are defined according to ISIC Rev. 3. "Market" Services: ISIC 50-74; "Non-market" Services: ISIC 75-99; Industry: ISIC 10-41 (i.e. Mining, Manufacturing and Utilities); Construction: ISIC 45; and Agriculture: ISIC 01-05.

OECD and BRIICS: un-weighted averages (means) of the countries' shares.

Value added measured in basic prices except for Indonesia, Japan, United States: market prices; and India: factor costs.

For Canada, figures refer to 2007.

For Australia and India, figures refer to fiscal year 2007/08.

\section{US gross domestic product and trademark applications at the USPTO, 1999-2011}

Goods (resp. services) trademarks represent trademark applications designating only good (resp. service) classes; finance, insurance and real estate trademarks represent trademark applications designating Class 036 of the Nice Classification.

The US gross domestic product is based on the series of seasonally adjusted GDP, expenditure approach, in volume (chained volume estimates) contained in the OECD Quarterly National Accounts Database (May 2011).

Raw GDP and trademark applications series were treated using the OECD's Composite Leading Indicators methodology. Monthly data were used for trademark applications and quarterly data for GDP, converted to a monthly frequency via linear interpolation and aligned with the mid-quarter month. This treatment removes seasonal patterns and trends (using the Hodrick-Prescott filter) in order to extract the cyclical pattern. The cyclical pattern presented on the graph is expressed as a percentage deviation from the long-term trend. Considering the filters applied, the remaining cycles are those with a period of between 18 months and 10 years. The analysis was performed on series from January 1990 to February 2011 for trademark applications and to March 2011 for GDP. For more information on the methodology, see OECD (2008), OECD System of Composite Leading Indicators, OECD Publishing, Paris, www.oecd.org/dataoecd/26/39/41629509.pdf.

The graph shows a peak around 2004 for the trademark series which does not correspond to the economic activity. It corresponds to the accession of the United States to the Madrid Agreement in November 2003, which facilitated the filing procedure for foreign applications.

\section{Venture capital investment in the United States (1995-2010) and in Europe (2005-09)}

Europe includes: Austria, Belgium, Bosnia-Herzegovina, Bulgaria, Croatia, the Czech Republic, Denmark, Estonia, Finland, France, Germany, Greece, Hungary, Ireland, Italy, Latvia, Lithuania, Luxembourg, Montenegro, the Netherlands, Norway, Poland, Portugal, Romania, Serbia, Spain, the Slovak Republic, Slovenia, Sweden, Switzerland, Ukraine and the United Kingdom.

\section{Investment by business angel groups/networks in the United States and Europe, 2006-09}

A business angel is a private investor who generally provides finance and business expertise to a company in return for an equity share in the firm. Some business angels form syndicates or networks in order to take on larger deals and spread risk.

Business angel groups are formed by individual angels joining together with other angels in order to evaluate and invest in entrepreneurial ventures. The angels can pool their capital to make larger investments.

A business angel network is an organisation whose aim is to facilitate the matching of entrepreneurs with business angels.

Data refer to networks and groups surveyed by the business angel associations.

Europe includes: Andorra, Austria, Belgium, Bosnia-Herzegovina, Bulgaria, Croatia, the Czech Republic, Denmark, Finland, France, Germany, Greece, Hungary, Ireland, Italy, Latvia, Lithuania, Luxembourg, Malta, the Netherlands, Norway, Poland, Portugal, the Russian Federation, Serbia, Slovenia, Spain, Sweden, Switzerland, Turkey, Ukraine and the United Kingdom. 


\section{R\&D in OECD and non-OECD countries, 2009 or latest available year}

For Australia (2008), Canada (2008), Chile (2008), France (2008), Greece (2007), Iceland (2008), Korea (2008), Mexico (2007), New Zealand (2007), South Africa (2008), Switzerland (2008) and the United States (2007).

\section{R\&D tax incentives versus direct support to business R\&D, 2004 and 2009}

Estimates of R\&D tax expenditures do not cover sub-national R\&D tax incentives.

China, Greece, Iceland, Israel, Italy, the Slovak Republic and the Russian Federation provide R\&D tax incentives but cost estimates are not available.

Mexico and New Zealand repealed tax schemes in 2009. No cost estimates are available for Mexico. In 2008, the cost for R\&D tax incentives for New Zealand was NZD 103 million but BERD government funding data are not available for that year.

Estimates for Australia and Hungary are based on country responses to the 2010 OECD R\&D tax incentives questionnaire.

2008 instead of 2009 for Australia, France, Hungary, Ireland, Japan, Portugal, South Africa and the United States. 2007 instead of 2009 for Austria, Belgium and Spain.

2005 instead of 2004 for Belgium, Canada, the Czech Republic, Denmark, the Netherlands, Norway and the United States.

2006 instead of 2004 for Poland, Portugal and South Africa.

2007 instead of 2004 for Slovenia.

The estimate for Austria covers the refundable research premium but excludes other R\&D allowances. The value of the research premium has been removed from direct government funding of business R\&D to avoid double counting. For 2008 and 2004, estimates for France are based on accrual accounting measures of tax costs instead of cash-based measures of foregone tax. Before 2009, unused credits in France could not be refunded for three years, resulting in significant differences in tax cost estimates according to the method used. For 2008, claims exceeded paid credits by EUR 2.7 billion while in 2009, as a result of exceptional stimulus measures that allowed for the immediate payment of tax credit liabilities, tax expenditures exceeded claims by nearly EUR 1.5 billion. 2009 data for France are not reported due to the unavailability of comparable estimates for business R\&D direct funding for that year.

The United States estimate covers the research tax credit but excludes the expensing of R\&D.

\section{Global Internet Protocol (IP) traffic, 2005-10}

VoD: video on demand. WAN: wide area network.

\section{New uses of the Internet: social networking and health information, 2010}

Social networking is considered as posting messages to chat sites, blogs, newsgroups or online discussion forums or for instant messaging (European countries). For Korea, only online community data were taken into account.

\section{Routed IPv4 addresses per country, year end 2010}

The Internet Protocol (IP) enables different types of physical networks, such as cable TV systems, telephony systems, or wireless networks, to transport packets of data. It uses an addressing system to identify the end points for the data sent and received on the Internet.

The Internet Protocol version 4, or "IPv4", uses a 32-bit address scheme and was first implemented in 1983.

The Internet Protocol version 6, or "IPv6", provides a greatly expanded address range of 128 -bits (or $2^{128}$ possible addresses). Its core set of protocols was developed by the Internet Engineering Task Force from 1993 to 1998.

\section{OECD countries with IPv6-enabled networks, 2010}

The Internet Protocol (IP) enables different types of physical networks, such as cable TV systems, telephony systems, or wireless networks, to transport packets of data. It uses an addressing system to identify the end points for the data sent and received on the Internet.

The Internet Protocol version 4, or "IPv4", uses a 32-bit address scheme and was first implemented in 1983.

The Internet Protocol version 6, or "IPv6", provides a greatly expanded address range of 128 -bits (or $2^{128}$ possible addresses). Its core set of protocols was developed by the Internet Engineering Task Force from 1993 to 1998. 


\section{KNOWLEDGE ECONOMIES: TRENDS AND FEATURES}

University hotspots - geographical distribution of highest impact institutions, 2009

Analysis based on Scopus data processed by SCImago, SIR-SCImago Institutions Rankings, June 2011, www.scimagoir.com.

Innovation hotspots in ICT, biotechnologies and nanotechnologies, 2006-08

Data relate to patent applications filed under the Patent Cooperation Treaty (PCT) in ICT and in biotechnology and nanotechnology. Patent counts are based on the priority date, the inventor's region of residence and fractional counts. The regional breakdown used is based on the OECD's Territorial Level 2. Only the top 20 regions patenting in ICT (and in biotechnology and nanotechnology) are included in the figure.

\section{Service-related trademarks applications at USPTO and OHIM, OECD and BRIICS, 1997-99 and 2007-09}

Shares of service trademarks are calculated using fractional counts of the classes designated in the trademark application. Classes 1 to 34 relate to goods; classes 35 to 45 relate to services.

\section{Trademarks in knowledge-intensive services, OECD and BRIICS, 2007-09}

Shares of knowledge-intensive service trademarks are calculated using fractional counts of the classes designated in the trademark application. Business trademark applications designate Class 35; finance, Class 36 , telecommunications, Class 38, and R\&D, Class 42 of the Nice classification.

\section{Patents and trademarks per capita, 2007-09}

"Triadic" patent families refer to patents filed at the European Patent Office (EPO), the Japan Patent Office (JPO) and the US Patent and Trademark Office (USPTO) which protect the same invention. Patent families are counted according to the earliest priority date (first patent application worldwide), the inventor's country of residence and fractional counts.

"Trademarks abroad" refer to the average number of trademark applications filed at the USPTO, the Office for Harmonization in the Internal Market (OHIM) and the JPO. For US, EU countries and Japan, figures are calculated based on the trademarks filed in the two other foreign offices. Counts are rescaled taking into account the relative average propensity of other countries to file in the three offices. Trademarks abroad are counted according to the application date and the address of the applicant.

\section{The impact of scientific production and the extent of international scientific collaboration, 2003-09}

Analysis based on Scopus data processed by SCImago, SIR-SCImago Institutions Rankings, June 2011, www.scimagoir.com.

\section{International collaboration in science and innovation, 2007-09}

International co-authorship of scientific publications is measured as the share of scientific articles with at least one author from a different country in total scientific articles. The scientific publication indicators are developed from the information contained in the Scopus ${ }^{\circledR}$ Database (Elsevier B.V.).

International co-inventions are measured as the share of patent applications filed under the Patent Cooperation Treaty (PCT) with at least one co-inventor located in a different country in total patents invented domestically. Patent counts are based on the priority date and the inventor's country of residence.

\section{Co-inventions with BRIICS countries, 1991-2009}

Co-inventions are measured as the share of patent applications with at least one co-inventor located in one of the BRIICS countries over total patents invented domestically.

Data relate to total PCT patent applications, at international phase, published by the World Intellectual Property Organization (WIPO). Patent counts are based on the priority date and the inventor's country of residence.

\section{The innovation-science link in "clean" energy technologies, 2000-09}

The data refers to a set of patents published by the EPO, the USPTO or through the Patent Co-operation Treaty (PCT) route. Patents cover technologies or applications for mitigation or adaptation with respect to climate change: capture, storage, sequestration or disposal of greenhouse gases (Y02C); and reduction of greenhouse gases emission related to energy generation, transmission or distribution (Y02E). Analysis of the link between patents and scientific literature 
is based on the "non-patent literature" (NPL) listed as relevant references in patent documents. The NPL is matched with the scientific literature database (Scopus) which makes it possible to determine whether or not the NPL is a scientific article and to obtain bibliographical information recorded in the NPL.

Triadic patent families by blocs, 1999 and 2009

"Triadic" patent families refer to patents filed at the European Patent Office (EPO), the Japan Patent Office (JPO) and the US Patent and Trademark Office (USPTO) which protect the same invention.

Technology transfers to selected BRIICS, 2005-07

The data refer to claimed priorities, i.e. patents for which protection has been requested at at least two patent offices. Patent counts are based on the earliest priority date, the inventor's country of residence and intellectual property (IP) offices in the BRIICS area, using fractional counts.

\section{Biggest net $\mathrm{CO}_{2}$ importers and exporters, 2005}

Countries are sorted by their production-based $\mathrm{CO}_{2}$ emissions, in descending order on the left-hand side and in ascending order on the right-hand side.

\section{R\&D spending for energy and the environment, OECD countries, 1990-2009}

Chile and Turkey are not included. The Czech Republic, Estonia and Poland are included from 2002. Hungary and Luxembourg are included from 2005. Korea is included from 1999.

\section{Trends in patents by technology fields, 1995-2008}

Claimed priorities refer to patents for which protection has been requested to at least two patent offices. Patent counts are based on the earliest priority date, the inventor's country of residence and fractional counts. Data for 2008 are estimates based on more recent patent series.

Patents in biotechnologies and health- and ICT-related technologies are based on a selection of International Patent Classification (IPC) classes.

Patents in environment-related technologies are defined using combinations of IPC classes and codes Y02 of the European Classification (ECLA).

Patents in nanotechnologies are identified by the ECLA Code Y01.

\section{Transition to alternative-fuel vehicle (AFV) technologies, 1990-99 and 2000-07}

Claimed priorities refer to patents for which protection has been requested to at least two patent offices. Patent counts are based on the earliest priority date, the inventor's country of residence and fractional counts.

Patents in technologies for alternative-fuel vehicles and motor vehicles are defined using combinations of International Patent Classification (IPC) codes.

Convergence in the old-age support ratio across the OECD and BRIICS, historical and projected values, 1950-2050

Younger OECD countries have the highest old-age support ratio as of 2011.

Older OECD countries have the lowest old-age support ratio as of 2011.

Transition from upper secondary education to graduation at the university level, 2008

Graduation rates for single year of age.

Upper secondary graduation rates refer to general programmes.

Graduation rates at university level refer to first degree graduation at tertiary-Type A (ISCED-5A).

Gender gap in employment, 1980, 1990, 2000 and 2009

Labour force participation rates are computed for the population aged 15-64.

Earning differentials at tertiary level educational attainment, 1999 and 2009

Belgium, Korea and Turkey report earnings net of income tax.

Slovenia reports earnings excluding data for individuals in part-time and/or part-year earnings.

Data on part-time employment refers to 2007 for Israel. 


\section{KNOWLEDGE ECONOMIES: TRENDS AND FEATURES}

\section{References}

Ahmad, N. and A. Wyckoff (2003), "Carbon Dioxide Emissions Embodied in International Trade of Goods", OECD Science, Technology and Industry Working Papers, No. 2003/15. Doi: http://dx.doi.org/10.1787/421482436815.

Ark, B. van, J.X. Hao, C. Corrado and C. Hulten (2009), "Measuring Intangible Capital and its Contribution to Economic Growth in Europe", EIB Papers, Vol. 14(1), Luxembourg. www.eib.org/attachments/efs/eibpapers/ eibpapers_2009_v14_n01_en.pdf.

Barnes, P. and A. McClure (2009), "Investments in Intangible Assets and Australia's Productivity Growth", Productivity Commission Staff Working Paper, Canberra. www.pc.gov.au/_data/assets/pdf_file/0006/86496/intangible-investment.pdf.

Belhocine, N. (2009), “Treating Intangible Inputs as Investment Goods: The Impact on Canadian GDP”, IMF Working Paper, No. WP/09/240, Washington DC. www.imf.org/external/pubs/ft/wp/2009/wp09240.pdf.

Carbon Dioxide Emissions Embodied in International Trade (OECD, online document), www.oecd.org/document/22/0,3746,en_2649_ 34445_46878038_1_1_1_1,00.html.

COINVEST, www.coinvest.org.uk.

Corrado, C., C. Hulten and D. Sichel (2006), "Intangible Capital and Economic Growth", NBER Working Paper Series, Vol. w11948. www.nber.org/papers/w11948.

Corrado, C., C. Hulten and D. Sichel (2009), "Intangible Capital and US Economic Growth", Review of Income and Wealth, Vol. 55(3), September, pp. 661-685.

Edquist, H. (2009), "How Much Does Sweden Invest in Intangible Assets", IFN Working Paper, No. 785, Research Institute of Industrial Economics, Stockholm. www.ifn.se/Wfiles/wp/wp785.pdf.

Fukao, K., T. Miyagawa, K. Mukai, Y. Shinoda and K. Tonogi (2009), "Intangible Investment in Japan: Measurement and Contribution to Economic Growth", Review of Income and Wealth, Vol. 55(3), pp. 717-736.

Haščič, I., N. Johnstone, F. Watson and C. Kaminker (2010), "Climate Policy and Technological Innovation and Transfer: An Overview of Trends and Recent Empirical Results", OECD Environment Working Paper, No. 2010/30, OECD, Paris. Doi: http://dx.doi.org/10.1787/5km33bnggcd0-en.

ISIC Rev. 3 Technology Intensity Definition (OECD, online document), www.oecd.org/dataoecd/43/41/48350231.pdf.

Japan Patent Office (JPO) (2008-10), Annual Reports, Japan Patent Office (JPO), Tokyo.

Lev, B. (2001), Intangibles: Management, Measurement and Reporting, Brookings Institution Press, Washington DC.

Marrano, G.M., J.E. Haskel and G. Wallis (2009), "What Happened to the Knowledge Economy? ICT, Intangible Investment and Britain's Productivity Record Revisited", Review of Income and Wealth, Vol. 55(3), pp. 686-716.

Millot, V. (2009), "Trademarks as an Indicator of Product and Marketing Innovations", OECD Science, Technology and Industry Working Papers, No. 2009/06. Doi: http://dx.doi.org/10.1787/224428874418.

Miroudot, S., R. Lanz and A. Ragoussis (2009), "Trade in Intermediate Goods and Services", OECD Trade Policy Working Papers, No. 93. Doi: $h t t p: / / d x . d o i . o r g / 10.1787 / 5 k m l c x t d l k 8 r-e n$.

Nakano, S., A. Okamura, N. Sakurai, M. Suzuki, Y. Tojo and N. Yamano (2009), “The Measurement of $\mathrm{CO}_{2}$ Embodiments in International Trade: Evidence from the Harmonised Input-Output and Bilateral Trade Database", OECD Science, Technology and Industry Working Papers, No. 2009/03. Doi: http://dx.doi.org/10.1787/227026518048.

OECD (2001), Measuring Productivity - OECD Manual: Measurement of Aggregate and Industry-level Productivity Growth, OECD Publishing. Doi: http://dx.doi.org/10.1787/9789264194519-en.

OECD (2002), Frascati Manual 2002: Proposed Standard Practice for Surveys on Research and Experimental Development, The Measurement of Scientific and Technological Activities, OECD Publishing, Paris. Doi: http://dx.doi.org/10.1787/ 9789264199040-en.

OECD (2005), "A Framework for Biotechnology Statistics", OECD, Paris, available at: www.oecd.org/dataoecd/5/48/34935605.pdf.

OECD (2005), Measuring Globalisation: OECD Handbook on Economic Globalisation Indicators, OECD Publishing, Paris. Doi: http://dx.doi.org/10.1787/9789264108103-en.

OECD (2008), "OECD System of Composite Leading Indicators", OECD, Paris, available at: www.oecd.org/dataoecd/26/39/ 41629509.pdf.

OECD (2009), "Guidelines for a Harmonised Statistical Approach to Biotechnology Research and Development in the Government and Higher Education Sectors", Working Party of National Experts on Science and Technology Indicators, DSTI/EAS/STP/NESTI(2009)1/FINAL, OECD, Paris, available at: www.oecd.org/dataoecd/33/9/44279076.pdf.

OECD (2009), Innovation in Firms: A Microeconomic Perspective, OECD Publishing, Paris. Doi: http://dx.doi.org/10.1787/ 9789264056213-en.

OECD (2009), “OECD Biotechnology Statistics 2009”, OECD, Paris, available at: www.oecd.org/dataoecd/4/23/42833898.pdf.

OECD (2009), OECD Patent Statistics Manual, OECD Publishing, Paris. Doi: http://dx.doi.org/10.1787/9789264056442-en. 
OECD (2010), Measuring Globalisation: OECD Economic Globalisation Indicators 2010, OECD Publishing. Doi: http://dx.doi.org/ 10.1787/9789264084360-en.

OECD (2010), Measuring Innovation: A New Perspective, OECD Publishing, Paris. Doi: http://dx.doi.org/10.1787/9789264059474-en. OECD (2010), OECD Handbook on Deriving Capital Measures of Intellectual Property Products, OECD Publishing, Paris. Doi: http://dx.doi.org/10.1787/9789264079205-en.

OECD (2010), The OECD Innovation Strategy: Getting a Head Start on Tomorrow, OECD Publishing, Paris. Doi: http://dx.doi.org/ 10.1787/9789264083479-en.

OECD (2011), Economic Policy Reforms 2011: Going for Growth, OECD Publishing. Doi: http://dx.doi.org/10.1787/growth-2011-en. OECD (2011), Education at a Glance 2011: OECD Indicators, OECD Publishing, Paris. Doi: http://dx.doi.org/10.1787/eag-2011-en. OECD (2011), Invention and Transfer of Environmental Technologies, OECD Publishing, Paris. Doi: http://dx.doi.org/10.1787/ 9789264115620-en.

OECD (2011), OECD Communications Outlook 2011, OECD Publishing, Paris. Doi: http://dx.doi.org/10.1787/comms_outlook2011-en.

OECD (2011), OECD Guide to Measuring the Information Society 2011, OECD Publishing, Paris. Doi: http://dx.doi.org/10.1787/ 9789264113541-en.

OECD (2011), OECD Regions at a Glance 2011, OECD, Paris. Doi: http://dx.doi.org/10.1787/reg_glance-2011-en.

OECD (2011), Pensions at a Glance 2011: Retirement-Income Systems in OECD and G20 Countries, OECD Publishing, Paris. Doi: http://dx.doi.org/10.1787/pension_glance-2011-en.

OECD (2011), Towards Green Growth: Monitoring Progress: OECD Indicators, OECD Publishing. Doi: http://dx.doi.org/10.1787/ 9789264111356-en.

OECD and Eurostat (2005), Oslo Manual: Guidelines for Collecting and Interpreting Innovation Data, 3rd edition, OECD Publishing, Paris. Doi: http://dx.doi.org/10.1787/9789264013100-en.

OECD and SCImago Research Group (CSIC) (forthcoming), Report on Scientific Production.

Van Rooijen-Horsten, M., D. Van den Bergen, M. de Haan, A. Klinkers and M. Tanriseven (2008), "Intangible Capital in the Netherlands: Measurement and Contribution to Economic Growth", Statistics Netherlands Discussion Paper, No. 08016, The Hague/Heerlen. www.cbs.nl/NR/rdonlyres/DE0167DE-BFB8-4EA1-A55C-FF0A5AFCBA32/0/200801x10pub.pdf.

WTO and IDE-JETRO (2011), Trade Patterns and Global Value Chains in East Asia: From Trade in Goods to Trade in Tasks, Geneva, www.wto.org/english/res_e/booksp_e/stat_tradepat_globvalchains_e.pdf. 



\section{BUILDING KNOWLEDGE}

1. New doctorate graduates

2. Career of doctorate holders

3. Science and technology occupations

4. Researchers

5. $R \& D$ expenditure

6. Higher education and basic research

7. Business R\&D

8. Investment in ICT

Notes

References

Education and research, together with innovation, are often referred to as the knowledge triangle. They are at the core of today's economies and drive economic growth. A first set of indicators relates to human capital in science and technology. The number of university graduates indicates a country's capacity to absorb, develop and diffuse knowledge. Comparisons focus on doctorate holders, who are specifically trained for research, and their career path. Additional indicators look beyond the education system to labour market outcomes, in particular for human resources in science and technology and researchers. A second set of indicators looks at investment in R\&D performed by the business sector, government and higher education. Experimental indicators of public funding "modes" (e.g. institutional versus project funding) are also included. Finally, investment in information and communication technology (ICT) shows the potential to increase innovation and makes a positive contribution to economic performance. 


\section{BUILDING KNOWLEDGE}

\section{New doctorate graduates}

Graduation rates at doctorate level, 2000 and 2009

As a percentage of population in reference age cohort

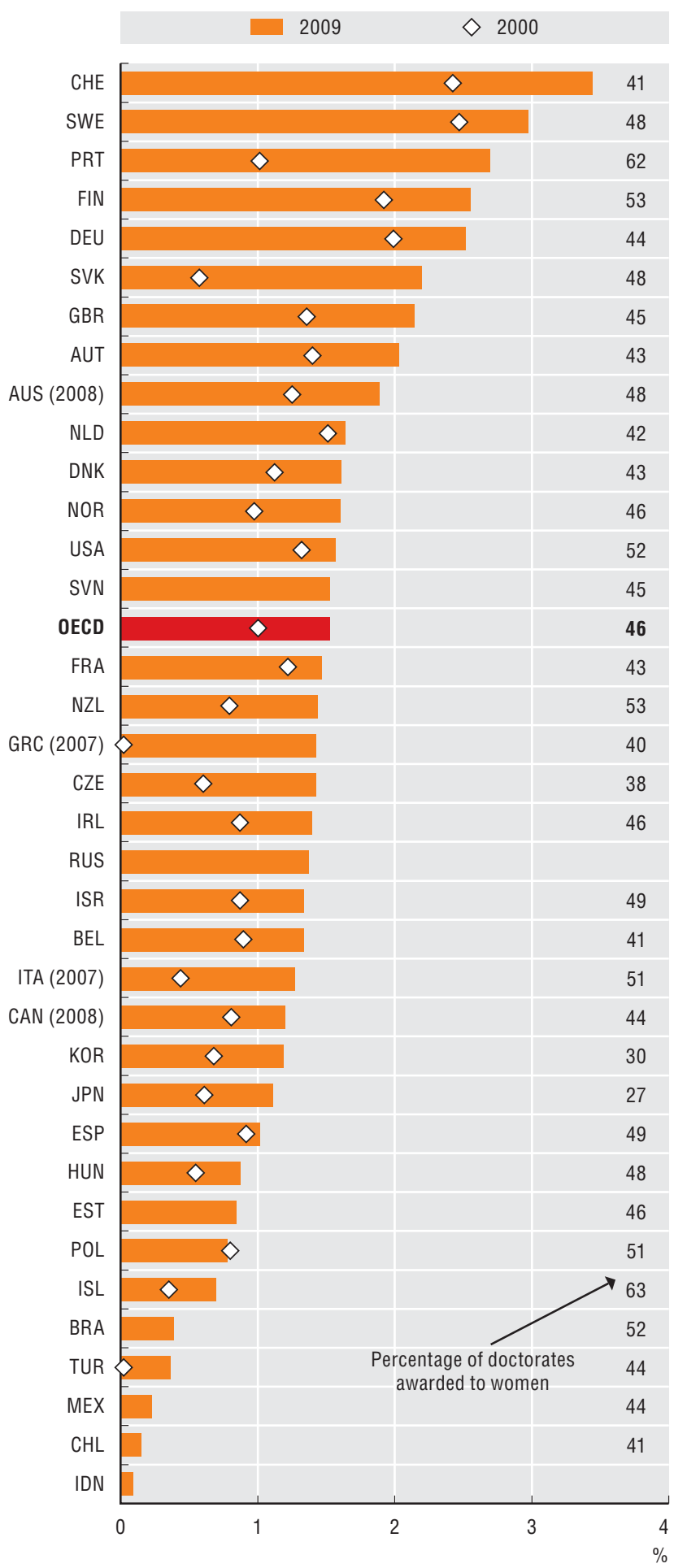

Source: OECD (2011), Education at a Glance 2011: OECD Indicators, and OECD (2009), Education at a Glance 2009: OECD Indicators, OECD Publishing, Paris. See chapter notes.

StatLink तiाsस $h t t p: / / d x . d o i . o r g / 10.1787 / 888932485728$
Doctoral graduates are key players for research and innovation. They have been specifically trained to conduct research and are considered the best qualified for the creation and diffusion of scientific knowledge.

While only a small proportion of students obtained advanced research degrees in 2009, the share showed an upward trend in all countries over the last decade. In Switzerland and Sweden, graduation rates reached 3.4\% and 3.0\%, respectively. The relative increase was largest in the Slovak Republic and Portugal.

The increasing presence of women in doctoral programmes partly explains the overall increase in doctorates over the past decade. In 2009 , women received $46 \%$ of the OECD average of total doctorate degrees awarded. However, they remain underrepresented in science and engineering (S\&E), accounting for only $34 \%$ of all degrees in these subjects. Exceptions are found in Iceland (64\%) and Portugal (49\%).

The largest share of new doctorate degrees is in S\&E followed by the social sciences for men and by health and welfare for women. While absolute numbers of S\&E doctorates have increased significantly since 2000 , their relative share has been declining in a majority of OECD countries. Nonetheless, nearly $39 \%$ of doctoral graduates in the OECD area obtained a degree in S\&E fields in 2009 and more than $55 \%$ in Chile, France and China.

A focus on the top ten countries with the largest shares of S\&E doctorates shows that the United States is the largest single contributor of new doctorates with more than a quarter of the nearly 89000 OECD total in 2009. It is followed by Germany, the United Kingdom and France. The $20 \mathrm{EU}$ countries combined account for more than half of the total number of OECD doctoral degrees in S\&E.

\section{Definitions}

Doctoral graduates have attained the second stage of university education and obtained a degree at ISCED Level 6. They have successfully completed an advanced research programme and gained an advanced research qualification, e.g. Ph.D. Science degrees include: life sciences; physical sciences; mathematics and statistics; and computing. Engineering degrees comprise: engineering and engineering trades; manufacturing and processing; and architecture and building. Graduation rates represent the estimated percentage of an age cohort that will complete the corresponding level of education during their lifetime. These are calculated as net graduation rates (i.e. as the sum of age-specific graduation rates). Gross graduation rates are used for countries that are unable to provide more detailed data. The number of graduates, regardless of their age, is divided by the population at the typical graduation age. 
Science and engineering graduates at doctorate level, 2009

As a percentage of all new degrees awarded at doctorate level

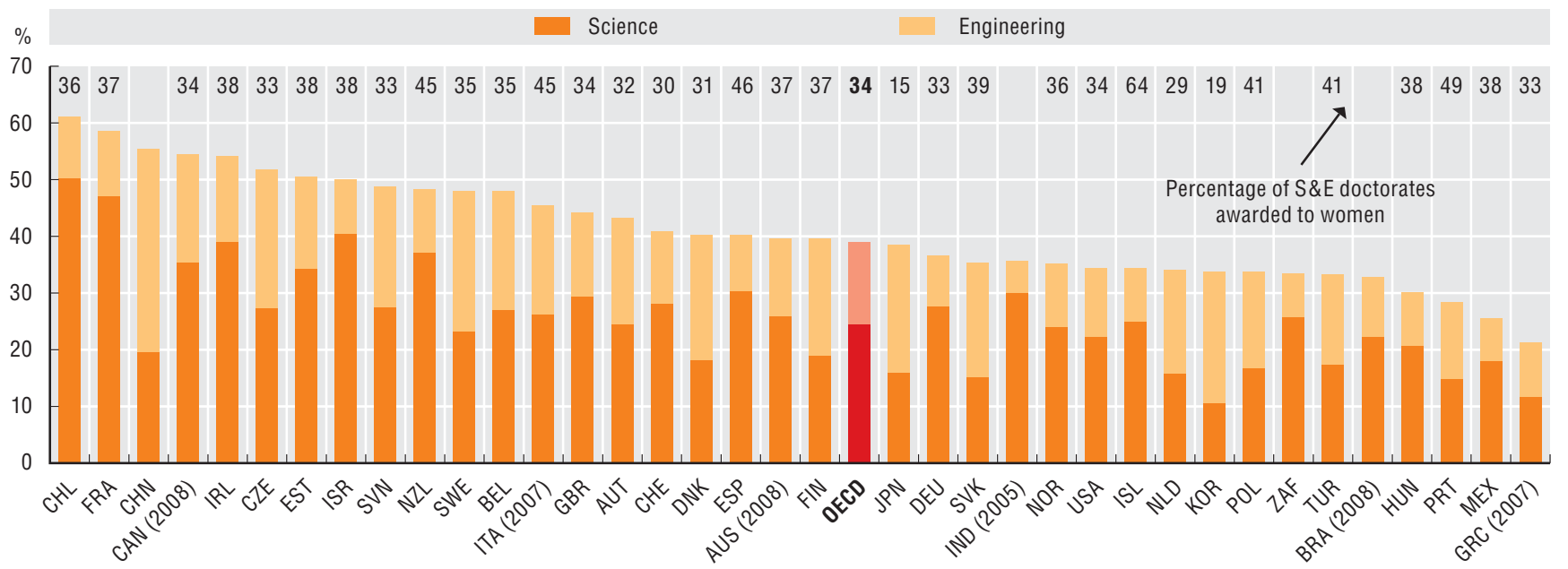

Source: OECD, Education Database, September 2011; and OECD, calculations based on national sources, May 2011. See chapter notes.

StatLink 시내 $h t t p: / / d x . d o i . o r g / 10.1787 / 888932485747$

Science and engineering graduates at doctorate level, by country of graduation, 2009

As a percentage of total OECD new science and engineering degrees at doctorate level

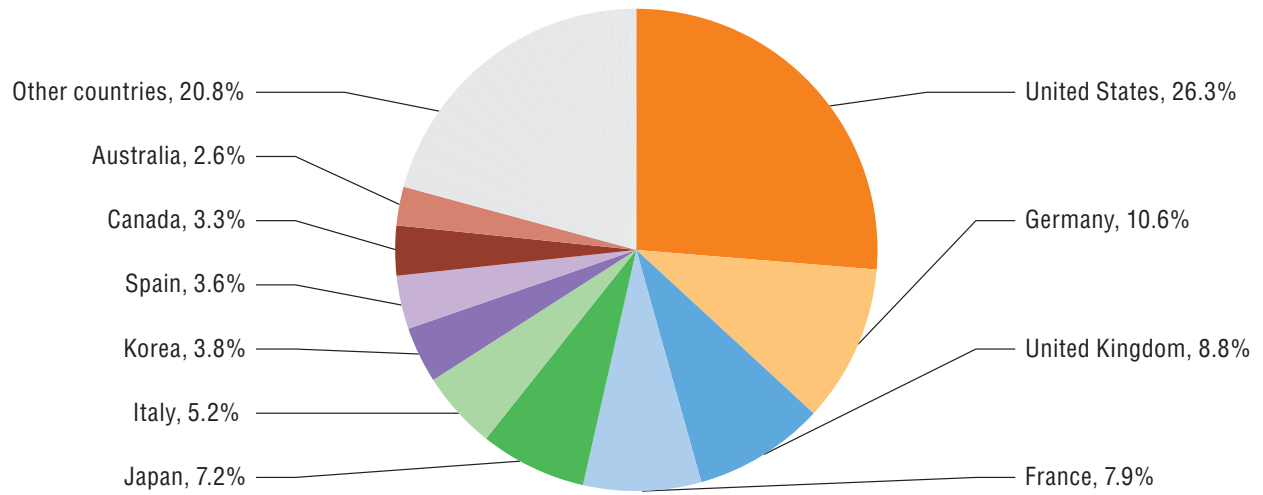

Source: OECD, Education Database, September 2011; and OECD, calculations based on Nordic Institute for Studies in Innovation, Research and Education (NIFU), May 2011. See chapter notes.

StatLink ants http://dx.doi.org/10.1787/888932485766

\section{Measurability}

Graduation rates are computed on the basis of annual data jointly collected by UNESCO-UIS/OECD/Eurostat. This data collection aims to provide internationally comparable information on key aspects of education systems, specifically on participation and completion levels for education programmes in more than 60 countries worldwide.

A graduate from a programme is defined as a student who has successfully completed all requirements of that programme. Because of national differences regarding what is understood as graduation, the international comparability of "successful graduation" is a major issue. Avoiding double-counting of individuals graduating from several programmes in the same year, or remaining at the same educational level over time, are other measurement challenges.

In contrast to the flow of new graduates in a given period, the number of graduates at a point in time is a stock measure which is often part of an analysis of the educational attainment of the population. Attainment data are typically computed from labour force or other household surveys, whereas graduation rates are mainly based on administrative records from educational organisations and authorities. 


\section{BUILDING KNOWLEDGE}

\section{Career of doctorate holders}

Employment rate of doctorate holders by gender, 2009

As a percentage of total doctorate holders

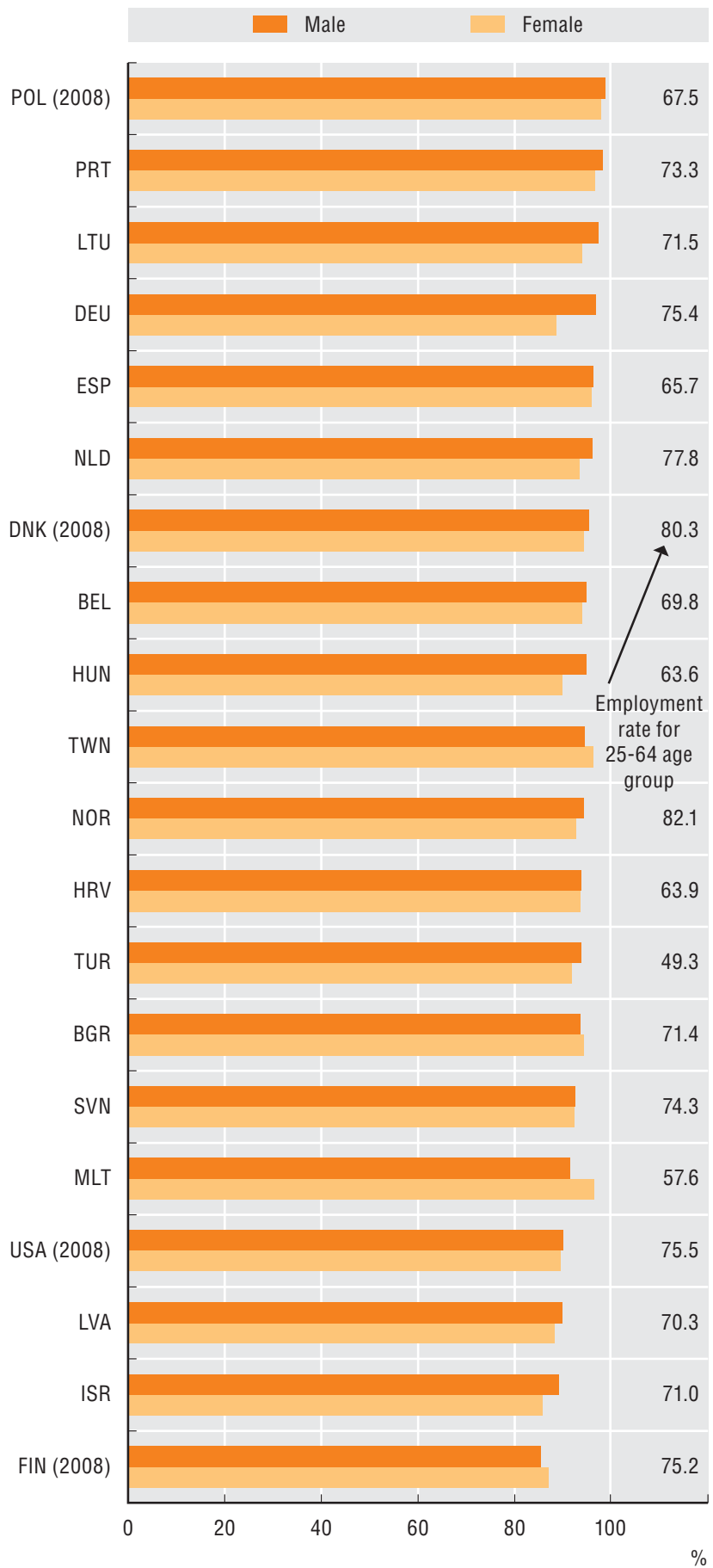

Source: OECD, based on OECD/UNESCO Institute for Statistics/Eurostat data collection on careers of doctorate holders 2010, June 2011; and OECD, Employment Database, June 2011. See chapter notes.

StatLink Aाs http://dx.doi.org/10.1787/888932485785
An economy's capacity to draw human resources into research is the basis for creating new knowledge and advancing economic activity. Factors that are likely to influence career choices of doctoral graduates include stability, earnings and motivation.

The average employment rate of male and female doctorate holders who obtained their degrees after 1970 is $93 \%$, compared to $70 \%$ for all individuals aged 25 to 64 within the economies for which data are available. The difference is particularly marked for Malta, Turkey, Poland and Spain. In most economies, male employment rates slightly exceed those of females. The opposite is true for Bulgaria, Finland, Malta and Chinese Taipei.

Over $23 \%$ of graduates at the doctorate level hold fixedterm contracts in the first five years after graduation in 10 out of 16 countries for which data are available, a situation that does not persist in the long run, except in Latvia and the Russian Federation. In the majority of countries, however, temporary employment remains more frequent for doctoral graduates than for other employees.

In all economies for which data are available, gross annual earnings of doctorate holders employed as researchers exceed those of non-researchers in the higher education sector. The picture is mixed for other sectors. Gross annual earnings of doctorate holders in the business enterprise and government sectors fall short of those of their researcher counterparts in higher education in the Netherlands, Portugal and Romania. The opposite is true for Belgium. In the business enterprise sector, gross annual earnings for doctorate holders employed as researchers exceed those of other doctorate holders in half of the 13 countries for which data are available.

\section{Definitions}

Doctorate holders are all economically active or inactive residents below the age of 70 who have completed, anywhere in the world, the second stage of tertiary education (ISCED level 6) leading to an advanced research qualification. The employment rate of doctorate holders is the ratio of the number of doctorate holders in employment (employees and self-employed) to the total number of doctorate holders residing in the country. The percentage of doctorate holders with temporary contracts is calculated as the share of doctorate holders on fixed-term contracts in all doctorate holders employed. The percentage difference in median gross annual earnings between doctorate holders working as researchers and those not working as researchers is calculated as the difference between the former and latter groups, divided by median gross annual earnings of doctorate holders not working as researchers. 


\section{A corrigendum has been issued for this page. See: http://www.oecd.org/dataoecd/26/8/48742541.pdf} Doctorate holders on temporary contracts over career path, 2009

As a percentage of employed doctorate holders

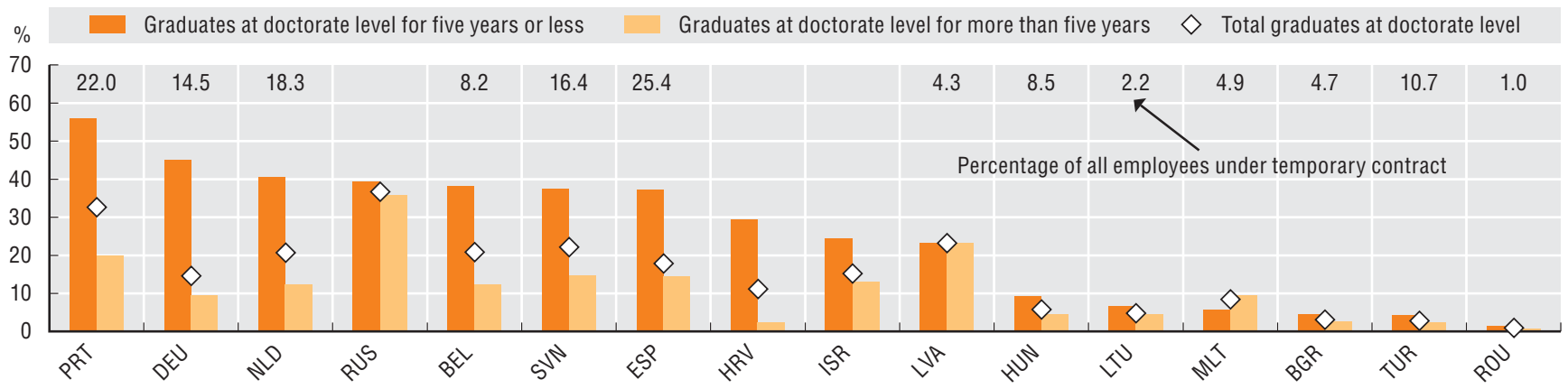

Source: OECD, based on OECD/UNESCO Institute for Statistics/Eurostat data collection on careers of doctorate holders 2010, June 2011; OECD, Employment Database, June 2011; and Eurostat, June 2011. See chapter notes.

StatLink AाISL http://dx.doi.org/10.1787/888932485804

Difference in median gross annual earnings of doctorate holders working as researchers and as non-researchers, 2009 As a percentage of median gross annual earnings of doctorate holders not working as researchers

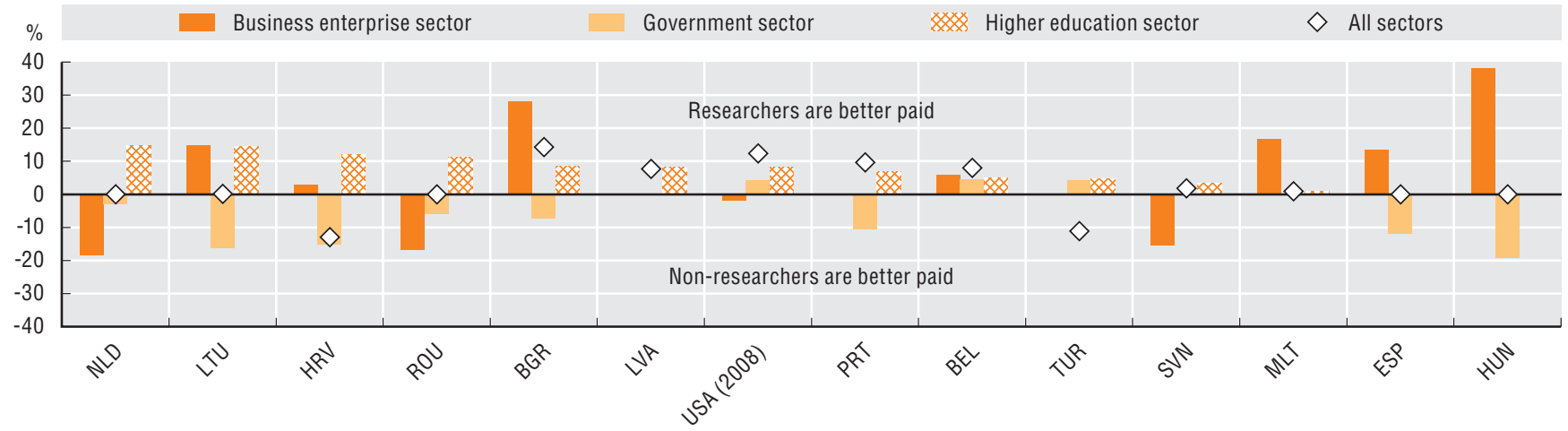

Source: OECD, based on OECD/UNESCO Institute for Statistics/Eurostat data collection on careers of doctorate holders 2010, June 2011. See chapter notes. StatLink काIs http://dx.doi.org/10.1787/888932485823

\section{How to read this figure}

In the Netherlands (NLD) there is no overall earning difference between doctorate holders working as researchers and those not working as researchers. However, as researchers they earn $15 \%$ more than non researchers when employed in higher education, and $18 \%$ less than non researchers if employed in business enterprises.

\section{Measurability}

The Careers of Doctorate Holders (CDH) project is a joint OECD/UNESCO Institute for Statistics/Eurostat effort which aims to better understand the labour market, career path and mobility of a population regarded as key to the production and diffusion of knowledge and innovation. As part of the project, methodological guidelines, a model questionnaire and templates for output tables were developed with the help of an expert group composed of statisticians from the participating countries. Owing to the methodological challenges involved, notably the development of national registers of doctorate holders, alternative data sources such as censuses, registers or labour force surveys are used in some countries. This may have an impact on the coverage of the target population, the availability of certain variables or the comparability of the data, although every effort is made to minimise and document the differences. While some large countries such as France, Japan and the United Kingdom still do not formally participate in the project, an increasing number is joining it. 


\section{BUILDING KNOWLEDGE}

\section{Science and technology occupations}

A corrigendum has been issued for this page. See: http://www.oecd.org/dataoecd/26/8/48742541.pdf

HRST occupations, 2010

As a percentage of total employment

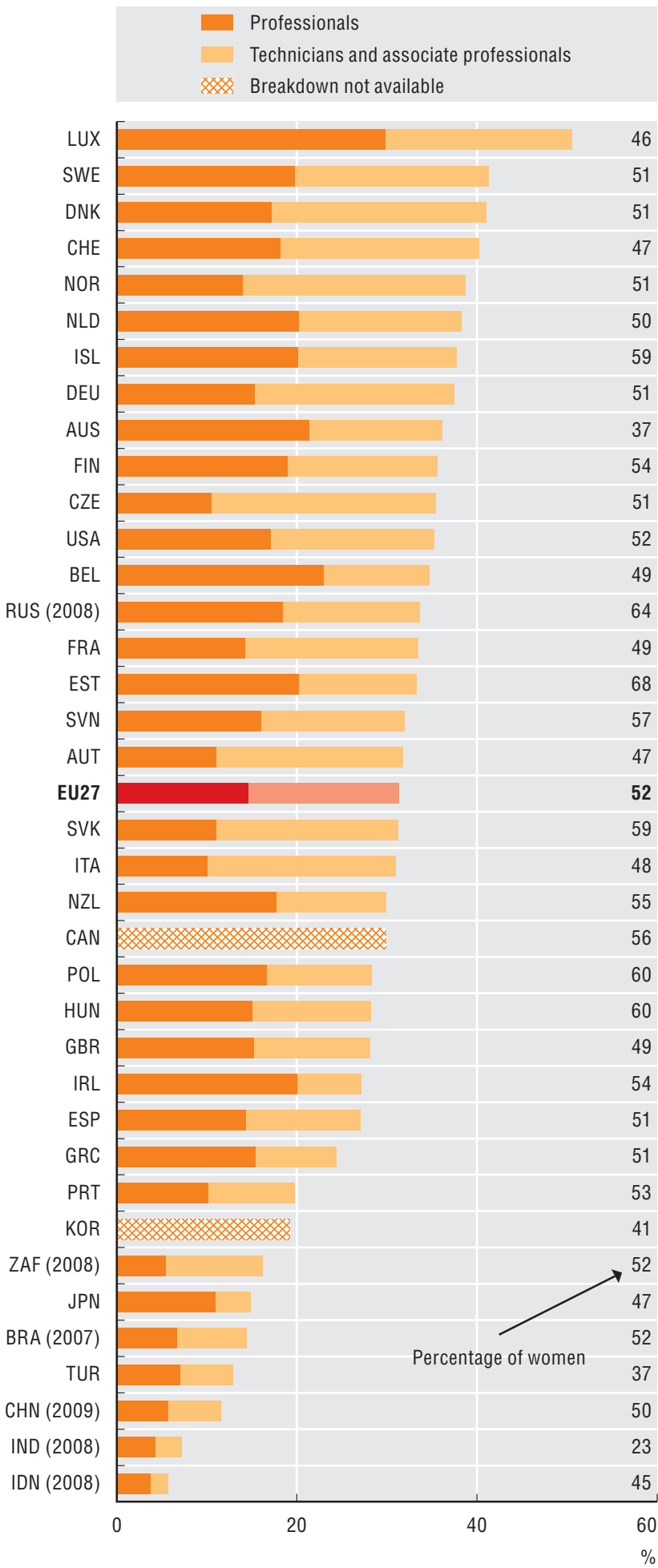

Source: OECD, calculations based on EU Labour Force Survey; US Current Population Survey; Australian, Canadian, Japanese and New Zealander labour force surveys; Korean Economically Active Population Survey; China Labour Statistical Yearbook 2010; Indian National Sample Survey; and ILO, Laborsta Database, May 2011. See chapter notes.

StatLink ins $h t$ ttp://dx.doi.org/10.1787/888932485842
Human resources in science and technology (HRST) play a key role in innovation. In most OECD countries, they represented more than a quarter of total employment in 2010. The share was over 40\% in Luxembourg, Sweden, Denmark and Switzerland; in India and Indonesia, HRST workers accounted for less than $10 \%$ of total employment. The split between professionals and technicians differs across countries.

A particular characteristic of HRST employment is the increasing share of women. In the majority of countries, women are now more numerous than men among HRST employees. In Estonia, the Russian Federation, Poland and Hungary, more than $60 \%$ of HRST in 2010 were women.

The industry structure of employment shows that HRST employees are more concentrated in services than in manufacturing. In 2008, the share of professionals and technicians in services varied between 19.3\% (in Japan) and $46.9 \%$ (in Luxembourg) and it is mostly concentrated in community, social and personal services, as well as business services; in manufacturing it was around $20 \%$ on average in OECD countries for which data were available.

Over 1998-2008, HRST occupations increased more rapidly than total employment in most OECD countries. In services, their average annual growth rate has always been positive, ranging from $1.2 \%$ (in Japan) to $6.3 \%$ (in Iceland). However, in manufacturing, the share of professionals and technicians decreased by an average annual rate of more than $1 \%$ in Luxembourg $(-2.3 \%)$ and Japan $(-1.3 \%)$.

\section{Definitions}

Human resources in science and technology (HRST) are defined according to the Canberra Manual (OECD and Eurostat, 1995) as persons having graduated at the tertiary level of education or employed in a science and technology occupation for which a high qualification is normally required and the innovation potential is high. While tertiary level graduates give a measure of supply, demand for HRST is better gauged by occupations. Professionals (ISCO Group 2) includes: physical, mathematical and engineering science professionals; life science and health professionals; teaching professionals; and other professionals. Technicians and associate professionals (ISCO Group 3) includes: physical and engineering science associate professionals; life science and health associate professionals; teaching associate professionals; other associate professionals. 
HRST employees by industry, 2008

As a percentage of all employees in the industry

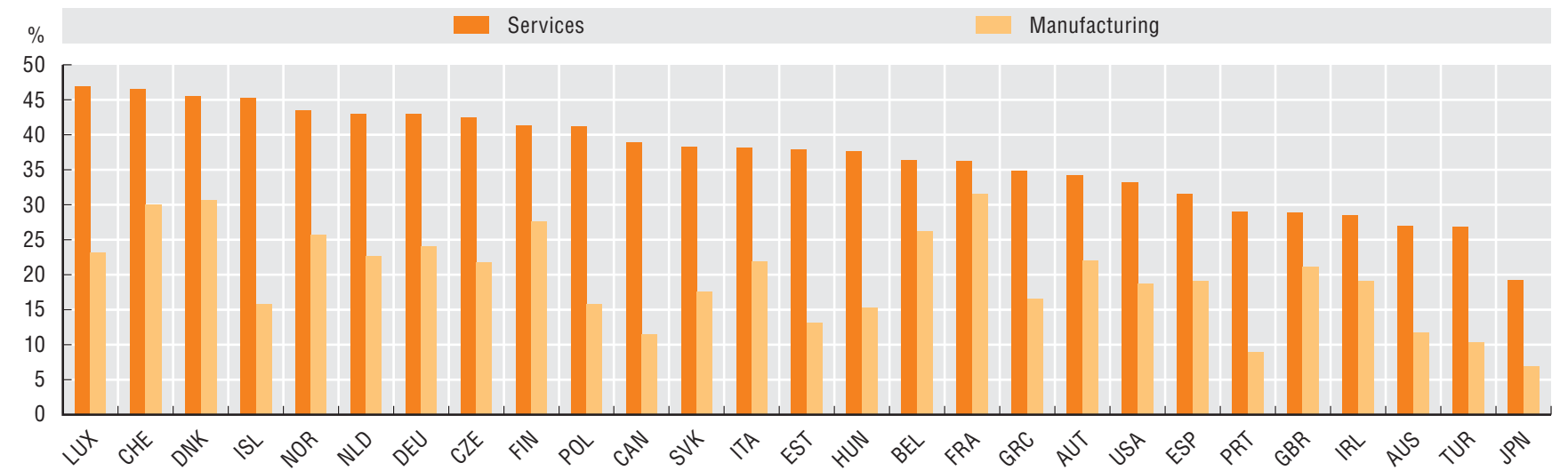

Source: OECD, ANSKILL Database (internal use only), June 2011. See chapter notes.

HRST growth by industry, 1998-2008

Average annual growth rate

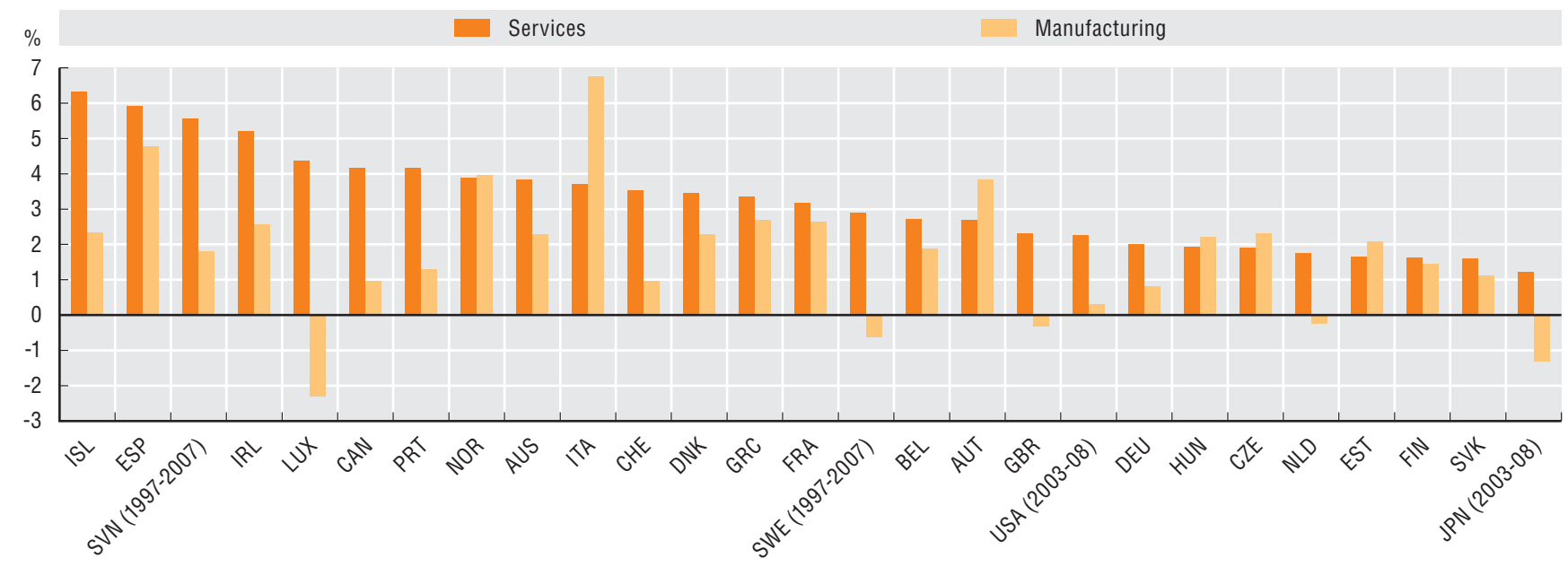

Source: OECD, ANSKILL Database (internal use only), June 2011.

StatLink AाISL $h t t p: / / d x . d o i . o r g / 10.1787 / 888932485880$

\section{Measurability}

Human resources in science and technology (HRST) are defined on the basis of both educational attainment and occupations. Cross-tabulations of both variables are available from labour force surveys. However, when the industry dimension is added to the breakdown, sample sizes become smaller and the representativeness of the data can be weakened. The use of labour force survey tabulations with the unique occupation dimension is mainly motivated by the availability and comparability of such data across countries. Human resource indicators can also be built from administrative data such as linked employer and employee surveys.

On the basis of earlier work by the OECD and Eurostat in the framework of the "Manual on the Measurement of Human Resources Devoted to S\&T", the Canberra Manual, a new dataset, namely ANSKILL, was developed at the OECD. Its main objective is to add a "skill" dimension to the STAN Database for Structural Analysis at the industry level. Differences in national sources limit the ability to produce detailed sectoral breakdowns. ANSKILL covers European countries, Australia, Canada, Japan and the United States over 1997-2008. 


\section{BUILDING KNOWLEDGE}

\section{Researchers}

Researchers by R\&D performing sector, 2009

Per thousand employment

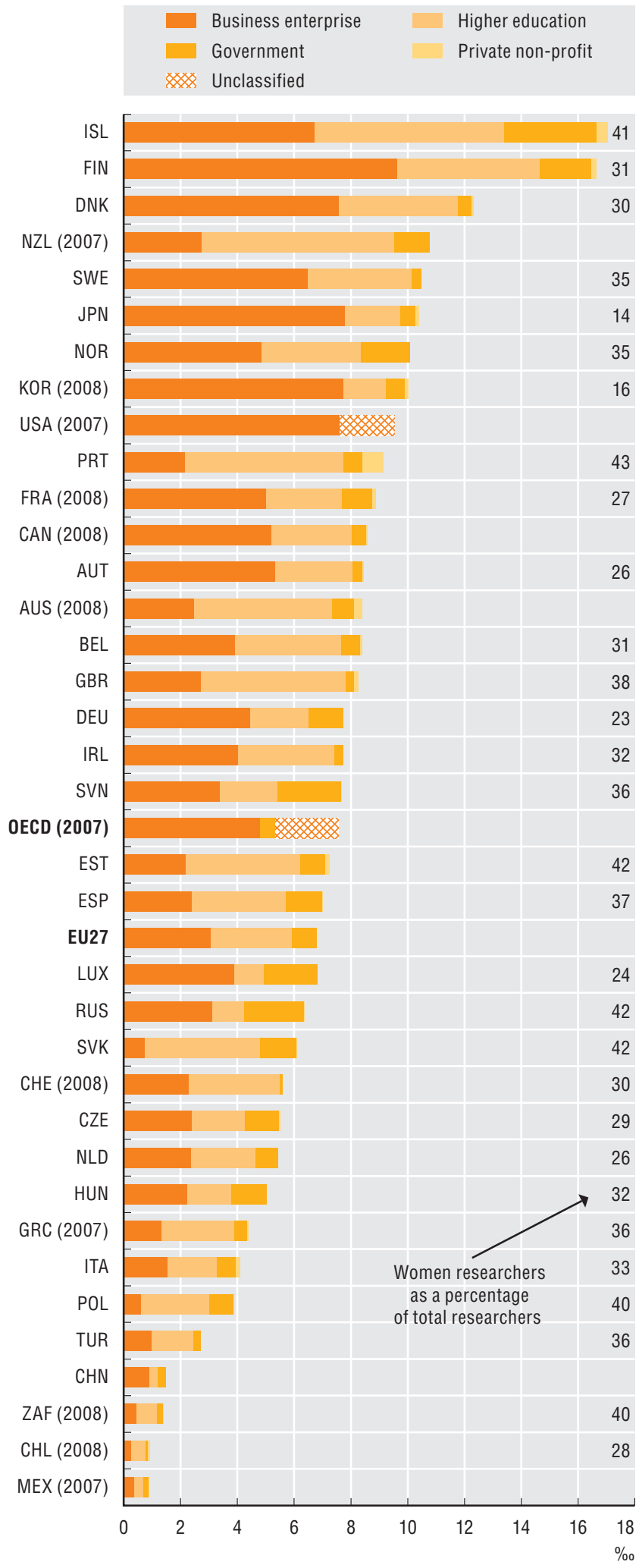

Source: OECD, Main Science and Technology Indicators Database, June 2011.
In 2009, more than 4.2 million researchers were engaged in $R \& D$ in the OECD area, about 7.6 researchers per 1000 employees, a significant increase from 6.6 per 1000 in 1999. The five Nordic countries (Denmark, Finland, Iceland, Norway and Sweden), Japan, Korea and New Zealand employed more than ten researchers per 1000 employees.

The share of women varies but is generally below that of men, especially in the business sector. In Germany, Japan, Korea and Luxembourg, less than a quarter of researchers are women.

In 2009, the OECD-area business enterprise sector employed more than 2.7 million researchers (about $65 \%$ of the total). The higher education sector employed a quarter of OECD researchers and $40 \%$ of those in the European Union. The government sector employed at least $20 \%$ of the researchers in Central and Eastern European countries where the academies of sciences, which are traditionally separate from the universities, play a prominent role.

The share of business researchers in the national totals differs widely. In the United States, four out of five work in businesses, three out of four in Japan, but less than one out of two in the EU. In Denmark, Finland, Japan and the United States, business researchers exceed ten per 1000 employees; they are respectively seven and six per 1000 in France and Germany (close to the OECD average) and 3.5 per 1000 in the United Kingdom (close to the EU average).

Chile, Mexico, Poland, the Slovak Republic and South Africa have a low intensity of business researchers (less than one per 1000 employees in industry). In these countries, the business sector plays a much smaller role in the national $R \& D$ system than the higher education and government sectors.

A non-negligible and increasing share of business researchers are employed in service industries owing to the growing importance of services in the knowledge economy.

\section{Definitions}

Researchers are defined as professionals engaged in the conception and creation of new knowledge, products, processes, methods and systems and are directly involved in the management of projects. The number of researchers is here expressed in full-time equivalent (FTE) units. A person working half-time on $\mathrm{R} \& \mathrm{D}$ is counted as 0.5 person year in FTE. FTE refers to staff engaged in $R \& D$ during the course of a given year. FTE data are a more accurate measure of the volume of research conducted by a country's researchers. Researchers are shown relative to total employment in the OECD National Accounts. Employment in industry excludes persons engaged in real estate, public administration and defence, education, health and social work and private households. 


\section{Business researchers, 1999 and 2009}

Per thousand employment in industry

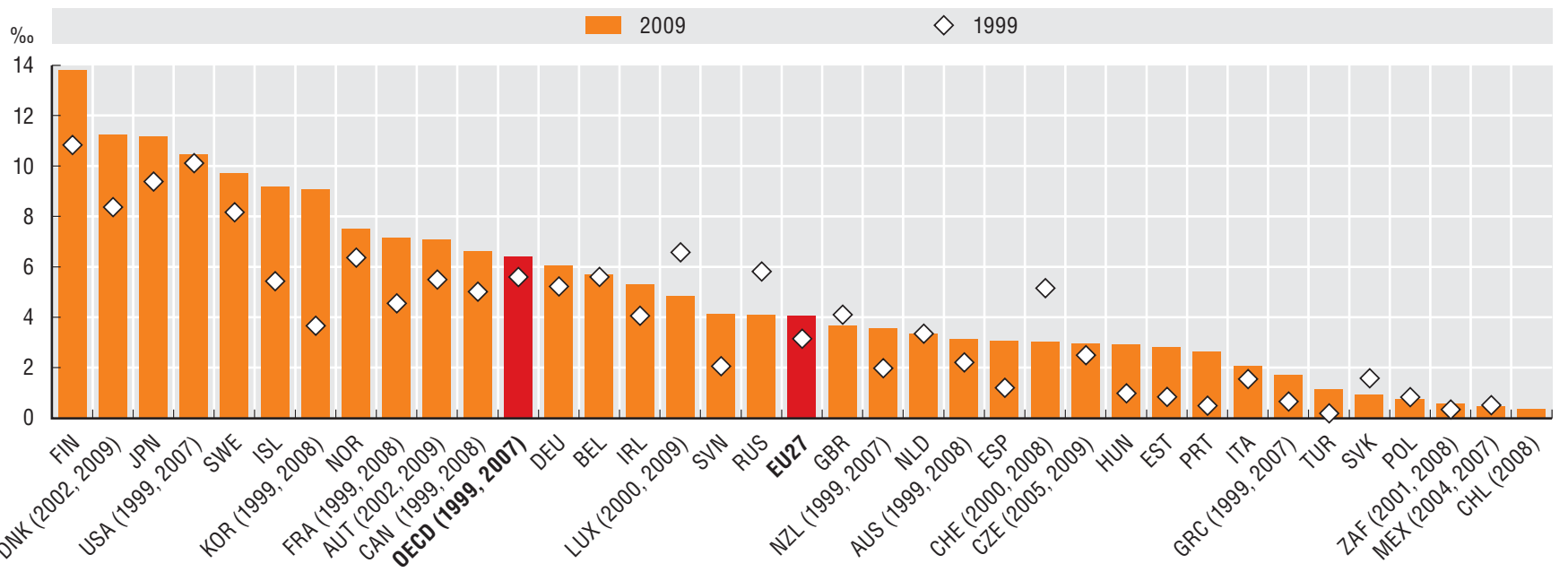

Source: OECD, Main Science and Technology Indicators Database, June 2011.

\section{Researchers in manufacturing and services, 2009}

Per thousand employment in industry

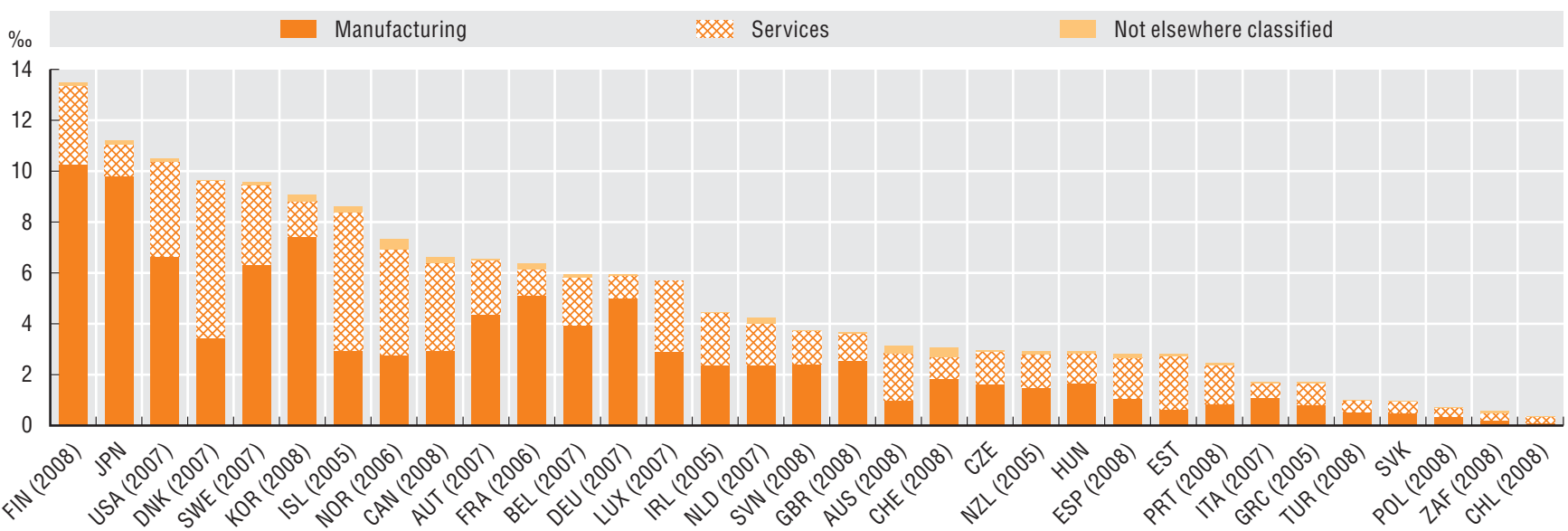

Source: OECD, Research and Development Database, May 2011. See chapter notes.

\section{Measurability}

Data on researchers suffer from a series of limitations which are currently the focus of OECD methodological work. For example, the methods used to calculate FTE (full-time equivalent) may vary not only from country to country but even from sector to sector. Estimating FTE is particularly challenging in the higher education sector, as researchers share their time with other activities such as teaching or administrative tasks. In addition, the demand for more detailed data on researchers by fields of science or other variables needs to be addressed. At present, the breakdown of researchers by gender is not available in countries such as Australia, Canada and the United States. 


\section{BUILDING KNOWLEDGE}

\section{R\&D expenditure}

Gross domestic expenditure on R\&D, 1999 and 2009 As a percentage of GDP

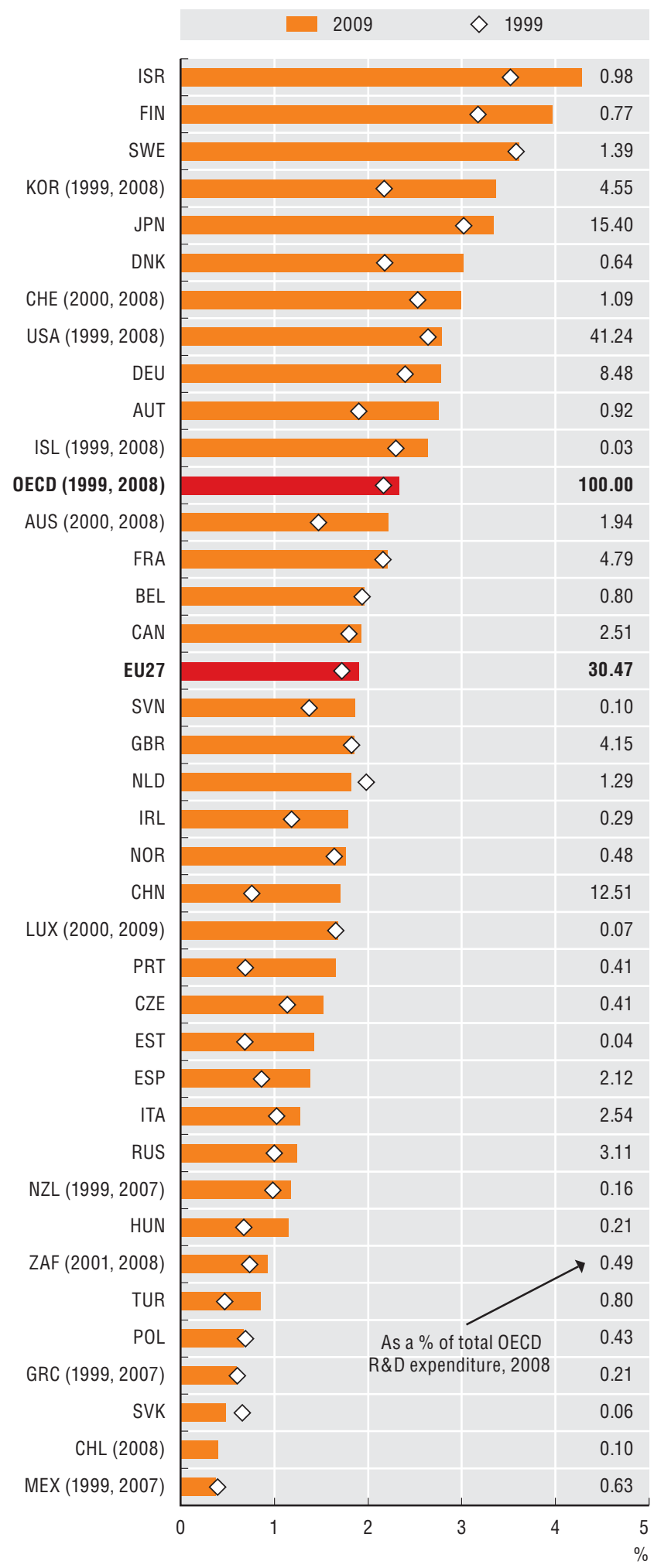

Source: OECD, Main Science and Technology Indicators Database, June 2011. See chapter notes.

StatLink ज्ञाs $h$ ttp://dx.doi.org/10.1787/888932485956
Expenditure on research and development (R\&D) is one of the most widely used measures of innovation inputs. R\&D intensity (R\&D expenditure as a percentage of GDP) is used as an indicator of an economy's relative degree of investment in generating new knowledge. Several countries have adopted "targets" for this indicator to help focus policy decisions and public funding. Israel has the highest R\&D intensity, with gross domestic expenditure on R\&D (GERD) in excess of $4 \%$ of gross domestic product (GDP). The OECD average stands at $2.3 \%$. The United States accounts for $41 \%$ of OECD-area GERD, followed by Japan with 15\% and Germany with $8 \%$. China's domestic expenditure on R\&D is the equivalent of $12 \%$ of total OECD GERD; it is therefore the world's third largest R\&D performer.

The business sector continues to be the main performer of R\&D in most economies and accounts for nearly $70 \%$ of R\&D performed in the OECD area. Israel's business sector makes the largest contribution to GERD, with nearly $80 \%$ of total R\&D, closely followed by Japan and Korea. Business $R \& D$ is exceeded by $R \& D$ in the higher education sector only in Turkey, Greece and Poland. Across the OECD, higher education R\&D accounts for nearly $17 \%$ of total GERD. The government is the main performer of $R \& D$ only in Argentina, where it accounts for nearly $40 \%$ of GERD.

Within countries, even in the most R\&D-intensive, there is also considerable variation in R\&D intensity. In making international and regional comparisons, it is important to be aware of differences in industrial structure and research capabilities. New Mexico is the most R\&D-intensive region with $7.5 \%$ of regional GDP. In Australia, France, Germany, Korea, Norway, the United Kingdom and the United States, the R\&D intensity of the leading region is at least twice the national average.

\section{Definitions}

The main aggregate used for international comparisons of R\&D expenditures is gross domestic expenditure on R\&D (GERD). GERD data and their components are compiled on the basis of the OECD Frascati Manual 2002 methodology, which defines R\&D as "creative work undertaken on a systematic basis in order to increase the stock of knowledge, including knowledge of man, culture and society, and the use of this stock of knowledge to devise new applications". GERD is usually broken down among four sectors of performance: business enterprise, higher education, government and private not-for-profit institutions serving households (PNP). GERD is often reported in relative terms as a percentage of GDP, to denote the R\&D intensity of an economy. Regional R\&D intensity is defined as total intramural expenditures on $R \& D$ performed in the sub-national territory (the region) in a given year, and it is defined relative to regional GDP. 
R\&D expenditure by performing sectors, 2009

As a percentage of GERD

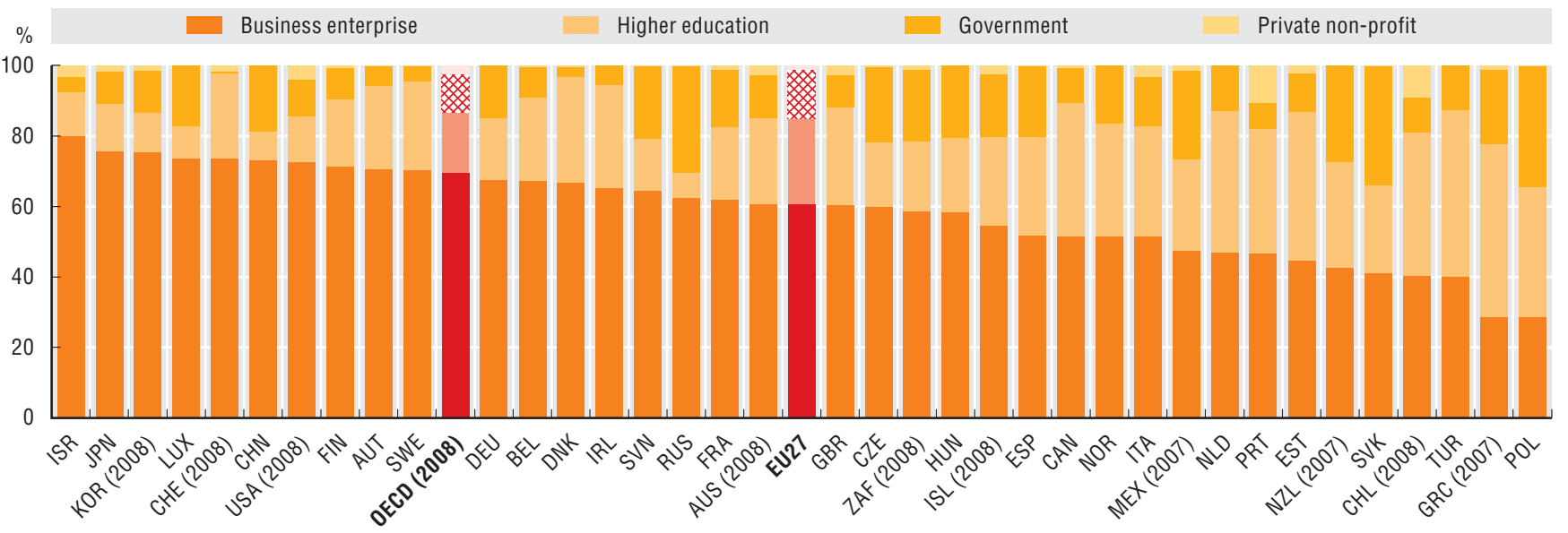

Source: OECD, Main Science and Technology Indicators Database, May 2011. See chapter notes.

StatLink काIS http://dx.doi.org/10.1787/888932485975

R\&D intensity by region, 2007

As a percentage of regional GDP

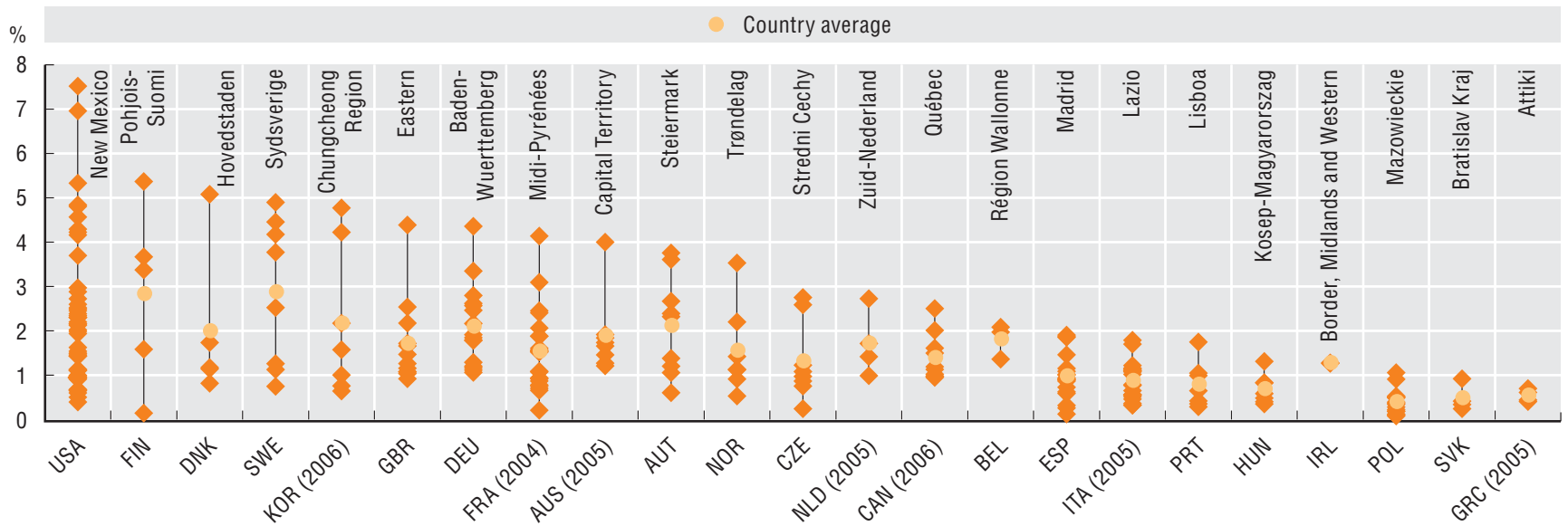

Source: OECD, Regional Database, July 2010. See chapter notes.

StatLink AाISL http://dx.doi.org/10.1787/888932485994

\section{Measurability}

Estimated resources allocated to R\&D are affected by national characteristics: coverage of national surveys on R\&D across sectors and industries; firms and organisations of different sizes; use of different sampling and estimation methods. Because R\&D typically involves a few large performing organisations, R\&D surveys use various techniques to maintain up-to-date registers of known performers. They have developed ways to avoid double counting of R\&D by performers and companies that contract with them or fund R\&D activities of third parties. Following changes to the System of National Accounts, countries have begun to include investment in R\&D (from an ownership perspective) in their estimates of gross fixed capital formation, thus helping to raise the estimated level of GDP. Estimating R\&D intensity by region or other sub-national units presents additional challenges. In addition to information on regional GDP levels, it requires domestic R\&D performers to break down R\&D activities across sites in different national territories or regions. 


\section{BUILDING KNOWLEDGE}

\section{Higher education and basic research}

Higher education expenditure on R\&D, 1999 and 2009 As a percentage of GDP

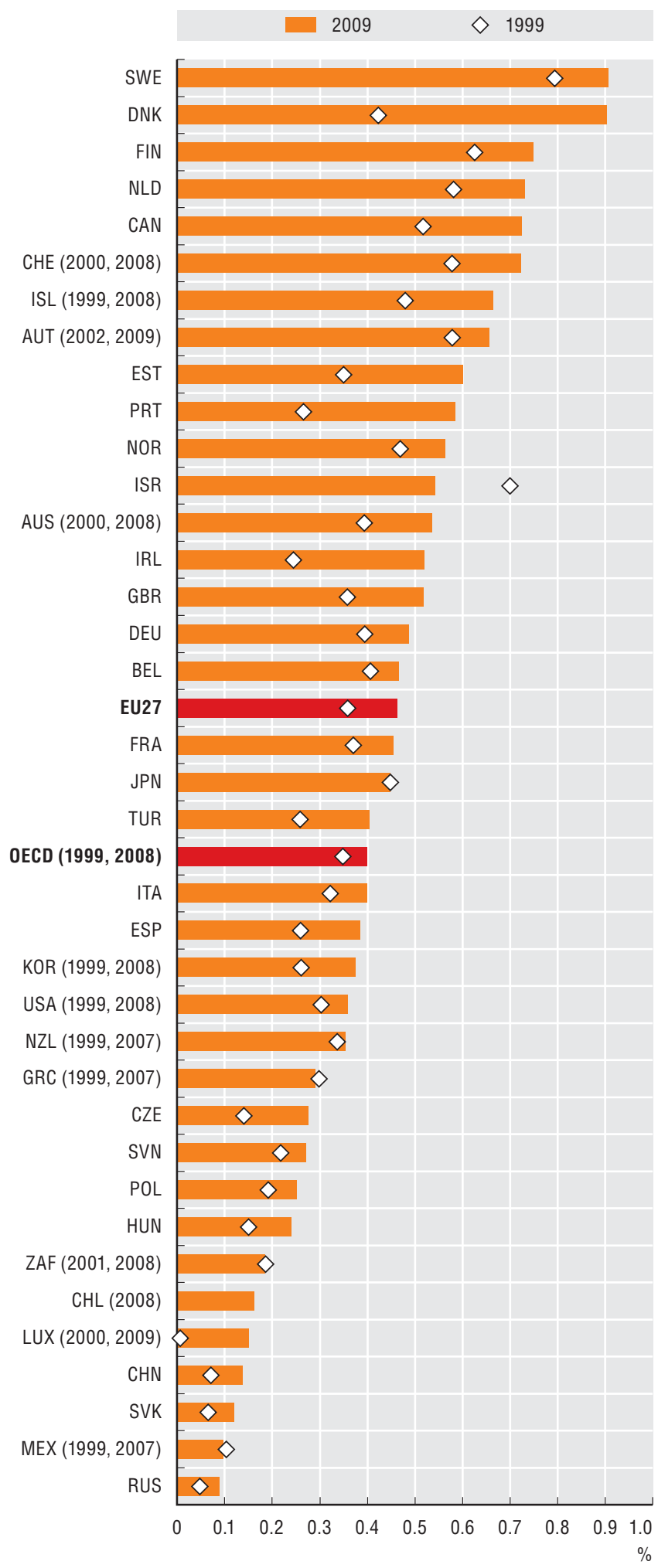

Source: OECD, Main Science and Technology Indicators Database, June 2011. See chapter notes.

StatLink Aiाst http://dx.doi.org/10.1787/888932486013
Most basic research is performed in universities and in public research organisations, and public support is crucial. Total higher education spending on R\&D (HERD) accounts for $0.4 \%$ of GDP in the OECD area, a share that has increased in most countries over the last decade. Sweden has the highest research intensity in the higher education sector at $0.9 \%$ of GDP. Denmark and Portugal have nearly doubled their HERD intensity over the decade.

Governments rely on two main modes of direct R\&D funding: institutional and project-based. Institutional funding can help ensure stable long-run funding of research, while project-based funding can promote competition within the research system and target strategic areas. This is covered by a new indicator on modes of public funding of the higher education sector. Government R\&D funding modes vary widely and reflect the institutional settings of countries' research systems. In Denmark, Israel, New Zealand, Austria and Germany, institutional funding is the principal mode, while Belgium and Korea rely mainly on project funding. The mix of funding modes only changes over the longer run through reforms of the research system.

On average, government and universities perform more than three-quarters of all OECD basic research. The higher education sector's contribution to basic research ranges from $80 \%$ in Chile, Ireland and Denmark to approximately $20 \%$ in Korea, the United Kingdom and the Russian Federation. The government sector's contribution to basic research is largest in the Russian Federation, followed by the Czech Republic, the Slovak Republic, Hungary and China.

\section{Definitions}

Project funding is defined as funding attributed on the basis of a project submission by a group or individuals for an R\&D activity that is limited in scope, budget and time. Institutional funding is defined as the general funding of institutions with no direct selection of $R \& D$ project or programmes. Basic research is experimental or theoretical work undertaken primarily to acquire new knowledge of the underlying foundation of phenomena and observable facts, without any particular application or use in view. For the purpose of these figures, the public sector is defined to comprise the government and higher education sectors but to exclude public-sector corporations which are part of the business enterprise sector, as defined in the Frascati Manual. The higher education sector may include private and public corporations, as well as private not-for-profit organisations as defined in the System of National Accounts. 


\section{Government funding of R\&D in higher education, by type of funding, 2008}

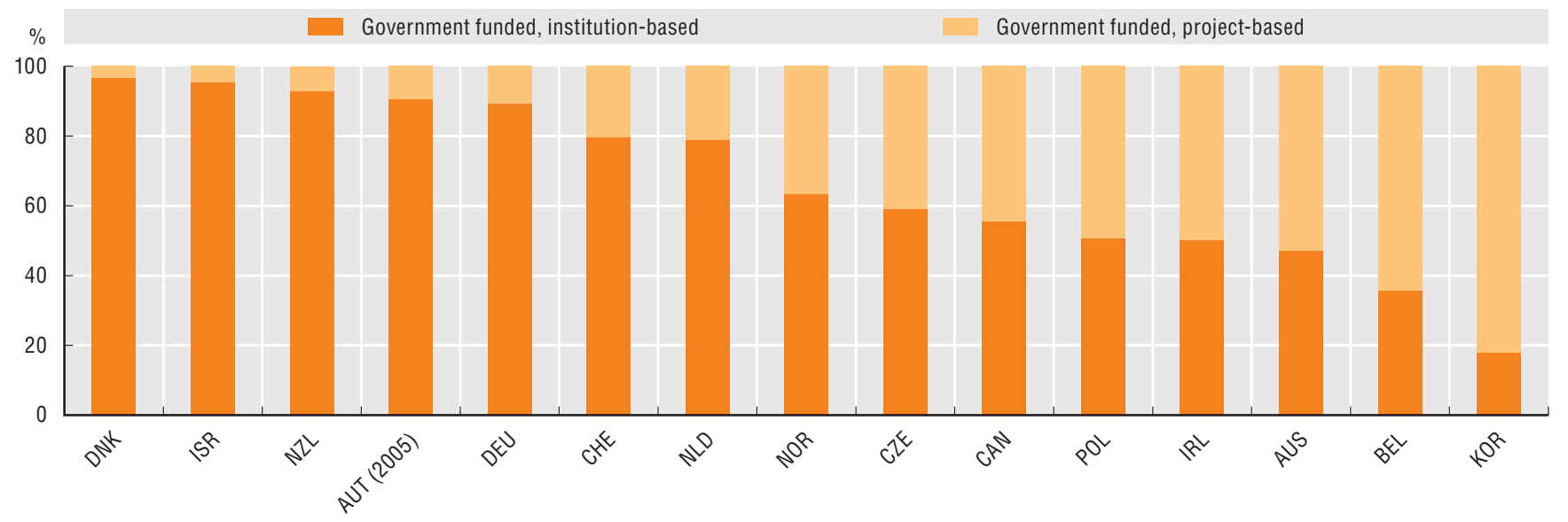

Note: This is an experimental indicator. International comparability is currently limited.

Source: OECD, based on preliminary data from the Microdata project on public R\&D funding, $2009 / 10$.

StatLink AाIs http://dx.doi.org/10.1787/888932486032

Basic research performed in the public sector, 2009

As a percentage of national basic research
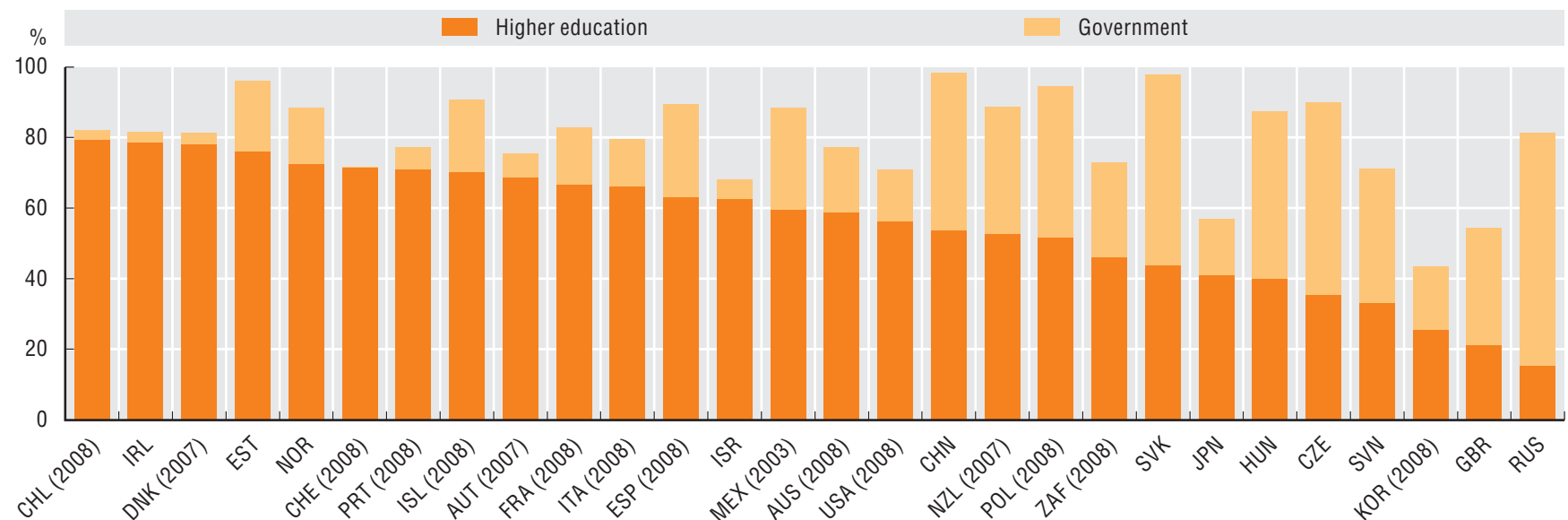

Source: OECD, Research and Development Database, May 2011. See chapter notes.

\section{Measurability}

Measures of R\&D performance in the higher education sector are often estimates by national authorities and evaluation methods are periodically revised. It is necessary to review the design and conduct of higher education surveys to ensure the comparability of these indicators. Project-based funding to higher education includes national R\&D contracts, while institution-based funding to higher education includes general university funds (GUF) and other institutional funds. The NESTI (OECD Working Party of National Experts in Science and Technology Indicators) project on modes of public funding of R\&D is developing new indicators by exploiting existing budget data. A NESTI Task Force has also been set up to provide recommendations on how to improve the measurement of higher education R\&D. 


\section{BUILDING KNOWLEDGE}

\section{Business R\&D}

Business enterprise expenditure on R\&D, 1999 and 2009 As a percentage of GDP

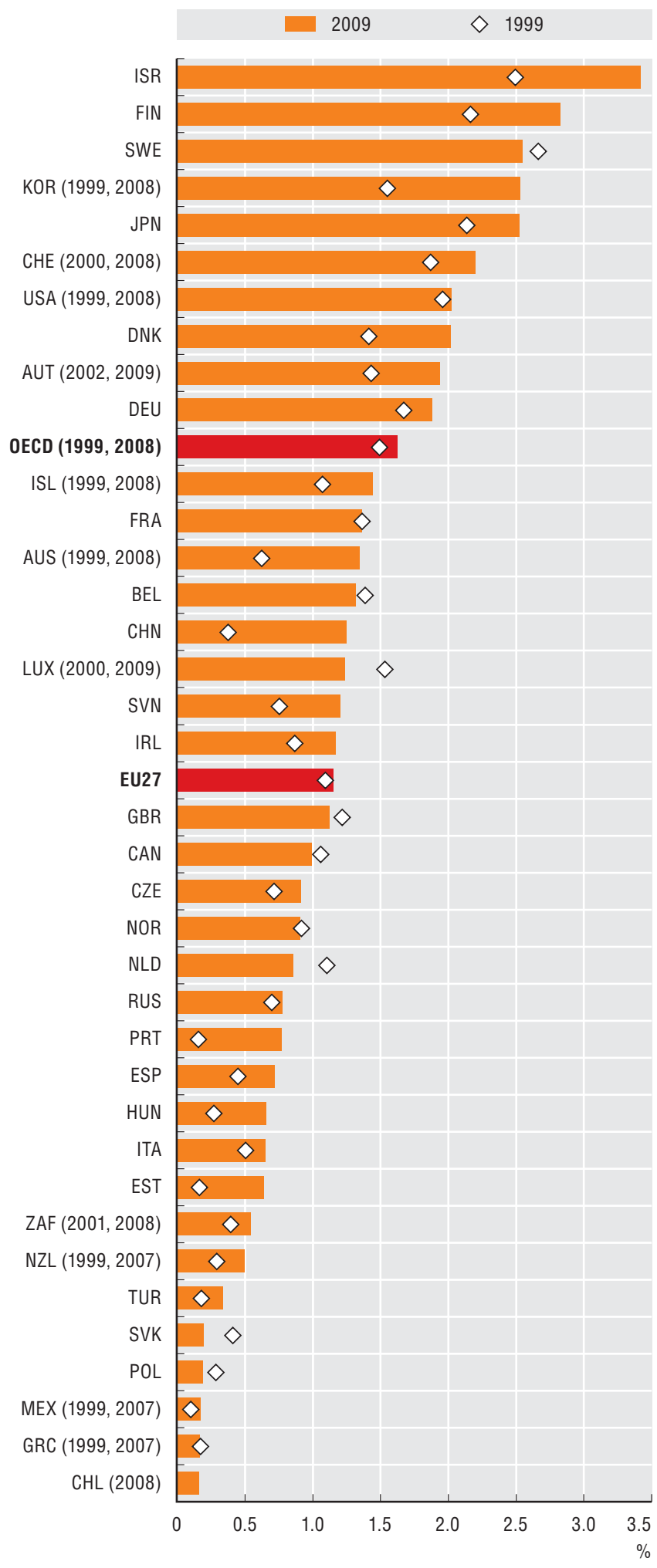

Source: OECD, Main Science and Technology Indicators Database, June 2011. See chapter notes.

StatLink ताIst $h t t p: / / d x . d o i . o r g / 10.1787 / 888932486070$
Business enterprise expenditure on research and development (BERD) is considered important for innovation and economic growth. In OECD countries, business R\&D accounts for the bulk of R\&D in terms of both funding and performance. Business R\&D reached $1.6 \%$ of OECD GDP in 2008, up slightly from $1.5 \%$ in 1999.

Foreign affiliates can play an important role in national R\&D efforts. In 2007-08 they accounted for more than onefifth of total business R\&D in most OECD members. In some smaller open economies, their share exceeded one-half of total BERD. It reached $61.8 \%$ in Israel and $72.4 \%$ in Ireland. However, their share was lowest in the two OECD economies with the largest values for BERD: $14.3 \%$ in the United States and less than $5 \%$ in Japan.

Small and medium-sized firms (SMEs) also play an important role in the R\&D effort of most OECD countries. Their share in total BERD tends to be larger in smaller economies: $73 \%$ in New Zealand, $71 \%$ in Estonia and $63 \%$ in Chile, compared to less than $20 \%$ in France, Sweden, Finland, the United States and Germany, and only $6 \%$ in Japan.

\section{Definitions}

Business enterprise expenditure on R\&D (BERD) covers R\&D activities carried out in the business sector by performing firms and institutes, regardless of the origin of funding. While the government and higher education sectors also carry out R\&D, industrial R\&D is arguably most closely linked to the creation of new products and production techniques, as well as to a country's innovation efforts. The business enterprise sector includes:

- All firms, organisations and institutions whose primary activity is the production of goods and services for sale to the general public at an economically significant price.

- The private and not-for-profit institutions mainly serving them.

The term "foreign affiliate" refers to affiliates under foreign control; the geographical origin of a foreign affiliate is the country of residence of the ultimate controller. An investor (company or individual) is considered to be the investor of ultimate control if it is at the head of a chain of companies and controls directly or indirectly all the enterprises in the chain without itself being controlled by any other company or individual. The notion of control implies the ability to appoint a majority of administrators empowered to direct an enterprise, to guide its activities and determine its strategy. In most cases, this ability can be exercised by a single investor holding more than $50 \%$ of the shares with voting rights. 
R\&D expenditures generated by foreign-controlled affiliates, 2008

As a percentage of $B E R D$

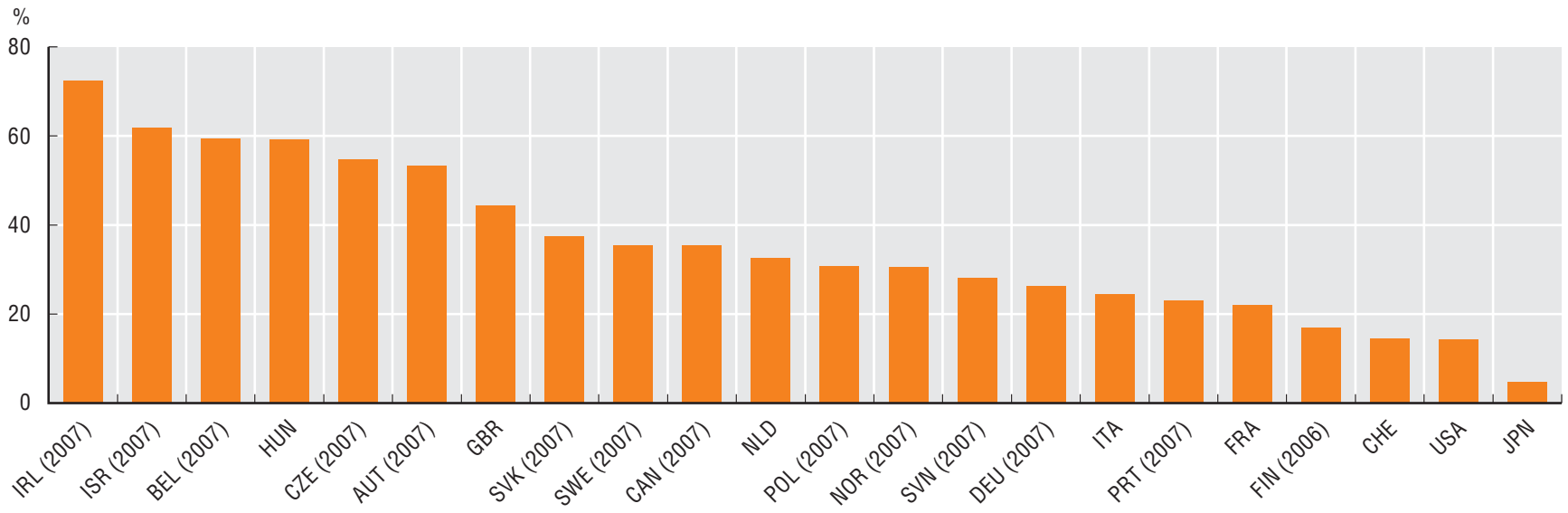

Source: OECD, AFA, FATS and AMNE Databases, May 2011. See chapter notes.

StatLink AाISL http://dx.doi.org/10.1787/888932486089

Business R\&D by size class of firms, 2009

As a percentage of total BERD

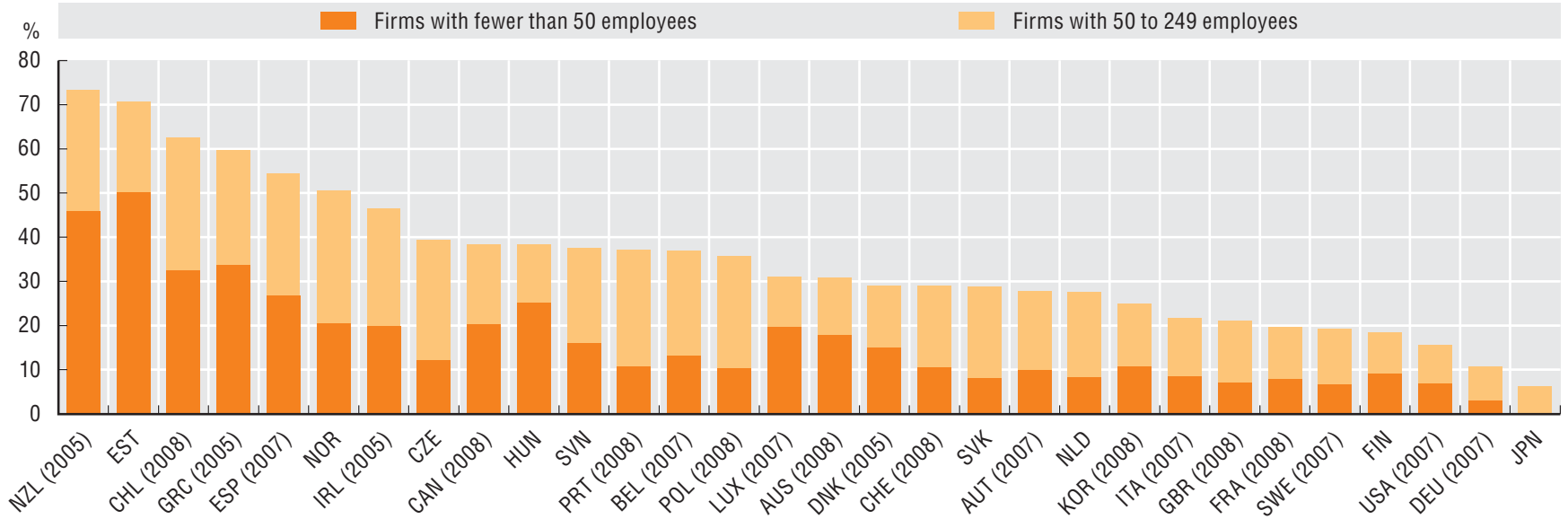

Source: OECD, Research and Development Database, May 2011. See chapter notes.

StatLink काIsL http://dx.doi.org/10.1787/888932486108

\section{Measurability}

When assessing changes in BERD over time, it is necessary to take account of changes in methods and breaks in series, notably in terms of the extension of survey coverage, particularly in the services sector, and the privatisation of publicly owned firms. Identifying new and occasional R\&D performers is also a challenge and OECD countries take different approaches in their BERD surveys.

Not all activities related to foreign affiliates' R\&D are recorded in company transactions. There are intra-company transfers (e.g. intra-company mobility of researchers) with no monetary counterparts which lead to R\&D efforts that do not appear in the statistics as R\&D spending by foreign affiliates. 


\section{BUILDING KNOWLEDGE}

\section{Investment in ICT}

ICT investment by asset in OECD countries, 2009

Percentage of non-residential gross fixed capital formation, total economy

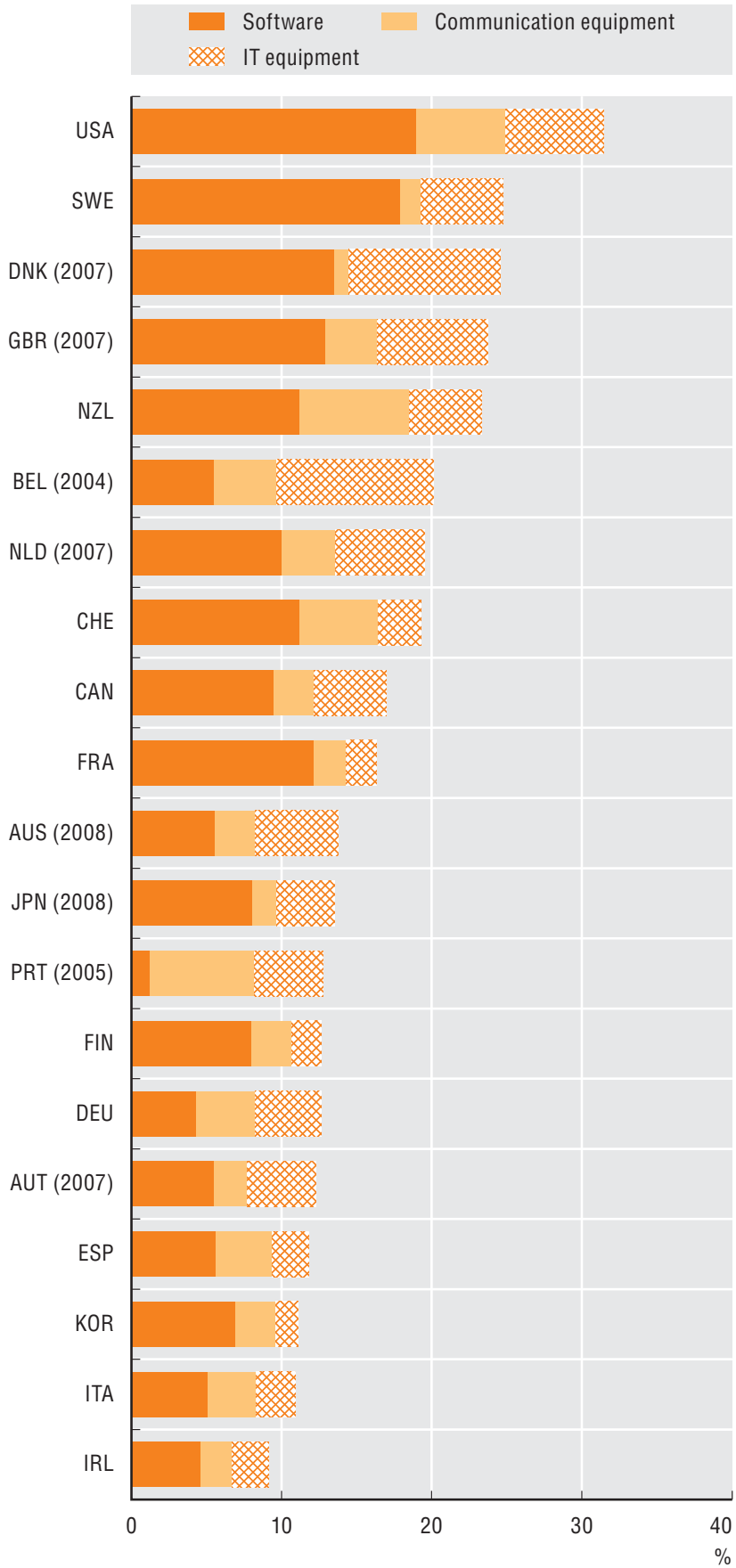

Source: OECD, Productivity Database, May 2011. See chapter notes. StatLink तारा http://dx.doi.org/10.1787/888932486127
Investment in physical capital is important for growth. It is a way to expand and renew the capital stock and enable new technologies to enter the production process.

Information and communication technology (ICT) investment accounts for a considerable share of total fixed nonresidential investment. In 2007-09, it represented over $30 \%$ in the United States, about 25\% in Sweden and Denmark, and over $20 \%$ in the United Kingdom and New Zealand.

Software has been the fastest-growing component of ICT investment, reaching $19 \%$ of total fixed non-residential investment in the United States, $18 \%$ in Sweden and over $12 \%$ in Denmark, the United Kingdom and France. Communications equipment accounted for $7.3 \%$ of total fixed nonresidential investment in New Zealand and $6 \%$ in the United States, while information technology (IT) equipment accounted for over $10 \%$ in Denmark in 2007. In the last two decades, software has been the fastest-growing component of ICT investment, reaching 74\% in France, $72 \%$ in Sweden, 63\% in Korea and $60 \%$ in the United States. Communications equipment accounted for over $30 \%$ of ICT investment in Spain, Germany and New Zealand; the share of IT equipment was over $40 \%$ in Denmark and Australia, $37 \%$ in Austria and over 30\% in Germany, the United Kingdom and New Zealand.

Over 2000-09, ICT investments provided a significant contribution to labour productivity growth in a number of OECD countries. They accounted for $66 \%$ of labour productivity growth in Denmark, over 50\% in Switzerland, Belgium and Canada, and no less than $40 \%$ in the Netherlands, New Zealand and Australia. However, the higher growth rates in labour productivity in Korea, Ireland, the United Kingdom, the United States and Japan are mainly explained by the rise in multi-factor productivity.

\section{Definitions}

Investment is defined in accordance with the 1993 System of National Accounts. ICT investment covers the acquisition of equipment and computer software used in production for more than one year. ICT has three components: information technology equipment (computers and related hardware); communications equipment; and software. Software includes acquisition of pre-packaged software, customised software and software developed in-house.

Labour productivity is defined as GDP per hour worked. Multi-factor productivity measures overall efficiency in the use of production inputs. Labour productivity growth is explained by the rate of growth in capital inputs (ICT and non-ICT capital) and by multi-factor productivity growth. 


\section{BUILDING KNOWLEDGE}

Contribution of ICT capital growth to labour productivity growth, 2000-09

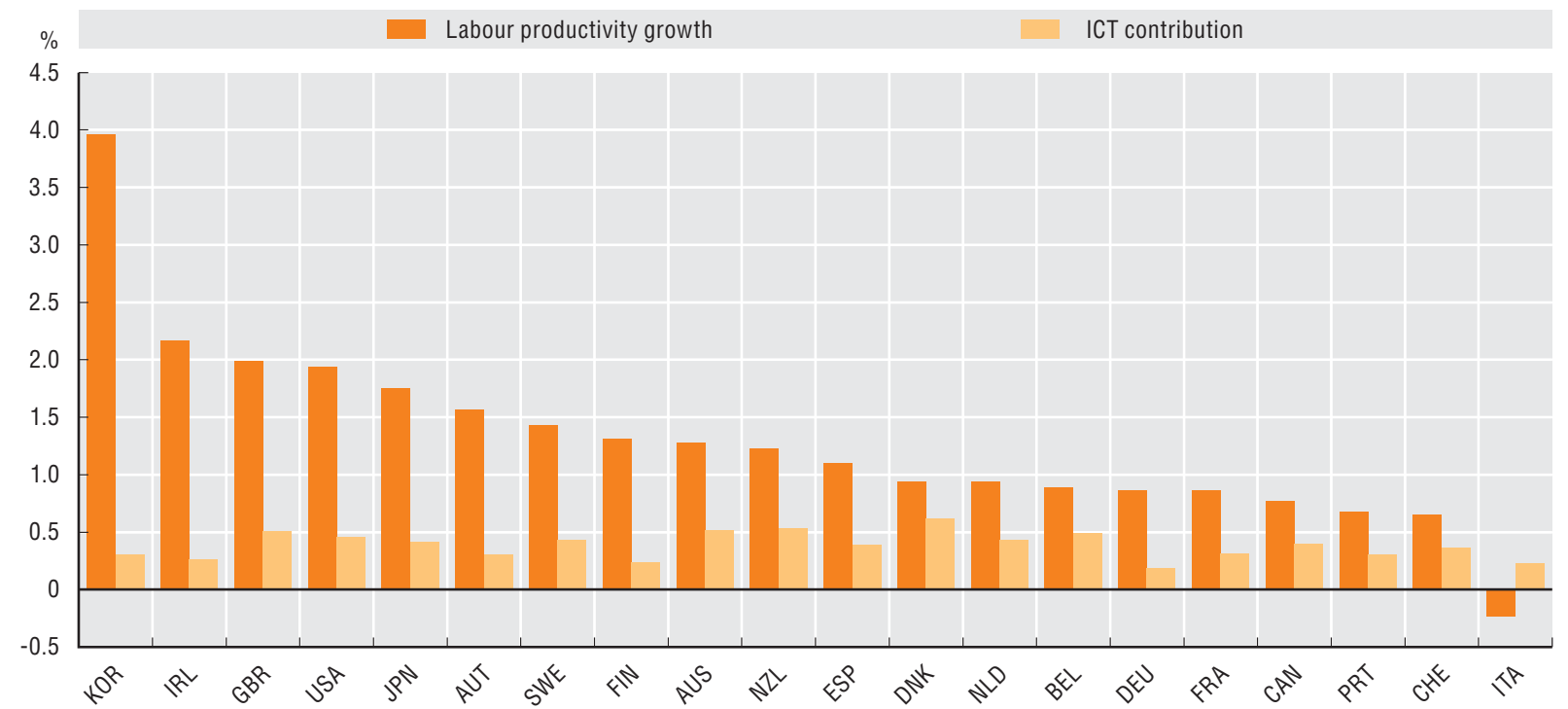

Source: OECD, Productivity Database, June 2011.

\section{Measurability}

Correct measurement of investment in ICT, in both nominal and volume terms, is crucial for estimating the contribution of ICT to economic growth and performance. In the national accounts, expenditure on ICT products is considered investment only if the products can be physically isolated (i.e. ICT embodied in equipment is considered not as investment but as intermediate consumption). This means that ICT investment may be underestimated and the order of magnitude may differ depending on how countries treat intermediate consumption and investment. In particular, expenditure on software has only recently been treated as capital expenditure in national accounts, and methodologies still vary considerably. Difficulties for measuring software investment are also linked to how software is acquired, e.g. via rental and licence or embedded in hardware. Moreover, software is often developed on own account. To tackle specific problems regarding software in the SNA93 revision of national accounts, a joint OECD-EU Task Force on the Measurement of Software in the National Accounts has developed recommendations for the capitalisation of software. These are being implemented by OECD member countries. Other issues that affect international comparability of ICT capital relate to deflators applied, breakdown by institutional sector and temporal coverage. 


\section{BUILDING KNOWLEDGE}

\section{Notes}

\section{Cyprus}

The following note is included at the request of Turkey:

"The information in this document with reference to 'Cyprus' relates to the southern part of the Island. There is no single authority representing both Turkish and Greek Cypriot people on the Island. Turkey recognises the Turkish Republic of Northern Cyprus (TRNC). Until a lasting and equitable solution is found within the context of the United Nations, Turkey shall preserve its position concerning the 'Cyprus issue'."

The following note is included at the request of all the European Union member states of the OECD and the European Commission:

"The Republic of Cyprus is recognised by all members of the United Nations with the exception of Turkey. The information in this document relates to the area under the effective control of the Government of the Republic of Cyprus."

\section{Israel}

"The statistical data for Israel are supplied by and under the responsibility of the relevant Israeli authorities. The use of such data by the OECD is without prejudice to the status of the Golan Heights, East Jerusalem and Israeli settlements in the West Bank under the terms of international law."

"It should be noted that statistical data on Israeli patents and trademarks are supplied by the patent and trademark offices of the relevant countries."

\section{Graduation rates at doctorate level, 2000 and 2009}

Gross graduation rates for France, Ireland, Japan, Mexico, the Netherlands, Poland, the United States and the Russian Federation.

\section{Science and engineering graduates at doctorate level, 2009}

National sources are: Nordic Institute for Studies in Innovation, Research and Education (NIFU), May 2011 for Norway; China Statistical Yearbook 2010 for China; The Ibero-American and Inter-American Network for Science and Technology Indicators (RICYT), Indicators Database, May 2011 for Brazil; the Ministry of Science and Technology of India, Research and Development Statistics 2007-08 for India and South African Council of Higher Education, May 2011 for South Africa.

For Norway, data are based upon NIFU's Doctoral Degree Register which includes all doctoral and licentiate degrees (equivalent to a PhD degree).

For Brazil, China, India and South Africa, available breakdowns by field of study were adapted in order to map as much as possible to ISCED-1997 fields of study.

For South Africa, data refer exclusively to public universities where $99.6 \%$ of the doctorate holders graduated in 2009.

\section{Science and engineering graduates at doctorate level, by country of graduation, 2009}

For Greece and Italy, data refer to 2007.

\section{Employment rate of doctorate holders by gender, 2009}

For Belgium, Germany, the Netherlands and Spain, data relate to graduates from 1990 onwards only.

For Denmark, Finland, Israel, Poland and the United States, the total economy employment rate refers to 2008.

For Spain, the sample has limited coverage of doctorate holders for the years 2007 to 2009.

\section{Doctorate holders on temporary contracts over career path, 2009}

For Belgium, the Netherlands and Spain, data relate to graduates from 1990 onwards only. For the Russian Federation, data relate only to those doctoral graduates employed as researchers and teachers. For Spain, the sample has limited coverage of doctorate holders for the years 2007 to 2009. 
Difference in median gross annual earnings of doctorate holders working as researchers and as non-researchers, 2009

All sectors include the business enterprise, government, higher education, other education and private non profit sectors.

For Belgium, the Netherlands and Spain, data relate to graduates from 1990 onwards only.

For Spain, the sample has limited coverage of doctorate holders for the years 2007 to 2009.

\section{HRST occupations, 2010}

Technicians and associate professionals include trade workers for Australia.

For Brazil, data exclude rural population of Rondõnia, Acre, Amazonas, Roraima, Pará and Amapá.

For India, data refer to July 2007-June 2008 period covered by the Indian National Sample Survey.

\section{HRST employees by industry, 2008}

In Japan, teaching professionals' data by industry are suppressed due to confidentiality, which is likely to result in underestimation of total HRST numbers.

\section{Researchers in manufacturing and services, 2009}

Different national practices in the distribution of researchers across industries may affect the breakdown between manufacturing and services.

\section{Gross domestic expenditure on R\&D, 1999 and 2009}

For Israel defence is excluded.

\section{R\&D expenditure by performing sectors, 2009}

For Israel defence is excluded.

\section{R\&D intensity by region, 2007}

The regional breakdown is provided at Territorial Level 2 (TL2).

Data for Chile, Estonia, Iceland, Israel, Japan, Mexico, New Zealand, Slovenia, Switzerland and Turkey are not available at the regional level.

Higher education expenditure on R\&D, 1999 and 2009

Excluding R\&D in the social sciences and humanities: Israel (1999 and 2009) and Korea (1999).

Excludes most or all capital expenditure for the United States.

Basic research performed in the public sector, 2009

Higher education data excludes R\&D in the social sciences and humanities for Israel.

Total cost (current and capital) included for all countries except Chile, Estonia, Norway, Poland, the Russian Federation, Spain and the United States, for which only current costs are included.

For Switzerland for Government, Federal or Central government only.

\section{Business enterprise expenditure on R\&D, 1999 and 2009}

Excludes most or all capital expenditure for the United States.

For Israel defence is excluded.

\section{R\&D expenditures generated by foreign-controlled affiliates, 2008}

Financial intermediation excluded for Japan.

Community, social and personal services excluded for Austria and Slovenia. 


\section{BUILDING KNOWLEDGE}

\section{Notes}

Business R\&D by size class of firms, 2009

Small firms (fewer than 50 employees): for the United States, 5-49 employees; for Luxembourg, the Netherlands and Sweden, 10-49 employees. Medium-sized firms (50-249 employees): for Japan, fewer than 299 employees. For Japan, the survey excludes firms with a capital of less than JPY 10 million.

\section{ICT investment by asset in OECD countries, 2009}

ICT equipment is defined here as computer and office equipment and communication equipment; software includes both purchased and own account software. Software investment in Japan is likely to be underestimated, owing to methodological differences. 
Auriol, L. (2010), “Careers of Doctorate Holders: Employment and Mobility Patterns”, OECD Science, Technology and Industry Working Papers, No. 2010/4. Doi: http://dx.doi.org/10.1787/5kmh8phxuvf5-en.

Auriol, L., B. Felix and M. Schaaper (2010), "Mapping Careers and Mobility of Doctorate Holders: Draft Guidelines, Model Questionnaire and Indicators - Second Edition", OECD Science, Technology and Industry Working Papers, No. 2010/1. Doi: http://dx.doi.org/10.1787/5kmlfbn2ddtd-en.

OECD and Eurostat (1995), "Manual on the Measurement of Human Resources Devoted to S\&T", Canberra Manual, OECD general distribution document, OCDE/GD(95)77, available at: www.oecd.org/dataoecd/34/0/2096025.pdf.

OECD (2002), Frascati Manual 2002: Proposed Standard Practice for Surveys on Research and Experimental Development, The Measurement of Scientific and Technological Activities, OECD Publishing, Paris. Doi: http://dx.doi.org/10.1787/ 9789264199040-en.

OECD (2009), Education at a Glance 2009: OECD Indicators, OECD Publishing, Paris. Doi: http://dx.doi.org/10.1787/eag-2009-en.

OECD (2009), OECD Patent Statistics Manual, OECD Publishing, Paris. Doi: http://dx.doi.org/10.1787/9789264056442-en.

OECD (2009), OECD Science, Technology and Industry Scoreboard 2009, OECD Publishing, Paris. Doi: http://dx.doi.org/10.1787/ sti_scoreboard-2009-en.

OECD (2010), Measuring Globalisation: OECD Economic Globalisation Indicators 2010, OECD Publishing, Paris. Doi: http://dx.doi.org/ 10.1787/9789264084360-en.

OECD (2010), Measuring Innovation: A New Perspective, OECD Publishing, Paris. Doi: http://dx.doi.org/10.1787/9789264059474-en.

OECD (2010), OECD Handbook on Deriving Capital Measures of Intellectual Property Products, OECD Publishing, Paris. Doi: http://dx.doi.org/10.1787/9789264079205-en.

OECD (2011), Education at a Glance 2011: OECD Indicators, OECD Publishing, Paris. Doi: http://dx.doi.org/10.1787/eag-2011-en.

OECD (2011), OECD Guide to Measuring the Information Society 2011, OECD Publishing, Paris. Doi: http://dx.doi.org/10.1787/ 9789264113541-en.

Van Steen, J. (2011), "Public Funding of R\&D: Towards Internationally Comparable Indicators", DSTI/EAS/STP/ NESTI(2010)20/FINAL, OECD Publishing, Paris. 


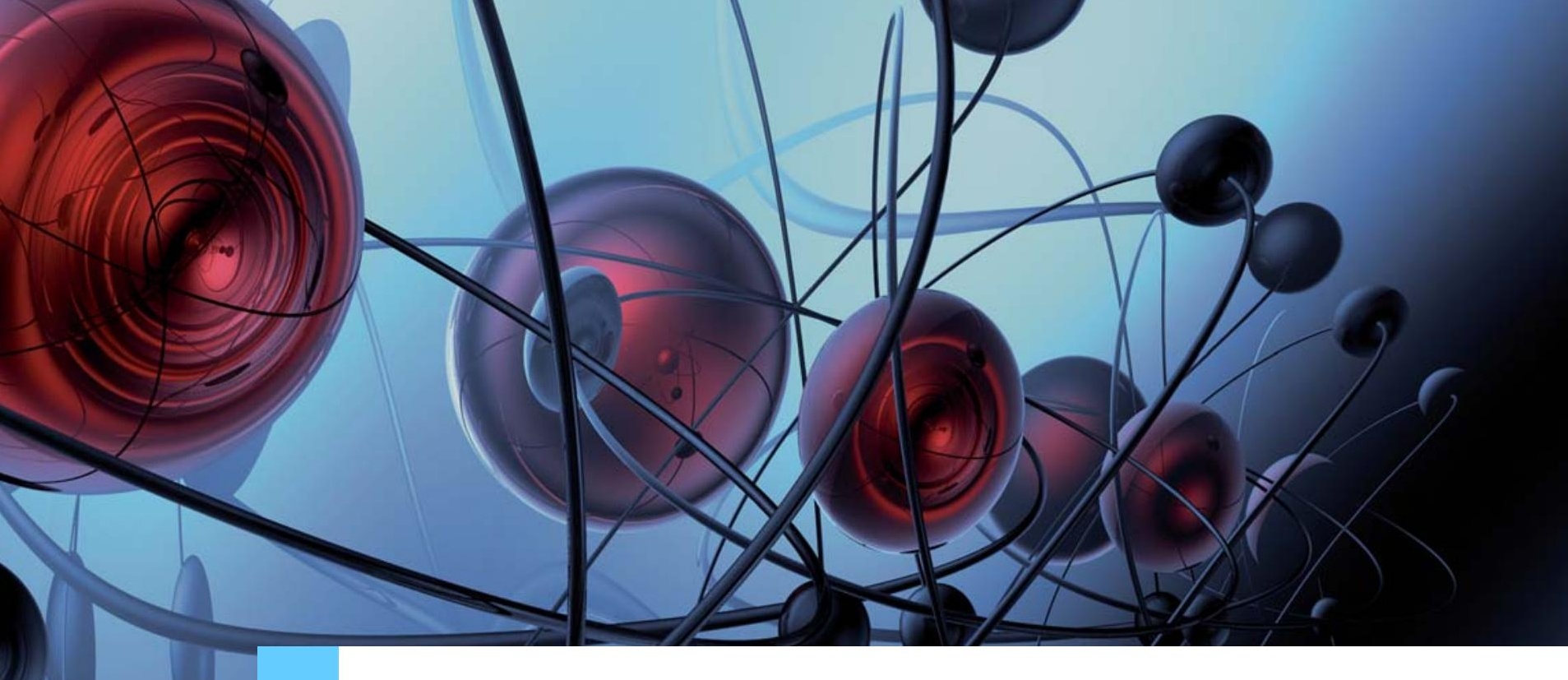

\section{CONNECTING TO KNOWLEDGE}

1. Public-private cross-funding of $R \& D$

2. International funding of $R \& D$

3. Science links

4. Technology-science linkages

5. International mobility

6. Mobility at the workplace

7. Innovation and knowledge flows

8. Collaboration in business value chains

9. International collaboration on innovation

10. Technology flows

Notes

References

In an economy increasingly based on knowledge and innovation, the development of fully functioning knowledge transmission channels can have a significant impact on the efficiency and effectiveness of the innovation effort. Knowledge linkages and diffusion are hard to measure. One first channel of transmission is the cross-funding of $R \& D$, both among institutions at home and internationally. New citation based indicators on the impact of scientific output show that collaboration among institutions is an increasingly pervasive and important feature of top quality research. Citation analysis is one way to capture science and industry linkages. Another set of indicators tries to deal with dimensions which are much harder to measure: the mobility of students and workers (and the tacit knowledge they carry with them). Innovation is a complex process which often involves many actors and linkages. Innovation surveys can help shed light on sources of knowledge and on the value of collaboration for innovative firms. Who is capturing the returns to innovation? Indicators of technology flows show that knowledge has no borders and is increasingly applied in a different country from the one in which it was obtained. New ways of looking at traditional indicators (for example, foreign ownership of inventions) can shed some light, although it is clear that developing metrics of knowledge flows, as well as of markets for knowledge, is still uncharted territory. 


\section{CONNECTING TO KNOWLEDGE}

Government-financed R\&D in business, 1999 and 2009

As a percentage of $R \& D$ performed in the business sector

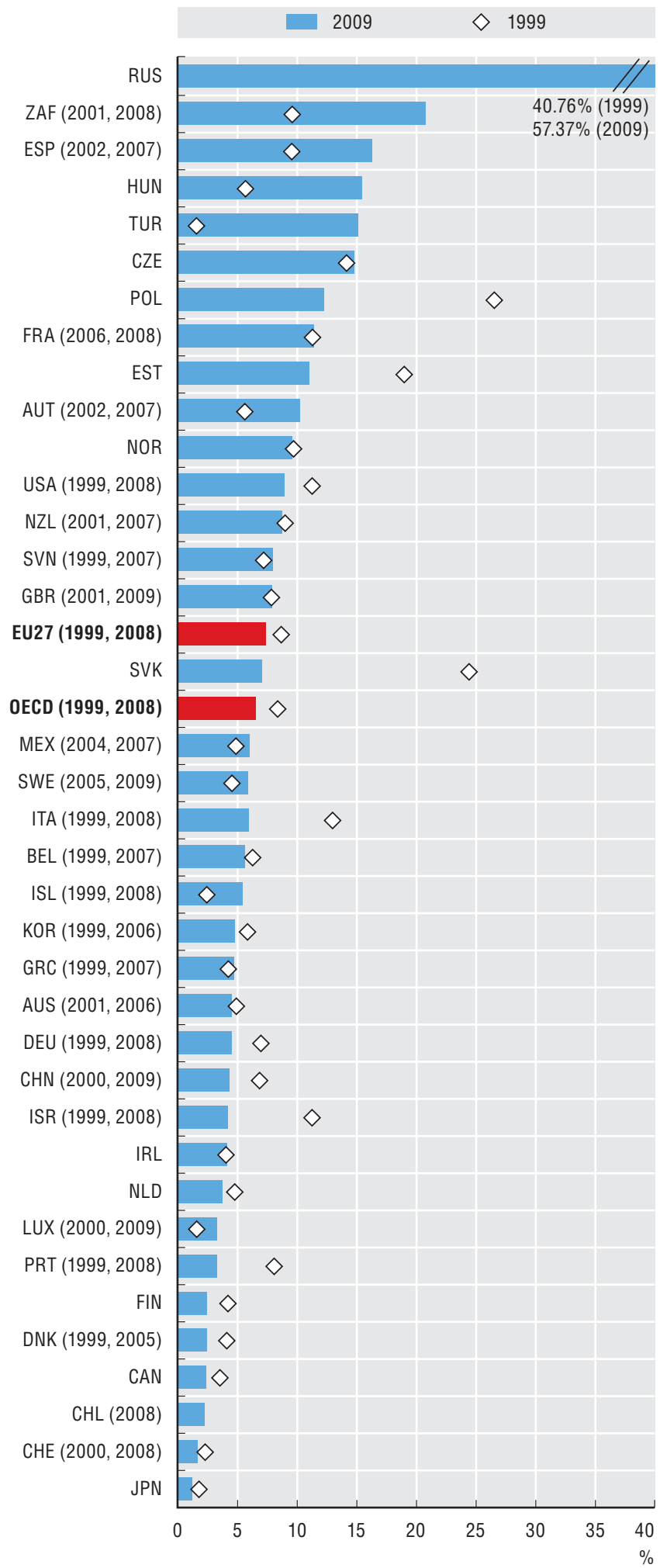

Source: OECD, Research and Development Database, June 2011. See chapter notes.

StatLink AाIS http://dx.doi.org/10.1787/888932486165
There is a complex interplay between the public and private sectors in the funding and performance of R\&D. Governments choose among various tools to leverage business sector R\&D. Traditionally, they fund R\&D activities directly via grants or procurement. More than $15 \%$ of business R\&D (BERD) is funded directly by government in the Russian Federation, South Africa, Spain, Hungary and Turkey. In the OECD area, the government funds nearly $7 \%$ of total BERD, down from nearly $9 \%$ in 1999 . The countries with the largest funding by government have had the largest increases; in the Russian Federation it rose from $40 \%$ to $57 \%$. Poland, Estonia, the Slovak Republic, Italy, Israel (which excludes defence $\mathrm{R} \& \mathrm{D})$ and Portugal had the sharpest reductions in the relative importance of government funding. Reductions have been smaller in the United States, Germany and China. Countries differ significantly in their "public" systems of R\&D performance, with varying combinations of government research institutes and private or public universities relying to different degrees on government funding. To analyse the business sector's contribution to R\&D performed in this quasi-public domain, the government and higher education sectors are pooled in order to improve international comparability. Business-sector funding of $\mathrm{R} \& \mathrm{D}$ in the domestic higher education and government sectors is highest in Hungary, the Netherlands, China, Turkey, the Russian Federation and Germany. Across the OECD, the situation has not changed significantly over time in this respect, but there are substantial increases in Germany, the Netherlands and Hungary and substantial decreases in Slovenia, South Africa, Poland and the United Kingdom.

\section{Definitions}

Government-funded business R\&D is the component of BERD that companies attribute to direct government (central, regional or local) funding when describing the sources of funds for intramural R\&D expenditures. It includes grants, some types of loans and procurement, but not R\&D tax incentives or equity investments as in the case of public corporations. Business-funded R\&D in the higher education and government sectors (in the form of grants, donations and contracts) is the domestic business enterprise sector's contribution to intramural R\&D expenditures in those sectors. 


\section{CONNECTING TO KNOWLEDGE}

Business-funded R\&D in the higher education and government sectors, 1999 and 2009

As a percentage of $R \& D$ performed in these sectors (combined)

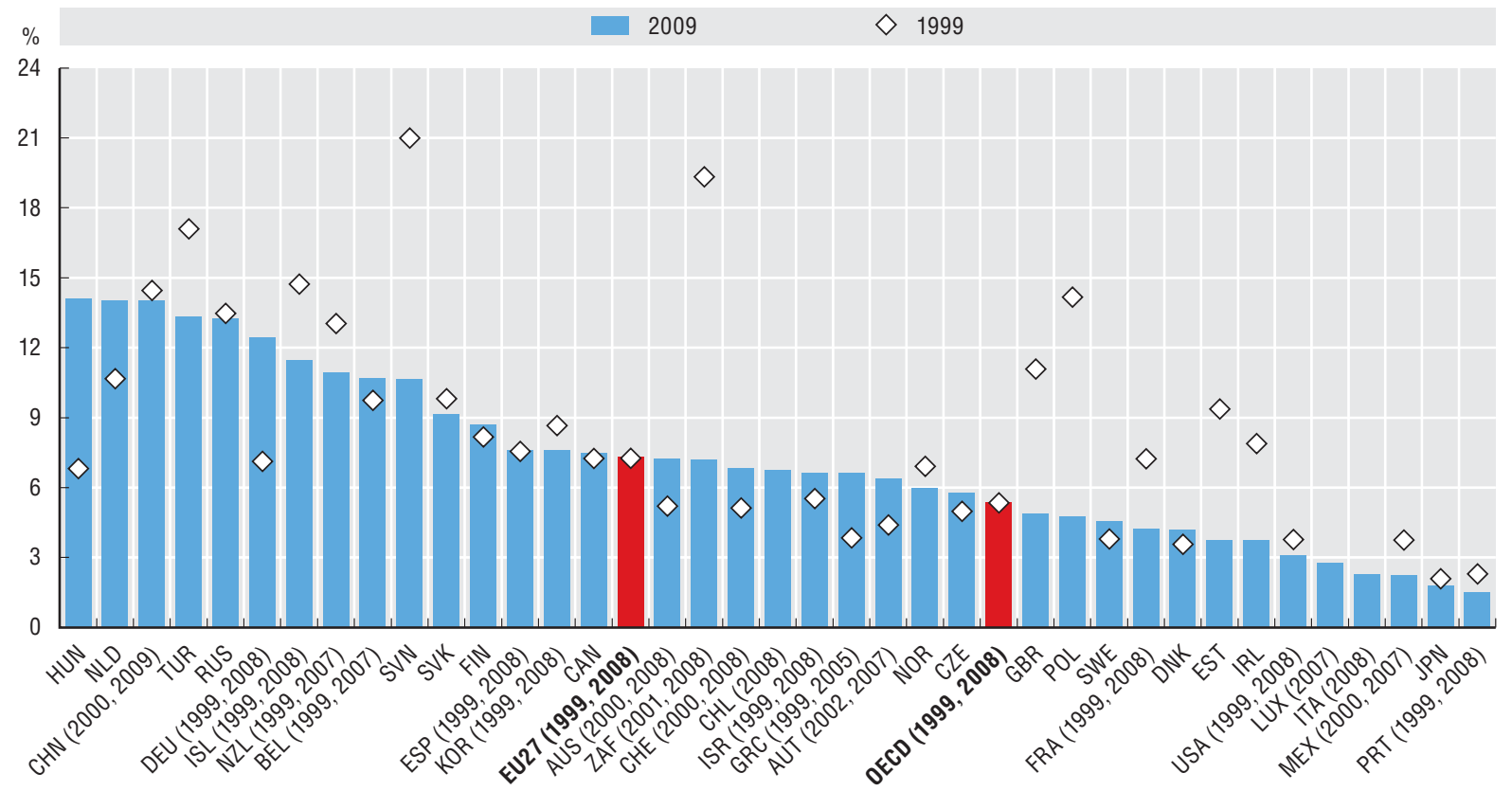

Source: OECD, Research and Development Database, May 2011. See chapter notes.

StatLink काוाSL http://dx.doi.org/10.1787/888932486184

\section{Measurability}

Estimating cross-sector funding flows for R\&D relies mainly on the ability of surveys and other statistical instruments to identify the various sources of funding for intramural $R \& D$ expenditures. According to the OECD Frascati Manual, identification of a flow of funds requires a direct transfer of resources and the transfer must be both intended and used for the performance of R\&D. Loans to be repaid under normal market conditions are not considered transfers and therefore are not covered by the definition. Because some loans may ultimately not be repaid in full, it can be complex to identify in advance which types of loans should be excluded in practice. The existence of subcontracting and intermediaries also raises a challenge for identifying the ultimate source of funds, for example in the case of funding from supranational organisations that is distributed by national intermediaries. 


\section{CONNECTING TO KNOWLEDGE}

R\&D funds from abroad, 2009

As a percentage of business enterprise $R \& D$

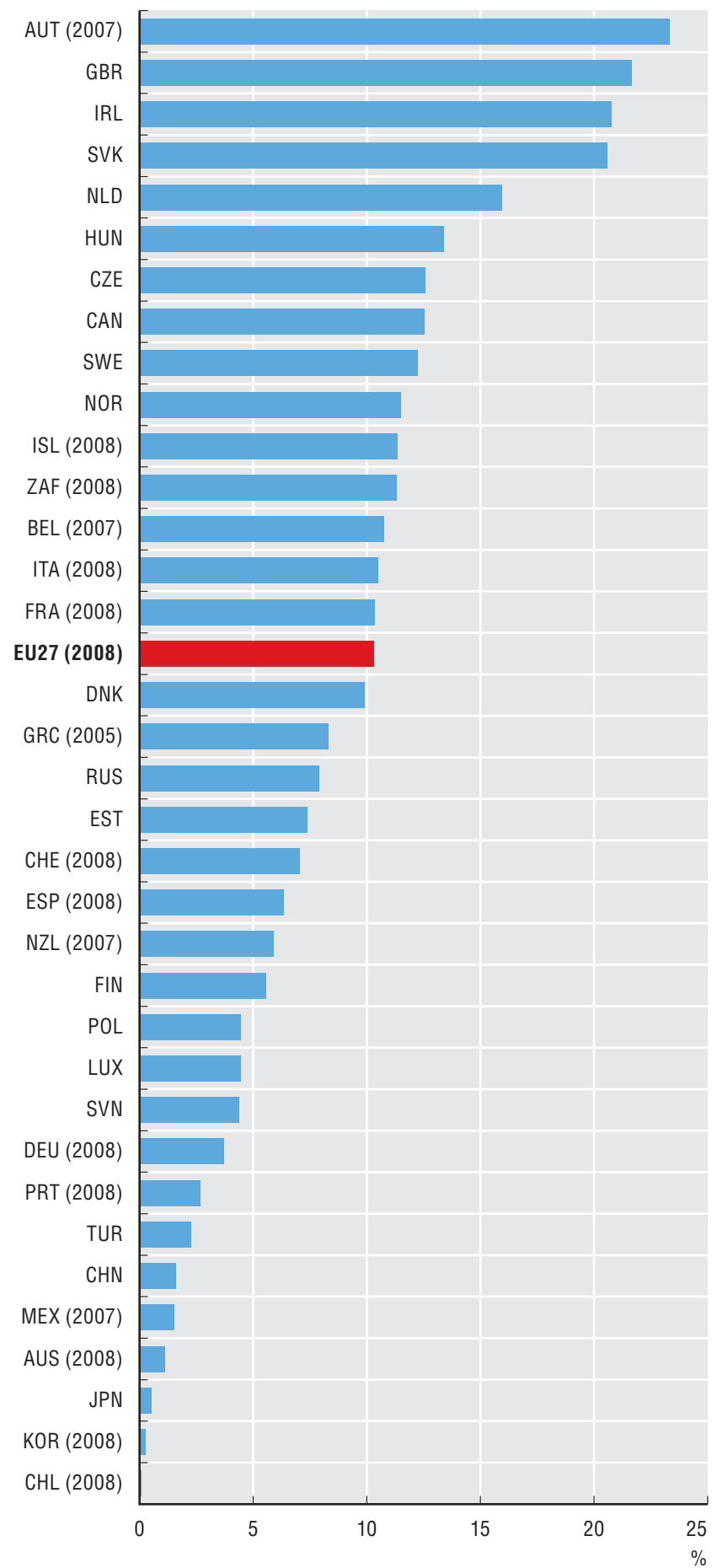

Source: OECD, Main Science and Technology Indicators Database, June 2011.

StatLink तiाst $h t t p: / / d x . d o i . o r g / 10.1787 / 888932486203$
Funding of business enterprise research and development (BERD) may be national or foreign. It may originate from private business, public institutions (government and higher education), or international organisations. Research and development (R\&D) funding from abroad includes, for instance, $R \& D$ performed by affiliates of foreign-owned companies, R\&D undertaken under contract on behalf of companies based abroad or research grants from international organisations. On average, R\&D funding from abroad plays quite an important role in the funding of business R\&D. In the EU, it represented around $10 \%$ of total business enterprise R\&D in 2008. The weight of foreign multinationals in the economy and in the domestic production of technology appears to matter. For Austria, Ireland, the Slovak Republic and the United Kingdom, funds from abroad represented $20 \%$ or more of total business enterprise R\&D.

In most countries, the financing of business enterprise R\&D from abroad comes mainly from other business enterprises. In a group of 19 countries for which data are available, only France, Spain, Slovenia and Portugal report foreign business enterprises contributing less than $80 \%$ of the total foreign funds for R\&D. Korea, the United Kingdom, the Slovak Republic and Austria report the highest values.

Within the R\&D funds reported to come from foreign enterprises, 16 countries are able to report the proportion corresponding to intra-company funding or funding from other firms. Among these, only Slovenia reports a higher share of funds from non-related companies, which account for nearly $70 \%$ of total funds from abroad. The proportion accounted for by enterprises from the same group is largest for Finland, Hungary, Portugal and the Slovak Republic.

\section{Definitions}

R\&D surveys collect information from R\&D performers about the sums which one unit, organisation or sector has received or will receive from another unit, organisation or sector for the performance of intramural R\&D during a specific period. Companies are required to provide a breakdown of their R\&D expenditures according to the sources of funds, which can be either internal or received from units belonging to the different sectors specified in the Frascati Manual, one of which is "Abroad". This consists of all institutions and individuals located outside the political borders of a country, excluding vehicles, ships, aircraft and satellites operated by domestic entities and testing grounds acquired by such entities. It also includes all international organisations (except business enterprises), including facilities and operations within the country's borders. 


\section{CONNECTING TO KNOWLEDGE}

Business enterprise R\&D funded from abroad, 2009

By source of funds

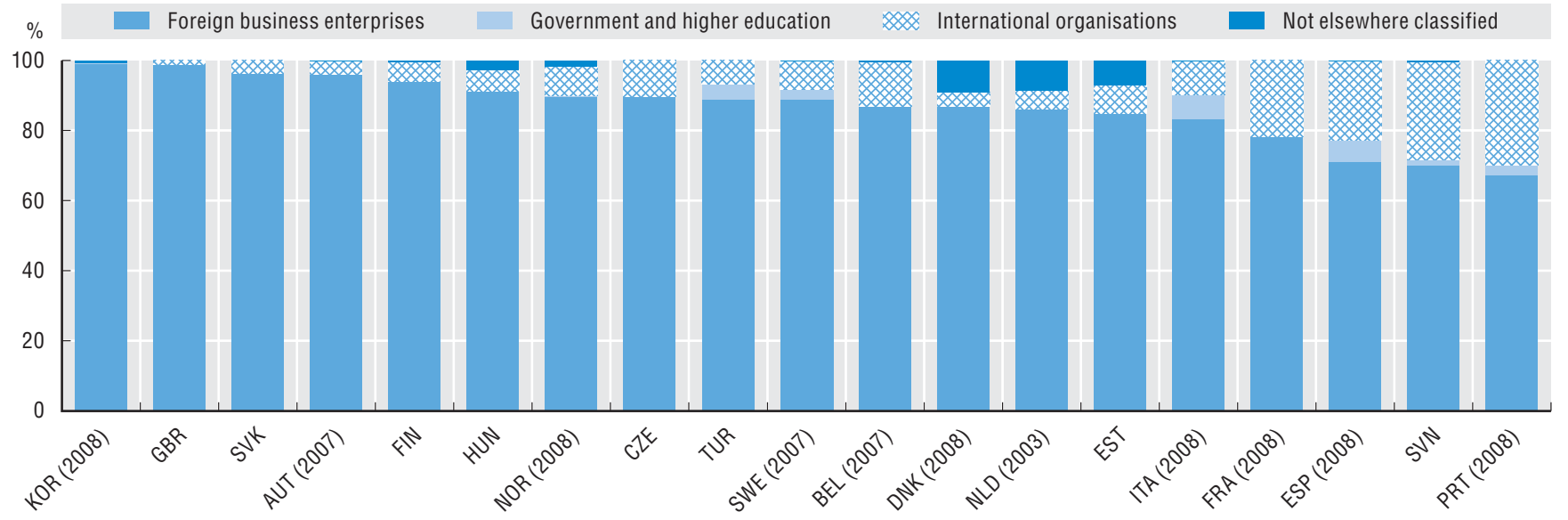

Source: OECD, Research and Development Database, May 2011.

R\&D funding from foreign enterprises, 2009

As a percentage of funds from abroad

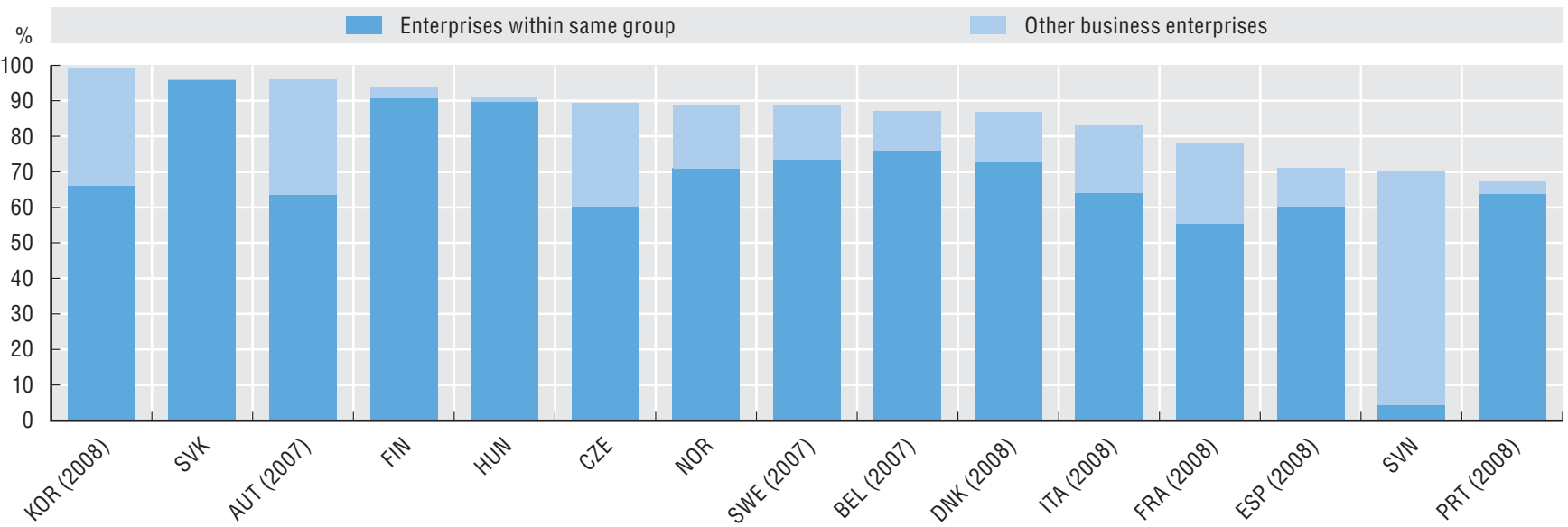

Source: OECD, Research and Development Database, May 2011.

\section{Measurability}

The increasing internationalisation of research and development (R\&D) and other economic activities makes it difficult to identify accurately inflows of R\&D funds to companies and their precise nature. For example, there is a growing need to measure international R\&D transactions properly and to deal with the problem of non-priced transfer of R\&D within multinational enterprises. R\&D surveys are commonly used to collect statistics on international flows of funds for R\&D. A new Task Force of the OECD Working Party of National Experts on Science and Technology Indicators (NESTI) has begun a review of the design of business R\&D surveys with a view to ensuring that the questions in these surveys can help achieve better measurement of international R\&D transactions in order to help meet the needs of the System of National Accounts (SNA) and build a bridge between R\&D and globalisation statistics. 


\section{CONNECTING TO KNOWLEDGE}

The quantity and quality of scientific production, 2009

Publications (whole counts)

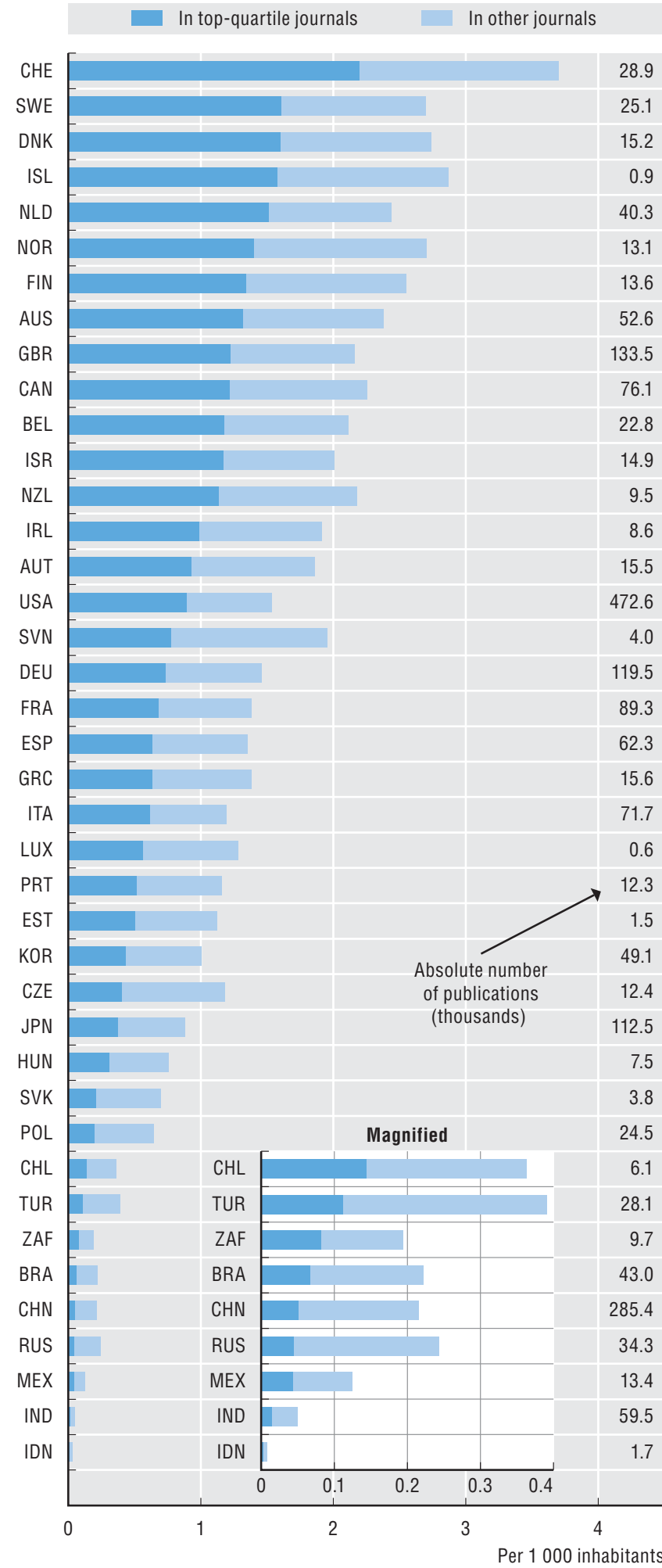

Source: OECD and SCImago Research Group (CSIC) (forthcoming), Report on Scientific Production, based on Scopus Custom Data, Elsevier, June 2011. See chapter notes

StatLink AाIS http://dx.doi.org/10.1787/888932486260
Publications in top journals provide a measure of "qualityadjusted" research output. Switzerland has the highest rate of high-quality publications on a per capita basis among OECD and BRIICS (Brazil, the Russian Federation, India, Indonesia, China, South Africa) countries, followed by Sweden and Denmark. In absolute numbers, the United States is the leading producer of publications in top journals, followed by the United Kingdom. If total publications are considered, independently of quality, the United States remains the leader but China takes the second position. The share of emerging economy publications in the world total is rising fast although the percentage published in top quartile journals is below the world average.

Collaboration among institutions is an increasingly pervasive and important feature of scientific research. The indicators show that international scientific collaboration results in research with high impact (as measured by citations) - and that the broader the collaboration, the higher the impact of the research.

Small countries are generally more likely to engage in international collaboration than larger ones although this is not always the case and there are differences among disciplines. The average impact of publications not involving international collaboration tends to be, at best, above the world average (medium impact). The best average outcomes for publications not involving any type of institutional collaboration are reported for countries with high publication output per capita or with sizeable research institutions that offer broad scope for significant collaboration among researchers.

\section{Definitions}

Publication counts in top quartile journals are defined as publications in the reference period by authors affiliated to an institution in a given country published in the most influential $25 \%$ of the world's scholarly journals in their category, as ranked by the SCImago Journal Rank (SJR) indicator (www.scimagoir.com) on the basis of citation data. Collaboration is defined as co-authorship involving different institutions. International collaboration refers to publications co-authored with institutions in another country. International and national collaboration refers to co-authorship involving both foreign and domestic institutions. National collaboration concerns publications co-authored with institutions within the reference country. No collaboration refers to publications not involving co-authorship across institutions and includes single-author articles as well as intrainstitutional collaboration. Normalised impact is the ratio of the average number of citations received by the documents published by a specific unit to the world average of citations of the same time period, document type and subject area. If an article belongs to several subject areas, a mean value of the areas is calculated. 
The impact of international scientific collaboration by institutions on research output, 2009

Publications by impact and type of collaboration, per 1000 inhabitants

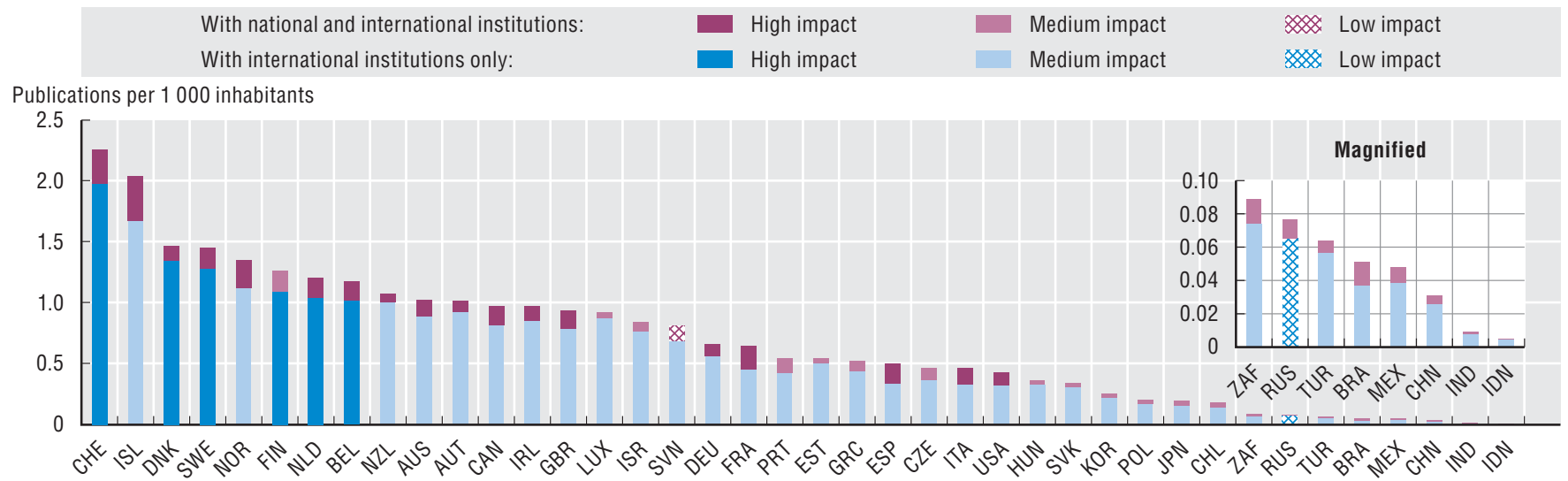

Source: OECD and SCImago Research Group (CSIC) (forthcoming), Report on Scientific Production, based on Scopus Custom Data, Elsevier, June 2011. See chapter notes.

StatLink Ailst http://dx.doi.org/10.1787/888932486279

The impact of domestic scientific collaboration by institutions on research output, 2009

Publications by impact and type of collaboration, per 1000 inhabitants

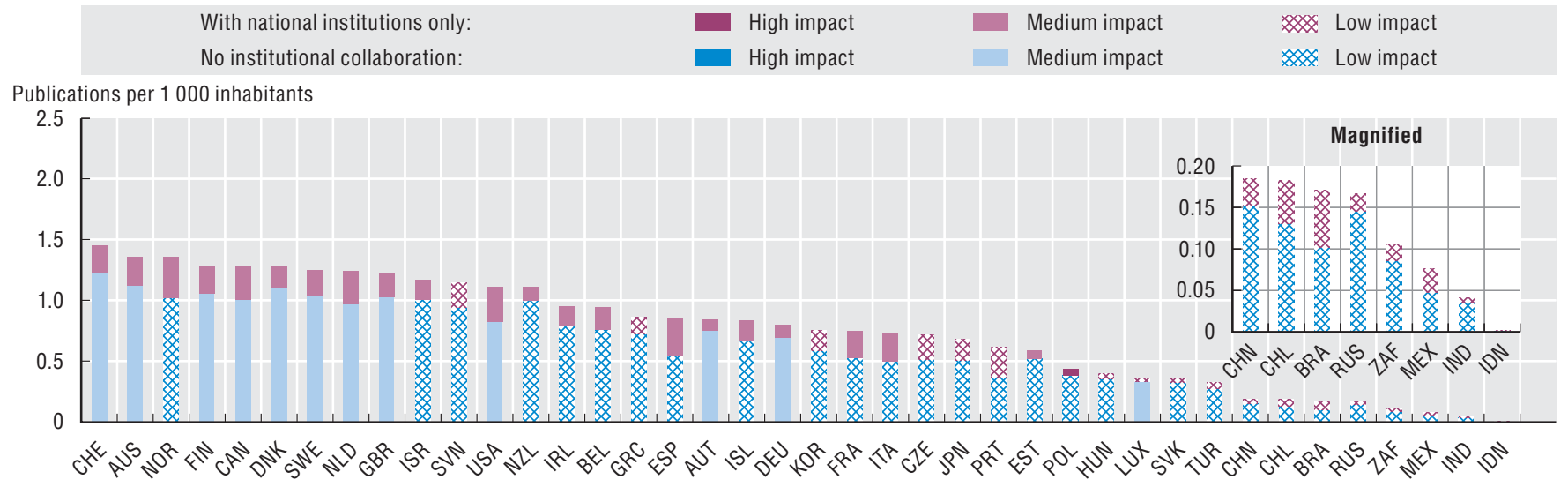

Source: OECD and SCImago Research Group (CSIC) (forthcoming), Report on Scientific Production, based on Scopus Custom Data, Elsevier, June 2011. See chapter notes.

StatLink तiाst $h t t p: / / d x . d o i . o r g / 10.1787 / 888932486298$

\section{Measurability}

The frequency of citations to journals in which scholars from different institutions and countries publish can be considered an objective measure of the quality of a journal's standards and the material it publishes. Information on institutions' publications in the top quartile of journals, ranked by the citations that those journals typically achieve, can therefore serve as an indicator of the expected impact of institutions' scientific production.

Publications are attributed to countries on the basis of the authors' institutional affiliations. When attributing publications to a given unit, such as a country, it is important to find an appropriate way to count publications that involve co-authorship across units. One approach is to fractionalise publications by contributing units; this allows the reported figures to add up to the total number of publications. An alternative, which does not penalise a unit for engaging in collaborative authorship, is to report total counts per unit; this is the "whole counts" approach. Although the chosen method does not greatly affect country rankings, care should be exercised when interpreting either type of results. 


\section{CONNECTING TO KNOWLEDGE}

\section{Patents citing non-patent literature (NPL) and average citations received per patent cited, by technology field, 2005-10}

Average share of NPL in total citations and average number of forward citations

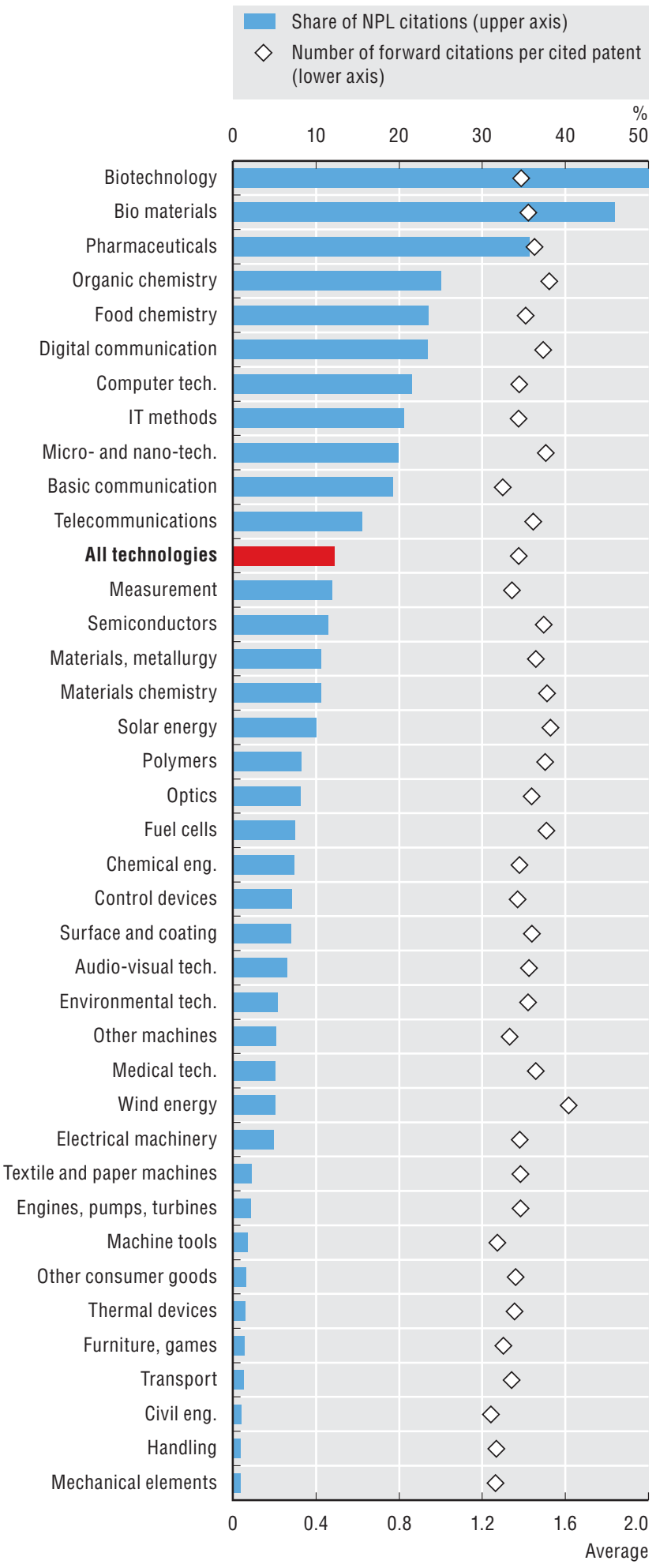

Source: OECD, calculations based on the Worldwide Patent Statistical Database, EPO, April 2011. See chapter notes.

StatLink तilst http://dx.doi.org/10.1787/888932486317
The degree to which applied technological developments, in the form of patented inventions, are linked to basic science is difficult to determine. However, most patent applications include a list of references - citations - to earlier patents and to non-patent literature (NPL), e.g. scientific papers, that set the boundaries of patents' claims for novelty, inventive activity and industrial applicability. References are added by the applicant or the patent examiner to reflect the "prior art" that inventions have built upon. Backward citations to NPL can show how close a patented invention is to scientific knowledge, whereas forward patent citations can show the importance of a patent for the development of other technologies.

The percentage of NPL cited in patent documents varies considerably across sectors. More than $30 \%$ of citations in biotechnology, biomaterials and pharmaceuticals patents refer to scientific papers, while patents in machinery and transport seem to rely less on basic science. Regardless of reliance on basic or applied knowledge, all sectors seem to receive the same average number of forward citations per cited patent - about 1.4 .

On average, $20 \%$ of citations to patents are to those containing NPL. This is much higher in biotechnology, pharmaceuticals and digital communications reflecting the relevance of scientific knowledge for subsequent developments. Patents that rely less on scientific knowledge are typical of mature technologies.

In general, the share of NPL in backward citations has increased over time, suggesting that patented inventions increasingly rely on scientific knowledge. Differences in country and sector patterns can reflect the maturity of technologies and countries' stage of economic development. Reliance on scientific knowledge is highest for biotechnology and in the BRIICS (Brazil, the Russian Federation, India, Indonesia, China and South Africa) during 2005-10.

\section{Definition}

Non-patent literature consists of peer-reviewed scientific papers, conference proceedings, databases (e.g. DNA structures, gene sequences, chemical compounds, etc.) and other relevant literature. Backward citations are references to patents and NPL contained in a patent document, whereas forward citations are citations received by a patent. A patent's share of NPL citations is calculated as the ratio between the number of NPL citations and the overall number of citations contained in a patent document. References to certain types of NPL such as patent abstracts and commercial patent databases are excluded. Technology fields are defined according Schmoch's classification (WIPO, 2010) and rely on the International Patent Classification (IPC) codes in the patent document. 
Citations to patents that include non-patent literature (NPL), by technology field, 2005-10

As a percentage of total forward citations

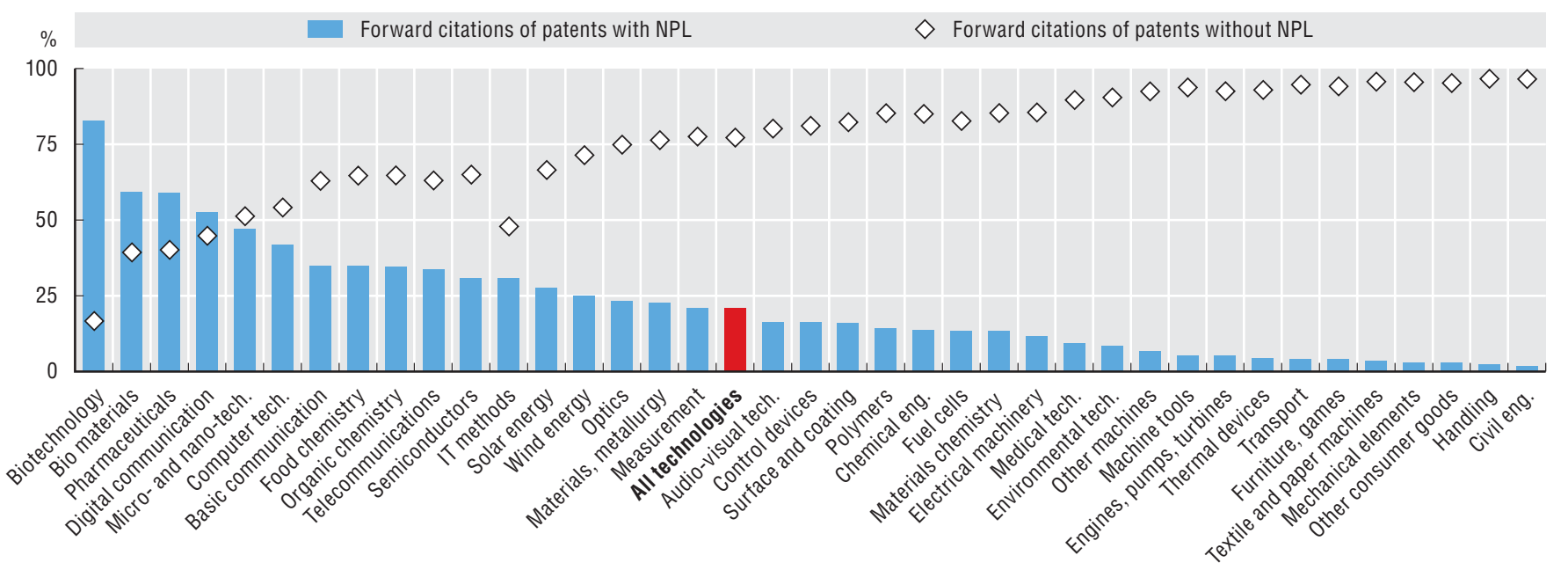

Source: OECD, calculations based on the Worldwide Patent Statistical Database, EPO, April 2011. See chapter notes.

StatLink जiाsय $h t t p: / / d x . d o i . o r g / 10.1787 / 888932486336$

Patents citing non-patent literature (NPL), selected technologies, 1995-2000 and 2005-10

Share of citations to NPL in backward citations, average

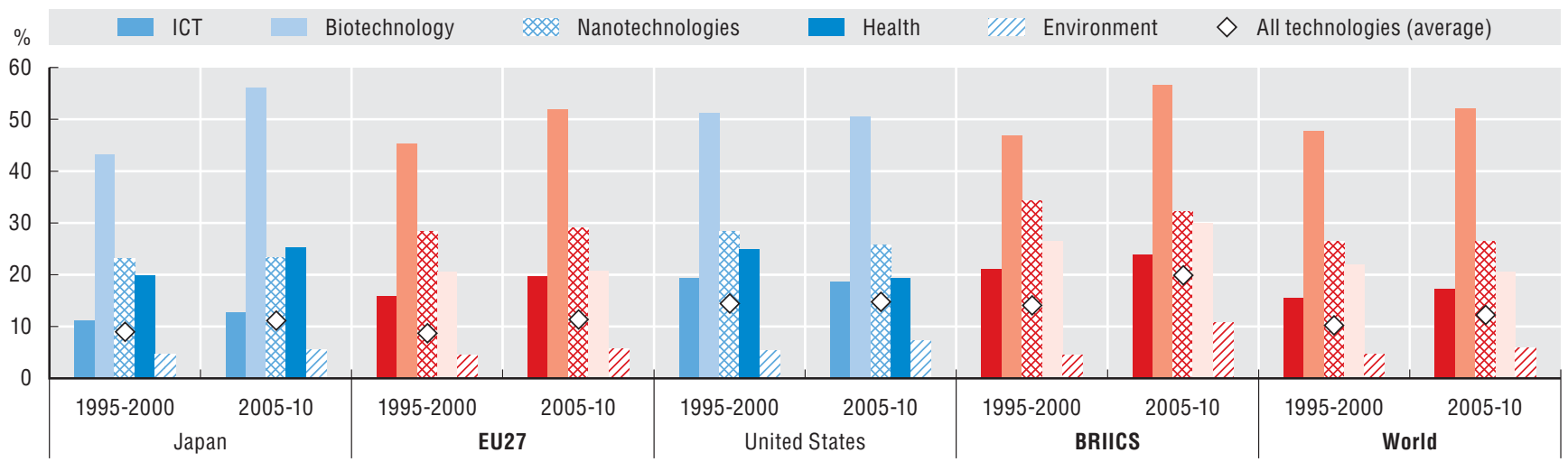

Source: OECD, calculations based on the Worldwide Patent Statistical Database, EPO, April 2011. See chapter notes.

StatLink Aiाst http://dx.doi.org/10.1787/888932486355

\section{Measurability}

Only patents published by the European Patent Office (EPO) are considered. Forward citation counts are based on EPO patents cited and take into account patent equivalents, that is, patent documents protecting the same invention at several patent offices. Only forward citations deemed particularly relevant for the examined patent - i.e. citations that examiners classify as X or Y (see OECD Patent Statistics Manual, 2009) - are considered. Forward citations are counted over a period of 5 years after the publication date (typically 18 months after the application filing date). This should allow observation of the different citation patterns in the technologies considered. Backward counts instead consider all NPL cited in the patent document and are not restricted to X or Y classes. Fractional counts are used to assign patents to technology fields and to countries for both backward and forward citations. All citation counts include self-citations. The results shown may be contingent upon the data source used, the citation and counting methods used and the observation period. 


\section{CONNECTING TO KNOWLEDGE}

\section{International and foreign students enrolled in tertiary education, 2009}

By field of education
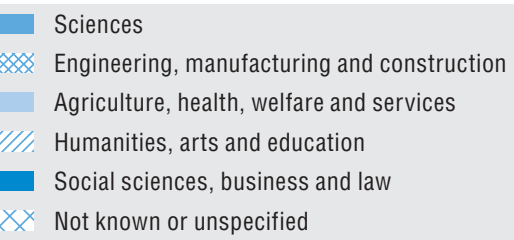

$\diamond$ All S\&E enrolments at the tertiary level (including domestic students)

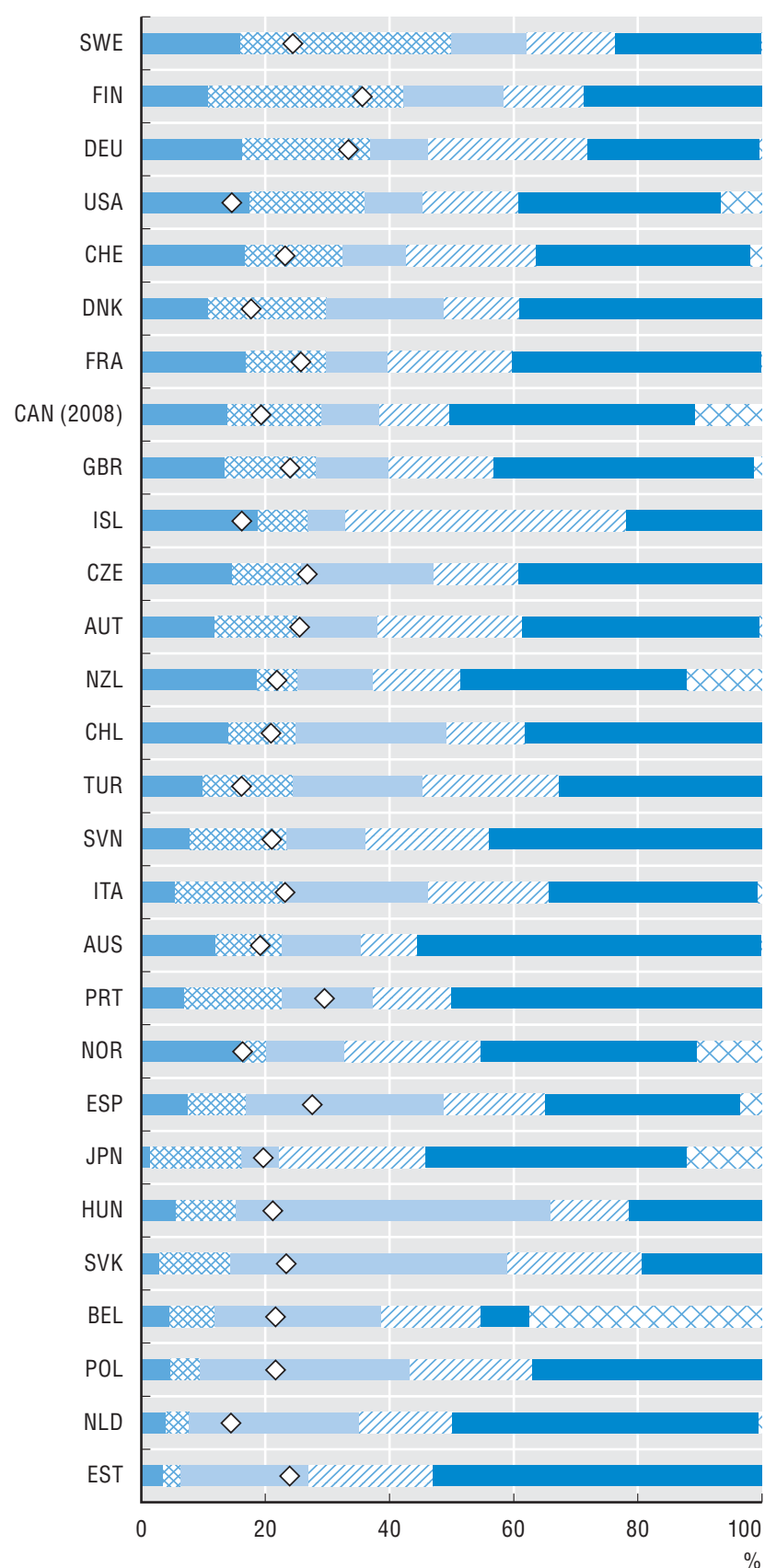

Source: OECD (2011), Education at a Glance 2011: OECD Indicators, OECD Publishing, Paris. See chapter notes.
Higher education and research systems have become more internationalised over the past decades. The internationalisation of higher education can be gauged by the international mobility of students and that of research systems by internationally mobile holders of doctorates. During their studies and afterwards, the latter contribute to the advancement of research in the host country. When returning home, they bring back new competences and connections with international research networks.

International students primarily study social sciences, business and law. Only in Sweden, Finland, Germany and the United States do science and engineering (S\&E) programmes attract more than one-third of all international students. In 16 out of 28 economies, the share of international and foreign students enrolled in science and engineering surpasses that of national students. This pattern is more pronounced at the doctoral level.

International mobility has involved an average of around $14 \%$ of doctorate holders over the past ten years. Although the United States stands as the first destination, intraEuropean flows, especially towards France, Germany and the United Kingdom, dominate in Europe. While outward mobility seems mainly academic or job-related, personal and family reasons are more prominent in decisions to return home.

\section{Definitions}

International students are students who have crossed borders expressly with the intention to study. The UNESCO Institute for Statistics, the OECD and Eurostat define as international students those who are not residents of their country of study or those who received their prior education in another country. When data on international students are not available, data on foreign students are used. Foreign students are defined according to their citizenship. The fields of education correspond to those defined in the International Standard Classification of Education (ISCED-97). A doctorate holder has received an advanced research qualification at Level 6 of ISCED-97. He/she is considered as internationally mobile if he/she has since moved to a country other than that of his or her usual residence for a period of at least 3 months, except when the move was for recreation, holiday, visits to friends and relatives, medical treatment or religious pilgrimage. 


\section{CONNECTING TO KNOWLEDGE}

5. International mobility

International mobility of doctorate holders, by last destination, 2009

Percentage of national citizens with a doctorate having lived/stayed abroad in the past ten years

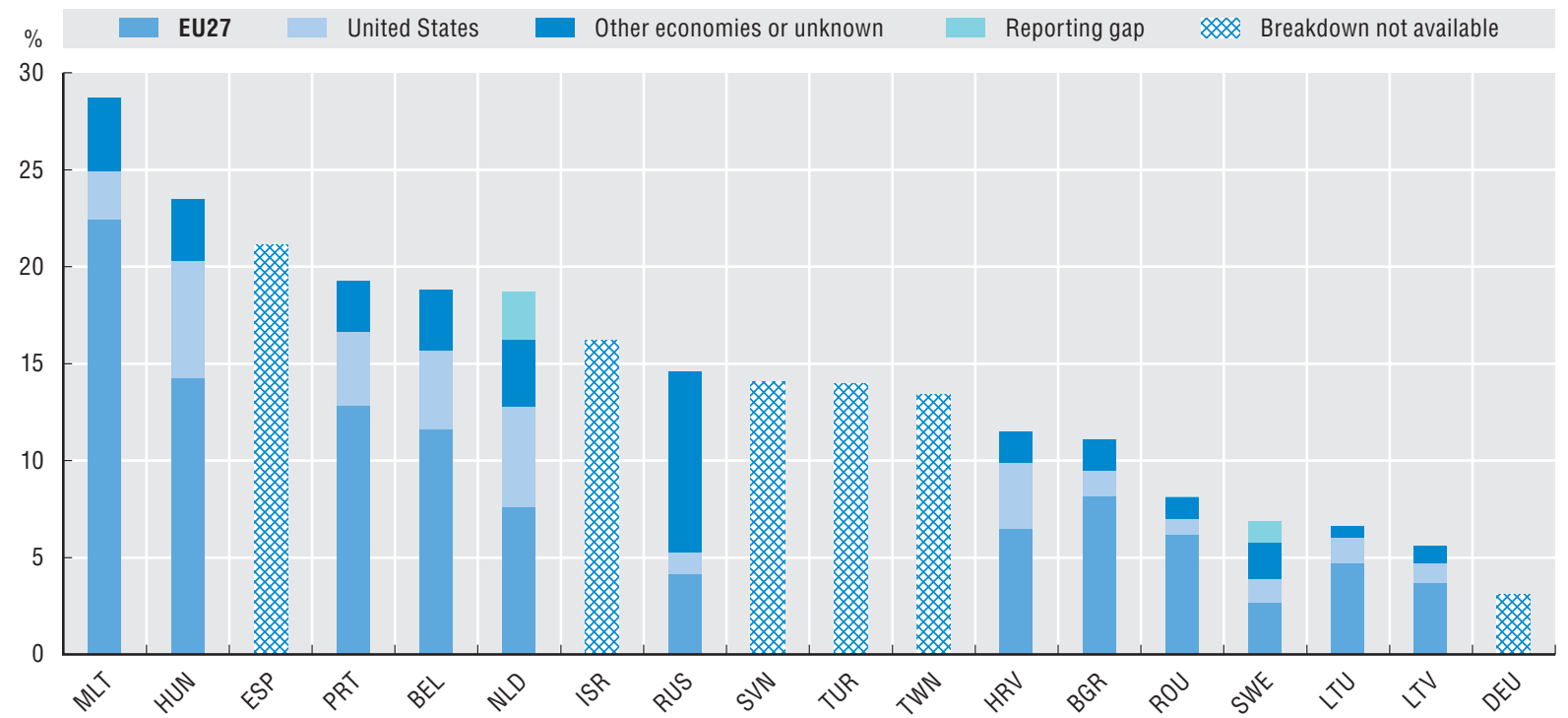

Source: OECD, based on OECD/UNESCO Institute for Statistics/Eurostat data collection on careers of doctorate holders 2010, June 2011. See chapter notes.

StatLink 게s/ http://dx.doi.org/10.1787/888932486393

\section{Measurability}

The measurement of international mobility poses a real challenge to statisticians, mainly because of the difficulty of tracking a moving target. International mobility is often approximated by measures of stocks (e.g. foreign citizens or foreign-born) and not of flows (move to another country). A further complication is the difficulty of differentiating temporary mobility from migration. The OECD has made good progress in developing better statistics on international mobility and migration, notably of international students and other categories, using the results of the 2000 worldwide cycle of censuses. The Careers of Doctorate Holders $(\mathrm{CDH})$ project has developed a new means of capturing mobility through the use of a new definition of internationally mobile doctorate holders and a series of questions on the national origin, the list of countries in which doctorate holders have studied, worked or carried out research and the reasons for mobility. 


\section{CONNECTING TO KNOWLEDGE}

\section{Job-to-job mobility of human resources in science and technology (HRST), 25-to-64-year-olds, 2000 and 2010}

As a percentage of total employed HRST

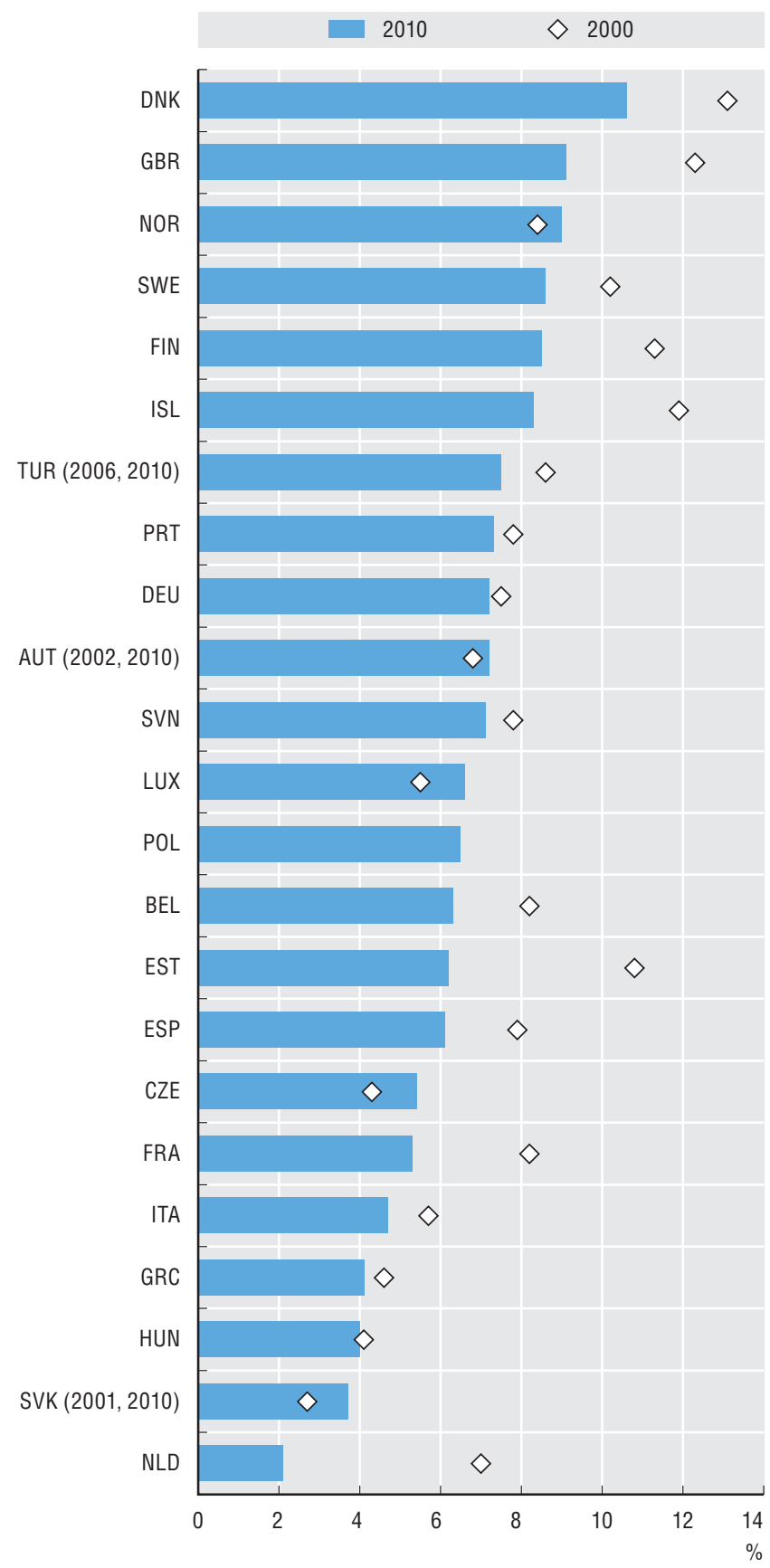

Source: OECD, based on ad hoc tabulations of European Labour Force Surveys, Eurostat, May 2011.

StatLink Ails $h t t p: / / d x . d o i . o r g / 10.1787 / 888932486412$
Interaction and learning within firms enable human resources in science and technology (HRST) to share information, challenge existing patterns, and experiment and collaborate to improve products and processes. "Brain circulation" across jobs, firms and sectors of activity can stimulate knowledge transfer, application of knowledge to new problems, and lead to the adoption of best practices, greater openness, creativity and innovation. It may also involve a loss of human capital for companies that invest in developing their workers' skills.

Job-to-job mobility figures for 2010 show that HRST workers in Nordic countries and the United Kingdom were more mobile than those in other EU countries, with at least $8 \%$ having changed jobs over the previous year. Although yearto-year estimates can be volatile, they suggest that mobility generally decreased from 2000 to 2010 .

A look at the occupational groups defined as HRST does not reveal systematic differences in mobility across categories of HRST. Their mobility appears to be similar to that of other employees, except in Austria, Turkey, Spain and Hungary where HRST are less mobile.

HRST acquire different knowledge and skills in different sectors. Sectoral mobility may reflect the fact that HRST skills can be applied to different domains of activity, or it may be due to a shift in the economic weight of certain industries or a change in demand for skilled workers. Mobility across sectors differs widely from country to country: it ranges from $9 \%$ to $60 \%$ of all HRST who change employers. In Estonia, France, Finland and the Slovak Republic, more than $50 \%$ of HRST who moved reported a change in sector of economic activity from 2009 to 2010. In contrast, most HRST mobility in Germany, Sweden and Slovenia occurred within sectors.

\section{Definitions}

Human resources in science and technology (HRST) describes individuals in science and technology occupations, such as professionals, technicians and associate professionals, as well as those in other occupations who successfully completed a tertiary-level education in science and technology. Job-to-job mobility is the movement of an employee from one job to another from one year to the next. It excludes inflows into the labour market from a situation of unemployment or inactivity. Inter-sector mobility reflects the flow of employed HRST whose economic activity at the NACE two-digit level differs from that of the previous year as a percentage of employed HRST who changed employers over the oneyear period. The rates are calculated for those employed both in the present and previous years and whose economic activity and HRST status could be identified. 
Job-to-job mobility of HRST by occupation, 25-to-64-year-olds, 2010

As a percentage of total employed in relevant group

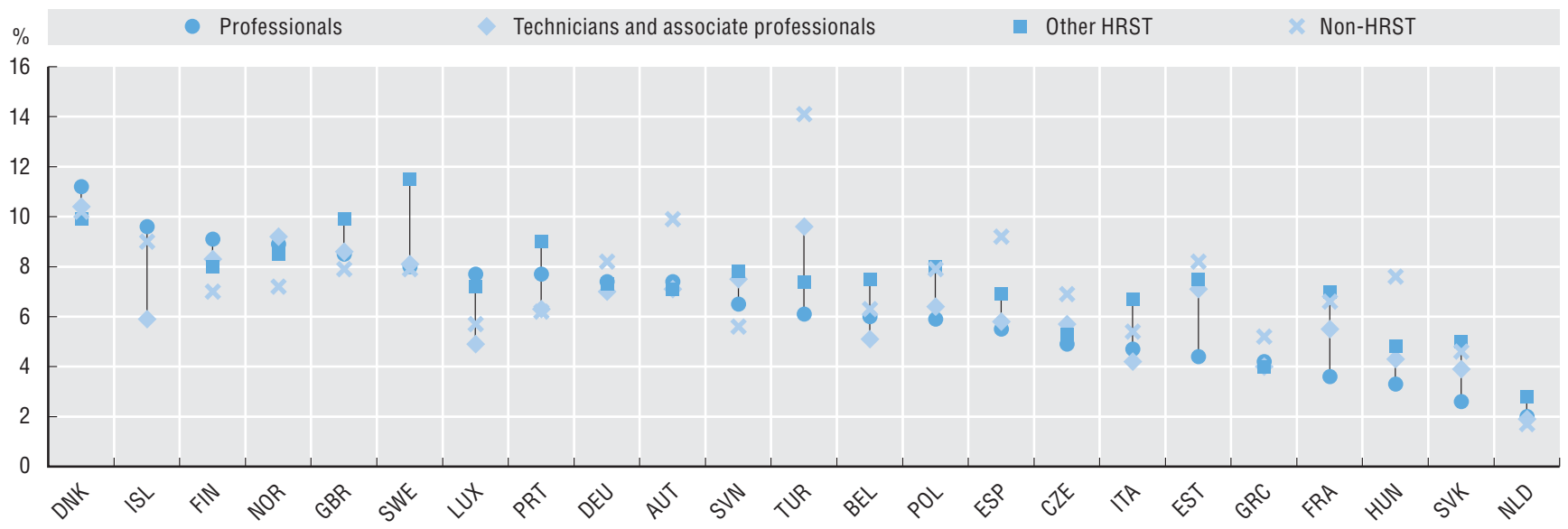

Source: OECD, based on ad hoc tabulations of European Labour Force Surveys, Eurostat, May 2011. See chapter notes.

Inter-sector mobility of HRST, 25-to-64-year-olds, 2010

As a percentage of HRST changing employer

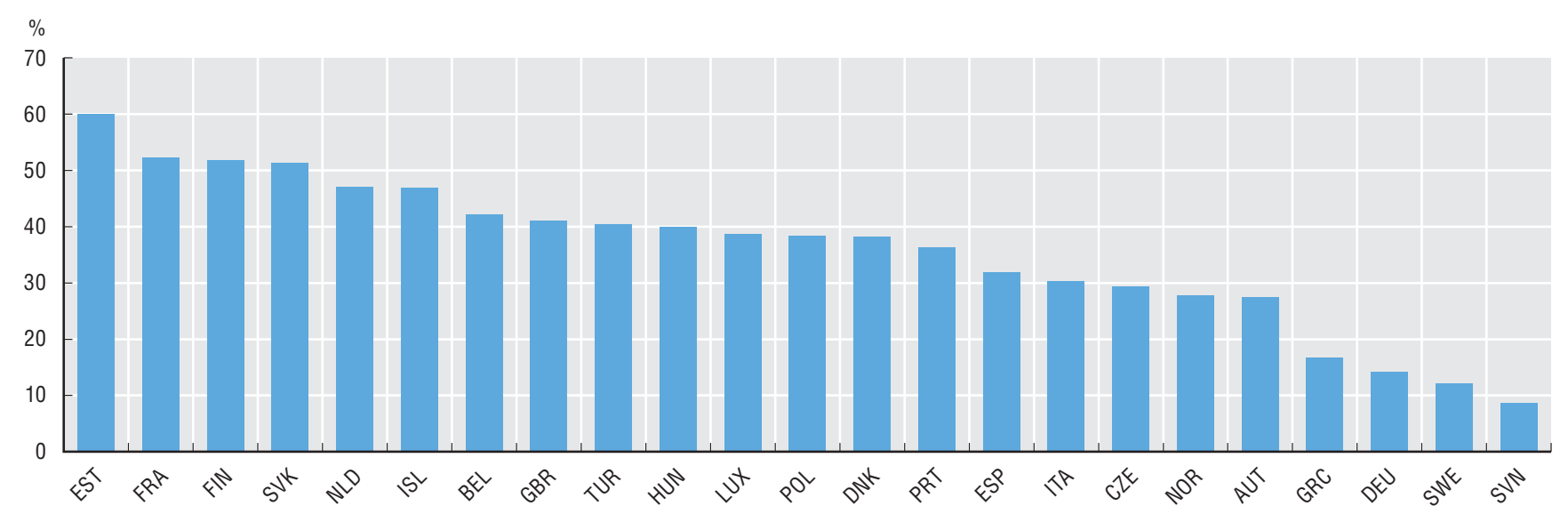

Source: OECD, based on ad hoc tabulations of European Labour Force Surveys, Eurostat, May 2011. See chapter notes.

\section{Measurability}

Although the importance of mobility of human resources in science and technology (HRST) is widely recognised, there are no internationally comparable data on their mobility. Very few labour-force or related household surveys collect information that can be used to estimate job and sector mobility patterns for sufficiently large samples. The European Labour Force Surveys are one of the few harmonised sources which can be reliably used for this purpose. The analysis of HRST mobility needs to take into account the problem of collecting retrospective information from respondents who typically constitute relatively small populations. These limitations make it difficult to obtain reliable estimates for analysing and comparing mobility patterns across groups and time, especially beyond NACE two-digit and/or ISCO two-digit levels. Inter-sector mobility rates may also depend on the level of aggregation in the NACE digits. To understand the effects of mobility of highly skilled workers on innovation, more detailed, internationally comparable statistics are required. 


\section{CONNECTING TO KNOWLEDGE}

\section{Innovation and knowledge flows}
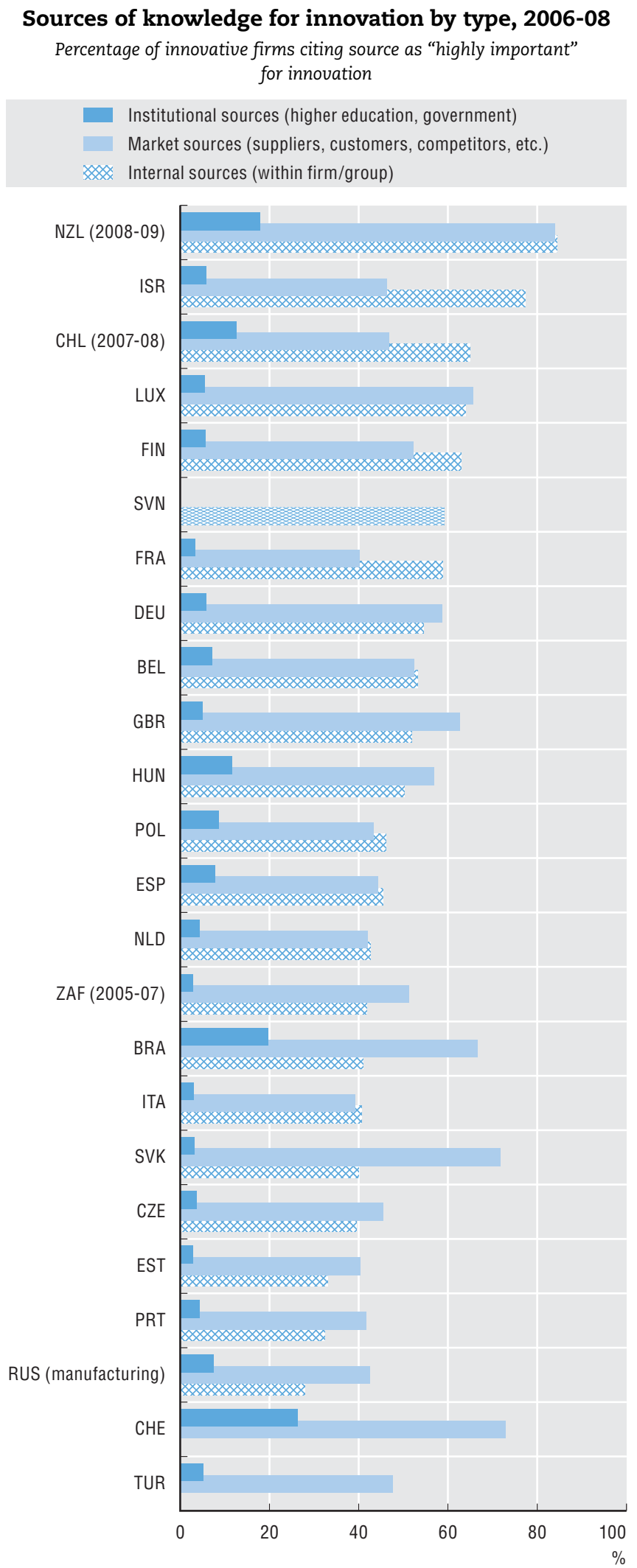

Source: OECD, based on Eurostat (CIS-2008) and national data sources, June 2011. See chapter notes.

StatLink काज्ञा http://dx.doi.org/10.1787/888932486469
Innovation is a complex process and often involves many actors and linkages. One way to capture its systemic dimension is to examine which information sources firms use for their innovation activities. Internal sources are often reported as the most important for innovation, but in some countries external market sources predominate. Institutional sources play a much smaller role: generally, less than $10 \%$ of innovating firms rank them as "highly important".

In addition to sourcing information from other firms or institutions, collaboration can be a key vector of innovationrelated knowledge flows. In particular, collaboration with public research organisations (higher education or government research institutes) can be an important source of knowledge transfer between science and industry. This mainly concerns large firms: in most countries large firms are usually twice to three times more likely than small and medium-sized enterprises (SMEs) to engage in such collaboration. More than half of all innovating large firms in Finland, Hungary, Austria and the Slovak Republic collaborate with public institutions, compared to less than one in ten in the Russian Federation, Chile and Mexico.

\section{Definitions}

The current Oslo Manual (OECD/Eurostat, 2005) defines innovation as the implementation of a new or significantly improved product (good or service) or process, a new marketing method, or a new organisational method in business practices, workplace organisation or external relations.

For the majority of indicators, innovative firms are defined as firms with product, process or ongoing/ abandoned innovation activities, following the approach of the Community Innovation Survey (CIS). In other national surveys, innovative refers to all types of innovation (including non-technological).

Internal sources of information include any source within the enterprise or enterprise group. Market sources include suppliers of equipment, materials, components or software, clients or customers, competitors or other enterprises of the same sector and consultants, commercial labs or private R\&D institutes. Institutional sources include universities or other higher education institutions and government or public research institutes.

The classification of firms by size follows the recommendations of the Oslo Manual. It is calculated on the basis of number of employees. SMEs are firms with 10-250 employees, with some exceptions: New Zealand: 6+; the Russian Federation 15+; China: at least CNY 5 million in turnover. For South Africa, firm size is based on turnover. 


\section{CONNECTING TO KNOWLEDGE}

\section{Firms collaborating on innovation with higher education or government research institutions by firm size, 2006-08}

As a percentage of innovative firms in each size category

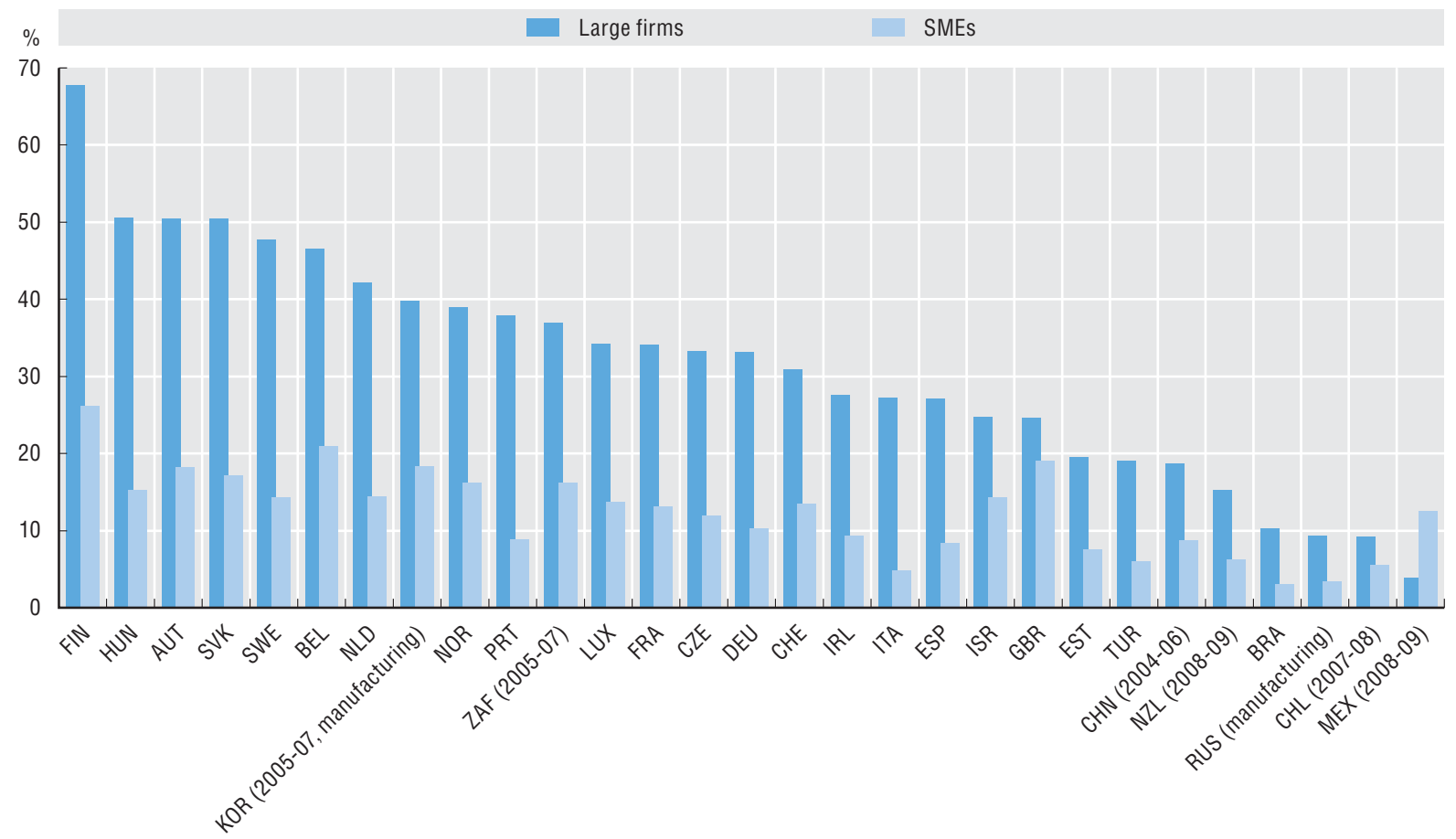

Source: OECD, based on Eurostat (CIS-2008) and national data sources, June 2011. See chapter notes.

\section{Measurability}

Despite a gradual process of harmonisation based on the Oslo Manual, there still remain some significant differences in methodology and survey design between the Community Innovation Survey (CIS), which is carried out throughout Europe, and other national innovation surveys. Differences that may affect the comparability of indicators include sectoral coverage, size thresholds, sampling methods as well as differences in the filtering of firms (innovators/non-innovators) throughout the survey questionnaire. There are also differences in the scope of some questions: for example, in the CIS questions on collaboration refer only to product/process innovation (so would not be asked to firms that only have non-technological innovation) while in other surveys they cover all types of innovators. Finally, the CIS uses a three-year reference period (i.e. firms are asked about their innovation activities over the last three years), while some countries use a shorter period (generally two years) which may also affect the comparability of some indicators. 


\section{CONNECTING TO KNOWLEDGE}

\section{Collaboration in business value chains}

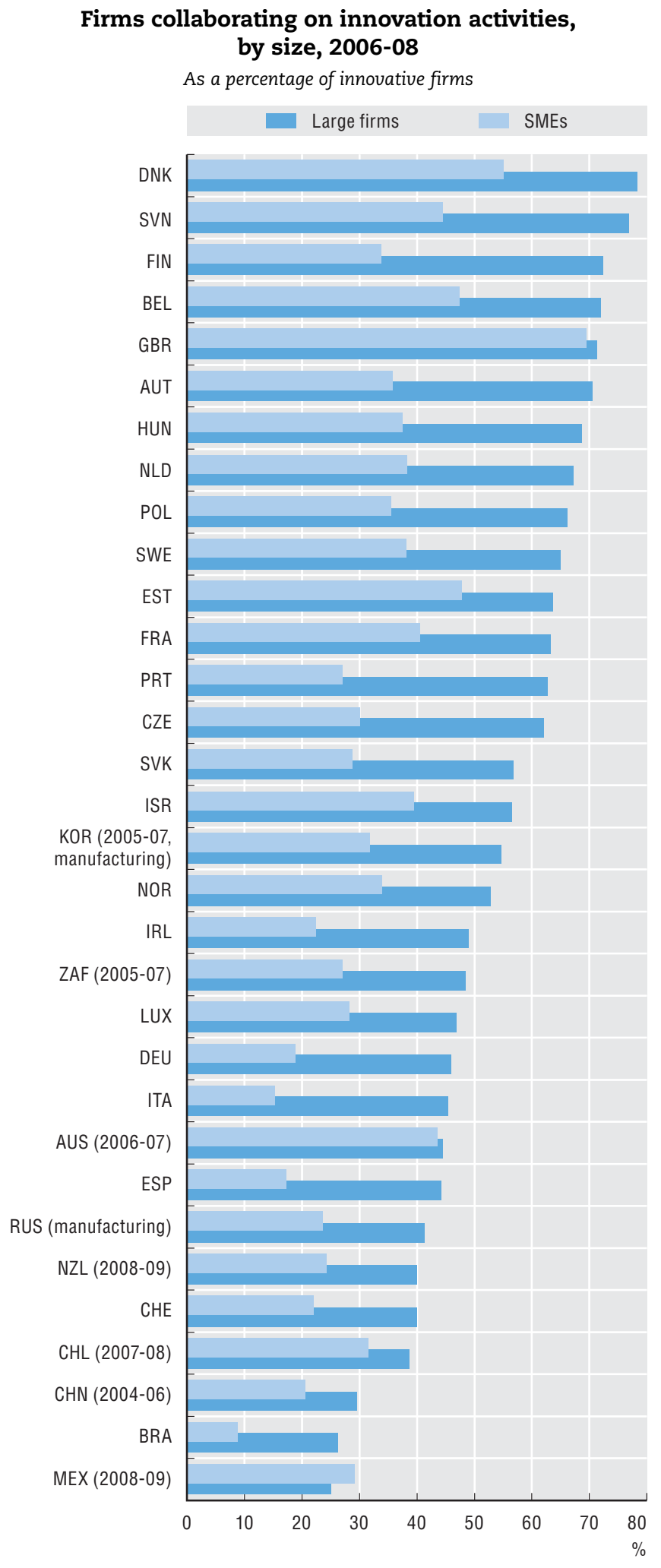

Source: OECD, based on Eurostat (CIS-2008) and national data sources, June 2011. See chapter notes.

StatLink Aाst http://dx.doi.org/10.1787/888932486507
During 2006-08, in the great majority of countries, large firms were significantly more likely to collaborate on innovation than small and medium-sized enterprises (SMEs). Among SMEs, the rate of collaboration is between $25 \%$ and $40 \%$ of innovative firms in half of the countries surveyed, but it varies widely for large firms. More than $70 \%$ of large innovative firms collaborated on innovation in Denmark, Slovenia, Finland, Belgium, the United Kingdom and Austria, while less than one-third did so in China, Brazil and Mexico.

In addition to firm size, patterns of collaboration differ in terms of types of partners. Among large firms, suppliers usually play a main role, but in the United Kingdom, Korea, Luxembourg, Australia and Germany, collaboration with clients is equally or even more important. This may reflect increasing integration along value chains as well as the growing importance of user-driven innovation.

\section{Definitions}

The classification of firms by size follows the recommendations of the Oslo Manual. It is calculated on the basis of number of employees. SMEs are firms with 10-250 employees, with some exceptions: New Zealand: 6+; the Russian Federation 15+; China: at least CNY 5 million in turnover. For South Africa, firm size is based on turnover.

Collaboration involves "active participation in joint innovation projects with other organisations" but excludes pure contracting out of work. It can involve the joint development of new products, processes or other innovations with customers and suppliers, as well as horizontal work with other enterprises or public research bodies. For Switzerland it only includes collaboration on research and development (R\&D). 


\section{CONNECTING TO KNOWLEDGE}

\section{Collaboration in business value chains}

Firms collaborating on innovation activities with suppliers and clients, by firm size, 2006-08

As a percentage of innovative firms

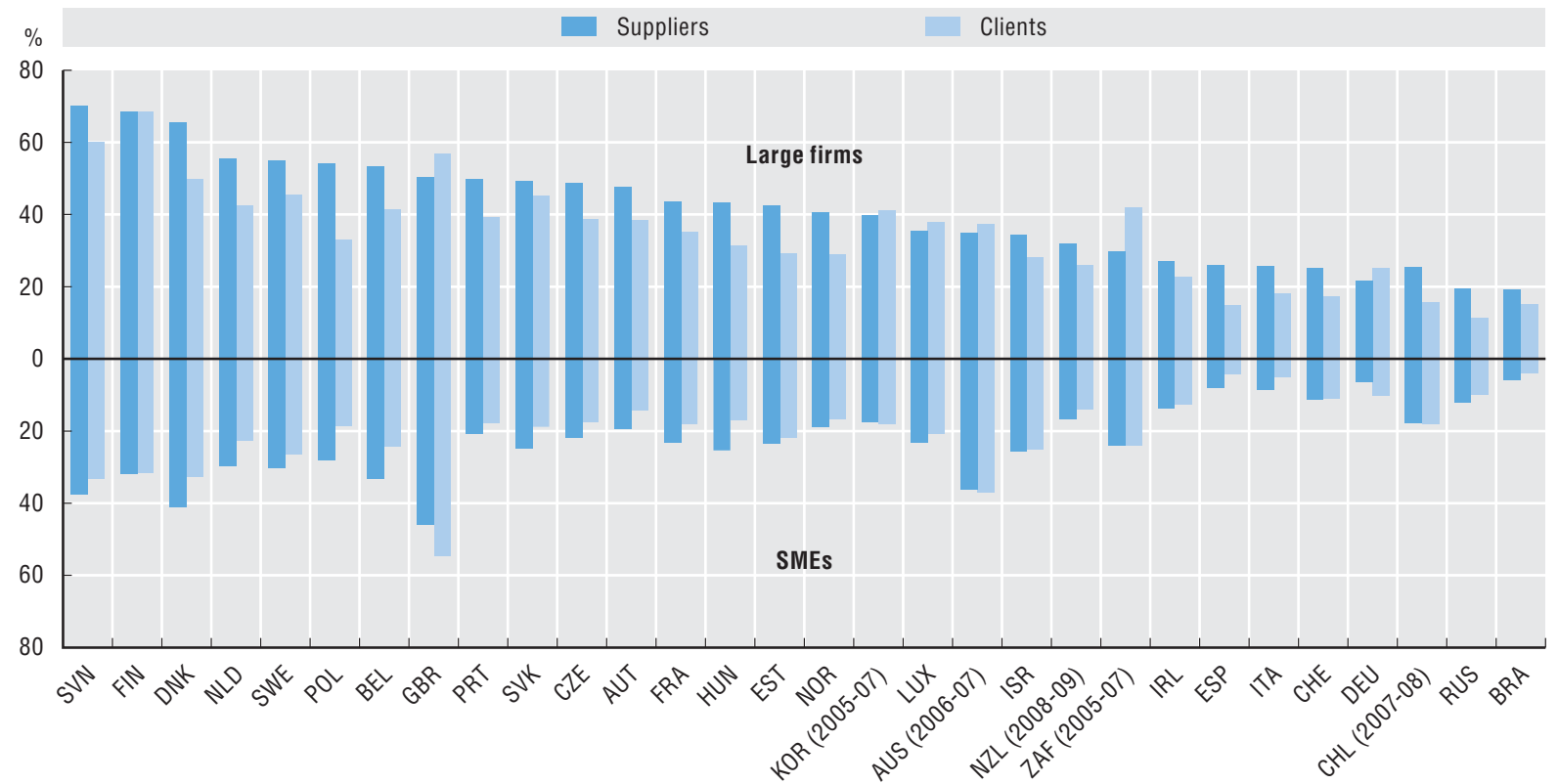

Source: OECD, based on Eurostat (CIS-2008) and national data sources, June 2011. See chapter notes.

\section{Measurability}

Indicators of collaboration on innovation only reflect the existence of some sort of collaboration, but not the type, frequency or intensity. Collaboration refers to product/process innovation in the Community Innovation Survey (CIS), but to all types of innovation (including non-technological) in some other surveys. In the CIS, innovative firms have product/process or ongoing/abandoned innovations, but in some other surveys they include all types of innovators (including non-technological). 


\section{CONNECTING TO KNOWLEDGE}

\section{National and international collaboration on innovation by firms, 2006-08}

As a percentage of innovative firms

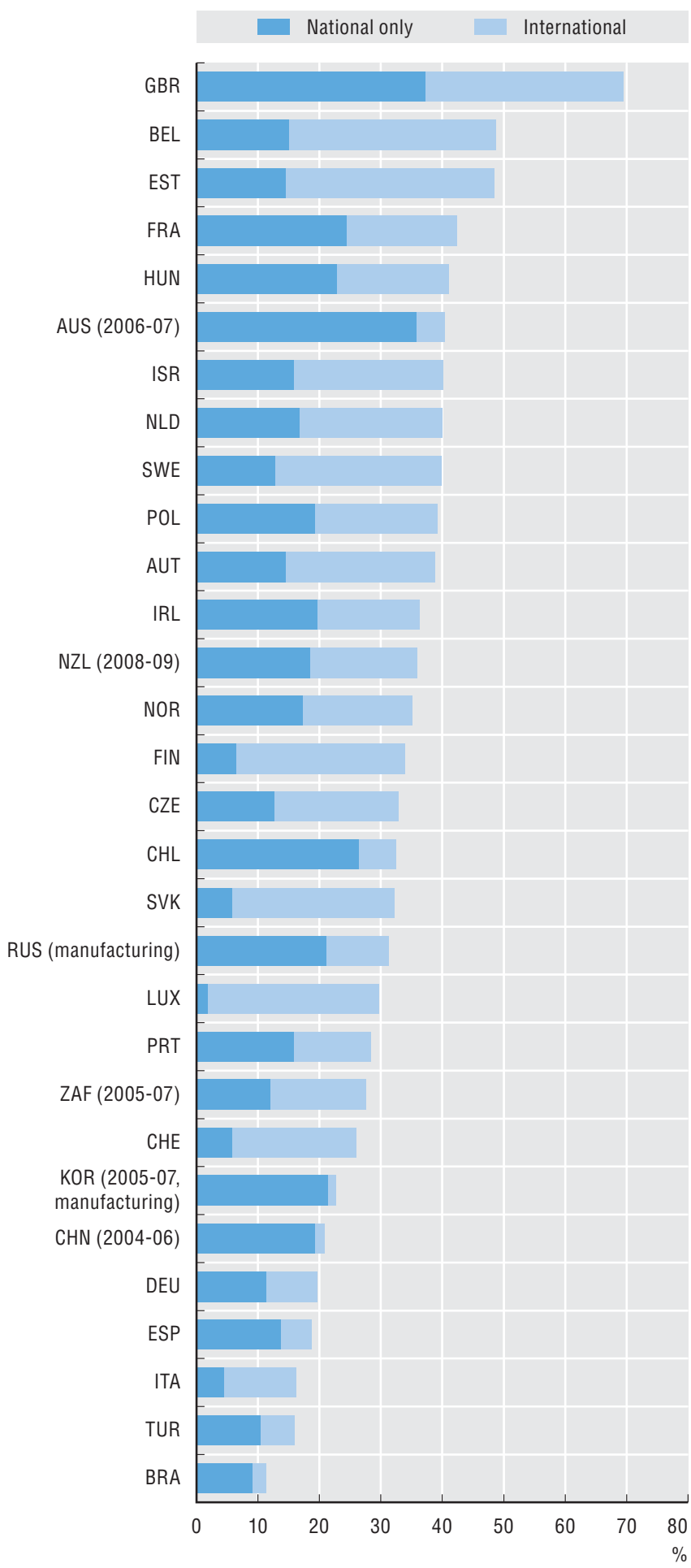

Source: OECD, based on Eurostat (CIS-2008) and national data sources, June 2011. See chapter notes.

StatLink तारुस http://dx.doi.org/10.1787/888932486545
Collaboration with foreign partners can play an important role in the innovation process by allowing firms to gain access to a broader pool of resources and knowledge at lower cost and to share the risks. It can take a variety of forms and levels of interaction ranging from simple one-way information flows to highly interactive and formal arrangements.

Collaboration rates vary widely across countries. In some, collaboration mainly involves national partners (e.g. Korea, China, Australia, Chile), but in most there is a greater balance between national and foreign partners. In some countries firms are strongly oriented towards international collaboration (e.g. Luxembourg, the Slovak Republic, Finland and Switzerland).

Size is a strong determinant of foreign collaboration: large firms have a much higher propensity to collaborate internationally than SMEs (usually twice to three times as much), but in Australia, the United Kingdom and Israel the gap is narrower. In Korea, Brazil, China and Spain, which have relatively low international collaboration rates, there is almost no participation by SMEs.

Among European firms, intra-European collaboration remains the predominant form of cross-country co-operation on innovation. In terms of collaboration outside Europe, European firms tend to partner mainly with US firms, although collaboration with firms in China and India is significant in Sweden, Finland and Belgium.

\section{Definitions}

The classification of firms by size follows the recommendations of the Oslo Manual. It is calculated on the basis of the number of employees. SMEs are firms with 10-250 employees, with some exceptions: New Zealand: 6+; the Russian Federation: 15+; China: at least CNY 5 million in turnover. For South Africa, firm size is based on turnover.

Collaboration refers to active participation even if both parties do not benefit commercially and excludes pure contracting out. For Switzerland it only includes collaboration on R\&D. 


\section{CONNECTING TO KNOWLEDGE}

\section{International collaboration on innovation}

Firms engaged in international collaboration by firm size, 2006-08

As a percentage of innovative firms in each size category

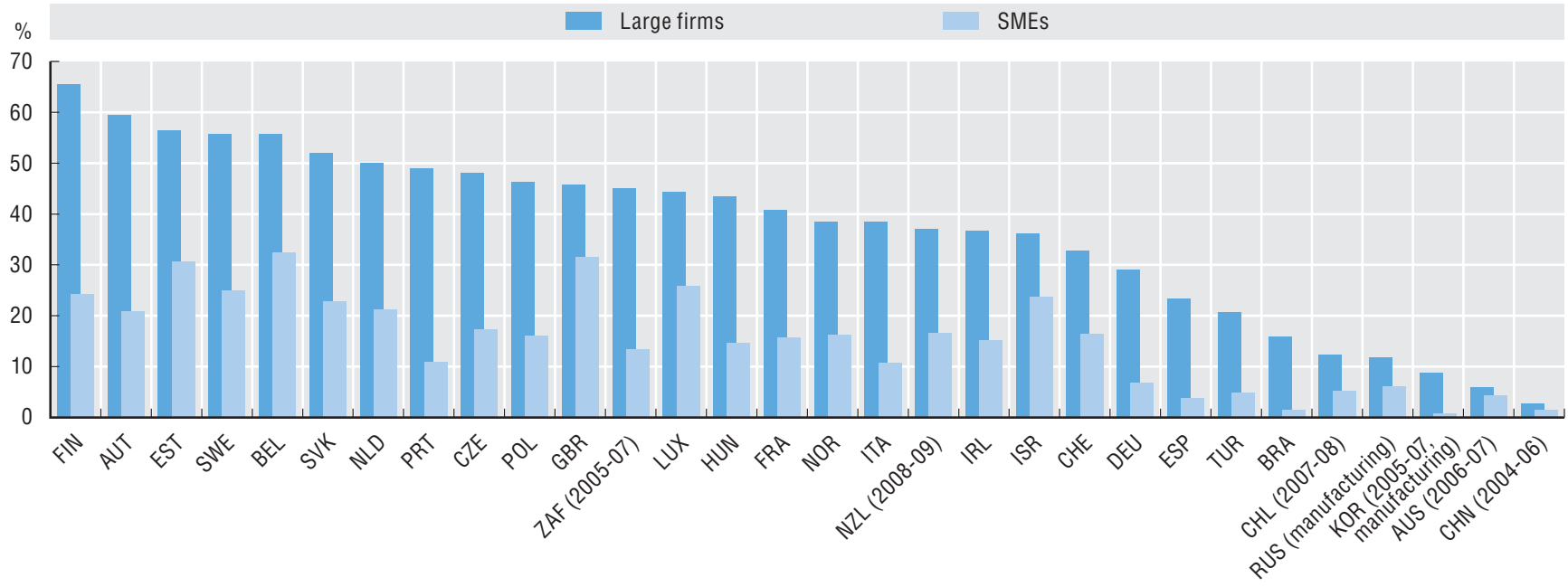

Source: OECD, based on Eurostat (CIS-2008) and national data sources, June 2011. See chapter notes.

StatLink Aits http://dx.doi.org/10.1787/888932486564

Firms engaged in international collaboration by partner country, 2006-08 As a percentage of innovative firms

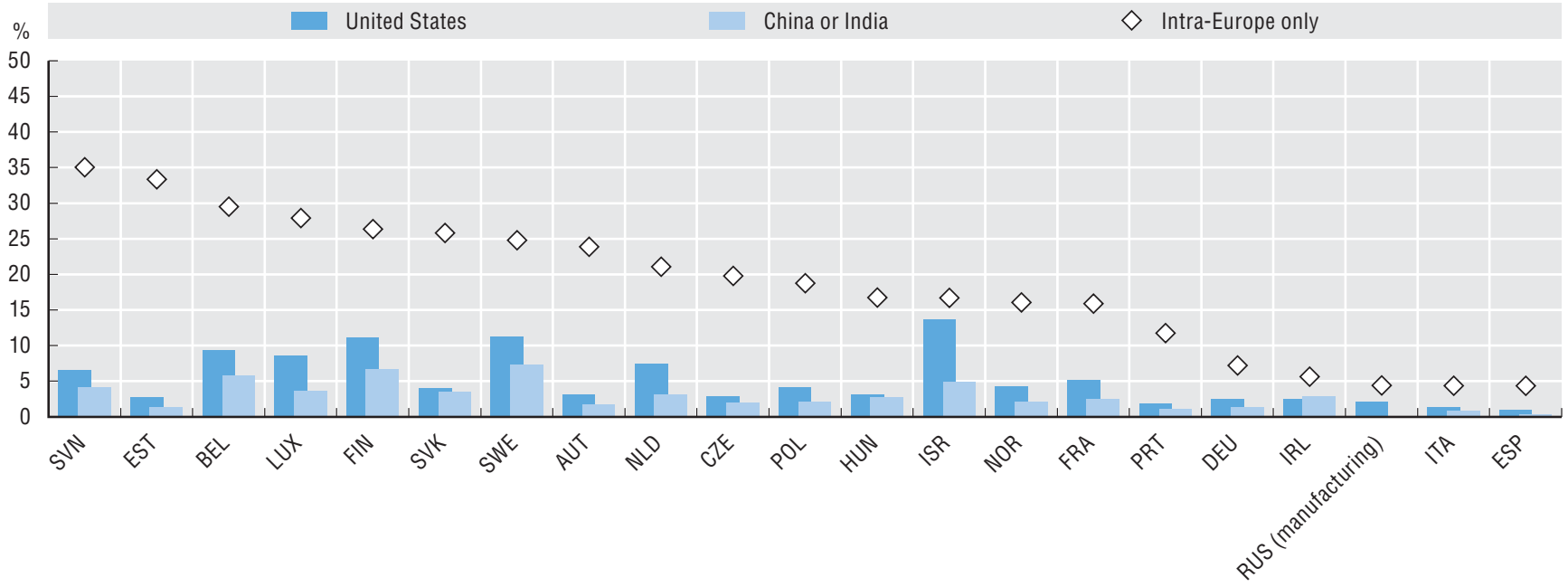

Source: OECD, based on Eurostat (CIS-2008) and national data sources, June 2011. See chapter notes.

StatLink तilst http://dx.doi.org/10.1787/888932486583

\section{Measurability}

Collaboration refers to product/process innovation in the Community Innovation Survey (CIS), but to all types of innovation (including non-technological) in some other surveys.

Innovative firms have product/process or ongoing/abandoned innovations in the CIS, but in some other surveys they include all types of innovators (including non-technological).

In some national surveys, firms are asked about the relative importance of each partner/location but in some others they are only asked to identify the main location for each type of partner. 


\section{CONNECTING TO KNOWLEDGE}

\section{Technology flows}

\section{International technology flows (average of receipts and payments) as a percentage of GDP, 1999 and 2009}

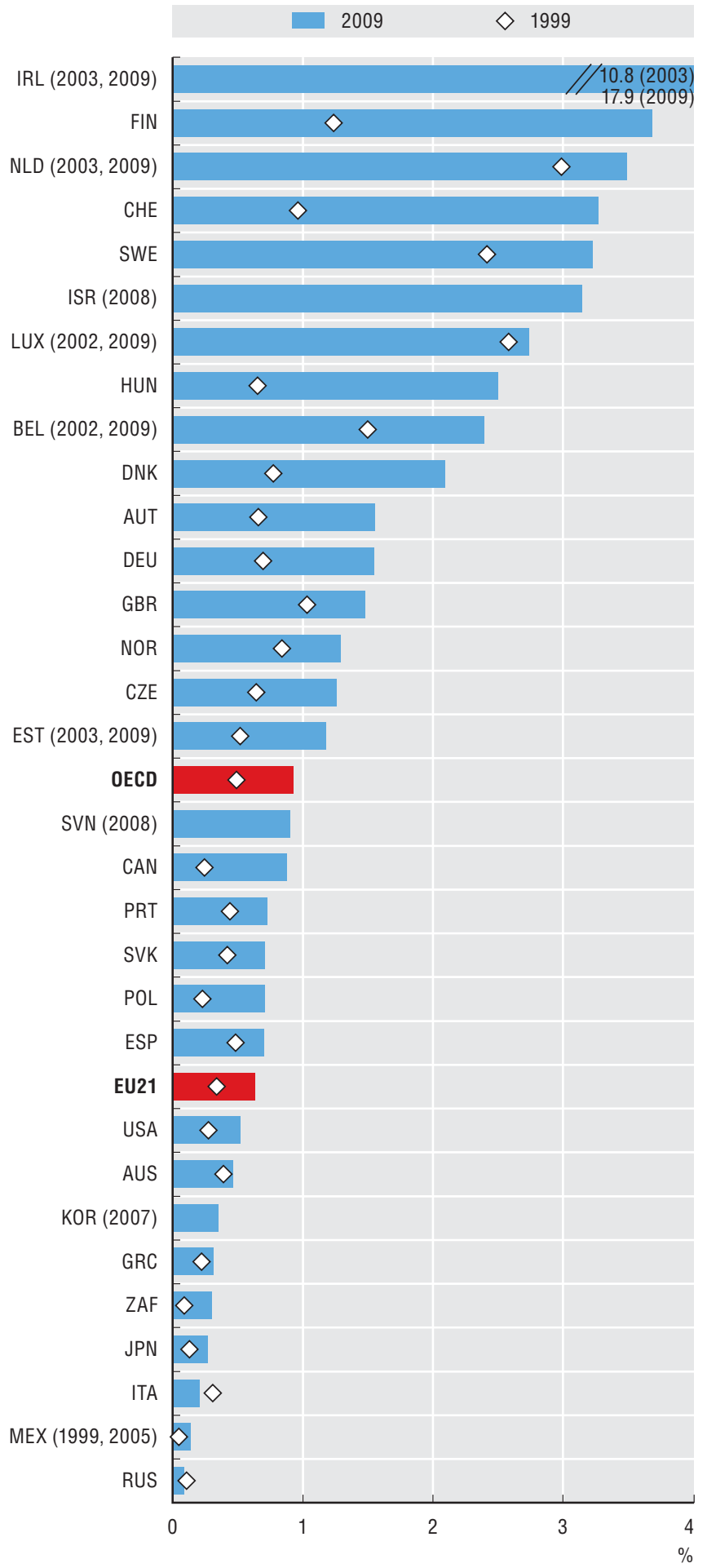

Source: OECD, Technology Balance of Payments Database, May 2011. See chapter notes.

StatLink काजा http://dx.doi.org/10.1787/888932486602
Technology receipts from patents and licences and payments for $R \& D$ services are the main source of information on disembodied technology diffusion and indicate the internationalisation of technology flows.

These flows reflect to some extent cross-border trade in R\&D outcomes. Unlike R\&D expenditures, such payments are for production-ready technologies. Over the years, international technology flows have increased, showing that knowledge generated in one country is increasingly used in another. While it is not possible to distinguish between intra- (parents and affiliates) and inter-firms transactions, the figures point to the importance of foreign affiliates' activities. For instance, technology flows to and from Ireland are mainly due to the strong presence of foreign affiliates (particularly US and UK firms). The figures may however be affected by intra-firm transactions and transfer pricing.

Royalties are an important category of international technology flows. In almost all countries for which data are available, transactions involving royalties and licence fees grew on average more than the rate of GDP growth over the last decade. In the Russian Federation, China, Estonia and India, international flows of royalties increased by more than 20\% annually between 1997 and 2009.

The rise in international technology flows shows that knowledge is increasingly implemented in a different country from the one in which it was developed. Many countries with a high share of patents invented by foreign businesses either have large multinational firms that perform $R \& D$ abroad or are low-tax countries with no track record of innovation activities. In this case, the intellectual property (IP) may be located there as a way to minimise taxes.

\section{Definitions}

Technology flows refer to the average of technological payments and receipts. Trade in technology comprises four main categories: transfer of techniques (through patents and licences, disclosure of know-how); transfer (sale, licensing, franchising) of designs, trademarks and patterns; services with a technical content, including technical and engineering studies as well as technical assistance; industrial R\&D. Royalties and licence fees are payments and receipts between residents and non-residents for the authorised use of intangible, non-produced, non-financial assets and proprietary rights (such as patents, copyrights, trademarks, industrial processes and franchises) and for the use, through licensing agreements, of produced originals or prototypes (such as manuscripts, cinematographic works and sound recordings). Foreign inventions refer to patents none of whose inventors resides in the country in which a resident owns the patent. Patent applications are filed through the Patent Cooperation Treaty (PCT) at international phase. 
International technology flows through royalties and licence fees, 1997-2009

Average annual growth rate, based on USD, percentage

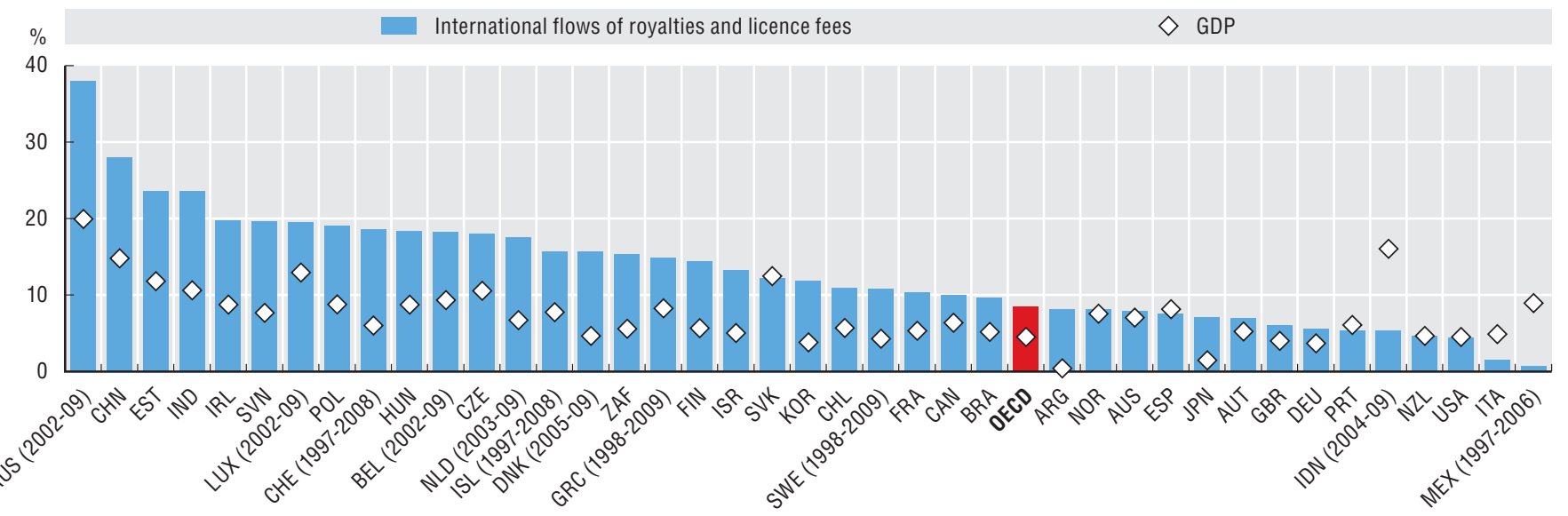

Source: OECD, Technology Balance of Payments Database, May 2011; OECD, Trade in Services Database, May 2011; World Bank, World Development Indicators, May 2011; and OECD, Annual National Accounts Database, May 2011.

StatLink AाISL http://dx.doi.org/10.1787/888932486621

Foreign inventions owned by countries, 2006-08

Relative to country share in patent applications, percentages, axis in logarithmic scale

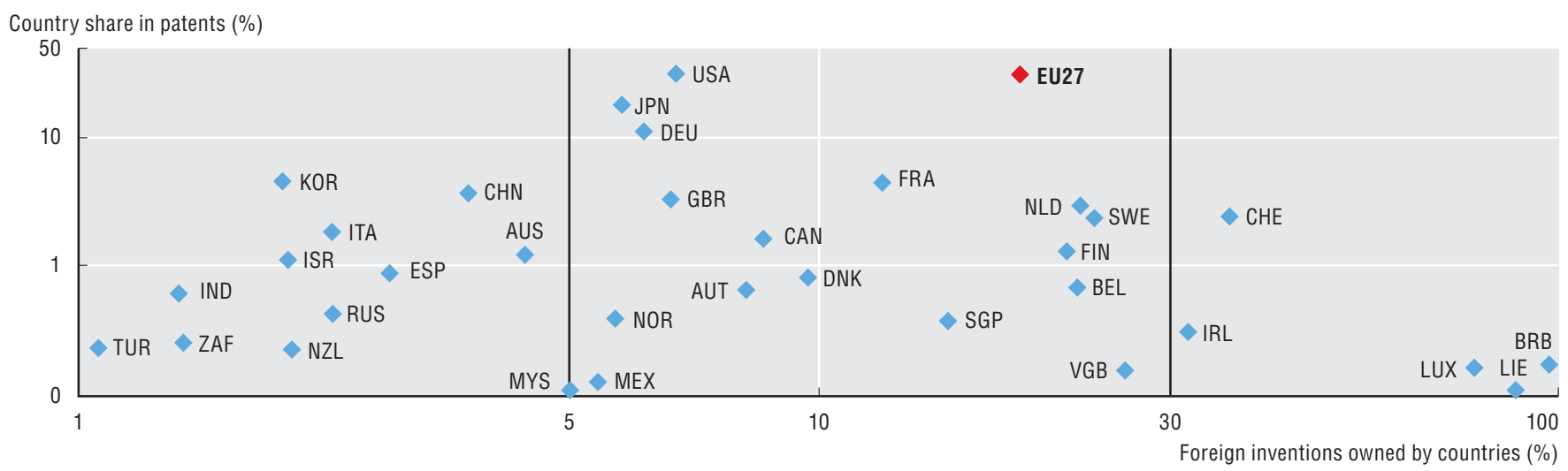

Source: OECD, Patent Database, May 2011. See chapter notes.

StatLink काIsL $h t t p: / / d x . d o i . o r g / 10.1787 / 888932486640$

\section{Measurability}

Technology receipts and payments show a country's ability to sell technology abroad and its use of foreign technologies, respectively. Further qualitative and quantitative information is needed to analyse a country's deficit or surplus since a deficit (surplus) on the technology balance does not necessarily indicate a lack (or presence) of competitiveness.

Measurement errors may lead to underestimation or overestimation of technology transfers. Licensing contracts provide payment channels other than technology payments, and payment/receipt flows may be only part of the total price paid and received. Alternatively, national tax and control regulations on technology payments and receipts may bias data on technology flows, notably for international transfers of multinationals. If royalties are less taxable than profits, royalties may be preferred to other transfer channels and exceed the value of technology transferred. On the contrary if limitations are imposed on royalty remittances, some part of repatriated profits will represent remuneration of technology transfer.

The location of patent ownership may reveal the importance of IP tax shifting and may indirectly reveal attractive tax incentives for IP revenue and tax planning strategies. However, the data currently available do not include revenue generated by patents. This limits the analysis that can be undertaken. 


\section{CONNECTING TO KNOWLEDGE}

\section{Cyprus}

The following note is included at the request of Turkey:

"The information in this document with reference to 'Cyprus' relates to the southern part of the Island. There is no single authority representing both Turkish and Greek Cypriot people on the Island. Turkey recognises the Turkish Republic of Northern Cyprus (TRNC). Until a lasting and equitable solution is found within the context of the United Nations, Turkey shall preserve its position concerning the 'Cyprus issue'."

The following note is included at the request of all the European Union member states of the OECD and the European Commission:

"The Republic of Cyprus is recognised by all members of the United Nations with the exception of Turkey. The information in this document relates to the area under the effective control of the Government of the Republic of Cyprus."

\section{Israel}

"The statistical data for Israel are supplied by and under the responsibility of the relevant Israeli authorities. The use of such data by the OECD is without prejudice to the status of the Golan Heights, East Jerusalem and Israeli settlements in the West Bank under the terms of international law."

"It should be noted that statistical data on Israeli patents and trademarks are supplied by the patent and trademark offices of the relevant countries."

\section{Government-financed R\&D in business, 1999 and 2009}

In Austria the research premium is considered a part of "government funding" for the first time in 2006. In the previous regular R\&D surveys (before 2006, reference years 2004 and 2002) the "research premium" was not listed as a separate "source of funds" in the national questionnaire.

For year 2005 the Danish Government funds estimates include funding from the Higher education sector.

Defense is excluded for Israel.

Excludes R\&D in the social sciences and humanities for Korea.

Excludes most or all capital expenditure for the United States.

Business-funded R\&D in the higher education and government sectors, 1999 and 2009

Business-funded R\&D in the higher education only in Switzerland.

\section{The quantity and quality of scientific production, 2009}

Analysis based on Scopus data processed by SCImago, SIR-SCImago Institutions Rankings, June 2011, www.scimagoir.com.

\section{The impact of international scientific collaboration by institutions on research output, 2009}

The average normalised impact values are expressed for a unit (e.g. country) relative to the world average which is set at one. For example, a score of 1.3 means the unit is cited 30\% above average. In order to help illustrate the relationship between collaboration types and impact, the average impact of a given country and type of collaboration is described as low, medium or high depending on whether it lies below one, between one and 1.75 or higher, respectively.

Analysis based on Scopus data processed by SCImago, SIR-SCImago Institutions Rankings, June 2011, www.scimagoir.com. 
The impact of domestic scientific collaboration by institutions on research output, 2009

The average normalised impact values are expressed for a unit (e.g. country) relative to the world average which is set at one. For example, a score of 1.3 means the unit is cited $30 \%$ above average. In order to help illustrate the relationship between collaboration types and impact, the average impact of a given country and type of collaboration is described as low, medium or high depending on whether it lies below one, between one and 1.75 or higher, respectively.

Analysis based on Scopus data processed by SCImago, SIR-SCImago Institutions Rankings, June 2011, www.scimagoir.com.

Patents citing non-patent literature (NPL) and average citations received per patent cited, by technology field, 2005-10

Data refers to the citations made in patent applications filed at the European Patent Office (EPO) during the search, according to the publication date of the citing patent. The average share of citations to non-patent literature (NPL) is compiled on citations received in EPO patents. The average number of forward patent citations is based on all EPO patents as particularly relevant documents $(\mathrm{X}-\mathrm{Y})$ by EPO patents up to 5 years after the first publication, and cover patents without backward citations. Technology fields are defined according Schmoch's classification (WIPO, 2010) and rely on the International Patent Classification (IPC) codes contained in the patent document.

\section{Citations to patents that include non-patent literature (NPL), by technology field, 2005-10}

Data refers to the citations made in patent applications filed at the European Patent Office (EPO) during the search, according to the publication date of the citing patent. Forward citations of patents refer to patents with or without NPL backward citations that are cited as particularly relevant documents (X-Y) by EPO patents up to five years after the first publication. Technology fields are defined according Schmoch's classification (WIPO, 2010) and rely on the International Patent Classification (IPC) codes contained in the patent document.

\section{Patents citing non-patent literature (NPL), selected technologies, 1995-2000 and 2005-10}

Data refers to the citations made in patent applications filed at the European Patent Office (EPO) during the search, according to the publication date and the inventor's country of residence. The average number of citations of non-patent literature (NPL) is compiled on citations received in EPO patents. Patents are allocated to technological fields using the International Patent Classification (IPC) or the European Patent Classification (ECLA) - Tags Y01N and Y02.

BRIICS refers to Brazil, the Russian Federation, India, Indonesia, China and South Africa.

\section{International and foreign students enrolled in tertiary education, 2009}

Data refer to foreign students for the Czech Republic, France, Italy, Poland, the Slovak Republic and Turkey. International students' data exclude tertiary-Type B programmes for Austria, Finland, Germany, Italy, Japan, Poland, Spain and Switzerland.

International students' data exclude advanced research programmes for Germany, Italy, the Netherlands and Spain. "Not known or unspecified" for Belgium includes all the students that are subject to mobility and enrolled at the ISCED-5A and 6 levels in universities of the French community.

"All S\&E enrolments at the tertiary level (including domestic students)" exclude tertiary-Type B for all countries and advanced research programmes for Finland and Norway.

\section{International mobility of doctorate holders, by last destination, 2009}

"Other economies" refer to those located in Africa, America, Asia, Europe and Oceania.

For Belgium, Germany, the Netherlands and Spain, data relate to graduates from 1990 onwards only.

For Germany, the data reported are for a minimum length of stay abroad of six months as compared to three months for the other countries.

For the Netherlands, Portugal and Romania the reporting gap is caused by rounding.

For the Russian Federation, data relate only to those doctoral graduates employed as researchers and teachers.

For Spain, the sample has limited coverage of doctorate holders for the years 2007 to 2009.

For Sweden, the reporting gap is due to data that have not been disclosed for national citizens at the individual country level and respondents that have not been assigned to countries or classified as unknown. 


\section{CONNECTING TO KNOWLEDGE}

Job-to-job mobility of HRST by occupation, 25-to-64-year-olds, 2010

Limited reliability of "Other HRST" for Luxembourg.

Inter-sector mobility of HRST, 25-to-64-year-olds, 2010

Limited reliability for the Slovak Republic.

\section{Sources of knowledge for innovation by type, 2006-08}

For Brazil only the following activities are included in the services sector: ISIC Rev. 4 Divisions 58, 61, 62 and 72. For Chile, data refer to 2007-08 and firms with ongoing or abandoned innovative activities are not identified. Data are based on ISIC Rev. 3.1 and include a wider range of activities such as agriculture, forestry, fishing, construction, and some services.

For New Zealand, data refer to 2008-09 and include firms with six or more employees. Innovative firms include technological and non-technological innovators.

For the Russian Federation, data refer to manufacturing firms with 15 or more employees.

For South Africa, data refer to 2005-07 and include the retail trade sector.

For Turkey, data are based on NACE Rev. 1.1 and exclude some activities within NACE Rev. 2 Divisions J58 and J63.

\section{Firms collaborating on innovation with higher education or government research institutions by firm size, 2006-08}

For Brazil, only the following activities are included in the services sector: ISIC Rev. 4 Divisions 58, 61, 62 and 72. For Chile, data refer to 2007-08 and firms with ongoing or abandoned innovative activities are not identified. Data are based on ISIC Rev. 3.1 and include a wider range of activities such as agriculture, forestry, fishing, construction, and some services

For China, data refer to 2004-06 and exclude all services. In addition, large firms are defined as firms with over 2000 employees, over CNY 300 million turnover and over CNY 400 million capital. SMEs are the remaining firms with at least CNY 5 million turnover.

For Korea, data refer to 2005-07 and cover only firms with more than 10 employees in the manufacturing sector. For Mexico, data refer to 2008-09 and cover firms with 20 or more employees. The industries covered are based on ISIC Rev. 3.1 and include a wider range of activities such as agriculture, construction and some services. Data refer to collaboration with Higher Education institutions only.

For New Zealand, data refer to 2008-09 and include firms with six or more employees. Innovative firms include technological and non-technological innovators.

For the Russian Federation, data refer to manufacturing firms with 15 or more employees.

For South Africa, data refer to 2005-07 and include the retail trade sector. Firm size is based on turnover.

For Turkey, data are based on NACE Rev. 1.1 and exclude some activities within NACE Rev. 2 Divisions J58 and J63.

\section{Firms collaborating on innovation activities by size, 2006-08}

For Australia, data refer to 2006-07 and innovative firms include technological and non-technological innovators. For Brazil, only the following activities are included in the services sector: ISIC Rev. 4 Divisions 58, 61, 62 and 72. For Chile, data refer to 2007-08 and firms with ongoing or abandoned innovative activities are not identified. Data are based on ISIC Rev. 3.1 and include a wider range of activities such as agriculture, forestry, fishing, construction, and some services.

For China, data refer to 2004-06 and exclude all services. In addition, large firms are defined as firms with over 2000 employees, over CNY 300 million turnover and over CNY 400 million capital. SMEs are the remaining firms with at least CNY 5 million turnover.

For Korea, data refer to 2005-07 and cover only firms with more than 10 employees in the manufacturing sector. For Mexico, data refer to 2008-09 and cover firms with 20 or more employees. The industries covered are based on ISIC Rev. 3.1 and include a wider range of activities such as agriculture, construction and some services.

For New Zealand, data refer to 2008-09 and include firms with six or more employees. Innovative firms include technological and non-technological innovators.

For the Russian Federation, data refer to manufacturing firms with 15 or more employees. 
For South Africa, data refer to 2005-07 and include the retail trade sector. Firm size is based on turnover.

For Switzerland, data only include R\&D collaboration.

For Turkey, data are based on NACE Rev. 1.1 and exclude some activities within NACE Rev. 2 Divisions J58 and J63.

\section{Firms collaborating on innovation activities with suppliers and clients, by firm size, 2006-08}

For Australia, data refer to 2006-07 and innovative firms include technological and non-technological innovators. For Brazil, only the following activities are included in the services sector ISIC Rev. 4 Divisions 58, 61, 62 and 72.

For Chile, data refer to 2007-08 and firms with ongoing or abandoned innovative activities are not identified. Data are based on ISIC Rev. 3.1 and include a wider range of activities such as agriculture, forestry, fishing, construction, and some services.

For Korea, data refer to 2005-07 and cover only firms with more than 10 employees in the manufacturing sector. For New Zealand, data refer to 2008-09 and include firms with 6 or more employees. Innovative firms include technological and non-technological innovators.

For the Russian Federation, data refer to manufacturing firms with 15 or more employees.

For South Africa, data refer to 2005-07 and include the retail trade sector. Firm size is based on turnover.

For Switzerland, data only include R\&D collaboration.

\section{National and international collaboration on innovation to firms, 2006-08}

For Australia, data refer to 2006-07 and innovative firms include technological and non-technological innovators. For Brazil, only the following activities are included in the services sector: ISIC Rev. 4 Divisions 58, 61, 62 and 72. For Chile, data refer to 2007-08 and firms with ongoing or abandoned innovative activities are not identified. Data are based on ISIC Rev. 3.1 and include a wider range of activities such as agriculture, forestry, fishing, construction, and some services.

For China, data refer to 2004-06 and exclude all services. In addition, large firms are defined as firms with over 2000 employees, over CNY 300 million turnover and over CNY 400 million capital. SMEs are the remaining firms with at least CNY 5 million turnover.

For Korea, data refer to 2005-07 and cover only firms with more than 10 employees in the manufacturing sector. International collaboration may be underestimated.

For New Zealand, data refer to 2008-09 and include firms with 6 or more employees. Innovative firms include technological and non-technological innovators.

For the Russian Federation, data refer to manufacturing firms with 15 or more employees.

For South Africa, data refer to 2005-07 and include the retail trade sector.

For Switzerland, data only include R\&D collaboration.

For Turkey, data are based on NACE Rev. 1.1 and exclude some activities within NACE Rev. 2 Divisions J58 and J63.

\section{Firms engaged in international collaboration by firm size, 2006-08}

For Australia, data refer to 2006-07 and innovative firms include technological and non-technological innovators. For Brazil, only the following activities are included in the services sector: ISIC Rev. 4 Divisions 58, 61, 62 and 72.

For Chile, data refer to 2007-08 and firms with ongoing or abandoned innovative activities are not identified. Data are based on ISIC Rev. 3.1 and include a wider range of activities such as agriculture, forestry, fishing, construction, and some services.

For China, data refer to 2004-06 and exclude all services. In addition, large firms are defined as firms with over 2000 employees, over CNY 300 million turnover and over CNY 400 million capital. SMEs are the remaining firms with at least CNY 5 million turnover.

For Korea, data refer to 2005-07 and cover only firms with more than 10 employees in the manufacturing sector. International collaboration may be underestimated.

For New Zealand, data refer to 2008-09 and include firms with 6 or more employees. Innovative firms include technological and non-technological innovators.

For the Russian Federation, data refer to manufacturing firms with 15 or more employees.

For South Africa, data refer to 2005-07 and include the retail trade sector. Firm size is based on turnover.

For Turkey, data are based on NACE Rev. 1.1 and exclude some activities within NACE Rev. 2 Divisions J58 and J63. 


\section{CONNECTING TO KNOWLEDGE}

\section{Notes}

Firms engaged in international collaboration by partner country, 2006-08

For the Russian Federation, data refer to manufacturing firms with 15 or more employees.

International technology flows (average of receipts and payments) as a percentage of GDP, 1999 and 2009

Technology flows include intra-area flows for EU21 and OECD total.

OECD total does not include Chile, Iceland and Turkey. Data partially estimated.

EU21 includes Austria, Belgium, the Czech Republic, Denmark, Estonia, Finland, France, Germany, Greece, Hungary, Ireland, Italy, Luxembourg, the Netherlands, Poland, Portugal, the Slovak Republic, Slovenia, Spain, Sweden and the United Kingdom. Data partially estimated.

\section{Foreign inventions owned by countries, 2006-08}

The data refer to counts of patent applications filed through the Patent Cooperation Treaty, at international phase, by applicant's country of residence and priority date. Foreign inventions owned by countries are the share of patents owned by a resident of a country, for which no inventors reside in the country, as a share of total patents owned by that country. Only economies that applied for more than 250 patents over the period are included in the figure. 
Auriol, L. (2010), “Careers of Doctorate Holders: Employment and Mobility Patterns”, OECD Science, Technology and Industry Working Papers, No. 2010/4. Doi: http://dx.doi.org/10.1787/5kmh8phxuvf5-en.

Auriol, L., B. Felix and M. Schaaper (2010), "Mapping Careers and Mobility of Doctorate Holders: Draft Guidelines, Model Questionnaire and Indicators - Second Edition", OECD Science, Technology and Industry Working Papers, No. 2010/1. Doi: http://dx.doi.org/10.1787/5kmlfbn2ddtd-en.

OECD (2002), Frascati Manual 2002: Proposed Standard Practice for Surveys on Research and Experimental Development, The Measurement of Scientific and Technological Activities, OECD Publishing, Paris. Doi: http://dx.doi.org/10.1787/ 9789264199040-en.

OECD (2005), Measuring Globalisation: OECD Handbook on Economic Globalisation Indicators 2005, OECD Publishing, Paris. Doi: http://dx.doi.org/10.1787/9789264108103-en.

OECD (2009), OECD Patent Statistics Manual, OECD Publishing, Paris. Doi: http://dx.doi.org/10.1787/9789264056442-en.

OECD (2009), OECD Science, Technology and Industry Scoreboard 2009, OECD Publishing, Paris. Doi: http://dx.doi.org/10.1787/ sti_scoreboard-2009-en.

OECD (2010), Measuring Innovation: A New Perspective, OECD Publishing, Paris. Doi: http://dx.doi.org/10.1787/9789264059474-en.

OECD (2011), Education at a Glance 2011: OECD Indicators, OECD Publishing, Paris. Doi: http://dx.doi.org/10.1787/eag-2011-en. OECD and SCImago Research Group (CSIC) (forthcoming), Report on Scientific Production.

OECD/Statistical Office of the European Communities, Luxembourg (2005), Oslo Manual: Guidelines for Collecting and Interpreting Innovation Data, The Measurement of Scientific and Technological Activities, 3rd edition, OECD Publishing, Paris. Doi: $h t t p: / / d x . d o i . o r g / 10.1787 / 9789264013100-e n$.

Schmoch, U. (2008), “Concept of a Technology Classification for Country Comparisons”, Final Report to the World Intellectual Property Organisation (WIPO), revised November 2010, WIPO, www.wipo.int/export/sites/www/ipstats/en/ statistics/patents/pdf/wipo_ipc_technology.pdf. 


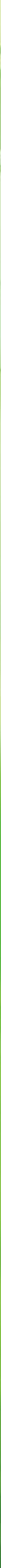





\section{TARGETING NEW GROWTH AREAS}

\section{Government funding of R\&D}

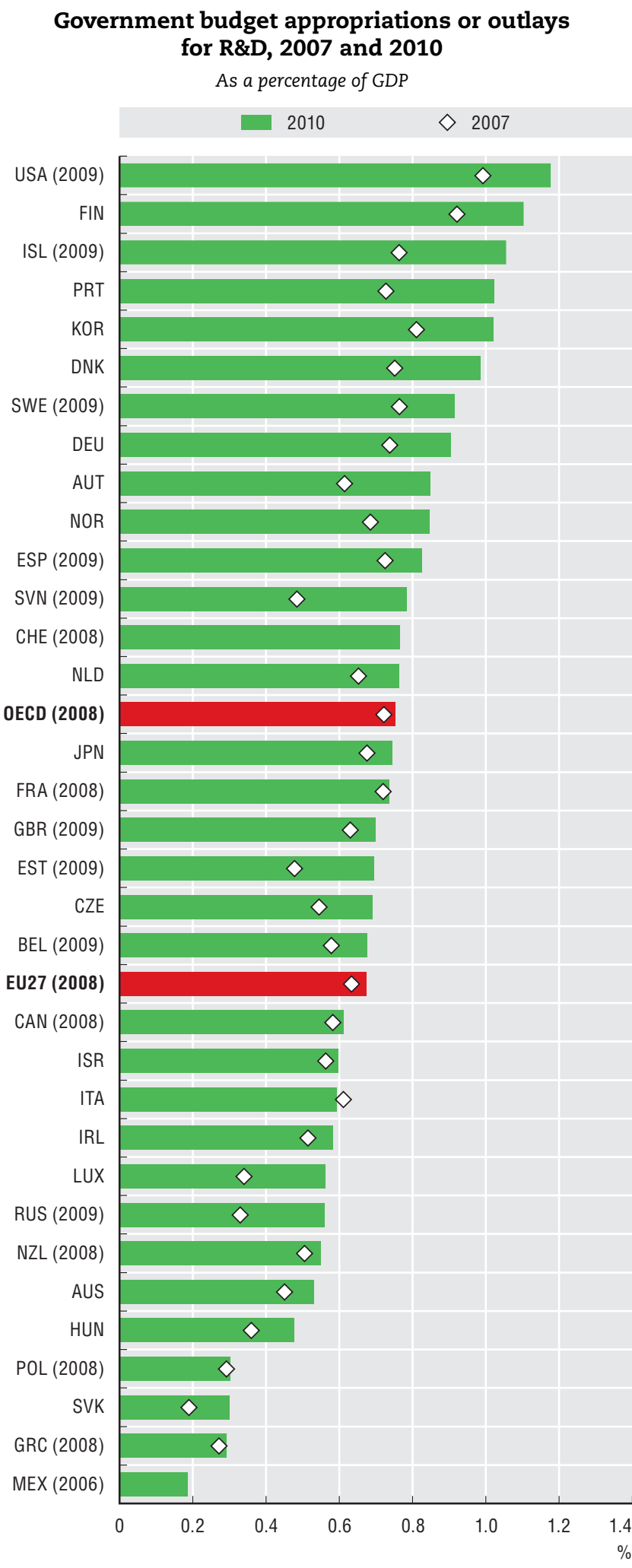

Source: OECD, Main Science and Technology Indicators Database, June 2011. See chapter notes.

StatLink AाISL http://dx.doi.org/10.1787/888932486659
Public policy can play an important role in orienting innovation efforts so that they help address domestic and global challenges. Government R\&D budgets (GBAORD) provide an indication of the relative importance of various socio-economic objectives, such as defence, health and the environment, in public R\&D spending. In 2009, governments across the OECD invested the equivalent of nearly $0.75 \%$ of GDP in direct funding of R\&D activities. $R \& D$ budgets as a percentage of GDP are largest in the the United States, followed by Finland, Iceland, Portugal and Korea, ranging from nearly $0.2 \%$ to $1.2 \%$. In most countries, this indicator is up relative to pre-recession levels, reflecting both the use of stimulus packages to support R\&D and the drop in GDP growth rates.

Countries vary widely in terms of the importance of funding by socio-economic objective and by performance sector. These differences reflect national priorities and differences in countries' national innovation systems. Support for the advancement of knowledge, through non-oriented research, is particularly significant in Switzerland, New Zealand, Austria and Sweden, where more than $60 \%$ of total funding is directed towards research financed through general university funds (GUF) and other non-oriented research. For the OECD as a whole, the share is only $27 \%$, although this is partly because GUF is funded at the state level in countries such as the United States and not included in GBAORD.

Analysis of the allocation of GBAORD across national R\&Dperforming sectors for countries that produce this information reveals that universities are the main beneficiary of R\&D support. The higher education sector accounts for nearly $90 \%$ of GBAORD in Switzerland. Among the 15 reporting countries, only in Poland, Germany, the Czech Republic and Korea is a higher share of GBAORD performed in the government sector.

\section{Definitions}

GBAORD (government budget appropriations of outlays for R\&D) measures the funds committed by governments (principally federal/central) for $R \& D$ to be carried out domestically or abroad (including by international organisations). These funds are reported by socio-economic objective, a classification system intended to capture the primary objective of the research being funded, as described in the OECD Frascati Manual. Economic development includes support for agriculture, industry and energy research. The "Other" category includes support for research on "Education and society" and "Exploration and exploitation of space". 


\section{Government budget appropriations or outlays for R\&D, by selected socio-economic objectives, 2010}

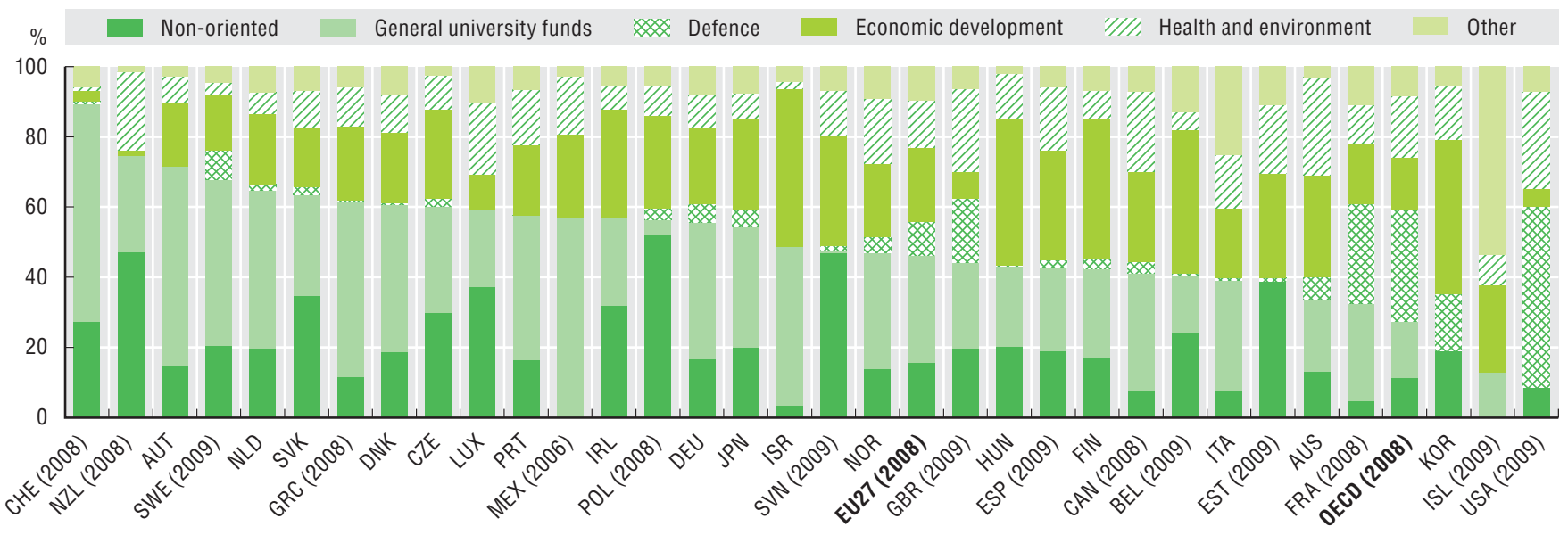

Source: OECD, Research and Development Database, May 2011. See chapter notes.

Government budget appropriations or outlays for R\&D, by national sector of performance, 2008

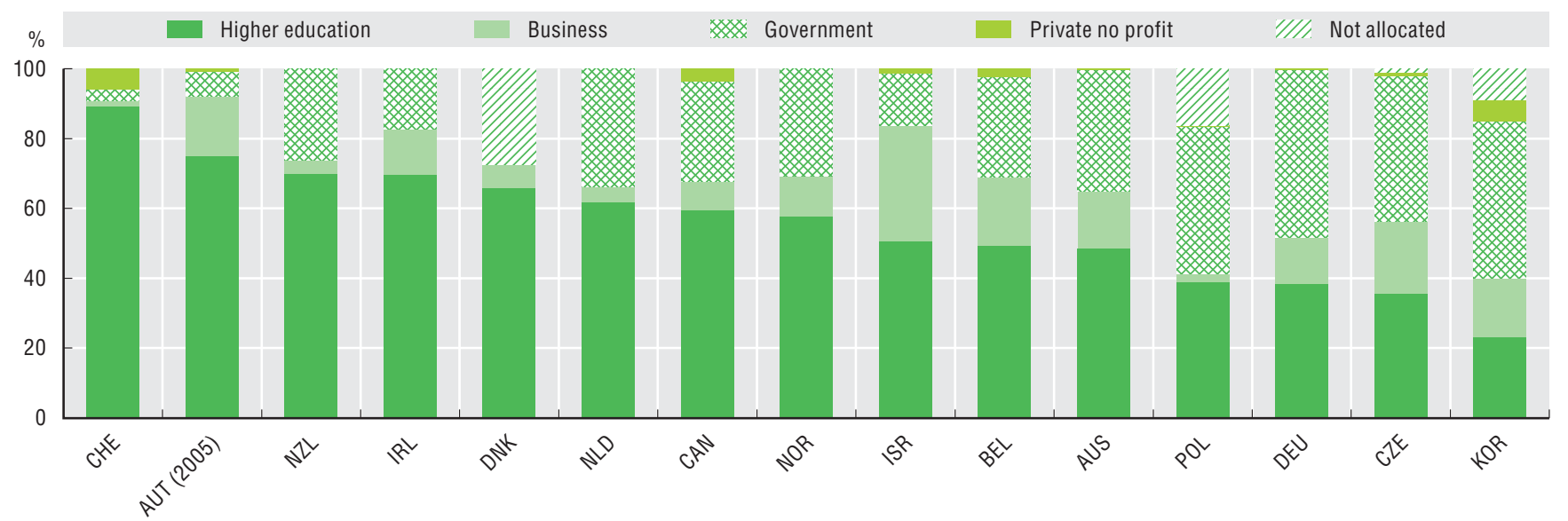

Note: This is an experimental indicator. International comparability is currently limited.

Source: OECD, based on preliminary data from the Microdata project on public R\&D funding, 2009-10. See chapter notes.

StatLink काIsL http://dx.doi.org/10.1787/888932486697

\section{Measurability}

GBAORD data are usually based on budgetary sources and reflect assessments by funding agencies. They are generally considered less internationally comparable than the perfomer-reported data used in other tables and graphs but have the advantage of being more timely and reflecting government priorities, as set out in the breakdown of funding by socio-economic objectives. Some countries do not include in their estimates the funding of general support of universities (e.g. the United States) or R\&D funded as part of military procurement (Japan, Israel). It is currently not possible for all countries to report, on the basis of budget data, which sectors are responsible for performing the R\&D funded by government. Improving the mapping of public funding objectives to perfomers is one of the objectives of the NESTI project on Modes of Public Funding of R\&D. 


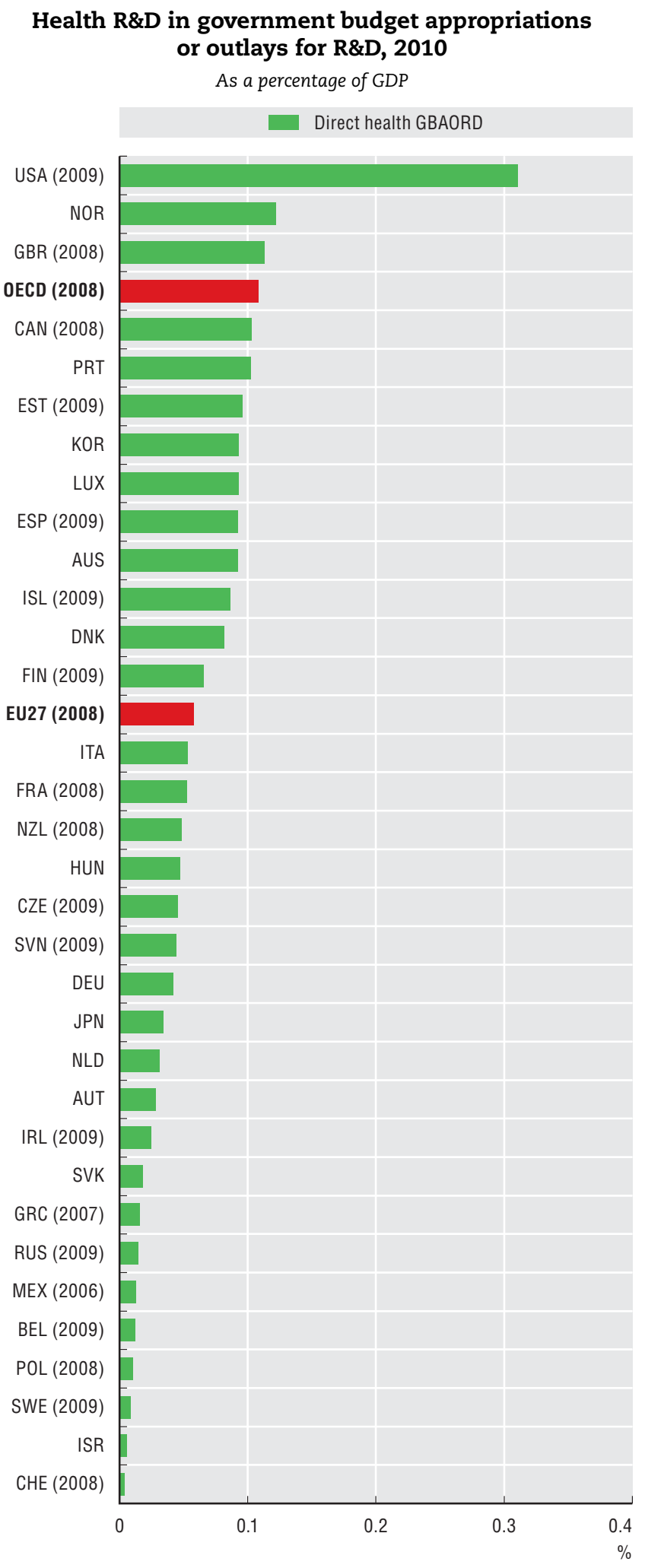

Source: OECD, Research and Development Database, May 2011.

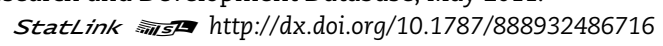

OECD countries are faced with the health-care challenges of ageing populations and others, such as increasingly drug-resistant diseases and the risk of global pandemics. Innovation is a critical means of improving the capacity of health systems to address these problems while containing escalating costs. The public sector plays a significant role alongside business and non-profit organisations, by supporting R\&D directly but also through the procurement of new treatments resulting from R\&D. Government budget appropriations or outlays for R\&D (GBAORD) indicate that direct government support of health-related R\&D in OECD countries was about $0.1 \%$ of their combined GDP in 2008. The United States is by far the largest funder in both absolute and relative terms, at just over $0.3 \%$ of GDP spent on health R\&D.

However, when data from additional information are used to adjust for institutional differences in the funding of health $R \& D$, the United States ceases to be such a strong outlier. For example, Germany's health R\&D goes from $0.05 \%$ to nearly $0.15 \%$ while for Austria it increases from $0.03 \%$ to $0.25 \%$ as a percentage of GDP.

Filings for patents in medical technologies increased at an average annual rate of $5 \%$ in the 2000 s, at the same pace as total patent applications filed under the Patent Cooperation Treaty (PCT), while pharmaceutical patents remained constant. In relative terms, patents in pharmaceuticals represented $7.5 \%$ of all patents in 2007-09, a severe drop from more than $11 \%$ in the late 1990 s, whereas medical technology patents remained an average $8 \%$ of total patents. In the late 2000s, the United States led in health patenting, with more than $40 \%$ of health-related PCT patent applications. The BRIICS countries (Brazil, the Russian Federation, India, Indonesia, China and South Africa) made an increasing number of PCT filings in pharmaceuticals to reach more than $7 \%$ of all such patents.

\section{Definitions}

The International Patent Classification (IPC) was used to identify health-related inventions among patent applications filed under the Patent Cooperation Treaty (PCT) according to the technology classification presented in Schmoch (2008). Patents in medical technologies are defined by classes A61 [B, C, D, F, G, H, J, L, M, $\mathrm{N}]$ and H05G. Patents in pharmaceuticals cover class A61K, excluding Codes A61K8/* (cosmetics). Although medical technology is generally associated with high technology, it covers less sophisticated products and technologies such as operating tables, massage devices, bandages, etc. Pharmaceuticals are considered an area of application rather than a specific technology, even though the key sub-class $\mathrm{A} 61 \mathrm{~K}$ is primarily organised by technology (e.g. medicinal preparations containing inorganic active ingredients). For further details on the IPC, see the World Intellectual Property Organization (WIPO) website at www.wipo.int/ipcpub/. 
Public funding of health-related R\&D, 2010

As a percentage of GDP

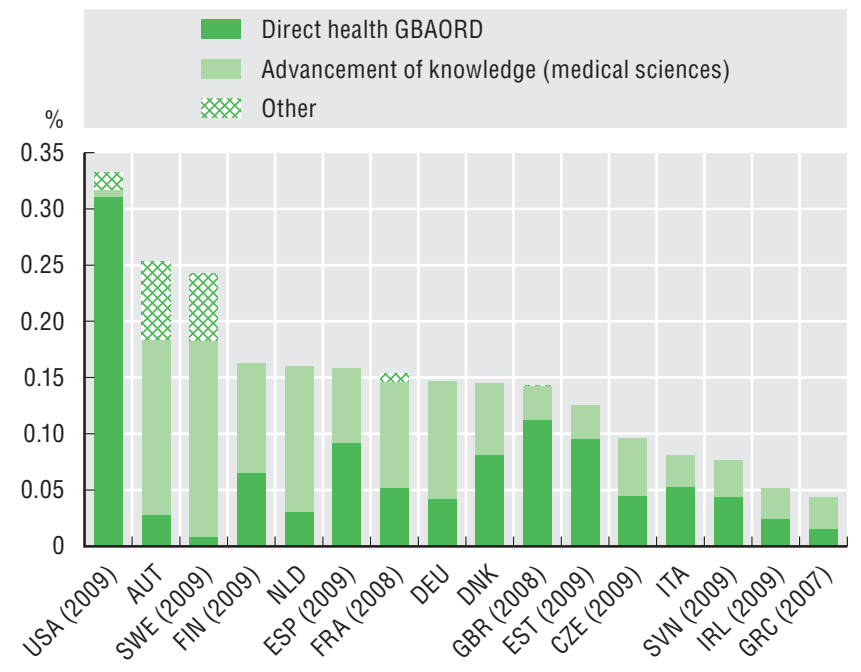

Source: OECD calculations based on the Research and Development Database and national sources, May 2011. See chapter notes.

StatLink ज्ञाS http://dx.doi.org/10.1787/888932486735
Health-related patents, 1997-99 and 2007-09

As a percentage of total PCT patent applications

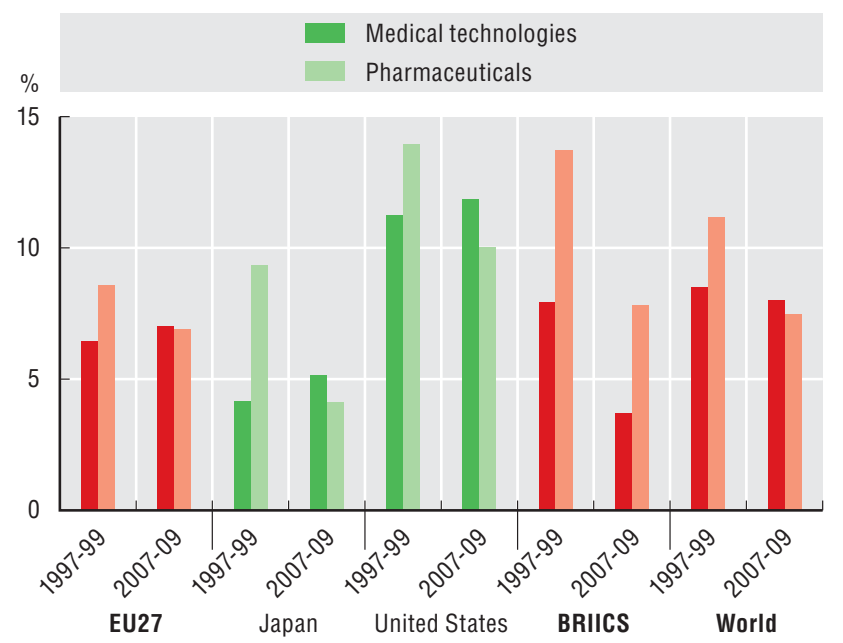

Source: OECD, Patent Database, May 2011. See chapter notes. StatLink (illst $h t t p: / / d x . d o i . o r g / 10.1787 / 888932486754$

\section{Countries' share of pharmaceutical patents filed under the PCT, 2007-09}

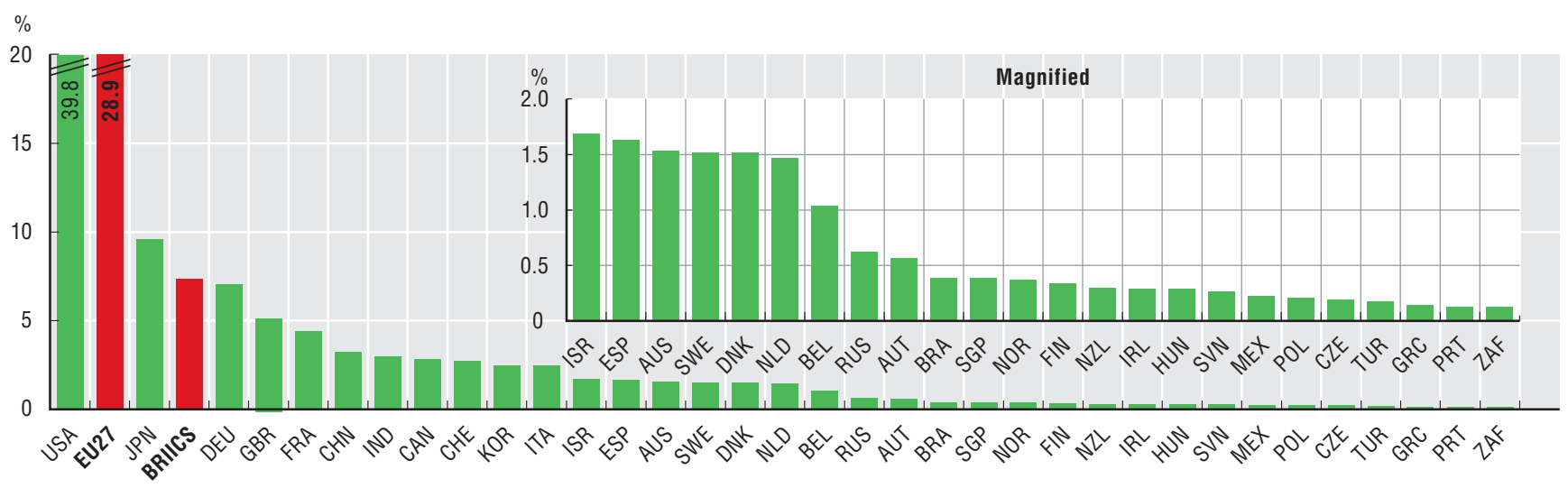

Source: OECD, Patent Database, May 2011. See chapter notes.

StatLink AाISL $h t t p: / / d x . d o i . o r g / 10.1787 / 888932486773$

\section{Measurability}

Public funding of health R\&D is difficult to measure owing to institutional complexity and diversity; it may be publicly or privately funded and be carried out in firms, universities, hospitals and private not-for-profit institutions. Government budget appropriations or outlays for R\&D (GBAORD) can be broken down by socio-economic objective, such as the protection and improvement of public health, as defined by the OECD Frascati Manual. The GBAORD health category is used here as a proxy for total central government funding of health-related R\&D. However, this category only covers programmes for which health is the primary objective. Furthermore, the classification of funding depends on how governments present their R\&D priorities as well as on the formal mandate of the institutions concerned. Arrangements for funding R\&D in hospitals also vary. To address some of these limitations and to provide a more complete picture of health-related R\&D, funding of medical sciences via non-oriented research and general university funds is included when available as are other relevant funds, notably general support for R\&D in hospitals. 


\section{Government R\&D budgets for energy and the environment, 2010}

As a percentage of the total government $R \& D$ budget

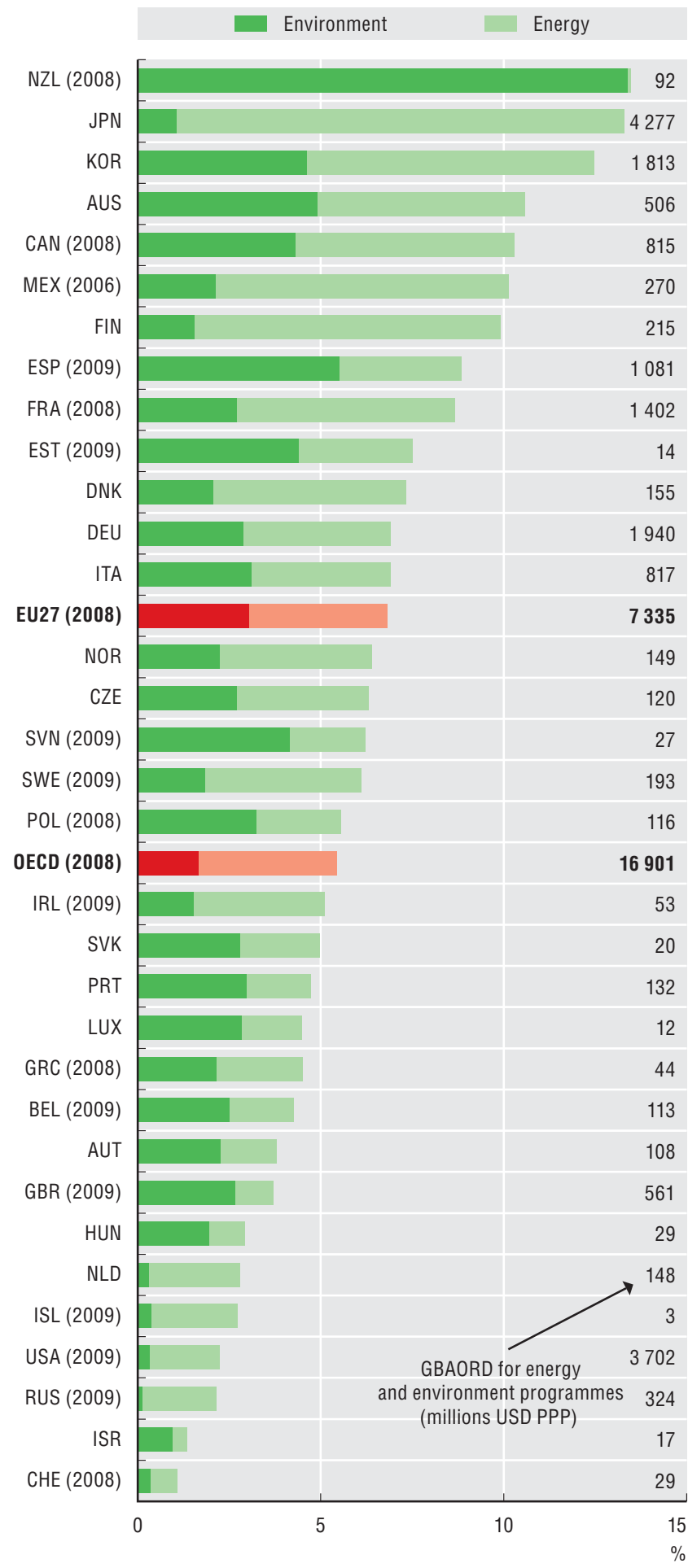

Source: OECD, Research and Development Database, May 2011. StatLink तारा http://dx.doi.org/10.1787/888932486792
Finding cleaner, affordable and reliable energy sources and promoting sustainable growth have become major preoccupations of countries around the world. To this end, governments support research, foster innovation and the use of new technologies in production, and encourage the creation of markets for and consumers' uptake of "green" technologies.

Data on government budget appropriations or outlays for R\&D (GBAORD) can be used to measure publicly funded research priorities to achieve policy objectives such as energy and environment. New Zealand for example allocates nearly $14 \%$ of its direct public funding of R\&D to these two fields, most of which is environment-related. Japan follows very closely but mainly funds energy R\&D. Across the OECD, countries emphasise energy (3.7\% of total GBAORD) over environment (1.7\%).

At the other end of the spectrum, the United States, the Russian Federation, Switzerland and Israel provide the least relative support with $2 \%$ or less of their budgets to these areas. However, in absolute terms, the United States is the second largest funder at USD 3.7 billion, just behind Japan with USD 4.2 billion.

From a relatively small base, innovations in technologies related to climate change mitigation and solar energy are an increasing share of patent portfolios. In 2007-09, the share of Patent Cooperation Treaty (PCT) patents in solar energy was three times their share in 1997-99. However, patent applications in energy storage or material recycling technologies are increasing at a slower pace than total patents. In terms of geographic distribution, inventive activity in energy generation from renewable and nonfossil sources remains centred in European countries: in the late 2000s, the EU27 represented 37\% of all PCT filings in this field, followed by the United States and Japan. China's share in such patents now ranks eighth worldwide.

\section{Definitions}

Government budget appropriations or outlays for $R \& D$ (GBAORD) measures the funds committed by the federal/central government for R\&D. It can be broken down by various socio-economic objectives, defined on the basis of the primary purpose of the funder, including control and care for the environment as well as energy. Environmental technologies cover seven thematic areas including energy generation; climate change mitigation; emissions abatement and fuel efficiency; energy efficiency in buildings and lighting (see www.oecd.org/dataoecd/4/14/47917636.pdf). Clean energy technologies are a subset of environmental technologies, consisting notably of renewable energy generation, biofuels, carbon capture and storage. Patents for energy generation from renewable and non-fossil sources cover solar, wind, geothermal energy, energy from sea, hydro-energy, biofuels and fuels from waste. 
Patents in selected environmental technologies, 1997-99 and 2007-09

As a percentage of total PCT patent applications

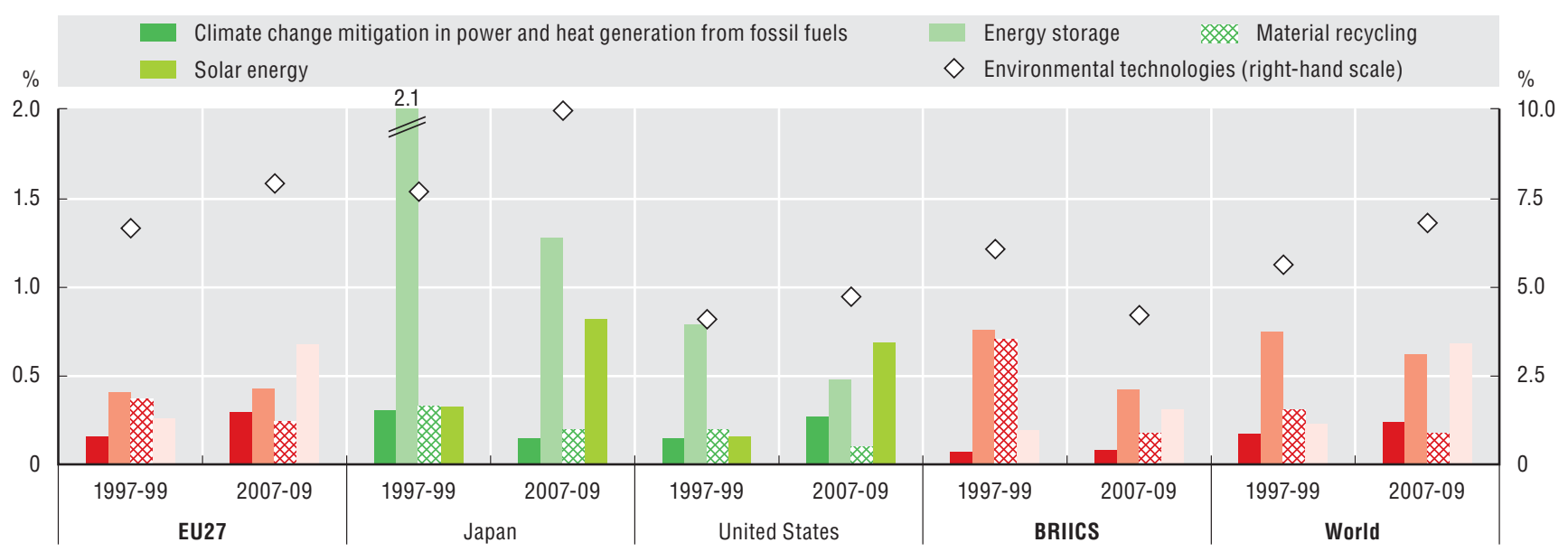

Source: OECD, Patent Database, May 2011. See chapter notes.

\section{Countries' share of patents for energy generation from renewable and non-fossil sources, 2007-09}

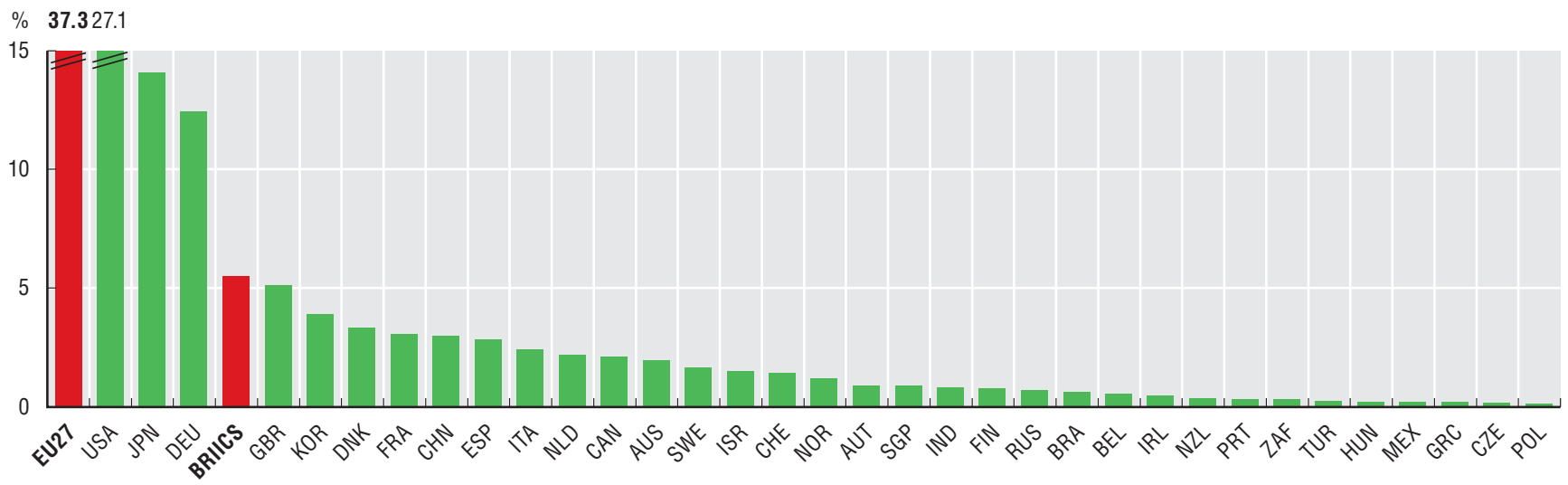

Source: OECD, Patent Database, May 2011. See chapter notes.

StatLink लाIsय http://dx.doi.org/10.1787/888932486830

\section{Measurability}

R\&D budgets for control and care for the environment include research on the control of pollution and on developing monitoring facilities to measure, eliminate and prevent pollution. Energy R\&D budgets include research on the production, storage, transport, distribution and rational use of all forms of energy, but exclude research on prospecting and on vehicle and engine propulsion, an important area for energy efficiency. In addition to R\&D (which includes basic research, applied research and experimental development), the International Energy Agency collects and publishes data on government energy R\&D which includes funding for demonstration projects. These expenditures are typically referred to as RD\&D.

The European Patent Office (EPO), with the help of experts, including from the Intergovernmental Panel on Climate Change (IPCC), introduced a new classification scheme for technical attributes of technologies that can be broadly called clean energy technologies. The OECD Environment Directorate has developed search strategies based on patent classification systems to separate environmental technologies into seven categories, including clean energy technologies. 


\section{TARGETING NEW GROWTH AREAS}

\section{Motivations of firms introducing environmental innovations, 2006-08}

Firms citing factors as motivations, percentage of innovative firms
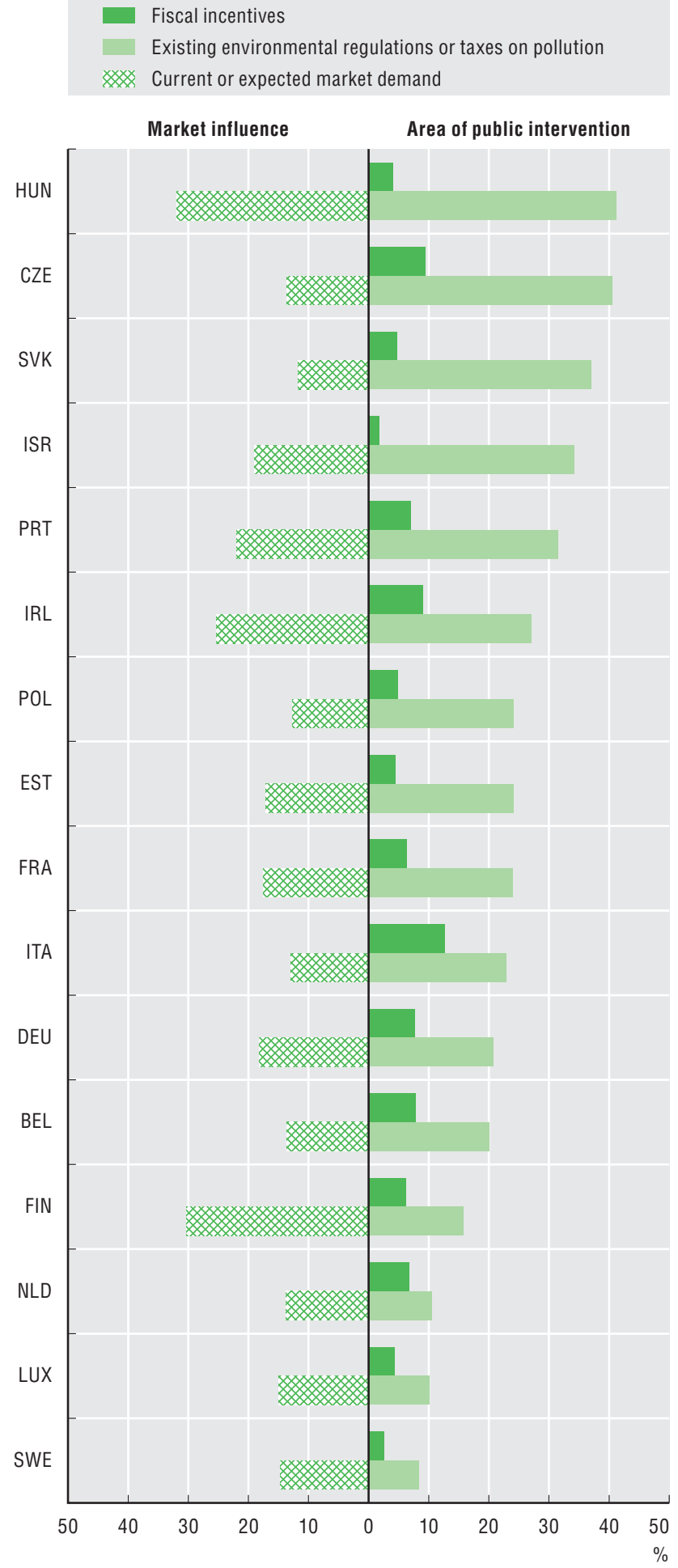

Source: OECD, based on Eurostat (CIS-2008) and national data sources, June 2011.

StatLink ताsस $h$ ttp://dx.doi.org/10.1787/888932486849
Innovation can be a source of environmental benefits for the firm that introduces the innovation (as part of its production process) as well as for customers that purchase the innovation (as part of its end use). Firms introduce innovations in response to factors such as regulations, the availability of public support or (current or future) market demand. In most countries regulations (existing or future) are the main driver, followed by market demand from customers. In Sweden, Luxembourg, the Netherlands and Finland, market demand is identified as the main driver of environmental innovations.

The effects of environmental innovation take many forms: reducing material or energy use per unit of output, reducing the enterprise's $\mathrm{CO}_{2}$ "footprint", reducing waste or pollution, etc. For both producers and end users, reduced energy consumption appears to be an important effect of environmental innovations: more than $40 \%$ of all innovating firms report this in Switzerland, Germany and Portugal.

\section{Definitions}

In the CIS-2008, an environmental innovation is defined as an innovation that leads to more environmental benefits than alternatives. It can be a product (good or service), process, organisational or marketing innovation. The environmental benefits can be the primary objective or the result of other innovation objectives. The environmental benefits of an innovation can occur during the production of a good or service (producer benefits), or during the after sales use of a good or service by the end user (end-user benefits).

For these two indicators, innovative firms refers to firms with any of the four types of innovation (product, process, marketing and organisational). 
Benefits of environmental innovations, 2006-08

As a percentage of innovative firms

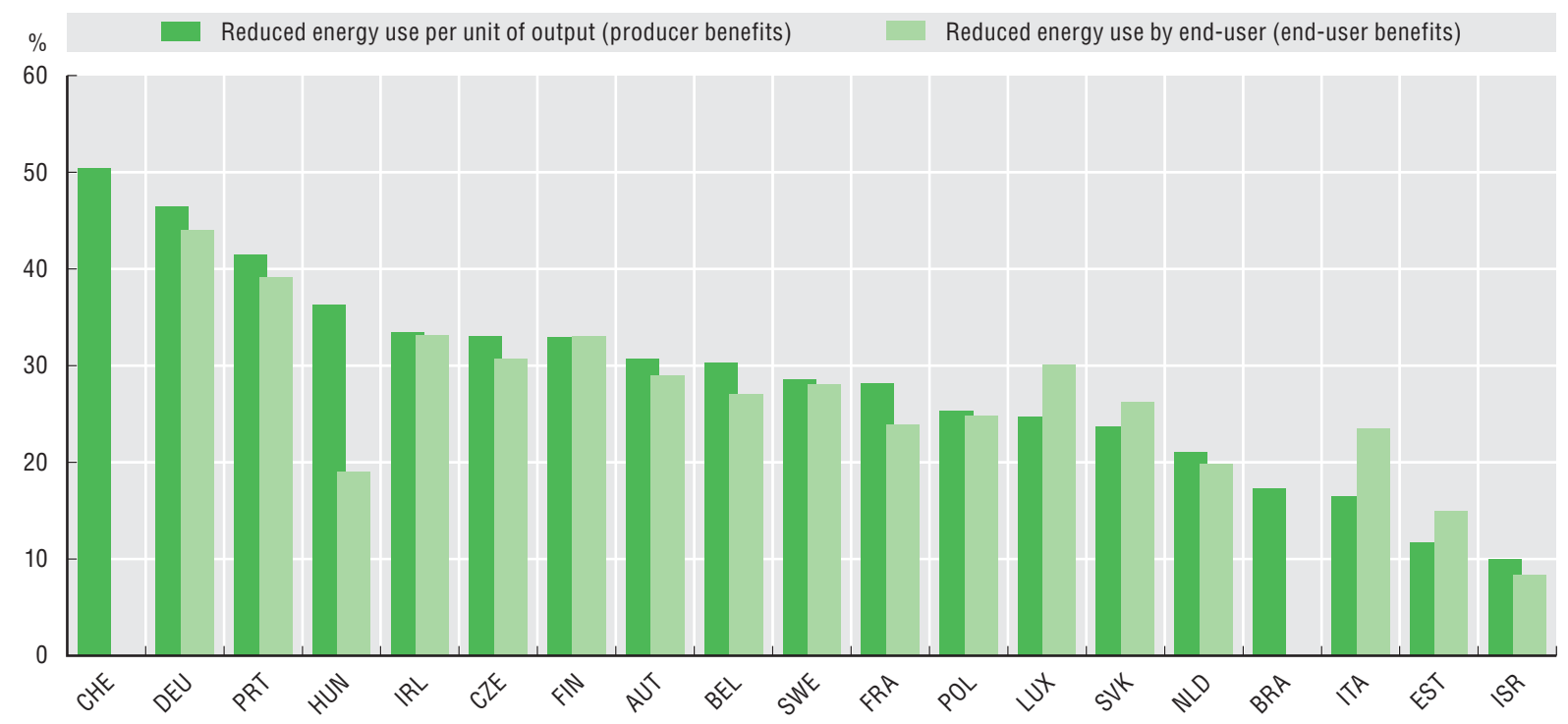

Source: OECD, based on Eurostat (CIS-2008) and national data sources, June 2011. See chapter notes.

StatLink AाISt http://dx.doi.org/10.1787/888932486868

\section{Measurability}

The CIS-2008 survey was the first to introduce an ad hoc (voluntary) module on environmental innovation. Given that some of the concepts were new to respondents, some results may be less robust than those of more established indicators. In principle, all firms were asked questions on innovations with environmental benefits (not just innovators) although this may not have been the case in some countries. Some respondents may have found the distinction between (intended) objectives and (observed) effects, as well as certain concepts, confusing. For example, in some countries data on energy-related benefits for end users are almost identical to those for producers. 
Average and median advertised download speeds, September 2010

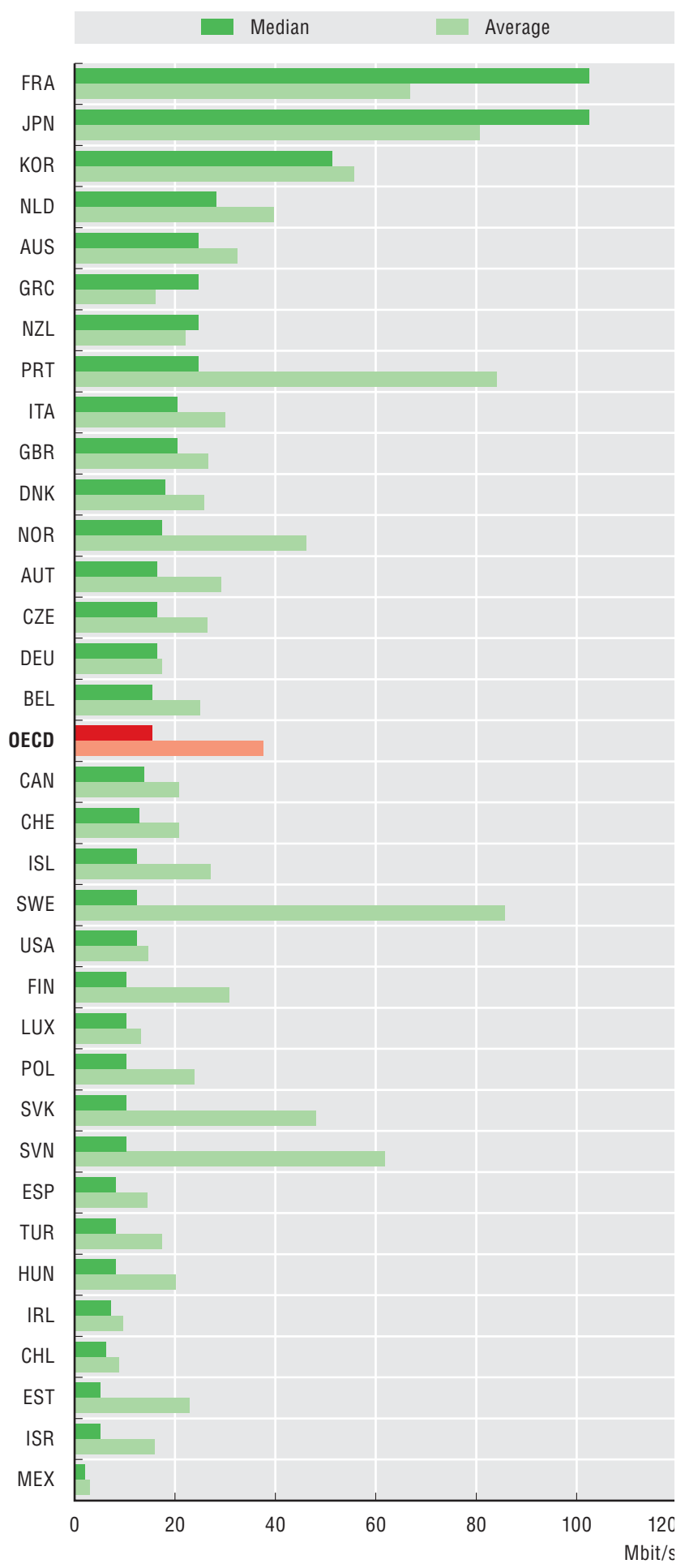

Source: OECD (2011), OECD Communications Outlook 2011, OECD Publishing, Paris.

StatLink ताsस $h t t p: / / d x . d o i . o r g / 10.1787 / 888932486887$
Broadband prices have declined continuously over the past decade across the OECD area, while connection speeds have increased. Most OECD countries have at least one operator actively offering fibre-based, high-speed broadband connections, although these may be limited to certain geographical areas. Fibre-to-the-home (FTTH) and fibre-tothe-building (FTTB) also enable symmetrical upload and download speeds, which permit new functionalities and better user experience for a range of online activities, such as sharing pictures, video conferencing or uploading content onto social-networking websites.

In September 2010, France and Japan had the fastest median advertised download speed of up to $100 \mathrm{Mbit} / \mathrm{s}$ (megabit per second). In all OECD countries, the median advertised download speed was $15.4 \mathrm{Mbit} / \mathrm{s}$ in September 2010, compared to the average advertised download speed of $37.5 \mathrm{Mbit} / \mathrm{s}$.

In some countries, there is a considerable difference in broadband entry prices depending on whether or not line charges are included. For example, Spain's broadband entry price without the line charge was USD 28.29 PPP but USD 44.48 with the line charge. Spain's broadband prices are the most expensive in the OECD area if line charges are included but the seventh most expensive if they are not. Italy offers a similar example (USD 21.72 versus USD 30.68). Chile, Korea, New Zealand and Spain had the most expensive broadband entry prices, while Estonia, Japan, the Slovak Republic and Turkey had the most affordable. Some countries boasted a wide range of broadband prices. Prices in Slovenia range from USD 21 a month to over USD 1000 a month for a 1 gigabit per second offer. In Greece instead, prices only varied between USD 21 and USD 35 per month.

\section{Definition}

For the purpose of this data collection, speeds are those advertised by three operators and likely do not correspond to typical throughput. When not explicitly stated, maximum speeds have been imputed based on the technological limitations of the installed technologies.

Prices are divided between those that include fixed line (PSTN) rental changes and those that do not, designated as "no line charge". This also applies to cable television service offers that cannot be disaggregated, including cable and fibre-based services. Some offers include phone and television service (triple play) which cannot be disaggregated. Prices include modem rental charges (when priced separately). The pricing information is presented in purchasing power parity (PPP) terms. 
Range of broadband prices for a monthly subscription - no line charge, September 2010

USD PPP

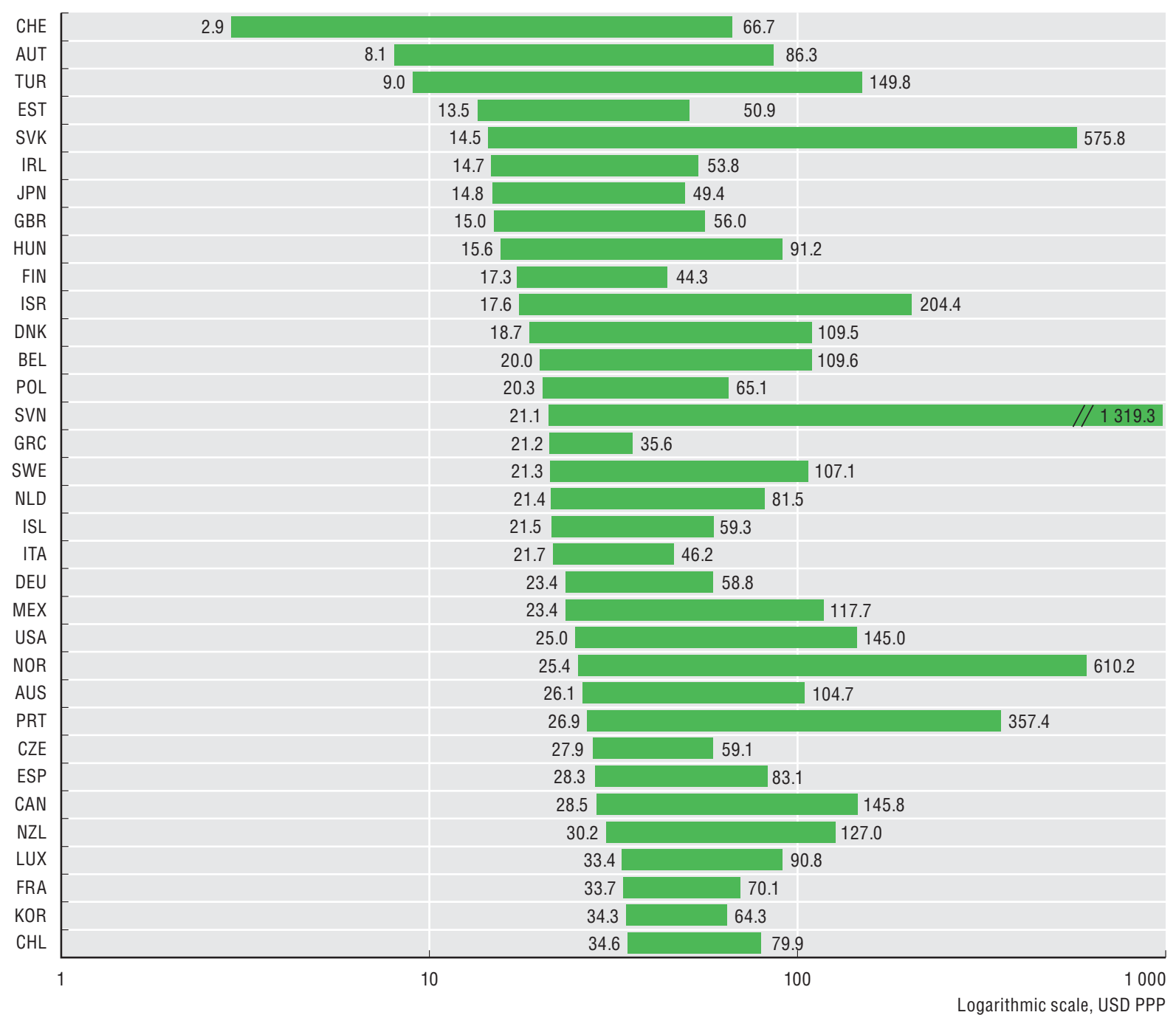

Source: OECD (2011), OECD Communications Outlook 2011, OECD Publishing, Paris.

StatLink ताIs $h t t p: / / d x . d o i . o r g / 10.1787 / 888932486906$

\section{Measurability}

To gather broadband price and speed data, a survey of 686 stand-alone broadband offers from 102 operators across the 34 OECD countries was undertaken for the OECD Communications Outlook 2011. A set of three operators per country was chosen (with an average of seven offers per operator): the incumbent telecommunications operator, the largest cable provider (if cable exists) and one alternative provider, if available, over DSL, cable or fibre. The offers must be advertised clearly on the operator's website; all DSL, cable and fibre offers are recorded but not used in calculations if speeds are lower than $256 \mathrm{kbit} / \mathrm{s}$; offers are for month to month service and should be available in the country's largest city or in the largest regional city for firms with only regional coverage. 
OECD terrestrial mobile wireless broadband subscriptions per 100 inhabitants, by technology, June 2010

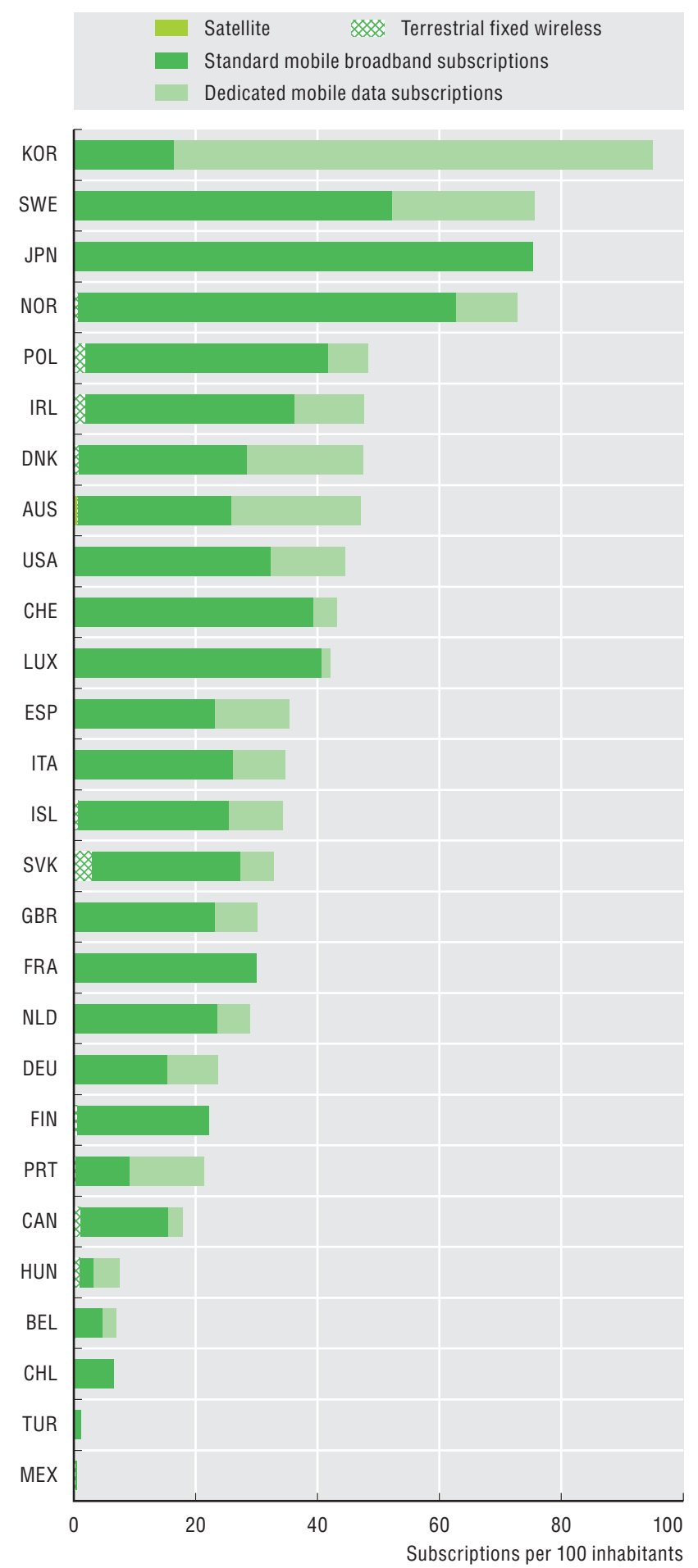

Source: OECD, OECD Broadband Portal, June 2011.

StatLink Aाज्या http://dx.doi.org/10.1787/888932486925
Fixed broadband subscriptions in the OECD area reached 292 million in June 2010. Broadband has expanded every year since cable and DSL services were first launched in the mid-1990s. Subscriptions grew at an annual compound growth rate of $39.7 \%$ between 2000 and 2009. The largest growth over the last two years was in Mexico (46\%), followed by Greece (33\%), the Slovak Republic $(23 \%)$ and Turkey (21\%).

The growing popularity of smartphones and tablet computers is driving growth in mobile broadband services. Wireless broadband subscriptions in OECD countries had exceeded 450 million by June 2010. Korea is in the lead, with 91.8 per 100 inhabitants, followed by Sweden (76\%), Japan $(75 \%)$ and Norway (73\%). The OECD average is $37 \%$.

In OECD countries, the average penetration of fixed broadband was 23.1 subscriptions per 100 inhabitants in 2009, up from 19.7 subscriptions in 2007. Denmark had the highest broadband penetration rate with $37.4 \%$, followed by the Netherlands (37.1\%) and Switzerland (35.8\%). Less expensive and faster broadband Internet access has superseded dial-up connections. In the United States, dial-up's share of the overall household Internet market declined from 11\% to $5 \%$ between 2007 and 2009. Such households are likely to be located in rural areas and have lower income levels.

In June 2010 in the OECD area, DSL continued to lead broadband subscriptions (excluding wireless broadband) with $58 \%$, followed by cable $(29 \%)$, fibre $(12 \%)$ and others $(1 \%)$. Greece, Italy and Turkey have a very large share of DSL (more than 95\%), while cable is the main source of broadband access in Canada (56\%) and the United States (54\%). Leading countries in fibre subscriptions are Japan (where $58 \%$ of fixed broadband subscriptions are fibre-based), Korea (55\%), the Slovak Republic (29\%) and Sweden (26\%).

\section{Definition}

The broadband indicator is made up of two categories: fixed (wired) and wireless broadband. These are presented separately. Fixed broadband includes the following technologies: DSL, cable, FTTH and other fixed broadband connections. Wireless broadband includes satellite, terrestrial fixed wireless and terrestrial mobile wireless. This last is divided into two sub-categories: standard mobile subscriptions (with active use) and dedicated data subscriptions. All components include only connections with advertised data speeds of $256 \mathrm{kbit} / \mathrm{s}$ or greater. 


\section{OECD fixed (wired) broadband subscriptions per 100 inhabitants, by technology, June 2010}

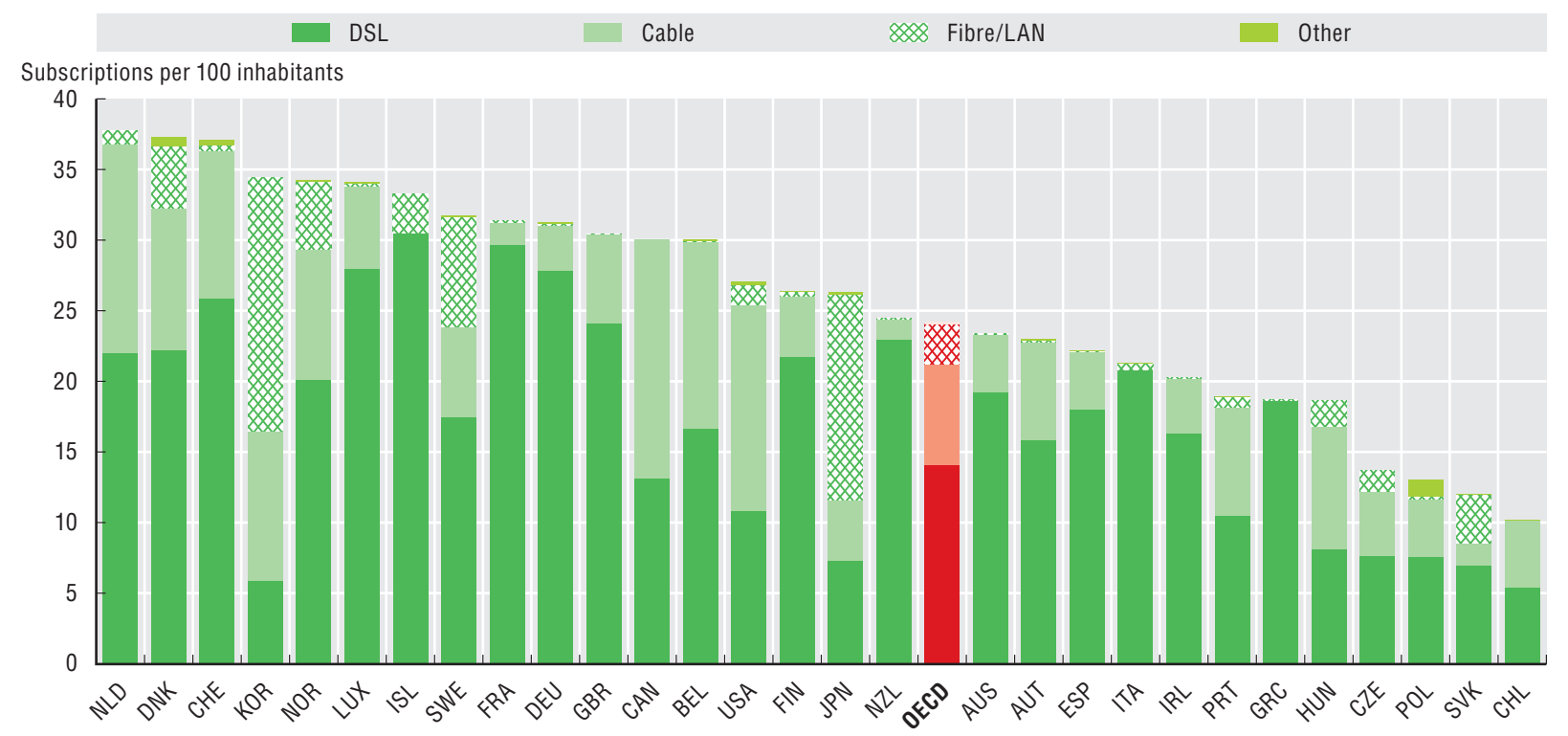

Source: OECD, Broadband statistics, June 2011.

StatLink AाISL http://dx.doi.org/10.1787/888932486944

\section{Measurability}

Wireless connections using satellite or terrestrial fixed wireless have historically been based on a monthly data subscription model which corresponds to the fixed broadband methodology currently used by the OECD. These two technologies are now included in the wireless broadband definition along with terrestrial mobile wireless. It is the terrestrial mobile segment which raises particular challenges for statistics as many mobile phones are "broadband capable" but never use Internet data services.

A standard mobile subscription is counted as an "active" broadband subscription under two conditions:

1. The subscription must allow for access to the Internet via HTTP. Subscriptions which only offer "walled garden" or email-only services do not count. A subscription is not counted if the terrestrial mobile operator only provides access to a limited number of websites, content and/or applications such as games, ring tones, music and pictures which are customised for its network and devices.

2. "Active use" on a standard mobile subscription requires an Internet data connection to content or services using the Internet Protocol (IP) during the previous three months. 


\section{TARGETING NEW GROWTH AREAS}

\section{Access to broadband}

\section{Business and household access to broadband, 2010}

Percentage of businesses with ten or more employees and percentage of all households

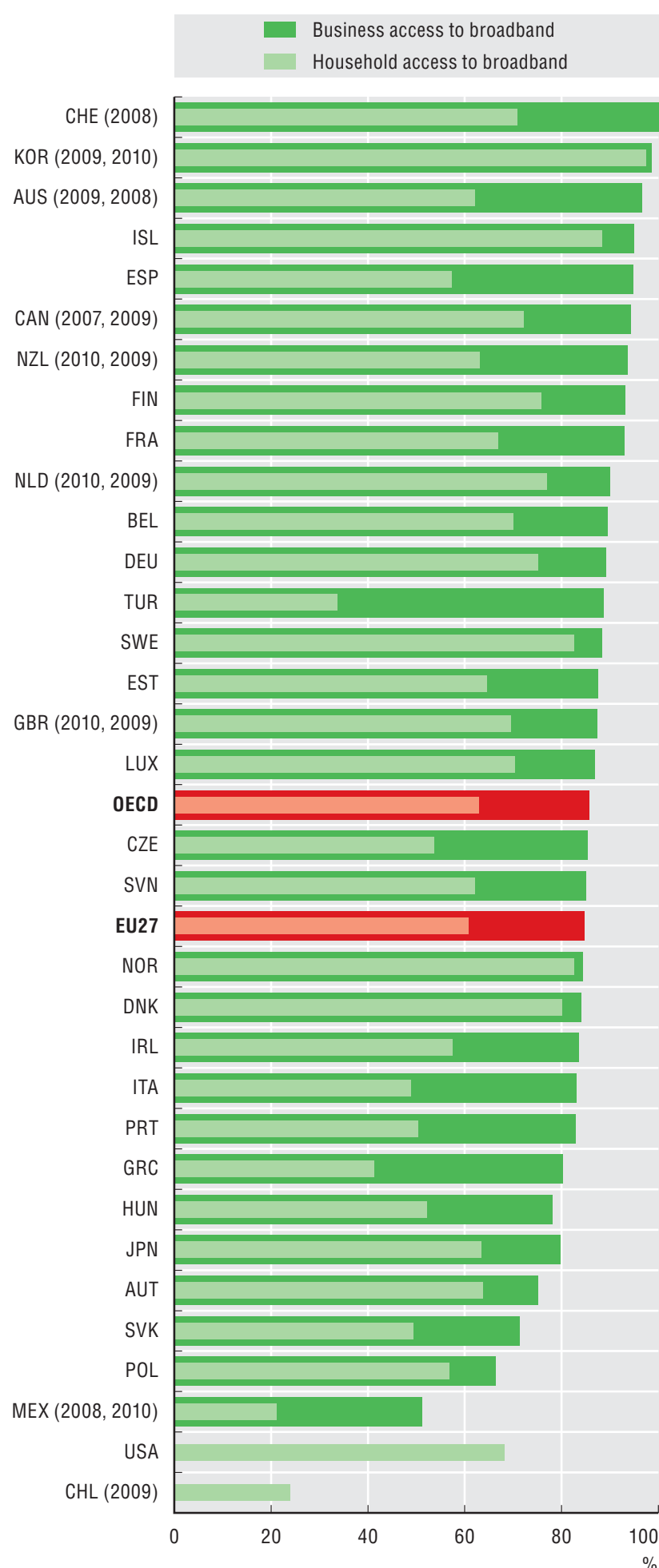

Source: OECD, ICT Database, May 2011; and Eurostat, Community Survey on ICT Usage in Enterprises and Survey on ICT Usage in Households and by Individuals, April 2011. See chapter notes.

StatLink जाISL http://dx.doi.org/10.1787/888932486963
Households and individuals in many OECD countries are now accustomed to using broadband (high-speed) connections at home. At present, more than one household out of two has broadband Internet access in three-quarters of OECD countries. Korea has the largest share of households with a broadband connection via a computer or mobile phone (97\%). In OECD countries the share ranges from $21 \%$ in Mexico to $97 \%$ in Korea, for an OECD average of approximately $62 \%$.

In every OECD country the share of businesses with access to broadband exceeds that of households. In fact, the average is over 20 percentage points higher for businesses than for households. At 100\%, Switzerland has the highest penetration rate among business with ten or more employees. The range is from $51 \%$ in Mexico to $100 \%$ in Switzerland.

Data on regional broadband access, available for 19 countries, show that differences within countries may be large. Geography seems to matter - small countries such as the Slovak Republic, the Netherlands and Denmark have the lowest regional differences in broadband access - but it is not the main explanation. The difference in broadband access between the top and the bottom region is the same in the United States and Germany (32 percentage points) but the territory of the United States is over 25 times that of Germany. Spain and Australia also have the same range of regional differences in broadband access (25 percentage points) but very different sizes and geography.

\section{Definitions}

The OECD Guide to Measuring the Information Society 2011 defines broadband as an Internet access service - including optic fibre cable, some mobile phone access (e.g. UMTS, EDGE), power line, satellite and fixed wireless - with an advertised download speed greater than or equal to $256 \mathrm{kbps}$.

Since 2010, the OECD and the United Nations' International Telecommunication Union (ITU) broadband statistics are categorised as fixed (wired) broadband subscriptions and wireless broadband subscriptions. Fixed (wired) broadband subscriptions include: DSL, cable modem, fibre to the home/building subscriptions and other fixed (wired) broadband subscriptions such as power lines. Wireless broadband subscriptions include: satellite subscriptions, terrestrial fixed wireless subscriptions, terrestrial mobile wireless subscriptions (the sum of active mobile broadband and dedicated mobile data subscriptions). 


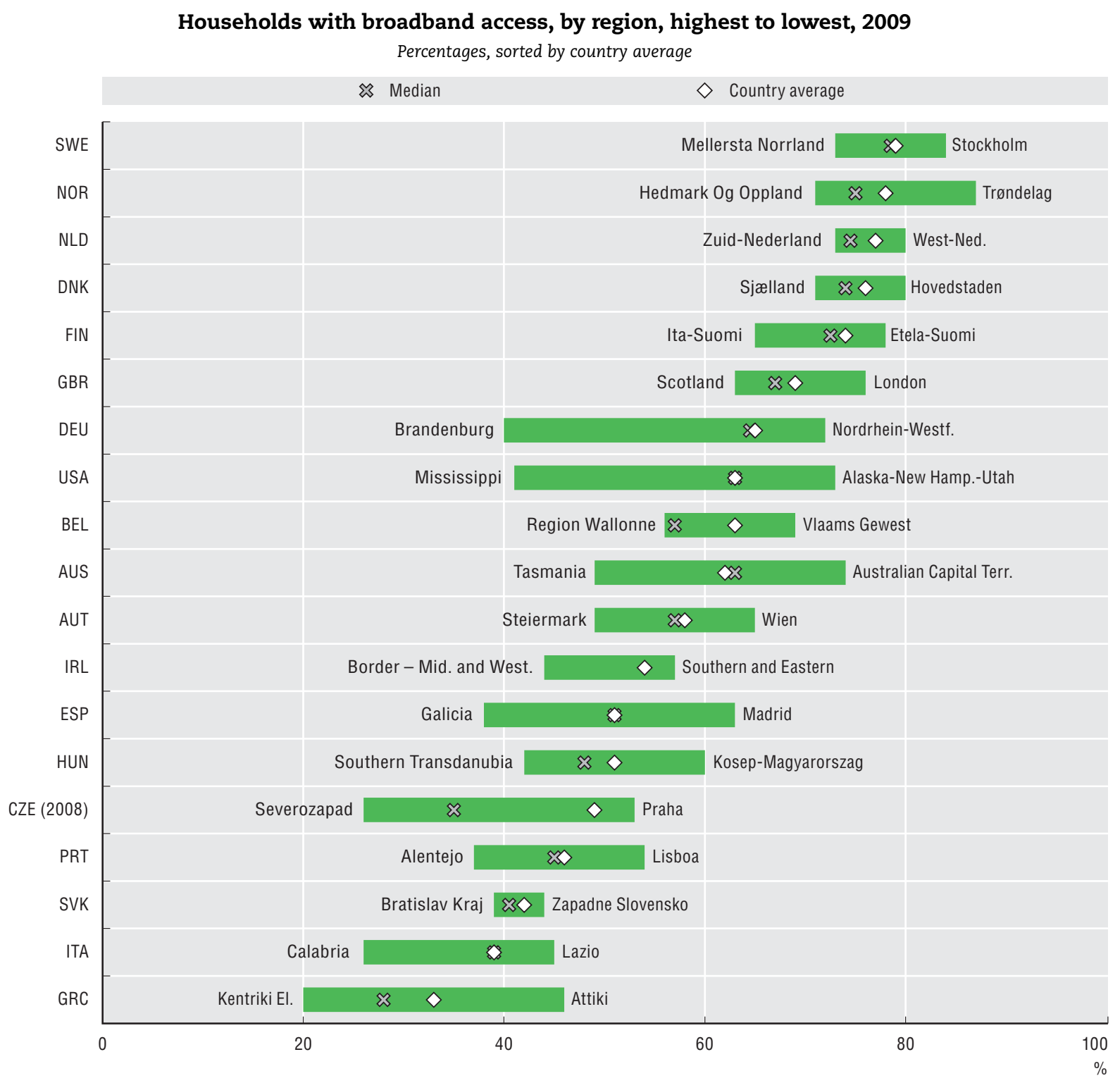

Source: OECD, Regional Database, April 2011. See chapter notes.

StatLink AाIs http://dx.doi.org/10.1787/888932486982

\section{Measurability}

There is no universally adopted definition of the threshold speed for broadband. In addition, advertised speeds are often very different than the actual speeds users may experience. As a result some countries define broadband in terms of technology (e.g. ADSL, cable, etc.) rather than speed.

Policy makers have an interest in the take-up of various broadband speeds because some services are better utilised and provide greater customer experience at higher speeds. In the past, broadband has been classified by advertised broadband speeds but there are several initiatives underway that seek to measure the actual speeds on broadband lines using a combination of hardware and software solutions. These advancements in measurement will help policy makers better understand which areas have more robust connectivity and which other may need additional investment to support the emergence of new, innovative services. 


\section{TARGETING NEW GROWTH AREAS}

\section{Biotechnology R\&D}

\section{Number of firms active in biotechnology, 2009}

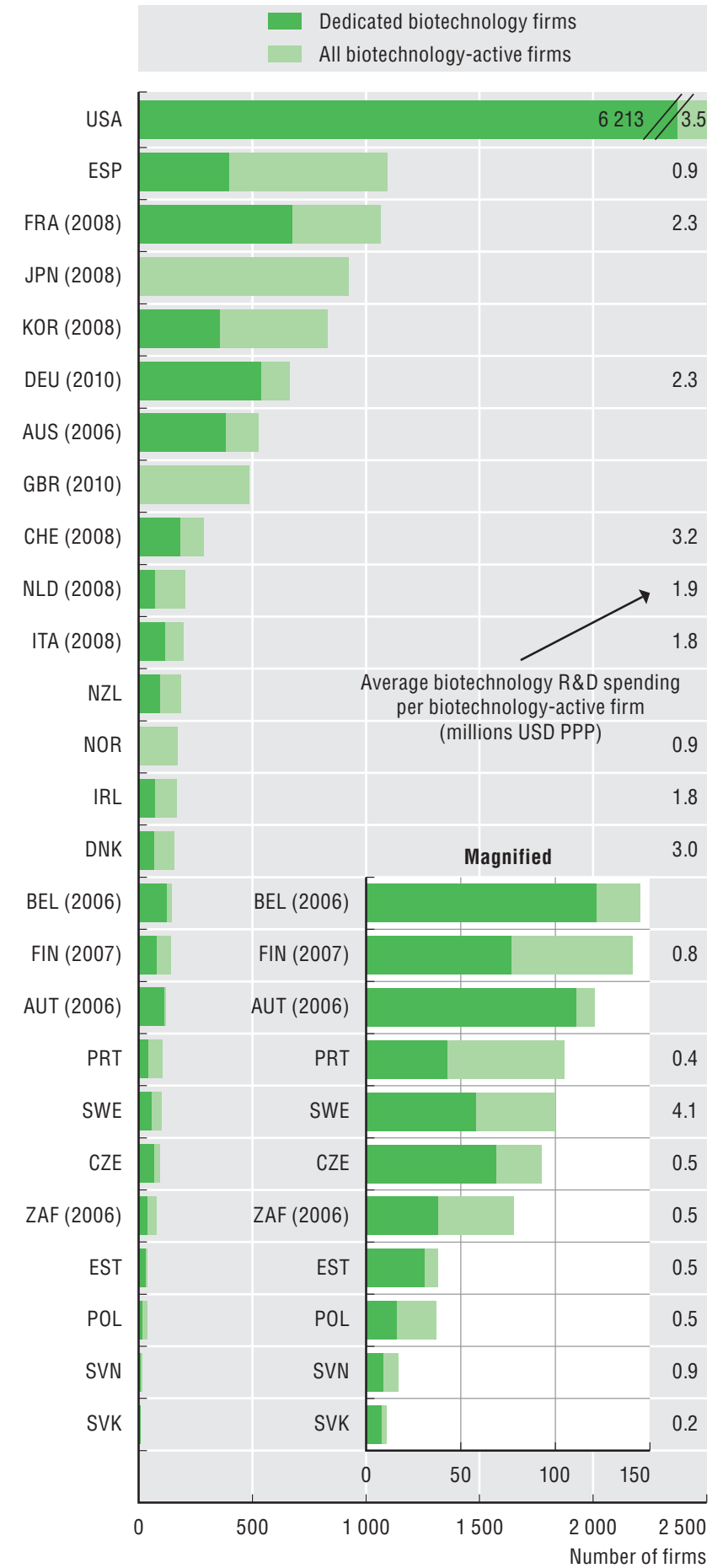

Source: OECD, Biotechnology Statistics Database, May 2011. See chapter notes.

StatLink Aाs $h t$ ttp://dx.doi.org/10.1787/888932487001
The economic, environmental and social impacts of advances in the life sciences create policy interest in relevant economic and innovation indicators of biotechnology. The number of biotechnology firms is the most widely available indicator but not the best measure of a country's effort, owing to large differences in firm sizes. The United States has the most biotechnology-active firms (6 213), followed by Spain (1 095) and France (1 067).

Business enterprise research and development (BERD) expenditures on biotechnology provide a better measure of the research effort. In Sweden, every biotechnologyactive firm spent an average of USD 4.1 million PPP on biotechnology R\&D, followed by the United States, Switzerland and Denmark (all between USD 3.5 million and USD 3.0 million PPP).

The United States spends the most on biotechnology BERD (USD 22030 million PPP), approximately 7\% of total US BERD. It accounts for almost $70 \%$ of total biotechnology BERD expenditures in the 23 countries for which data are available.

Business expenditure on biotechnology R\&D as a share of total business sector $R \& D$ expenditure is an indicator of a country's research effort. On average, it accounted for $5.7 \%$ of BERD in 2009. Ireland spends the most as a percentage of BERD (15.1\%). Belgium and Switzerland follow with 12.6\%.

Although most biotechnology firms have fewer than 50 employees, most biotechnology $R \& D$ is performed by firms with over 50 employees. For the United States and France, which spend the most on biotechnology R\&D, approximately $88 \%$ of all biotechnology $R \& D$ was performed by firms with over 50 employees.

\section{Definitions}

The OECD has both a single definition and a list-based definition of biotechnology. The single definition is broad. It covers all modern biotechnology but also many traditional or borderline activities. For this reason, the single definition should always be accompanied by the list-based definition. The single definition is:

"The application of science and technology to living organisms, as well as parts, products and models thereof, to alter living or non-living materials for the production of knowledge, goods and services."

The (indicative) list-based definition has seven categories and serves as an interpretative guideline to the single definition. Respondents are usually given a write-in option for new biotechnologies that do not fit in any category. A firm that reports activity in one or more categories is defined as a biotechnology firm. The categories are: DNA/RNA, proteins and other molecules, cell and tissue culture and engineering, process biotechnology techniques, gene and RNA vectors, bioinformatics, and nanobiotechnology. 


\section{Total biotechnology R\&D expenditures in the business sector, 2009}

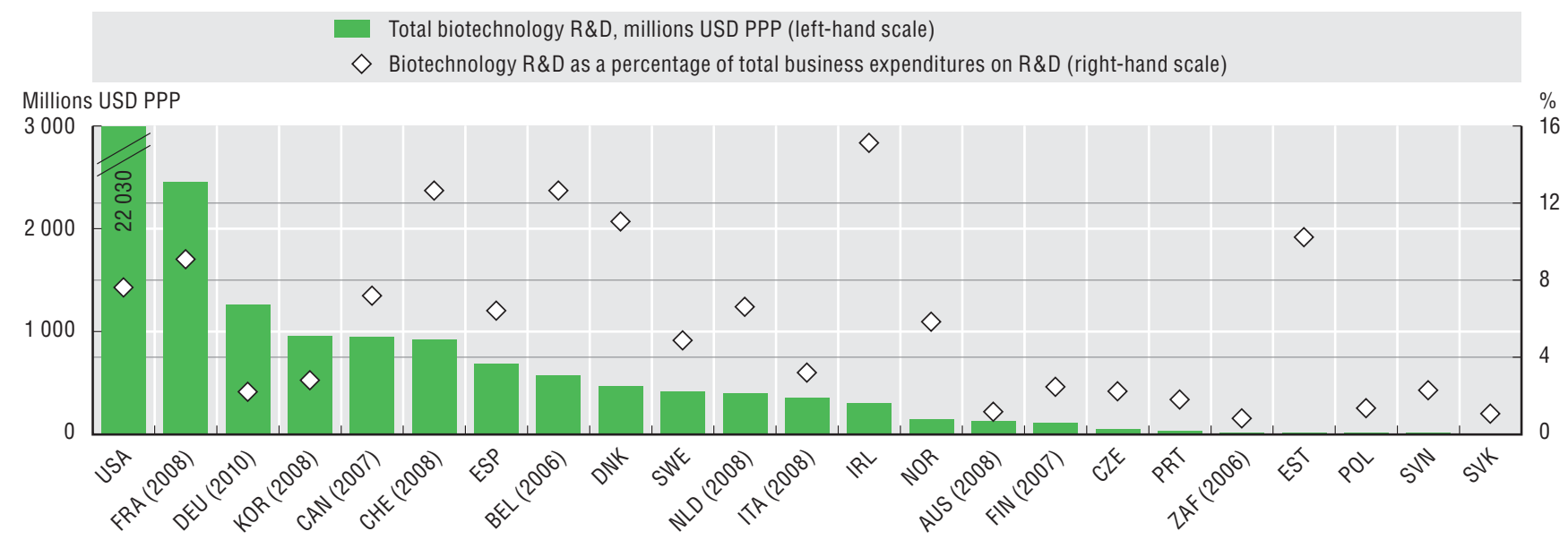

Source: OECD, Biotechnology Statistics Database, May 2011; and OECD, Main Science and Technology Indicators Database, May 2011. See chapter notes. StatLink AाIst http://dx.doi.org/10.1787/888932487020

\section{Biotechnology R\&D expenditures by size class, 2009}

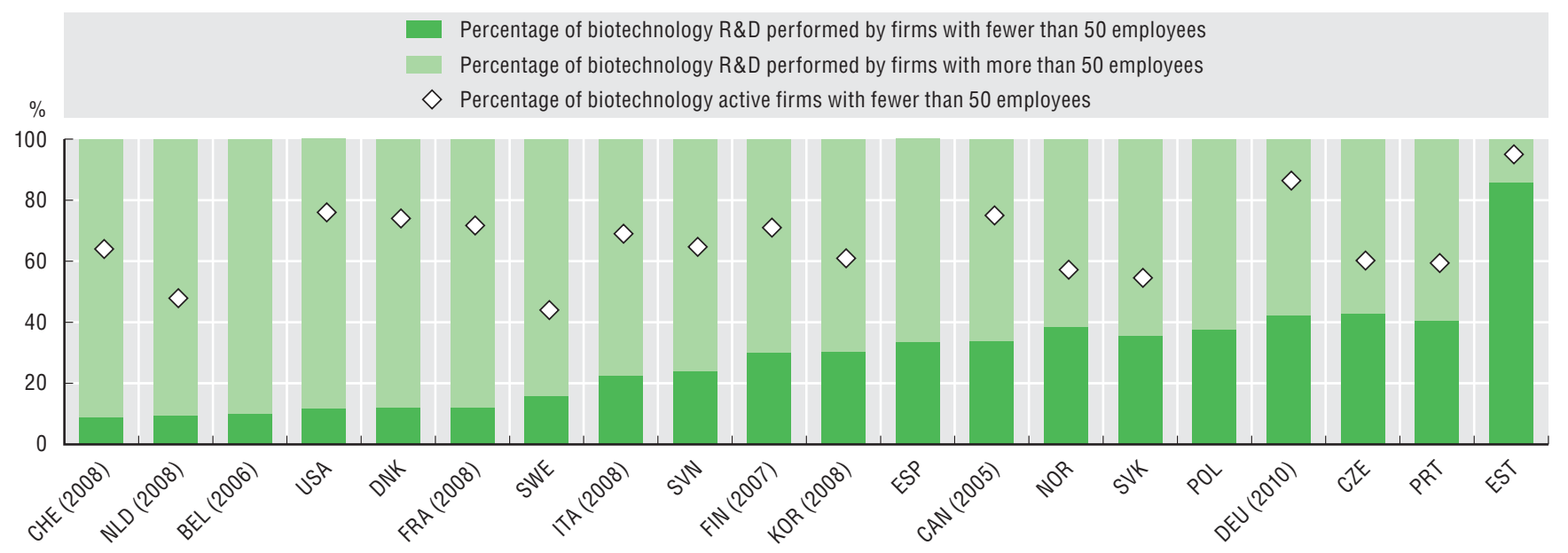

Source: OECD, Biotechnology Statistics Database, May 2011. See chapter notes.

StatLink AाISL http://dx.doi.org/10.1787/888932487039

\section{Measurability}

Data comparability depends on how biotechnology statistics are collected. Biotechnology activities can be measured in three ways:

- Dedicated surveys of firms active in biotechnology.

- Adding questions on biotechnology to national R\&D firm surveys.

- Constructing databases with information on biotechnology firms from secondary sources and/or data-linking exercises. Biotechnology firms can be broken down into three types:

1. Biotechnology firm: A firm engaged in biotechnology using at least one biotechnology technique (as defined in the OECD list-based definition) to produce goods or services and/or to perform biotechnology R\&D. These firms are captured by biotechnology firm surveys.

Two subgroups are largely defined by the data collection method.

2. Dedicated biotechnology firm: Firms whose main activity involves the application of biotechnology techniques to produce goods or services and/or to perform biotechnology R\&D. These firms are captured by biotechnology firm surveys.

3. Biotechnology R\&D firm: Firms that perform biotechnology R\&D. Dedicated biotechnology R\&D firms, a subset of this group, are firms that devote $75 \%$ or more of their total R\&D to biotechnology R\&D. These firms are captured by R\&D surveys. 


\section{TARGETING NEW GROWTH AREAS}

\section{Cyprus}

The following note is included at the request of Turkey:

"The information in this document with reference to 'Cyprus' relates to the southern part of the Island. There is no single authority representing both Turkish and Greek Cypriot people on the Island. Turkey recognises the Turkish Republic of Northern Cyprus (TRNC). Until a lasting and equitable solution is found within the context of the United Nations, Turkey shall preserve its position concerning the 'Cyprus issue'."

The following note is included at the request of all the European Union member states of the OECD and the European Commission:

"The Republic of Cyprus is recognised by all members of the United Nations with the exception of Turkey. The information in this document relates to the area under the effective control of the Government of the Republic of Cyprus."

\section{Israel}

"The statistical data for Israel are supplied by and under the responsibility of the relevant Israeli authorities. The use of such data by the OECD is without prejudice to the status of the Golan Heights, East Jerusalem and Israeli settlements in the West Bank under the terms of international law."

"It should be noted that statistical data on Israeli patents and trademarks are supplied by the patent and trademark offices of the relevant countries."

\section{Government budget appropriations or outlays for R\&D, 2007 and 2010}

For Israel, defence is excluded.

In the United States, general support for universities is the responsibility of state governments; therefore general university funds (GUF) is not included in total GBAORD.

\section{Government budget appropriations or outlays for R\&D, by selected socio-economic objectives, 2010}

For Israel, defence is excluded.

For Japan, military procurement contracts are excluded from defence in government budget appropriations or outlays for R\&D (GBAORD).

\section{Government budget appropriations or outlays for R\&D, by national sector of performance, 2008}

This is an experimental indicator. International comparability is currently limited.

\section{Public funding of health-related R\&D, 2010}

Government budget appropriations or outlays for R\&D (GBAORD) measures the funds committed by the federal/ central government for R\&D. It can be broken down by various socio-economic objectives, including health care. Advancement of knowledge comprises non-oriented R\&D and general university funds (the estimated R\&D content of government block grants to universities). Other includes other relevant national and international categories such as general support for R\&D in hospitals.

\section{Health-related patents, 1997-99 and 2007-09}

Data relate to patent applications filed under the Patent Cooperation Treaty (PCT), at international phase, published by the WIPO. Patent counts are based on the priority date, the inventor's country of residence and fractional counts.

BRIICS refers to Brazil, the Russian Federation, India, Indonesia, China and South Africa.

\section{Countries' share of pharmaceutical patents filed under the PCT, 2007-09}

Data relate to patent applications filed under the Patent Cooperation Treaty (PCT), at international phase, published by the WIPO. Patent counts are based on the priority date, the inventor's country of residence and fractional counts.

BRIICS refers to Brazil, the Russian Federation, India, Indonesia, China and South Africa. 
Patents in selected environmental technologies, 1997-99 and 2007-09

Data relate to patent applications filed under the Patent Cooperation Treaty (PCT), at international phase, published by the WIPO. Patent counts are based on the priority date, the inventor's country of residence and fractional counts.

Patents in technologies related to climate change mitigation in power and heat generation from fossil fuels, energy storage and solar energy are identified using subclasses of the European Classification (ECLA) Code Y02.

Patents in technologies related to material recycling are based on codes of the International Patent Classification (IPC).

BRIICS refers to Brazil, the Russian Federation, India, Indonesia, China and South Africa.

\section{Countries' share of patents for energy generation from renewable and non-fossil sources, 2007-09}

Data relate to patent applications filed under the Patent Cooperation Treaty (PCT), at international phase, published by the WIPO. Patent counts are based on the priority date, the inventor's country of residence and fractional counts.

Patents in technologies related to energy generation from renewable and non-fossil sources are identified using subclasses of the European Classification (ECLA) Code Y02.

BRIICS refers to Brazil, the Russian Federation, India, Indonesia, China and South Africa.

\section{Benefits from environmental innovations, 2006-08}

For Brazil, only the following activities are included in the services sector: ISIC Rev. 4 Divisions 58, 61, 62 and 72.

\section{Business and household access to broadband, 2010}

Business access to broadband:

- For Japan, businesses with 100 or more employees.

- For Mexico, businesses with 20 or more employees.

- For New Zealand, businesses with six or more employees and with a turnover greater than NZD 30000.

- For Switzerland, businesses with five or more employees.

Household access to broadband:

- For Japan, households with Internet access via FTTx, ADSL, cable and fixed wireless broadband.

- For Korea, broadband access modes such as xDSL, cable and other fixed and wireless broadband via computers, including mobile phone access.

- For Mexico, households with Internet access via cable, ADSL or fixed wireless.

- For New Zealand, the information is based on households in private occupied dwellings. Visitor-only dwellings, such as hotels, are excluded.

\section{Households with broadband access, by region, highest to lowest, 2009}

Geographic coverage: All regions within OECD member countries at the TL2 level (See "Territorial Grids of OECD member countries" available at: www.oecd.org/dataoecd/24/41/42740381.pdf).

Data for the region of Aland in Finland, for the regions of Bremen and Saarland in Germany, and for Northern Ireland in the United Kingdom are not available.

Ireland has only two regions, the median is therefore not calculated.

\section{Number of firms active in biotechnology, 2009}

Biotechnology firm: a firm that uses biotechnology to produce goods or services and/or to perform biotechnology $R \& D$. These firms are captured by biotechnology firm surveys.

Biotechnology R\&D firms: a firm that performs biotechnology R\&D. These firms are captured by R\&D surveys.

Dedicated biotechnology firm: a biotechnology firm whose predominant activity involves the application of biotechnology techniques to produce goods or services and/or to perform biotechnology R\&D. These firms are captured by biotechnology firm surveys.

Dedicated biotechnology R\&D firms devote $75 \%$ or more of their total R\&D to biotechnology R\&D. These firms are captured by R\&D surveys. 


\section{TARGETING NEW GROWTH AREAS}

Biotechnology R\&D per firm in the type of firm unless otherwise specified.

For Germany, biotechnology R\&D per dedicated biotechnology firm.

For South Africa, biotechnology R\&D per dedicated biotechnology firm.

For Spain, biotechnology R\&D per biotechnology R\&D firm.

For Switzerland, dedicated biotechnology R\&D firms are defined as firms that have dedicated $100 \%$ or more of their total R\&D to biotechnology R\&D.

For the Netherlands, results of the Dutch R\&D survey are grossed up to the total target population which corresponds to all firms with 10 and more employees. However, due to the special way the survey population was established (i.e. some firms which were identified as biotechnology firms based on registers were added). The number of 206 biotechnology R\&D firms also includes some firms with less than 10 employees. Their results were not grossed-up.

For the United Kingdom, results exclude firms outside the medical and industrial biotechnology sectors, e.g. agribiotech and aquaculture-biotech firms; however, it is estimated that the majority of biotechnology companies in the UK are included.

For Switzerland, dedicated biotechnology R\&D firms are defined as firms that have dedicated $100 \%$ or more of their total R\&D to biotechnology R\&D.

\section{Total biotechnology R\&D expenditures in the business sector, 2009}

Biotechnology firm: a firm that uses biotechnology to produce goods or services and/or to perform biotechnology R\&D. These firms are captured by biotechnology firm surveys.

Biotechnology R\&D firms: a firm that performs biotechnology R\&D. These firms are captured by R\&D surveys.

Dedicated biotechnology firm: a biotechnology firm whose predominant activity involves the application of biotechnology techniques to produce goods or services and/or to perform biotechnology R\&D. These firms are captured by biotechnology firm surveys.

Dedicated biotechnology R\&D firms devote $75 \%$ or more of their total R\&D to biotechnology R\&D. These firms are captured by R\&D surveys.

For Germany, Business Expenditures on R\&D (BERD) refers to 2009, 2010 BERD was not available.

For the United States, BERD refers to 2008, 2009 BERD was not available.

\section{Biotechnology R\&D expenditures by size class, 2009}

For the Netherlands, results of the Dutch R\&D survey are grossed up to the total target population which corresponds to all firms with 10 and more employees. However, due to the special way the survey population was established (i.e. some firms which were identified as biotechnology firms based on registers were added). The percentage of biotechnology R\&D performed by small biotechnology R\&D firms also includes some R\&D expenditures by firms with less than 10 employees. Their results were not grossed-up.

For Switzerland, firms with fewer than 100 employees. 
OECD (2002), Frascati Manual 2002: Proposed Standard Practice for Surveys on Research and Experimental Development, The Measurement of Scientific and Technological Activities, OECD Publishing, Paris. Doi: http://dx.doi.org/10.1787/ 9789264199040-en.

OECD (2005), “A Framework for Biotechnology Statistics”, OECD, Paris, www.oecd.org/dataoecd/5/48/34935605.pdf.

OECD (2009), "Guidelines for a Harmonised Statistical Approach to Biotechnology Research and Development in the Government and Higher Education Sectors", Working Party of National Experts on Science and Technology Indicators, DSTI/EAS/STP/NESTI(2009)1/FINAL, OECD, Paris, available at: www.oecd.org/dataoecd/33/9/44279076.pdf.

OECD (2009), “OECD Biotechnology Statistics 2009”, OECD, Paris, available at: www.oecd.org/dataoecd/4/23/42833898.pdf.

OECD (2009), OECD Patent Statistics Manual, OECD Publishing, Paris. Doi: http://dx.doi.org/10.1787/9789264056442-en.

OECD (2009), OECD Science, Technology and Industry Scoreboard 2009, OECD Publishing, Paris. Doi: http://dx.doi.org/10.1787/ sti_scoreboard-2009-en.

OECD (2010), Measuring Innovation: A New Perspective, OECD Publishing, Paris. Doi: http://dx.doi.org/10.1787/ 9789264059474-en.

OECD (2011), Invention and Transfer of Environmental Technologies, OECD Studies on Environmental Innovation, OECD Publishing, Paris. Doi: http://dx.doi.org/10.1787/9789264115620-en.

OECD (2011), OECD Communications Outlook 2011, OECD Publishing, Paris. Doi: http://dx.doi.org/10.1787/comms_outlook-2011-en.

OECD (2011), OECD Guide to Measuring the Information Society 2011, OECD Publishing, Paris. Doi: http://dx.doi.org/10.1787/ 9789264113541-en.

OECD/Statistical Office of the European Communities, Luxembourg (2005),Oslo Manual: Guidelines for Collecting and Interpreting Innovation Data, The Measurement of Scientific and Technological Activities, 3rd edition, OECD Publishing, Paris. Doi: http://dx.doi.org/10.1787/9789264013100-en.

Schmoch, U. (2008), “Concept of a Technology Classification for Country Comparisons", Final Report to the World Intellectual Property Organisation (WIPO), revised in November 2010, WIPO, www.wipo.int/export/sites/www/ipstats/en/ statistics/patents/pdf/wipo_ipc_technology.pdf.

Van Steen, J. (2011), "Public Funding of R\&D: Towards Internationally Comparable Indicators", DSTI/EAS/STP/ NESTI(2010)20/FINAL, OECD, Paris. 


\section{UNLEASHING INNOVATION IN FIRMS}

\section{Mixed modes of innovation}

\section{Innovation strategies by firm size, 2006-08}

As a percentage of all SMEs and large firms

Product or process innovation only

Product or process and marketing or organisational innovation

Marketing or organisational innovation only

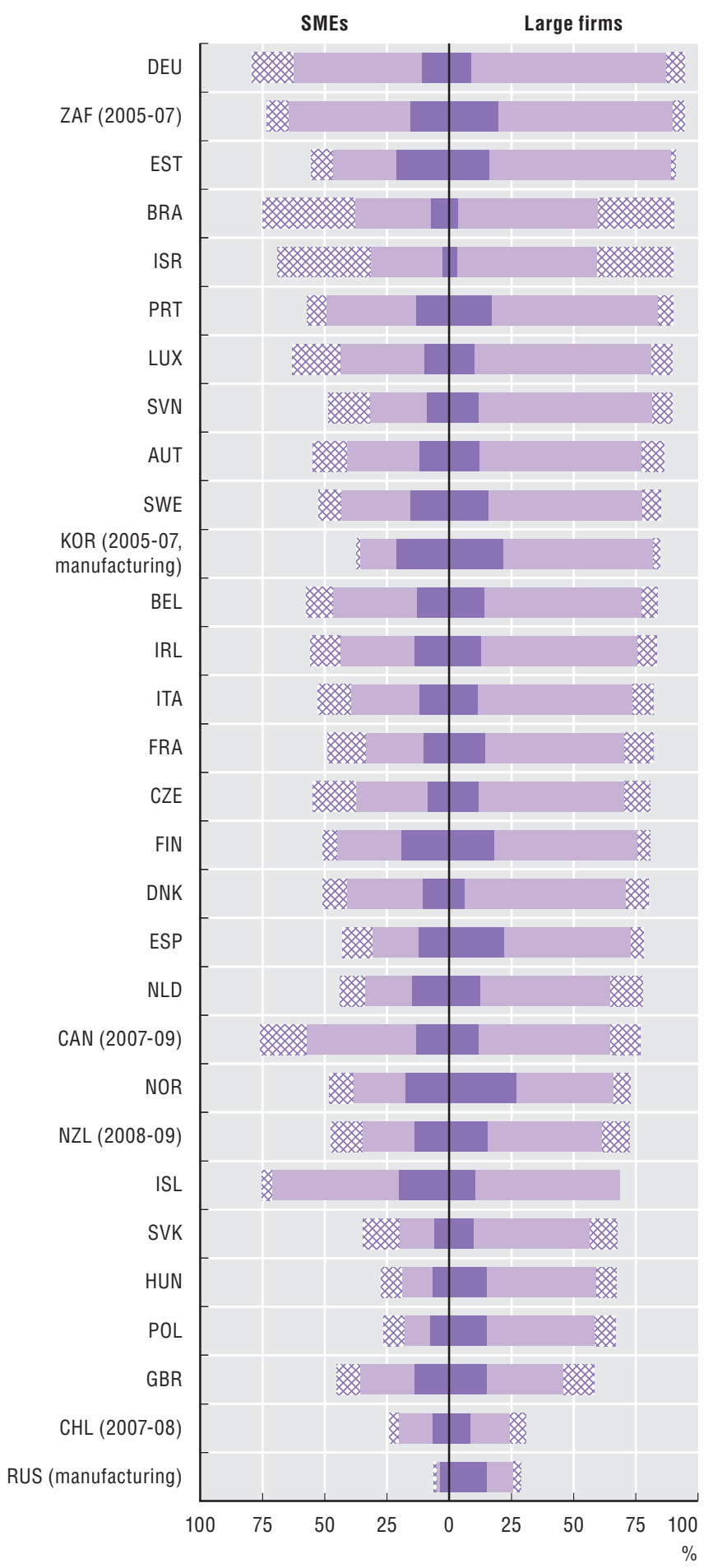

Source: OECD, based on Eurostat (CIS-2008) and national data sources, June 2011. See chapter notes.

StatLink तारु http://dx.doi.org/10.1787/888932487058
Firm-level innovation data reveal complementary strategies. The majority of innovative firms (both large firms and SMEs) introduce product or process innovations, as well as marketing/organisational innovations. This is true for firms in manufacturing and services.

Brazil, Germany and Israel have the largest share of nontechnological innovators: more than $85 \%$ of large firms and more than two-thirds of all SMEs introduced organisational or marketing innovations in 2006-08. Korea, Hungary, Chile and Poland have the smallest shares with less than $25 \%$ of all firms introducing non-technological innovations. In most countries the shares of non-technological innovating firms are relatively similar across manufacturing and services firms. Exceptions are Portugal, with significantly more non-technological innovators in services (54\% versus $40 \%$ ), and Germany, with a share almost 10 percentage points higher in manufacturing.

\section{Definitions}

The current edition of the Oslo Manual identifies four types of innovation:

- Product innovation: the introduction of a good or service that is new or significantly improved with respect to its characteristics or intended uses. This includes significant improvements in technical specifications, components and materials, incorporated software, user friendliness or other functional characteristics.

- Process innovation: the implementation of a new or significantly improved production or delivery method. This includes significant changes in techniques, equipment and/or software.

- Marketing innovation: the implementation of a new marketing method involving significant changes in product design or packaging, product placement, product promotion or pricing.

- Organisational innovation: the implementation of a new organisational method in the firm's business practices, workplace organisation or external relations.

Complementary innovation strategies refer to the introduction of both technological and non-technological innovations.

The sectoral coverage is based on the "core" list of industries included in the CIS-2008 (ISIC Rev. 4/NACE Rev. 2):

- Manufacturing: C.

- Services: G46 (Wholesale trade, except of motor vehicles and motorcycles), $H$ (Transportation and storage), J58 (Publishing activities), J61 (Telecommunications), J62 (Computer programming, consultancy and related activities), J63 (Information service activities), $\mathrm{K}$ (Financial and insurance activities), M71 (Architectural and engineering activities; technical testing and analysis).

- Total = Manufacturing + Services + B (Mining and quarrying) + D (Electricity, gas, steam and air conditioning supply) + E (Water supply; sewerage, waste management and remediation activities). 
Innovation strategies in the manufacturing sector, 2006-08

As a percentage of all manufacturing firms

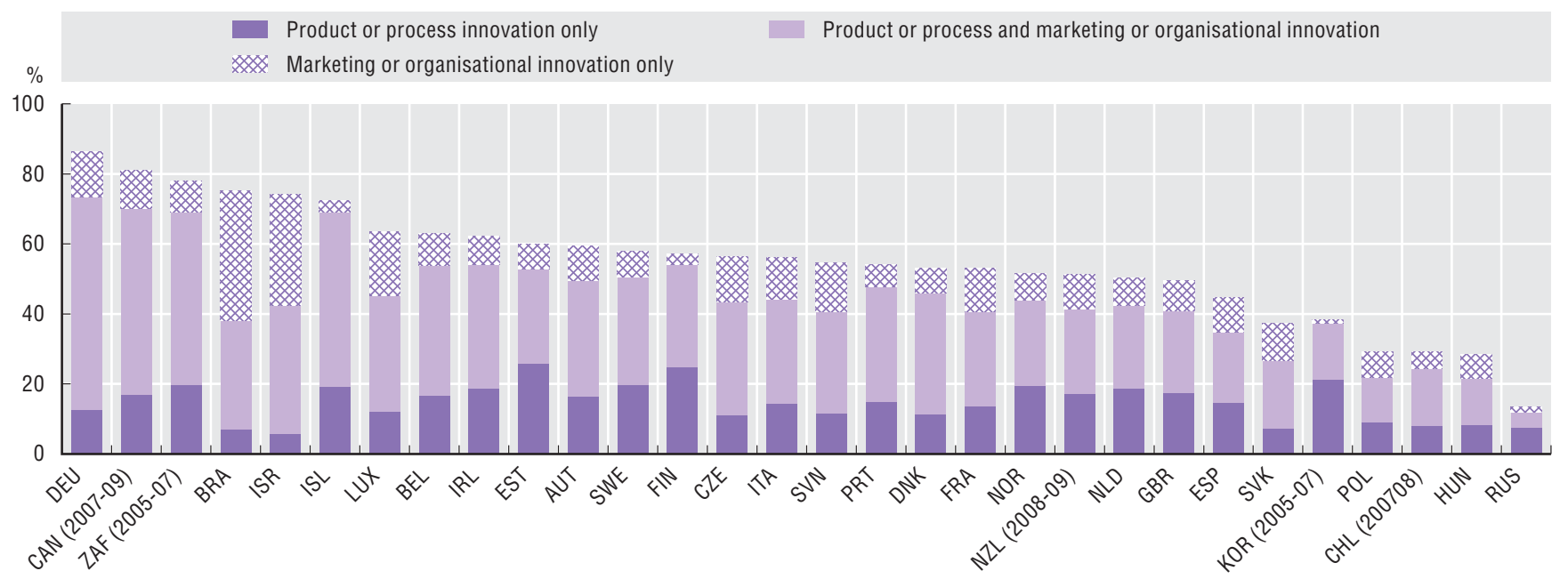

Source: OECD, based on Eurostat (CIS-2008) and national data sources, June 2011. See chapter notes.

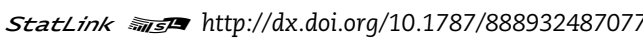

Innovation strategies in the services sector, 2006-08

As a percentage of all services firms

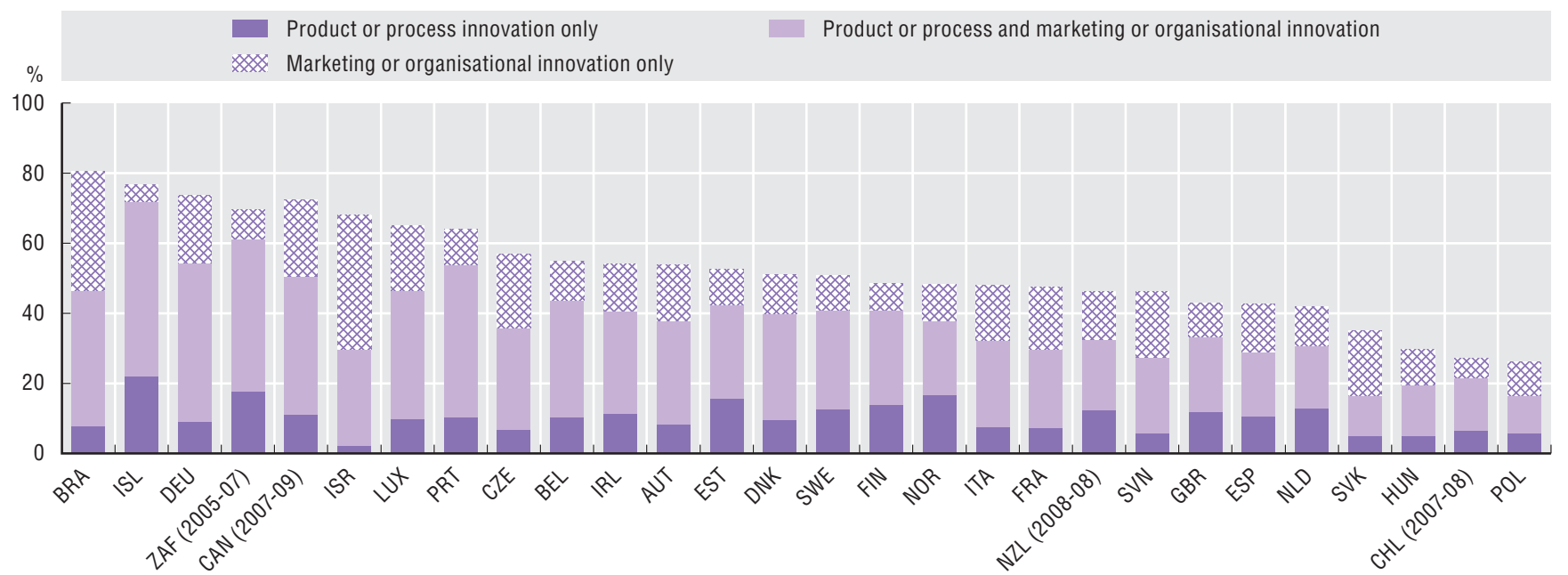

Source: OECD, based on Eurostat (CIS-2008) and national data sources, June 2011. See chapter notes.

StatLink काIs $h t t p: / / d x . d o i . o r g / 10.1787 / 888932487096$

\section{Measurability}

These indicators may be affected by differences in the sectoral coverage of innovation surveys across countries. Although an effort was made to align the data for non-European countries to what is included in the "core" coverage of the Community Innovation Survey (CIS), this is not always possible due to survey and sample design. For example in Korea and the Russian Federation, these data only cover the manufacturing sector. Similarly, differences in the sectoral coverage for Brazil, Canada, Chile, New Zealand and South Africa may have an impact on some indicators.

Some countries do not identify firms with ongoing/abandoned innovation activities, so that (contrary to the CIS data) these are not included in the figures for innovative (or innovation-active) firms. 


\section{UNLEASHING INNOVATION IN FIRMS}

\section{Broader innovation}

\section{Firms engaged in innovation collaboration by R\&D status, 2006-08}

As a percentage of $R \& D$-active and $R \& D$ non-active firms

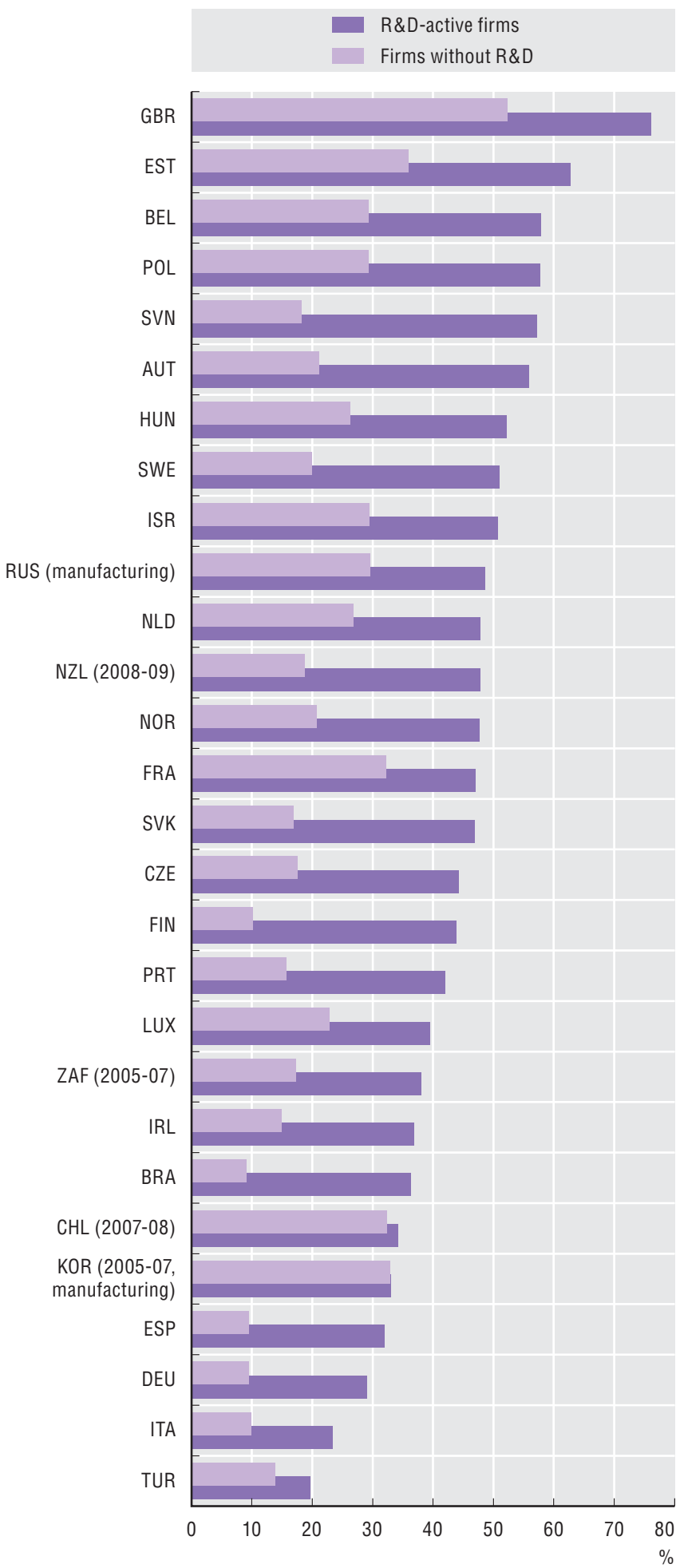

Source: OECD, based on Eurostat (CIS-2008) and national data sources, June 2011. See chapter notes.

StatLink AाISL $h$ ttp://dx.doi.org/10.1787/888932487115
Firms follow various innovation strategies and these are not always based on R\&D. Collaboration is part of innovation processes whether firms perform $R \& D$ or not. In all countries $R \& D$-active firms tend to collaborate more frequently on innovation (usually twice as much) than nonR\&D-active firms. In Chile and Korea, R\&D status does not seem to affect collaboration on innovation. In the United Kingdom, collaboration is embedded in innovation processes and over $50 \%$ of non-R\&D-active firms engage in it. Policies that stimulate collaboration and network initiatives might affect the entire spectrum of innovative firms.

Product innovation is often associated with R\&D activities. Indeed, in most countries, more than half of all productinnovating firms are also active in R\&D (whether they carry out intramural $R \& D$ or purchase extramural $R \& D$ ). Conversely, more than two-thirds of product innovators are not engaged in R\&D in New Zealand and the United States and more than $90 \%$ in Chile and Brazil.

For process innovation, the overall share of firms engaged in $R \& D$ is slightly lower. In France and Spain, there is a relatively larger difference between product and process innovators in terms of R\&D activity.

\section{Definitions}

$R \& D$ status is defined as follows: R\&D-active firms are those with intramural or extramural R\&D. 
Product innovators by R\&D status, 2006-08

As a percentage of product innovators
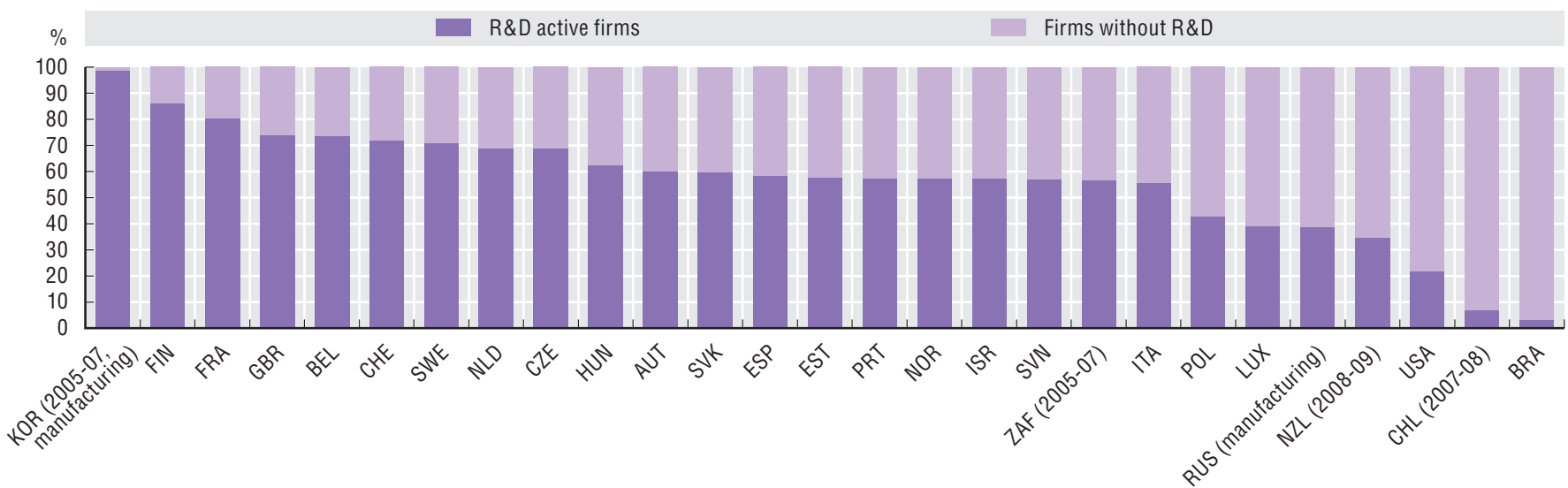

Source: OECD, based on Eurostat (CIS-2008) and national data sources, June 2011. See chapter notes.

StatLink AाIS http://dx.doi.org/10.1787/888932487134

Process innovators by R\&D status, 2006-08

As a percentage of process innovators

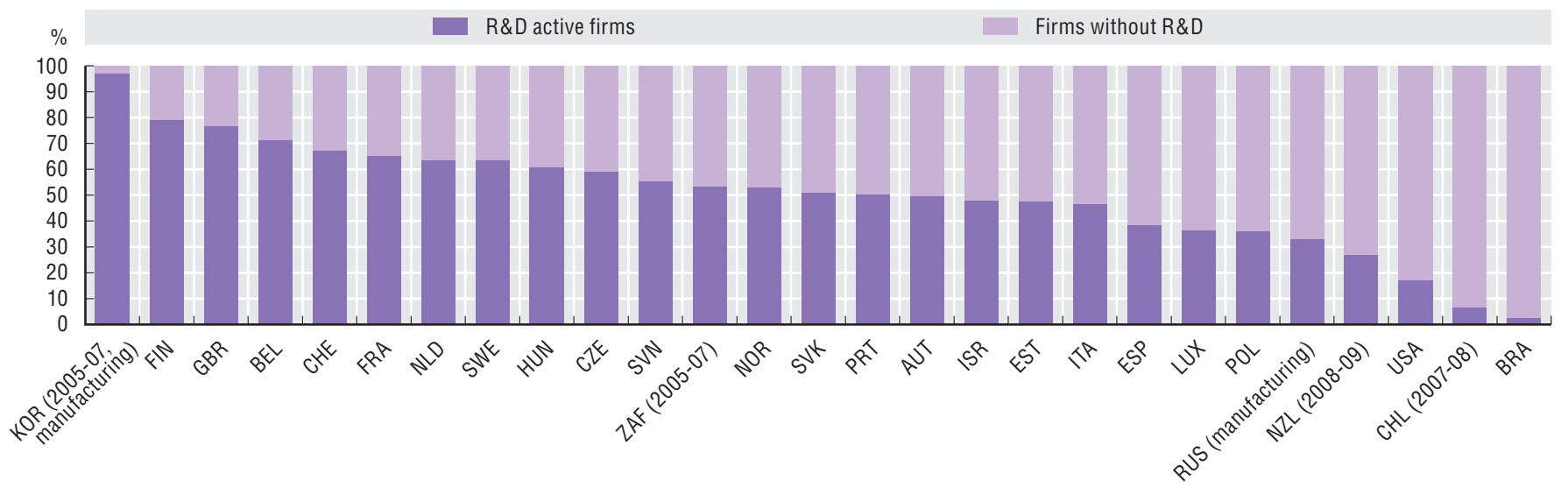

Source: OECD, based on Eurostat (CIS-2008) and national data sources, June 2011. See chapter notes.

StatLink Aाs $h t$ ttp://dx.doi.org/10.1787/888932487153

\section{Measurability}

In the Community Innovation Survey (CIS) R\&D status is found in the section on innovation activities which is only answered by product/process innovators. In other innovation surveys this information is asked of all innovative firms (including firms with only non-technological innovation).

Differences in sectoral coverage across surveys affect the comparability of the data based on R\&D status since some non-CIS surveys cover less R\&D-intensive industries much more extensively. Two extremes are the US survey (BRDIS) which covers all industries and the Korean survey which only covers manufacturing. Differences in the size thresholds used also affect comparability since very small firms are on average less likely to carry out or purchase R\&D.

There are also differences among countries in the type of survey used to collect innovation and R\&D data. Most use separate surveys, but some have combined them into single instruments (even in CIS countries). Given that R\&D surveys target R\&D performers while innovation surveys have a much wider target population, these differences may also affect the comparability of R\&D-related data collected from different types of instruments. 


\section{UNLEASHING INNOVATION IN FIRMS}

\section{Trademarks}

\section{Trademark applications at JPO, OHIM and USPTO, 2007-09 average}

Trademarks relative to GDP, OECD and BRIICS countries

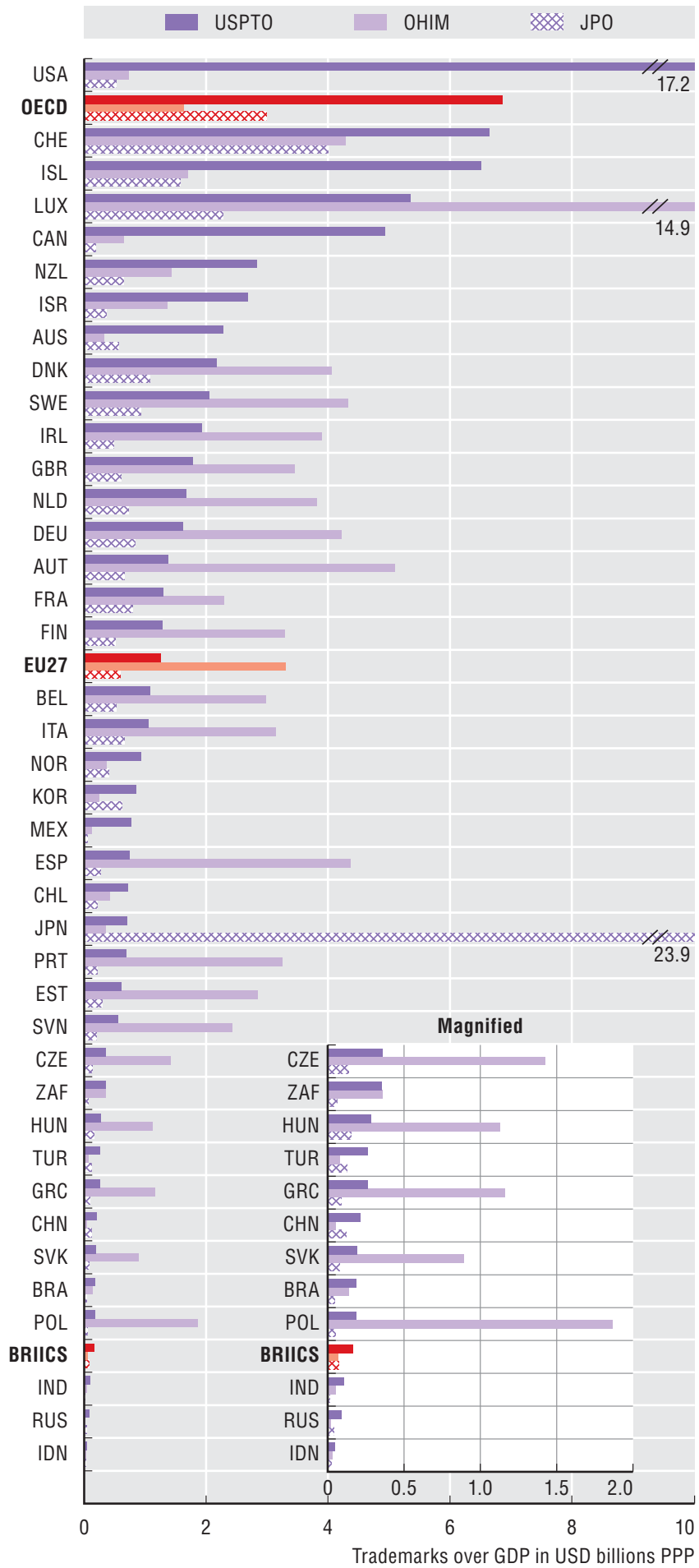

Source: US Patent and Trademark Office (2011), "The USPTO Trademark Casefile Dataset (1884-2010)"; OHIM Community Trademark Database; CTM Download, April 2011; JPO (2008-10), Annual Reports; OECD, National Accounts Database, June 2011; and IMF, World Economic Outlook Database, June 2011. See chapter notes.

StatLink Aाst http://dx.doi.org/10.1787/888932487172
Trademarks (TM) may serve as indicators of innovative and marketing activity, and may proxy non-technological innovations and innovation in services. Firms tend to register trademarks primarily in their home country. Trademarks registered by non domestic firms can be used as a measure of market penetration and may help understand the kind of products, whether goods or services, exported.

Japan, Luxembourg and the United States show the highest ratio of trademark activity to GDP at the Japanese Patent Office (JPO), the European Office for Harmonization in the Internal Market (OHIM) and the United States Patent and Trademark Office (USPTO) combined. Korea and Japan register more trademarks at the USPTO than at OHIM, and US firms register more at OHIM than at JPO. On average, European firms register trademarks more at the USPTO than at the JPO. Australia and New Zealand register more trademarks at the USPTO, followed by the JPO for Australia and OHIM for New Zealand. Both Mexico and Chile show stronger ties with the United States than with Europe and Japan.

BRIICS' (Brazil, the Russian Federation, India, Indonesia, China and South Africa) trademark activity abroad is low compared to OECD countries, with South Africa the most outward-oriented, followed by China and Brazil. The number of trademarks registered at the respective national offices cannot be compared as different class systems exist (e.g. China, India. See chapter notes).

TMs for goods have the highest number of applications for all countries at both OHIM and USPTO. The share of TMs for services is highest for the United States at the USPTO and for Norway at the OHIM. Countries tend to file proportionally more service TMs in their home markets. In addition, most countries show a higher share of trademarks services at the OHIM than at the USPTO.

Geographic distance and cultural proximity, the presence and location of foreign affiliates, countries' competitive advantages and industrial specialisation, and trade agreements may explain the patterns observed.

\section{Definitions}

Trademarks are distinctive signs identifying goods or services. They help consumers choose products that meet their needs and expectations in terms of nature, quality and price. Trademarks are a form of intellectual property protection granting owners the exclusive right to use them. This protection is enforced by the courts, which in most systems may block infringements. A trademark's country of origin is defined according to the address of the firm or economic agent listed in the trademark document. The word trademark is sometimes used as a synonym for brand, but the concept of brand is wider than that of trademark. Brands combine tangible and intangible elements such as image and reputation, and may or may not involve trademarks. 
Trademark applications by BRIICS countries at national IP offices, USPTO, OHIM, and JPO, ratio to GDP, 2007-09 average

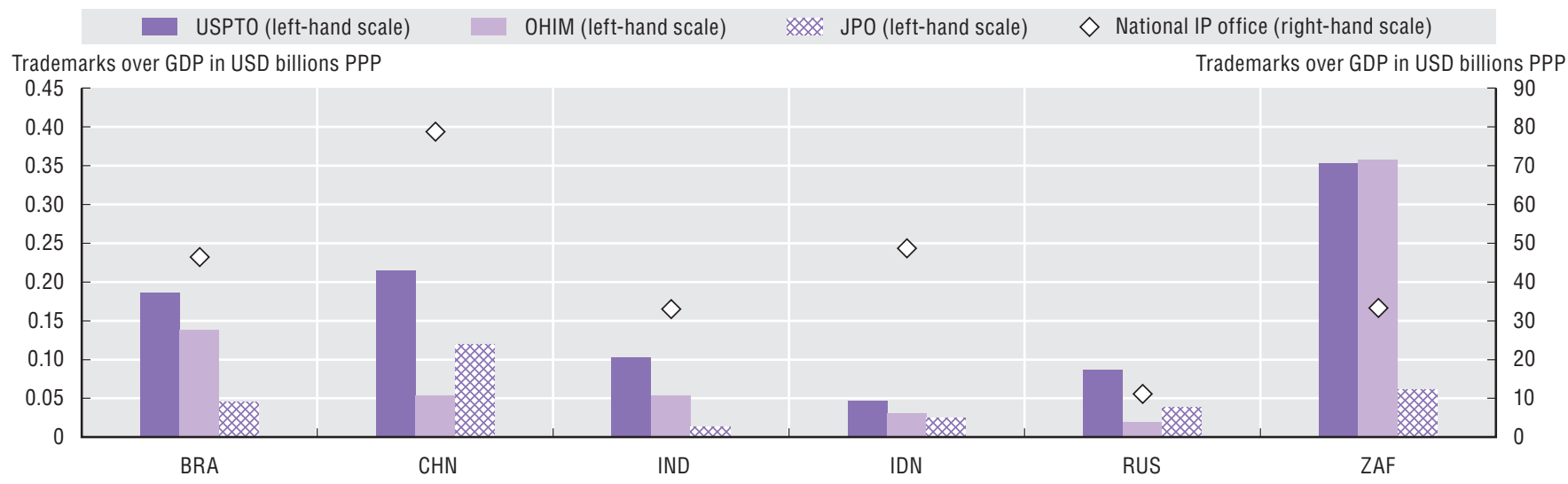

Source: WIPO, Statistics on Trademarks, May 2011; US Patent and Trademark Office (2011), "The USPTO Trademark Casefile Dataset (1884-2010)"; OHIM Community Trademark Database; CTM Download, April 2011; JPO (2008-10), Annual Reports; OECD, National Accounts Database, June 2011; and IMF, World Economic Outlook Database, June 2011. See chapter notes.

Share of goods and services trademark applications at USPTO and OHIM, 2007-09

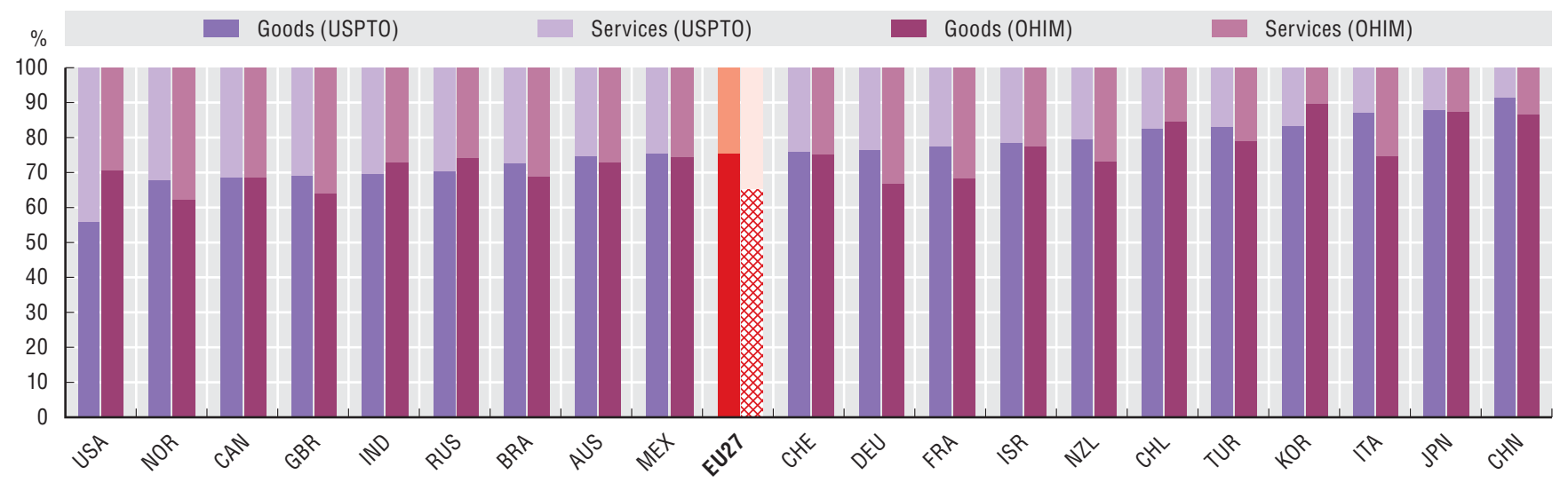

Source: US Patent and Trademark Office (2011), “The USPTO Trademark Casefile Dataset (1884-2010)"; OHIM Community Trademark Database; CTM Download, April 2011. See chapter notes.

StatLink (ilst http://dx.doi.org/10.1787/888932487210

\section{Measurability}

Applications to register trademarks must be filed with the relevant national or regional trademark offices and contain the list of goods or services (or both) to which the sign would apply. The current edition of the International Classification of Goods and Services for the Purposes of the Registration of Marks, known as the "Nice Classification" (ninth edition, entered into force on 1 January 2007) contains 34 classes of goods and 11 classes of services. Good trademarks relate to classes 1-34; service trademarks correspond to classes 35-45. Fractional counts based on the classes designated in the TM application are used to quantify good and service trademarks. Most countries allow for multi-class filings; a few countries allow only single-class applications (e.g. China). The period of protection may vary - it is typically ten years and trademarks can be renewed indefinitely upon payment of fees. Fees are generally proportional to the number of classes designated, with exceptions such as OHIM allowing for up to three designated classes for the same initial fee. 


\section{UNLEASHING INNOVATION IN FIRMS}

\section{Public support to R\&D}

\section{Government-financed BERD by firm size, 2009}

As a percentage of total government-financed $B E R D$

Firms with fewer than 50 employees

Firms with 50 to 249 employees

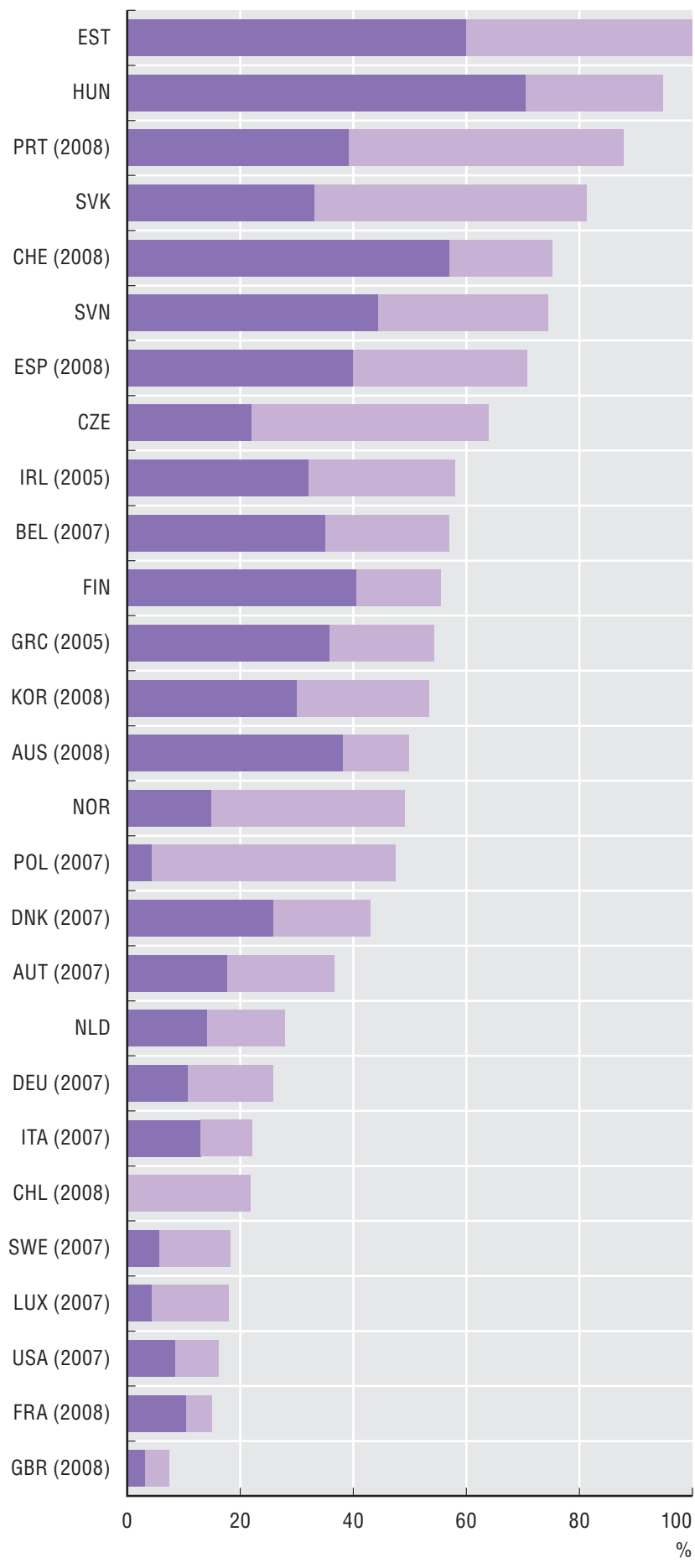

Source: OECD, Research and Development Database, May 2011. See chapter notes.

StatLink Aाsस http://dx.doi.org/10.1787/888932487229
SMEs play an important role in innovation. There are concerns that the recent economic crisis may have affected them disproportionally in terms of securing funding for R\&D and other innovation-related activities. In some countries governments play a key role in funding $R \& D$ activities of SMEs. In most, between $40 \%$ and $80 \%$ of government-financed business expenditures in research and development (BERD) goes to SMEs, a figure that reaches over $90 \%$ in Estonia and Hungary. However, in larger countries such as the United Kingdom, France and the United States, the bulk of public support goes to large firms.

Regular training is one of the means by which firms can maximise the potential of their human capital and is thus a key part their innovation activities. There is wide variation across countries in the use of innovation-related training. Large firms tend to do more, although the gap is quite narrow in some countries. Compared to earlier data, the share of firms with innovation-related training appears to be declining slightly on average, both in larger firms and SMEs.

Many countries offer various financial incentives for firms to engage in innovation activities ( $R \& D$ and other) but the rate of uptake varies widely. In most countries large firms tend to be the main beneficiaries of such schemes but the rate of uptake among innovative firms seems to be declining over time.

\section{Definitions}

Government-financed BERD includes all forms of direct support such as grants, some types of loans as well as procurement contracts. It does not include R\&D tax credits or other indirect support measures.

Training relates to internal or external training for personnel specifically for the development of and/or introduction of new or significantly improved products or processes.

Public support for innovation includes financial support via tax credits or deductions, grants, subsidised loans, and loan guarantees. It excludes research and other innovation activities conducted entirely for the public sector under contract. 
Firms engaged in innovation-related training by firm size, 2002-04 and 2006-08

As a percentage of innovative firms

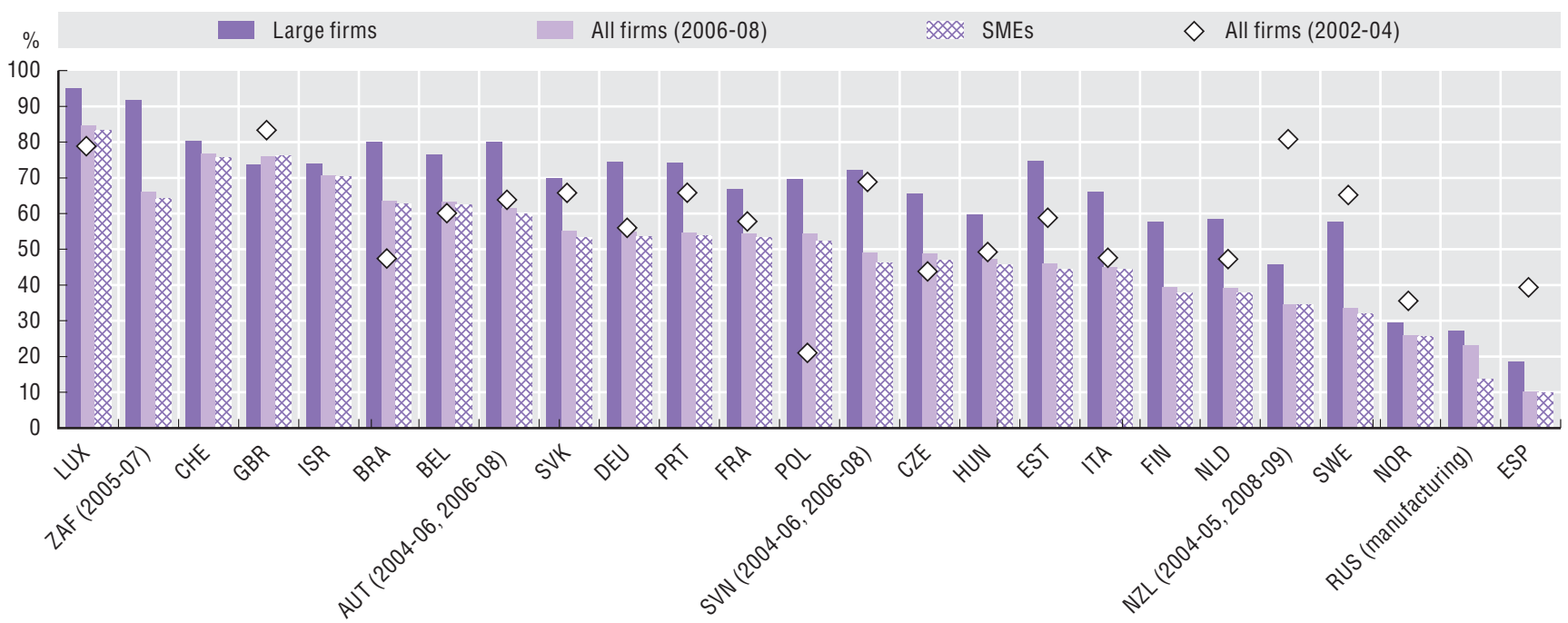

Source: OECD, based on Eurostat [CIS-2008, CIS-2006 and CIS-2004 (CIS4)] and national data sources, June 2011. See chapter notes.

StatLink atis http://dx.doi.org/10.1787/888932487248

\section{Firms receiving public support for innovation by firm size, 2002-04 and 2006-08}

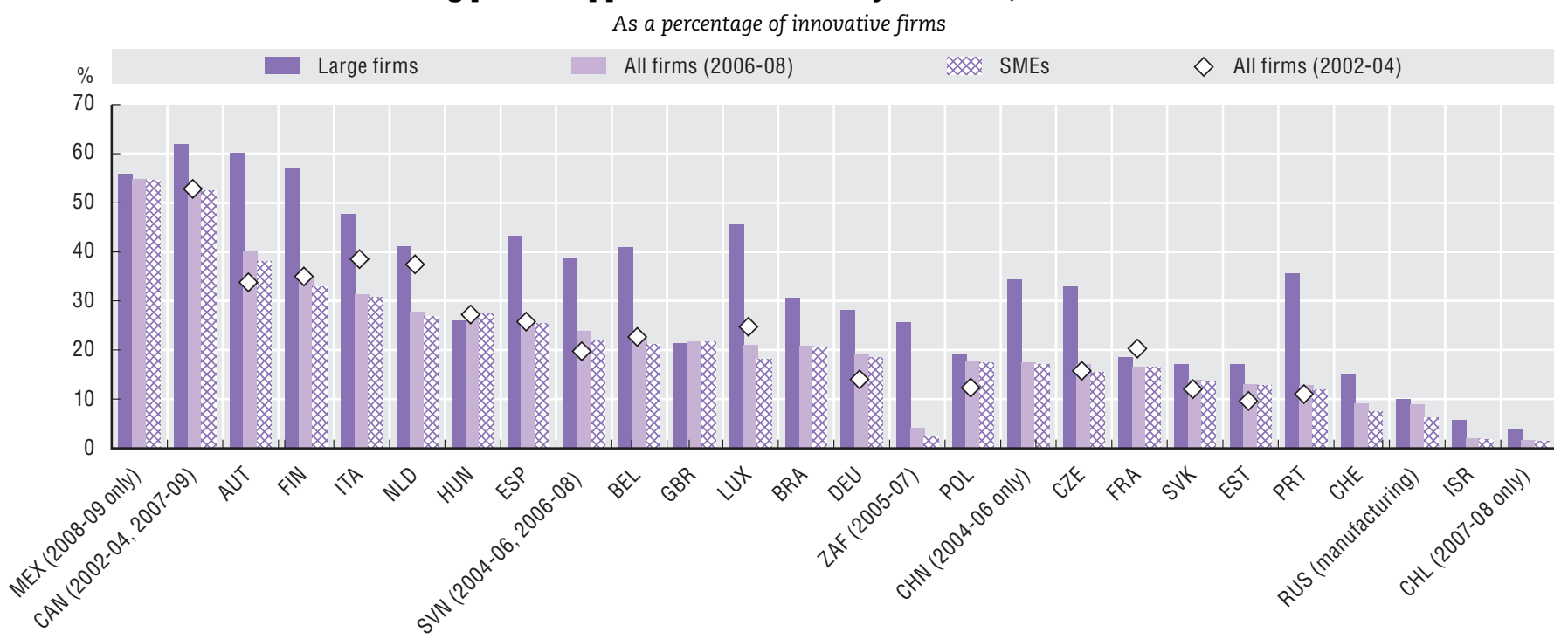

Source: OECD, based on Eurostat [CIS-2008, CIS-2006 and CIS-2004 (CIS4)] and national data sources, June 2011. See chapter notes.

StatLink काISL $h t t p: / / d x$.doi.org/10.1787/888932487267

\section{Measurability}

BERD data only cover direct support (grants as well as contracts) and should be complemented with additional information on indirect support (such as foregone revenue from R\&D tax credits) to obtain a broader picture of public support to business R\&D.

The data on training and public support refer only to product/process innovations in Community Innovation Survey (CIS) countries, but could include other types of innovation (notably, non-technological) in other countries. 


\section{UNLEASHING INNOVATION IN FIRMS}

\section{Tax incentives for business R\&D}

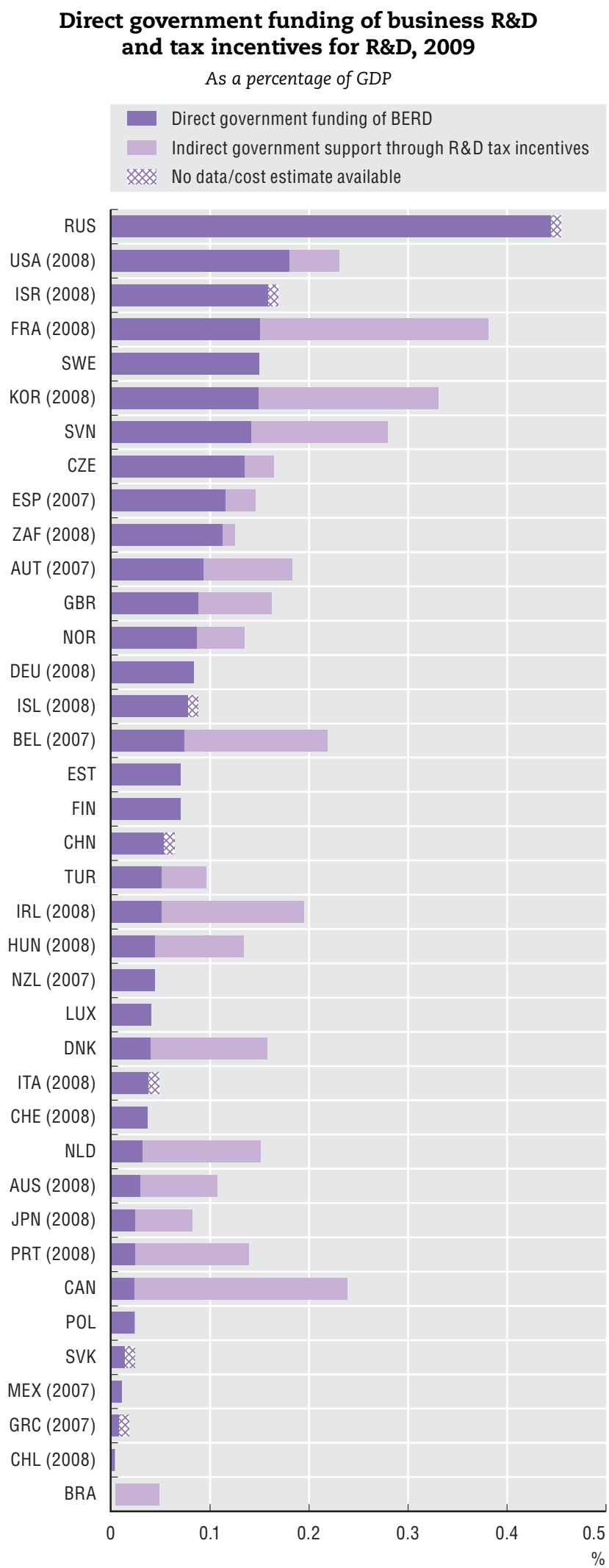

Source: OECD, based on OECD R\&D tax incentives questionnaires, January 2010 and June 2011; and OECD, Main Science and Technology Indicators Database, June 2011. See chapter notes.

StatLink तार्म http://dx.doi.org/10.1787/888932487400
Governments foster business research and development (R\&D) with direct support via grants or procurement and fiscal incentives, such as $R \& D$ tax incentives. Today, 26 OECD governments use fiscal incentives to promote business expenditure on R\&D, up from 12 in 1995 and 18 in 2004. Among those that do not (Germany, Finland, Sweden), some are discussing their introduction. Brazil, China, India, the Russian Federation, Singapore and South Africa also offer incentives for investment in R\&D.

The United States and Spain rely more on direct support, while Canada, the Netherlands, Portugal and Japan mostly use indirect tax support to foster industrial R\&D. The balance of direct and indirect R\&D support varies from country to country, as each tool addresses different market failures in various ways and stimulates different types of R\&D activity. The Russian Federation, France and Korea provide the largest combined support relative to GDP.

The United States, France, Canada, Japan and Korea provide the largest volumes of tax incentives for $R \& D$ volumes. Countries that spend relatively more in funding business R\&D appear to have a higher business R\&D intensities. However, this does not imply a causal relationship and there are some notable exceptions. Finland and Japan have relatively high business $R \& D$ intensity compared to their degree of government support, while the Russian Federation and France have high rates of support relative to countries with similar business R\&D intensities. Finland and Sweden have high intensities without the use of tax incentives. Identifying the impact of past or future government incentives requires data on policy inputs and research and economic outputs and careful research design to identify the counterfactual against which to compare observed performance.

\section{Definitions}

Government tax incentives for R\&D include R\&D tax credits, R\&D allowances, reductions in R\&D workers' wage taxes and social security contributions, as well as accelerated depreciation of capital used for R\&D. These tax rebates are excluded from the definition of direct government funding of R\&D captured in estimates of government budget appropriations or outlays for R\&D (GBAORD). The value of remitted taxes is also excluded from reported government funding of firms' R\&D intramural expenditures, which only include direct transfers of R\&D funds. Some governments also provide tax incentives in the form of favourable treatment of income generated through the exploitation of intellectual property that may be due to previous R\&D activities. These incentives are not included. 
Business R\&D intensity and government support to business R\&D, 2009

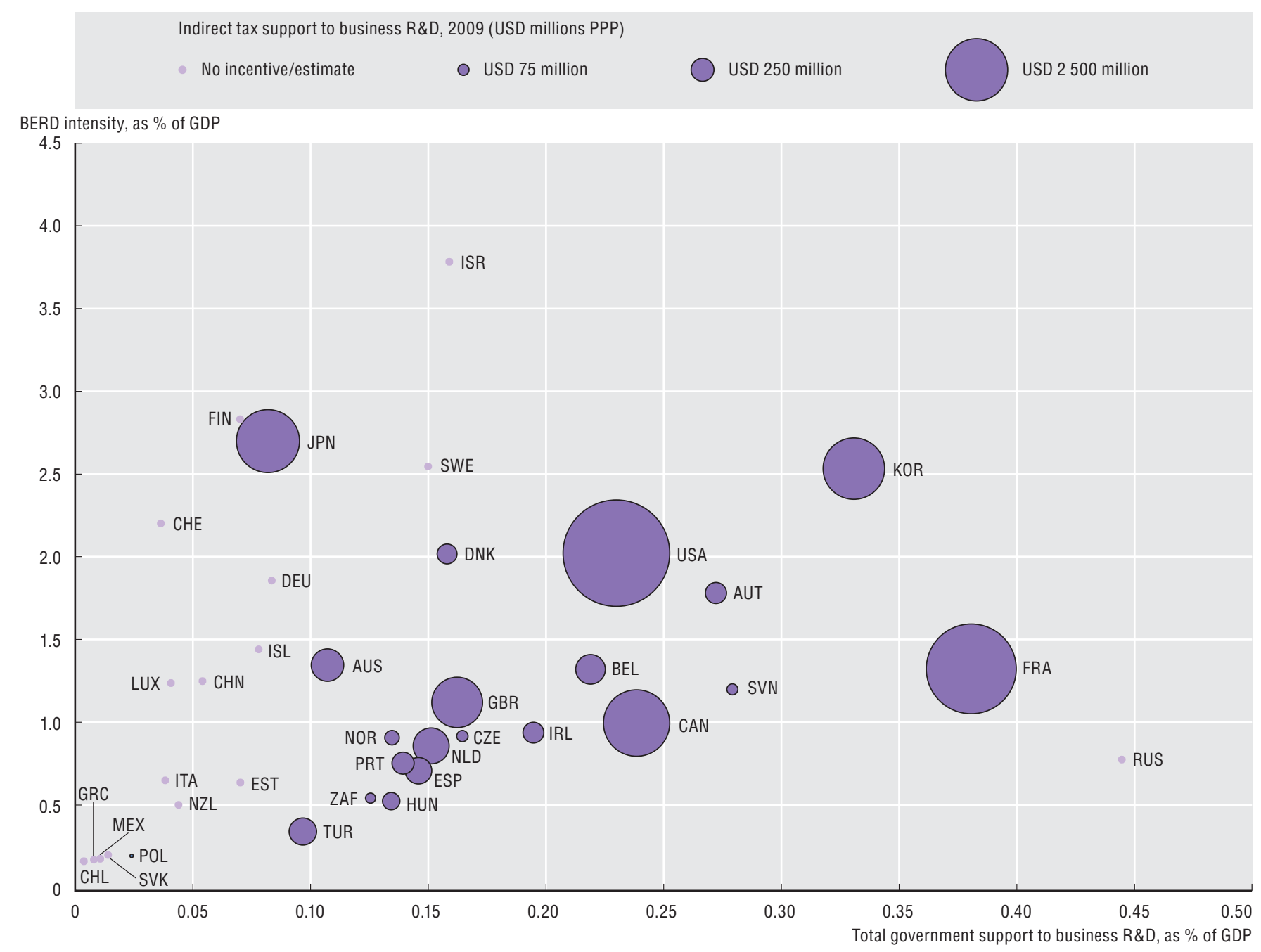

Source: OECD, based on OECD R\&D tax incentives questionnaires, January 2010 and June 2011; and OECD, Main Science and Technology Indicators Database, June 2011. See chapter notes.

StatLink AilsL http://dx.doi.org/10.1787/888932487419

\section{Measurability}

Most countries provide fiscal incentives through tax credits or allowances and capital expensing. Corporate taxation is typically the main conduit, but Belgium, Denmark, France, Korea, the Netherlands and Spain also provide reductions in R\&D workers' wages, taxes and social security contributions. Sub-national tax incentives for R\&D are generally not captured in the national sources, as in US states and Canadian regions. The cost of tax incentives is estimated and reported in different ways. The experimental nature of these indicators needs to be recalled when comparing them to other R\&D indicators. For example, when comparing to business intramural expenditures, eligible R\&D expenditures can differ; R\&D tax incentives can be used by companies in some circumstances to fund intramural or extramural R\&D, some of which can take place in other sectors. In line with Frascati Manual guidance, tax incentives are excluded from the definition of government-funded BERD to minimise the risk of double counting. Administrative data from government R\&D budgets (GBAORD) share features with tax incentive data but sectoral breakdowns are rarely available and cannot be used to estimate support for business R\&D to compare with tax incentive data. The OECD is working on improving the comparability of these statistics for use in policy analysis. 


\section{UNLEASHING INNOVATION IN FIRMS}

\section{Fntry, exit and survival}

Two-year survival of firms in manufacturing and services, 2004 cohort

As a percentage of the total population of employer enterprises

$\diamond$ Three-year survival

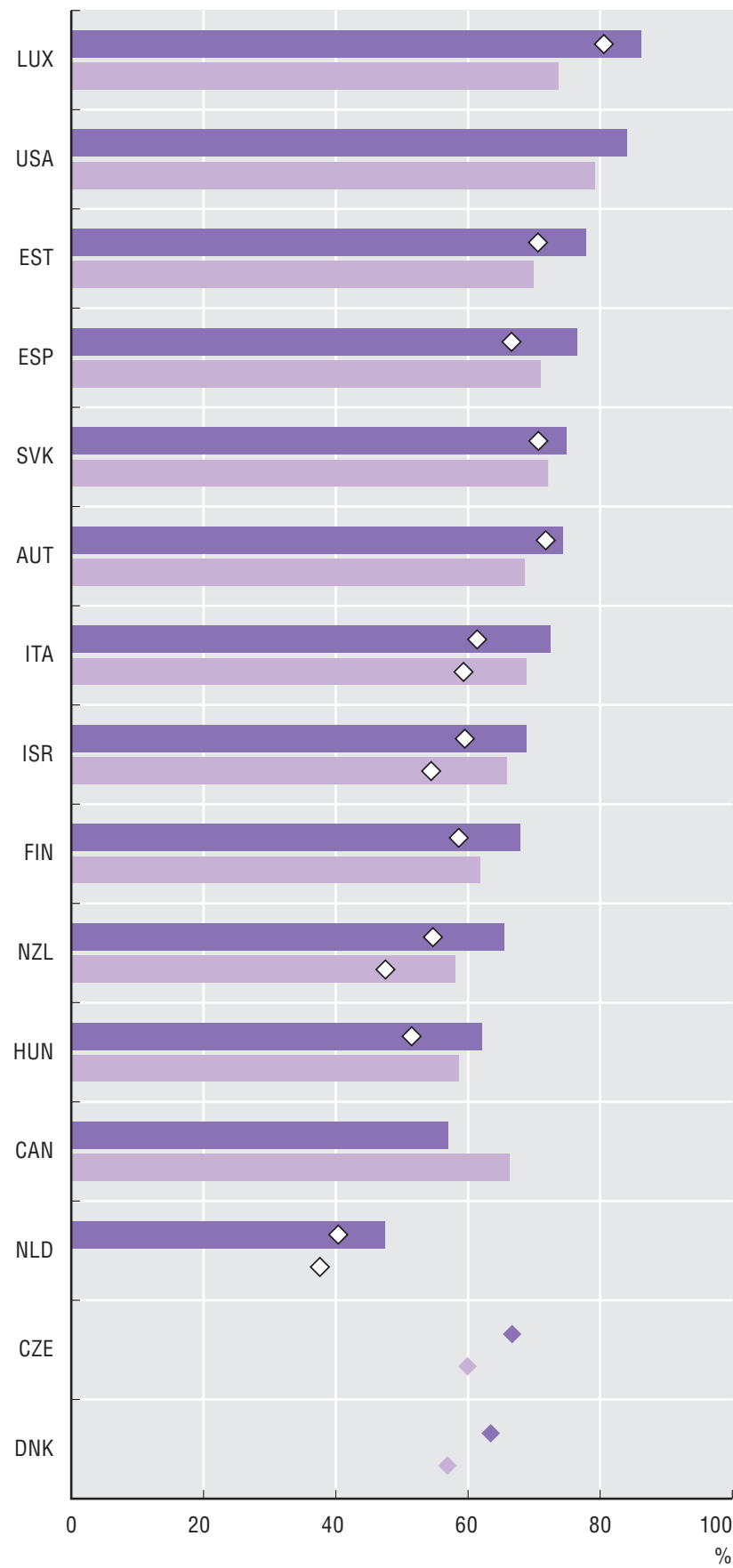

Source: OECD (2011), Entrepreneurship at a Glance 2011, OECD Publishing, Paris.
The birth and death of new enterprises are key indicators of business dynamism. Birth rates reflect an important dimension of entrepreneurship: the capacity to start up entirely new businesses. Death rates can give policy makers an indication of the impact of downturns on businesses and show that running a business often also involves failure.

Together, employer enterprise birth and death rates reflect the process of creative destruction. An efficient process of firm entry and exit makes an important contribution to aggregate employment and productivity growth: market selection leads to the death of less productive firms and the success of more productive ones.

A breakdown by industry shows that there is more entry and exit in services than in manufacturing, with a net entry of services enterprises in most countries, and especially in Estonia and the Slovak Republic. The picture is less clear in manufacturing; relatively lower birth and death rates result in net entry of manufacturing enterprises in the Slovak Republic and Estonia, whereas a net exit is observed in others, notably the United States, Portugal and Canada.

Figures on the survival rates of enterprises can provide insights into key issues such as how long start-ups survive after creation and the differences in enterprises' survival rates across countries and industries. In OECD countries for which the data are available, two-year survival rates in manufacturing and in services are on average $71 \%$ and $67 \%$, respectively. Survival rates of employer enterprises are generally higher in manufacturing than in services.

\section{Definitions}

The $n$-year survival rate for a reference year $t$ is calculated as the number of n-year survival enterprises as a percentage of all enterprises that reported at least one employee for the first time in year $t-n$. In the OECD Structural and Demographic Business Statistics Database, an enterprise is also considered to have survived if the linked legal unit(s) has (have) ceased to be active, but their activity has been taken over by a new legal unit set up specifically to take over the factors of production of that enterprise (survival by takeover). This definition of survival excludes cases in which enterprises merge or are taken over by an existing enterprise in year $t-n$. The employer enterprise birth and death rates are calculated as the number of births and deaths of employer enterprises, respectively, as a percentage of the population of active enterprises with at least one employee. 
Employer enterprise birth rate (2007) and death rate (2006) in the manufacturing sector As a percentage of the population of active enterprises with at least one employee

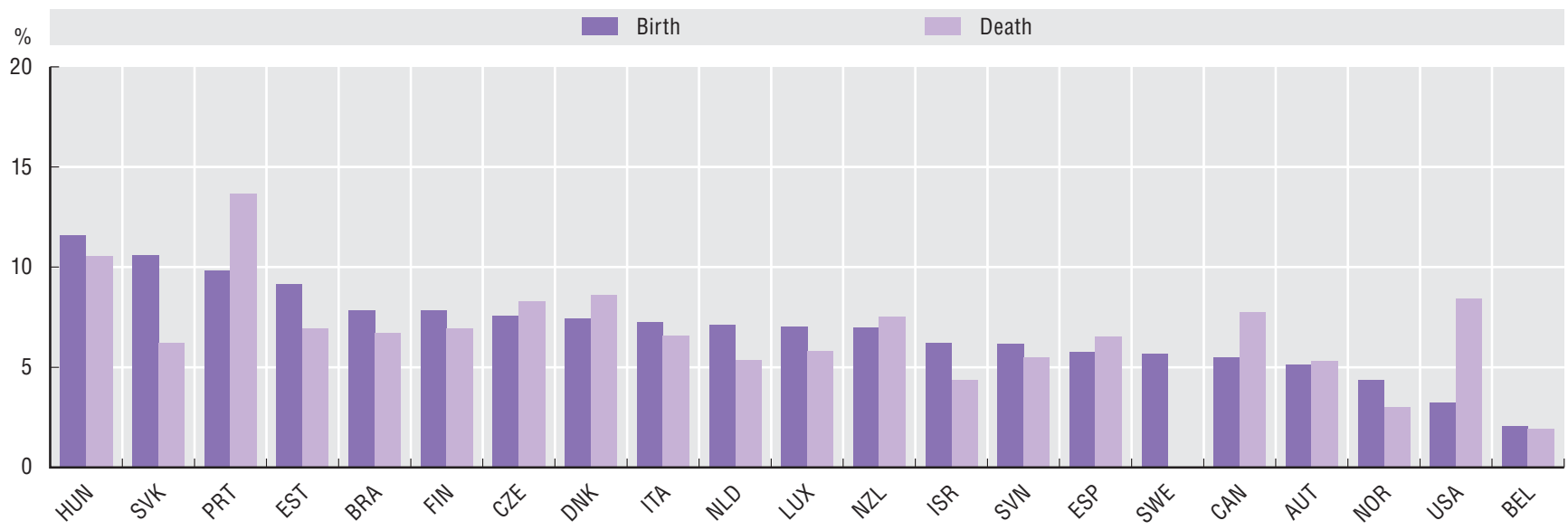

Source: OECD (2011), Entrepreneurship at a Glance 2011, OECD Publishing, Paris.

Employer enterprise birth rate (2007) and death rate (2006) in the services sector As a percentage of the population of active enterprises with at least one employee

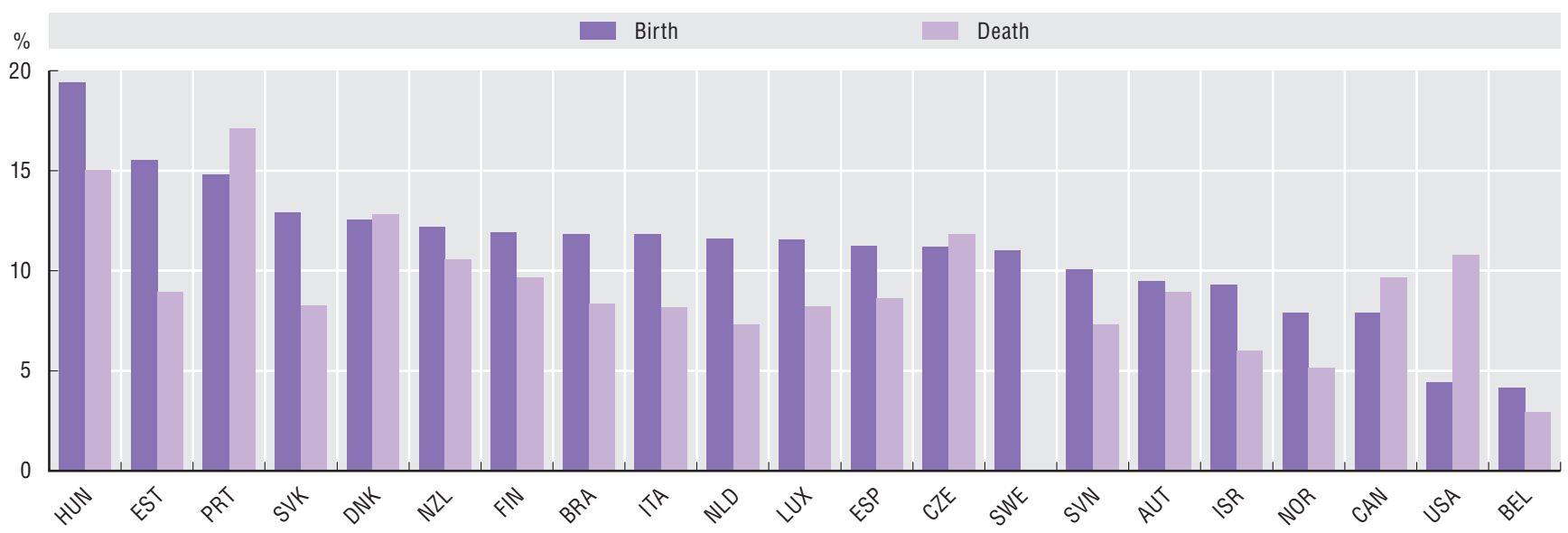

Source: OECD (2011), Entrepreneurship at a Glance 2011, OECD Publishing, Paris.

StatLink काISL http://dx.doi.org/10.1787/888932487324

\section{Measurability}

The OECD defines an employer enterprise birth as the birth of an enterprise with at least one employee. This employer-based indicator, developed in the framework of the OECD-Eurostat Entrepreneurship Indicators Programme (EIP) and included in the OECD Structural and Demographic Business Statistics Database (SDBS), distinguishes between start-ups without employees (self-proprietor/self-employed businesses) and the creation of new businesses with employees. The latter typically have greater growth potential and economic significance. The data are collected only through official sources, e.g. national statistical offices, and thus ensure the international comparability of the data, as the main difference in coverage of business registers is due to the inclusion/exclusion of enterprises with no employees. The current country coverage of EIP will increase progressively over the coming years to cover more OECD member and non-member economies. 


\section{UNLEASHING INNOVATION IN FIRMS}

\section{Access to capital}

Ease of access to loans, 2007-08 and 2009-10

Scale from 1 to 7 from hardest to easiest, weighted averages

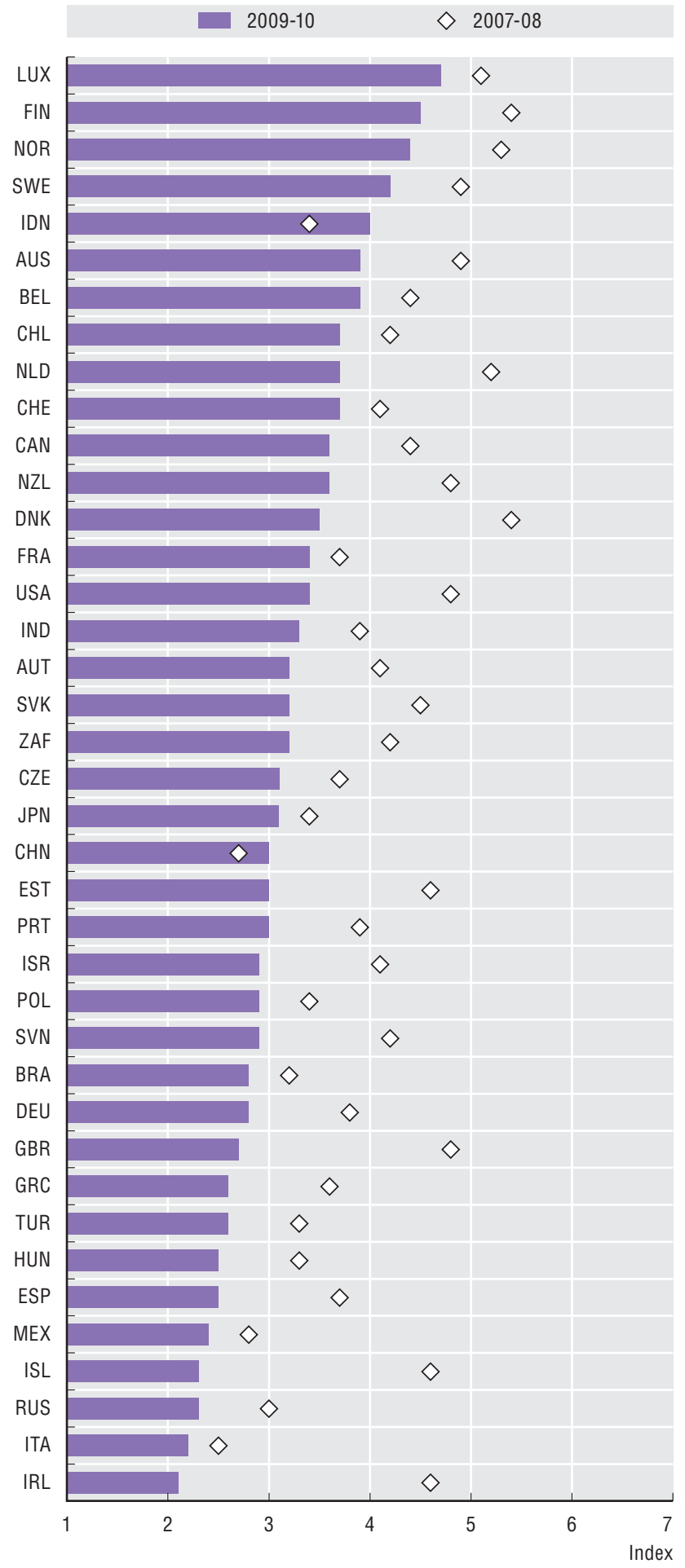

Source: World Economic Forum (2010), The Global Competitiveness Report 2010-2011; and World Economic Forum (2008), The Global Competitiveness Report 2008-2009, World Economic Forum, Geneva.

StatLink iाIs http://dx.doi.org/10.1787/888932487343
Bank loans are an important source of financing for starting a new business or expanding an existing one. The World Economic Forum's Global Competiveness Report, which collects data through executive opinion surveys, provides insight on individuals' views on access to bank loans in different countries. The data show that bank financing became more difficult to obtain between 2007 and 2010 in all countries owing to the financial crisis.

Debt financing is the most common source of financing for small, young firms, although innovative and high-growth firms seek equity financing more than other types of small firms (OECD, 2010). Often entrepreneurs seeking equity investment start with their own funds and those of friends and family. Depending on the size and scope of the venture, entrepreneurs may need other external sources of equity seed capital such as angel investment or venture capital.

Venture capital differs significantly among countries and is very sensitive to market cycles in terms both of amounts invested and stages of investment. Under conditions such as today's financial environment, venture capital funds may invest in later stages, leaving gaps at the pre-seed and seed stages where profit expectations are less clear and risks much higher.

Business angels, who are often experienced entrepreneurs or business people, are increasingly recognised as an important source of equity capital at the seed and early stage of company formation. Angel investors have sought to fill the financing gap left by venture capitalists by investing with other angel investors through groups and syndicates and increasing the deal size for companies seeking early stage financing.

\section{Definitions}

The ease of access to loans indicator measures how easy it is to obtain bank loans with only a good business plan and no collateral on a scale of one to seven; higher values suggesting easier access. Venture capital is private capital provided by specialised firms acting as intermediaries between primary sources of finance (insurance, pension funds, banks, etc.) and private start-up and high-growth companies whose shares are not freely traded on any stock market. A business angel is a private investor who generally provides finance and business expertise to a company in return for an equity share in the firm. Some business angels form syndicates or networks in order to take on larger deals and spread risk.

Business angel groups are formed by individual angels joining together with other angels in order to evaluate and invest in entrepreneurial ventures. The angels can pool their capital to make larger investments.

A business angel network is an organisation whose aim is to facilitate the matching of entrepreneurs with business angels. 


\section{Venture capital investment, 2009}

As a percentage of GDP

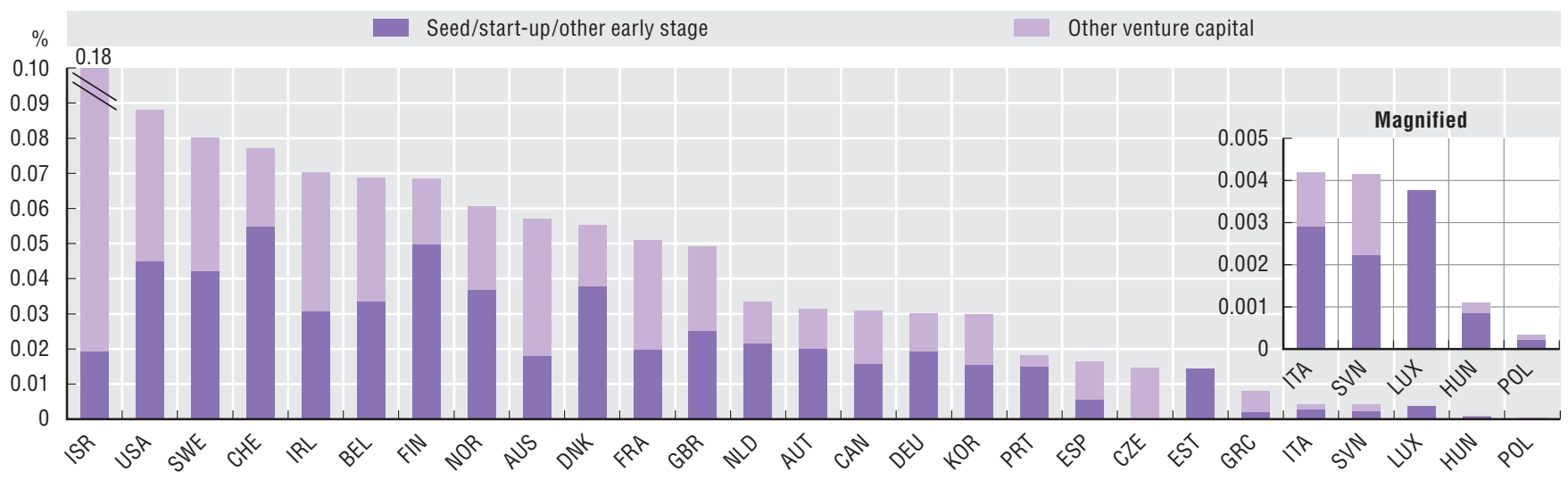

Source: OECD (2011), Entrepreneurship at a Glance 2011, OECD Publishing, Paris, based on OECD Entrepreneurship Financing Database, June 2011. See chapter notes.

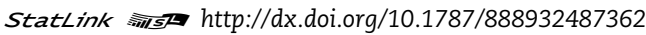

\section{Business angel networks/groups, 2009}

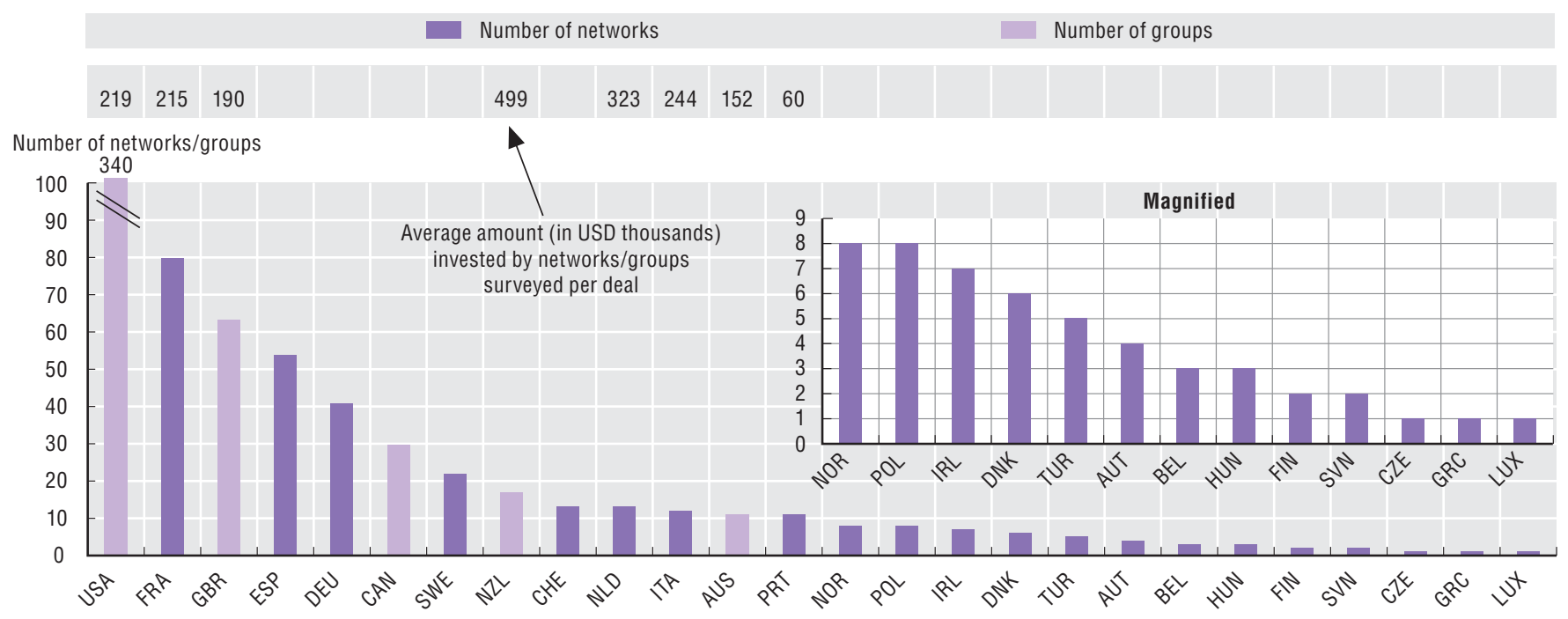

Source: OECD, calculations based on EBAN (The European Trade Association for Business Angels, Seed funds and other Early Stage Market Players), ACA (Angel Capital Association), NACO (National Angel Capital Organization) and AANZ (Angel Association New Zealand), March 2011. See chapter notes. statLink तार्य http://dx.doi.org/10.1787/888932487381

\section{Measurability}

The access to loan index is based on the World Economic Forum's Executive Opinion Survey of business executives' views of their operating environment. In collaboration with 150 partner institutes in 139 countries, 13607 surveys were conducted in 2010 with an average of 98 respondents per country. National and regional venture capital associations collect data from members. Until recently, these data were not fully comparable internationally, owing to differences in definitions and classification methods. Given recent changes in methodology, comparability has improved: inward and outward flows are treated the same way across countries and comparability of industry classifications has improved (OECD, Entrepreneurship at a Glance 2011). National and regional angel capital associations are beginning to collect data on the informal angel investment sector. The US Angel Capital Association (ACA) and the European Business Angel Network (EBAN) work to expand the set of angel investment statistics beyond those currently available. Angel investment is growing in Asia and other regions, although data are not yet collected in a way that allows for cross-country and regional comparisons. 


\section{UNLEASHING INNOVATION IN FIRMS}

\section{Policy environment}

Days needed to start a business, 2003 and 2010

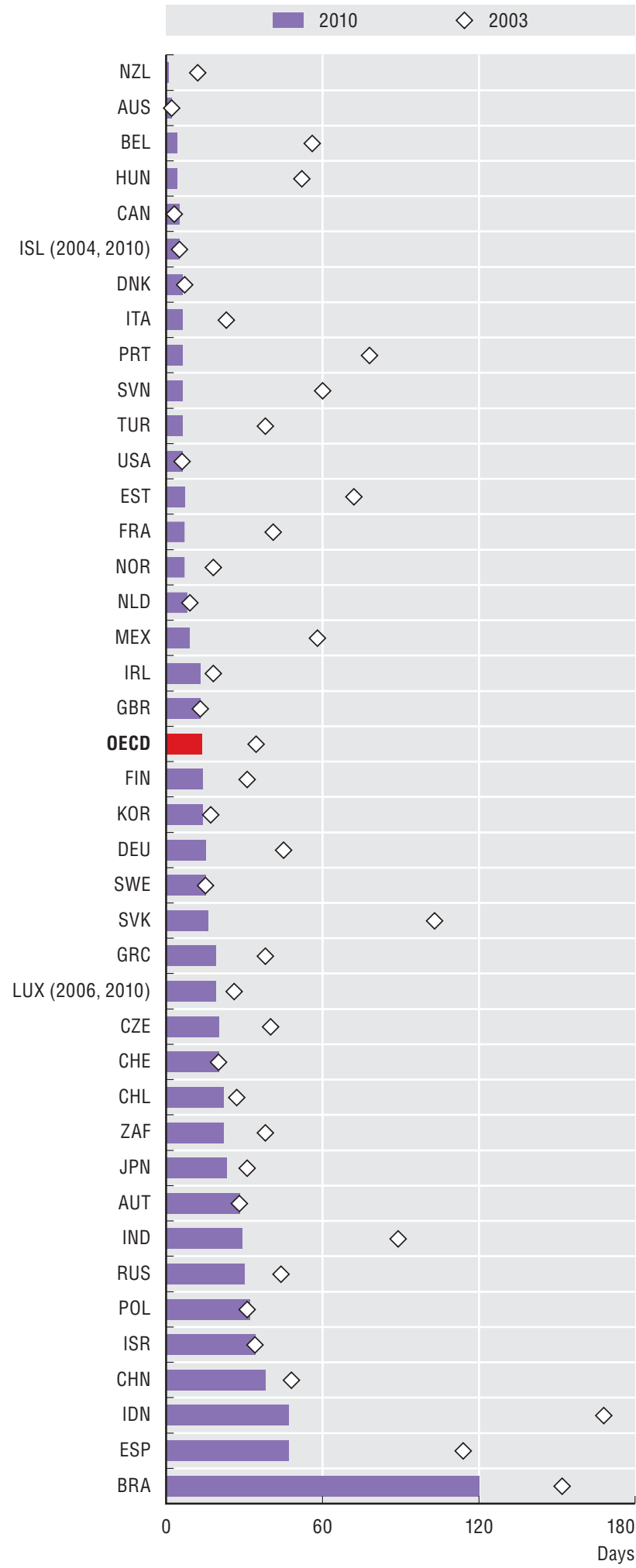

Entry and growth of new firms is important, as is their adaptability to changes in the economy and their ability to exit when necessary. New enterprises drive a large number of obsolete firms out of the market and often do not survive very long themselves. A policy environment that fosters the start-up and growth of new firms is essential for innovation to flourish.

Cutting red tape to improve the quality of regulation is important for facilitating business creation. The decrease in the number of days needed to open a business shows significant progress in this direction. On average in the OECD area it takes 14 days to start a business, down from 34 days in 2003. In Indonesia the number has dropped substantially from 168 to 47 days, while in Brazil it still took 120 days to open a business in 2010.

A high-quality regulatory framework allows businesses to enter the market and grow. During the last decade, most OECD countries have lowered barriers to entrepreneurship. In 2008, barriers to entrepreneurship were highest in China and India (among OECD and BRIICS countries), especially owing to administrative burdens on start-ups.

Individuals' decisions to start a business are also affected by taxes and tax policy: general taxes (personal income, corporate and capital gain tax rates, social security contributions) and targeted tax policies (tax incentives for start-ups, young firms and SMEs). OECD analysis finds that reducing top marginal personal income tax rates raises productivity in industries with potentially high rates of enterprise creation.

\section{Definitions}

Days needed to start a business is the median duration indicated by incorporation lawyers as necessary to complete the procedures. The barriers to entrepreneurship indicator measures regulations affecting entrepreneurship on a scale of zero to six; lower values suggest lower barriers. The index is composed of barriers to competition (legal barriers, antitrust exemptions, barriers in network sectors and in retail and professional services); regulatory and administrative opacity (licences, permits, simplicity of procedures); and administrative burdens for creating new firms. The marginal tax rate covers employees' and employers' social security contributions and personal income tax. The corporate income tax rate is the statutory tax rate applicable to incorporated businesses. It combines the central and sub-central (statutory) corporate income tax rate. 
Barriers to entrepreneurship, 2008

Scale from 0 to 6 from least to most restrictive

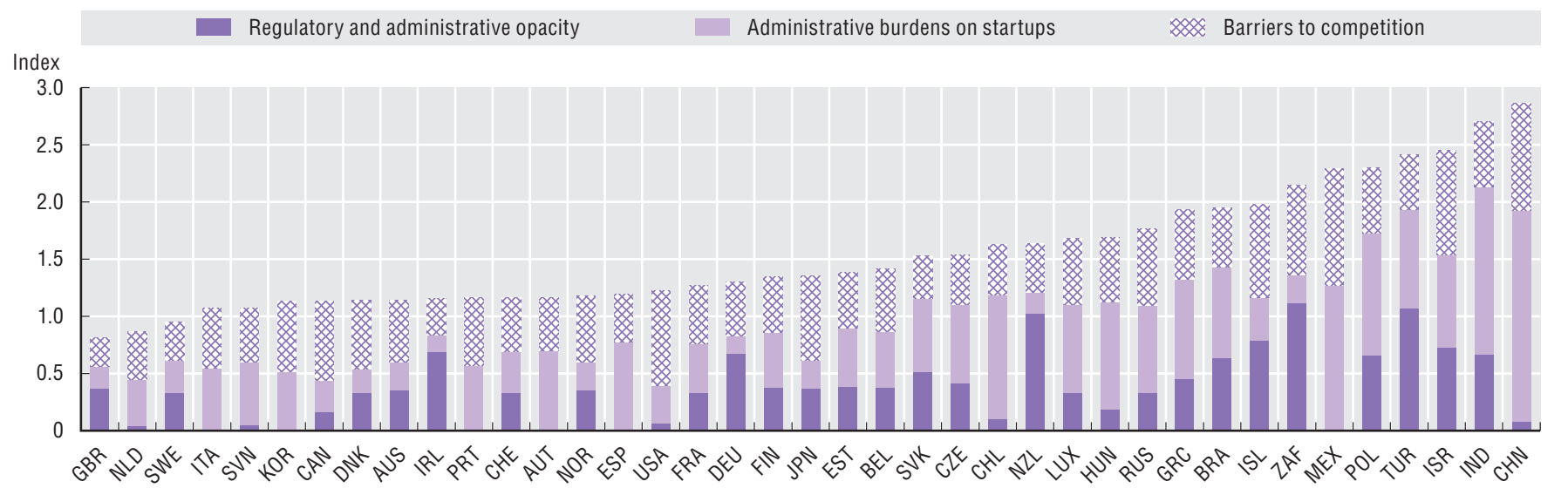

Source: OECD, Product Market Regulation Database, May 2011.

StatLink क्ञाइ http://dx.doi.org/10.1787/888932487457

Taxation on personal income and corporate income, 2010

Marginal personal income tax and social security contribution rates on gross labour income and statutory corporate income tax rates

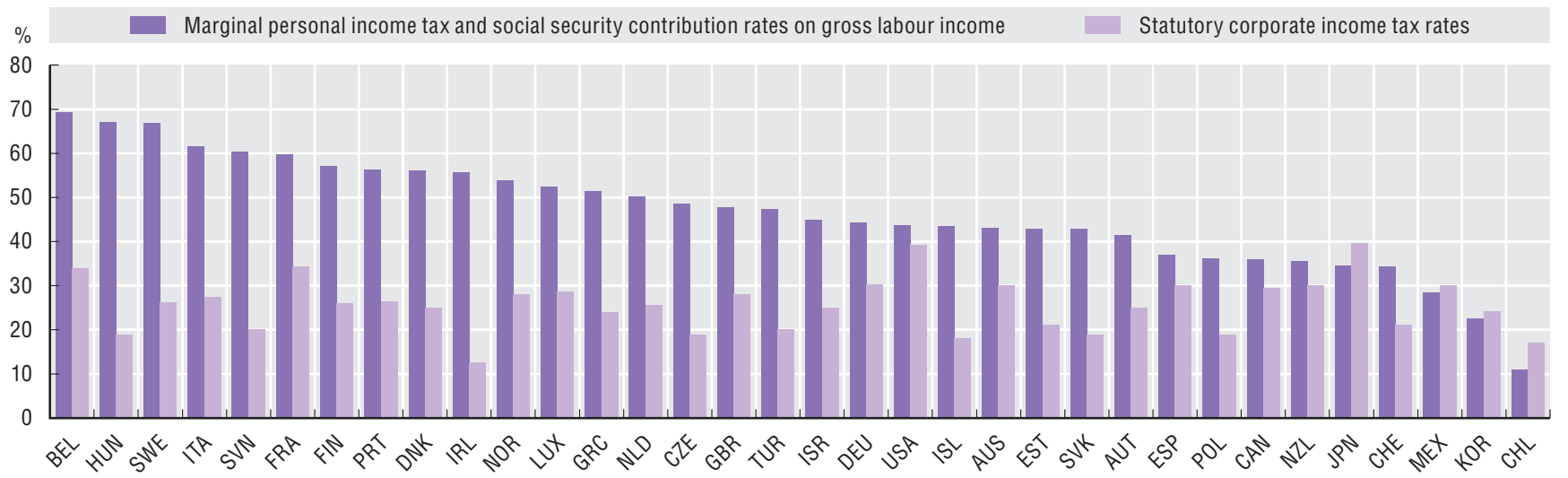

Source: OECD (2011), Taxing Wages 2009-2010, OECD Publishing, Paris. See chapter notes.

StatLink काISL http://dx.doi.org/10.1787/888932487476

\section{Measurability}

Product market regulations indicators are quantitative indicators derived from qualitative information on laws and regulations that may affect competition. The qualitative information mainly comes from a questionnaire filled by national administrations. Higher-level (composite) indicators, such as the barrier to entrepreneurship indicator, are calculated as weighted averages of their lower-level indicators using equal weights for aggregation. Personal income taxes and the differential between the treatment of self-employment income and wage income affect individuals' decision to start a business. Corporate taxes determine the after-tax returns on investment and therefore drive firms' investment decisions. Personal income tax rates on gross wage income are calculated within the OECD Taxing Wages framework, which allows for international comparability across countries. 


\section{UNLEASHING INNOVATION IN FIRMS}

\section{Entrepreneurial talent and culture}

Self-employed by place of birth, 2007-08

As a percentage of all employed persons, two-year average

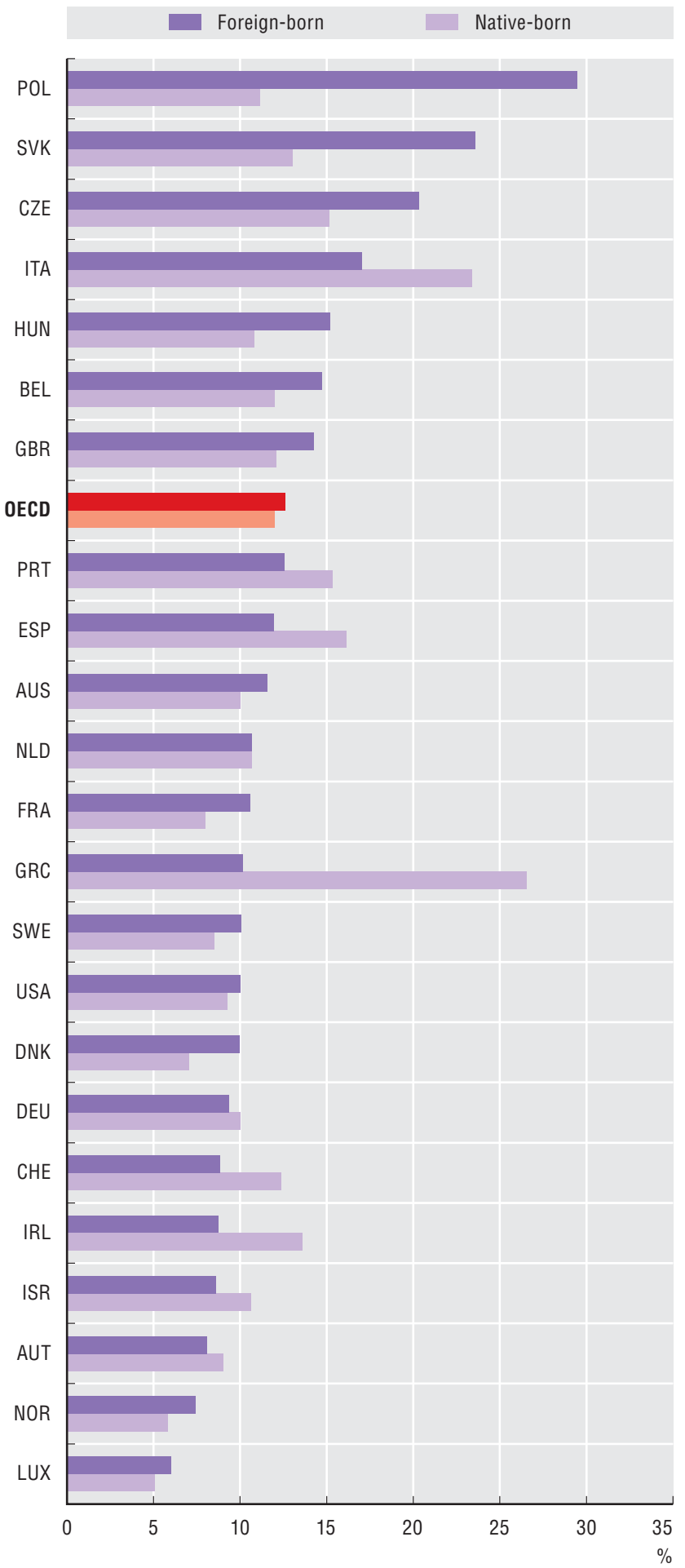

Source: OECD (2011), International Migration Outlook 2011, OECD Publishing, Paris.

StatLink तiाst http://dx.doi.org/10.1787/888932487495
Entrepreneurship empowers people to take their future into their own hands, whether through self-employment or by creating a firm that employs other individuals. A country's entrepreneurial activity ranges from self-employment to the creation of high-growth firms. While data is not available for all these types of entrepreneurs, selfemployment data is available and helps shed some light into the diversity of entrepreneurs in a country.

Foreign migrants often pursue entrepreneurial activities in their country of residence. The potential contribution of migrant entrepreneurs to the host-country's economic growth has drawn the attention of policy makers and several OECD countries have introduced specific migration policies to support them. While a first type of measures consists in supporting migrant entrepreneurs already established in the host country, a second type includes specific admission policies that regulate the entry and stay of foreign entrepreneurs and investors. Self-employment ratio is indeed higher among the foreign-born population than the native-born population in most of the OECD countries over the 2007-08 period. This share is particularly high in Poland, the Slovak Republic and the Czech Republic.

Enabling people throughout the economy and society to become entrepreneurs will provide new ideas, knowledge and capabilities, and enhance the influence of market demand on innovation. Developing entrepreneurial talent is important for turning innovations into opportunities which create value, jobs and economic growth. There are no internationally comparable data on the gender dimension of entrepreneurship; however surveys from the Global Entrepreneurship Monitor (GEM) Consortium provide insights on entrepreneurial activity of women in different countries. This data shows that the share of women entrepreneurs has increased between 2005 and 2010, however women still represent on average one third of entrepreneurs, except in Mexico and the Russian Federation where they are on a par with men.

Contrary to popular belief, the majority of entrepreneurs start companies later in life. On average across countries, half of entrepreneurs are over 45 years old. In addition, the average age of entrepreneurs increased from 2005 to 2010.

\section{Definitions}

Self-employed persons are those who work in their own business, professional practice or farm for the purpose of earning a profit. They may or may not have employees. Entrepreneurially active population is defined by GEM as adults in the working-age population who are actively involved in business start-ups (nascent entrepreneurs or owner-managers of new firms) and business owners who have paid salaries and wages for more than 42 months (established business owners). 
Women entrepreneurs, 2005 and 2010

As a percentage of all entrepreneurs

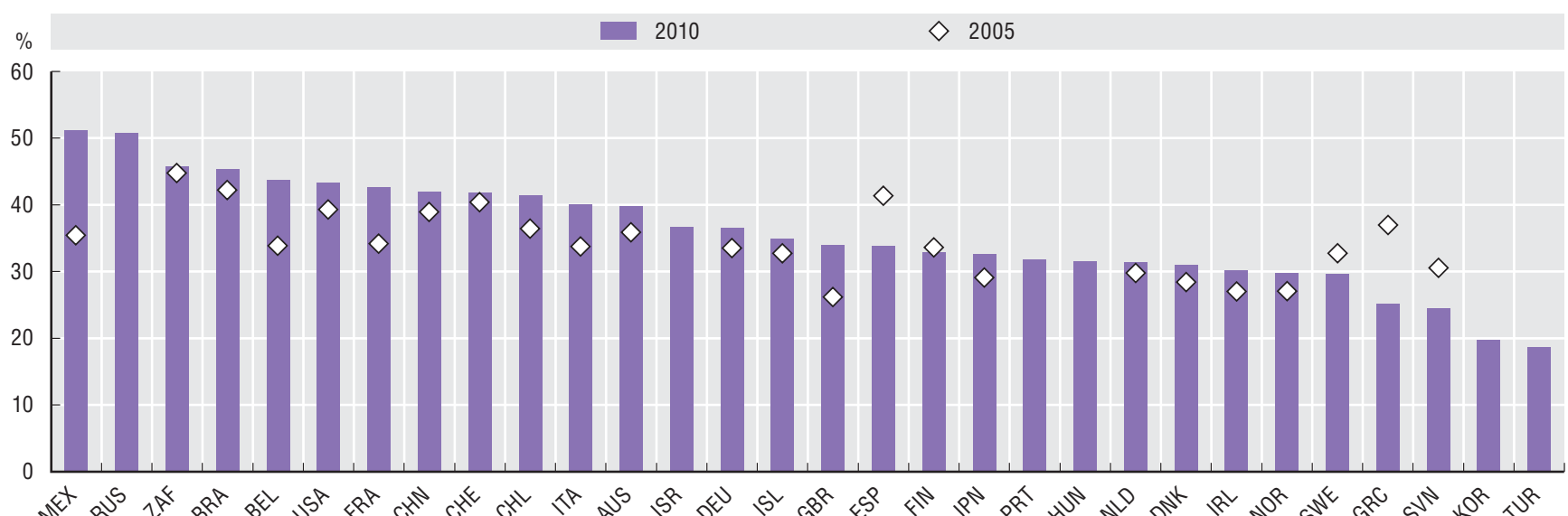

Source: GEM, Global Entrepreneurship Monitor Database, July 2011.

\section{Entrepreneurs aged less than 45 years-old, 2005 and 2010}

As a percentage of all entrepreneurs

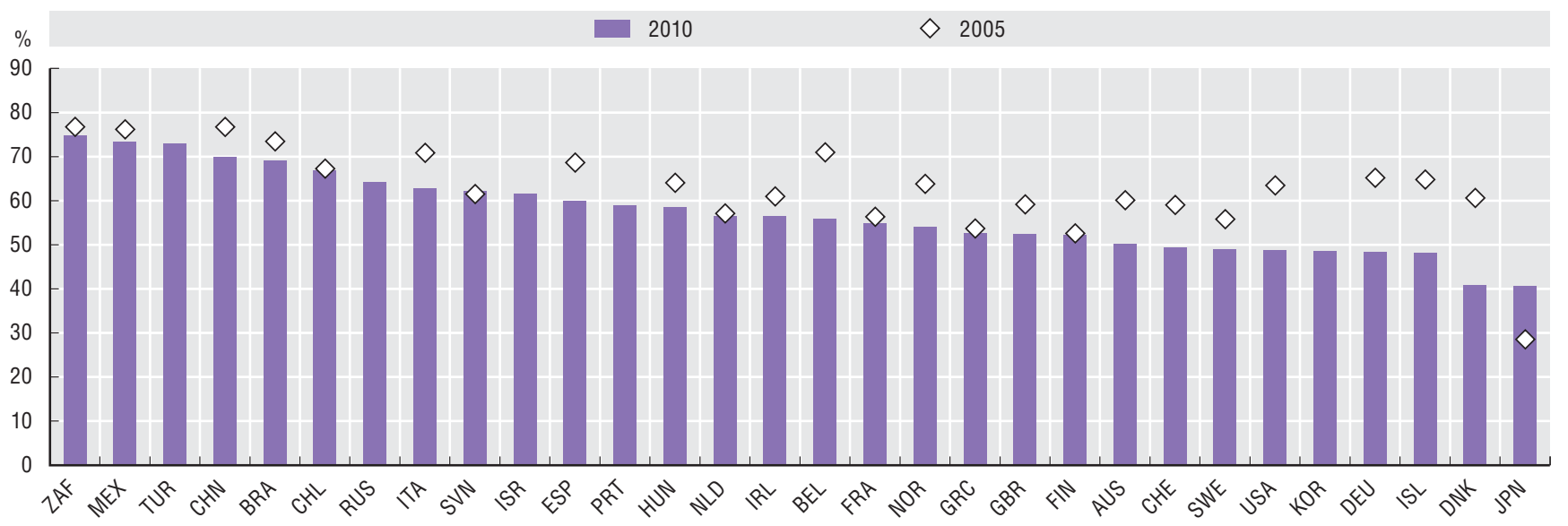

Source: GEM, Global Entrepreneurship Monitor Database, July 2011.

StatLink AाsL http://dx.doi.org/10.1787/888932487533

\section{Measurability}

While several proxies have been used to determine the level of entrepreneurship in countries, more work is needed to develop metrics that provide a complete picture of entrepreneurial activity.

Data on self-employment is based on the European and national labour force surveys whose concepts and definitions are based upon the ILO's guidelines to guarantee international comparability. Indicators on entrepreneurial characteristics by gender and age are derived from the Global Entrepreneurship Monitor (GEM) survey which collects information on personal assessments, attitudes and perceptions, in addition to intentions of starting a business. Run by national teams, the GEM survey is conducted among at least 2000 people within a country's adult population. See www.gemconsortium.org for more details on the methodology. 


\section{UNLEASHING INNOVATION IN FIRMS}

\section{Notes}

\section{Cyprus}

The following note is included at the request of Turkey:

"The information in this document with reference to 'Cyprus' relates to the southern part of the Island. There is no single authority representing both Turkish and Greek Cypriot people on the Island. Turkey recognises the Turkish Republic of Northern Cyprus (TRNC). Until a lasting and equitable solution is found within the context of the United Nations, Turkey shall preserve its position concerning the 'Cyprus issue'."

The following note is included at the request of all the European Union member states of the OECD and the European Commission:

"The Republic of Cyprus is recognised by all members of the United Nations with the exception of Turkey. The information in this document relates to the area under the effective control of the Government of the Republic of Cyprus."

\section{Israel}

"The statistical data for Israel are supplied by and under the responsibility of the relevant Israeli authorities. The use of such data by the OECD is without prejudice to the status of the Golan Heights, East Jerusalem and Israeli settlements in the West Bank under the terms of international law."

"It should be noted that statistical data on Israeli patents and trademarks are supplied by the patent and trademark offices of the relevant countries."

\section{Innovation strategies by firm size, 2006-08}

For Brazil, only the following activities are included in the services sector: ISIC Rev. 4 Divisions 58, 61, 62 and 72. For Canada, data refer to 2007-09 and cover firms with 20 or more employees. Firms with ongoing/abandoned innovation activities are not identified. The industries covered are NAICS (2007) 31-33, 41, 48, 49, 51,52 and 54.

For Chile, data refer to 2007-08 and firms with ongoing or abandoned innovative activities are not identified. Data are based on ISIC Rev. 3.1 and include a wider range of activities such as agriculture, forestry, fishing, construction, and some services.

For Korea, data refer to 2005-07 and cover only firms with more than 10 employees in the manufacturing sector. Product innovation only covers innovation for goods.

For New Zealand, data refer to 2008-09 and include firms with 6 or more employees.

For the Russian Federation, data refer to manufacturing firms with 15 or more employees.

For South Africa, data refer to 2005-07 and include the retail trade sector. Firm size is based on turnover.

\section{Innovation strategies in the manufacturing sector, 2006-08}

For Canada, data refer to 2007-09 and cover firms with 20 or more employees. Firms with ongoing/abandoned innovation activities are not identified.

For Chile, data refer to 2007-08 and firms with ongoing or abandoned innovative activities are not identified.

For Korea, data refer to 2005-07 and cover only firms with more than 10 employees. Product innovation only covers innovation for goods.

For New Zealand, data refer to 2008-09 and include firms with 6 or more employees.

For the Russian Federation, data refer to firms with 15 or more employees.

For South Africa, data refer to 2005-07.

\section{Innovation strategies in the services sector, 2006-08}

For Brazil, only the following activities are included in the services sector: ISIC Rev. 4 Divisions 58, 61, 62 and 72. For Canada, data refer to 2007-09 and cover firms with 20 or more employees. Firms with ongoing/abandoned innovation activities are not identified. The industries covered are NAICS (2007) 41, 48, 49, 51, 52 and 54.

For Chile, data refer to 2007-08 and firms with ongoing or abandoned innovative activities are not identified. Data are based on ISIC Rev. 3.1 and include the following sectors: G, I(60-64), J, K72 and K74.

For New Zealand, data refer to 2008-09 and include firms with 6 or more employees.

For South Africa, data refer to 2005-07 and include the retail trade sector. 


\section{Firms engaged in innovation collaboration by R\&D status, 2006-08}

For Brazil, only the following activities are included in the services sector: ISIC Rev. 4 Divisions 58, 61, 62 and 72. For Chile, data refer to 2007-08 and firms with ongoing or abandoned innovative activities are not identified. Data are based on ISIC Rev. 3.1 and include a wider range of activities such as agriculture, forestry, fishing, construction, and some services.

For Korea, data refer to 2005-07 and cover only firms with more than 10 employees in the manufacturing sector. For New Zealand, data refer to 2008-09 and include firms with six or more employees. Innovative firms include technological and non-technological innovators.

For the Russian Federation, data refer to manufacturing firms with 15 or more employees.

For South Africa, data refer to 2005-07 and include the retail trade sector.

For Spain, R\&D status corresponds to 2008 only.

For Turkey, data are based on NACE Rev. 1.1 and exclude some activities within NACE Rev. 2 Divisions J58 and J63.

\section{Product innovators by R\&D status, 2006-08}

For Brazil, only the following activities are included in the services sector: ISIC Rev. 4 Divisions 58, 61, 62 and 72. For Chile, data refer to 2007-08 and firms with ongoing or abandoned innovative activities are not identified. Data are based on ISIC Rev. 3.1 and include a wider range of activities such as agriculture, forestry, fishing, construction, and some services.

For Korea, data refer to 2005-07 and cover only firms with more than 10 employees in the manufacturing sector. Product innovation only covers goods innovation.

For New Zealand, data refer to 2008-09 and include firms with six or more employees.

For the Russian Federation, data refer to manufacturing firms with 15 or more employees.

For South Africa, data refer to 2005-07 and include the retail trade sector.

For Spain, R\&D status corresponds to 2008 only.

For the United States, data cover all firms with more than five employees across all industries.

\section{Process innovators by R\&D status, 2006-08}

For Brazil, only the following activities are included in the services sector: ISIC Rev. 4 Divisions 58, 61, 62 and 72. For Chile, data refer to 2007-08 and firms with ongoing or abandoned innovative activities are not identified. Data are based on ISIC Rev. 3.1 and include a wider range of activities such as agriculture, forestry, fishing, construction, and some services.

For Korea, data refer to 2005-07 and cover only firms with more than 10 employees in the manufacturing sector. For New Zealand, data refer to 2008-09 and include firms with six or more employees.

For the Russian Federation, data refer to manufacturing firms with 15 or more employees.

For South Africa, data refer to 2005-07 and include the retail trade sector.

For Spain, R\&D status corresponds to 2008 only.

For the United States, data cover all firms with more than five employees across all industries.

\section{Trademark applications at JPO, OHIM and USPTO, 2007-09 average}

Average number of trademark applications at the various offices over the period 2007-09, expressed as a ratio to GDP. Counts are presented according to the application date and the address of the applicant. Countries are ordered according to USPTO figures.

\section{Trademark applications by BRIICS countries at national IP offices, USPTO, OHIM, and JPO, ratio to GDP, 2007-09 average}

Average number of trademark applications at the various offices over the period 2007-09, expressed as a ratio to GDP. Counts are presented according to the application date and the residence of the applicant.

National offices' figures are not directly comparable as some countries have single-class systems (Brazil, China, South Africa) whereas others have adopted a multi-class system (India, the Russian Federation), and some countries are currently in a transition phase from single-class to multi-class systems (Indonesia). 


\section{UNLEASHING INNOVATION IN FIRMS}

For Brazil national office figure refers to 2006-08.

For India, national office figure refers to 2003-05.

For Indonesia, national office figure refers to 2004-06.

\section{Share of goods and services trademark applications at USPTO and OHIM, 2007-09}

Shares of good and service trademarks are calculated using fractional counts of the classes designated in the trademark application. Classes 1 to 34 relate to goods; classes 35 to 45 relate to services.

Countries are ordered according to the share of good trademarks at USPTO.

\section{Government-financed BERD by firm size, 2009}

Small firms (fewer than 50 employees): for the United States, 5-49 employees; for Luxembourg, the Netherlands and Sweden, 10-49 employees.

\section{Firms engaged in innovation-related training by firm size, 2002-04 and 2006-08}

For Austria and Slovenia, the periods are 2004-06 and 2006-08.

For Brazil, only the following activities are included in the services sector: ISIC Rev. 4 Divisions 58, 61, 62 and 72.

For New Zealand, data refer to 2004-05 and 2008-09 and include firms with six or more employees. Innovative firms include technological and non-technological innovators.

For the Russian Federation, data refer to manufacturing firms with 15 or more employees.

For South Africa, data refer to 2005-07 and include the retail trade sector. Firm size is based on turnover.

\section{Firms receiving public support for innovation by firm size, 2002-04 and 2006-08}

For Brazil, only the following activities are included in the services sector: ISIC Rev. 4 Divisions 58, 61, 62 and 72. For Canada, data refer to 2002-04 and 2007-09 and cover firms with 20 or more employees. Firms with ongoing/ abandoned innovation activities are not identified. The industries covered are NAICS (2007) 31-33, 41, 48, 49, 51, 52 and 54 for 2007-09, and manufacturing only for 2002-04.

For Chile, data refer to 2007-08 and firms with ongoing or abandoned innovative activities are not identified. Data are based on ISIC Rev. 3.1 and include a wider range of activities such as agriculture, forestry, fishing, construction, and some services.

For China, data refer to 2004-06 and exclude all services. In addition, large firms are defined as firms with over 2000 employees, over CNY 300 million turnover and over CNY 400 million capital. SMEs are the remaining firms with at least CNY 5 million turnover.

For Israel, data refer to public support for R\&D.

For Mexico, data refer to 2008-09 and cover firms with 20 or more employees. The industries covered are based on ISIC Rev. 3.1 and include a wider range of activities such as agriculture, construction and some services.

For the Russian Federation, data refer to manufacturing firms with 15 or more employees.

For Slovenia, the periods are 2004-06 and 2006-08.

For South Africa, data refer to 2005-07 and include the retail trade sector. Firm size is based on turnover.

Direct government funding of business R\&D and tax incentives for R\&D, 2009

The estimates of R\&D tax expenditures do not cover sub-national R\&D tax incentives.

Estonia, Finland, Germany, Luxembourg, Sweden and Switzerland do not provide R\&D tax incentives.

China, Greece, Iceland, Israel, Italy , the Slovak Republic and the Russian Federation provide R\&D tax incentives but cost estimates are not available.

Estimates for Australia, Hungary and Korea are based on country responses to the 2010 OECD R\&D tax incentives questionnaire.

2008 instead of 2009 for Australia, Chile, France, Germany, Hungary, Iceland, Ireland, Israel, Italy, Japan, Korea, Portugal, South Africa, Switzerland and the United States.

2007 instead of 2009 for Austria, Belgium, Greece, Mexico, New Zealand and Spain.

The estimate for Austria covers the refundable research premium but excludes other R\&D allowances. The value of research premium has been taken out of direct government funding of business R\&D to avoid double counting. 
For 2008, estimates for France are based on accrual accounting measures of tax costs instead of cash-based measures of foregone tax. Before 2009, unused credits in France could not be refunded for three years, resulting in significant differences in tax cost estimates according to the method used. For 2008, claims exceeded paid credits by EUR 2.7 billion while in 2009, as a result of exceptional stimulus measures that allowed for the immediate payment of tax credit liabilities, tax expenditures exceeded claims by nearly EUR 1.5 billion. 2009 data for France are not reported due to the unavailability of comparable estimates for business R\&D direct funding for that year.

The United States estimate covers the research tax credit but excludes the expensing of R\&D.

\section{Business R\&D intensity and government support to business R\&D, 2009}

The estimates of R\&D tax expenditures do not cover sub-national R\&D tax incentives.

Estonia, Finland, Germany, Luxembourg, Sweden and Switzerland do not provide R\&D tax incentives.

China, Greece, Iceland, Israel, Italy, the Slovak Republic and the Russian Federation provide R\&D tax incentives but cost estimates are not available.

Mexico and New Zealand repealed tax schemes in 2009. No cost estimates are available for Mexico. In 2008, the cost for R\&D tax incentives for New Zealand was NZD 103 million but BERD government funding data are not available for that year.

Estimates for Australia, Hungary and Korea are based on country responses to the 2010 OECD R\&D tax incentives questionnaire.

2008 instead of 2009 for Australia, Chile, France, Germany, Hungary, Iceland, Ireland, Israel, Italy, Japan, Korea, Portugal, South Africa, Switzerland and the United States.

2007 instead of 2009 for Austria, Belgium, Greece, Mexico, New Zealand and Spain.

The estimate for Austria covers the refundable research premium but excludes other R\&D allowances. The value of research premium has been taken out of direct government funding of business R\&D to avoid double counting. For 2008 and 2004, estimates for France are based on accrual accounting measures of tax costs instead of cashbased measures of foregone tax. Before 2009, unused credits in France could not be refunded for three years, resulting in significant differences in tax cost estimates according to the method used. For 2008, claims exceeded paid credits by EUR 2.7 billion while in 2009, as a result of exceptional stimulus measures that allowed for the immediate payment of tax credit liabilities, tax expenditures exceeded claims by nearly EUR 1.5 billion. 2009 data for France are not reported due to the unavailability of comparable estimates for business R\&D direct funding for that year.

The United States estimate covers the research tax credit but excludes the expensing of R\&D.

\section{Venture capital investment, 2009}

Other venture capital stage: Includes early expansion for Australia, later stage for European countries and expansion for the United States.

For European countries, bridge financing have been removed from later stage.

Seed/Start-up/Other early stage: Includes pre-seed stage for Australia.

Data providers are: EVCA (European countries), ABS (Australia), KVCA (Korea), PwCMoneyTree (Israel and the United States) and Thomson Reuters (Canada).

\section{Business angel networks/groups, 2009}

Data refer to networks and groups surveyed by the business angel associations.

Business angel groups are formed by individual angels joining together with other angels in order to evaluate and invest in entrepreneurial ventures. The angels can pool their capital to make larger investments.

A business angel network is an organisation whose aim is to facilitate the matching of entrepreneurs with business angels.

For Canada, data refer to 2010. 


\section{UNLEASHING INNOVATION IN FIRMS}

Taxation on personal income and corporate income, 2010

General notes on the chart:

- Marginal tax rate covers employees' and employers' social security contributions and personal income tax, with respect to a change of gross labour costs. It is given for a single person without dependent, at $167 \%$ of the average wage earner/average production worker. It assumes a rise in gross earnings of the principal earner in the household. The outcome may differ if the wage of the spouse goes up, especially if partners are taxed individually.

- The marginal rates are expressed as a percentage of gross labour costs.

- Corporate income tax shows the basic combined central and sub-central (statutory) corporate income tax rate given by the adjusted central government rate plus the sub-central rate.

Notes on statutory corporate income tax rate:

- For Australia, New Zealand and the United Kingdom, all with a non-calendar tax year, the rates shown are those in effect as of 1 July, 1 April and 5 April respectively.

- In Belgium, the effective CIT rate can be substantially reduced by a notional allowance for corporate equity.

- In Chile, individuals and legal entities that are not resident or domiciled in Chile are taxed on any income derived from Chilean sources with a general tax rate of 35\% (lower rates apply for some types of income and are available under double taxation agreements).

- In Estonia, since 1 January 2000, the corporate income tax is levied on distributed profits.

- For France, the rates include a surcharge, but do not include the local business tax (Taxe professionnelle) or the turnover based solidarity tax (Contribution de Solidarité).

- For Germany, the rates include the regional trade tax (Gewerbesteuer) and the surcharge.

- For Hungary, the rates do not include the turnover based local business tax, the innovation tax, the financial institutions' surtaxes, the energy suppliers' surtax and the crisis taxes.

- In Israel, within the VAT law, financial institutions pay taxes on the combination of their wages and salaries and their profits. These amounts are deductible from profits in the assessment of corporate income tax.

- For Italy, these rates do not include the regional business tax (Imposta Regionale sulle Attività Produttive; IRAP).

- In Poland, there is no sub-central government tax; however local authorities (of each level) participate in tax revenue at a given percentage for each level of local authority.

- In Portugal since 2009, two general tax rates are applied at a Central Government Level. A general tax rate of $12.5 \%$ is applied for the first EUR 12500 of taxable income and a $25 \%$ tax rate is applied for the remaining amount of taxable income (when the total taxable income exceeds EUR 12 500).

- For Switzerland, church taxes, which cannot be avoided by enterprises, are included.

- For the United States, the sub-central rate is a weighted average state corporate marginal income tax rate.

- The Netherlands applies to taxable income over EUR 200000.

Note on marginal personal income tax rate:

- For Turkey, wage figures are based on the old definition of average worker (ISIC D, Rev. 3). 
International Finance Corporation, International Bank for Reconstruction and Development and World Bank (2010), Doing Business 2011, Washington DC.

ISIC Rev. 3 Technology Intensity Definition (OECD, online document), www.oecd.org/dataoecd/43/41/48350231.pdf.

Japan Patent Office (JPO) (2008-10), Annual Reports, JPO, Tokyo.

Kelley, D.J., N. Bosma and J.E. Amorós (2011), Global Entrepreneurship Monitor: 2010 Global Report, Global Entrepreneurship Research Association (GERA), www.gemconsortium.org.

Millot, V. (2009), “Trademarks as an Indicator of Product and Marketing Innovations”, OECD Science, Technology and Industry Working Papers, No. 2009/06. Doi: http://dx.doi.org/10.1787/224428874418.

OECD (2002), Frascati Manual 2002: Proposed Standard Practice for Surveys on Research and Experimental Development, The Measurement of Scientific and Technological Activities, OECD Publishing, Paris. Doi: http://dx.doi.org/10.1787/ 9789264199040-en.

OECD and Eurostat (2005), Oslo Manual: Guidelines for Collecting and Interpreting Innovation Data, 3rd edition, OECD Publishing, Paris. Doi: http://dx.doi.org/10.1787/9789264013100-en.

OECD (2009), Innovation in Firms: A Microeconomic Perspective, OECD Publishing, Paris. Doi: http://dx.doi.org/10.1787/ 9789264056213-en.

OECD (2010), Measuring Innovation: A New Perspective, OECD Publishing, Paris. Doi: http://dx.doi.org/10.1787/ 9789264059474-en.

OECD (2011), Economic Policy Reforms 2011: Going for Growth, OECD Publishing, Paris, http://dx.doi.org/10.1787/growth-2011-en. OECD (2011), Entrepreneurship at a Glance 2011, OECD Publishing, Paris. Doi: http://dx.doi.org/10.1787/9789264097711-en.

OECD (2011), "Financing High-Growth Firms: The Role of Angel Investors”, OECD Publishing, Paris (forthcoming).

OECD (2011), International Migration Outlook 2011, OECD Publishing, Paris, http://dx.doi.org/10.1787/migr_outlook-2011-en.

OECD (2011), “R\&D Tax Incentives: Rationale, Design, Measurement and Evaluation”, DSTI/EAS/STP/NESTI(2011)2/FINAL, OECD Publishing, Paris (forthcoming).

OECD (2011), Taxing Wages 2009-2010, OECD Publishing, Paris. Doi: http://dx.doi.org/10.1787/tax_wages-2010-en. World Economic Forum (2008), The Global Competitiveness Report 2008-2009, World Economic Forum, Geneva.

World Economic Forum (2010), The Global Competitiveness Report 2010-2011, World Economic Forum, Geneva. 


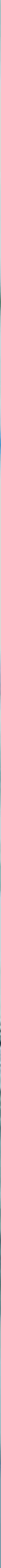




\section{Employment in services, 2009 \\ As a percentage of total employment \\ "Market sector" services $\diamond$ Industry}

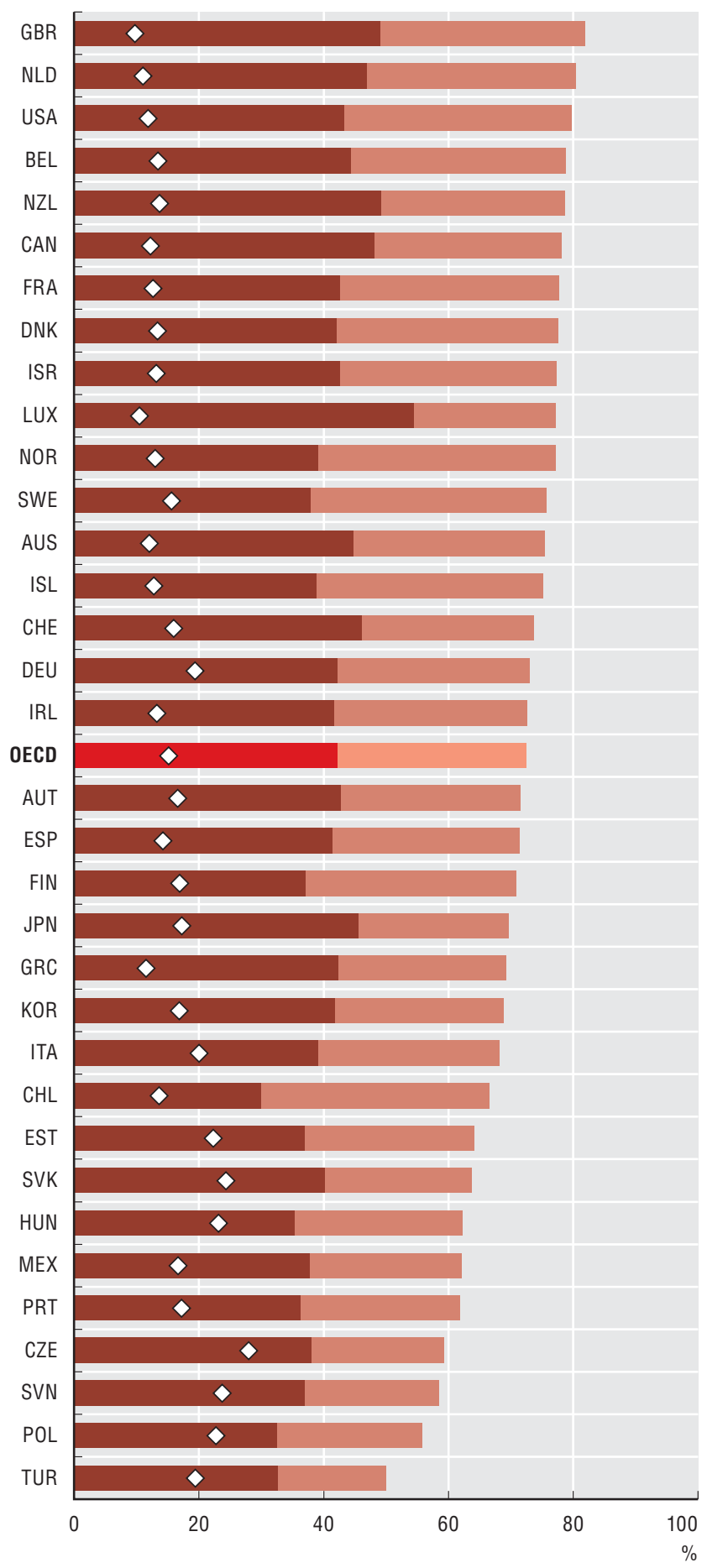

Source: OECD, Annual National Accounts Database, June 2011. See chapter notes.

StatLink ला15य http://dx.doi.org/10.1787/888932487552
With employment in manufacturing and construction being particularly badly hit during the recent crisis, the role of services in many OECD countries became even more significant. By 2009 services accounted for over $72 \%$ of OECD employment reaching about $80 \%$ in the United Kingdom, the Netherlands and United States. Public services continue to be significant employers; the OECD average was about $30 \%$ in 2009 and reached over 35\% in some countries, particularly in Scandinavia. Countries that still have a significant industrial or agricultural base (such as Poland, Slovenia and Turkey), inevitably rely less on services; however, services are still responsible for over half of their employment.

All industries generate or exploit new technology and knowledge, but some are more technology- or knowledgeintensive than others. They are leading producers of hightechnology goods and activities (notably services) that are intensive users of high technology and/or have the highly skilled workforce needed to benefit fully from technological innovations.

In general, the share of employment in knowledge-intensive services increased steadily between 2000 and 2008, mainly driven by business activities (e.g. IT-related services, legal, engineering and other technical services) and buoyant financial sectors. In a few countries these sectors account for over $20 \%$ of employment.

In contrast, the share of high- and medium-high-technology manufacturing in OECD employment has declined steadily in recent years due to rapid productivity growth and the continuing shift of such activities to non-OECD countries, including off-shoring by multinational firms. The decline has been particularly marked in Ireland and the United Kingdom, while the Czech Republic, the Slovak Republic, Hungary and Poland have experienced increases.

\section{Definitions}

Market sector services are defined according to ISIC Rev. 3 Divisions 50-74; public sector services as Divisions 75-99: Government (75), Education (80), Health (85), Other community, social and personal services (90-93) and Private households (95); and industry as Divisions 10-41: Mining (10-14), Manufacturing (15-37) and Utilities (40-41).

Knowledge intensive "market services": Post and telecommunications (64), Finance and insurance (65-67) and Business activities (71-74).

High and medium-high technology manufactures: Chemicals and chemical products (24), Manufacture of machinery and equipment, n.e.c. (29), Electrical and optical equipment (30-33) and Transport equipment (34-35) - determined by analysis of industry R\&D intensity ( $R \& D$ expenditure relative to output) for an aggregate of OECD countries. 
Employment in knowledge-intensive "market" services, 2008

As a percentage of total employment

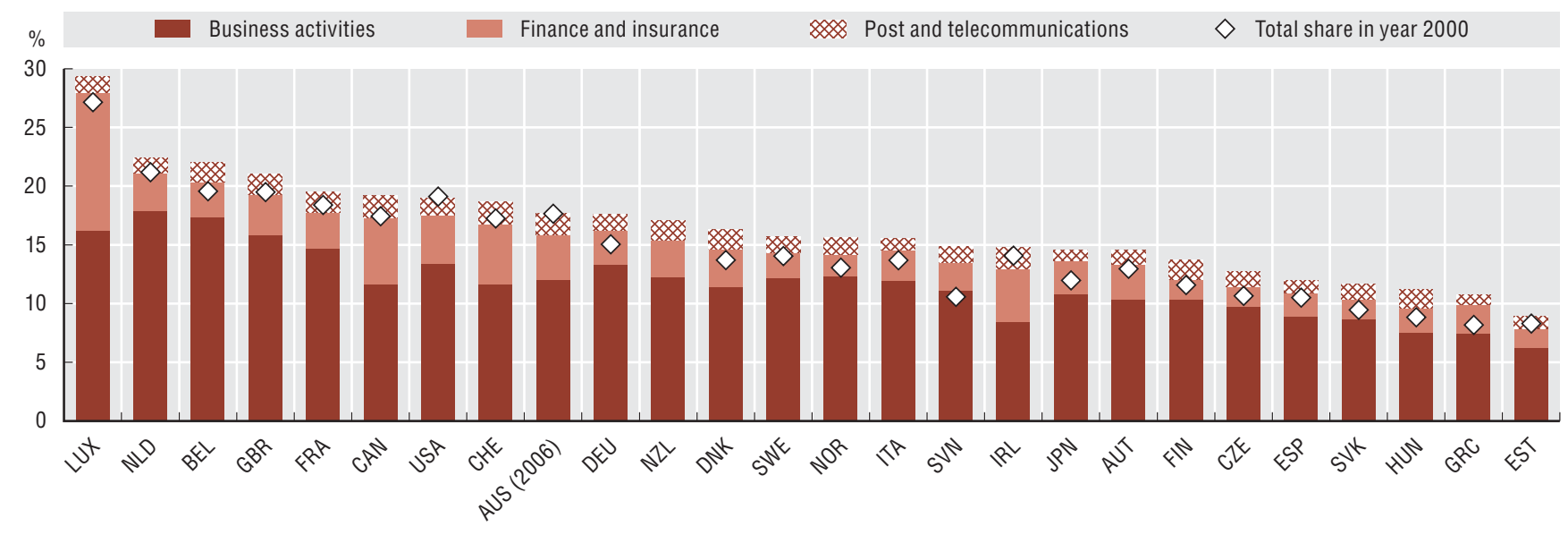

Source: OECD, Structural Analysis Database (STAN), May 2011. See chapter notes.

StatLink काISL $h t t p: / / d x . d o i . o r g / 10.1787 / 888932487571$

Employment in high- and medium-high technology manufacturing industries, 2000 and 2008

As a percentage of total employment

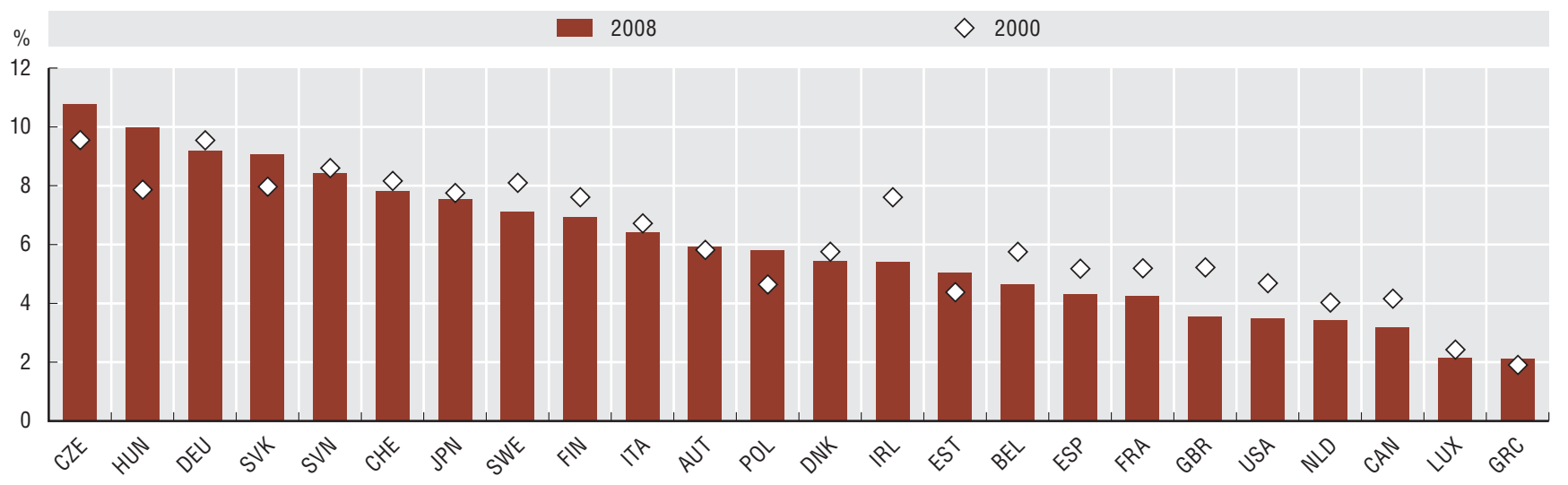

Source: OECD, Structural Analysis Database (STAN), May 2011. See chapter notes.

\section{Measurability}

Using an industry-based definition, the distinction between market and public services is an approximate one. In OECD countries, private education and health services are available to varying degrees while some transport and postal services remain in the public realm.

While there have been established methods for classifying manufacturing industries according to technological intensity (e.g. measurement of direct and indirect, or embodied, R\&D expenditure relative to output), determining the "knowledge-intensive" services sectors has proved more challenging. As many services perform relatively limited amounts of formal R\&D, other metrics have to be used, such as skill composition of the workforce and intensity of investment in ICT equipment. Recent work has focused on using data from innovation surveys. The development of such classifications also has to take into account the level of industry detail present in the data collections to be analysed. 


\section{Services-related occupations in manufacturing, 2000 and 2008 \\ As a percentage of all employees in manufacturing}

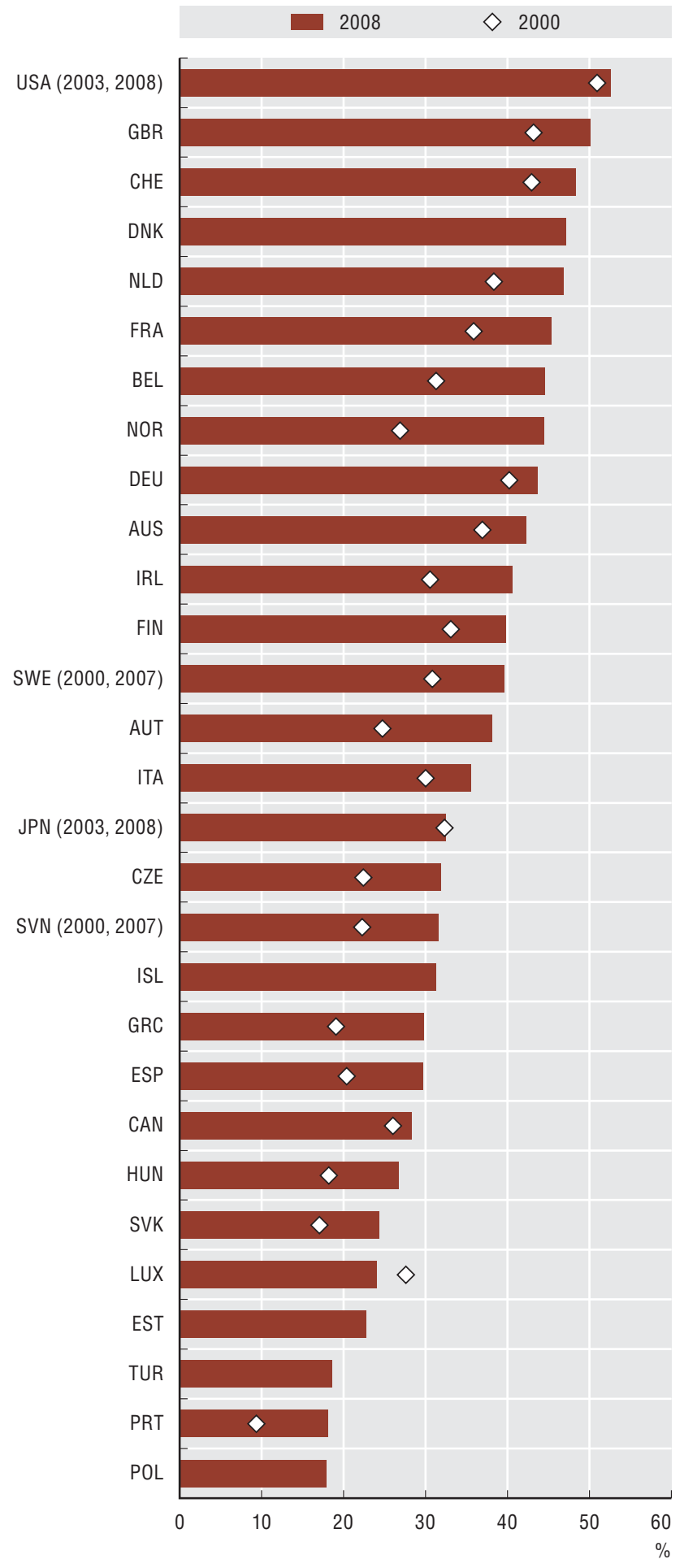

Source: OECD, calculations based on EU Labour Force Survey; US Current Population Survey; Australian, Canadian and Japanese Labour Force Surveys, May 2011. See chapter notes.

StatLink तiाsस http://dx.doi.org/10.1787/888932487609
Manufacturing production in many OECD economies has declined in recent decades so that, on average, services now account for about $70 \%$ of OECD GDP. In fact, in the United States and the United Kingdom, employment in manufacturing industries is now less than $10 \%$ of total employment. As part of this general decline, the scope and nature of manufacturing has changed so that what was once dominated by skilled trades and vocations, machine operators, assembly line workers, etc., now relies increasingly on service occupations and service inputs. This reflects the increasing use of technology in production, international sourcing of more sophisticated intermediate inputs and a range of social factors (such as the changing skill composition of populations).

Measuring trends in the interdependence of services and manufacturing industries is not easy. However, the two indicators presented here suggest that for many countries, the share of service activities necessary for manufacturing production has increased in recent years.

Data on occupations show that in the last decade there has been a steady increase in the share of employees in the manufacturing sector who are employed in occupations that can be considered as services-related, such as management, business, finance and legal professionals. In 2008, on average, the share in the OECD area had reached about 35\% although it varied between 18\% (Poland) and $52 \%$ (United States).

Estimates based on OECD's "harmonised" input-output tables can reveal the amount of services embodied in one unit of final demand for manufactured goods. The contribution of services value added needed to satisfy demand for manufactured products varies between 10 and 30\%again highlighting the symbiotic nature of the two sectors. Between 1995 and 2005, significant increases in total services embodied in manufacturing were evident in Poland, Turkey and the United States. Such changes over time may reflect a shift in industrial structures towards manufacturing products that are more service intensive.

\section{Definitions}

Services related occupations are defined here as ISCO-88 major groups: 1. "Legislators, Senior Officials and Managers"; 2. "Professionals"; 3. "Technicians and Associate Professionals"; 4. "Clerks"; and 5. "Service workers and shop and market sales workers". Manufacturing refers to ISIC Rev. 3 (NACE Rev. 1) Divisions 15 to 37 . 


\section{Service sector value-added embodied in manufacturing output, 1995 and 2005}

As a percentage of total value added of manufactured goods in final demand

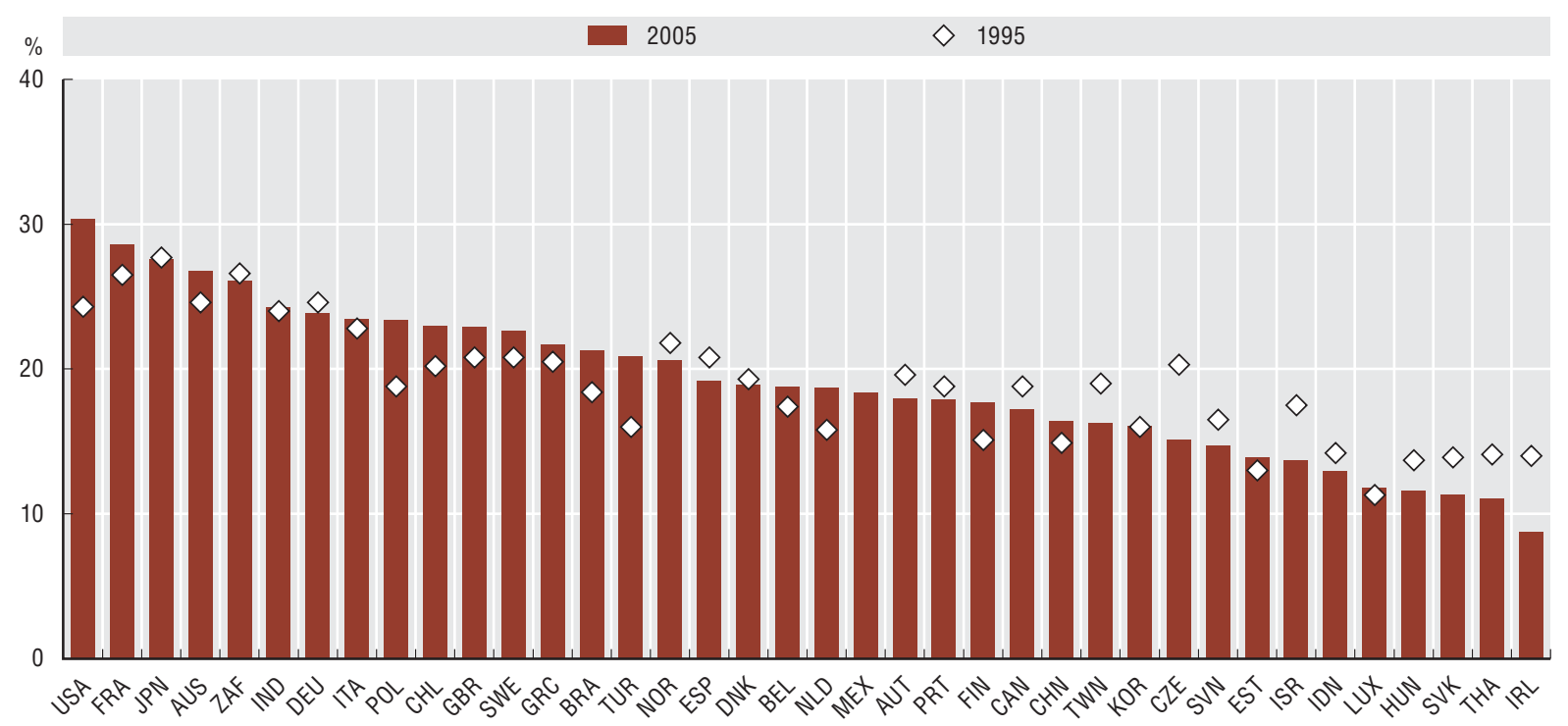

Source: OECD, STAN Input-Output Database, May 2011.

StatLink क्ञाSL $h t t p: / / d x . d o i . o r g / 10.1787 / 888932487628$

\section{Measurability}

In an input-output framework, domestic services indirectly embodied in manufactured goods produced for final demand can be shown to be equal to:

$v(I-A)^{-1} y^{\prime}$

where $v$ is a $1 \times n$ vector with components $v j$ (the ratio of value added to output in industry $j$ for service industries and zero otherwise), $y^{\prime}$ is the $1 \times n$ vector of domestically produced final demand with zero entries for non-manufacturing goods and services, and $A$ is an input coefficient matrix describing the ratio of the inputs from industry $i$ used to make the output of industry $j$.

Similarly, imported services embodied in manufactured goods is defined as:

$m(I-A)^{-1} y^{\prime}$

where $m$ is a $1 \times n$ vector with components of import ratio for service industries and zero otherwise.

Thus, the percentage of final demand in manufactured goods that reflects services sector value added of domestic origin and from imports can be calculated thus:

$v(I-A)^{-1} y^{\prime} / \sum y^{\prime}$ and $m(I-A)^{-1} y^{\prime} / \sum y^{\prime}$.

Considering domestically sourced and imported services separately reveals widespread increases in the presence of imported services embodied in domestic manufacturing output, albeit from a low level of about $2 \%$. 


\section{COMPETING IN THE GLOBAL ECONOMY \\ 3. Firm size and dynamics}

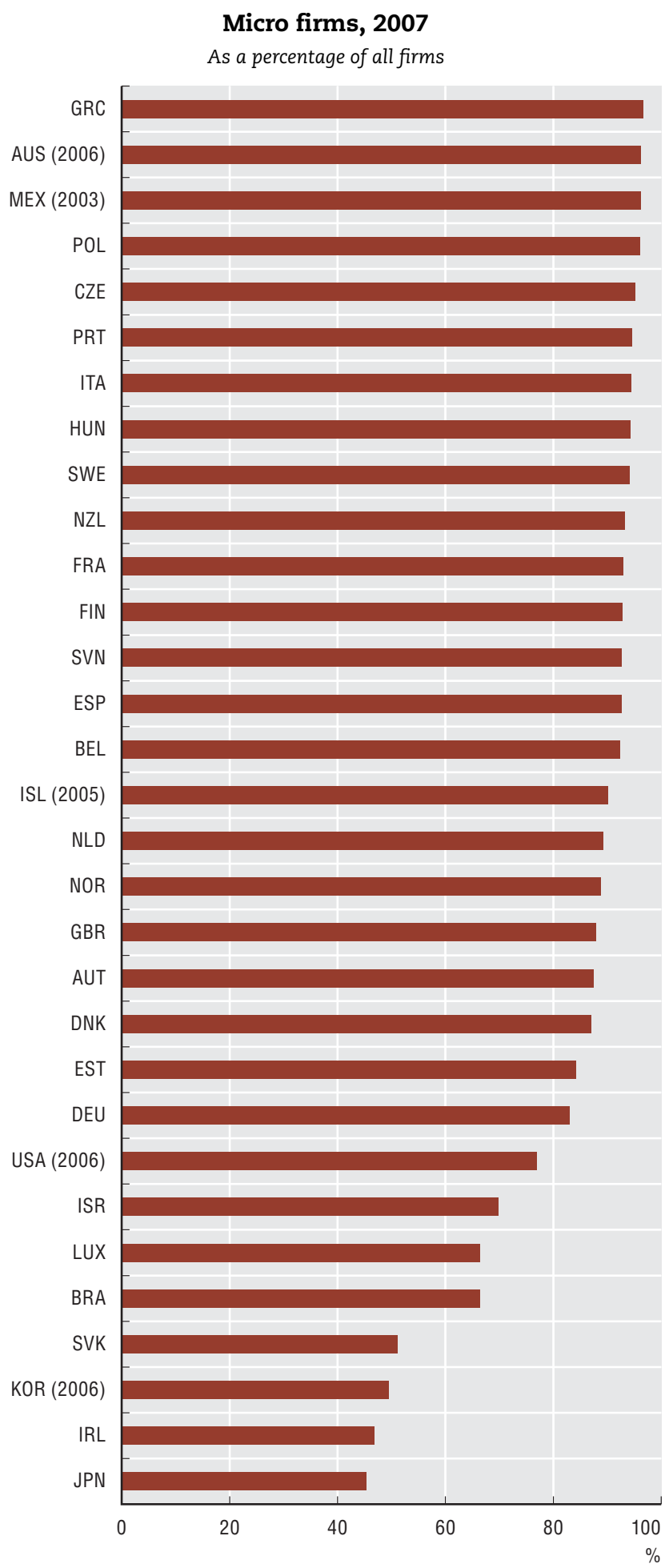

Source: OECD (2011), Entrepreneurship at a Glance 2011, OECD Publishing, Paris. See chapter notes.

StatLink 시내 $h t t p: / / d x . d o i . o r g / 10.1787 / 888932487647$
Business dynamics have a significant impact on an economy's overall productivity growth, and this in turn affects a country's ability to compete globally. There is mixed empirical evidence on the relation between firm size and business dynamics, but small and medium enterprises (SMEs) play a key role in all countries and are significant generators of employment and income. In the OECD area, SMEs employ more than half of the private sector's labour force. In the European Union, they account for over 99\% of all enterprises. SMEs employing between 1 and 9 persons, also called micro firms, represent more than $80 \%$ of all firms in most OECD countries.

In spite of the strong presence of micro firms, a considerable part of the business sector's value added is due to enterprises with more than 250 employees. In 2007 in Brazil and Luxembourg, more than $70 \%$ of total value added was created by such firms.

While all forms of entrepreneurship play a critical role in the economy, whether through self-employment or the creation of SMEs, high-growth firms contribute most to productivity, economic growth and job creation. They are a key source of radical and high-impact innovation and key actors in the entrepreneurial ecosystem. They contribute to growth not only directly through the introduction and adoption of novel technologies, but also indirectly through the increased competitive pressure they put on incumbent firms.

Despite their key role in the economy, high-growth enterprises (measured by employment growth) represent on average a small share of the total population of enterprises. In 2007, the share of high-growth firms was larger in services than in manufacturing in most of the countries for which data are available.

\section{Definitions}

Micro firms have between 1 and 9 employees. Highgrowth enterprises, as measured by employment, are enterprises with average annualised growth in employees of over $20 \%$ a year, over a three-year period, and with ten or more employees at the beginning of the observation period. The share of highgrowth enterprises is compiled as the number of highgrowth enterprises as a percentage of the population of enterprises with ten or more employees. In defining high-growth firms, the OECD Entrepreneurship Indicators Programme sets the size threshold at ten employees at the start of any observation period to avoid the small size class bias that the definition of high growth inevitably implies. 


\section{COMPETING IN THE GLOBALECONQMY}

3. Firm size and dynamics

Value added by size class, 2007

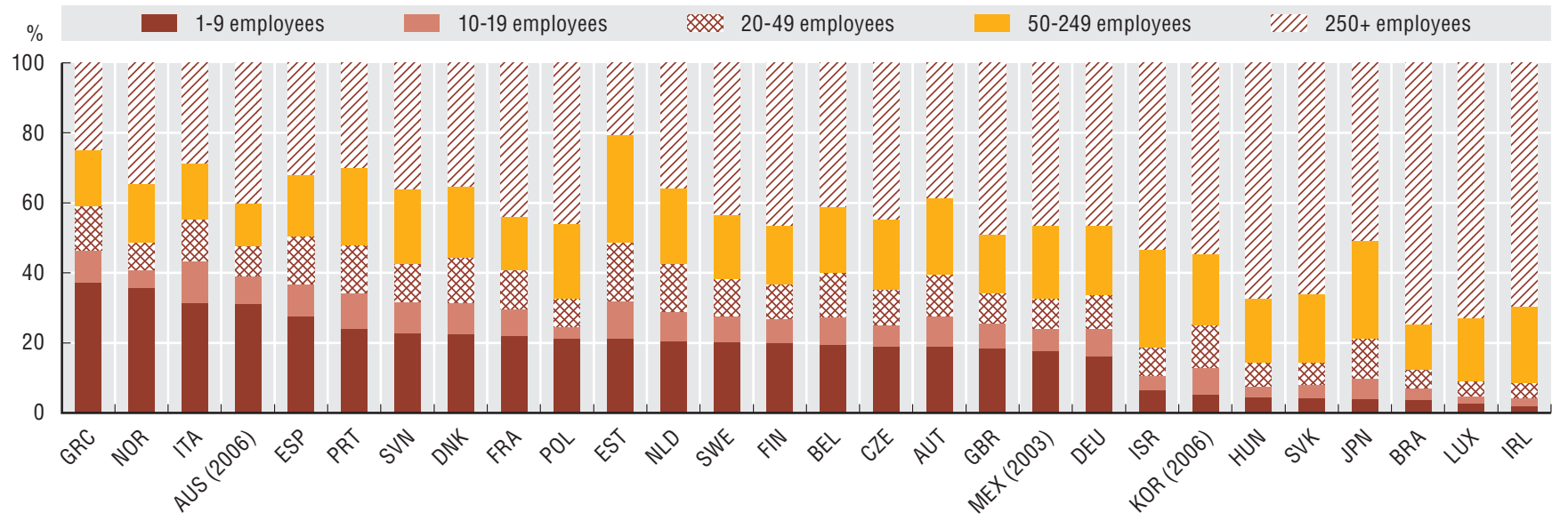

Source: OECD (2011), Entrepreneurship at a Glance 2011, OECD Publishing, Paris. See chapter notes.

High-growth firms (based on growth in employment), 2007

As a percentage of all firms with ten or more employees

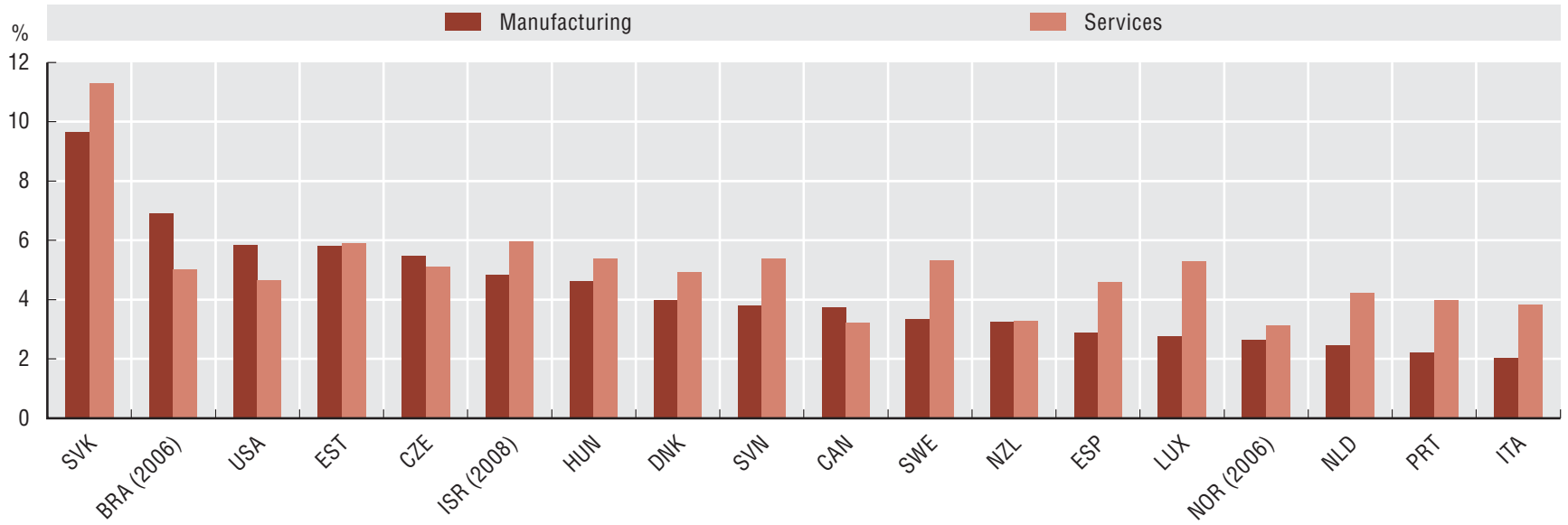

Source: OECD (2011), Entrepreneurship at a Glance 2011, OECD Publishing, Paris. See chapter notes.

StatLink तiाs $h t t p: / / d x . d o i . o r g / 10.1787 / 888932487685$

\section{Measurability}

The OECD-Entrepreneurship Indicators Programme (EIP) relies on data from national business registers. In spite of the aim of full coverage of existing businesses in a given country, there are cross-country differences in terms of coverage of business registers owing to national circumstances and data availability. To safeguard the international comparability of its indicators, the OECD-EIP collaborates closely with national statistical offices when using these sources.

Firms' growth is traditionally assessed in terms of turnover and employment. Employment-based measures are less affected by the main problems that affect turnover, in particular those related to price changes. Ideally, employment should be counted in full-time equivalents rather than headcounts, but many countries do not collect this information in business registers. In addition, changes in employment and turnover figures do not always reflect firms' organic growth; they can result from events such as mergers or acquisitions. When constructing comparable business demography statistics, the OECD-EIP corrects, as much as possible, for such endogenous factors. 


\section{COMPETING IN THE GLOBAL ECONOMY}

\section{Sectoral specialisation}

A corrigendum has been issued for this page. See: http://www.oecd.org/dataoecd/26/8/48742541.pdf Industrial specialisation, 1998 and 2008

Hannah-Kay index, calculated for theta equal to 2

2008

$\diamond 1998$

$x>10$ : Diversification

$6<x<10$ : Moderate diversification

$6<\mathrm{x}$ : Moderate specialisation

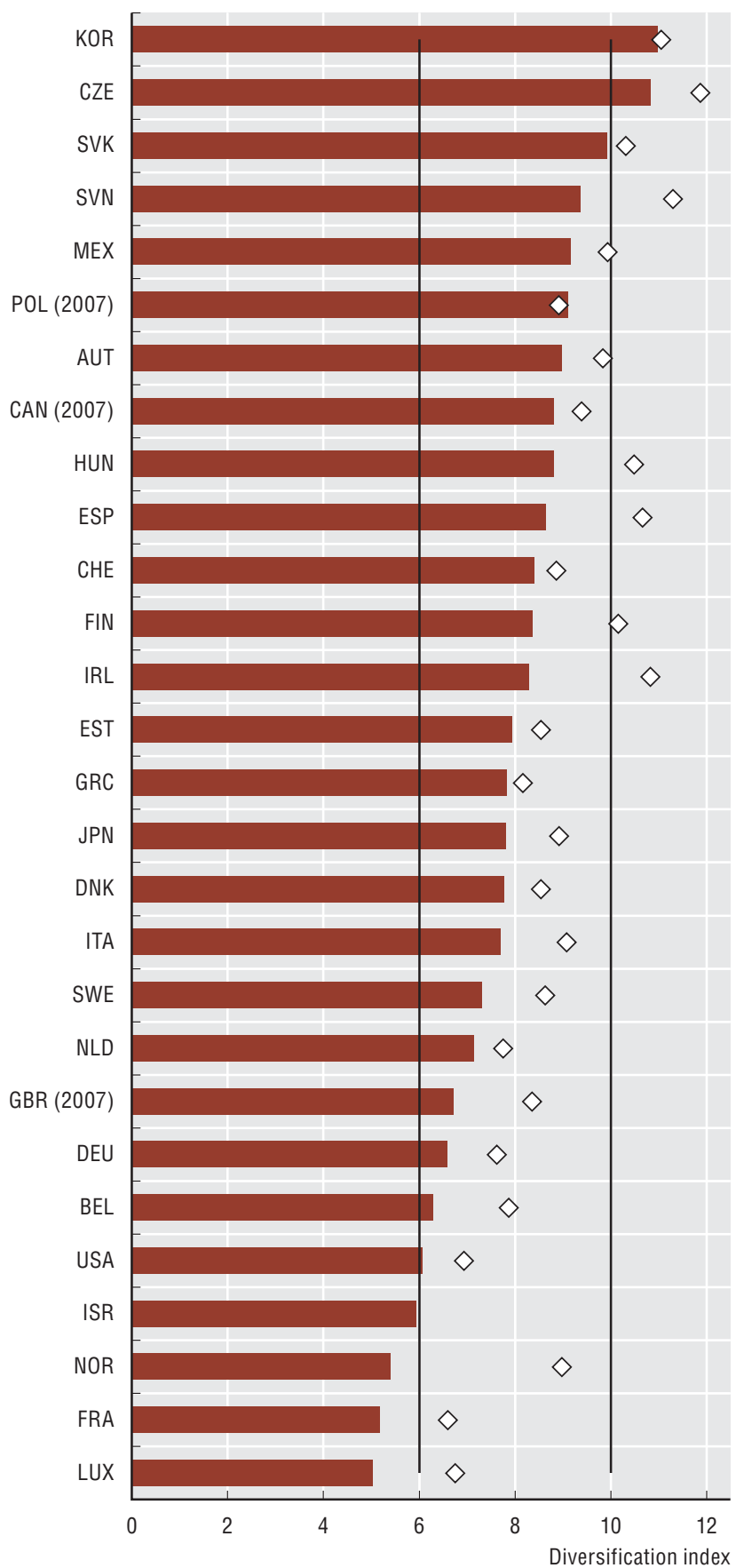

Source: OECD, Structural Analysis Database (STAN), May 2011. See chapter notes.

StatLink बiाs http://dx.doi.org/10.1787/888932487704
An economy can be defined as "specialised" if a few sectors account for a relatively large share of the country's GDP, whereas it is "diversified" if each of a relatively high number of sectors accounts for a small share of GDP. Industrial specialisation or diversification patterns relate to economies' long-run productivity, resilience to a crisis, investment patterns, innovativeness and performance of firms and sectors. The Hannah-Kay (HK) diversification index captures a country's full sectoral composition and accounts for the influence of larger sectors. A lower HK corresponds to rising sectoral specialisation. The concentration ratio (CR) index shows the share of value added accounted for by the economy's top four sectors.

In the last decade almost all economies became more specialised albeit to different extents. Diversified economies show HK values above 10 (the Czech Republic and Korea in 1998 and 2008); less diversified economies have values between 6 and 7 (France, Luxembourg and the United States in 1998 and 2008; Norway, Israel, Belgium, Germany and the United Kingdom in 2008). Between 1998 and 2008 Norway had the greatest increase in sectoral specialisation (the HK index decreased by almost $40 \%$ ). Poland is the only country showing slightly greater diversification in 2008 than in 1998, whereas Korea's HK index fluctuated but remained basically unchanged between 1998 and 2008.

A few broad sectors, typically "Wholesale and retail" and "Business activities", are consistently among the top four in terms of share of value added. The size of the two leading sectors differs considerably across countries: in Norway, Mining and quarrying is three times the size of the second largest sector but in Spain, the top sectors are more evenly distributed. In the G7 countries, the concentration ratio has grown over the last 30 years; the top four sectors represent on average $55 \%$ of total value added.

\section{Definition}

The Hannah-Kay (HK) index is calculated for a value of $\theta$ (theta) equal to 2 , value for which the HK corresponds to the inverse of the Herfindahl index. $\theta$ measures the extent to which the index is influenced by large sectors. The HK(2) is calculated on 20 sectors and takes values ranging from 1 to 20 . According to the measure used, and in analogy to the threshold values suggested by the concentration literature, countries can be considered diversified if $\mathrm{HK}(2)$ is bigger than 10 , moderately diversified for $\mathrm{HK}(2)$ values between 10 and 6, moderately specialised if $\mathrm{HK}(2)$ values are between 6 and 4 and specialised for $\mathrm{HK}(2)$ smaller than 4 . The concentration ratio $\mathrm{CR}(4)$ is calculated on four sectors and is defined as the cumulative share of the top four sectors in an economy in terms of share of value added. 
Value added of the top four industries, 2008

As a percentage of total value added (excluding real estate and the public sector)

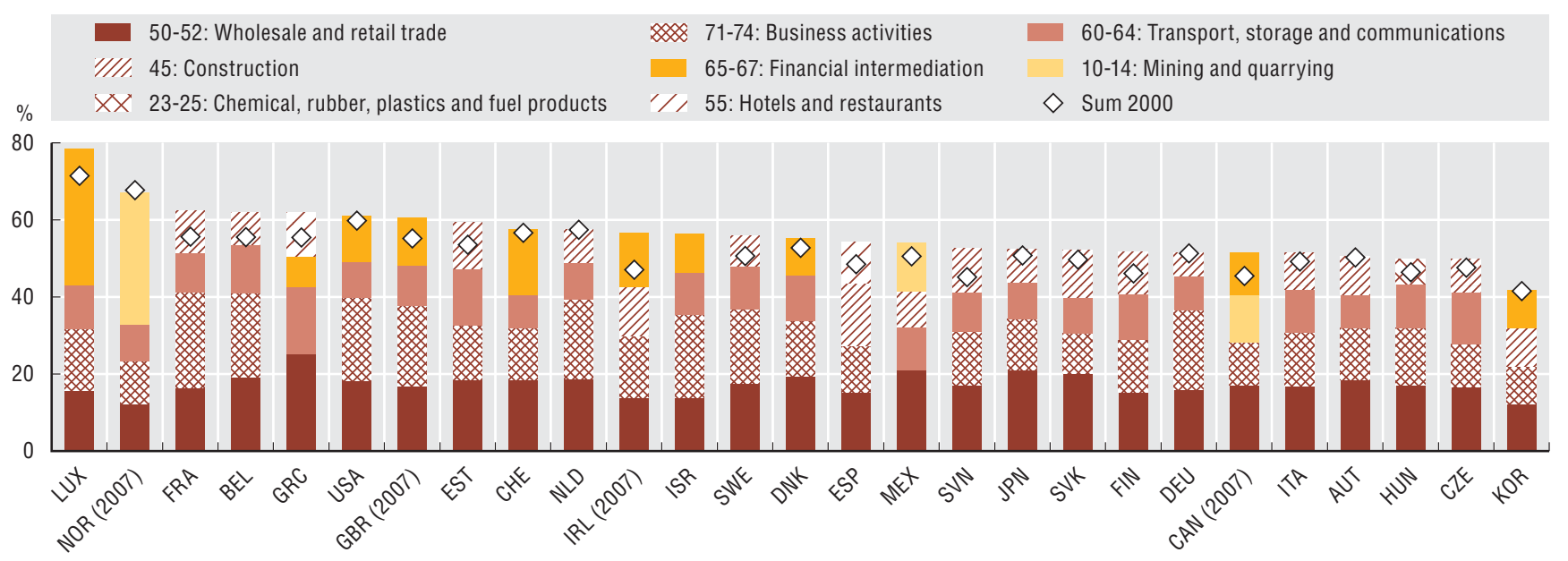

Source: OECD, Structural Analysis Database (STAN), May 2011. See chapter notes.

StatLink AाISL http://dx.doi.org/10.1787/888932487723

Value added of the top four industries, G7, 1980-2009

As a percentage of total value added (excluding real estate and the public sector)

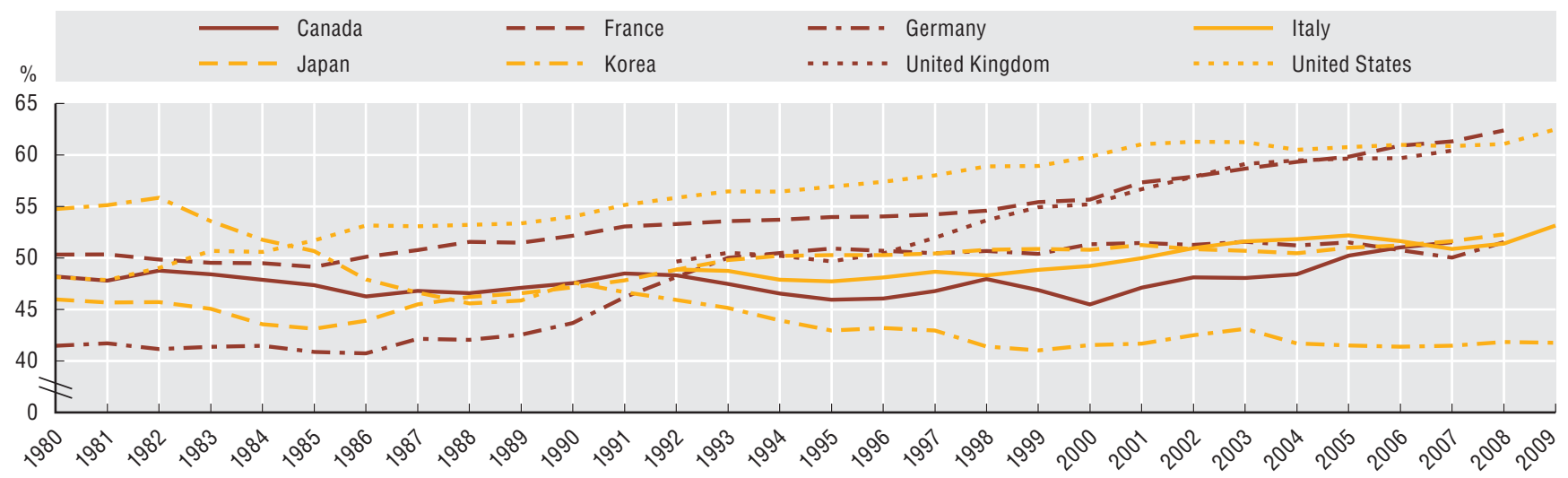

Source: OECD, Structural Analysis Database (STAN), May 2011. See chapter notes.

StatLink क्ञाs http://dx.doi.org/10.1787/888932487742

\section{Measurability}

Given data availability and coverage, and to ensure comparability across countries and over time, sectors are considered individually (e.g. 45 is the construction sector) or at an aggregate level (e.g. 65-67 is the financial intermediation sector). The $\mathrm{HK}(2)$ and $\mathrm{CR}(4)$ indicators shown rely on 20 main industries. Value added is taken at current prices and non-market sectors are excluded from the calculation. Different levels of sectoral aggregation, reference periods, value added measures and parameters would change the results. Greater sectoral disaggregation improves the ability of the HK and CR indicators to identify key industries and trends. The indicators should be considered experimental. 


\section{COMPETING IN THE GLOBAL ECONOMY \\ 5. Foreign affiliates}

\section{Distribution of foreign-controlled employment by broad sectors, 2008}

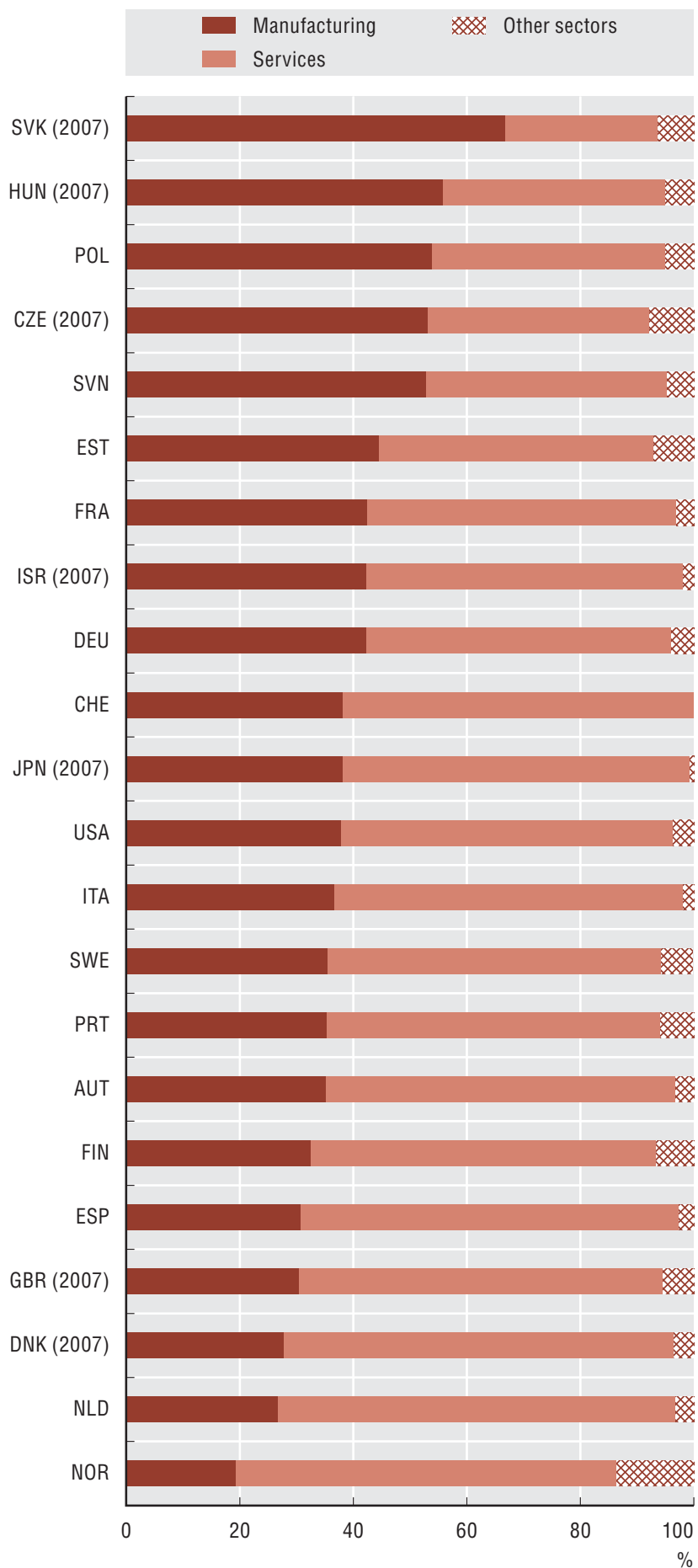

Source: OECD, AFA, FATS and AMNE Databases, May 2011; Eurostat, NewCronos Database, April 2011. See chapter notes.

StatLink क्ञाs $h$ ttp://dx.doi.org/10.1787/888932487761
Foreign affiliates contribute to a host country's international competitiveness through several channels. They provide access to new markets and new technologies for domestic suppliers and buyers, generate knowledge spillovers for domestic firms and typically invest a higher share of their revenues in R\&D. Foreign affiliates are responsible for a large part of host countries' employment, turnover and value added. The share of foreign-controlled employment in OECD countries ranged from close to $5 \%$ to $35 \%$ in 2008. In terms of value added, the foreign share is higher, partly because multinational enterprises are typically active in capital- and scale-intensive industries. Smaller countries such as the Czech Republic, the Slovak Republic and Hungary have a stronger presence of foreign-owned firms; in addition, the presence of foreign affiliates has increased significantly in these countries during the last decade. Foreign affiliates account for a significantly smaller share of total activity in the United States and Italy.

In most OECD countries, the largest number of jobs controlled by foreign affiliates in 2008 was in service industries. This was particularly true in Norway, the Netherlands, Denmark, Spain and the United Kingdom. The growing importance of foreign affiliates' activities in service industries is due to various factors: the shift from manufacturing to services in developed economies; the growing tradability of services following improvement in information and communication technologies; and more open policies for foreign investment in services.

Foreign affiliates' employment in manufacturing is significantly larger in central European countries. Many western European companies have relocated production facilities to the Slovak Republic, the Czech Republic, Hungary and Poland over the past decade, especially following these countries' accession to the European Union.

\section{Definitions}

The term foreign affiliate is restricted to affiliates under foreign control. The notion of control implies the ability to appoint a majority of administrators empowered to direct an enterprise and determine its strategic choices. In most cases, this ability can be exercised by a single investor holding more than $50 \%$ of the shares with voting rights. The notion of control allows all of a company's activities (turnover, staff, value added) to be attributed to the controlling investor. An investor (company or individual) is considered to be the investor of ultimate control if it is at the head of a chain of companies and controls directly or indirectly all the enterprises in the chain without itself being controlled by any other company or individual. 
Share of national employment under control by foreign affiliates, 2000 and 2008

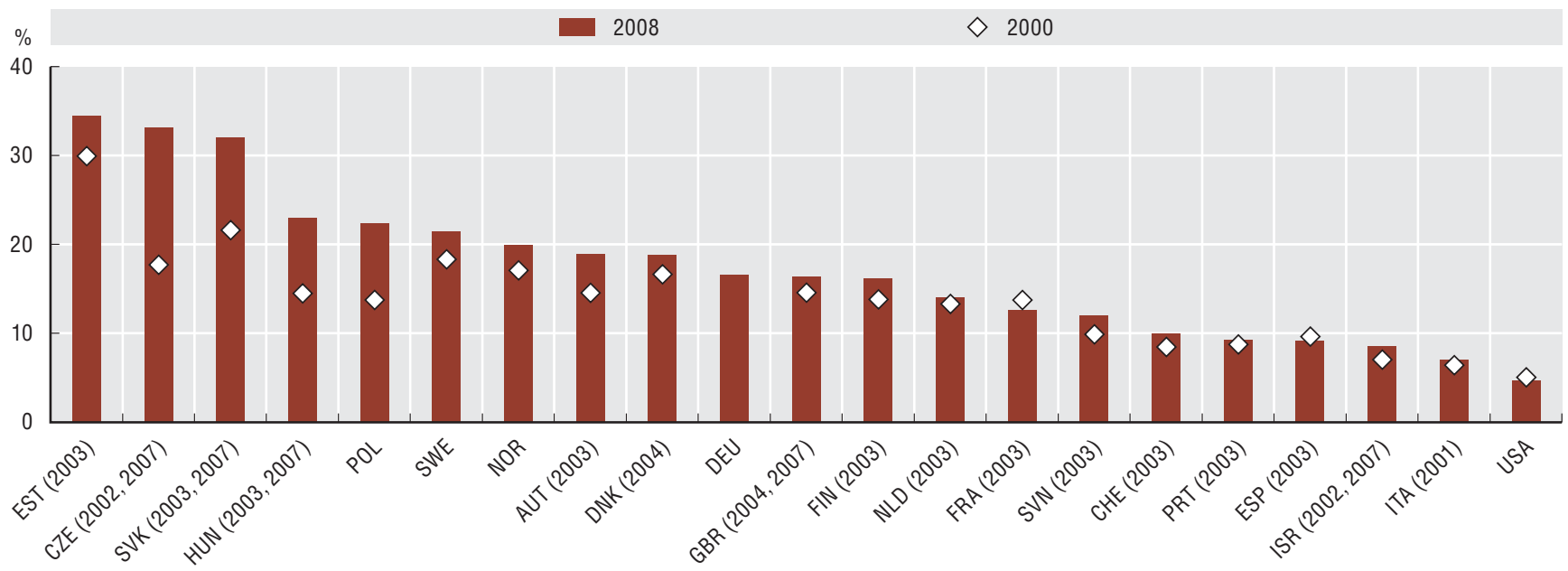

Source: OECD, AFA, FATS and AMNE Databases, May 2011; Eurostat, NewCronos Database, April 2011. See chapter notes.

StatLink Ailst http://dx.doi.org/10.1787/888932487780

Share of national value added under control by foreign affiliates, 2000 and 2008

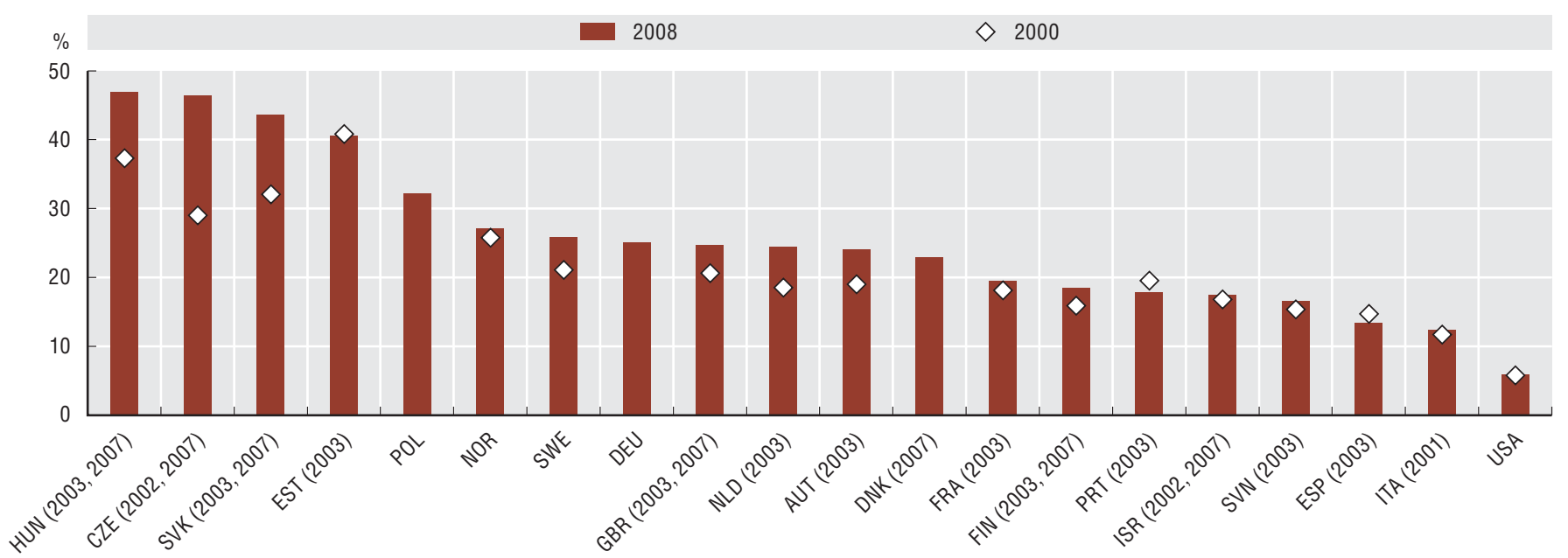

Source: OECD, AFA, FATS and AMNE Databases, May 2011; Eurostat, NewCronos Database, April 2011. See chapter notes.

StatLink काIs http://dx.doi.org/10.1787/888932487799

\section{Measurability}

The share of affiliates under foreign control in host country employment may reflect the importance of foreign direct investment in maintaining and/or creating employment in a compiling country. However, this information is not sufficient to evaluate the net job creation of foreign investment in the compiling country.

Value added is the portion of an enterprise's output that originates within the enterprise. It therefore provides a better measure than turnover since foreign affiliates largely source intermediates within their multinational network.

The data come from the Activity of Multinational Enterprises (AMNE) database, which provides comparable data on the performance of foreign affiliates and parent companies in the business sector. It contains 17 variables broken down by country of origin (inward investment) or location (outward investment) and by industrial sector (based on ISIC Rev. 4). These data provide a measure of the impact of foreign direct investment on the economies of OECD countries. 


\section{Average of total exports and imports as a percentage of GDP, 2000, 2008 and 2009}

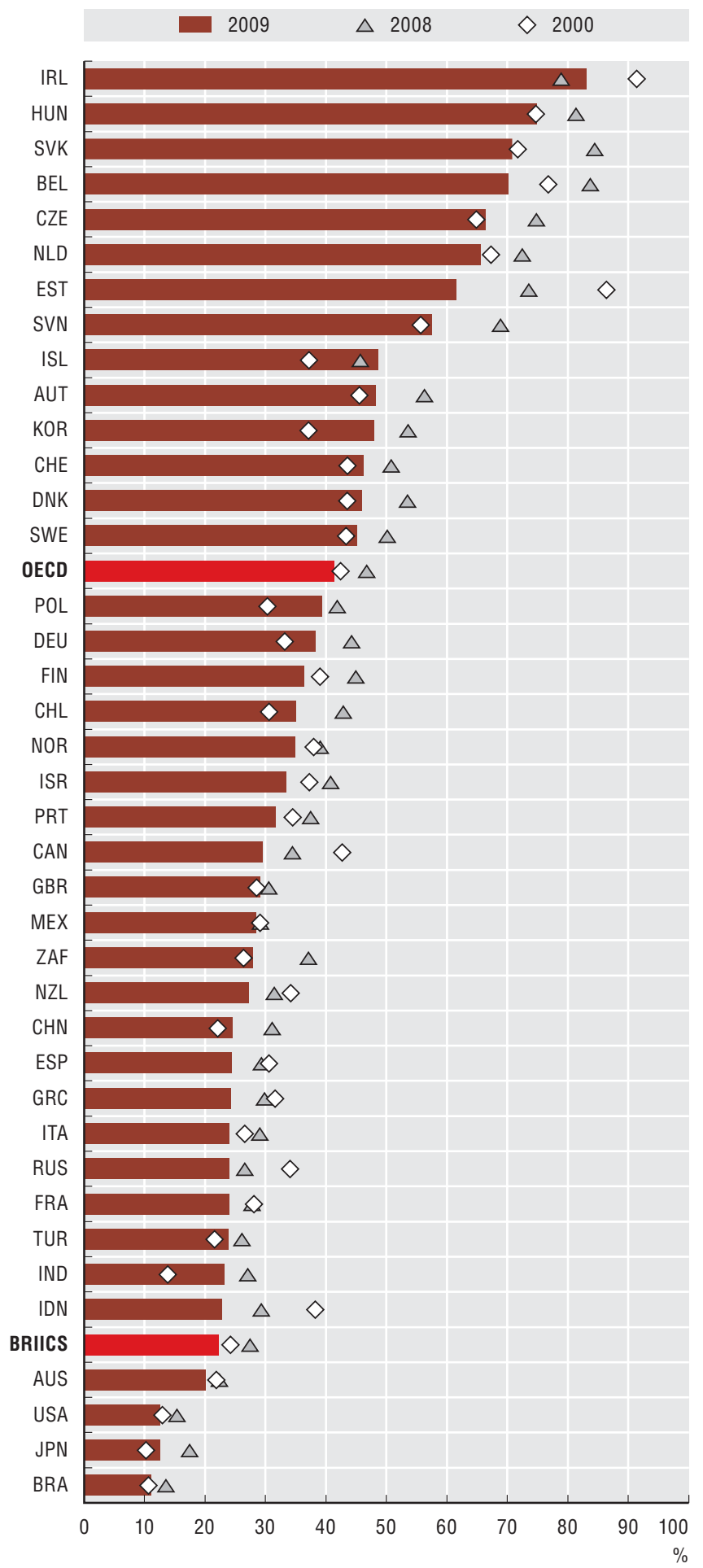

Source: OECD, National Accounts Database, June 2011; International Monetary Fund, World Economic Outlook and Balance of Payments Databases, May 2011. See chapter notes.

StatLink Niाst $h t t p: / / d x . d o i . o r g / 10.1787 / 888932487818$
The relative impact of the economic crisis on international trade can be seen in a comparison of exports and imports as a percentage of gross domestic product (GDP) between 2008 and 2009. GDP was severely affected in many countries, but international trade suffered even more. After widespread increases in the trade-to-GDP ratio between 2000 and 2008, all OECD countries (except Iceland and Ireland) and the BRIICS (Brazil, the Russian Federation, India, Indonesia, China, South Africa) saw a drop in this ratio between 2008 and 2009, mostly owing to significant drops in trade in goods. In many countries it fell below the ratio recorded at the beginning of the decade.

For Canada, Estonia, Ireland and New Zealand as well as Indonesia and the Russian Federation, the decline in the relative importance of trade started before 2008 , owing in part to the expansion and changing structure of their domestic economies.

In 2009, the average trade-to-GDP ratio of OECD countries was about $41 \%$, nearly double that of the BRIICS. In part, this is because the OECD includes many relatively small economies. Considering the OECD as a single aggregate, with high weights for Japan and the United States, would give a ratio closer to $20 \%$, similar to that of the BRIICS.

Despite significant falls in 2009, trade in goods remains many countries' principal channel for economic integration. It represents, on average, three times the value of trade in services in OECD countries and more than four times in the BRIICS. However, the crisis had a much smaller impact on trade in services than in goods; few countries experienced significant falls in the ratio of trade in services to GDP.

International trade in services continues to expand. Countries such as Ireland and India are particularly active in this area.

\section{Definitions}

The trade-to-GDP ratio is frequently used to measure the importance of international transactions relative to domestic transactions. This indicator is calculated for each country as the simple average (i.e. the mean) of total trade (i.e. the sum of exports and imports of goods and services) relative to GDP. This ratio is often called the trade openness ratio, although the term "openness" may be somewhat misleading, since a low ratio does not necessarily imply high (tariff or nontariff) barriers to foreign trade, but may be due to factors such as size of the economy and geographic remoteness from potential trading partners. For the OECD and the BRIICS the unweighted averages of countries' shares of GDP are presented to indicate, for example, a typical OECD country's share rather than an aggregate share heavily influenced by countries such as the United States and Japan. 
Average of exports and imports of goods as a percentage of GDP, 2000, 2008 and 2009

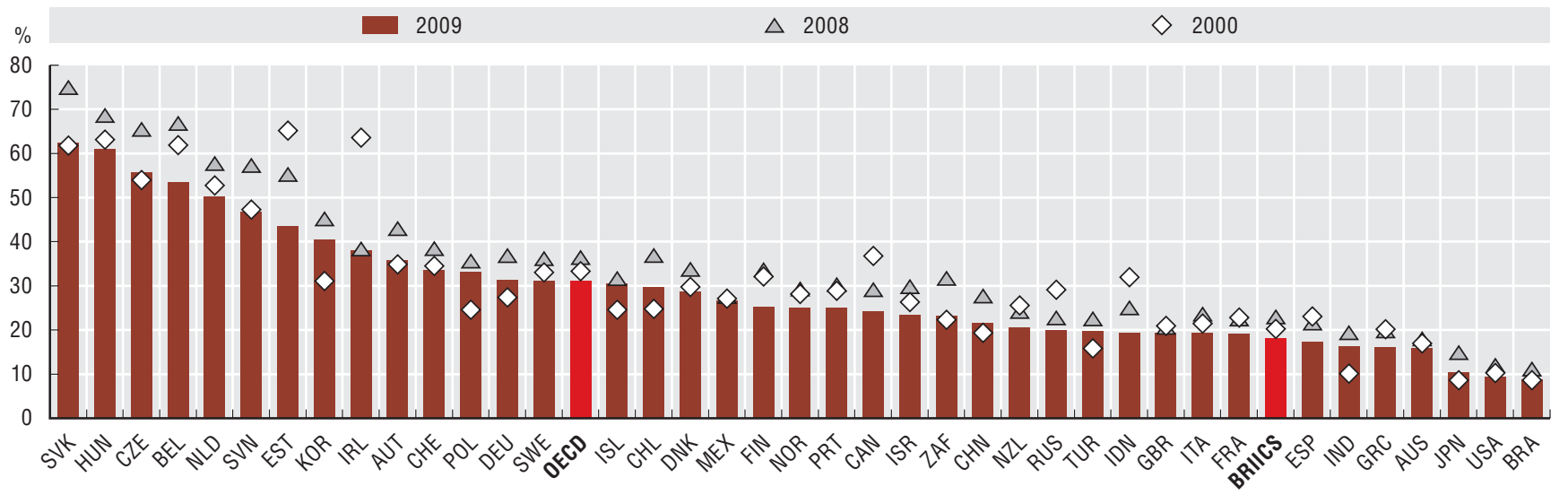

Source: OECD, National Accounts Database, June 2011; International Monetary Fund, World Economic Outlook and Balance of Payments Databases, May 2011. See chapter notes.

Average of exports and imports of services as a percentage of GDP, 2000, 2008 and 2009

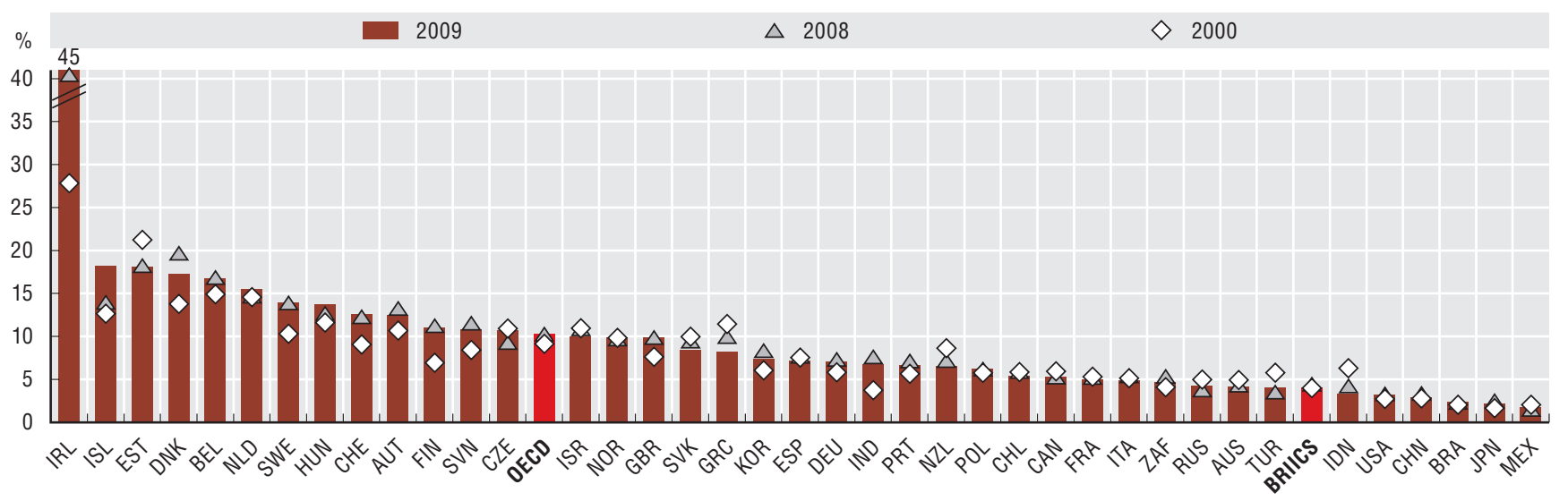

Source: OECD, National Accounts Database, June 2011; International Monetary Fund, World Economic Outlook and Balance of Payments Databases, May 2011. See chapter notes.

StatLink Niाst http://dx.doi.org/10.1787/888932487856

\section{Measurability}

The aggregate value of international trade in goods and services reflects countries' integration into the world economy. Small countries are generally more integrated: their exports tend to be in a limited number of sectors and they need to import more goods and services than larger countries in order to satisfy domestic demand. Nonetheless, size is not the only determinant of trade integration. Other factors help to explain differences across countries: geography, history, culture, trade policy, structure of the economy (in particular the weight of non-tradable services) and integration in global production chains, where measured trade may include a significant proportion of re-exports and intra-firm trade linked to the presence of multinational firms. 
Import content of exports, 1995 and 2005

As a percentage of total exports

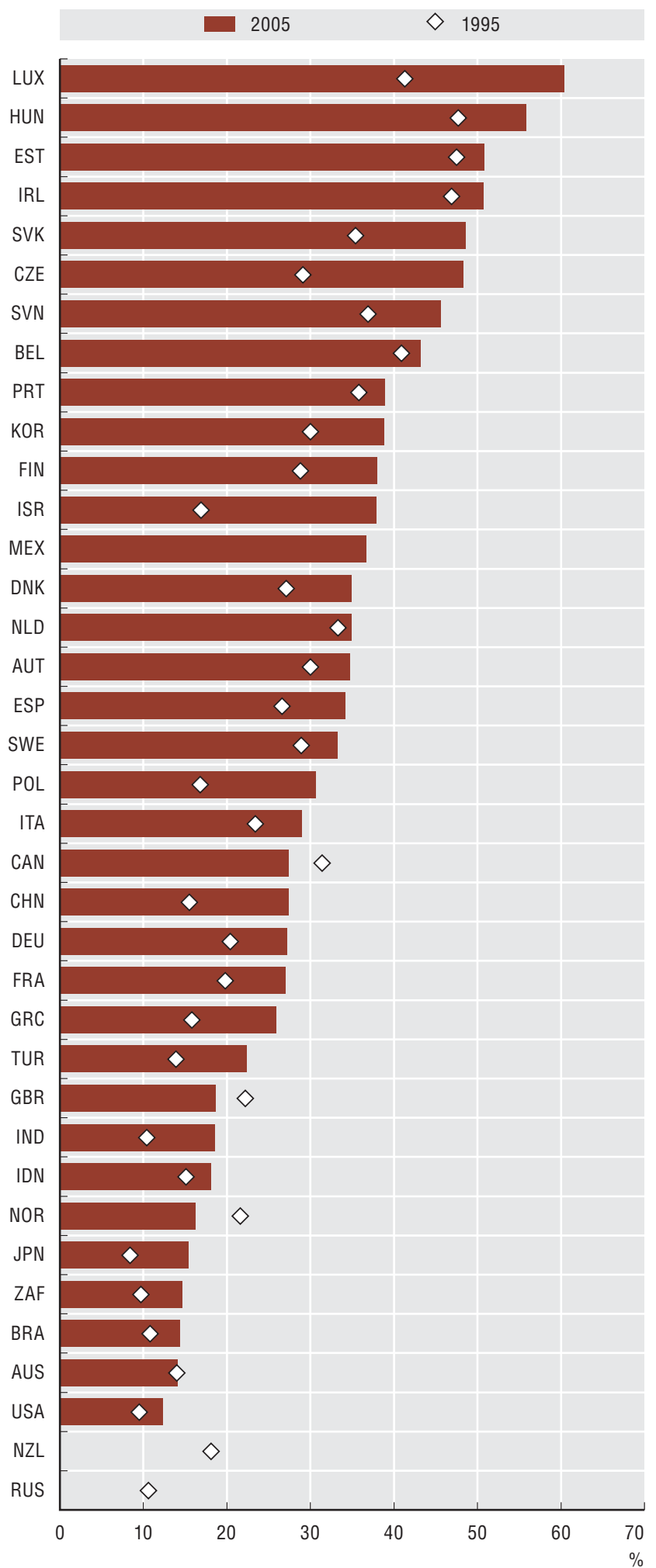

Source: OECD, STAN Input-Output Database, May 2011. See chapter notes. StatLink Aाs $h t t p: / / d x . d o i . o r g / 10.1787 / 888932487875$
The "import content of exports" measure (proposed by Hummels et al., 2001), provides an indication of the increasing importance of the international fragmentation of production processes. By linking OECD's "harmonised" national input-output tables (which show countries' interindustry transaction patterns) with bilateral trade by industry statistics, the value of imported intermediate goods and services subsequently embodied in exports can be estimated. While this highlights the imports required to meet the demand for exports, changes in the import content of exports can also reveal the evolution of domestic value added due to exporting activities.

Smaller economies tend to have higher shares of imports embodied in their exports. The availability of a wider variety of domestically sourced intermediate goods means that larger countries are less reliant on imports of intermediates, such as primary goods and parts and components, for their production of export-oriented goods. Countries with substantial natural resources such as Australia, Norway, South Africa and the Russian Federation also have lower shares of import content of exports, as mining activities require few intermediate consumption goods to produce their output. Imported capital goods, such as machinery and equipment, are excluded from this analysis.

Between 1995 and 2005, the share of import content increased in most of the countries covered - 31 OECD and the 6 BRIICS (Brazil, the Russian Federation, India, Indonesia, China, South Africa) - owing to sharp increases in import penetration rates of many intermediate goods. However, factor analysis by Meng et al. (2011) suggests that changes in the composition of goods exported have also driven changes in import content shares, in particular shifts in exports from labour- and domestic resource-intensive sectors to assembly-oriented machinery sectors.

The import content of household final consumption can also be estimated using a similar methodology. This indicator includes both direct imports and indirect intermediate imports for final consumption. As for total exports, the import content share in household consumption increased between 1995 and 2005 in most countries, reducing the contribution of domestic value added. In China, India and Brazil, the share of indirect import content is relatively high owing to lower import penetration of final goods and services for household consumption compared to OECD countries.

\section{Definitions}

Import content of exports (vertical specialisation shares) is measured as the share of total intermediate imports used in the production of a country's total exports. The vertical specialisation aggregate can be broken down by import-sourcing countries using bilateral trade statistics on goods and services. 
Import content of household final consumption, 1995 and 2005

As a percentage of total household final consumption

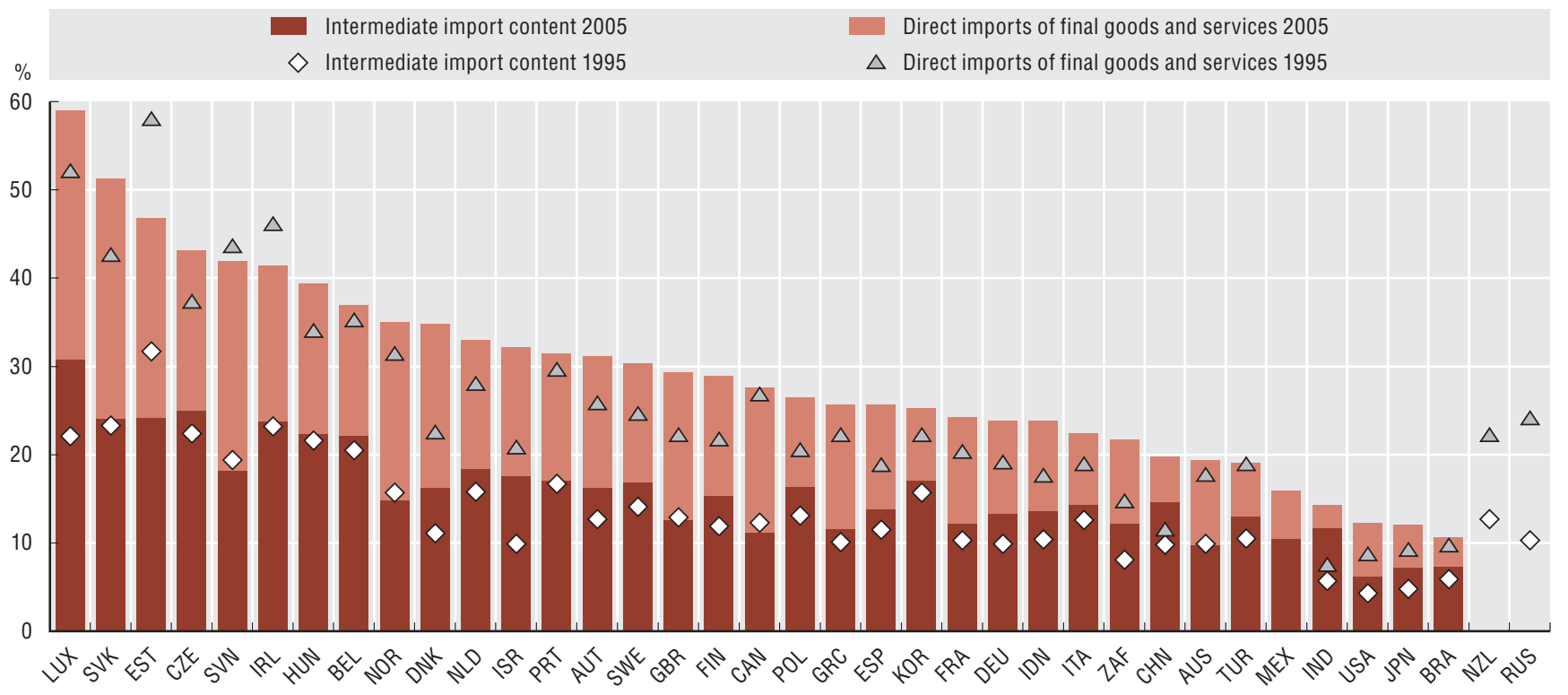

Source: OECD, STAN Input-Output Database, May 2011. See chapter notes.

StatLink का1sL http://dx.doi.org/10.1787/888932487894

\section{Measurability}

Import content of exports is measured using the domestic input coefficients and import matrices of the OECD's harmonised Input-Output Database.

Import content of exports $=\frac{\mathrm{uAm}(\mathrm{I}-\mathrm{Ad})^{-1} \mathrm{Ex}}{\mathrm{u} \mathrm{Ex}}$

where Am and Ad are input coefficient matrices ( $n$ sectors by $n$ sectors) of imported and domestic goods and services, respectively; $E x$ is the export vector; and $u$ is a ( 1 by $n)$ vector with all elements equal to 1.

Import content of household final consumption $=\frac{u(C P m)+u A m(I-A d)^{-1} \mathrm{CPd}}{u(C P d+C P m)}$

where CPd and CPm are the household consumption vectors of domestic and imported goods and services, respectively. 
Business R\&D intensity adjusted for industrial structure, 2008

As a percentage of value added in industry

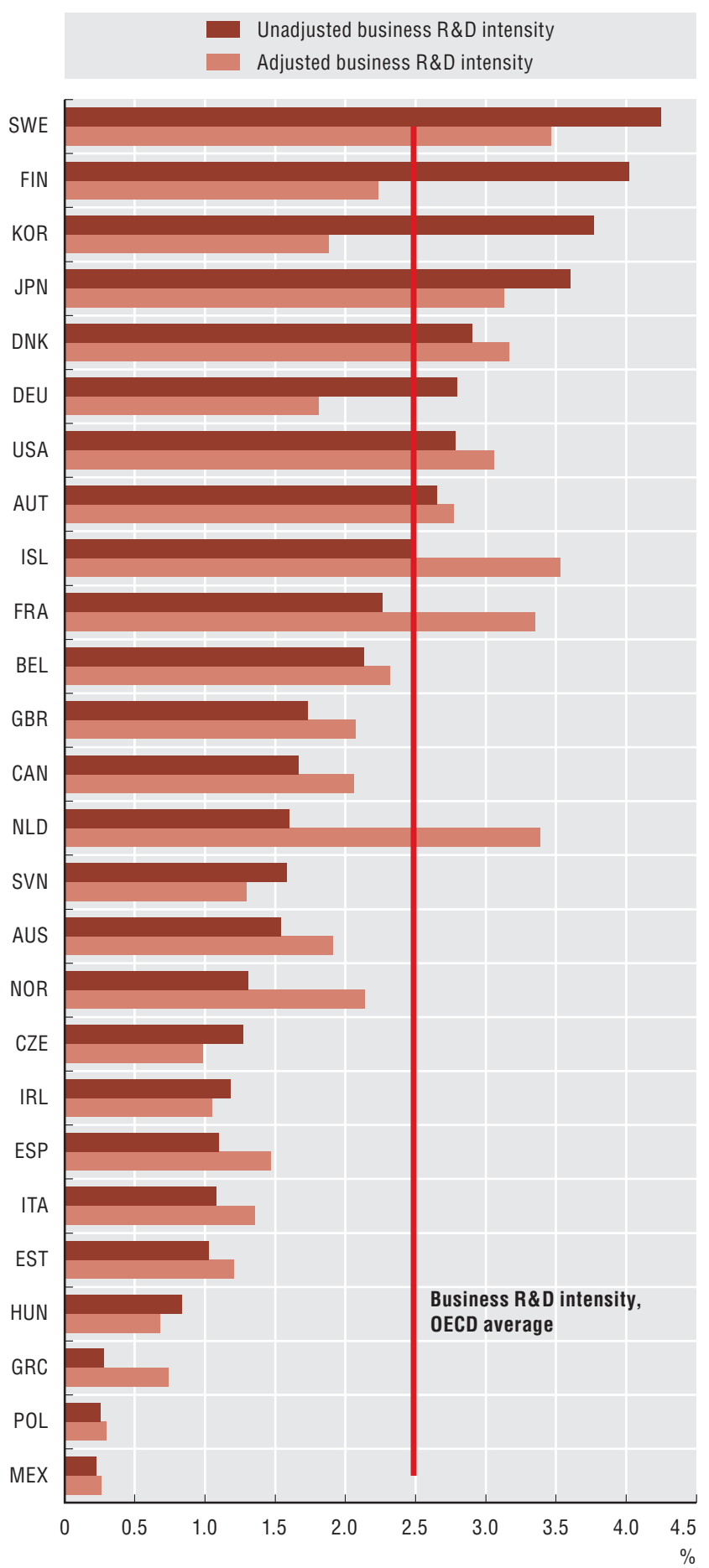

Source: OECD, calculations based on the Structural Analysis (STAN) and ANBERD Databases, July 2011; OECD, Main Science and Technology Indicators Database, June 2011. See chapter notes.

StatLink तारा $h t t p: / / d x . d o i . o r g / 10.1787 / 888932487913$
When comparing total business research and development $(R \& D)$ intensity ( $R \& D$ expenditure relative to value added or gross domestic product) across countries it is important to take into account differences in their industrial structure. While there is significant variation in R\&D intensity within sectors, some sector-specific patterns make it very difficult for a country to raise its R\&D intensity significantly without fundamentally changing its industrial structure. An understanding of the extent to which structural differences can account for observed differences in overall business $R \& D$ intensity can be achieved by constructing an indicator that shows what a country's total R\&D intensity would be if it had the same industrial structure as the average for OECD countries.

In Finland, Germany and Korea, adjusted business R\&D intensity would be below the OECD average of $2.5 \%$ : these economies are relatively specialised in high- and mediumhigh-technology industries such as information and communication technology (ICT) or motor vehicles. If France, Iceland and the Netherlands had an average OECD industry structure, their business R\&D intensity would be higher. For countries in southern and eastern Europe and for Mexico, an industry structure closer to the OECD average would not raise their overall R\&D intensity. This indicates that their business $R \& D$ is lower than average regardless of sectoral specialisation.

High-technology industries in Ireland, Finland, the United States and Iceland perform more than two-thirds of all manufacturing $R \& D$, while medium-high-technology industries account for more than half of manufacturing R\&D in the Czech Republic, Turkey, Germany and Austria. In Mexico, Australia, Estonia and Portugal, manufacturing $R \& D$ is still mainly concentrated in medium-low- and low-technology industries.

Many service industries are increasingly knowledgeintensive and R\&D often plays a significant role. In most OECD countries services account for one-third or more of business R\&D expenditure (BERD), a share that has increased over the last decade. Cross-country comparisons of the sectoral distribution of BERD should nonetheless be made with care owing to differences in how countries allocate $R \& D$ to various industries.

\section{Definitions}

$R \& D$ intensity adjusted for industry structure is a weighted average of the R\&D intensities of a country's industrial sectors, using the OECD industrial structure's sector value added shares as weights instead of the actual shares used in the calculation of the unadjusted measure of R\&D intensity. Manufacturing industries are classified by level of technology (high-, medium-high-, medium-low- and low-technology activities) on the basis of average OECD R\&D intensity as revealed by R\&D relative to value added and gross output statistics. 
Business R\&D in the manufacturing sector by technological intensity, 2008

As a percentage of manufacturing business enterprise $R \& D$

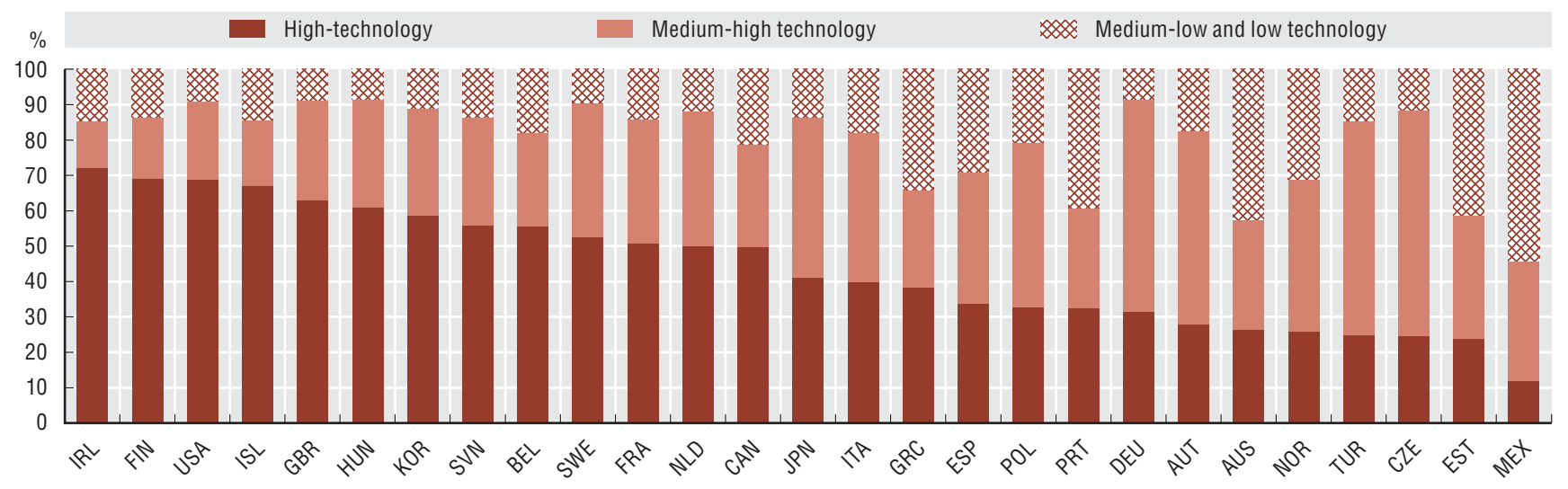

Source: OECD, ANBERD Database, May 2011. See chapter notes.

\section{Share of services in business R\&D, 1998 and 2008}

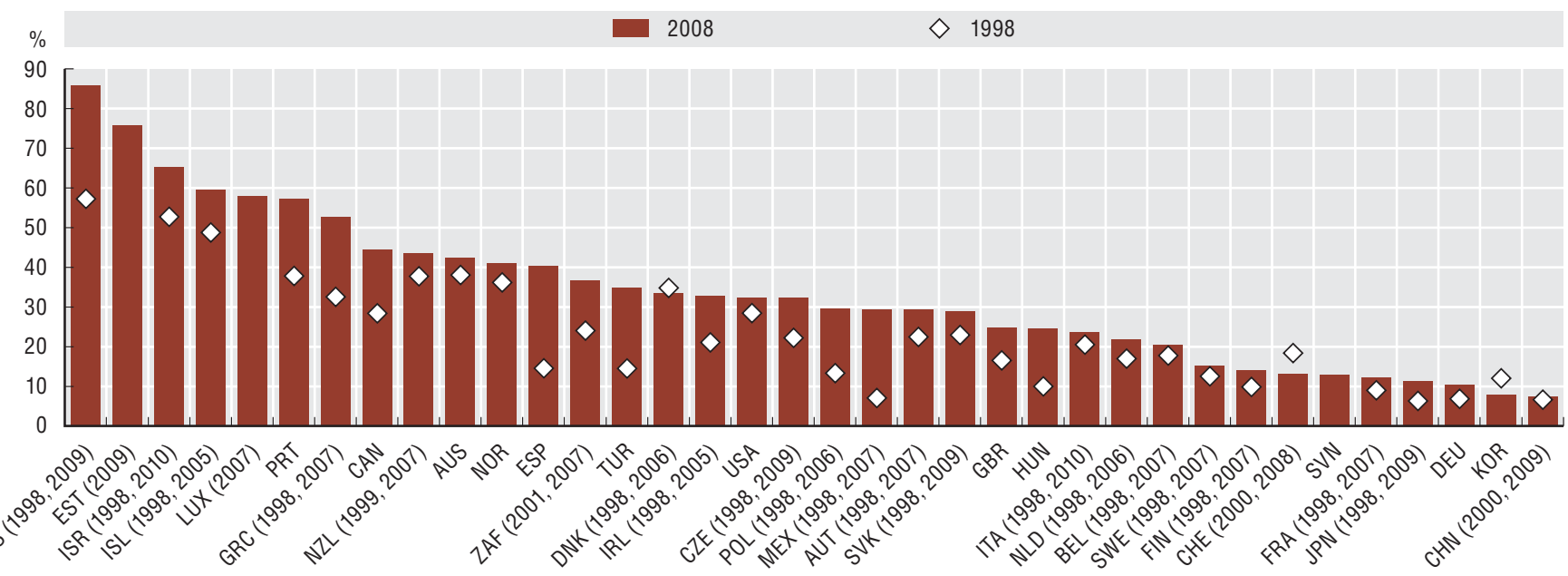

Source: ANBERD Database, May 2011. See chapter notes.

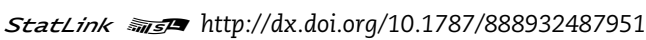

\section{Measurability}

Allocating R\&D by industry presents a number of challenges. Some countries adopt a "principal activity" approach whereby a firm's R\&D expenditure is assigned to that firm's principal industrial activity code. Other countries collect information on R\&D by "product field", so the R\&D is assigned to the industries of final use, allowing reporting companies to break down expenditures across product fields when more than one applies. Many countries follow a combination of these approaches, as product breakdowns are often not required in short-form surveys. The Frascati Manual (2002) recommends following a main activity approach when classifying statistical units, but for firms carrying out significant R\&D for several kinds of activities it recommends subdividing the R\&D by units or product fields. This applies to all industry groups and, at a minimum, to the R\&D industry (ISIC Rev. 3 Division 73), although not all countries follow this method. The ANBERD Database is based on the product field breakdown whenever countries can provide such information. This may cause comparability problems with countries that only report on the basis of the main activity. 


\section{Revealed technological advantage in ICT, 1997-99 and 2007-09}

Index based on patent applications filed under the PCT

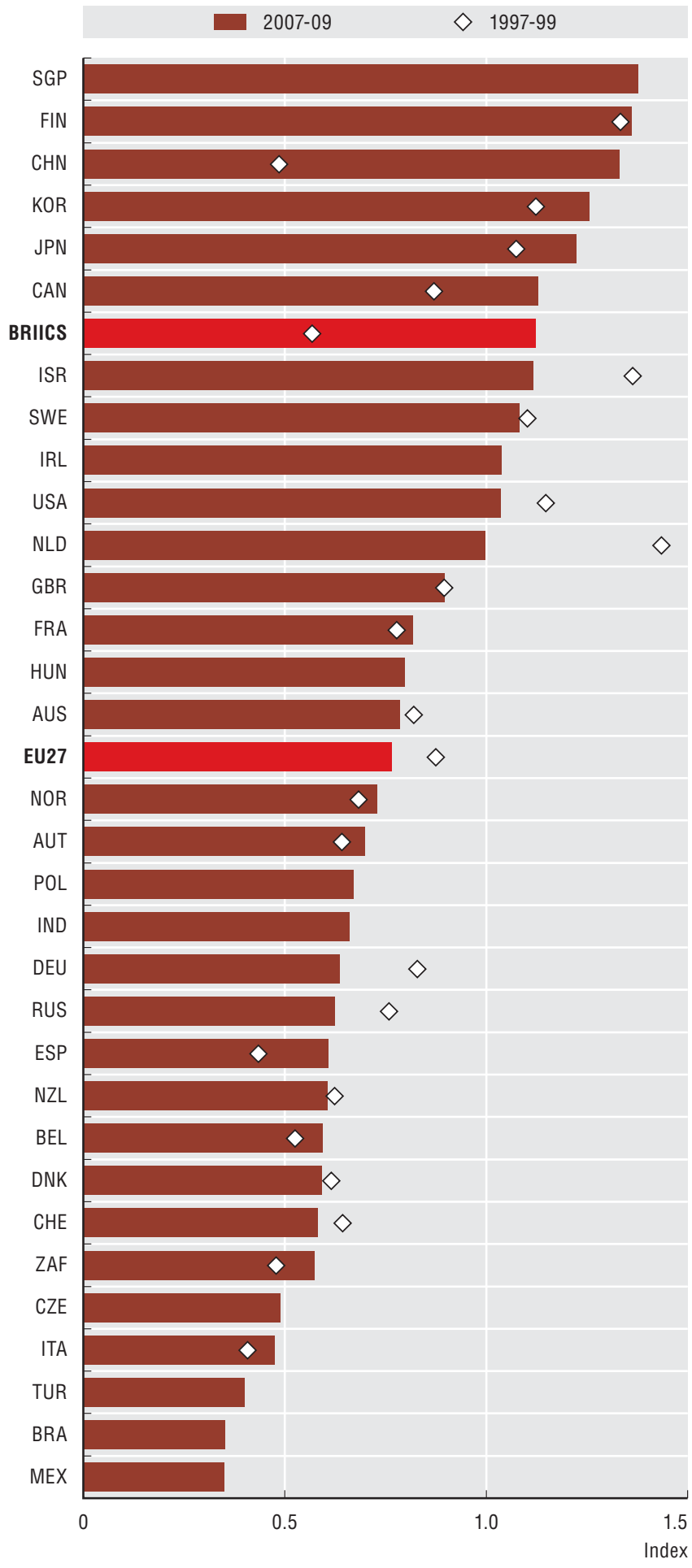

Source: OECD, Patent Database, May 2011. See chapter notes.

StatLink तारा http://dx.doi.org/10.1787/888932487970
Patent documents contain several types of information (e.g. technical class code, title, abstract, claims, etc.) which are useful for classifying patents in particular fields and investigating the emergence and growth patterns of new technologies. The rise in patent applications filed under the Patent Cooperation Treaty (PCT) stabilised at an average rate of $5 \%$ in the 2000 s. The increase was not evenly distributed across countries or technological fields. Since 2000, patenting in the information and communication technology (ICT) and nanotechnology sectors grew at a similar pace (respectively $3 \%$ and $4 \%$ ), whereas biotechnology patenting showed an inverse trend (-4\%).

The revealed technological advantage index is based on patent counts and provides an indication of the relative specialisation of a given country in selected technological domains. In 2007-09, the share of ICT-related patents applied for by Asian countries (China, Korea, Japan and Singapore) was above the average. China (39\%) had the largest increase in ICT-related PCT filings in the 2000s; this is reflected in its larger ICT specialisation index in 2007-09 as compared to 1997-99. The ICT specialisation index for Europe has been decreasing since the late 1990s, with a significant drop in Germany and the Netherlands.

While the number of biotechnology patents remained fairly stable during the 2000s, most countries' relative specialisation in biotechnology patenting increased. Denmark had the largest specialisation ratio in biotechnology in 2007-09, with nearly $15 \%$ of Danish patented inventions relating to biotechnology.

In 2007-09 nanotechnology patenting activity remained low, and represented only $0.8 \%$ of all filings, a share similar to 1997-99. The revealed technological advantage in nanotechnology was highest in Singapore (2.6), followed by the Czech Republic (1.6), Ireland (1.5) and the Netherlands (1.5). In the late 2000s Japan and the United States generated more than half of PCT filings in nanotechnology, an indication of their importance in the field.

\section{Definitions}

The index of revealed technological advantage is based on patent applications filed under the Patent Cooperation Treaty. It is defined as a country's share of patents in a particular technology field divided by the country's share in all patent fields. The index is equal to zero when the country holds no patents in a given sector; is equal to 1 when the country's share in the sector equals its share in all fields (no specialisation); and above 1 when a positive specialisation is observed. 


\section{COMPETING IN THE GLOBALECONQMY}

9. Technology specialisation

A corrigendum has been issued for this page. See: http://www.oecd.org/dataoecd/26/8/48742541.pdf Revealed technological advantage in biotechnologies, 1997-99 and 2007-09

Index based on patent applications filed under the PCT

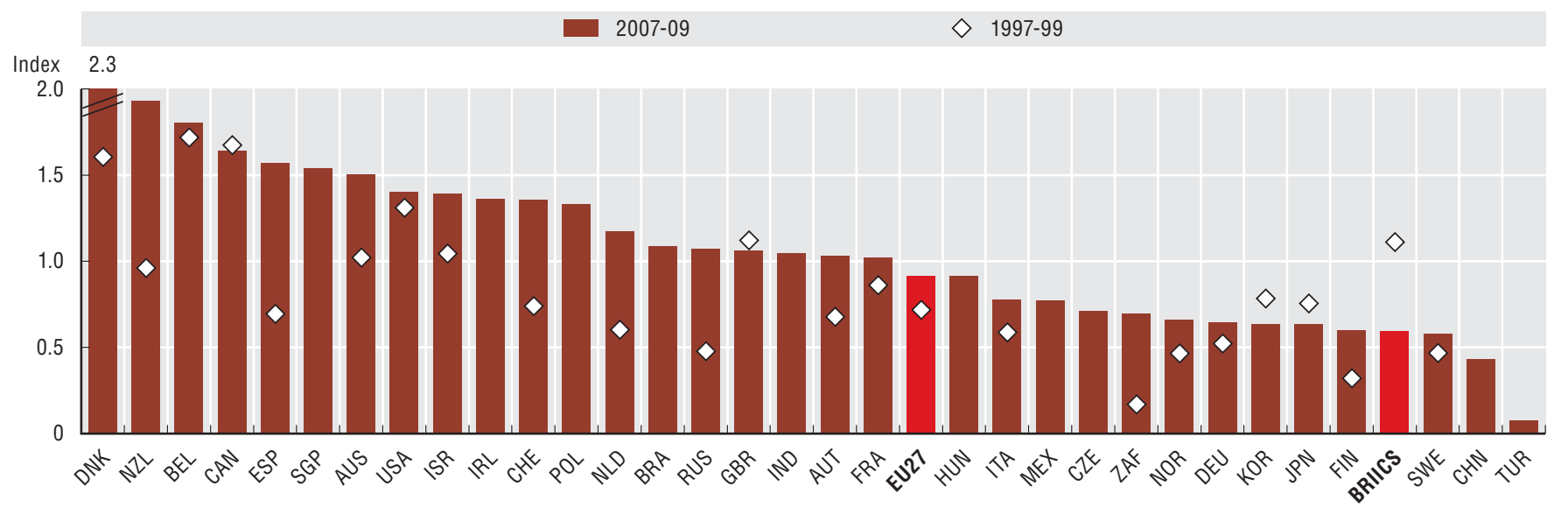

Source: OECD, Patent Database, May 2011. See chapter notes.

Revealed technological advantage in nanotechnologies, 1997-99 and 2007-09

Index based on patent applications filed under the PCT

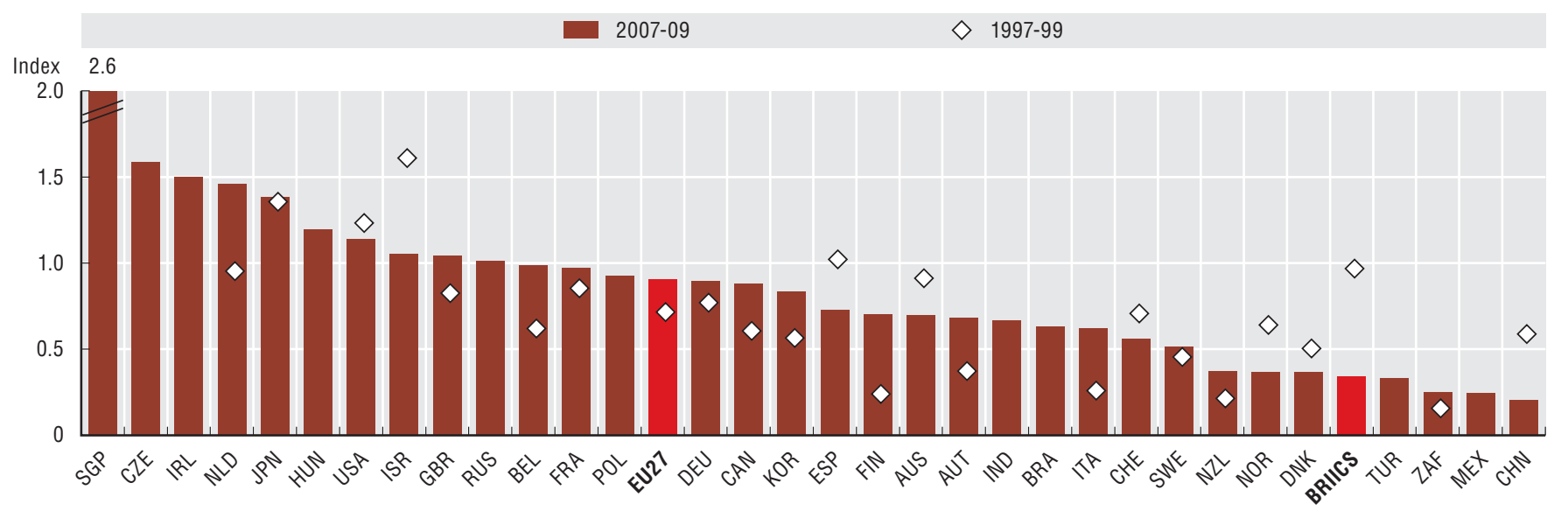

Source: OECD, Patent Database, May 2011. See chapter notes.

StatLink AाsL http://dx.doi.org/10.1787/888932488008

\section{Measurability}

The information provided by the International Patent Classification (IPC) constitutes a first reference for identifying patents in a specific domain. One or several IPC codes are attributed to the patent during the examination process. However, for emerging or enabling technologies, the patent classification system may not have a specific class. The OECD has designed definitions of ICT and biotechnology patents consisting of a list of IPC classes (www.oecd.org/sti/ipr-statistics). The definitions, like the technologies, can evolve over time. This has been the case for nanotechnologies: in 2003 the EPO created a working group (NTWG) to develop a definition of the field that would identify nanotechnology patents through keyword searches and expert analysis. Patent applications from 15 countries or organisations were analysed and documents tagged as Y01N. 
Firms' turnover from e-commerce, 2010

As a percentage of total firm turnover

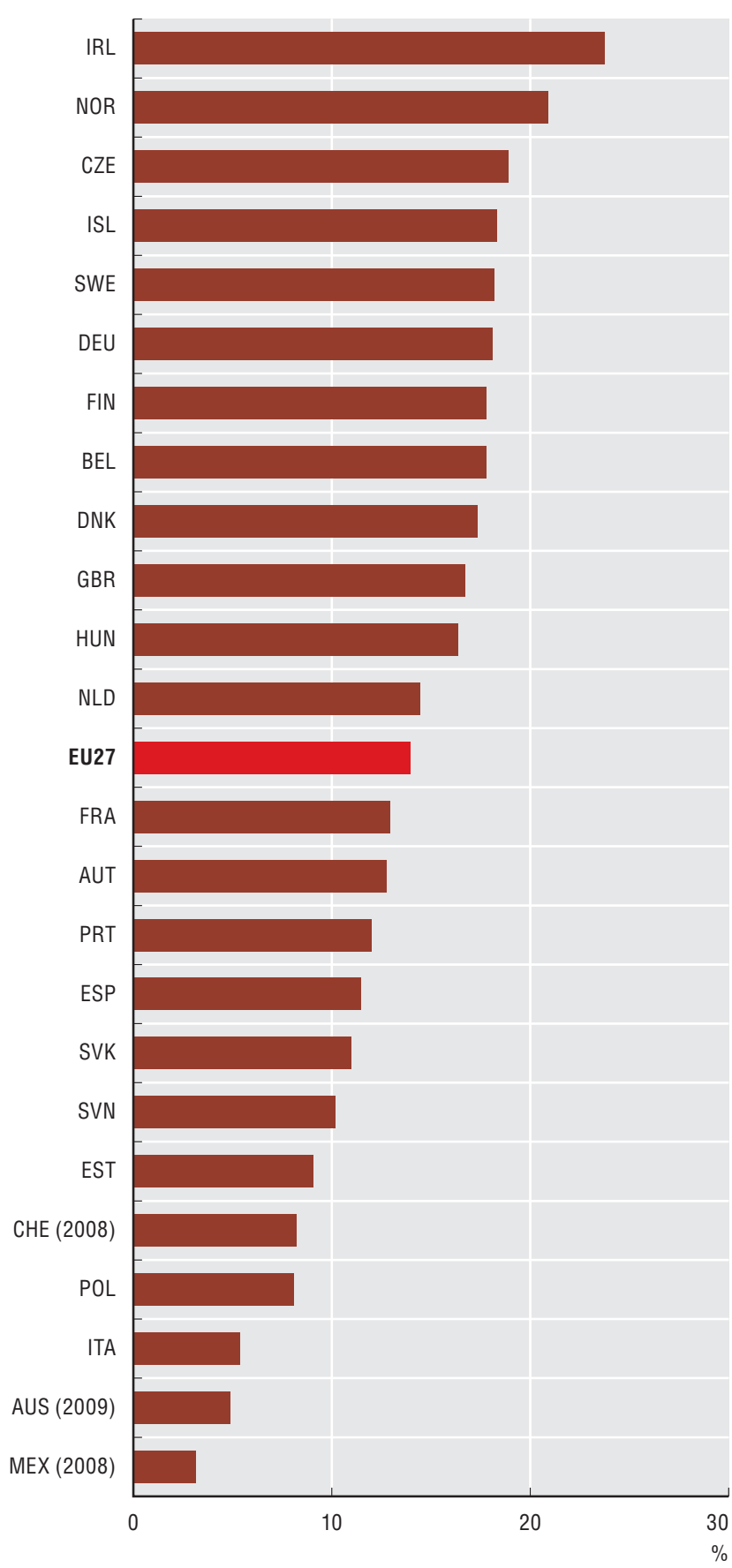

Source: OECD, ICT Database, May 2011; and Eurostat, Community Surveys on ICT Usage in Enterprises, April 2011.

StatLink काiाs http://dx.doi.org/10.1787/888932488027
In 2010, Internet and other e-commerce sales transactions averaged $13 \%$ of total turnover in countries for which data are available. Ireland, Norway and the Czech Republic reported the largest shares. In Ireland the share of e-commerce sales is almost twice the average.

Use of the Internet to sell goods or services varies across countries. In all OECD countries the share of business-tobusiness (B2B) transactions exceeds business-to-consumer (B2C) transactions. On average, over $35 \%$ of all businesses (with ten or more employees) use the Internet for purchasing and about $18 \%$ for selling goods or services.

In Switzerland, New Zealand, Canada, Australia, Norway and Sweden, over half of all businesses purchase via the Internet. For sales of goods or services via the Internet, the leaders are New Zealand, Israel, Norway, Australia and Switzerland, with approximately one-half to one-third of all businesses doing so.

Security concerns remain an important impediment to e-commerce. The growth of broadband has created a greater need for users to protect their security and privacy actively in the online environment. Both individual users and businesses report that computer viruses are the "malware" they encounter the most.

The Slovak Republic, Hungary, Italy and Estonia reported the largest shares of Internet users encountering viruses. For businesses, incidents include: destruction or corruption of data due to hardware or software failures and unavailability of information and communication technology (ICT) services following attacks from outside, e.g. denial of service attack; destruction or corruption of data due to infection or malicious software or unauthorised access; and disclosure of confidential data due to intrusion or phishing. The countries reporting the most incidents were Japan, Portugal, Greece, Denmark and Finland.

\section{Definitions}

In 2009, OECD member countries reviewed the OECD definition of e-commerce, which dated from 2001.

The 2009 OECD definition of e-commerce is: "An e-commerce transaction is the sale or purchase of goods or services, conducted over computer networks by methods specifically designed for the purpose of receiving or placing of orders. The goods or services are ordered by those methods, but the payment and the ultimate delivery of the goods or services do not have to be conducted online. An e-commerce transaction can be between enterprises, households, individuals, governments, and other public or private organisations. To be included are orders made over the web, extranet or electronic data interchange. The type is defined by the method of placing the order. To be excluded are orders made by telephone calls, facsimile or manually typed e-mail." 
Internet selling and purchasing for total industry, 2010

Percentage of businesses with ten or more employees

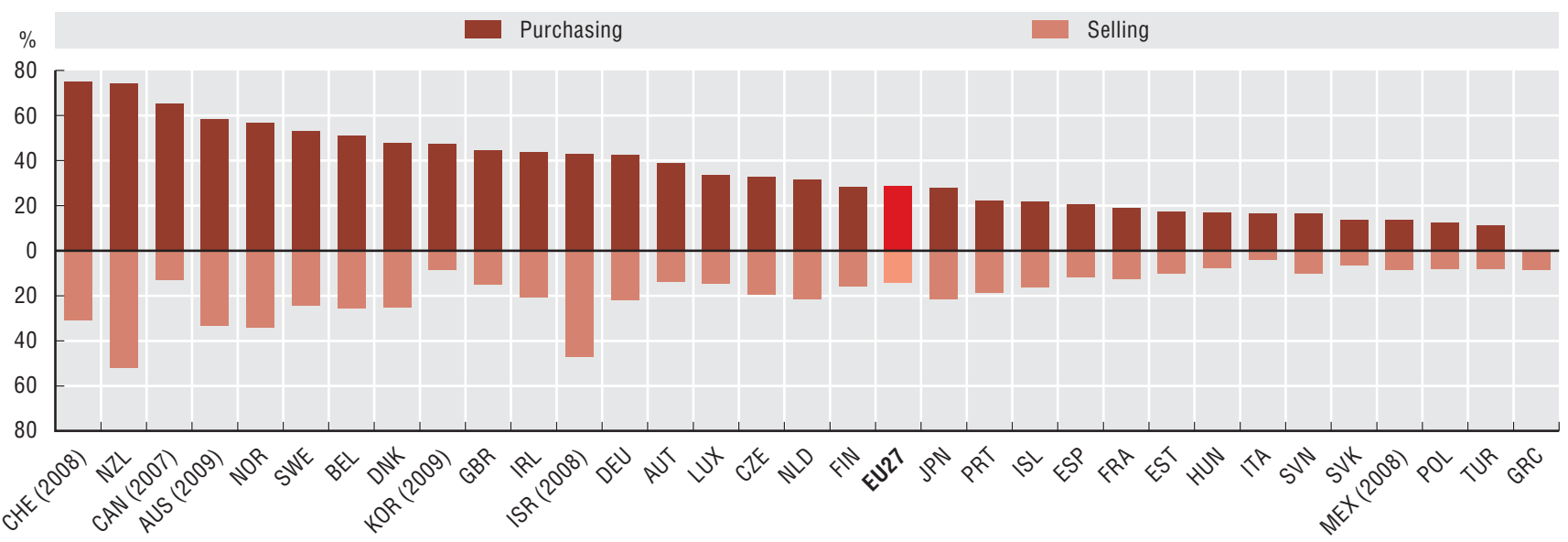

Source: OECD, ICT Database, May 2011; and Eurostat, Community Survey on ICT Usage in Enterprises, April 2011. See chapter notes. StatLink Ailst http://dx.doi.org/10.1787/888932488046

Businesses and individuals experiencing ICT security incidents, 2010

Percentage of businesses with ten or more employees and percentage of Internet users

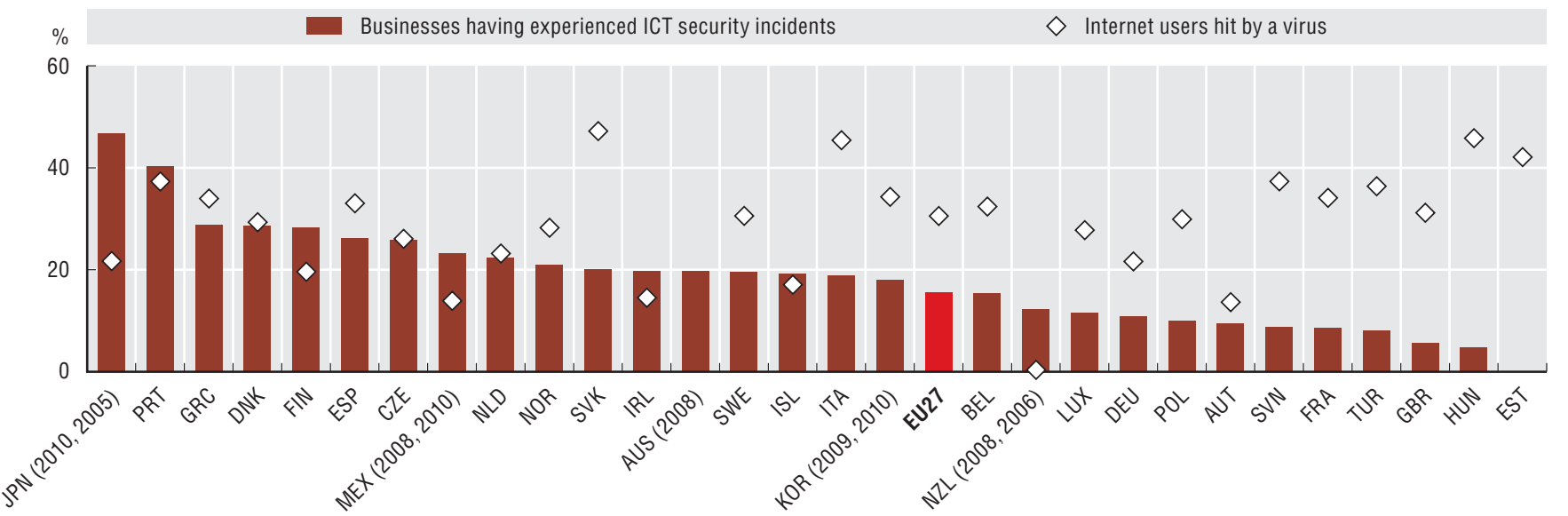

Source: OECD, ICT Database, May 2011; and Eurostat, Community Survey on ICT Usage in Enterprises and Survey on ICT Usage in Households and by Individuals, April 2011. See chapter notes.

StatLink aाIS http://dx.doi.org/10.1787/888932488065

\section{Measurability}

While Internet security is a challenging area to measure, differences among countries can highlight progress in working towards a culture of security. An important statistical challenge in terms of measurement is the fact that questions about security incidents encountered are problematic. There is significant anecdotal evidence that businesses will either not answer such questions or will understate the extent of any problems. 
Patenting activity by sector, 2007-09

As a percentage of patents filed by firms, at the EPO and USPTO

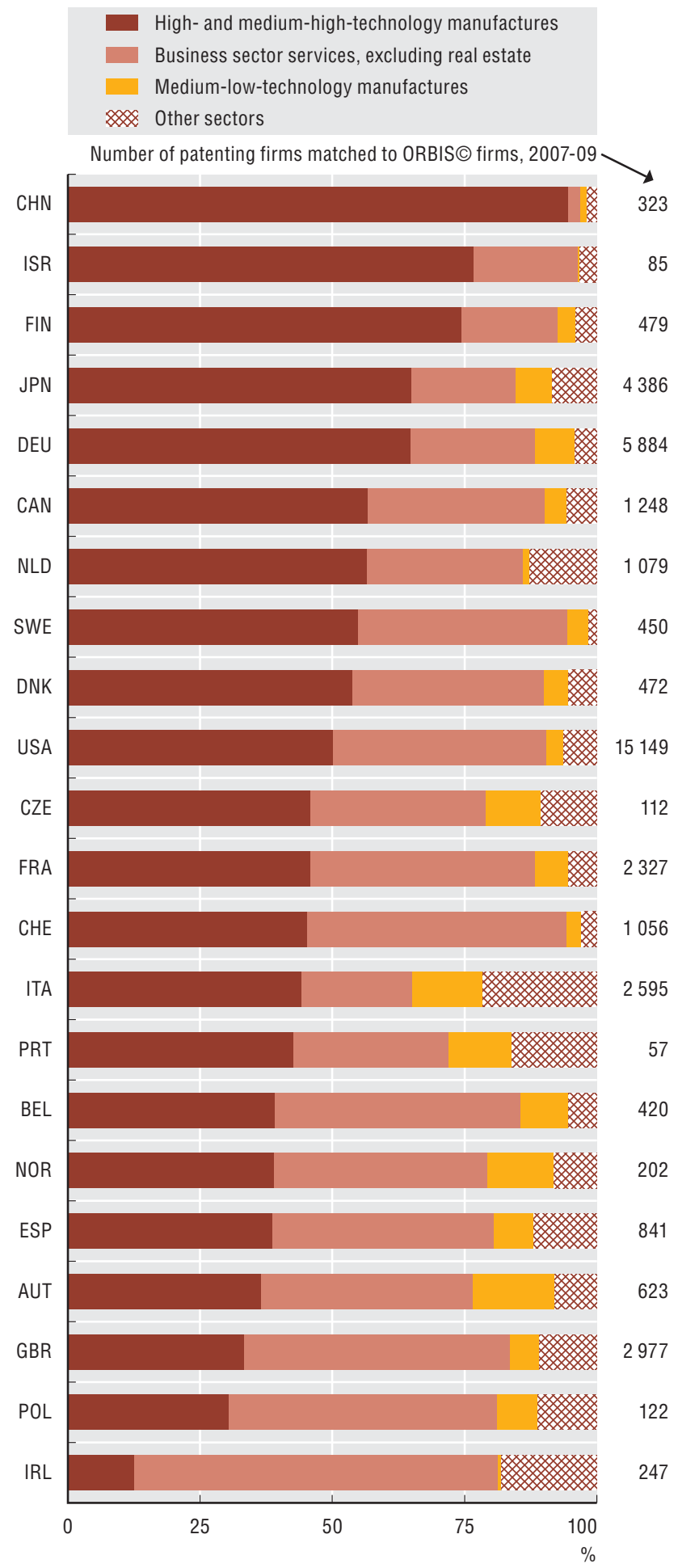

Source: OECD, calculations based on the Worldwide Patent Statistical Database, EPO, April 2011; and ORBIS@ Database, Bureau van Dijk Electronic Publishing, December 2010; matched using algorithms in the Imalinker system developed for the OECD by IDENER, Seville, 2011. See chapter notes.

StatLink ताIsय $h t t p: / / d x . d o i . o r g / 10.1787 / 888932488084$
Applicants in patent documents can be enterprises, organisations or persons. Business registers include information on enterprises and their main characteristics. By matching patent applicants' names to enterprise names in business registers the patenting behaviour of firms can be linked to firm characteristics such as industrial sector, age and size. Matched patent and firm data can also review industries' contribution to the development of key technologies, such as biotechnology and information and communication technology (ICT).

Statistics obtained by matching patent and enterprise data show that firms in high- and medium-high-technology manufacturing sectors perform on average $56 \%$ of all patenting. Exceptions are Ireland, Poland and the United Kingdom, where more than $50 \%$ of patents come from firms in the business services sector. Medium-low-technology manufacturing firms seldom contribute more than $10 \%$ of patent filings.

Matched enterprise and patent data also reveal the broad industrial basis of key enabling technologies. Chemical firms contribute to the advancement of pharmaceuticals and biotechnologies, and to a lesser extent to nanotechnologies. Not surprisingly, research and development service providers are essential to these fields, as are institutions such as universities. New ICT-related technologies are concentrated in a set of computer and communications industries, while environmental technologies are shaped by the patenting activity of specialised machinery manufacturers and certain technical and engineering service activities.

The presence of young firms among patent applicants underlines the inventive dynamics of firms early in their development and their desire to develop new activities and products; this may affect their survival and growth. During 2007-09 firms less than five years old filing at least one patent application represented on average $25 \%$ of all patenting firms, and generated $10 \%$ of patent applications. The share of young patenting firms varies considerably across countries, led by Ireland (42\%) and followed by the Nordic economies.

\section{Definitions}

Patenting firms were linked to the ORBIS॰ database using combinations of string matching algorithms that optimise the precision of the match. The patent portfolio of firms refers to patents filed at the European Patent Office (EPO) and at the US Patent and Trademark Office (USPTO) between 2007 and 2009. The industry list is based on ISIC Rev. 3. Young patenting firms are those with an incorporation date in ORBIS॰ between 2004 and 2009. 
Top three industries patenting in selected technology fields, 2007-09

Share of industries' contribution to patent applications in selected technology fields, EPO and USPTO patents

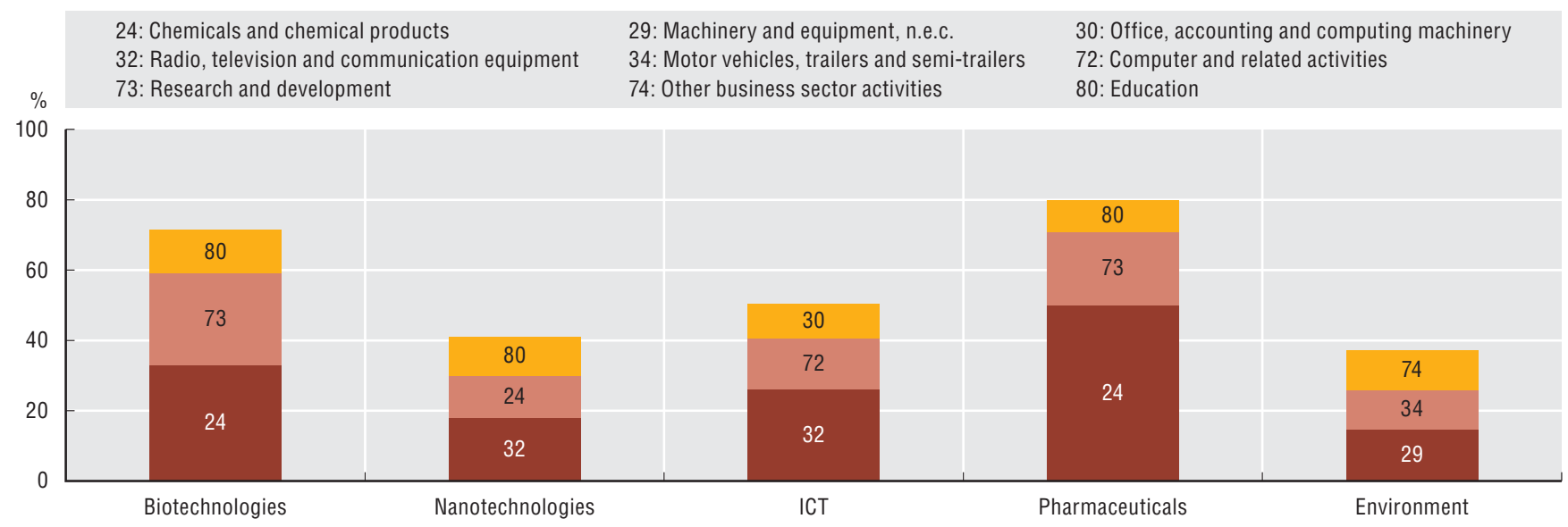

Source: OECD, calculations based on the Worldwide Patent Statistical Database, EPO, April 2011; and ORBIS@ Database, Bureau van Dijk Electronic Publishing, December 2010; matched using algorithms in the Imalinker system developed for the OECD by IDENER, Seville, 2011. See chapter notes.

StatLink iㅣs http://dx.doi.org/10.1787/888932488103

\section{Patenting activity of young firms, 2007-09}

Share of young patenting firms and share of patents filed by young patenting firms, EPO and USPTO

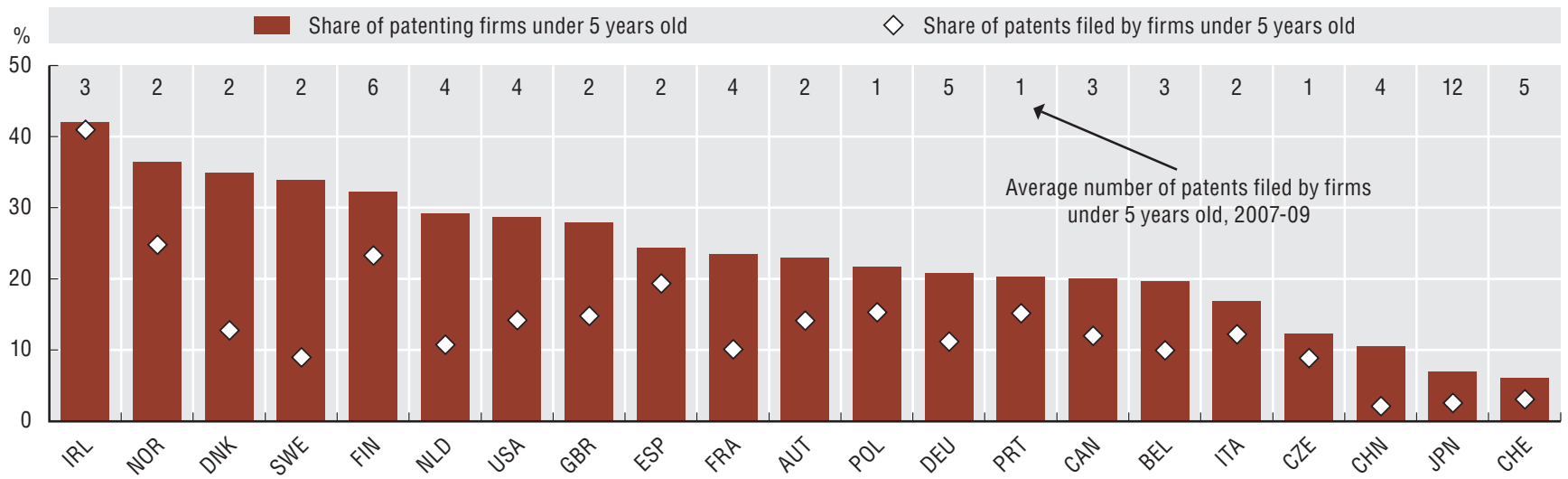

Source: OECD, calculations based on the Worldwide Patent Statistical Database, EPO, April 2011; and ORBIS๑ Database, Bureau van Dijk Electronic Publishing, December 2010; matched using algorithms in the Imalinker system developed for the OECD by IDENER, Seville, 2011. See chapter notes.

StatLink कीजा http://dx.doi.org/10.1787/888932488122

\section{Measurability}

Linking patent data to enterprise data requires harmonising firms' names. This is done using country-specific "dictionaries" covering legal entities, common names and expressions, as well as phonetic and linguistic rules that may affect how enterprise names are written. String matching algorithms - mainly token-based and string-metric-based - then use this information to compare the names in the different datasets and provide a matching accuracy score. Using software developed for OECD by IDENER, Seville, 68 million patents in EPO's Worldwide Patent Statistical Database (PATSTAT) and 80 million companies in Bureau van Dijk's ORBIS๑ firm data were matched for enterprises worldwide. Ideally, the matching should be performed on official data such as national business registers, as ORBIS's firm coverage is not exhaustive and differs across countries - in particular small firms are underrepresented. To partially address this and other selection and data consistency issues, the analysis is restricted to countries with matching rates above $60 \%$ of patent filings over the period considered. 
Innovation intensity in sectors, 2002-06

Aggregate rank based on combined CIS 2004 and CIS 2006 results

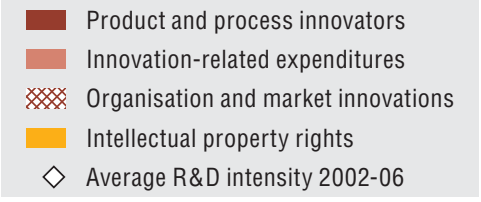

Combined CIS ranking score

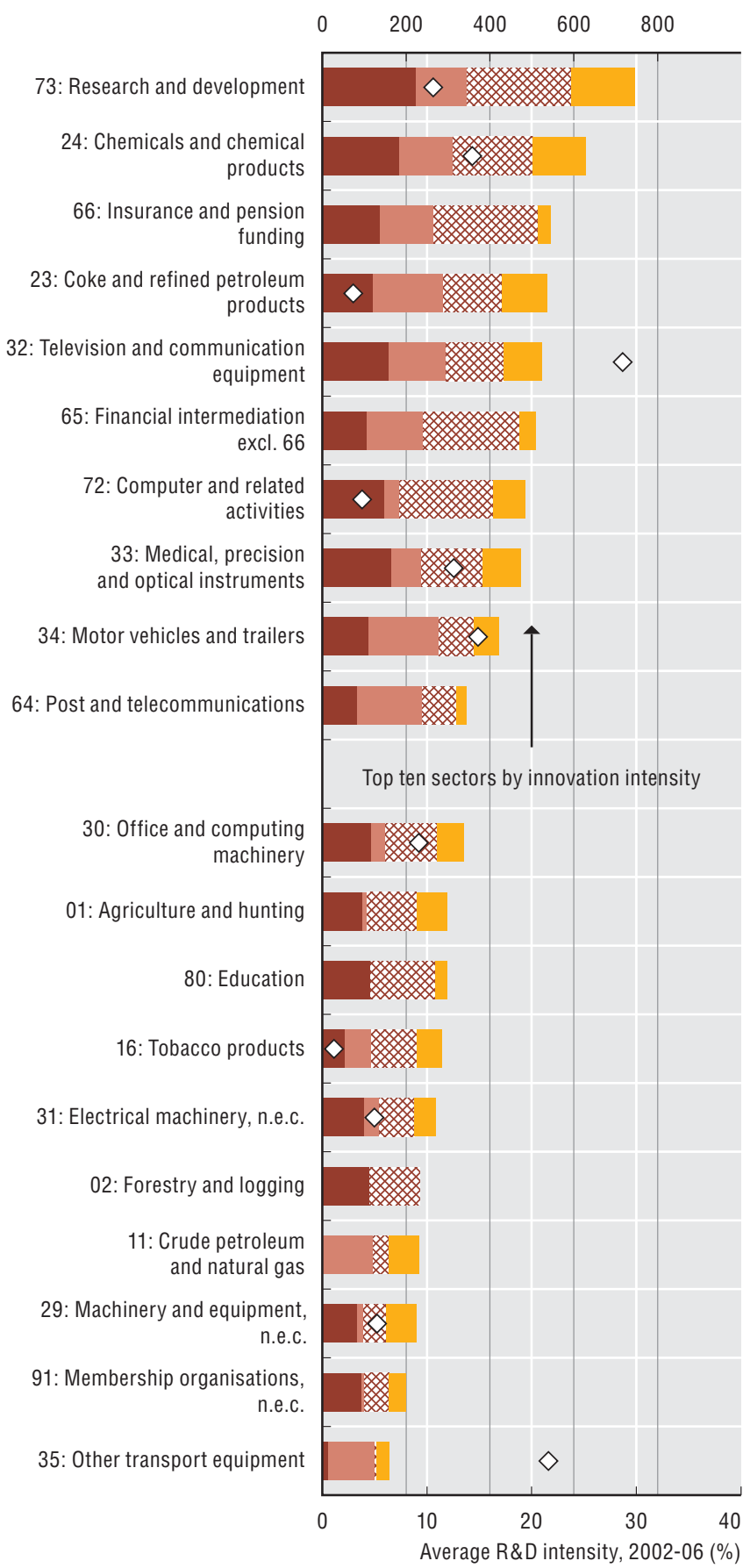

Source: OECD, based on Eurostat [CIS-2006 and CIS-2004 (CIS4)], June 2011. See chapter notes.

StatLink Aाज्य http://dx.doi.org/10.1787/888932488141
A classification based on innovation can complement the established and widely used technology classification that is based on industry R\&D intensities. By considering the more general scope of innovation it draws on sectors, particularly services, that do not undertake relatively high levels of formal R\&D. Innovation surveys capture a broad range of innovation activities from product and process to marketing and organisational innovations and account for both innovation inputs and outputs.

The experimental methodology presented here uses results from Eurostat's Community Innovation Survey (CIS), for the periods 2002-04 (CIS4) and 2004-06 (CIS6), to identify "innovation-intensive sectors". NACE Rev. 1 (ISIC Rev. 3) 2-digit industry divisions are ranked according to the innovative performance resulting from combined CIS scores of firms within each industry. Sectors that perform high levels of formal R\&D do not necessarily rank high when broader innovation inputs are considered. For example, "Manufacturing of transport equipment" (Division 35) is relatively $R \& D$-intensive but only just features in the top 20 innovation ranking. Meanwhile, like many services, "Computer and related activities" (Division 72) has a low R\&D intensity but ranks highly for innovation intensity reflecting its role as a source of non-technological innovation.

According to this preliminary classification and available data, innovation-intensive manufacturing sectors seem to account for about $25 \%$ of manufacturing value added, on average. Innovation-intensive services account for a similar share of total "market" services value added, for the countries shown, mainly owing to telecommunications, financial and computing services.

\section{Definition}

Innovation-intensive sectors are defined on the basis of a combined CIS score. To this end, a number of CIS variables are grouped into four main categories that are homogenous with respect to the information provided and the innovation-related feature addressed, namely: product and process innovations, organisation and market innovations, intellectual property rights and innovation-related expenditures. Some of these variables are dichotomous (i.e. yes/no answers), whereas the expenditure questions are considered as a continuous variable. Sectoral "performance" of the dichotomous variables is calculated as the share of firms answering "yes" to the total number of respondents to that question. In the case of the continuous variable, sectors are ranked on the basis of average expenditures. 


\section{COMPETING IN THE GLOBALECONQMY}

12. Innovative sectors

Value added of innovation-intensive manufacturing sectors, 2008

As a percentage of total manufacturing value added

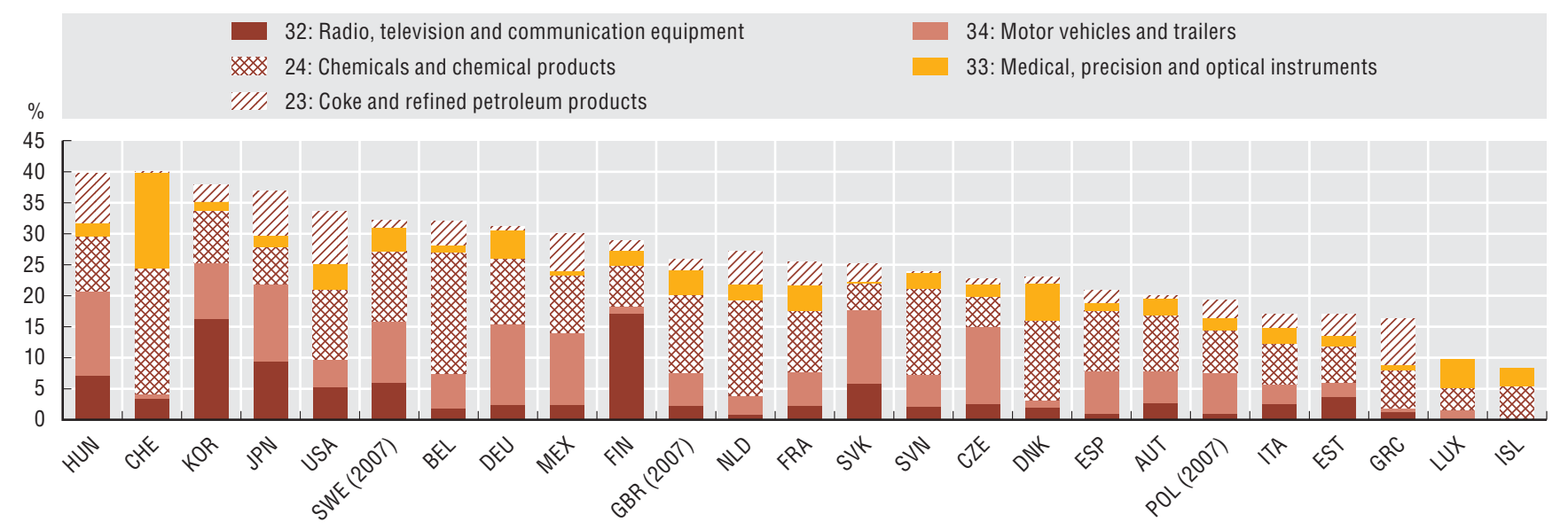

Source: OECD, Structural Analysis (STAN) Database, June 2011. See chapter notes.

StatLink लाड़ http://dx.doi.org/10.1787/888932488160

Value added of innovation-intensive service sectors, 2008

As a percentage of "market" services value added

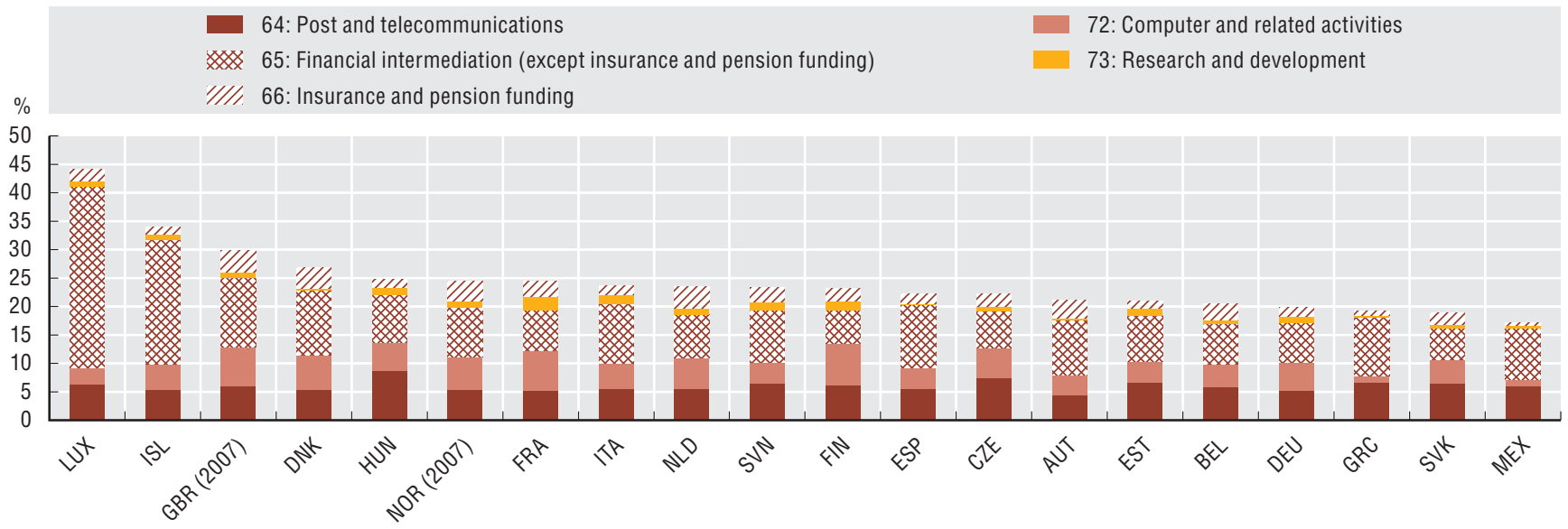

Source: OECD Structural Analysis Database (STAN), June 2011. See chapter notes.

StatLink Aाsस http://dx.doi.org/10.1787/888932488179

\section{Measurability}

The most innovative sectors are identified by means of a distribution-based approach which only considers the sectors performing above the mean in all four innovation dimensions. Sectors are then assigned a score proportional to their position, with top performers assigned 20 points. The others receive a progressively lower score and the last ranked sector in the upper part of the distribution has one point. The scores are then aggregated to produce an overall ranking. Sectoral estimates rely on unweighted statistics (data are not adjusted for the representativeness of the respondent firm) and company data aggregated at the most detailed NACE Rev. 1 level enabled by national sampling designs and Eurostat's data disclosure rules. Sectoral coverage varies across countries and tabulations may rely on a subset of countries and not be fully representative. Rankings rely on the same set of variables in CIS4 and CIS6 to ensure consistency and comparability over time. In this type of exercise, cut-off points for the top innovative sectors may sometimes not be clear. For example, the top ten sectors in this preliminary selection do not include Sector 30 (Manufacture of computing and office equipment), which is 11th in the ranking and thus could arguably be included in the innovation intensive group. 
Patent quality index by country, 1990-2000 and 2000-10

Composite index based on patents granted by the EPO

Average 2000-10

Average 1990-2000

$\diamond$ Median 2000-10

$\triangle$ Median 1990-2000

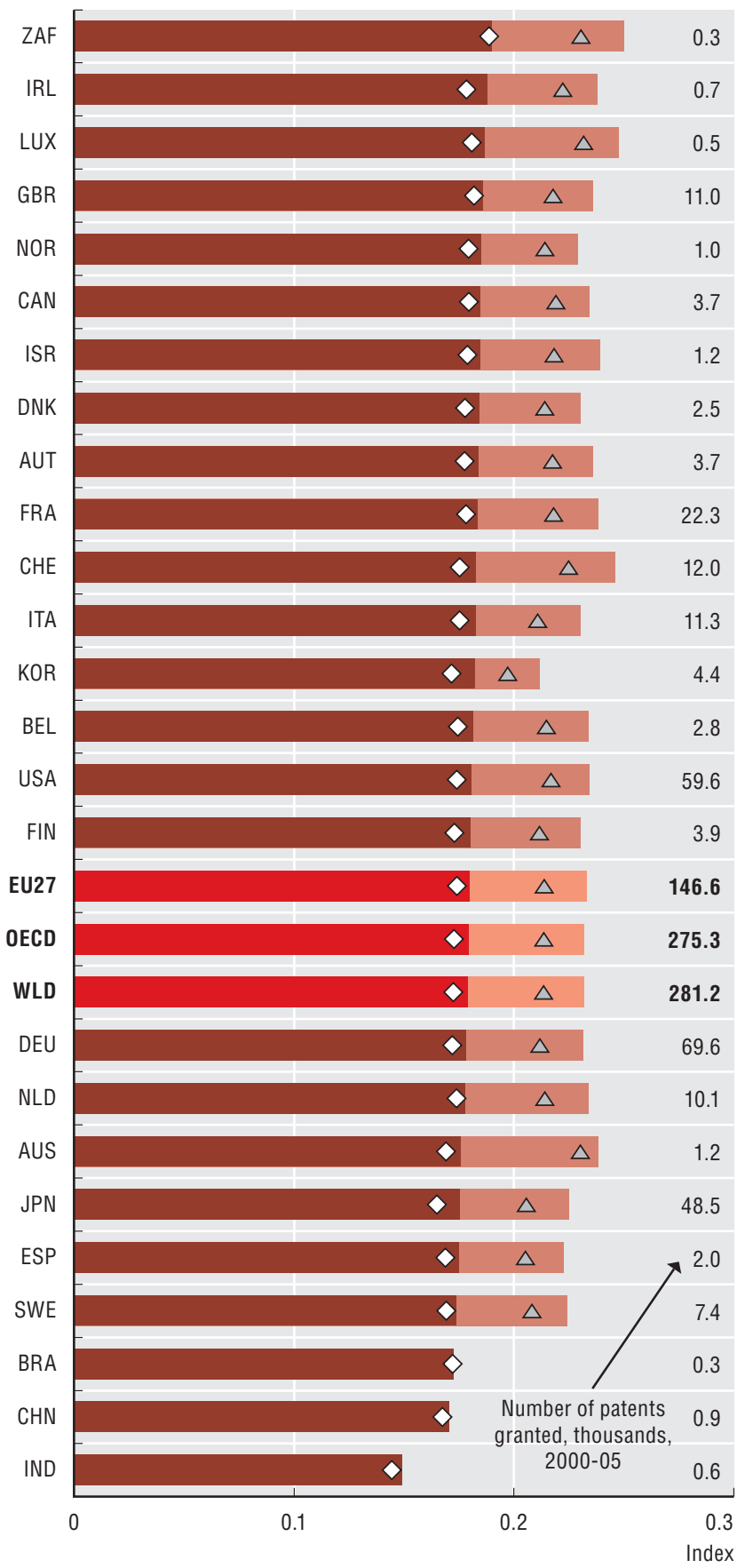

Source: OECD, calculations based on the Worldwide Patent Statistical Database, EPO, April 2011. See chapter notes.

StatLink AाIst $h t t p: / / d x . d o i . o r g / 10.1787 / 888932488198$
Patent quality indicators try to capture both the technological and the economic value of innovations, and are typically based on patent citations, claims, patent renewals and patent family size. They are considered meaningful measures of research productivity and are found to be correlated with the social and private value of the patented inventions. The difference in average patent quality across firms is generally associated with the market evaluation of firms.

A new composite index suggests that patent quality has declined steadily in the last decade. It shows an average $20 \%$ decline between the two periods considered. Comparisons of the differences between median and mean values indicate reduced quality dispersion in recent years, i.e. there are in general smaller differences between patents of different quality levels. The difference in average patent quality between top and bottom ranking countries has also decreased over time, passing from $15 \%$ in the 1990 s to about $9 \%$ in the 2000s. A selection effect - the tendency to file relatively high-quality patents abroad - may explain the higher average scores of some non-European countries for patents filed at the European Patent Office (EPO).

Renewable energy technologies, nanotechnologies and information technology methods exhibit the highest patent quality index during 2000-10, although statistics rely on small samples for these sectors. Differences between top performers and average sector quality levels may be indicative of competitive advantages. Sectors generally believed to be highly innovative and known to rely more on basic science, e.g. biotechnology and pharmaceuticals, show on average relatively lower patent quality.

\section{Definitions}

The patent quality index is a composite indicator based on six dimensions of patents' underlying quality: forward citations (number of citations a patent receives); backward citations (number of patents and scientific papers a patent cites); patent family size, i.e. the number of countries in which the patent is taken; number of claims; generality index, measuring the dispersion of citing patents over technology classes; and grant lag. The index does not use weights. All components are normalised and given equal importance. Data refer to EPO patents granted for which the application document was published during 1990-95 and 2000-05. Forward citations are counted up to five years after the publication date. This means considering citation lengths of 6.5 years, as publication normally occurs 18 months after the patent filing date. Self-citations are not controlled for. Technology fields are defined according to Schmoch's classification (WIPO, 2010) and rely on the International Patent Classification (IPC) codes contained in the patent document. 
Patent quality index by technology field, 2000-10

Composite index based on patents granted by the EPO

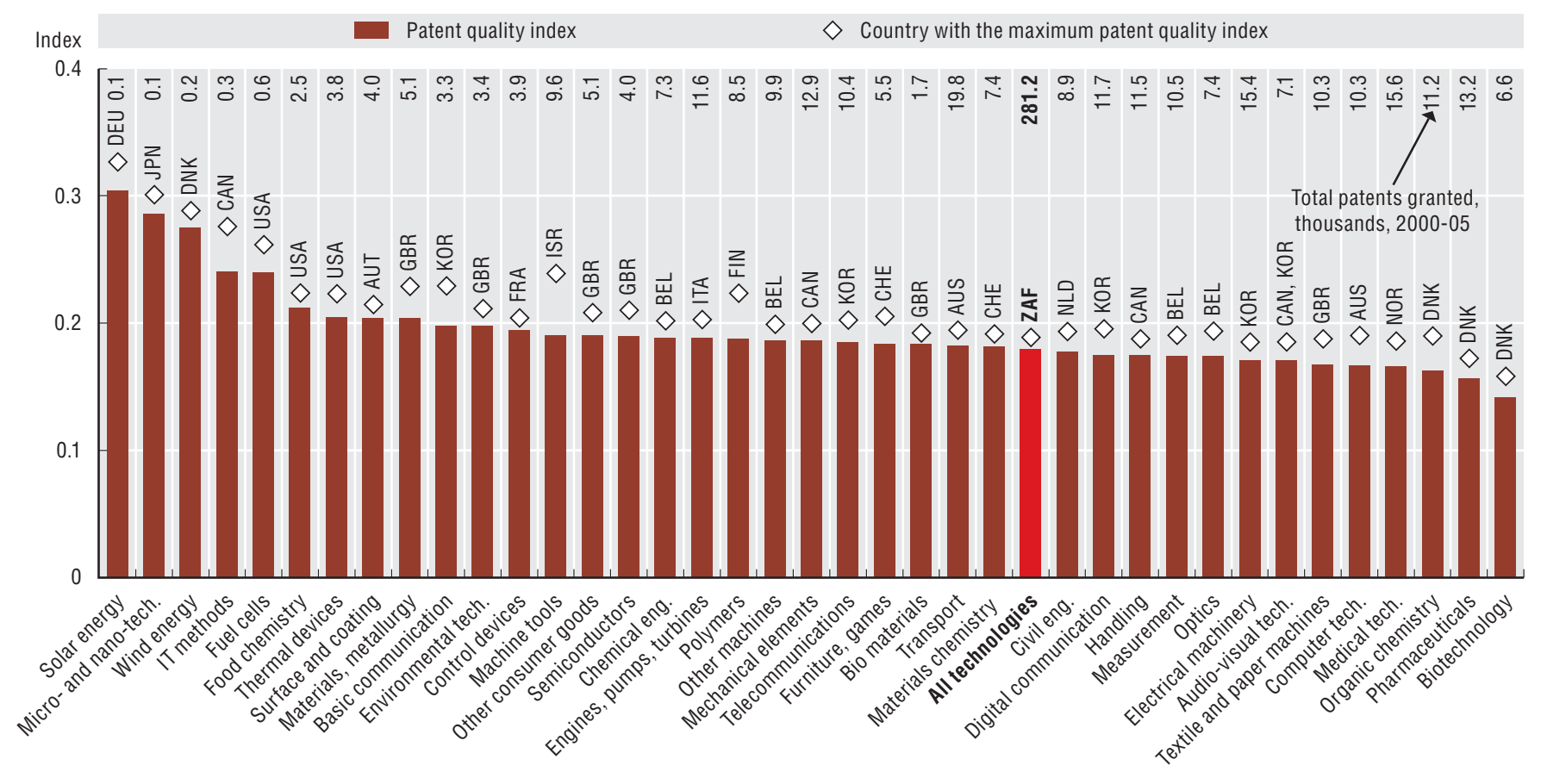

Source: OECD, calculations based on the Worldwide Patent Statistical Database, EPO, April 2011. See chapter notes.

StatLink 에내 http://dx.doi.org/10.1787/888932488217

\section{Measurability}

Patent cohorts are stratified by year and sector. All six components of the patent quality index are normalised on the basis of the cohort's maximum values. For each patent, the grant lag indicator is calculated as follows: $1-[\Delta t / \max (\Delta t)]$, where $\Delta t$ is the number of days between application and granting date; and $\max (\Delta t)$ is the maximum number of days it has taken any patent belonging to the same cohort to be granted. The patent quality indicator is bounded between 0 (not included) and 1 (maximum value). Zone aggregates are based on weighted averages over the periods considered. The patent quality indicator is an experimental index of the OECD and may be subject to further refinement. It builds on Lanjouw and Shankerman (2004) and incorporates the generality measure proposed by Hall and Trajtenberg (2004), and a measure accounting for the length of the examination process (Régibeau and Rockett, 2010). Using different data sources, e.g. US Patent and Trademark Office or Japan Patent Office, different methodologies or observation periods may affect patents' scores, countries' rank and sectors' positions. 
Generality of patent applications, 1996-2000 and 2001-05 Average index based on patent applications to the EPO

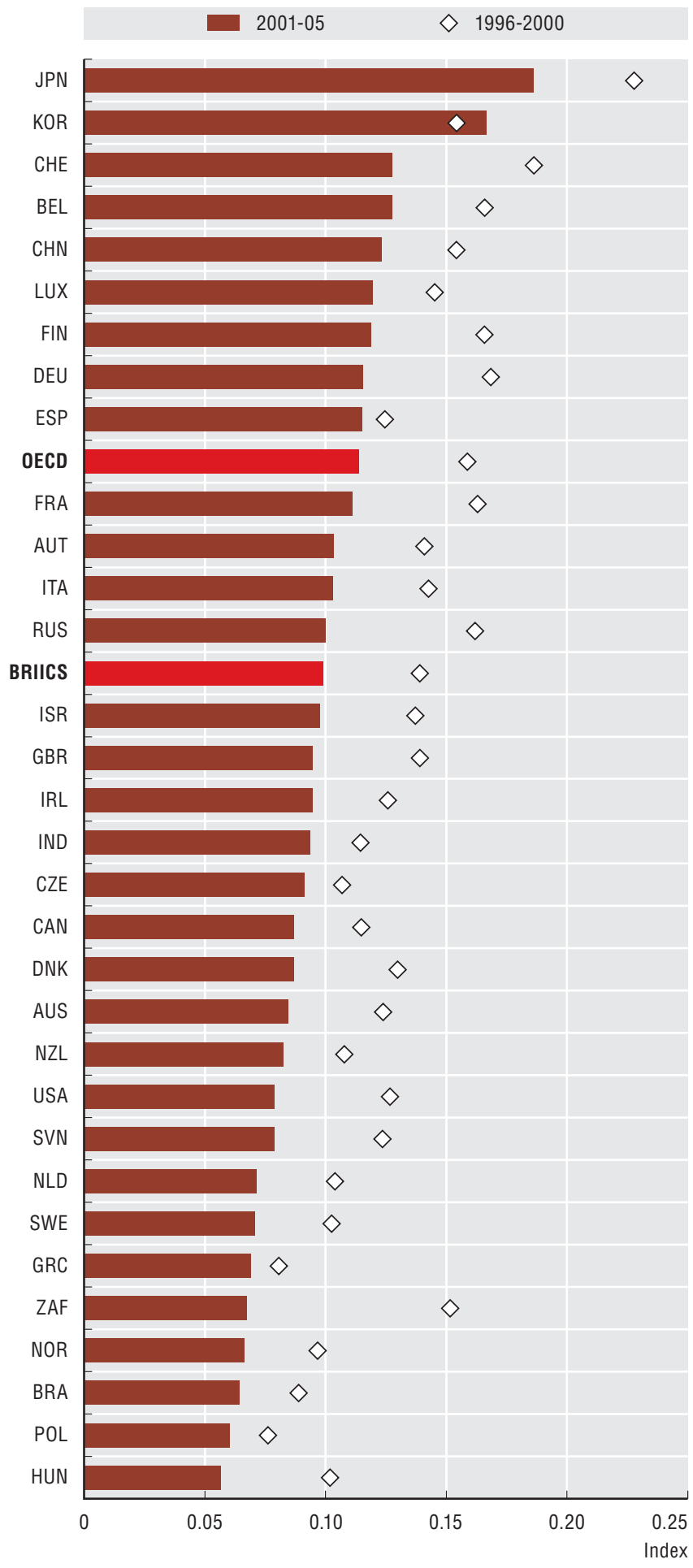

Source: OECD, calculations based on the Worldwide Patent Statistical Database, EPO, April 2011. See chapter notes.

StatLink AाIs/ $h t t p: / / d x . d o i . o r g / 10.1787 / 888932488236$
A number of indicators use information on the technological fields of patents based on the International Patent Classification (IPC) system and on the forward citations (citations a patent receives) and backward citations (patents and scientific papers a patent cites).

The "generality index" captures the range of 4-digit IPC technology classes covered by citing patents: the wider the range, the higher the index for the cited patent. Patents associated with a high generality index are relevant to later inventions spanning in several technology areas. Conversely, low index values mean that the citations received are concentrated in a few fields and reflect the technological specialisation of the cited patent.

The index of patent "scope" measures the breadth of the patented invention by counting the number of technology classes assigned to each patent during the patent examination. The larger the number of distinct 4-digit IPC classes, the broader the "scope" index. Finally, a third indicator aims to identify breakthrough inventions, defined as the top $1 \%$ of cited patents in each technology field for a given year's cohort. On average, patent generality differs across countries and has decreased over time in OECD and BRIICS economies (Brazil, the Russian Federation, India, Indonesia, China, South Africa) by almost $30 \%$ and $40 \%$, respectively. In both periods considered, the highest values are more than twice the lowest values. There are also differences among top values: for instance, for patent applications published in 2001-05, Japan and Korea have $46 \%$ and $30 \%$ higher generality index values, respectively, than the third country, Switzerland.

The "scope" index varies much less and differences across countries are smaller. Except in a few countries, there is a general but moderate increase in patent scope over time.

Many countries generate breakthrough inventions. In both periods considered, the United States, Japan and Germany have a significant proportion of highly cited patents (about $70 \%$ in $1996-2000$ and $60 \%$ in $2001-05$ ). In recent years China and India have emerged and Korea has gained in importance.

\section{Definitions}

The generality index follows Hall and Trajtenberg (2004):

Generality $\equiv G_{i}=1-\sum_{j}^{n_{i}} s_{i j}^{2}$

where $s_{i j}$ is the percentage of citations received by patent $i$ belonging to patent class $j$ out of $n_{i}$ patent classes.

The scope index is based on Lerner (1994) and is the number of international patent classes to which a European Patent Office (EPO) patent is assigned. Breakthrough inventions are defined following Ahuja and Lampert (2001) as the top 1\% of cited patents in each field and year. Technology fields are defined according to Schmoch's classification (WIPO, 2010) and rely on the International Patent Classification codes in the patent document. 
Patent scope by country, 1996-2000 and 2001-05

Average number of IPC classes per patent application to the EPO

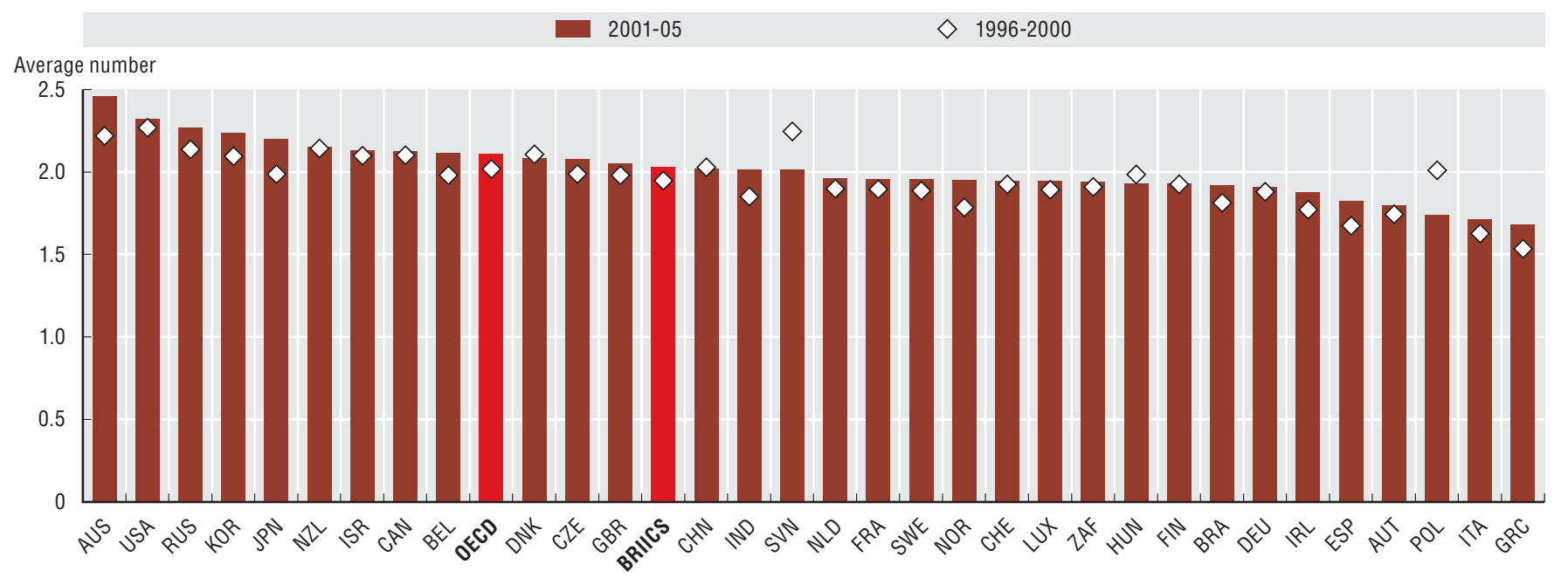

Source: OECD, calculations based on the Worldwide Patent Statistical Database, EPO, April 2011. See chapter notes.

StatLink Ants http://dx.doi.org/10.1787/888932488255

Highly cited patent applications to the EPO (top 1\%), 1996-2000 and 2001-05

As a share of all EPO patent applications in the top $1 \%$ in their field

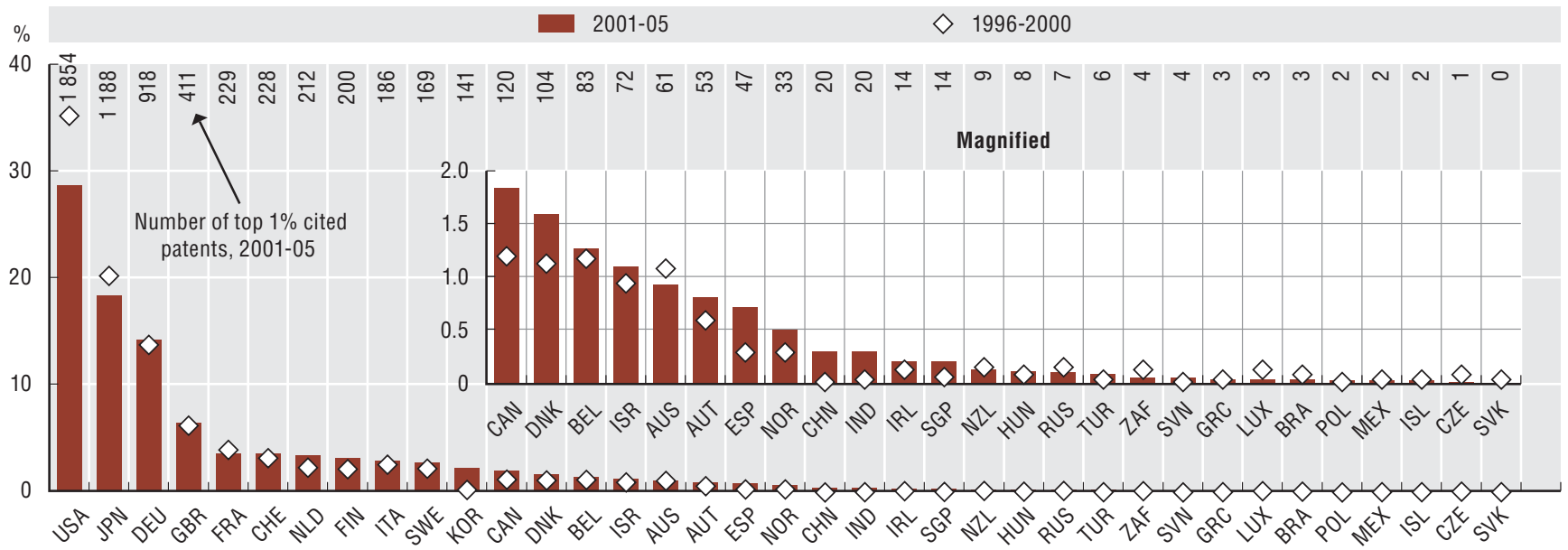

Source: OECD, calculations based on the Worldwide Patent Statistical Database, EPO, April 2011.

StatLink AाIS http://dx.doi.org/10.1787/888932488274

\section{Measurability}

The generality index is based on the Hirschman-Herfindahl Index (HHI) and relies on information concerning the number and distribution of citations received and the IPC classes of the patents these citations come from. Highly cited patents are computed by grouping all published applications by technology fields and year of publication. Applications belonging to more than one field are assigned to the field of the majority of its 4-digit IPC subclasses. Within each year's cohort, applications are weighted by the number of citations received up to five years after publication. The top $1 \%$ of patent applications are considered highly cited. For all three indicators, the values displayed are calculated as averages (shares in the case of breakthrough inventions) of the inventor's country and are based on all applications published in the period. 


\section{Cyprus}

The following note is included at the request of Turkey:

"The information in this document with reference to 'Cyprus' relates to the southern part of the Island. There is no single authority representing both Turkish and Greek Cypriot people on the Island. Turkey recognises the Turkish Republic of Northern Cyprus (TRNC). Until a lasting and equitable solution is found within the context of the United Nations, Turkey shall preserve its position concerning the 'Cyprus issue'."

The following note is included at the request of all the European Union member states of the OECD and the European Commission:

"The Republic of Cyprus is recognised by all members of the United Nations with the exception of Turkey. The information in this document relates to the area under the effective control of the Government of the Republic of Cyprus."

\section{Israel}

"The statistical data for Israel are supplied by and under the responsibility of the relevant Israeli authorities. The use of such data by the OECD is without prejudice to the status of the Golan Heights, East Jerusalem and Israeli settlements in the West Bank under the terms of international law."

"It should be noted that statistical data on Israeli patents and trademarks are supplied by the patent and trademark offices of the relevant countries."

\section{Employment in services, 2009}

"Market sector services" is defined according to ISIC Rev. 3 Divisions 50-74.

"Public sector services" is defined according to ISIC Rev. 3 Divisions 75-95, i.e. Government (75), Education (80), Health (85), Other community, social and personal services (90-93) and Private households (95).

"Industry" is defined according to ISIC Rev. 3 Divisions 10-41, i.e. Mining (10-14), Manufacturing (15-37) and Utilities (40-41).

Using an industry based definition, the distinction between market and public services is an approximate one. In OECD countries private education and health services are available to varying degrees while some transport and postal services remain in the public realm.

Iceland and Turkey: Labour Force Survey (LFS) data by industry are used in the absence of employment by activity statistics published in a National Accounts (SNA) context.

New Zealand: based on employment estimates for fiscal years 2008-09 and 2009-10.

\section{Employment in knowledge-intensive "market" services, 2008}

Knowledge-intensive "market services" refers to Post and telecommunications (ISIC Rev. 3 Division 64), Finance and insurance (Divisions 65-67) and Business activities (Divisions 71-74).

\section{Employment in high- and medium-high technology manufacturing industries, 2008}

High- and medium-high technology manufacturing is defined as Chemicals and chemical products (ISIC Rev. 3 Division 24); Manufacture of machinery and equipment, n.e.c. (Division 29); Electrical and optical equipment (Division 30-33); and Transport equipment (34-35).

\section{Services-related occupations in manufacturing, 2000 and 2008}

Services-related occupations correspond to ISCO-88 major groups: 1. "Legislators, senior officials and managers"; 2. "Professionals"; 3. "Technicians and associate professionals", 4. "Clerks"; and 5. "Service workers and shop and market sales workers".

Manufacturing refers to ISIC Rev. 3 (NACE Rev. 1) divisions 15 to 37.

For Australia, manufacturing does not include publishing of recorded media.

For Japan, estimations include the self-employed. 


\section{Micro firms, 2007}

Micro firms have between 1 and 9 employees.

The statistical unit for all countries is enterprise except for Japan, Korea and Mexico which refer to establishments. Data cover the market economy (excluding financial intermediation) except for Brazil, Ireland, Israel, Japan, Korea, Luxembourg, and the Slovak Republic where data refer to manufacturing sectors only.

\section{Value added by size class, 2007}

The statistical unit for all countries is enterprise except for Japan, Korea and Mexico which refer to establishments. Data cover the market economy (excluding financial intermediation) except for Brazil, Hungary, Ireland, Israel, Japan, Korea, Luxembourg and the Slovak Republic where data refer to manufacturing sectors only.

\section{High-growth firms (based on growth in employment), 2007}

As measured by employment, high-growth enterprises have an average annualised growth in employees greater than $20 \%$ a year, over a three-year period, and with ten or more employees at the beginning of the observation period.

\section{Industrial specialisation, 1998 and 2008}

The HK index is specified as:

$$
H K(\theta)=\left(\sum_{i=1}^{N} s_{i}^{\theta}\right)^{1 /(1-\theta)}
$$

where $s_{i}$ is the relative output of the ith sector, $N$ the total number of sectors in an economy, and $\theta$ measures the extent to which the index is influenced by large sectors. The HK(2) is calculated for a value of $\theta$ (theta) equal to 2 , value for which it corresponds to the inverse of the Herfindahl Index.

The index is constructed using the OECD STAN Structural Analysis Database. The sectors considered cover the following ISIC Rev. 3 Divisions: 01-05 (Agriculture), 10-14 (Mining and quarrying), 15-16 (Food products, beverages and tobacco), 17-19 (Textiles, textile products, leather and footwear), 20 (Wood and products of wood and cork), 21-22 (Pulp, paper, paper products, printing and publishing), 23-25 (Chemical, rubber, plastics and fuel products), 26 (Manufacture of other non metallic mineral products), 27-28 (Basic metals and fabricated metal products), 29 (Manufacture of machinery and equipment, n.e.c.), 30-33 (Electrical and optical equipment), 34-35 (Transport equipment), 36-37 (Manufacturing, n.e.c.), 40-41 (Electricity, gas and water supply), 45 (Construction), 50-52 (Wholesale and retail trade; repair of motor vehicles, motorcycles and personal and household goods), 55 (Hotels and restaurants), 60-64 (Transport, storage and communications), 65-67 (Financial intermediation), 71-74 (Renting of machinery and equipment and other business activities).

\section{Value added of the top four industries, 2008}

The sector Concentration Ratio index shown is the analogous to the $\mathrm{K}$-firm concentration ratio and is defined as the cumulative share of the Kth sector, where $s_{i}$ is the relative output of the ith sector. $\mathrm{CR}(4)$ is calculated for a value of $K$ equal to 4.

$$
C R K=\sum_{i=1}^{K} s_{i}
$$

The index is constructed using the OECD STAN Structural Analysis database. The sectors considered cover the following ISIC Rev. 3 Divisions: 01-05 (Agriculture), 10-14 (Mining and quarrying), 15-16 (Food products, beverages and tobacco), 17-19 (Textiles, textile products, leather and footwear), 20 (Wood and products of wood and cork), 21-22 (Pulp, paper, paper products, printing and publishing), 23-25 (Chemical, rubber, plastics and fuel products), 26 (Manufacture of other non-metallic mineral products), 27-28 (Basic metals and fabricated metal products), 29 (Manufacture of machinery and equipment, n.e.c.), 30-33 (Electrical and optical equipment), 34-35 (Transport equipment), 36-37 (Manufacturing, n.e.c.), 40-41 (Electricity, gas and water supply), 45 (Construction), 50-52 (Wholesale and retail trade; repair of motor vehicles, motorcycles and personal and household goods), 55 (Hotels and restaurants), 60-64 (Transport, storage and communications), 65-67 (Financial intermediation), 71-74 (Renting of machinery and equipment and other business activities).

The denominator "total value added" excludes "Real estate activities" (ISIC Rev. 3 Division 70) and "Community, social and personal services" (Divisions 75-99). 
Value added of the top four industries, G7, 1980-2009

Data for Germany prior to 1991 are for western Germany only.

The denominator "total value added" excludes "Real estate activities" (ISIC Rev. 3 Division 70) and "Community, social and personal services" (Divisions 75-99).

Distribution of foreign-controlled employment by broad sectors, 2008

Financial intermediation excluded completely or in part for all countries except Austria, the Czech Republic, Denmark, Finland, Italy, Sweden, Switzerland and the United States.

Community, social and personal services excluded for Austria, Denmark, France, Germany, Hungary, Israel, Italy, the Netherlands, Norway, Poland, Portugal, the Slovak Republic, Slovenia and Spain.

For Switzerland, manufacturing includes other sectors.

\section{Share of national employment under control by foreign affiliates, 2000 and 2008}

Financial intermediation excluded completely or in part for all countries except Austria, the Czech Republic, Denmark, Finland, Italy, Sweden, Switzerland and the United States.

Community, social and personal services excluded for Austria, France, Germany, Hungary, Israel, Italy, the Netherlands, Norway, Poland, Portugal, the Slovak Republic, Slovenia and Spain.

Share of national value added under control by foreign affiliates, 2000 and 2008

Financial intermediation excluded completely or in part for all countries except Austria, the Czech Republic and the United States.

Community, social and personal services excluded for Austria, France, Germany, Hungary, Israel, Italy, the Netherlands, Norway, Poland, Portugal, the Slovak Republic, Slovenia and Spain.

Average of total exports and imports as a percentage of GDP, 2000, 2008 and 2009

OECD and BRIICS refer to the simple averages (un-weighted means) of the countries' shares of GDP.

OECD excludes Luxembourg.

Average of exports and imports of goods as a percentage of GDP, 2000, 2008 and 2009

OECD and BRIICS refer to the simple averages (un-weighted means) of the countries' shares of GDP. OECD excludes Luxembourg.

Average of exports and imports of services as a percentage of GDP, 2000, 2008 and 2009

OECD and BRIICS refer to the simple averages (un-weighted means) of the countries' shares of GDP OECD excludes Luxembourg.

Import content of exports, 1995 and 2005

Data refer to fiscal years 1994/95 and 2004/05 for Australia; fiscal years 1993/94 and 2006/07 for India; 1996 and 2002 for Turkey.

Data refer to 2004 (instead of 2005) for Israel; Ireland, Slovenia and South Africa: data refer to 1998, 1996 and 1993, respectively (instead of 1995).

\section{Import content of household final consumption, 1995 and 2005}

Data refer to fiscal years 1994/95 and 2004/05 for Australia; fiscal years 1993/94 and 2006/07 for India; 1996 and 2002 for Turkey.

Data refer to 2004 (instead of 2005) for Israel; Ireland, Slovenia and South Africa: data refer to 1998, 1996 and 1993, respectively (instead of 1995). 


\section{Business R\&D intensity adjusted for industrial structure, 2008}

The structure-adjusted indicator of R\&D intensity is a weighted average of the R\&D intensities of a country's industrial sectors, using the OECD industrial structure - sector value added shares in 2007 - as weights instead of a country's actual shares (which are used in the calculation of the unadjusted measure of BERD intensity).

BERD data are from 2009 for the Czech Republic, Estonia and Italy. 2007 for Austria, Belgium, Finland, France, Germany, Greece, Mexico, Norway, Sweden, the United Kingdom and the United States. 2006 for Denmark, the Netherlands and Poland. 2005 for Australia, Canada, Iceland and Ireland.

R\&D series are presented as a percentage of value added in industry estimated as the value added in all activities excluding "Real estate activities" (ISIC Rev. 3 70), "Public administrations and defence" (ISIC Rev. 3 75), "Education" (ISIC Rev. 3 80), "Health and social work" (ISIC Rev. 3 85) and "Private households with employed persons" (ISIC Rev. 3 95).

\section{Business R\&D in the manufacturing sector by technological intensity, 2008}

Technology groupings give a broad sense of the relative specialisation of countries in terms of business R\&D, but do not take into account the fact that in some countries the technology intensity of a given industry may be significantly different from that of the OECD average. Further details on the technology classification are available at: $h t t p: / / o e c d . o r g /$ dataoecd/43/41/48350231.pdf.

2010 data for Italy. 2009 data for the Czech Republic, Estonia and Japan. 2007 data for Austria, Belgium, Canada, Finland, France, Germany, Greece, Mexico, Sweden and the United States. 2006 data for the Netherlands and Poland. 2005 data for Iceland and Ireland.

\section{Share of services in business R\&D, 1998 and 2008}

For the Slovak Republic, estimates are also based on additional national sources in order to allocate the R\&D by firms engaged primarily in R\&D (registered in ISIC 73 in ANBERD) to industry served. For this country, the redistribution of ISIC 73 by industry served was not directly implemented in ANBERD because the breakdown is not available at a detailed sector level.

\section{Revealed technological advantage in ICT, 1997-99 and 2007-09}

Data relate to patent applications filed under the Patent Cooperation Treaty (PCT), at international phase, published by the WIPO. Patent counts are based on the priority date, the inventor's country of residence and fractional counts.

The revealed technological advantage index is calculated as the share of country in ICT-related patents relative to the share of country in total patents. Only countries with more than 500 patents in 2007-09 are included in the figure.

BRIICS refers to Brazil, the Russian Federation, India, Indonesia, China and South Africa.

\section{Revealed technological advantage in biotechnologies, 1997-99 and 2007-09}

Data relate to patent applications filed under the Patent Cooperation Treaty (PCT), at international phase, published by the WIPO. Patent counts are based on the priority date, the inventor's country of residence and fractional counts.

The revealed technological advantage index is calculated as the share of country in biotechnology patents relative to the share of country in total patents. Only countries with more than 500 patents in 2007-09 are included in the figure.

BRIICS refers to Brazil, the Russian Federation, India, Indonesia, China and South Africa.

\section{Revealed technological advantage in nanotechnologies, 1997-99 and 2007-09}

Data relate to patent applications filed under the Patent Cooperation Treaty (PCT), at international phase, published by the WIPO. Patent counts are based on the priority date, the inventor's country of residence and fractional counts.

The revealed technological advantage index is calculated as the share of country in nanotechnology patents relative to the share of country in total patents. Only countries with more than 500 patents in 2007-09 are included in the figure.

BRIICS refers to Brazil, the Russian Federation, India, Indonesia, China and South Africa. 


\section{Internet selling and purchasing for total industry, 2010}

The definition of Internet selling and purchasing varies between countries, with some explicitly including orders placed by conventional e-mail (e.g. Australia and Canada) and others explicitly excluding such orders (e.g. Ireland, the United Kingdom and some other European countries). Most countries explicitly use the OECD concept of Internet commerce, that is, goods or services are ordered over the Internet but payment and/or delivery may be off line.

For Australia, Internet income results from orders received via the Internet or the web for goods or services, where an order is a commitment to purchase.

For Japan, businesses with 100 or more employees.

For Mexico, businesses with 50 or more employees.

For New Zealand, businesses with 6 or more employees and with a turnover greater than NZD 30000.

For Switzerland, businesses with 5 or more employees and connections equal to or faster than 144 kbits per second (mobile and fix).

\section{Businesses and individuals experiencing ICT security incidents, 2010}

For businesses, ICT related incidents can include: destruction or corruption of data due to hardware or software failures, unavailability of ICT services due to attacks from outside, e.g. denial of service attack, destruction or corruption of data due to infection or malicious software or unauthorised access, or disclosure of confidential data due to intrusion, pharming, phishing attacks.

For Japan, Mexico, Korea: just incidents involving virus' , trojans or worms.

For New Zealand, Internet users having been victim of fraudulent activity which has resulted in some loss (e.g. money).

\section{Patenting activity by sector, 2007-09}

Patenting firms were linked to the ORBIS@ database, using combinations of string matching algorithm that maximise the precision of the match. The patent portfolio of firms refers to patents applied at the European Patent Office (EPO) and at the US Patent and Trademark Office (USPTO) between 2007 and 2009. Only countries with matching rates above $60 \%$ of patent filings over the period considered are shown.

The list of industries follows the ISIC, Rev. 3. High and medium-high technology manufactures cover Sectors 24, 29-35 less 351; medium-low technology manufactures include 23, 25-28, 351; and business sector services - excluding real estate - refer to 50-67, 71-74.

\section{Top three industries patenting in selected technology fields, 2007-09}

Patenting firms were linked to the ORBIS $\odot$ database, using combinations of string matching algorithm that maximise the precision of the match. The patent portfolio of firms refers to patents applied at the European Patent Office (EPO) and at the US Patent and Trademark Office (USPTO) between 2007 and 2009. Only countries with matching rates above $60 \%$ of patent filings over the period considered are included.

The list of industries follows the ISIC, Rev. 3.

Patents in biotechnologies and health- and ICT-related technologies are based on a selection of International Patent Classification (IPC) classes.

Patents in environment-related technologies are defined using combinations of IPC classes (for EPO and USPTO) and codes Y02 of the European Classification (ECLA) for EPO only.

Patents in nanotechnologies are identified by the ECLA Code Y01.

\section{Patenting activity of young firms, 2007-09}

Patenting firms were linked to the ORBIS $\odot$ database, using combinations of string matching algorithm that maximise the precision of the match. The patent portfolio of firms refers to patents applied at the European Patent Office (EPO) and at the US Patent and Trademark Office (USPTO) between 2007 and 2009. Only countries with matching rates above $60 \%$ of patent filings over the period considered are shown.

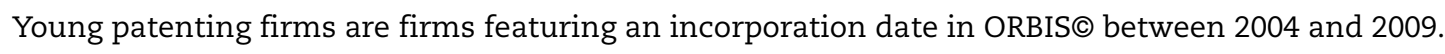




\section{Innovation intensity in sectors, 2002-06}

Industries are defined according to 2-digit ISIC Rev. 3 (NACE Rev. 1) divisions:

- 73 Research and development.

- 24 Chemicals and chemical products.

- 66 Insurance and pension funding, except compulsory social security.

- 23 Coke, refined petroleum products and nuclear fuel.

- 32 Radio, television and communication equipment.

- 65 Financial intermediation except insurance and pension funding.

- 72 Computer and related activities.

- 33 Medical, precision and optical instruments, watches and clocks.

- 34 Motor vehicles, trailers and semi-trailers.

- 64 Post and telecommunications.

- 30 Office, accounting and computing machinery.

- 01 Agriculture, hunting and related service activities.

- 80 Education.

- 16 Tobacco products.

- 31 Electrical machinery and apparatus, n.e.c.

- 02 Forestry, logging and related service activities

- 11 Extraction of crude petroleum and natural gas; service activities incidental to oil and gas extraction surveying.

- 29 Manufacture of machinery and equipment, n.e.c.

- 91 Membership organisations, n.e.c.

- 35 Other transport equipment.

Industry R\&D intensity defined as R\&D expenditure as a percentage of value added.

\section{Value added of innovation-intensive manufacturing sectors, 2008}

Industries are defined according to 2-digit ISIC Rev. 3 (NACE Rev. 1) classes.

\section{Value added of innovation-intensive service sectors, 2008}

Industries are defined according to 2-digit ISIC Rev. 3 (NACE Rev. 1) classes.

"Market" services are defined as ISIC Rev. 3 Divisions 50-74 excluding 70 (real estate).

\section{Patent quality index by country, 1990-2000 and 2000-10}

The Patent Quality Index is a composite index based on a set of normalised indicators (backward and forward citations, family size, number of claims, grant lag and patent generality), ranging from 0 to 1 (maximum quality). The data refers to patents granted by the European Patent Office (EPO) up to 2010, by applicant's residence country and filing date. Only countries with more than 250 granted patents are included in the figure.

BRIICS refers to Brazil, the Russian Federation, India, Indonesia, China and South Africa.

\section{Patent quality index by technology field, 2000-10}

The Patent Quality Index is a composite index based on a set of normalised indicators (backward and forward citations, family size, number of claims, grant lag and patent generality), ranging from 0 to 1 (maximum quality). The data refers to patents granted by the European Patent Office (EPO) up to 2010, by applicant's residence country and filing date. Patents are allocated to technology fields using International Patent Classification (IPC) codes following the classification presented in Schmoch (2008). Only countries with more than 50 granted patents per field over the period are included in the figure. The threshold is lower to 10 granted patents for solar energy, micro-structural and nano-technology, wind energy technology and IT methods for management. 


\section{COMPETING IN THE GLOBAL ECONOMY}

\section{Notes}

\section{Generality of patent applications, 1996-2000 and 2001-05}

The generality index measures the dispersion of citing patents over technology classes, and follows the specification proposed by Hall and Trajtenberg (2004). It relies on information concerning the number and distribution of citations received, and the IPC classes of the patents these citations come from. The measure is high if a patent is cited by subsequent patents belonging to a wide range of fields - i.e. the considered invention has been relevant for a number of later inventions, and not only in its own technology class. Conversely, if most citations are concentrated in a few fields the generality index is low, i.e. close to zero.

Data refer to patent applications published by the European Patent Office (EPO) up to 2005, by inventor's residence country and publication date. Only OECD and BRIICS countries with at least 250 patent applications are included.

BRIICS refers to Brazil, the Russian Federation, India, Indonesia, China and South Africa.

\section{Patent scope by country, 1996-2000 and 2001-05}

The scope of each patent application is calculated as the number of distinct IPC subclasses (i.e. 4-digit IPC classification) into which the application is assigned by the EPO. The graph displays the average by inventor's residence country and publication date, up to 2005.

Data refer to patent applications published by the European Patent Office (EPO) up to 2005, by inventor's residence country and publication date. Only OECD and BRIICS countries with at least 250 patent applications are included.

BRIICS refers to Brazil, the Russian Federation, India, Indonesia, China and South Africa.

\section{Highly cited patent applications to the EPO (top 1\%), 1996-2000 and 2001-05}

The top $1 \%$ patent applications in terms of received citations within a field and year are considered highly cited. The data refers to patent applications published by the EPO up to 2005, by inventor's residence country and date of publication.

Countries included are OECD countries, BRIICS countries and Singapore. Only countries with at least one highly cited patent application are shown. 
Ahmad, N. and E. Gonnard (2007), "High-Growth Enterprises and Gazelles", paper prepared for the International Consortium on Entrepreneurship (ICE), Copenhagen, Denmark, http://ice.foranet.dk/upload/highgrowth.pdf.

Ahmad, N. and D. Rude Petersen (2007), "High-Growth Enterprises and Gazelles - Preliminary and Summary Sensitivity Analysis", OECD-FORA, Paris, www.oecd.org/dataoecd/47/4/39639605.pdf.

Ahuja, G. and C.M. Lampert (2001), "Entrepreneurship in the Large Corporation: A Longitudinal Study of How Established Firms Create Breakthrough Inventions", Strategic Management Journal, Vol. 22, No. 6-7, pp. 521-543. Doi: $h$ ttp://dx.doi.org/10.1002/smj.176.

Bravo Biosca, A. (2010), "Growth Dynamics: Exploring business growth and contraction in Europe and the US", Research Report, London: FORA and NESTA, www.nesta.org.uk/ibrary/documents/Dynamic_Growth.pdf.

Eurostat/OECD (2007), Eurostat-OECD Manual on Business Demography Statistics, OECD Publishing, Paris, http://ec.europa.eu/ eurostat/ramon/statmanuals/files/KS-RA-07-010-EN.pdf.

Hall, B.H. and M. Trajtenberg (2004), "Uncovering GPTS with Patent Data", NBER Working Papers, No. 10901, National Bureau of Economic Research, Inc., www.nber.org/papers/w10901.

Hummels, D., I. Jun and Y. Kei-Mu (2001), "The Nature and Growth of Vertical Specialization in World Trade”, Journal of International Economics, Vol. 54, Issue 1, June, pp. 75-96. Doi: http://dx.doi.org/10.1016/S0022-1996(00)00093-3.

ISIC Rev. 3 Technology Intensity Definition (OECD, online document), www.oecd.org/dataoecd/43/41/48350231.pdf.

Lanjouw, J. and M. Schankerman (2004), "Patent Quality and Research Productivity: Measuring Innovation with Multiple Indicators", The Economic Journal, Vol. 114, No. 495, pp. 441-465. Doi: http://dx.doi.org/10.1111/j.1468-0297.2004.00216.x.

Lerner, J. (1994), “The Importance of Patent Scope: An Empirical Analysis”, The RAND Journal of Economics, Vol. 25, No. 2, pp. 319-333, www.jstor.org/stable/2555833.

Meng, Bo., N. Yamano and C. Webb (2011), "Application of Factor Decomposition Techniques to Vertical Specialisation Measurements", Institute of Developing Economies Discussion Papers, No. 276, Japan External Trade Organization (JETRO), www.ide.go.jp/English/Publish/Download/Dp/276.html.

OECD (2005), Measuring Globalisation: OECD Handbook on Economic Globalisation Indicators 2005, OECD Publishing, Paris. Doi: http://dx.doi.org/10.1787/9789264108103-en.

OECD (2009), OECD Patent Statistics Manual, OECD Publishing, Paris. Doi: http://dx.doi.org/10.1787/9789264056442-en.

OECD (2010), Measuring Globalisation: OECD Economic Globalisation Indicators 2010, OECD Publishing, Paris. Doi: http://dx.doi.org/10.1787/9789264084360-en.

OECD (2010), Measuring Innovation: A New Perspective, OECD Publishing, Paris. Doi: http://dx.doi.org/10.1787/9789264059474-en.

OECD (2011), Entrepreneurship at a Glance 2011, OECD Publishing, Paris. Doi: http://dx.doi.org/10.1787/9789264097711-en.

OECD (2011), OECD Guide to Measuring the Information Society 2011, OECD Publishing, Paris. Doi: http://dx.doi.org/10.1787/ 9789264113541-en.

Pilat, D. and A. Wölfl (2005), "Measuring the Interaction Between Manufacturing and Services", OECD Science, Technology and Industry Working Papers, No. 2005/05, OECD Publishing, Paris. Doi: http://dx.doi.org/10.1787/882376471514.

Ragoussis, A. and E. Gonnard (2011), “The OECD-ORBIS Database - Treatment and Benchmarking Procedures", OECD Statistics Working Papers, OECD, Paris (forthcoming).

Régibeau, P. and K. Rockett (2010), "Innovation Cycles and Learning at the Patent Office: Does the Early Patent Get the Delay?", The Journal of Industrial Economics, Vol. 58, No. 2, pp. 222-246. Doi: http://dx.doi.org/10.1111/j.1467-6451.2010.00418.x.

Schmoch, U. (2008), "Concept of a Technology Classification for Country Comparisons, Final Report to the World Intellectual Property Organisation (WIPO)", revised in November 2010, WIPO, www.wipo.int/export/sites/www/ipstats/ en/statistics/patents/pdf/wipo_ipc_technology.pdf.

The OECD Analytical BERD (ANBERD) Database (OECD, online document), www.oecd.org/dataoecd/52/23/47840198.pdf.

Yamano, N. and N. Ahmad (2006), "The OECD Input-Output Database: 2006 Edition”, OECD Science, Technology and Industry Working Papers, No. 2006/08, OECD Publishing, Paris. Doi: http://dx.doi.org/10.1787/308077407044. 



\section{Data Sources}

Bureau van Dijk Electronic Publishing, ORBIS@ Database, www.bureauvandijk.com/en/ORBIS.html.

Elsevier, Scopus Custom Data, www.scopus.com/home.url.

EU KLEMS Database, www.euklems.net.

European Patent Office, Worldwide Patent Statistical Database, www.epo.org/searching/subscription/raw/ product-14-24.html.

Eurostat, Community Innovation Survey (CIS) Database, http://epp.eurostat.ec.europa.eu/portal/page/ portal/science_technology_innovation/data/database.

Eurostat, Community Survey on ICT Usage in Enterprises Database, http://epp.eurostat.ec.europa.eu/ portal/page/portal/information_society/data/database.

Eurostat, Community Survey on ICT Usage in Households and by Individuals Database, http:// epp.eurostat.ec.europa.eu/portal/page/portal/information_society/data/database.

Eurostat, EU Labour Force Survey, http://epp.eurostat.ec.europa.eu/portal/page/portal/employment_ unemployment_lfs/data.

Eurostat, NewCronos Database, http://epp.eurostat.ec.europa.eu/portal/page/portal/statistics/search_database.

GEM, Global Entrepreneurship Monitor Database, www.gemconsortium.org/about.aspx?page=gem_datasets.

International Labour Organization, Key Indicators of the Labour Market Database, www.ilo.org/empelm/ pubs/WCMS_114060/lang—en/index.htm.

International Monetary Fund, Balance of Payments Database, www.imf.org/external/data.htm.

International Monetary Fund, World Economic Outlook Database, www.imf.org/external/data.htm.

OECD, Activities of Foreign Affiliates (AFA) Database.

OECD, Activity of Multinational Enterprises (AMNE) Database.

OECD, ANBERD Database, www.oecd.org/sti/anberd.

OECD, Annual National Accounts Database, www.oecd.org/std/ana.

OECD, ANSKILL Database (internal use only).

OECD, Biotechnology Statistics Database, www.oecd.org/sti/biotechnology/indicators.

OECD, Broadband Portal, www.oecd.org/sti/ict/broadband.

OECD, Education Database, www.oecd.org/education/database.

OECD, Employment Database, www.oecd.org/employment/database.

OECD, Entrepreneurship Financing Database, www.oecd.org/statistics/measuringentrepreneurship.

OECD, Foreign Affiliates Trade in Services (FATS) Database.

OECD, ICT Database on ICT Usage in Enterprises.

OECD, ICT Database on ICT usage in Households and by Individuals.

OECD, International Direct Investment Database.

OECD, Main Science and Technology Indicators Database, www.oecd.org/sti/msti.

OECD, Patent Database, www.oecd.org/sti/ipr-statistics.

OECD, Product Market Regulation Database, www.oecd.org/eco/pmr.

OECD, Productivity Database, www.oecd.org/statistics/productivity.

OECD, Quarterly National Accounts Database, www.oecd.org/std/qna. 
OECD, Regional Database, www.oecd.org/gov/regional/statisticsindicators.

OECD, REGPAT Database, www.oecd.org/sti/ipr-statistics.

OECD, Research and Development Database, www.oecd.org/sti/rds.

OECD, STAN Bilateral Trade Database, www.oecd.org/sti/btd.

OECD, STAN Bilateral Trade Database by Industry and End Use (forthcoming).

OECD, STAN Input-Output Database, www.oecd.org/sti/inputoutput.

OECD, Structural Analysis (STAN) Database, www.oecd.org/sti/stan.

OECD, Technology Balance of Payments Database (internal use only).

OECD, Trade in Services Database, www.oecd.org/std/trade-services/statistics.

OECD/UNESCO Institute for Statistics/Eurostat data collection on careers of doctorate holders 2010 (internal use only), www.oecd.org/sti/cdh.

OHIM Community Trademark Database, CTM Download.

United Nations Statistical Division, National Accounts Main Aggregates Database, http://unstats.un.org/ unsd/snaama/Introduction.asp.

US Patent and Trademark Office, “The USPTO Trademark Casefile Dataset (1884-2010)".

US Patent and Trademark Office, Trademark Electronic Search System (TESS).

World Bank, Doing Business Database, http://doingbusiness.org/.

World Bank, World Development Indicators Database, http://data.worldbank.org/data-catalog/worlddevelopment-indicators.

World Intellectual Property Organization, Statistics on trademarks, www.wipo.int/ipstats/en/statistics/ marks/. 


\section{ORGANISATION FOR ECONOMIC CO-OPERATION AND DEVELOPMENT}

The OECD is a unique forum where governments work together to address the economic, social and environmental challenges of globalisation. The OECD is also at the forefront of efforts to understand and to help governments respond to new developments and concerns, such as corporate governance, the information economy and the challenges of an ageing population. The Organisation provides a setting where governments can compare policy experiences, seek answers to common problems, identify good practice and work to co-ordinate domestic and international policies.

The OECD member countries are: Australia, Austria, Belgium, Canada, Chile, the Czech Republic, Denmark, Estonia, Finland, France, Germany, Greece, Hungary, Iceland, Ireland, Israel, Italy, Japan, Korea, Luxembourg, Mexico, the Netherlands, New Zealand, Norway, Poland, Portugal, the Slovak Republic, Slovenia, Spain, Sweden, Switzerland, Turkey, the United Kingdom and the United States. The European Union takes part in the work of the OECD.

OECD Publishing disseminates widely the results of the Organisation's statistics gathering and research on economic, social and environmental issues, as well as the conventions, guidelines and standards agreed by its members. 


\section{OECD Science, Technology and Industry Scoreboard 2011}

\section{INNOVATION AND GROWTH IN KNOWLEDGE ECONOMIES}

This tenth edition of the OECD Science, Technology and Industry (STI) Scoreboard builds on the OECD's 50 years of indicator development to present major world trends in knowledge and innovation. It analyses a wide set of indicators of science, technology, innovation and industrial performance in OECD and major non-OECD countries (notably Brazil, the Russian Federation, India, Indonesia, China and South Africa) and includes some experimental indicators that provide insight into new areas of policy interest.

\section{Contents}

Chapter 1. Knowledge Economies: Trends and Features

Chapter 2. Building Knowledge

Chapter 3. Connecting to Knowledge

Chapter 4. Targeting New Growth Areas

Chapter 5. Unleashing Innovation in Firms

Chapter 6. Competing in the Global Economy

Data sources

For more information about the OECD STI Scoreboard, see www.oecd.org/sti/scoreboard.

Please cite this publication as:

OECD (2011), OECD Science, Technology and Industry Scoreboard 2011, OECD Publishing.

http://dx.doi.org/10.1787/sti_scoreboard-2011-en

This work is published on the OECD iLibrary, which gathers all OECD books, periodicals and statistical databases.

Visit www.oecd-ilibrary.org, and do not hesitate to contact us for more information. 